\title{
LA FUNDAMENTALIDAD DEL DERECHO A LA SALUD EN COLOMBIA Y SU
} DESARROLLO

\section{JACKELINE GRANADOS FERREIRA}

\author{
UNIVERSIDAD SANTO TOMÁS DE AQUINO \\ FACULTAD DE DERECHO \\ DOCTORADO EN DERECHO \\ BOGOTÁ D. C. \\ 2018
}




\title{
LA FUNDAMENTALIDAD DEL DERECHO A LA SALUD EN COLOMBIA Y SU DESARROLLO
}

\section{JACKELINE GRANADOS FERREIRA}

\section{Trabajo de grado para optar al título de Doctora en Derecho}

Director Doctor:

JHEISON TORRES ÁVILA

\author{
UNIVERSIDAD SANTO TOMÁS DE AQUINO \\ FACULTAD DE DERECHO \\ DOCTORADO EN DERECHO \\ BOGOTÁ D. C.




\section{AGRADECIMIENTOS}

A Dios artífice de todo lo creado, quien buen artesano moldea mi vida.

A mi esposo, compañía incondicional en este hermoso camino de la vida, por su apoyo e impulso hacia el logro de mis metas.

A mi hijo, mi razón de ser, mi máximo orgullo y mi más grande logro: una lección para que persiga sus propósitos con constancia.

Al Doctor Jheison Torres Ávila, por sus sabias observaciones y por su constante acompañamiento. 


\section{CONTENIDO}

INTRODUCCIÓN Pág.

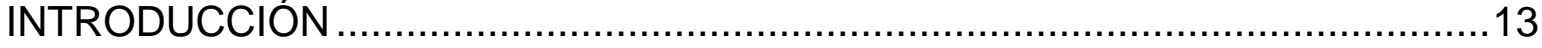

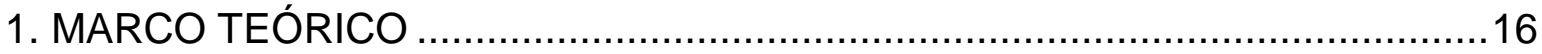

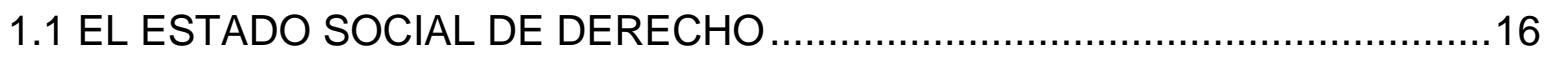

1.1.1 Generalidades del Estado Social de Derecho........................................16

1.1.2 Origen del Estado Social de Derecho ...................................................17

1.1.3 Noción del Estado Social de Derecho ...................................................25

1.1.4 Fines del Estado Social de Derecho. ......................................................

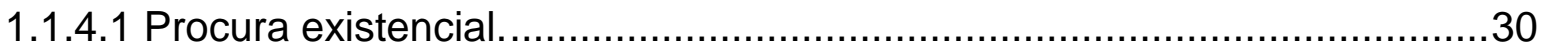

1.1.4.2 Hacer efectivos los valores básicos del Estado …...................................31

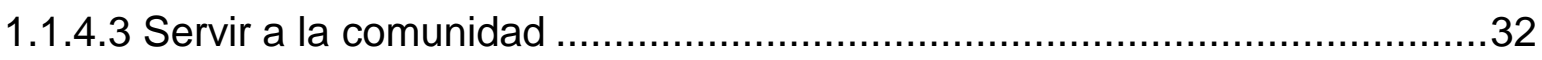

1.1.4.4 Promover la prosperidad general y la efectividad de la Constitución..........32

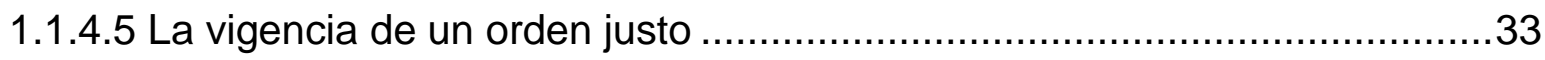

1.1.5 Contenido del Estado Social de derecho ….............................................33

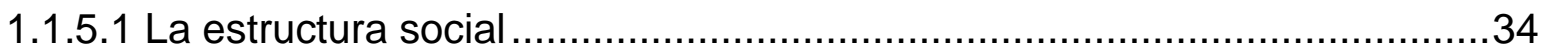

1.1.5.2 Nueva dimensión de los derechos fundamentales..................................34

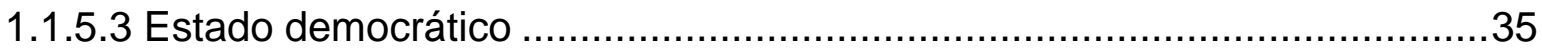

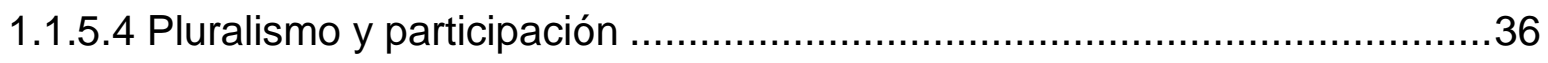

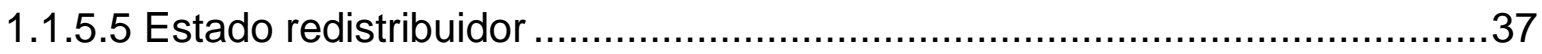

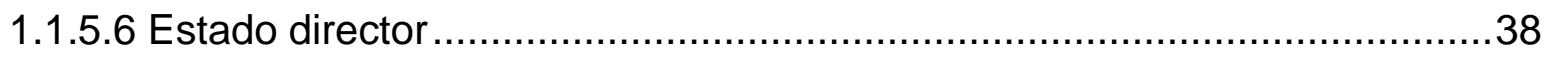

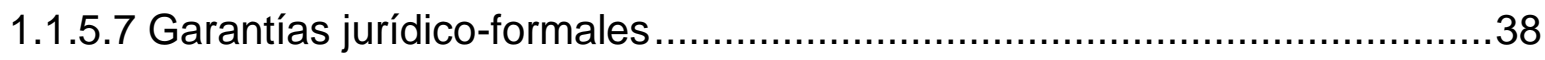


1.1.6.1 La perspectiva histórica y la influencia internacional en el tránsito de Estado de Derecho a Estado Social de Derecho en Colombia en la construcción del modelo de estado.

1.1.6.2 La configuración del Estado Social de Derecho en Colombia en la Asamblea Nacional Constituyente

1.1.6.3 La postura gnoseológica de Estado Social Derecho derivada de la interpretación efectuada por el máximo órgano constitucional colombiano

1.1.6.4 Los retos en materia de efectividad prospectiva del Estado Social de Derecho en Colombia .52

1.2 LOS DERECHOS FUNDAMENTALES. .54

1.2.1 Obligados a la garantía de los derechos fundamentales. 57

1.2.1.1 El Estado. .57

1.3. TEORIAS DE LOS DERECHOS FUNDAMENTALES 60

1.3.1 Teoría Liberal 61

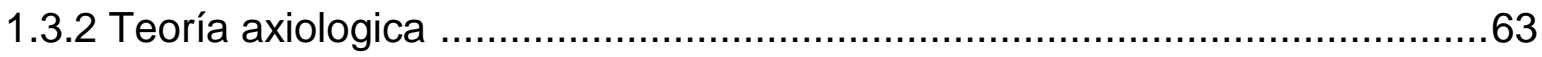

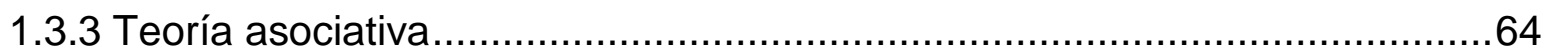

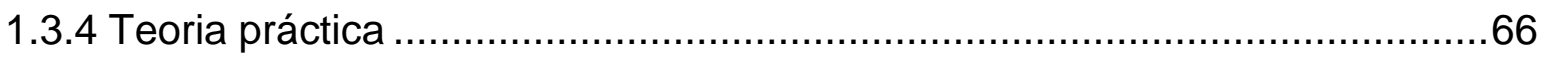

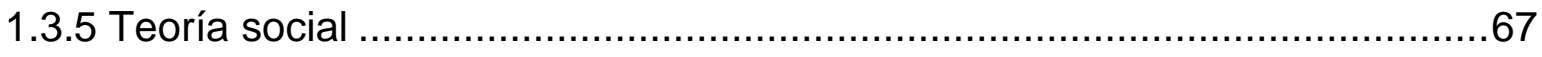

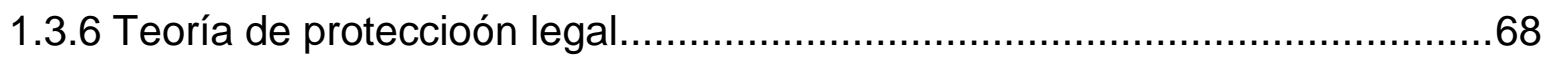

1.4. LA INTERPRETACIÓN DE LOS DERECHOS FUNDAMENTALES ...............70

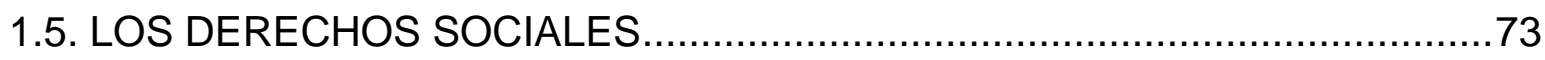

1.5.1. Fundamentación y perspectiva histórica ………....................................75

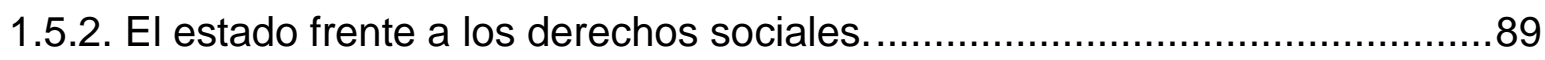

1.5.3. Caracterización de los derechos sociales...............................................90 
2. ANÁLISIS DE LA IUSFUNDAMENTALIDAD DEL DERECHO A LA SALUD.....95

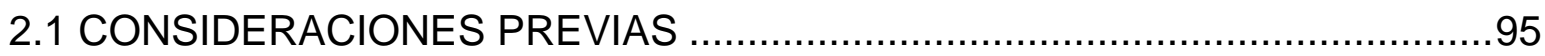

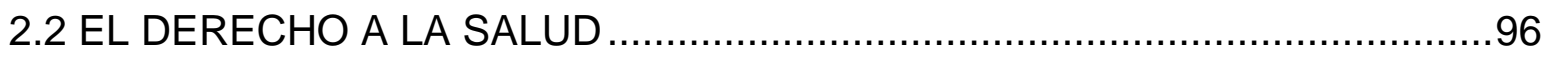

2.2.1 Evolución histórica del derecho a la salud ...............................................96

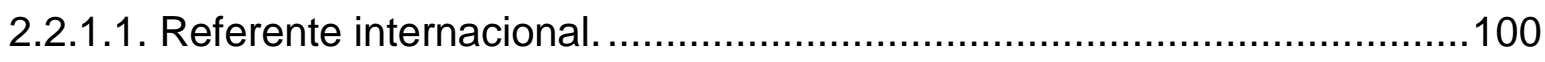

2.2.2 Principios del derecho a la salud ......................................................116

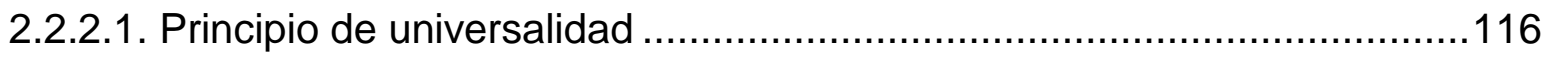

2.2.2.2. Principio de eficiencia ................................................................118

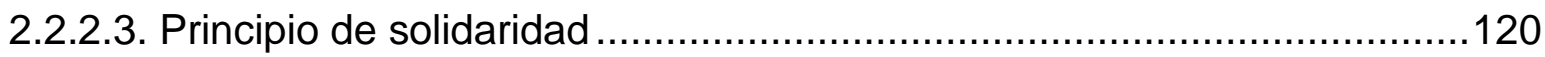

2.2.2.4. Principio de corresponsabilidad .................................................... 122

2.2.3. Evolución jurisprudencial. ....................................................................123

2.2.3.1. Análisis dinámico de la evolución jurisprudencial .................................141

2.2.4. Evolución conceptual del derecho a la salud. ........................................148

2.2.4.1. Noción de la salud como un servicio.................................................150

2.2.4.2. Noción de fundamentalidad por conexidad ........................................155

2.2.5 La salud como derecho fundamental ................................................158

2.2.6. Alcance del derecho fundamental a la salud..........................................163

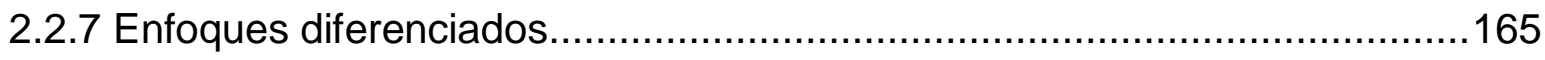

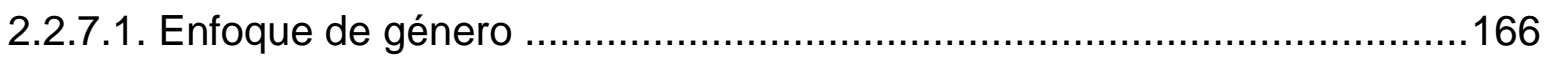

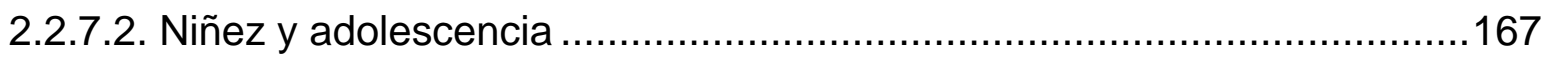

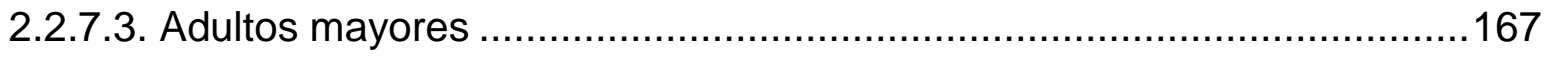

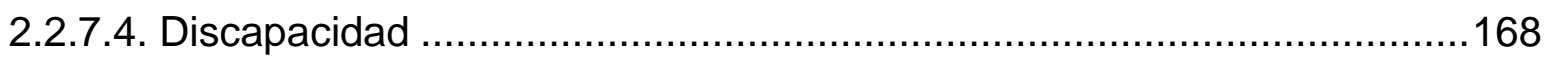

2.2.8 Obligaciones del estado frente al derecho a la salud...............................169 
2.2.9 Acciones para materializar el derecho fundamental a la salud.

2.2.10 Amenazas y barreras a la efectividad del derecho a la salud.

2.3 ESTADO DE COSAS INCONSTITUCIONALES

2.4 BLOQUE DE CONSTITUCIONALIDAD Y EL CONTROL DE CONVENCIONALIDAD.

2.4.1 Control de convencionalidad del derecho a la salud en Colombia 185

2.5 LA RESPONSABILIDAD POR OMISIÓN EN SALUD 189

2.5.1 La falla médica 190

2.5.2 Obligaciones de medio y de resultado incorporadas en la actividad médica 190

2.5.3 Particularidades de la carga de la prueba 193

2.6 PERJUICIOS INDEMNIZABLES: PRINCIPIO DE PÉRDIDA DE LA OPORTUNIDAD 198

2.7 SISTEMA COLOMBIANO DE SEGURIDAD SOCIAL EN SALUD 200

2.7.1 Diseño del sistema de seguridad social en salud. .208

2.7.2 Ley estatutaria de la salud como derecho fundamental 209

2.7.2.1. Perspectiva diacrónica. 209

2.7.2.2. Análisis de constitucionalidad. 211

2.7.2.3. Contenido de la Ley 1751 de 2015. .224

2.8 LOS DERECHOS ECONÓMICOS SOCIALES Y CULTURALES: DERECHO A LA SALUD. 228

2.8.1 Estructura de los derechos económicos sociales y culturales .229

2.8.1.1. Titulares .229

2.8.1.2. Objeto .230 
2.9 LOS DERECHOS ECONÓMICOS SOCIALES Y CULTURALES: EL DERECHO A LA SALUD

2.9.1 Derecho a la salud a la luz de los derechos económicos sociales y culturales. 232

3. ESTUDIO DE LA ECONOMÍA EN EL SISTEMA DE SALUD. 237

3.1 GENERALIDADES: .237

3.2 DEFINICION: .243

3.3 CARACTERISTICAS: 246

3.4 ELEMENTOS: .247

3.5 PRINCIPIO DE LIBERTAD ECONÓMICA EN SALUD 250

3.5.1. La salud y el principio de la libertad económica 256

3.5.2 Conflicto entre el derecho a la salud y el principio de la libertad económica.

3.5.2.1 Planteamientos de la Corte Constitucional de Colombia en relación con el derecho a la salud y el principio de la libertad económica.

3.5.2 Fines de la libertad económica .263

3.6 PRINCIPIO DE SOSTENIBILIDAD FISCAL .265

3.6.1 Decisiones artificiosas de carácter legislativo y administrativo .267

3.7 PRESUPUESTOS PARA EL RECONOCIMIENTO DEL DERECHO A LA SALUD.

3.8 COBERTURA, EXCLUSIONES, Y REGLAS JURISPRUDENCIALES APLICABLES

3.9 LÍMITES JURISPRUDENCIALES A LOS SERVICIOS Y TECNOLOGÍAS EN SALUD

3.10 CONTRADICCIONES ENTRE DERECHOS DE PRESTACIÓN Y LIBERTAD DE COMERCIO 288

4. POLITICAS PÚBLICAS EN EL SISTEMA DE SALUD COLOMBIANO 302 


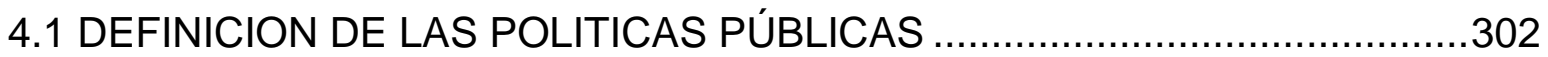

4.2 CARACTERISTICAS DE LAS POLITICAS PÚBLICAS .................................304

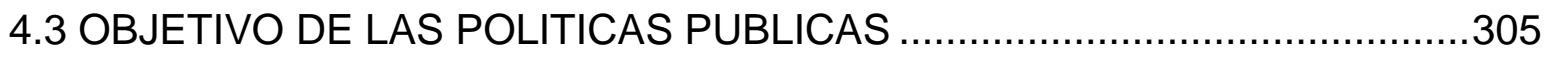

4.4 IMPACTO DE LAS POLITICAS PÚBLICAS.................................................305

4.5 GENERALIDADES DE LAS POLITICAS PÚBLICAS .................................306

4.6 POLITICAS PÚBLICAS EN SALUD: COLOMBIA ........................................308

4.7 POLÍTICAS PÚBLICAS ESTABLECIDAS POR EL PLAN DECENAL DE

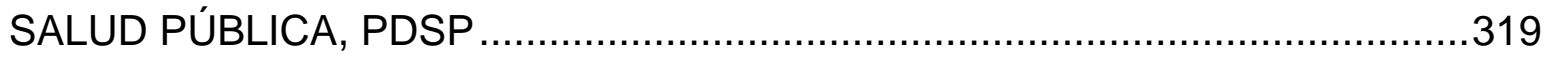

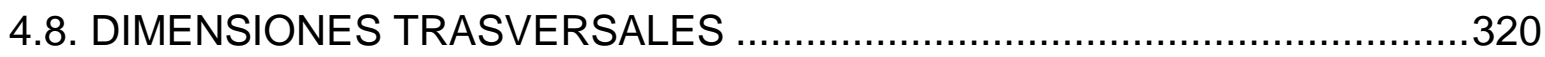

5. EL PRINCIPIO DE CORRESPONSABILIDAD EN EL DERECHO A LA SALUD

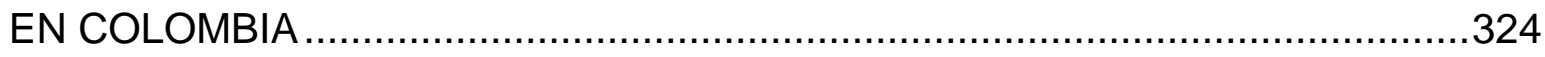

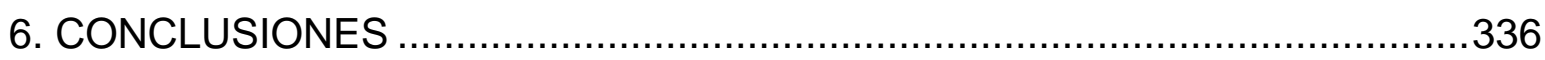

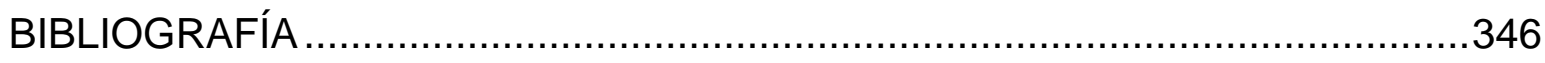




\section{LISTA DE FIGURAS}

Pág.

Figura 1. Naturaleza y evolución del derecho a la salud en Colombia................126

Figura 2. Análisis dinámico del derecho a la salud en Colombia ........................142

Figura 3. Balance del PIB colombia del año 1995 hasta el año 2014 .................242 


\section{RESUMEN}

A partir de la promulgación de la Constitución Política de 1991, coexistieron tres concepciones sobre la salud en el ordenamiento jurídico colombiano: La primera, la definía como servicio, negando su condición de derecho; la segunda, la consideraba como derecho fundamental por conexidad con el derecho a la vida o la integridad personal; la tercera, establecida sobre una base jurisprudencial, hoy positivada, que propugna por qué la salud es un derecho fundamental autónomo exigible.

Ante la ostensible indeterminación de la naturaleza del derecho a la salud antes de la promulgación de la Ley 1751 de 2015, se concentró el esfuerzo de este trabajo de investigación en documentar la misma partiendo de su inclusión en el Estado Social de Derecho, determinando su alcance como un derecho fundamental social; de igual forma se centró dicho esfuerzo en analizar la iusfundamentalidad del derecho a la luz de su evolución histórica, teórica y jurisprudencial, a efectos de determinar su alcance, obligaciones, límites, cobertura, caracterizando de paso el Sistema que lo materializa, y las instituciones jurídico procesales creadas en aras de invocar indemnización ante su conculcación.

Con base en este recorrido histórico, teórico y jurisprudencial, se realiza un análisis crítico de la Ley 1751 de 2015 que recientemente reconoció el derecho a la salud como fundamental, siguiendo la interpretación realizada por la Sentencia C-313 de 2014, la cual, en análisis previo a la norma estatutaria, estableció la prohibición de regresividad frente a las reglas jurisprudenciales sentadas en garantía del derecho.

Mediante la documentación, descripción y análisis de conceptos constitucionales y legales, así como mediante la definición de una clara y concisa delimitación de los supuestos de protección del derecho a la salud en Colombia, se espera aportar a la teoría jurídica elementos de significancia social y utilidad para los actores del Sistema y los operadores judiciales, en aras de la efectiva protección de este derecho fundamental a la salud, con una propuesta de elaboración de la política publica en el sistema de salud basada en el principio de corresponsabilidad.

Palabras clave: Estado Social de Derecho, Derechos Prestacionales, Derecho fundamental a la salud, Sentencia C-313 de 2014, y Ley 1751 de 2015, políticas publicas, principio de corresponsabilidad. 


\begin{abstract}
In the Colombian legal system, after the promulgation of the 1991 Constitution, they have coexisted three legal conceptions of health, first defined as a service that deny its right condition, the second that considered it like a fundamental right by connectedness with the right to life and personal integrity, and a third set on a jurisprudential support, in a law today, which defines health as an autonomous and enforceable fundamental right.
\end{abstract}

Given the uncertainty of the nature of the right to health before the creation of the Law 1751 of 2015, concentrated the effort of this research, document it based on their inclusion in the context of the Social State of Law, determining their scopel as a social fundamental right; likewise this effort focused in the analyze of the fundamental nature of this right, acording its historical, theoretical and jurisprudential evolution, in order to determine its scope, obligations, limits, coverage, characterizing of the System that materializes it, and the procedural legal institutions created for asking the compensation to their violation.

Also, from the study of some cases decided by the Constitutional Court, was intended to document the rules, and jurisprudential sub-rules created by the jurisdiction to ensure the fundamental right to health, with prohibition to regressive acording to the sentence $\mathrm{C}-313$ of 2014 . This historical, theoretical and jurisprudential course, allowed in turn support the critical analysis of the Law 1751 of 2015 , which recently recognized the right to health as fundamental.

Through documentation, analysis, construction and reconstruction of constitutional, legal concepts, and defining a clear and concise way for protecting the right to health in Colombia, I am expecting to contribute to the legal theory, elements of social significance and usefulness for the actors of the System, and for judicial officials, for the effective protection of this fundamental right.

Key Words: Social State of Law, Prestacional Rights, Fundamental right to health, Judgement C-313 of 2014, Law 1751/2015. 


\section{INTRODUCCIÓN}

En Colombia, el derecho a la salud ha sido trasegado por diversas teorías sobre los derechos fundamentales, derechos sociales, y postulados contrapuestos que han generado inseguridad jurídica y obstáculos en el camino a su exigibilidad. Debido a lo anterior, y a la carencia de una concepción jurídica clara sobre las obligaciones derivadas del derecho a la salud en el país, este trabajo de investigación pretendió documentar y consolidar criterios válidos sobre su naturaleza y alcance, para la construcción de un planteamiento teórico, analítico y descriptivo de las condiciones jurídicas y de significación social que determinan la naturaleza fundamental del derecho a la salud.

Este documento investigativo se encuentra dividido en cuatro capítulos: en la sección introductoria, se plantea el problema jurídico, los objetivos del proceso investigativo, el método de análisis utilizado y la hipótesis desarrollada. Posteriormente, en el segundo capítulo, se desarrolla la fundamentación teórica y de contexto, en la que se abordan conceptos como el constitucionalismo, derechos fundamentales, derechos sociales entre otros, conceptos de gran importancia para entender el alcance del derecho a la salud en el ordenamiento colombiano. En el tercer capítulo, se realiza el análisis de la naturaleza fundamental del derecho a la salud dentro de la órbita de la teoría jurídica. En el cuarto capítulo, se realiza un análisis de políticas públicas en el sistema de salud. En el quinto capítulo, se efectúa un examen del principio de ocrresponsabilidad en el sistema salud colombiano. Finalmente, en el capítulo de conclusiones, se discuten las implicaciones y el alcance del derecho fundamental a la salud en el ordenamiento jurídico colombiano, según sus características estructurales; asimismo, se expone cómo se superan las concepciones difusas que dificultan su aplicabilidad.

\section{El problema jurídico}

A partir de la promulgación de la Carta Política de 1992, en el ordenamiento jurídico colombiano, han coexistido tres diferentes concepciones sobre el derecho a la salud y las prestaciones derivadas de este. La primera concepción, niega su condición de derecho y lo considera como servicio y lo ubica como una prestación, que se suple a través de un servicio público esencial contenido por la ley 100 de 1993. La segunda, lo considera como un derecho fundamental por su conexión con el derecho a la vida o la integridad personal precedido por un sistema de reglas y sub reglas que permiten garantizar este derecho. Finalmente, la tercera, sobre una base jurisprudencial y recientemente legal, lo comprende como un derecho fundamental autónomo exigible por la totalidad de la población sin ninguna exclusión o limitante. 
Ante la inexistencia de un fundamento jurídico concreto sobre la naturaleza del derecho a la salud, corresponde determinar si este se caracteriza como un derecho fundamental autónomo, a partir del sistema de significaciones sociales construidas en nuestro ordenamiento jurídico bajo la estructura de principios y valores y bajo el concepto de dignidad humana sobre el que se soporta el Estado Social de Derecho incorporado en Colombia, con lo anterior proponer la elaboracion de una política publica basada en el principio de corresponsabilidad. Frente a este problema jurídico, surge la pregunta: ¿Es posible, en la concepción de los derechos fundamentales, estimar el derecho a la salud como fundamental dentro del marco del Estado Social de Derecho?

\section{Objetivos de estudio}

El objetivo general de este trabajo de investigación es construir un planteamiento teórico, analítico y descriptivo de las condiciones jurídicas y de significación social que determinan la naturaleza fundamental del derecho a la salud en Colombia.

En cumplimiento de este objetivo, se desarrollan los siguientes objetivos específicos:

- Documentar el desarrollo jurisprudencial del derecho fundamental a la salud impulsado por la Corte Constitucional.

- Determinar, desde los antecedentes del derecho a la salud y los sistemas jurídicos que nutren el constitucionalismo colombiano, la condición en la cual se materializó su desarrollo como derecho social, para de allí develar el proceso evolutivo de este derecho, y con ello proponer la elaboración de una política pública basada en el principio de corresponsabilidad.

- Establecer el marco de interpretación dentro del contexto de la teoría jurídica y constitucional, que explica las consecuencias políticas y sociales para el Estado frente al desconocimiento del derecho a la salud como derecho fundamental.

\section{Método y metodología de análisis}

El proceso investigativo se desarrolló a partir de un método analítico-descriptivo del problema jurídico planteado, basado en la documentación y análisis de cada uno de los componentes y elementos teóricos que integran el marco conceptual del derecho a la salud como derecho social y fundamental, desde su causa, naturaleza y efectos. 
Para realizar este análisis, en primera medida, se recopiló la información alusiva al derecho a la salud en archivos, normas, jurisprudencia, doctrinas, etc., y se clasificó según su validez, vigencia y reconocimiento. Luego, se hizo una evaluación y un estudio documental sobre el material seleccionado, fundamentado bibliográficamente. Posteriormente, se realizó un muestreo de casos de la Corte Constitucional en los que se involucraba este derecho, con el fin de identificar el problema planteado y derivar a partir de allí las reglas jurisprudenciales aplicables, estableciendo su vigencia en el marco jurisprudencial, se reviso y se analizo el tema de las políticas públicas, asociadas al principio de corresponsabilidad. Finalmente, se analizó la información y se cotejó con los principios y valores constitucionales que enmarcan el Estado Social de Derecho.

Desde este proceso metodológico, se abordó el derecho a la salud como un todo, analizando cada uno de los elementos teóricos que lo integran, así como su relación jurídica y política con el Estado Social de Derecho. Como resultado, se genera una contribución teórica interpretativa sobre el problema propuesto de utilidad en el marco de la teoría jurídica para sustentar la exigibilidad del derecho fundamental a la salud.

\section{Hipótesis}

Los derechos fundamentales en el Estado Social de Derecho representan, más que cláusulas de diferenciación entre condiciones de bienestar social, elementos de significancia para la garantía del principio y del derecho fundamental de la dignidad humana. Si el marco jurídico del Estado colombiano reconoce positivamente el derecho fundamental a la salud, pero solo cumplen frente al mismo las obligaciones de respeto y protección, y no las de prestación y garantía, los principios básicos de solidaridad y dignidad humana, sobre los cuales se constituye, se verán gravemente afectados.

El Estado colombiano al reconocer la salud como un derecho fundamental autónomo, a partir de la sentencia T-760 de 2008 y la actual vigencia de la Ley 1751 de 2015, cumple teóricamente con la concepción de Estado Social de Derecho. Sin embargo, la consagración escrita no es suficiente, pues la naturaleza del derecho fundamental requiere la aplicación de medidas que garanticen su efectividad y protección jurídica, lo que exige la intencionalidad de la acción protectora del Estado Social de Derecho, por ello, se propone la elaboración de una política pública en salud, basada en el principio de corresponsabilidad. 


\section{MARCO TEÓRICO}

Como punto de partida del presente trabajo de investigación, se abordó de manera exhaustiva el estudio de la literatura relacionada con el tema de la salud en el ordenamiento jurídico colombiano. Sin embargo, fueron encontrados muy pocos trabajos y escuelas que lo abordaran de manera directa o que teorizaran sobre el derecho objeto de estudio. Por esta razón, se emprendió el desarrollo del trabajo de investigación a partir de las perspectivas teóricas del Estado Social de Derecho, los derechos fundamentales, los derechos sociales y el contexto del génesis del derecho fundamental a la salud. Así mismo, y para efectos de sustentar la naturaleza fundamental de este derecho, se tomó como base la literatura existente en instrumentos internacionales, la normatividad colombiana y la jurisprudencia.

\subsection{EL ESTADO SOCIAL DE DERECHO}

La fundamentación teórica de esta investigación parte, inicialmente, de los postulados establecidos por el profesor Norberto Bobbio ${ }^{1}$, quien enmarca al Estado Social como un intento de adaptación del Estado tradicional - o Estado liberal burgués - a las condiciones sociales de la civilización industrial y posindustrial con nuevos y complejos problemas, con el objetivo principal de remediar las difíciles condiciones de vida de los estratos más deprimidos de la población. De aquí, se deriva el Estado Social de Derecho característico de los países de Europa occidental de la segunda posguerra, y que fuera por primera vez constitucionalizado en 1949 por la Ley Fundamental de la República Federal Alemana, adoptado en Colombia mediante la Constitución de 1991.

1.1.1 Generalidades del Estado Social de Derecho El Estado Social de Derecho es un marco jurídico adoptado por la Constitución Política de Colombia de 1991, que incorpora una dogmática compuesta por valores, principios y derechos encaminados a la protección del hombre como un ser ontológico sujeto de derechos y destinatario de la justicia. Bajo dicha definición, el Estado debe garantizar unos mínimos de bienestar en las condiciones de vida, haciendo imperativo el reconocimiento de los derechos sociales, económicos y culturales, entre los que se contempla el derecho a la salud.

${ }_{1}^{1}$ BOBBIO, Norberto. Presente y porvenir de los derechos humanos: El tiempo de los derechos. Madrid.: Ed. Sistema, 1991. p. 70-71. 
De esta manera, el término "social", incorporado a la clásica fórmula del Estado de Derecho y lejos de representar una muletilla con pretensiones filantrópicas, implica acciones representativas por parte del Estado, el cual asume deberes frente a sus ciudadanos a través de cambios institucionales, producto de transformaciones y luchas históricas, cuyo eje central se armoniza con la dignidad de la persona, razón de ser del Estado Social de Derecho.

Así, pues, la salud resulta ser un derecho fundamental contemplado en el Estado Social de Derecho. Su garantía y realización le compete al Estado. Esto, sustentado en el artículo primero de la Constitución Política de Colombia $^{2}$, en el que se consagran una serie de deberes de extrema trascendencia, dentro de los cuales se debe resaltar no solo la producción y aplicación del derecho, sino también el compromiso por la defensa de los contenidos jurídicos materiales. En ese sentido, el Estado Social de Derecho solo podrá ser tal en la medida en que sus componentes esenciales tengan relación directa con los ciudadanos, quienes han de gozar del pleno ejercicio de sus derechos.

Además, la seguridad y legalidad propias del Estado de Derecho se aúnan a la materialización del catálogo de derechos que ha de procurar el Estado y de los que son destinatarios los ciudadanos. De tal suerte que la consagración, efectividad y respeto de estos principios normativos se constituye bajo nuestra moderna forma de Estado en principios rectores de su actuar y en la extensión práctica de su filosofía.

Bajo esta finalidad, el reconocimiento de los derechos prestacionales, como la salud y la seguridad social, garantiza uno de los fines principales del Estado social de Derecho y este es: procurar por la capacidad real de autodeterminación de sus individuos ${ }^{3}$.

Así, atendiendo a la gran importancia que reviste el derecho a la salud en el marco jurídico colombiano, se hace necesario en este trabajo de investigación rememorar la génesis, evolución histórica, características y falencias del Estado Social de Derecho, pues sin duda es este el modelo de Estado que por excelencia permite el reconocimiento de derechos fundamentales de carácter prestacional.

1.1.2 Origen del Estado Social de Derecho El origen del Estado Social de Derecho se sitúa a mediados del siglo XIX. Este nace como réplica a las diferentes crisis de

2 COLOMBIA. Constitución Política de Colombia. Artículo 1 [Título I]. 35a Ed. Bogotá.: Legis, 2016.

${ }^{3}$ CORTE CONSTITUCIONAL. Sentencia T 760 de 2008. 
carácter sociopolítico que maximizaron sus consecuencias a mediados del siglo XX, debido al incipiente individualismo y abstencionismo estatal. Como lo señalan Marie Picard y Judith Useche ${ }^{4}$, estas crisis demostraron la ineficiencia e ineficacia del modelo de Estado actual frente a las necesidades sociales de la época.

Fueron diversos los elementos que incidieron en el nacimiento del Estado Social de Derecho. En primer lugar, se encuentra la pugna de la clase trabajadora o como la denominaría Marx, citado por Durán ${ }^{5}$, "el proletariado", una clase sometida a condiciones de precariedad que favorecen la desigualdad en el vínculo laboral y, por tanto, la eterna contradicción de acceso y propiedad del capital. El proletario fue una clase social duramente explotada en el proceso de fortalecimiento industrial de la sociedad moderna. Las condiciones de miseria e inequidad crearon un ambiente de enorme tensión entre las clases dominantes y los trabajadores. Las manifestaciones sociales, huelgas y, en algunos casos, revoluciones desembocaron en fuertes enfrentamientos entre las familias de poder de los gobiernos de turno y los grupos organizados de trabajadores. Como consecuencia, hubo grandes cambios institucionales que colocaron en entredicho las ventajas del sistema capitalista y el Estado Liberal para las grandes mayorías.

En segundo lugar, se encuentra el fortalecimiento de la doctrina política y económica Marxista y su aplicación en nuevos Estados socialistas, que puso en tela de juicio la obligatoriedad de un sistema capitalista de Estado Liberal como única opción. Además, recogió las reivindicaciones de la clase proletaria como estandarte. Por otro lado, la publicación del manifiesto comunista en el año de 1848, planteó una nueva posibilidad política y económica para el mundo, ya que manifestó la contradicción natural del capitalismo, su habitual tendencia a la crisis y su inminente autodestrucción, la cual fue aprovechada por el movimiento obrero para implementar una nueva sociedad basada en la propiedad social, la supresión del Estado liberal y la dictadura del proletariado ${ }^{6}$. Así mismo, en Rusia, este sistema fue implantado a través de la Revolución de 1917 con el triunfo de la Unión de Repúblicas Socialistas Soviéticas (URSS) sobre la Rusia Zarista. En el socialismo soviético hubo un fortalecimiento de las funciones de control del Estado, la repartición de las riquezas y la organización común. Además, constituyó un frente enemigo del modelo y políticas desarrolladas por el Estado Liberal-capitalista. ${ }^{7}$.

\footnotetext{
4 PICARD DE ORSINI, Marie y USECHE, Judith. Una Nueva Dimensión del Estado de Derecho: EI Estado Social de Derecho. Caracas.: Provincia, 2006. p. 196.

${ }^{5}$ DURÁN, Víctor Manuel. Estado Social de Derecho y Participación: Ponencia VII. En: Conferencia latinoamericana de trabajadores de los servicios públicos. México, 2001. p. 18 -19.

6 DURÁN, Víctor Manuel. Op. Cit. p. 19

7 DURÁN, Víctor Manuel. Op. Cit. p. 19.
} 
La obra de Karl Marx y Friedrich Engels constituyó un análisis pormenorizado de la sociedad capitalista de la época, enriquecido por las teorías liberales inglesas, las primeras propuestas de socialdemocracia francesa y la filosofía alemana clásica, especialmente, el pensamiento filosófico hegeliano. En su obra más representativa, El capital, Karl Marx demostró la contradicción histórica entre la clase burguesa y el proletariado, lo que generó un suelo propicio para la reformulación del Estado como ente capaz de crear las condiciones necesarias para la participación activa de masas en la dirección estatal. Como consecuencia de estos planteamientos, el proletariado comenzó a organizarse en el mundo, exigiéndole al Estado mayores garantías sociales y económicas. Si bien no en todos los casos hubo una reivindicación de carácter socialista, la obra de Marx y Engels representó una crítica científica al capitalismo y fue la base para posteriores propuestas teóricas garantistas y progresistas en el mundo.

Por otra parte, al finalizar la Segunda Guerra Mundial, se constituyeron dos grandes bloques políticos en el mundo: el Estado Liberal, dominado principalmente por los Estados Unidos de Norte América, y las Repúblicas Socialistas lideradas por la URSS. "[...] el sistema socialista liderado por la URSS empezó a expandirse vertiginosamente por todo el mundo, principalmente por Europa, en países como Alemania Oriental, Checoslovaquia, Hungría, Polonia, y Yugoslavia"8. Posteriormente, en 1949, el socialismo se expandió a la República China, bajo el mando del líder comunista Mao Tse Tung. Otros países también acogieron el mismo modelo, como Corea del Norte, Vietnam del Norte, Laos y Camboya. "Por su parte en el continente africano, el sistema socialista fue acogido por Angola y Mozambique, y en América por la isla cubana en 1959"9.

En tercer lugar, resulta relevante mencionar los aportes hechos por la Revolución mexicana y la Constitución de Weimar. El inicio de la Revolución mexicana se remonta al año 1910 y finaliza en 1917 con la creación de la Constitución de Querétaro, la cual consagra, por primera vez en el desarrollo histórico de la humanidad, "Ios derechos sociales de los trabajadores asalariados (artículo 123) y los derechos de los campesinos (artículo 27)"10. Esto es producto de las reclamaciones en materia agraria y laboral, principios fundamentales de la Revolución mexicana. Luego, en 1919, en el Estado Alemán fue aprobada la constitución de Weimar, la cual estableció el deber del Estado de realizar acciones positivas, encaminando su política para dar satisfacción y cumplimiento a los derechos sociales deteriorados por la acción de la guerra, tal y como relató Víctor Durán ${ }^{11}$, revelando así, la "[...] necesidad de una mayor intervención y posición

8 DURÁN, Víctor Manuel. Op. Cit. p. 19.

9 PICARD D'ORSINI, Maries-y USECHE, Judith. Op. Cit. p. 196.

10 Ibíd. p. 197.

${ }^{11}$ DURÁN, Víctor Manuel. Op. Cit. p. 19. 
activa por parte del Estado, trasladándolo a una posición más dinámica en la implementación de políticas urgentes en la gestión económica y social de Nación"12. Por otra parte, la Constitución de la República de Weimar se erige en estos términos como la primera Constitución en hacer alusión a disposiciones relacionadas con los derechos sociales y concretamente a la seguridad social en salud, avances impulsados por la socialdemocracia de la época.

Dicho lo anterior, es claro que, desde la perspectiva europea, o bien desde la perspectiva de la Constitución Weimariana, el Estado Social de Derecho se ve intrínsecamente relacionado con la clase trabajadora y todas sus formas de reconocimiento de derechos. Desde la perspectiva de la Constitución de Querétaro, se evidencia una tendencia notoria hacia la inclusión de los sectores marginados y discriminados, tanto agrícolas como urbanos, es decir, se entiende que la esencia del Estado Social "es de carácter heterogéneo compuesto, pues aparece integrada tanto por elementos de origen latinoamericano como europeos"13.

En cuarto lugar, como otro de los factores incidentes en la incorporación del Estado Social de Derecho, se encuentra la crisis que sufrió el sistema capitalista en el año 1929. Marx ${ }^{14}$, en sus diferentes estudios sobre tal modelo, expuso que el mismo modelo atravesaba por fases cíclicas compuestas por dos etapas: $1^{\circ}$. Expansión y $2^{\circ}$. Depresión. Esta última llevó a evidentes crisis en el siglo XX: "el llamado 'crack' que acaeció en 1929, el cual condujo al surgimiento del Estado Intervencionista Keynesiano en el año de 1970"15. Las consecuencias de la crisis de 1929 fueron muy significativas. Hubo bruscos cambios en la especulación financiera, con la baja de acciones, desastrosas quiebras empresariales, disminución de la producción industrial, alza en las tasas de desempleo y condiciones de miseria a nivel mundial. Esta situación obliga a los Estados Unidos a plantear una política de transformación de las instituciones, ubicando al Estado como motor intervencionista o regulador del mercado. A estas políticas se les denominó New Deal (nuevo trato) y fueron planteadas por el presidente estadounidense Franklin D. Roosvelt con el propósito de contrarrestar los efectos de La Gran Depresión en los Estados Unidos. De ahí que el economista John Maynard Keynes, citado en Durán, expusiera que "Los principales defectos de la sociedad en que vivimos son su incapacidad para proporcionar pleno empleo y su arbitraria y desigual distribución de riquezas y rentas" 16 .

12 PICARD DE ORSINI, M y USECHE, J. Op. Cit. p. 196.

${ }^{13}$ VALADÉS Diego. Problemas constitucionales del Estado Social de Derecho. 2a Ed. Buenos Aires.: Astrea, 2004. p. 63 - 64.

${ }^{14}$ DURÁN, Víctor Manuel. Op. Cit. p. 19

15 PICARD DE ORSINI, M y USECHE, J. Op. Cit. p. 197.

${ }^{16}$ DURÁN, Víctor Manuel. Op. cit. p. 20-21. 
Keynes propuso la adopción de los modelos denominados, Wefare State y New Deal, dentro de los cuales se le otorga al Estado mayor dinamismo e influencia en la economía mediante la generación de empleos, grandes inversiones públicas y la retribución de las rentas por medio de un sistema equitativo de hacienda pública, que incorporaba la noción de impuestos progresivos, es decir, la imposición de tributos de acuerdo a una tasación equilibrada que tenga en cuenta el poder adquisitivo del contribuyente. Esta política del New Deal fundamenta la denominada 'economía mixta', es decir, aquella política económica nacional que unifica dos tipos de agentes económicos: por una parte, la iniciativa privada dada por los particulares y, por otra, el Estado nacional. Según Víctor Durán ${ }^{17}$, Este modelo Keynesiano tuvo gran influencia en la Alemania Bismarch después de terminar la Primera Guerra Mundial, en Inglaterra, en la que también se aplicaron las leyes sociales del Lord Beveridge, implementadas a través de New Deal.

En quinto lugar, impulsando la configuración del Estado Social de Derecho se presenta la corriente social-demócrata, que con su aporte contribuye de forma trascendental a su desarrollo. Este movimiento se originó debido a los diferentes enfrentamientos suscitados entre Lasalle y Marx, así como entre Lenin y Kautsky, los cuales llevaron a que Lenin optara por dividir el movimiento socialista con la creación de la III Internacional en el año de 1919 ${ }^{18 .}$ En este contexto la socialdemocracia abandona el camino de la revolución y decide tomar el camino de la reforma, dejando a un lado pilares tales como la lucha de clases, la dictadura del proletariado y la abolición de la propiedad privada de los medios de producción. Esta teoría recoge algunos postulados del marxismo, pero sin considerar necesario abolir la sociedad capitalista ${ }^{19}$, ya que no opta por esperar al derrumbamiento del dicho modelo, sino que pretende conquistarlo por medio del sufragio y reformarlo desde las instituciones. Para la socialdemocracia, la transición de la sociedad capitalista al socialismo se debe buscar a través de reformas graduales dentro del mismo sistema capitalista; de tal suerte que se deslinda de las tesis y acciones del marxismo ortodoxo y se presenta como una propuesta teórico-práctica moderada ${ }^{20}$. Por su parte, el teórico Ricardo Combellas afirma que "la social democracia adopta una visión positiva del Estado para alcanzar el poder, lo cual implica el reconocimiento del Estado como instrumento adecuado para realizar la reforma social"21.

17 lbíd. p. 21.

18 DURÁN, Víctor Manuel. Op. cit. p. 21.

19 lbíd. Pág. 21.

20 FARRERA BRAVO, Gonzalo. Socialdemocracia (del Marxismo a la Tercera vía) En: Revista Matices. $N^{\circ} 6$ 2008. p. 66-83

${ }^{21}$ COMBELLAS, Ricardo. Una Constitución para el Futuro: El débâte Constitución en Venezuela. Caracas. : Fundación Konrad Adenauer, 1982. 
Esta nueva estructuración estatal convierte al Estado en un impulsor programático de una sociedad en donde la democracia se evidencia tanto en el campo económico como político, extendiendo la propiedad y sus formas. La aplicación de este modelo, que se encuentra ubicado dentro del modelo socialista puro y el modelo liberal clásico, se consolida después de la Segunda Guerra Mundial, instituyéndose una fórmula jurídico-constitucional del Estado Social ${ }^{22}$. En consecuencia, la socialdemocracia plantea reformas institucionales, en el marco del Estado burgués, con el propósito de construir una sociedad más democrática y justa.

Por otra parte, con respecto a la crítica del Estado de derecho, es importante mencionar al reconocido jurista socialdemócrata de origen alemán Hermann Heller, a quien se le adjudica haber hablado por primera vez de la concepción moderna del Estado Social de Derecho, en su trabajo titulado ¿Estado de Derecho o Dictadura? publicado en 1929. El planteamiento central de este jurista radica en el Estado Social de Derecho como una disyuntiva eficaz ante la anarquía que se presentaba en el ámbito económico y la dictadura fascista, proponiendo afirmativamente que dicho sistema alcanzaría la vía política para salvar los valores de la civilización ${ }^{23}$. Hermann Heller es probablemente el teórico más influyente, de las ideas sobre los derechos económicos y sociales actuales, al conceptualizar con mayor claridad la noción de Estado Social. En este sentido, el autor afirma que los problemas acaecidos por la crisis democrática y del Estado de Derecho (el problema del fascismo y la degeneración), no se solucionan con la renuncia a este paradigma, sino que, por el contrario, debe dársele un enfoque económico y social, por medio de la creación de un nuevo orden laboral que propicie la redistribución de bienes en busca de una mayor igualdad, resguardándose así, de la anarquía y la dictadura ${ }^{24}$. Precisamente, Heller en su texto Socialismo y Nación, recuerda a Lasalle cuando dice que "no basta la aplicación despejada y libre de las fuerzas individuales, sino que, en una sociedad éticamente ordenada, debe añadirse a ella la solidaridad en los intereses, la comunidad y la reciprocidad en el desenvolvimiento"25.

El Estado Social de Derecho planteado por Heller consiste en la viabilidad de un orden justo de la autoridad sobre la economía, alcanzado particularmente mediante la limitación de la propiedad privada, la subordinación del régimen laboral al Derecho y el traslado de la actividad económica al ámbito del interés público. Según este autor, la democracia solo es posible dentro de una situación de homogeneidad social, ya que "[...] sin homogeneidad social, la más radical igualdad formal, origina la más radical desigualdad, y la democracia formal desencadena en la dictadura de

22 DURÁN, Víctor Manuel. Op. cit. p. 22.

${ }^{23}$ HELLER, Herman. ¿Estado de derecho o dictadura? En: Escritos Políticos. Trad. GÓMEZ, S. Madrid.: Alianza, 1985. p. 283-301.

24 PICARD DE ORSINI, M y USECHE, J. Op. Cit. p. 197.

25 HELLER, Herman. Socialismo y Nación. En: Escritos Políticos. Trad. GÓMEZ, S. Madrid.: Alianza, 1985. p. 135-234. 
la clase dominante"26. Bajo este razonamiento, la democracia política se configura como el único marco dentro del cual se puedan librar las batallas por la democracia social y el Estado Social de Derecho.

Desde la perspectiva jurídica de Heller, el Estado Liberal debe transformarse en un Estado Social de Derecho, al acoger los aspectos facticos del medio de los asociados como problemas fundamentales. Así, este autor señala que el Estado de Derecho es insuficiente para hacer realidad el principio explícitamente consagrado de la igualdad, debido a que el legislador no tiene en cuenta, en su labor, las relaciones sociales de poder existentes y dicha inobservancia deja de lado la igualdad social real, pilar fundamental del Sistema Social de Derecho ${ }^{27}$. Villar Borda, considera que las ideas de Heller son la base de la Carta Fundamental de Bonn del año de 1949, que se caracteriza por la inclusión de la cláusula del Estado Social de Derecho ${ }^{28}$.

Posteriormente, las diversas crisis mundiales propiciaron nuevas discusiones sobre la aplicación de un modelo estatal. De allí, surgió la necesidad de crear obligaciones jurídicas para garantizar de manera plena la protección de los denominados derechos económicos y sociales, tales como el derecho al trabajo, a la igualdad de la mujer, de las juventudes, la educación, la seguridad social, la asistencia en salud, entre otros. Ahora bien, en los inicios del Estado Social de Derecho, describe el Villar Borda, esta configuración estatal se convertía en un concepto que hacía parte del campo banal y general, pero fue progresivamente contextualizado a través de la legislación y la jurisprudencia, incluyendo dentro de esta acepción principios tales como el de la dignidad humana, el libre desarrollo de la personalidad, la integridad personal, el derecho a la vida, la igualdad, la prohibición de la discriminación, la protección del matrimonio y la familia, el derecho a la vivienda, a la educación, al ambiente sano y el derecho a la cultura, así como también la función social de la propiedad $^{29}$.

La transformación del Estado de Derecho a Estado Social de Derecho tuvo como aportes fundamentales los planteamientos de teóricos del derecho como Karl-Heinz Schönerburg. Para este pensador, el origen de la idea del Estado Social de Derecho se sitúa en la Revolución Francesa, en 1848, en la "[...] fórmula de compromiso entre los partidos pequeños-burgueses y algunos miembros del movimiento obrero orientados por la corriente Owen de origen inglés. Esto se prescribió como la

\footnotetext{
${ }^{26}$ HELLER, Hermann. Op. Cit. p. 287.

27 Ibíd. p. 272.

28 VILLAR BORDA, Luis. Estado de Derecho y Estado Social de Derecho. En: Revista Derecho del Estado. $N^{\circ} 20$ (Feb. 2007). p. 82.

${ }^{29}$ VILLAR BORDA, Luis. Op. Cit. p. 82.
} 
exigencia de desplegar una estructura estatal capaz de avalar los derechos sociales 30". Dichas ideas son reflejadas por Louis Blanc en la corriente denominada "socialismo utópico", en la que la idea central no era la institucionalización de un Estado socialista, sino que dentro del entramado del sistema capitalista se lograra que cada uno pudiera garantizar el derecho al trabajo y la autodeterminación regida por el individuo, dándole su propio desarrollo en un Estado Social y Democrático de Derecho.

A partir de tales pensamientos y condicionamientos surgió el Estado Social de Derecho que "[...] se define a partir de la unión de tres elementos: Estado, derecho y sociedad"31, "[...] con la particularidad de buscar un equilibrio económico, social y cultural entre distintos sectores"32. De esta manera, se transforma la interacción de estos buscando una mayor equidad. Sin embargo, los fines de la configuración de este modelo derivan una discusión axiomática entre el ser y el deber ser del derecho, entre las condiciones de la realidad y el ideal con el cual nacen las normas, pues se denota, por lo menos durante su implementación "[...] que existe una enorme distancia entre la parte programática de la Constitución, y la realidad fáctica social que, con sus diferentes campos, agregan un nivel mayor en el momento de su institucionalización" 33 .

De lo anterior, puede inferirse una dicotomía entre la exposición escrita de los derechos y la imposibilidad de su garantía en un modelo económico que se sustenta en la desigualdad. Por ello, la sola incorporación del nuevo modelo de Estado, de corte garantista en la Carta constitucional, que reviste las reivindicaciones sociales anteriormente mencionadas, no garantiza la ejecución de las mismas, pues el contenido del modelo social de Estado de Derecho es absolutamente programático y filosófico, y más allá de ello, son las acciones gubernamentales las que deben hacerlo pragmático. De esta forma, Ernesto Benda se opuso a la incorporación de dicho modelo en la Ley fundamental de la República Federal Alemana, al advertir que el Estado Social de Derecho es "[...] un concepto en blanco carente de sustantividad" o "un debilitamiento del concepto de Estado de Derecho" ${ }^{44}$.

Entre los muchos adversarios, vale la pena resaltar el legado de Ernst Forsthof, en trabajos dentro del área de Derecho constitucional y administrativo, quien en la actualidad es uno de los teóricos que fundamenta la teoría de la crisis y los

30 lbíd. p. 87.

31 VALADÉS. Diego. Op. cit. p. 61.

32 GARCÍA HERRERA. Miguel Ángel. Poder Judicial y Estado social: Corrupción y Estado de derecho. Madrid.: Trotta, 1996. p. 69.

33 VILLAR BORDA, Op. cit. p. 91.

${ }^{34}$ BENDA, Ernesto. El Estado Social de Derecho: Manual de Derecho Constitucional. 2a ed. Madrid.: Marcial Pons, 2001. p. 74 
diferentes límites que se presentan a partir del modelo de Estado Social de Derecho ${ }^{35}$. Este autor plantea que al Estado le corresponde garantizar las posibilidades de realización de las condiciones existenciales que el individuo, sin embargo, no posee las condiciones naturales para hacerlo, por medio de la administración, y ello reviste una insalvable contradicción. Dicha consideración crítica también encuentra acogida en Colombia, con las tesis sostenidas por autores como Jorge Child, quien señala que el capitalismo, como cualquier otro sistema económico, tiene la necesidad de enfatizar jurídicamente en una justificación ética, por esto, busca la institucionalización de modelos sociales, que solo en apariencia parecen reformar un estado de cosas caóticas ${ }^{36}$. En similar consideración, César Rodríguez Garavito sostiene que el Estado Social de Derecho es una moda dogmática internacionalizada. Si bien es cierto en términos teóricos que representa algo que va más allá de la simple matización cosmética del clásico Estado demoliberal, sus componentes fácticos son muy moderados y no responden a las expectativas que genera. Avizorando tal falta de contenido práctico, fue que los autores Hermann Heller y Elías Díaz plantearon al Estado Social de Derecho como una etapa de transición. Heller afirmaba que se trataba de una etapa provisional para dar un paso hacia el Estado socialista.

A pesar de que durante el siglo XXI la cláusula del Estado Social de Derecho ha mantenido cierto nivel de aceptación y legitimidad, su desarrollo legal no guarda estricta correspondencia con los principios constitucionales, hecho que configura una contradicción entre ley y Constitución, generando la imposibilidad técnica de materializar los fines sociales propuestos. La proclamación constitucional del Estado Social de Derecho exige la transformación mediata y gradual de determinadas situaciones, lo que en ocasiones no sucede en la práctica, toda vez que detrás de la enunciación positiva de unos objetivos sociales loables, subyace una realidad que no podría conjurarse mediante ninguna ley por legítima que sea ${ }^{37}$.

1.1.3 Noción del Estado Social de Derecho. La noción de Estado Social de Derecho tiene origen en la ideología política alemana (Sozialstaat y Sozialrechsstaat) y plantea un sistema político en donde el Estado debe cumplir la función de garantizar derechos esenciales para el sustento mínimo de los ciudadanos, en consecuencia, su responsabilidad con las necesidades y retos sociales es mucho mayor. Se trata, entonces, de una estructura que interviene en la sociedad con el fin de brindar asistencia y redistribuir los recursos. Según el abogado Juan Fernando Silva, en Colombia pese a las dificultades metodológicas que se han presentado al respecto, este modelo fue instituido por la Constitución

\footnotetext{
35 VILLAR BORDA, Op. cit. p. 83.

${ }^{36}$ RODRÍGUEZ GARAVITO, Cesar. El derecho en América Latina. Un mapa para el pensamiento jurídico del siglo XXI. Bueno Aires.: Siglo Veintiuno Editores, 2011

37 PICARDO DE ORSINI, M y USECHE, J.Op. Cit. p. 197.
} 
Política en el año de $1991^{38}$. De otra parte, este especialista en temas constitucionales plantea otra definición sobre el Estado Social de Derecho. Silva expresa que es un punto medio entre sistemas liberales extremos y sistemas de carácter socialista, en donde, pese a sus naturales contradicciones

Pueden encontrar un punto de equilibrio al reconocerse valores fundamentales de uno y de otro, tales como el individualismo y la propiedad privada del modelo liberal, acompasados con las garantías sociales, tales como la función social de la propiedad, la regulación estatal de la economía, los sistemas de seguridad y asistencia social, entre muchas otras expresiones de inspiración socialista y capitalista ${ }^{39}$.

De esta forma, el Estado representa una respuesta a las necesidades sociales generadas por el modelo capitalista, al tiempo que toma conciencia de las implicaciones en la organización política, cuando se proclama la igualdad entre todas las personas.

Los derechos sociales incluidos en los valores programáticos del Estado Social de Derecho tienen la característica de ser derechos que garantizan el bienestar para las grandes mayorías y no solo para un sector específico de la población. La seguridad social, la educación, el trabajo, la salud y la cultura hacen parte de las nuevas garantías ganadas por la lucha de las grandes mayorías y por los nuevos planteamientos del Estado Social de Derecho. De acuerdo con Víctor Durán, el Estado Social de Derecho se plantea democrático, entendiendo la democracia en dos sentidos, por una parte, la democracia política que implica una regla de elección de los gobernantes en aras de la representación de todos los diversos sectores de la sociedad y, por otra parte, una democracia social que evidencia la pretensión institucional y social de igualdad material. "Dicha democracia social comprendería la implementación de mecanismos democráticos dentro de la toma de decisiones del Estado y que caracterizan a la sociedad"40.

En este sentido, el investigador Elías Díaz en su libro Estado de Derecho y sociedad democrática, considera que la democracia debe hacer parte de la toma de decisión y del reparto de los resultados y responsabilidades, asimismo, argumenta que existe

\footnotetext{
38 SILVA HENAO, Juan Fernando. Evolución y origen del concepto de "Estado Social" incorporado en la Constitución Política Colombiana de 1991. En: Revista Ratio Juris, Vol. 7, Nº 14 (Ene.-Jun. 2012). p. 141.

39 Ibíd. p. 152.

${ }^{40}$ DURÁN, Víctor Manuel. Op. cit. p. 24.
} 
la necesidad de una efectiva fundamentación de los derechos sociales en ese sentido ${ }^{41}$. Esto, debido a que el Estado Social de Derecho tiene la obligación jurídica de satisfacer a través de sus funcionarios y administrativos las prerrogativas vitales básicas del sujeto, en especial, a los más débiles. Con la obligación de generar un nivel de vida más elevado, es necesaria la repartición de bienes y servicios, haciendo que los derechos económicos y sociales estén cada día más al alcance de todos los ciudadanos, conciliando sus intereses y garantizando las diferentes formas de vivir. Según lo anterior, el Estado Social de Derecho está llamado a incentivar un desarrollo íntegro de un amplio margen de garantías sociales que desbordan los asuntos estrictamente económicos. Este ejercicio totalizante redunda en el beneficio y desarrollo político, social y cultural de la nación, lo que es en sí mismo un fin de rango constitucional ${ }^{42}$.

Por otra parte, es importante resaltar que, en el Estado Social de Derecho, la clásica tridivisión del poder se reconfigura, en el sentido de atribuir al poder judicial mayor trascendencia, proporcionada gracias al sistema de pesos y contrapesos de los poderes del Estado. Este avance del poder judicial está determinado por tres grandes progresos: en primer lugar, se encuentra el control judicial al cual están sometidos los actos administrativos expedidos por la administración pública, que garantizan el control del poder ejecutivo; en segundo lugar, se encuentra el control de constitucionalidad al cual están sometidas las leyes; y, en tercer lugar, se encuentra el desarrollo de la función que se le asignó a la Corte Constitucional como guardiana de la Constitución y la cual es un atributo exclusivo -mas no excluyentede la función judicial ${ }^{43}$. Dicho sistema de pesos y contrapesos se configura como requisito importante del buen funcionamiento del sistema democrático y del ejercicio del poder, pues permite temperar los poderes, ponerlos en acción y regularlos para que se produzca el equilibrio y la moderación en el manejo del Estado. Esto, en consideración al componente esencial del Estado Social de Derecho, transforma el poder social en poder político, como lo expresa el filósofo alemán Jürgen Habermas, citado por Durán: "[...] el poder social es hoy ipso poder político" 44 . Este poder social es incorporado al modelo a través de los partidos políticos que representan los intereses de algunos ciudadanos y los grupos de interés que se preocupan por la inclusión en los diversos programas gubernamentales.

De lo anterior, puede inferirse que el Estado Social de Derecho se manifiesta de la simbiosis entre la Sociedad - Estado, la cual expresa un doble desarrollo. Por una parte, el Estado participa en la sociedad cooperando como configurador y, por otra, la sociedad interviene en el Estado, a través de proceso de veeduría, participación

41 DÍAZ, Elías. Estado de Derecho y sociedad democrática. 9a ed. Madrid.: Taurus, 1998. p. 28.

42 DURÁN, Víctor Manuel. Op. cit. p. 25.

43 DURÁN, Víctor Manuel. Op. cit. p. 26.

44 Ibíd. p. 26. 
y control social del poder institucional, que inherente al concepto de Estado Social de Derecho, se encuentre la relación de beneficio colectivo entre el Estado y la sociedad ${ }^{45}$. Evidencia de lo dicho, es que entre las características estructurales propias del Estado Social de Derecho se debe reconocer el pluralismo como un elemento que impide el desarrollo de todo tipo de totalitarismos, ya que resulta necesario para su desarrollo el reconocimiento de los diversos sectores que componen la sociedad, los cuales, a su vez, aumentan el nivel de cobertura de los derechos expresados en este nuevo modelo de Estado ${ }^{46}$. El pluralismo proyectado en la organización del Estado es una muestra de la incidencia del carácter plural de las sociedades en el ordenamiento jurídico-político, que se aleja de las concepciones completamente homogeneizadas respecto de los derechos y libertades, para acercarse al concepto de multiplicidad del entramado social.

Además de los elementos antes citados, en el Estado Social de Derecho se encuentran principios básicos como el de razonabilidad, el cual plantea que la institución estatal debe tender a la integración y no a la estratificación de la sociedad. También, se encuentra consagrado el principio de equidad, el cual se fundamenta en el axioma de dar a cada quien lo que se merece, es decir, replanteando la idea de dar a cada ciudadano lo mismo a darle a cada ciudadano lo que necesita. Para el profesor García Pelayo ${ }^{47}$, el Estado Social de Derecho es la manera institucional de canalizar las condiciones materiales de la sociedad industrial y postindustrial, con el fin de enfrentar los incipientes problemas económicos y sociales en la realidad mundial. Por su parte, Vila Casado ${ }^{48}$ alega que la noción existente del Estado Social de Derecho es vaga, ya que, aunque su característica principal es la sujeción del Estado al Derecho, su significado tiende a ser polisémico.

Otro de los opositores del Estado Social de Derecho es el Alemán Ernst Fortsthof quien asevera que dicha concepción era imposible de representar, ya que llevaría a la unión de ideas completamente antitéticas: por un lado, la del Estado de Derecho fundamentado en pro de la garantía de la libertad de los ciudadanos ante la intervención del Estado y su principio de legalidad; y, por otro lado, el Estado Social de Derecho que propone un contenido programático, orientado al amparo de los grupos más desprotegidos de la sociedad, es decir, una intervención en la vida

\footnotetext{
45 DURÁN, Víctor Manuel. Op. cit. p. 27.

46 VALADÉS Diego. Op. Cit. p. 64.

47 GARCIA PELAYO, Manuel. las transformaciones del Estado contemporáneo. 2ª edición. Madrid.: Alianza Uuniversidad, 1995.

48 VILA CASADO, Iván. El estado. En: Fundamentos del Estado Derecho. 2ª edición. Bogotá.: Editorial Legis, 2007. p. 31-56.

Colombia
} 
pública49. Además, Fortsthof, citado en Pérez Luño, agrega que "la implementación de políticas sociales era una capacidad que tenía la Ley y no la Constitución, por lo tanto, agregar la cláusula de Estado Social era una tergiversación desde el punto de vista jurídico" 50 .

Al respecto, Aragón Reyes en su obra Los problemas del Estado Social, afirma que el Estado Social trae consigo la asunción de nuevas tareas que no vienen tampoco a sustituir a las antiguas (seguridad, orden público, defensa, etc.), sino a complementarlas. Estas nuevas tareas son las relativas a procurar una mayor igualdad social y, con ello, a proteger a los sectores menos favorecidos ${ }^{51}$.

Ha sido a través de la evolución histórica promovida por las luchas sociales y de los significativos aportes y críticas de los diversos teóricos, que ha conllevado a un relativo acuerdo sobre la manera en que se entiende al Estado Social de Derecho como un nuevo modelo de Estado que traspasa la legalidad, al resolver diligentemente, por lo menos de manera formal, los aspectos que de forma particular abordan el principio de igualdad. En tal sentido señala Manuela Aragón ${ }^{52}$, el Estado Social de Derecho comienza a darle una mayor trascendencia a la igualdad material, buscando garantizar que los menos favorecidos disfruten de manera efectiva del derecho a la libertad, acompañado de una protección judicial, igual a sus garantías y derechos sociales, económicos y culturales. Con respecto a la construcción del Estado Social y la justificación de sus derechos especiales existen varios cuestionamientos sobre el papel que desempeña el Estado con relación a su responsabilidad social con los ciudadanos. Estos interrogantes pueden resolverse a partir de la diferenciación entre El Estado Social de Derecho, asimilado por algunos como 'Estado Asistencial' o 'Estado Providencial' y el Estado de Bienestar.

En esta medida, el Estado Social de Derecho es una institución en la que los sujetos pueden disfrutar de bienes y servicios, interviniendo de manera activa por medio de los diferentes grupos, coadyuvando en la administración del Estado tanto en políticas redistributivas, como en todos aquellos servicios de carácter público. Por tanto, una de las cualidades del Estado Social es propugnar por el logro del bienestar general a favor de los ciudadanos y, desde luego, este interés no se enfoca en la única y exclusiva misión de los menos favorecidos de la población, sino también, a la de fomentar espacios comunes en la sociedad, en una gran cantidad

49 RODRÍGUEZ MUÑOZ, Iveth e IBARRA LOZANO, Jairo. Del Estado de Derecho al Estado Social de Derecho. En: Revista Justicia Juris. Vol. 10. (Oct., 2008). p. 11.

${ }^{50}$ FORTSTHOF, Ernst. Citado por PÉREZ LUÑO, Antonio Enrique. Derechos Humanos, Estado de Derecho y Constitución. 10a Edición.: TECNOS, 2010. p.225.

${ }^{51}$ ARAGÓN REYES, Manuel. Los problemas del Estado social. En: Sistema. № 118-119. 1994. p. 23.

52 Ibíd. p. 23. 
de aspectos, por ejemplo, en "recrear, proteger el medio ambiente, garantizar la participación de los ciudadanos, y la protección de todas las esferas sociales" 53 .

El Estado Social de Derecho contrae así funciones de intervención en la sociedad y en el modelo económico, asumiendo parte en la gestión, administración y planificación del campo social, incorporando a su vez funciones del Estado de Derecho, tales como la administración de justicia, el orden público y las relaciones internacionales. De tal suerte que al asumir dichas obligaciones, el "Estado adquiere el compromiso de ejercer la gestión pública, determinando funciones empresariales, implementando políticas públicas orientadas a la inversión y a la redistribución equitativa de los recursos en la sociedad" 54 , dejando claro que no se puede confundir el Estado Social de Derecho con el Estado Interventor, ya que este "tiene un carácter instrumental, mientras que el Estado Social cumple con un concepto finalista determinado por normas y valores, en aras de la exaltación del factor humano"55. Así las cosas, el Estado Social de Derecho se manifiesta mediante principios esenciales y axiomas que organizan a la sociedad, logrando que los gobernados y gobernantes se sientan identificados con los valores pragmáticos de la Carta de derechos ${ }^{56}$.

1.1.4 Fines del Estado Social de Derecho. Dentro de los fines que orientan el ejercicio de la función social de este modelo de Estado, se encuentran los derivados del Estado de Derecho, tales como la propiedad individual, la igualdad formal, la seguridad jurídica y la participación de los ciudadanos en la función del Estado por medio del voto. Además, los derivados de la connotación "social" del mismo, orientados a la igualdad material y la equidad social. En Colombia, estos fines se derivan de la Constitución Política y dentro de ellos encontramos:

1.1.4.1 Procura existencial. Este fin nace de la obligación del Estado a realizar acciones que garanticen el desarrollo de las habilidades del individuo, que como expone García Pelayo ${ }^{57}$, no están dirigidas solo a los sectores más discriminados, sino que también deben aplicarse a la sociedad en general. En virtud de este fin, el Estado garantiza las condiciones apropiadas para el buen desarrollo de la existencia del individuo, dichas garantías se logran realizar a través de la administración. En este sentido, el Estado debe ocuparse de controlar, dirigir y garantizar la estabilidad del espacio vital efectivo, es decir, "el conjunto de cosas y posibilidades de las que

53 RODRÍGUEZ MUÑOZ. Op. Cit. p. 11.

54 lbíd. p. 13.

55 RODRÍGUEZ MUÑOZ. Op. Cit. p. 13.

56 PINILLA CAMPOS, Ernesto. ¿Es viable el Estado Social de Derecho en la sociedad colombina? En: Revista Pensamiento Jurídico. No. 15. Universidad Nacional de Colombia. 1992.

${ }^{57}$ GARCÍA PELAYO, Manuel. Op. Cit. p. 97. 
se sirve, pero sobre las que no tiene control" 58 , de tal manera que, encauzada adecuadamente la tarea de la asistencia vital, se logre asegurar las bases materiales de la existencia individual y colectiva.

La procura existencial se infiere de la implementación por parte del Estado de ciertos servicios de carácter público estipulados en los textos constitucionales y que garantizan el cumplimiento del programa de un Estado Social de Derecho; entre ellos se destacan:

- La tasación de un salario mínimo independiente del rol asignado en la sociedad, haciendo necesario que este sea revisado de acuerdo con la realidad económica en la cual se implementa.

- La búsqueda de la garantía efectiva de un puesto de trabajo para todos los ciudadanos, dentro de las políticas de empleo.

- La garantía de la seguridad social para aquellos que se encuentran limitados en el ámbito laboral.

- "El aumento de garantías vitales a través de políticas que buscan una mejor redistribución de ingresos, mejorando así la prestación de servicios y ampliando el inventario de derechos y bienes culturales" 59 .

- La existencia de un régimen de salud subsidiado con presencia nacional, en beneficio de la población vulnerable.

1.1.4.2 Hacer efectivos los valores básicos del Estado. Es evidente que con el modelo de Estado Social de Derecho nace la obligación del Estado de garantizar la protección de los axiomas fundamentales del Estado Liberal, es decir, la propiedad privada, la igualdad formal y la participación del pueblo como soberano. Esta importante defensa debe darse en el marco de la garantía de la dignidad humana que se manifiesta en tres esferas: vivir bien, vivir sin humillaciones y vivir como se quiera, como requisito ‘sine qua non' para el ejercicio de la libertad.

Haciendo alusión a dicha obligación del Estado, vale la pena indicar que, aunque el Estado Social y el Estado Liberal se enfrentan en diversos planos, dichas contradicciones pueden conciliarse en la medida en que el Estado Social de Derecho proteja los bienes jurídicos tutelados en el Estado Liberal, tales como la libertad, la vida y la propiedad, otorgando además trascendencia a otros que son

58 Ibíd. p. 97.

59 GARCÍA PELAYO, Manuel. Op. Cit. p. 97-98. 
indispensables para la existencia en condiciones dignas. En este sentido, Wolfang Abendroth ${ }^{60}$ ve en el Estado Social un sucedáneo del Estado Liberal y sostiene una visión integradora en donde puede hacerse una "asimilación de forma no contradictoria con las instituciones anteriores, puesto que el Estado Social lo que viene a representar es una solución ante las deficiencias suscitadas en el esquema liberal". De esta manera, el Estado Social de Derecho mantiene el principio de legalidad, pero, de acuerdo con la Sentencia T-505 de 1992, lo supera y complementa al señalar entre sus finalidades la de "garantizar un orden político, económico y social justo, que supone un papel activo de las autoridades"61.

1.1.4.3 Servir a la comunidad. Dentro de esta categoría se encuentran los servidores públicos, quienes están sometidos a una relación especial de sujeción, lo que hace que la función pública esté siempre orientada al cumplimiento de los fines del Estado, por lo tanto, los servidores están siempre sometidos al servicio de la comunidad, tal como lo indica el artículo 123 de nuestra Constitución Política ${ }^{62}$.

1.1.4.4 Promover la prosperidad general y la efectividad de la Constitución. En la implementación del Estado Social es necesario que las normas existentes sean eficaces. Es así, como se ubica a la Constitución en la cúspide del ordenamiento jurídico, ya que esta es la manifestación de la voluntad soberana. Por lo tanto, se hace importante la incorporación de la cláusula de responsabilidad del Estado, que:

[...] actúa como un nexo entre todos los poderes públicos y adicionalmente protege a los ciudadanos de las actuaciones extralimitadas de los servidores que pueden ocasionar perjuicios tanto por su acción como por sus omisiones en el ejercicio de la función pública ${ }^{63}$.

En ese sentido, todos estos derechos serían irrisorios si no se dotara al ciudadano de acciones para acceder a los mismos; es por ello, que se establecen mecanismos

60 MEIL LANDWERLIN, G. El Estado Social de Derecho: Forsthoff y Abendroth, dos interpretaciones teóricas para dos posiciones políticas. En: Revista de Estudios Políticos. № 42 (Nov-Dic, 1984). p. 211-225.

61 COLOMBIA. CORTE CONSTITUCIONAL DE COLOMBIA. Sentencia T-505 de 1992. M.P Eduardo Cifuentes Muñoz. Bogotá. p. 11.

62 MARTÍNEZ CABALLERO, Alejandro. Apuntes sobre el concepto de Estado Social en la Constitución Colombiana. En: Revista del Colegio Mayor de Nuestra Señora del Rosario. No. 557. (Jun-Jul, 1992). p. 15.

63 SÁNCHEZ CANO, Hernán; QUINTERO GARCÍA, Harvey y ARDILA QUIRÓS, Juan. Modelo Económico para un Estado Social de Derecho: Caso Colombiano. Trabajo de grado Abogado. Medellín: Universidad de Antioquia. Facultad de Derecho. 2007. p. 99. 
tales como la acción de tutela, que "se convierte en un medio para la protección de los derechos fundamentales que se pueden ver afectados por acciones tanto del Estado como de particulares"64.

A su vez, se configura la prohibición de limitación de los derechos fundamentales bajo los denominados "estados de excepción", que constantemente derivaban en violaciones a los derechos humanos. Para la garantía de este amplio conjunto de derechos se considera necesaria la institucionalización de un guardia institucional de la Constitución, siendo así como nace la Corte Constitucional en el año de 1991, "con el principal objetivo precaver la violación de los derechos fundamentales que se puede dar en el ejercicio de actividades tanto estatales como particulares"65.

1.1.4.5 La vigencia de un orden justo. La vigencia de un orden justo resulta, según Martínez Caballero ${ }^{66}$, de la transformación de un Estado formal de Derecho a un Estado material de Derecho, con el fin de buscar la equidad en las relaciones de poder que se dan en los campos políticos, sociales y económicos, dentro de una interrelación entre la sociedad y el Estado que, además, está ajustada a los lineamientos en los distintos acuerdos internacionales de protección de los Derechos Humanos. Es vital resaltar que el modelo de Estado Constitucional aparece como un compuesto de dos tradiciones constitucionales: la perspectiva norteamericana, que plantea a la Constitución como un esquema que delimita la competencia social y política, garantizando a los sujetos la evolución de su plan personal de desarrollo de vida, dándole a la Constitución la ubicación en la cúspide del ordenamiento jurídico al reconocerla en un status jurídicamente superior a las demás normas.

1.1.5 Contenido del Estado Social de derecho. En la actualidad, el modelo de Estado Social de Derecho ha sido incorporado por gran parte de los países europeos, entre los cuales vale la pena resaltar a Alemania, Francia y España. Concretamente, en Colombia, este modelo fue acogido por la Constitución de 1991, sin embargo, "la extensión que se le ha dado ha estado condicionada a los diferentes aportes de carácter histórico, económico y social que le han dado características particulares"67; así las cosas, se toman como características fundamentales de este modelo de Estado:

\footnotetext{
64 Ibíd. p. 100.

${ }^{65}$ MARTÍNEZ CABALLERO, Alejandro. Op. Cit. p.15.

66 Ibíd. p. 100-101.

67 SÁNCHEZ CANO, Hernán; QUINTERO GARCÍA, Harvey y ARDILA QUIRÓS, Juan. Op. Cit. p. 86.
} 
1.1.5.1 La estructura social El modelo de Estado Social incorpora a la realidad jurídica el concepto de pluralidad, que se sustenta en la diversidad racial, religiosa, política, cultural de la realidad actual; esta inclusión de minorías en los programas estatales es una manifestación de la democracia. Teniendo en cuenta lo anterior, se plantea el concepto de democracia real, que implica desligarse de las decisiones y acciones individualistas. Es así como se "[...] busca la supresión del individualismo, dando paso al trabajo colectivo a través de los diferentes grupos de la sociedad, conllevando a la concertación y el trabajo con un solo fin"68.

La piedra angular del pluralismo es la solidaridad y la identidad con aspectos comunes, la discusión social torna sobre los aspectos grupales, delimitando la función del Estado hacia los intereses de comunidades, con el propósito de impulsar una política para la equidad. Esta particular estructura, tras reconocer el pluralismo cultural, tiene como acierto el gran desarrollo que se encuentra en las relaciones internas de los grupos y facilita la lucha entre paradigmas culturales diferentes, que reemplazan la interferencia estatal por usos, costumbres y organizaciones espontáneas nacidas en el seno de las comunidades, ya que estos grupos se identifican más con sus propios ideales que con los que pueden llegar a ser impuestos por el Estado.

1.1.5.2 Nueva dimensión de los derechos fundamentales Dentro de las características esenciales del Estado Social de Derecho, ha de resaltarse el respeto y protección de los derechos fundamentales, pues los mismos dejan de ser un mero límite estatal para transformarse en instrumentos que garantizan la actividad positiva destinada a posibilitar la inclusión de los sujetos y de los demás sectores en el ejercicio de la actividad estatal. Lo anterior, lleva a la inclusión de la Carta Fundamental de Derechos, no solamente en lo referente a libertades clásicas, sino también los derechos económicos, sociales y culturales, teniendo en cuenta que "no se trata únicamente de la necesidad de programarlos, antes bien, lo que se busca es que se puedan concretar en la realidad a través de los diferentes vehículos para su consecución" 69 .En la Constitución Política colombiana ${ }^{70}$, se pueden evidenciar diferentes derechos fundamentales, dentro de los cuales se pueden enunciar: el derecho a la vida, a la dignidad, a la integridad personal, a la autonomía, a la igualdad, a la asociación, a la defensa, a la libertad, a la seguridad y a la intimidad; también se incluyen las libertades de expresión, asociación, reunión y conciencia, entre muchos otros que son conquista del constitucionalismo colombiano y que observados en retrospectiva bajo la égida Constitución de 1886 resultarían impensables.

68 LUCAS VERDU, Pablo. La Lucha por el Estado de Derecho. Bolonia.: Publicaciones del Real Colegio de España, 1975. p. 96.

69 lbíd. p. 89.

70 COLOMBIA. Constitución Política de Colombia. [Título II]. 35a Ed. Bogotá.: Legis, 2016. 
Por otra parte, en el país, estos derechos gozan de aplicación inmediata o eficacia directa, siendo innecesaria su reglamentación a través de normas legales, a fin de lograr su efectividad ante cualquier autoridad, pues cualquier ciudadano goza del vehículo jurídico para invocar su existencia y exigir que sean respetados y procurados por los particulares y/o por las autoridades, constituyendo así un conjunto de garantías básicas, cuyo objetivo es buscar la supervivencia de la democracia y una interrelación respetuosa entre los diferentes individuos que forman parte de la sociedad.

1.1.5.3 Estado democrático La definición de un Estado democrático equivale a entender que todo poder público emana del pueblo soberano, el cual es la fuente que le otorga legitimidad a la Constitución dentro del entramado estatal. No obstante, tal afirmación infiere que todas las esferas del poder particular deben responder a principios eminentemente democráticos. Es así como se hace necesaria la implementación de procedimientos decisivos en los cuales las partes intervinientes deben ser tratadas de igual forma y con respeto, promoviendo mediante su actuar axiomas reconocidos constitucionalmente. El Estado Social además de fundarse en la idea de democracia política, se ubica dentro del enfoque de una instauración de democracia social, cuyas manifestaciones son la democracia económica y la democracia empresarial. Por ello, es evidente que el Estado Social de Derecho no solo se refiere a la participación en los criterios de distribución del producto, sino que también "exige la participación social en las decisiones de las corrientes económicas, la incentivación y gestión de la producción empresarial”"71.

Así, pues, el concepto de democracia reafirma la coexistencia de diversas concepciones sobre la realidad, cuestión que pese a fomentar la diferencia de intereses grupales, permite que en el proceso de una sana discusión entre los ciudadanos surja una sociedad de concepción universalistas compuesta por varias cosmogonías y formas de vida. En la democracia es común que se torne la discusión abierta y pacífica, pues es vista como algo inherente para la consecución de un acuerdo y solución consensuada e incluyente. Es aquí donde el valor de la mayoría termina convirtiéndose en el principio que fundan las decisiones políticas, claro está, proporcionando las garantías en un proceso integrador, igualitario, participativo y ecuánime, para dar una verdadera inclusión a las minorías y con ello a la igualdad política de éstas, así como la participación de todos los posibles afectados ${ }^{72}$.

Así las cosas, el Estado Social de Derecho es evidentemente contradictorio con el régimen autoritario, bajo la definición de este último como un sistema político en el

71 LUCAS VERDU, Pablo. Op. Cit. p. 90-91.

72 MANRIQUE REYES, Alfredo. La Constitución de la Nueva Colombia. Bogotá.: Editorial Presencia, 1991. p. 7. 
que la intervención de los bienes económicos y culturales no va acompañada de la participación en la voluntad soberana del Estado, ni de la participación de los afectados en el proceso de distribución o reasignación de los bienes y servicios. Por tanto, las decisiones se reducen al control de unos grupos de personas designadas por una autoridad superior, de modo que la participación sea mínima en las decisiones y políticas ${ }^{73}$. Aquí resulta evidente, entonces, que en dicho Estado autoritario, la autoridad se impone como un ejercicio de poder en donde se presenta una ausencia de mecanismos participativos para la adopción de decisiones, con lo que se origina un orden social carente de derechos y libertades, del que dista diametralmente el Estado Social de Derecho.

En consecuencia, el Estado democrático se caracteriza por organizarse socialmente atribuyendo la titularidad del poder al conjunto de la sociedad, adoptando decisiones colectivas gracias a mecanismos óptimos de participación ciudadana. Precisamente, la democracia ha de cumplir un papel preponderante como mecanismo para resolver las cuestiones en torno a la configuración y puesta en práctica del poder político.

1.1.5.4 Pluralismo y participación. La comprensión de la idea de democracia en el Estado Social de Derecho implica que en la institucionalización del Estado no se estructure en un tipo centralista excluyente; por consiguiente, es necesario, para alcanzar el correcto funcionamiento estatal, que las personas se integren de manera pluralista, es decir, "que los sujetos se vinculen y participen en los diferentes desarrollos políticos, económicos, sociales y culturales, haciendo un reconocimiento de la diversidad"74. Los valores de participación y pluralismo exigen una Carta Política que comprenda una relación dogmática y filosófica de la democracia. Desde esta perspectiva, la participación no solo hace referencia al campo político electoral, el cual podría reducirse a elegir y ser elegido, sino que además incorpora una participación en el campo social, económico y cultural. Precisamente, para que "se materialice la parte dogmática y programática, es necesario que se cumpla con una estructura que incorpore todos los campos, facilitando la participación de los ciudadanos" 75 .

Es así como el pluralismo se convierte en la forma de materialización institucional y social de la diversidad en el plano de la realidad, permitiendo la coexistencia recíproca de diversos grupos que comportan sus propios intereses, organización y valores, los cuales "necesariamente se deben incorporar en el desarrollo político, y

\footnotetext{
${ }^{73}$ GARCÍA PELAYO, Manuel. Manual de Derecho Constitucional Comparado. Madrid.: Alianza Editorial, 1984. p. 49.

74 SÁNCHEZ CANO. Op. Cit. p. 92.

75 lbíd. p. 92.
} 
que ofrecen diferentes visiones de contenido normativo, creando diferentes perspectivas de realidad e interacciones, entre ellas a través del juego político en la realidad heterogénea"76. De esta forma, la configuración del pluralismo como principio fundante del Estado Social de Derecho, es indispensable en tanto permite la coexistencia de diversas concepciones en un plano de igualdad, respeto y coordinación.

Respecto a la participación, "la Constitución ha de asumir un modelo que convierta en públicos los espacios antes vedados del poder estatal, en tanto que la participación es uno de los principales instrumentos para constituir el principio democrático en el sistema constitucional"77. De esta forma, la participación ciudadana es indispensable para ampliar los derechos que corresponden al cuerpo social y, al mismo tiempo, para ejercer un efectivo control sobre los órganos del poder, puesto que un Estado que prescinde del pluralismo tiende aceleradamente a adoptar formas autoritarias en el ejercicio de la autoridad.

1.1.5.5 Estado redistribuidor. A diferencia de un Estado de tendencia socialista, el Estado Social de Derecho no hace referencia al dominio de los medios de producción, sino que busca que los productos de estos se vean repartidos de manera equitativa en la sociedad. Esto permite evidenciar la pérdida del poder del Estado sobre el control de la propiedad privada, poniendo como "límite la función social de dicha propiedad y creando en consecuencia, un cuadro de acción que va estableciendo una delimitación para el ejercicio de los derechos absolutos de los titulares del derecho real de domino"78. Por lo tanto, aunque el Estado Social no tiene entre su política el control de los medios de producción, tiene el deber de garantizar la igualdad material, la cual se persigue a través de la imposición de medidas en materia económica que promuevan la equidad y la justicia material ${ }^{79}$.

Precisamente, uno de los principales propósitos del modelo de Estado en cuestión, es avanzar hacia una mejor redistribución del ingreso que logre corregir las diferentes situaciones de sectores desfavorecidos de la sociedad, entendiendo que tal redistribución debe presentarse no solo en el ámbito económico, sino también en el ámbito político.

\footnotetext{
${ }^{76}$ MANRIQUE REYES. Op. Cit. p. 7.

77 TORRES ÁVILA, Jheison. El mandato del Estado Social de Derecho en la Constitución colombiana: los derechos sociales y el mínimo vital. Bogotá.: Ediciones USTA, 2012. p. 67.

78 SÁNCHEZ CANO. Op. Cit. p. 93.

79 Ibíd. p. 93-94.
} 
1.1.5.6 Estado director. A partir de la función de redistribución adquirida por el Estado Social de Derecho, surge la necesidad de que el mismo sea el dirigente de todos los procesos económicos dentro de una economía de mercado, a través de la administración de una política de redistribución del producto social, regulado estructuralmente por el Estado. De esta manera, la función del Estado Social se diferencia de lo aplicado por el Estado Liberal, pues participa de manera activa en la estructuración y regulación del desarrollo económico, buscando a través de la implementación de políticas de injerencia directa, la consecución de metas que garanticen la evolución económica del país. Para la consolidación de esta nueva dinámica estatal es necesario que se supere el denominado "Estado legislativo", para darle paso a un Estado administrativo que no solo actúe bajo el imperio de la ley, sino que incorpore criterios en el ejercicio de la función estatal, garantizando una mayor eficacia en la gestión administrativa. "Es en este sentido que el legislador conserva como función principal la de ejercer un control político sobre el poder ejecutivo, direccionando de esta forma los objetivos del Estado"80.

1.1.5.7 Garantías jurídico-formales. El Estado Social de Derecho se enriquece, en función de su esencialismo democrático, de algunas nociones jurídicos-formales planteadas por el Estado de Derecho. El intercambio de principios sociales y democráticos del Estado Social con respecto a los planteamientos que le anteceden del Estado de Derecho se consolidan en la Constitución Política, considerada la cúspide del sistema jurídico, fuente de legitimidad a toda la estructura estatal. El desarraigo de la visión de un Estado formalista caracterizado por su tendencia conservadora "no infiere abandonar la actividad y la función de los poderes públicos sometida al principio de legalidad, sino evita la creación de vacíos y anomias jurídicas"81.

Es así como la dogmática jurídica se transforma en un instrumento de los sujetos de derecho para detener el ejercicio abusivo del poder estatal "el cual ocasiona perjuicios no sólo en el sentido individuo-Estado, sino que se transforma a su vez en una violación de valores y principios constitucionales que afectan a todos los ciudadanos"82. Con respecto a lo anterior, el Estado Social de Derecho debe dirigir la protección de diferentes valores que garanticen ante todo la subsistencia mínima del individuo en la sociedad, y esto lo resalta Silva Henao ${ }^{83}$, a través de la protección de los sectores menos favorecidos, creando así la necesidad de coordinación de diferentes servicios, tales como la asistencia sanitaria, la salud, la educación pública, la regulación del trabajo, la vivienda digna, los subsidios familiares, el acceso a recursos culturales y recreativos, la asistencia a los grupos vulnerables o

\footnotetext{
80 SÁNCHEZ CANO. Op. Cit. p. 94.

81 Ibíd. Pág. 95.

82 SÁNCHEZ CANO. Op. Cit. p. 95.

${ }^{83}$ SILVA HENAO, Juan Fernando. Op. Cit. 152.
} 
discriminados, (como minusválidos, ancianos y menores), la inclusión social, la protección del medio ambiente, la planificación del mercado e impuestos sobre la renta, entre otros.

En este orden de ideas, se puede inferir que el Estado Social de Derecho interviene en la sociedad para garantizar los valores jurídico-formarles, tales como la asistencia social, la procura de la existencia de los sujetos y la redistribución de bienes y servicios, para así darle garantía a la integración de los diferentes grupos y la consecución de la participación de estos en la dirección de políticas que repercutan en la sociedad en general.

1.1.6 El Estado Social de Derecho en Colombia. La Constitución Política de 1991 establece que "Colombia es un Estado social de derecho, organizado en forma de República unitaria, descentralizada, con autonomía de sus entidades territoriales, democrática, participativa y pluralista, fundada en el respeto de la dignidad humana, en el trabajo y la solidaridad de las personas que la integran y en la prevalencia del interés general" 84 . La consigna Estado Social de Derecho, que ha sido de amplia acogida mundial, se ve reflejada en Colombia en este precepto constitucional por medio del cual define su modelo de organización política y plasma los principios que rigen su actividad. No obstante, esto no funge solamente como un postulado para impregnar de un formalismo decorativo el pacto social colombiano, sino que es la definición de Estado que reclama cometidos de reivindicación social devenida de experiencias añosas en escenarios internacionales y que tímidamente se había intentado reformular en vigencia del decimonónico régimen constitucional que imperaba en Colombia.

De esta manera, en el panorama internacional, se abordó el modelo de Estado adoptado por Colombia en un tenue atisbo sobre la transición de Estado de Derecho al Estado Social con cotejo a la recepción acaecida en la legislación interna, en el que se incluyeron las premisas sostenidas en los cinco meses que tardaron las deliberaciones en la Asamblea Nacional Constituyente, partera de la conspicua definición de Estado que caracteriza al país.

En el trascurso del documento, se expondrán los destacados pronunciamientos de la Corte Constitucional colombiana en lo referente a la noción de Estado Social, su alcance y las implicaciones derivadas de procurar la materialización en su dimensión cuantitativa y cualitativa.

${ }^{84}$ COLOMBIA. Constitución Política de Colombia. [Título I]. 35a Ed. Bogotá.: Legis, 2016. 
En lo referente a la Constitución Politica de Colombia, el primer artículo de la Carta Magna de 1991, exhorta a que las normas no sean "vistas exclusivamente como reglas sino también como principios requeridos de ponderación y maximización"85 en virtud del componente axiológico que ostenta la cláusula social del Estado. De lo anterior, se destacan las implicaciones institucionales del Estado Social en pos de su sostenibilidad prospectiva y su posterior consolidación en el marco de un entorno económico, cada vez menos compatible con el ethos social del Estado.

\subsubsection{La perspectiva histórica y la influencia internacional en el tránsito de} Estado de Derecho a Estado Social de Derecho en Colombia en la construcción del modelo de estado. En 1991, se promulgó la actual Constitución Política de Colombia, con la que el país actualizó su estructura desde la perspectiva de la teoría constitucional, incorporando el modelo del Estado Social de Derecho. Sin embargo, es revelante mencionar que en ocasiones pretéritas, ya se había intentado la aplicación de postulados de índole social en el país como el del presidente López Pumarejo con la reforma constitucional de 1936, en el marco de la revolución en marcha, medio siglo después de la entrada en vigencia de la Constitución de 1886. Esta Carta Política fue objeto de plurales reformas que no ostentaron el calado suficiente para afrontar la realidad social colombiana del siglo XX y la tendencia mundial en pos de una vocación social predicable del cada vez más relevado Estado de Derecho, en lo que a la cuestión social repercute.

La premisa laissez faire, laissez passer, había rebosado la demanda social de la población invadida por un periodo de industrialización que agudizaba la desigualdad de las relaciones humanas de la época, que incitó el enaltecimiento de los trabajadores como actores políticos que propendían por la reivindicación de mejores condiciones en una sociedad capitalista y hegemónica que encontraba respaldo jurídico-político en una concepción de Estado abstencionista con aprehensión del individualismo. De esta manera, "los ideales de libertad, propios de la modernidad se enfrentaron a la necesidad de igualdad material, ideales deducidos de la marginalidad y del riesgo a 'los que se enfrentó uno de los actores políticos de esa época: los trabajadores" 86 . Consecuente con esa situación y procurando la no extinción de statu quo, se dió cabida a las proposiciones de carácter social relacionadas con el accionar de Estado del que solo se podría exigir un actitud parsimoniosa de no intromisión.

85 BASTIDAS MORA, Patricia. El modelo de organización política del estado social y democrático de derecho y sus desafíos. En: Constitucionalismos Comparado. Universidad Nacional de Colombia, Bogotá D.C., 2009. Pág. 45-59.

86 GOMEZ IZASA, Maria Cristina. La historia del Estado Social de Derecho. Universidad de Antioquia, 2006. (en línea) http://bibliotecadigital.udea.edu.co/bitstream/10495/2272/1/La\%20historia\%20del\%20estado\%20social\%20de\%20derecho.pdf. 
Así bien, Lorenz Von Stein, economista alemán a quien la historia le arroga ser uno de los precursores de la edificación del concepto Estado Social, es quien postula este modelo de Estado "como una manera de evitar la revolución socialista"87, debido a que se considera que el Estado Social es:

Un punto medio entre los sistemas totalmente liberales o de "derecha" y los sociales o de "izquierda", que pese a ser totalmente contrarios, pueden encontrar un punto de equilibrio al reconocerse valores fundamentales de uno y de otro, tales como el individualismo y la propiedad privada del modelo liberal, acompasados con las garantías sociales, tales como la función social de la propiedad, la regulación estatal de la economía, los sistemas de seguridad y asistencia social, entre muchas otras expresiones de inspiración socialistas y capitalista ${ }^{88}$

En razón a lo anterior y a la correlativa pululación de "tendencias surgidas en el siglo $\mathrm{XIX}$ y comienzos del XX para regular, en aquel entonces, aspectos parciales de la sociedad, regulación que sufre en nuestro tiempo un proceso de generalización, integración y sistematización" 89 , es que Colombia termina subsumiéndose en la línea ideológica de los prolíficos postulados recogidos en la Constitución de Querétaro en México (1917) y en la Constitución de Weimar en Alemania (1919), de las que hace su primer intento en la aludida reforma constitucional de 1936, tanto así, que Vidal Perdomo considera que "las bases del Estado social de derecho estaban echadas en nuestro país desde $1936 " 90$. No obstante, no es hasta la promulgación de la Carta Política de 1991 que "se considera la adopción de Estado Social de Derecho como principio rector de su actividad" 91.

Con fundamento en la ávida demanda de igualdad material reclamada desde de la base social y a la creciente afinidad internacional por que el Estado se inmiscuyera en los asuntos coyunturales de la realidad imperante de la sociedad, es que el constituyente primario adoptó el modelo de Estado Social de Derecho, advirtiéndose que así como en la Colombia de la última década del siglo XX "no existió [...] una "teoría" acerca del Estado Social, sino una pluralidad de propuestas y opiniones que reclamaban la intervención de Estado para corregir la situación social de miseria"92,

87 SILVA HENAO, Juan Fernando. Op. Cit. p. 149.

88 Ibíd. p. 150.

${ }^{89}$ GOMEZ ISAZA, Maria Cristina. Op. Cit. p. 79

90 GOMEZ MONTAÑEZ, Jaime Alberto. Derechos Humanos y estado social de derecho. Cúcuta.: Universidad Libre, 2011. p. 77.

91 lbíd.

92 GOMEZ ISAZA, Maria Cristina. Op. Cit. p. 86. 
tampoco hubo una posición unívoca para que la nominación de Estado, que hoy conocemos, se reflejara tal cual como se adoptó.

A su vez, es conveniente reparar en las similitudes en las que en escenarios internacionales se concibió y se adoptó el Estado Social de Derecho, el cual "nace en sociedades con economía de mercado, en sociedades industrializadas como una propuesta contradictoria: mantener el sistema capitalista de producción y evitar la acumulación de riqueza en unos pocos" ${ }^{33}$. Así, el panorama colombiano no dista mucho de esa referencia historicista, pues en 1991 gravitaba en el país la denominada apertura económica del gobierno del presidente Gaviria Trujillo y las correlativa pauperización social que acarrea la adaptación del país a políticas de tinte neoliberal.

\subsubsection{La configuración del Estado Social de Derecho en Colombia en la} Asamblea Nacional Constituyente. Es evidente que la insatisfacción de la población por la desatención social del Estado, mide el pulso de la implementación de políticas de asistencia social. El panorama que está afrontando Colombia en la segunda década del siglo XXI es diferente al que afrontaba el país en el ocaso del siglo XX y estos, a su vez, de los que motivaron la expedición de la Constitución de 1886 con sus respectivas reformas de tal modo que "los problemas que para finales de los años 80 del siglo $X X$ afrontaba la sociedad colombiana distaban mucho de aquellos para los cuales había sido concebida la Constitución de 1886 [...] Por esta razón, se reclamaban cambios institucionales que pusieran a tono el Estado con los requerimientos de la época" ${ }^{4}$. Lo anterior, precisamente, en la búsqueda de esa procura existencial, constituyéndose así en la justificación del movimiento llamado "Todavía podemos salvar a Colombia" y en la propuesta de la séptima papeleta como el propulsor para convocar la Asamblea Nacional Constituyente y la correlativa expedición de un nuevo pacto social.

En este punto, vale la pena mencionar el trasegar que sorteó el constituyente primario para la adopción del Estado Social de Derecho en Colombia. La Asamblea Nacional Constituyente recibió el aval de la Corte Suprema de Justicia el 9 de octubre de 1990 mediante sentencia que declaró constitucional su convocatoria. Dicha Asamblea se instaló en febrero de 1991 integrada por 70 delegatarios elegidos en las votaciones acaecidas el 9 de diciembre de 1990, elecciones que registraron una abstención del 84 por ciento de los votantes, siendo esta la más

${ }^{93}$ GOMEZ ISAZA, Maria Cristina. Op. Cit. p. 98.

94 LASPRILLA VILLALOBO, Carlos José y SANCLEMENTE MACHADO, Daniela. El Juez de Tutela como arquitecto del estado social de derecho. En: Tesis y Trabajos de Grado Ciencias Jurídicas. Pontificia Universidad Javeriana, Bogotá D.C., 2013. p. 18-19. 
alta registrada en la historia colombiana reciente ${ }^{95}$. En lo referente a su conformación, se tiene "[...] que los liberales y conservadores en sus distintas facciones y matices obtuvieron 43 de las 70 sillas. El movimiento AD-M19 consiguió 19 representantes, incluidos varios liberales y conservadores que figuraban en sus listas. Otros grupos obtuvieron los 8 escaños"96, delegados que tuvieron que analizar los misceláneos proyectos y propuestas sometidos a su consideración aportados por los diferentes sectores económicos, sociales y políticos. La Carta Política que se expidió contiene 380 artículos definitivos y 60 transitorios para hacerle frente a la crisis de gobernabilidad y de legitimidad del régimen ${ }^{97}$.

La Gaceta de la Asamblea Nacional Constituyente cuenta con 144 números, en la cual constan extractos de los proyectos presentados, de las propuestas aportadas por la sociedad civil y las decisiones adoptadas oficialmente. Es pertinente resaltar que la vocación con perfil social del Estado estuvo desde su creación.

Con fundamento en el análisis que hace Silva Henao del medio de comunicación oficial de la Asamblea Nacional Constituyente, las Gacetas Constitucionales, se advierte la tendencia social del modelo de Estado que se adoptó ulteriormente, a saber, una de las propuestas presentadas por delegatarios del Partido Liberal coincidían con ese raigambre social que querían inocularle al modelo de Estado, como el que se desprende de la propuesta "Colombia es un Estado de derecho, democrático, liberal, pluralista y social" 98 , visible en la Gaceta Constitucional No.4 de 1991. Algo similar, pero menos adjetivado al presentado por el representante liberal, el gobierno del presidente Gaviria propuso "Colombia es un estado de derecho, social y democrático" 99 , contenido en la Gaceta Constitucional No. 5 de 1991. Asimismo, otra de las tantas nominaciones propuestas fue la del delegatario Navarro Wolff, que propuso "Colombia es una República soberana e independiente [...] Se rige por los principios del Estado democrático y social de Derecho"100, contenido en la Gaceta Constitucional No.8 de 1991, proposición que se adhiere a la consagración del término social.

Ahora, acuñar este término no se trató de una exclamación reiterativa en todas las propuestas presentadas, ejemplo de esto, la de los conservadores Juan Gómez Martínez y Hernando Londoño: "Colombia es un Estado Unitario Descentralizado,

95 MATIAS CAMARGO, Sergio Roberto. La Asamblea Nacional Constituyente de 1991 y el Nuevo Constitucionalismo Latinoamericana. En: Diálogos de Saberes. No. 44 (Ene - Jun, 2016). p. 38.

96 Ibíd.

97 GRANDA MARÍN, Alberto. Asamblea Nacional Constituyente y Constitución Política de 1991 En: Revista Pensamiento Humanista. No. 2. (1994). p. 8.

98 SILVA HENAO, Juan Fernando Op. Cit. $p<.154$

99 lbíd.

100 Ibíd. p. 155 
con un gobierno presidencial y un régimen democrático"101, plasmada en la Gaceta Constitucional No.9 de 1991.

Así tan diversa fue la edificación del concepto de Estado Social de Derecho en el ocaso del Siglo XIX y en los albores del Siglo XX, como también, lo fue para Colombia encontrar una nominación que redundara en el amparo de la dignidad del hombre y en la prevalencia del interés general que relevara los vestigios individualistas del Carta Política de Núñez.

1.1.6.3 La postura gnoseológica de Estado Social Derecho derivada de la
interpretación efectuada por el máximo órgano constitucional colombiano. Abordando la noción de Estado Social de Derecho, en 1992, por medio de la sentencia T-406 102 , la Corte Constitucional aclaró algunas cuestiones sobre su tenor, entre estas, que el término "social" no es una simple muletilla retórica, sino el punto central de la Constitución. Con el constituyente del 91, la Constitución pasó a considerarse más que un presupuesto político programático, a una norma jurídica de carácter dinámico, que da cabida a interpretaciones y a la consagración de una amplia gama de derechos dentro de su cuerpo normativo.

La jurisprudencia de la Corte Constitucional ha dado una importante contribución al fortalecimiento de la estructuración del Estado Social de Derecho. A través de diversos fallos, la Corte ha corregido y establecido principios fundantes del Estado Social de Derecho, un ejemplo de estos casos es la sentencia C-131 de $1993^{103}$, en la cual se llega a la conclusión de que la expresión "imperio de la Ley", expuesta en el artículo 230 de la Carta, debe ser interpretada de manera material, y no de manera puramente formal (la que se deriva del poder del legislador), entendiendo a la Constitución como norma vinculante de carácter general, dado que se ubica en la cúspide del sistema jurídico colombiano.

Con base en una tenue asimilación de las implicaciones del Estado Social de Derecho, puede predicarse que "no es más que el proceso de adaptación de la vieja estructura del establecimiento político a las nuevas necesidades del desarrollo técnico, social y económico"104; una concepción rasa a la que el Tribunal Constitucional Colombiano le ha dedicado sendos pronunciamientos en aras de

101 lbíd.

102 COLOMBIA. CORTE CONSTITUCIONAL DE COLOMBIA. Sentencia T-406 de 1992. M.P. Ciro Angarita Barón. Bogotá.

${ }_{103}$ COLOMBIA. CORTE CONSTITUCIONAL DE COLOMBIA. Sentencia C-131 de 1993. M.P. Alejandro Martínez Caballero. Bogotá.

104 ÁLVAREZ DÍAZ, Oscar Luis. Estado Social de Derecho, Corte Constitucional y desplazamiento forzado en Colombia. Bogotá.: Siglo del Hombre Editores, 2008. p. 26. 
hacer comprensible una noción de Estado que va más allá de las erogaciones presupuestales que se desprenden de su actividad. En otras palabras, la cláusula que define el modelo de Estado refleja el sustento constitucional y político del país, el cual implica un cambio del paradigma funcional que permea a todas la instituciones estatales en búsqueda de esa empatía institucional y administrativa con el modelo adoptado formalmente, que propugna por hacer tangible la dignificación del ser humando simultaneo a la consolidación de "un doble fenómeno de socialización del Estado y estatalización de la sociedad"105. Esto último es lo que permite la deconstrucción de los vestigios del Estado gendarme, del que "el Estado social de derecho no desconoce en absoluto los valores esenciales del anterior régimen, como la libertad y la igualdad, sino que por el contrario los asume y los dinamiza, con la idea de que la sociedad y el individuo no pueden ser categorías aisladas y contradictorias, sino dos términos en tal implicación recíproca que no puede realizarse el uno sin el otro"106.

Desde 1991, según el docente Torres Ávila, el constitucionalismo colombiano se ha transformado profundamente. Las instituciones asumen los dictados presupuestos constitucionales orientados por lo nuevos compromisos del Estado y de la sociedad y en ello la Corte Constitucional desempeña un papel preponderante, pues constituye el paso para llegar a una forma más abierta y comprometida de entender la Carta Política. El Estado Social de Derecho con principios de carácter social transforma las nociones de las primeras constituciones republicanas enmarcadas en el Estado de Derecho. Esta nueva forma de entender el Estado está basada en principios establecidos hace más de medio siglo e inspirada en modelos constitucionales y en el principio de la solidaridad expuesto por diferentes doctrinantes, como el francés León Dugüit, y la expresión constitucional de las teorías sociológicas entonces en boga, en particular las de Emile Durkheim y Georges Gurvitch, entre otros autores que influenciaron las concepciones políticas y constitucionales en el país. De esta forma, se insertan en el ordenamiento jurídico colombiano valores como:

[...] la función social y ambiental de la propiedad, los deberes sociales, la intervención del Estado, la gratuidad de la enseñanza primaria y su obligatoriedad en el grado que señale la ley, así como la protección al trabajo y la asistencia pública ${ }^{107}$.

\footnotetext{
105 Ibíd. p. 28

${ }^{106}$ ÁLVAREZ DÍAZ, Oscar Luis. Estado Social de Derecho, Corte Constitucional y desplazamiento forzado en Colombia. Op. Cit. p. 29

107 TASCÓN, Enrique. Derecho Constitucional Colombiano. Citado por COPETE LIZARRALDE, Álvaro. Lecciones de Derecho Constitucional Colombiano. Bogotá.: Ediciones Lerner, 1960.
} 
La doctrina alemana, representada por Ernst Forsthoff, acuñó el término procura existencial para referirse "[...] al amplio espacio de necesidades que el individuo no está en capacidad de atender efectivamente, requiriendo por ello la asistencia del Estado"108. En consonancia con lo anterior, la Corte Constitucional en uno de sus pronunciamientos se refierió al alcance que detenta la referida "asistencia del Estado", acotando que:

[...] el término 'social' se señala que la acción del Estado debe dirigirse a garantizarles a los asociados condiciones de vida dignas. Es decir, con este concepto se resalta que la voluntad del Constituyente en torno al Estado no se reduce a exigir de éste que no interfiera o recorte las libertades de las personas, sino que también exige que el mismo se ponga en movimiento para contrarrestar las desigualdades sociales existentes y para ofrecerle a todos las oportunidades necesarias para desarrollar sus aptitudes y para superar los apremios materiales ${ }^{109}$.

El constituyente de 1991 postuló el cumplimiento de fines esencialmente sociales del Estado y con ello estableció la premisa ideológica del Estado Social de Derecho ${ }^{110}$. Por esta razón, es válido mencionar el importante cambio que se genera con la incorporación de los principios fundantes de este nuevo modelo, convirtiéndose en un pacto socio-político que incorpora diversos aspectos de la vida tradicionalmente marginados de las grandes decisiones políticas.

La Corte Constitucional ha definido en numerosos fallos el concepto constitucional del Estado Social de Derecho, dentro de los cuales cabe destacar algunas consideraciones que permiten arrojar más luz sobre los efectos de ese principio estatal. En la sentencia C-566 de 1995, con ponencia del magistrado Eduardo Cifuentes, se señala que:

El Estado Social de Derecho se erige sobre los valores tradicionales de la libertad, la igualdad y la seguridad, pero su propósito principal es procurar las condiciones materiales generales para lograr su efectividad y la adecuada integración social [...]. Las finalidades sociales del Estado, desde el punto de vista del individuo, son medios

\footnotetext{
108 MAGALDI, Nuria. Procura existencial, Estado de Derecho y Estado Social. Universidad Externado de Colombia. Bogotá D.C, 2007. Pág 15.

109 COLOMBIA. CORTE CONSTITUCIONAL DE COLOMBIA. Sentencia T-772 de 2003. M.P. Manuel José Cepeda Espinosa. Bogotá, D.C.

110 COLOMBIA. Constitución Política de Colombia. Artículo 2 [Título I]. 35a Ed. Bogotá.: Legis, 2016.
} 
para controlar su entorno vital y a partir de allí desarrollar libremente su personalidad, sin tener que enfrentarse a obstáculos cuya superación, dado su origen, exceda ampliamente sus fuerzas y posibilidades. [...]. El Estado Social de Derecho, se proyecta en la Constitución, en primer término en la consagración del principio de igualdad y en la prestación de los servicios públicos. En segundo término, a través de los derechos de participación de todos en las decisiones que los afectan y en la vida económica, política, administrativa y cultural de la nación, que se compendian en el principio democrático y gracias al cual se socializa el Estado y las diferentes instancias de poder dentro de la comunidad. La orientación social del Estado, elevada a rasgo constitutivo suyo, articulada en varias disposiciones de la Constitución, resulta vinculante y obligatoria para todas las ramas del poder público ${ }^{111}$.

En similar sentido y como precedente, se cuenta con lo establecido en la Sentencia C-587 del 12 de noviembre de 1992, con ponencia del magistrado Ciro Angarita Barón:

\begin{abstract}
En el Estado Social de Derecho -que reconoce el rompimiento de las categorías clásicas del Estado liberal y se centra en la protección de la persona humana atendiendo a sus condiciones reales al interior de la sociedad y no del individuo en abstracto-, los derechos fundamentales adquieren una dimensión objetiva, más allá del derecho subjetivo que reconoce a los ciudadanos. Conforman lo que se puede denominar el orden público constitucional, cuya fuerza vinculante no se limita a la conducta entre el Estado y los particulares, sino que se extiende a la órbita de acción de estos entre sí. En consecuencia, el Estado está obligado a hacer extensiva la fuerza vinculante de los derechos fundamentales en el trafico jurídico privado, el Estado juez debe interpretar el derecho siempre a través de la óptica de los derechos fundamentales ${ }^{112}$.
\end{abstract}

Adicionalmente, en la sentencia C-449 de 9 de julio del mismo año, con ponencia del Magistrado Alejandro Martínez Caballero, se argumenta que:

111 COLOMBIA. CORTE CONSTITUCIONAL DE COLOMBIA. Sentencia C-566 de 1995. M.P. EDUARDO CIFUENTES MUÑOZ. Bogotá.

112 COLOMBIA. CORTE CONSTITUCIONAL DE COLOMBIA. Sentencia C-587de 1992. M.P. Ciro Angarita Barón. Bogotá. p. 1. 
La concepción clásica del Estado de derecho no desaparece, sino que viene a armonizarse con la condición social del mismo, al encontrar en la dignidad de la persona el punto de fusión. Así, a la seguridad jurídica que proporciona la legalidad se le aúna la efectividad de los derechos humanos que se desprende del concepto de lo social. El respeto por los derechos humanos, de un lado, y el acatamiento de unos principios rectores de la actuación estatal, por otro lado, constituyen las consecuencias prácticas de la filosofía del Estado Social de Derecho. En este sentido el concepto de Estado Social de Derecho se desarrolla en tres principios orgánicos: legalidad, independencia y colaboración de las ramas del Poder Público para el cumplimiento de los fines esenciales del Estado y criterios de excelencia. [...]. La nueva Constitución Política definió a Colombia como un Estado Social de Derecho en su artículo $1 .^{\circ}$. Se trata de una definición ontológica del Estado, de suerte que el concepto Estado Social de Derecho no es una cualidad accesoria del Estado sino parte de su esencia misma ${ }^{113}$.

Es evidente la tendencia de los teóricos jurídicos contemporáneos por sustentar la incorporación del Estado Social de Derecho como la vía más adecuada para la resolución de los problemas sociales y estatales. En este sentido, el concepto "social" implica una disposición estatal, en la cual se ajustan los aparatos administrativos y las instituciones del Estado en función de garantizar los derechos de carácter social, de forma tal que esta noción no sea una ideal, sino que pueda ser materializada con el propósito de la igualdad fáctica con principios ético-políticos claros $^{114}$. Así, desde el punto de vista instrumental se dota al Estado de poderes suficientes para promover importantes cambios sociales, económicos y jurídicos, además, el Estado se erige como órgano garante de los Derechos Humanos y de la tolerancia con las diferentes expresiones políticas y sociales. De manera general, la interpretación que la Corte Constitucional ha dado al concepto de Estado Social tiene un notorio perfil progresista y las normas que se encuentran dentro de la misma Constitución se han encargado en buena medida de reflejarlo y desarrollarlo.

El desarrollo y aplicación del Estado Social de Derecho le corresponde al legislador, teniendo en cuenta lo que la interpretación constitucional señale, pero como núcleo central y definitivo de su razón de ser, uno de los activos determinantes en su proceso de definición y ejecución es la participación del ciudadano. Por otra parte, el poder ejecutivo, que en un régimen presidencialista dispone de tan poderosos instrumentos, tiene la responsabilidad de aplicar y reestructurar las normas:

113 COLOMBIA. CORTE CONSTITUCIONAL DE COLOMBIA. Sentencia C-449 de 1992. M.P. Alejandro Martínez Caballero. Bogotá. p. 1,6.

114 TORRES ÁVILA, Jheison. Op. Cit. p. 10. 
Convirtiendo a la administración en un instrumento eficaz para tales fines, haciendo al mismo tiempo que se orienten los recursos financieros a los fines del Estado. Tal será la garantía de que otro valor constitucional se cumpla: la paz y la convivencia pacífica de los ciudadanos ${ }^{115}$.

No en vano, la Corte Constitucional, en sus intentos por hacer legible la concepción de Estado que gravita en el país, demuestra que la radiografía del esqueleto que compone la estructura institucional del Estado Social de Derecho tiene cierta profundización en el poder legislativo y ejecutivo y en las ramificaciones del poder público pese a que la experiencia, aún manceba, permite colegir que ha sido el aparto judicial del Estado en cabeza de la Corte Constitucional y de los jueces de tutela, quienes más han invertido esfuerzos por la materialización de los principios dignidad humana y justicia material, que son pilares fundamentales del modelo de Estado vigente.

En ese estadio, la Corte Constitucional ha procurado impartir mediante sus pronunciamientos instrucciones que compatibilicen y armonicen los postulados del Estado Social con la actividad institucional en un empeño por extender el alcance interpretativo del mismo. Esto, con el fin de facilitar la interrelación del trinomio en el que se fracciona el poder público brindando una comprensión de Estado, puntualizar las obligaciones y contribuir a la materialización del perfil progresista en el que gestan sus decisiones de la mano a las interpretaciones que hace de los derechos fundamentales y la diafanidad de estos con los derechos sociales, económicos y culturales, también contemplados en la Constitución Política de 1991.

Contrario a lo anterior, la Constitución de 1991 plantea esta innovación política en el marco del sistema neoliberal y de apertura económica que contradice los principios anteriormente expresados. La naturaleza contradictoria del Estado Social de Derecho y el modelo económico neoliberal plantean un antagonismo teórico inevitable, en la medida que El Estado, según arguye Ivette Rodríguez ${ }^{116}$, renuncia a la administración y gestión proactiva, reconociendo en materia económica el control a diversos sectores privados. Es así como, en razón de las políticas neoliberales, se han ofuscado las funciones del mandato constitucional por parte del Estado, desembocando en consecuencias nefastas en materia social y de lucha contra la desigualdad. La causa de ello es, sin lugar a dudas, que el afán privatizador inhibe la redistribución equitativa del ingreso público y la riqueza social, ocasionando el desaparecimiento de pequeñas y medianas empresas que se vuelven incapaces

115 TORRES ÁVILA, Jheison. Op. Cit. p. 94,95.

116 Ibíd. p.14. 
de soportar todas las falencias, tales como el desempleo, la competencia desleal y la falta de inversión del sector público, entre otras.

Es precisamente en ese sentido que los derechos sociales no pueden considerarse solo como un instrumento y una institución jurídica de redistribución, sino que, entre otras cosas, ha de buscarse una extensión en donde la racionalidad del lucro desmedido no implique la reducción de los derechos sociales.

Para la consecución de la esencia del Estado Social de Derecho, resulta necesario propender por que las relaciones económicas y sociales sean reguladas de manera cabal, garantizando que el beneficio del crecimiento económico se destine a los sectores menos favorecidos y a la sociedad entera, para evitar de esta forma la privatización y conseguir un macro impulso de las políticas estatales que buscan la mayor participación de todos los sujetos en los beneficios económicos.

Sin duda, el Estado Social de Derecho, a pesar de loable, presenta notorias limitaciones en la aplicación a la realidad colombiana y requiere sobrenaturales esfuerzos, ya que dicha cláusula fue implementada en la Constitución de manera ideal, un tanto desenfocada de la realidad, lo que ha conllevando a que los presupuestos fácticos dados en el ámbito de lo material, tergiversen cada vez más la realización de un Estado Social de Derecho. Se evidencia con claridad que la implementación de esta Carta Política se dificulta debido al sinnúmero de problemas por los cuales atraviesa el país, con lo que procede que gran variedad de los principios enunciados en la Constitución no son llevados a la práctica, en razón a la ausencia de la infraestructura estatal y social que así lo permita, dando lugar a la ocurrencia de innumerables violaciones de derechos, como señalan Boaventura de Sousa y Manuel Leitao ${ }^{117}$. Siguiendo esta lógica, y en aras de solventar tal situación, el Estado tiene el deber de:

Brindar una protección a la diversidad de sectores como los grupos sociales y actores económicos, incorporándolos a la participación en el diseño de las políticas que los afectan, convirtiendo al Estado en árbitro de las relaciones que se dan entre estos, buscando siempre el cumplimiento de los valores de la carta fundante ${ }^{118}$.

117 DE SOUSA SANTOS, Boaventura y LEITAO MARQUES, Manuel. Los Tribunales en las Sociedades Contemporáneas. En: Revista Pensamiento jurídico. No.4. Universidad Nacional de Colombia (2007: Bogotá). p. 21.

118 lbíd. Pág. 15. 
Esto implica que el Estado asuma la responsabilidad que le atañe en la orientación de unas mejores condiciones para la sociedad, a través de la búsqueda de un mayor bienestar y del fomento del desarrollo económico del país, lo que infiere y hace necesaria la inclusión de los diferentes actores sociales y grupos regionales para la consecución de una reforma política que garantice el mejoramiento de todos los sectores que antes se veían excluidos, creando un entramado normativo más consecuente con los principios del pluralismo y la democracia participativa, los cuales son pilares fundamentales para el desarrollo y la consecución de los fines del Estado Social de Derecho. Los planteamientos del Estado Social pueden llegar a su exteriorización a través del desarrollo de políticas de inversión social, de fomento para la creación de empresas, de la disminución en la tasa de desempleo y de una mayor protección al sector agrícola que ha sido abandonado por diferentes gobiernos, creando abismales desigualdades cuyo desenlace histórico fue el nacimiento del conflicto armado que repercute en el ámbito social.

El desarrollo del modelo de Estado Social de Derecho constituye un cambio trascendental del paradigma estatal. En cuanto la concepción formal se transformó en responsabilidad material, el Estado debe garantizar los derechos sociales de los ciudadanos. Es así como la estructura política del Estado Social de Derecho no está determinada solo por la ley, sino que se crea una obligación constitucional de promoción positiva de la realización de los axiomas constitucionales que "significan una modificación en la teoría constitucional, convirtiendo al Estado de competencia en un Estado de axiología"119. El Estado Social de Derecho postulado en la Constitución no responde al inesperado triunfo de ninguna virtud filantrópica, sino a la actualización histórica de sus exigencias, las cuales no son ajenas al crecimiento de la economía y a la activa participación de los ciudadanos y de sus organizaciones en el proceso democrático"120.

El modelo teórico constitucional del Estado Social y Democrático de Derecho es el resultado de un proceso evolutivo e histórico. Su fin es transformar el Estado liberal clásico o Estado de Derecho hacia una concepción que garantice el acceso real a las garantías de los derechos sociales, materializados a través de las instituciones del Estado. Estos rasgos y condiciones son el resultado de las circunstancias de la evolución histórica de los derechos.

Por otra parte, el Estado Social de Derecho se nutre de los valores jurídico-políticos clásicos, los cuales han sido adquiridos de acuerdo a la orientación producida por los diferentes hechos históricos que llevaron a la satisfacción de las demandas

119 BASTIDAS MORA, Patricia. El modelo constitucional del Estado Social y democrático de derecho, sus desafíos y la constitucionalizarían del proceso. En: Revista Vía luris. № 7, 2009. p. 57

120 lbíd. p. 58. 
sociales, enriquecidos, además, con el mejoramiento de las condiciones de la sociedad a través de los derechos formulados por el Estado Social de Derecho, que se enfocan en garantizar una procura existencial, al incluir la delimitación de las herramientas que permiten controlar la acción del Estado y su ejecución real, las cuales están sujetas a la ley legítimamente establecida en la Constitución.

\subsubsection{Los retos en materia de efectividad prospectiva del Estado Social de}

Derecho en Colombia. En esta medida, la fórmula prevista en el artículo primero de la Constitución Política de $1991^{121}$, implica desde el punto de vista de la teoría jurídica, un actuar de parte del Estado en procura de la justicia material, con lo cual se resta importancia al texto legal y se le concede a la efectividad de los derechos. Bajo tal entendido, el modelo de Estado Social de Derecho requiere de una transformación institucional, la cual ha de buscarse más allá de la creación de normas que consagran derechos, en acciones que permitan su efectividad, lo que demanda al ente Estatal un mayor compromiso por la defensa de contenidos jurídicos materiales. Dicho esto, "el concepto de Estado Social de Derecho se desarrolla en tres principios orgánicos: legalidad, independencia y colaboración de las ramas del poder público, para el cumplimiento de los fines esenciales del Estado"122.

Ahora bien, se observa con claridad que para que se logre alcanzar un correcto desarrollo del modelo de Estado Social de Derecho, se tiene la obligación de traspasar la frontera meramente formal y darle cabida al cumplimiento de los diferentes valores programáticos materiales acordados en la Constitución, garantizando así el cumplimiento de sus postulados "a través de la implementación de planes garantes de una igualdad material, encaminados a la reducción paulatina de los grandes conflictos sociales, bajo el estandarte de la búsqueda de la igualdad material"123.

De esta forma, es notable que la reorientación del Estado Social de Derecho crea una estructura de valores y normas que constituyen el constitucionalismo de carácter material, en donde los poderes públicos deben dirigir sus acciones al servicio de los objetivos del Estado garante de derechos sociales. Así, al positivarse la fórmula del Estado Social de Derecho se genera un cambio en la forma de interpretación de las relaciones sociales-estatales, y al mismo tiempo, se presenta un nuevo marco ético de actuación del Estado. Como corolario de lo anterior, la carga prestacional que asume el Estado en razón de los derechos sociales,

121 COLOMBIA. Constitución Política de Colombia. Artículo 1 [Título I]. 35a Ed. Bogotá.: Legis, 2016. 122 COLOMBIA. CORTE CONSTITUCIONAL DE COLOMBIA. Sentencia C-449-1992. M.P. Alejandro Martínez Caballero. p. 1.

${ }^{123}$ BASTIDAS MORA, Patricia. Op. Cit. p. 57. 
económicos y culturales, representa uno de los desafíos de mayor trascendencia por el que debe el Estado dirigir su actuar a fin de procurar su efectividad, en tanto que:

Las finalidades sociales del Estado desde el punto de vista del individuo, son medios para controlar su entorno vital, y a partir de allí desarrollar libremente su personalidad, sin tener que enfrentarse a obstáculos cuya superación dado su origen, excedan ampliamente sus fuerzas y posibilidades ${ }^{124}$.

Resulta destacable precisar cómo los cambios intrínsecos de la sociedad a través de los años son el reflejo de la estructura vertebral del Estado, que, si se quiere ver, mantiene incólume ciertas reivindicaciones alcanzadas en el pasado, pero ajusta la actividad del Estado a ese sentir axiológico que se desprende del conglomerado social de turno, o mejor, de las necesidades sociales apremiantes. No existe entonces una cosa juzgada material en lo que al modelo de Estado respecta, por tanto representa para el poder público una concatenación programática que hace frente a la fluctuación de las carencias sociales fomentadas actualmente por el fenómeno de la globalización, concepto tan etéreo, pero que no solo aporta necesidades recientes, sino que a su vez incorpora nuevas acepciones a las ya existentes.

Con miras al futuro, los escenarios prospectivos de un modelo de Estado Social, como el que se ha venido implementando en Colombia formalmente desde 1991, exigen que toda la estructura estatal se permee de los mandatos programáticos que favorezcan al individuo tanto en su esfera social como en su dimensión personal. Es imperativo tener presente que los cambios en materia económica en conjunción con los que impone la globalización en las instituciones y en la sociedad inciden directamente sobre la política social ${ }^{125}$. Asimismo, esa tendencia descentralizadora, que acolita la privatización y la extirpación de las competencias de arrogación exclusiva para el Estado, hace que el modelo adoptado en nuestra Carta Política de 1991 presente fisuras que hagan insostenible un estado de gobernabilidad consolidado que impida brindar respuestas efectivas a las demandas sociales de la población en los periodos venideros.

124 COLOMBIA. CORTE CONSTITUCIONAL DE COLOMBIA. Sentencia C-566-1995. M.P.: Eduardo Cifuentes Muñoz. Bogotá. p. 11.

125 SOTELO, Ignacio. El Estado social: antecedentes, origen, desarrollo y declive. Madrid, Editorial Trotta, S.A., 2012. Pág 396 ProQuest ebrary. 


\subsection{LOS DERECHOS FUNDAMENTALES.}

Debemos explicitar que los derechos fundamentales, en este caso el derecho a la salud, consagrado como un derecho fundamental, es inesindible al catalogo de los derechos humanos, como fundamentos del orden jurídico colombiano. Este tipo de derechos universales son predicables a todos los seres humanos sin distinción alguna y, en ese sentido, están relacionados con las características de beneficio colectivo que promulga el modelo del Estado Social de Derecho. Por esta razón, el elemento esencial categórico de los derechos fundamentales es la defensa y la garantía de la dignidad humana, principio primordial de la organización estatal para este caso. Asimismo, la indisponibilidad y la inalienabilidad han sido identificados como elementos estructurales de la definición de los derechos fundamentales.

Desde el punto de vista normativo, se reconoce dentro de la categoría de los derechos fundamentales los derechos de aplicación inmediata, los cuales "se tratan de derechos de tal magnitud para el orden constitucional, que su vigencia no puede depender de decisiones políticas de los representantes de las mayorías"126. De esta forma, la Constitución Política de Colombia de 1991 al consagrar el modelo de Estado Social de Derecho incluye los derechos fundamentales que gozan de trascendencia en el ámbito propio de los derechos individuales y su efectividad da sentido a la moderna organización del Estado. Este avance jurídico y social constituye una evolución democrática para el bienestar general.

Así mismo, la jurisprudencia considera que:

para la identificación de un derecho de tal naturaleza existen unos criterios que ponen en evidencia los requisitos que el mismo ha de tener bajo tales requisitos, la Corte Constitucional con no poca incomprensión política y resistencia judicial, adopta el camino de la fundamentalización de algunas manifestaciones de los derechos sociales y económicos, y aun de otros derechos colectivos, bajo las reglas de su conexidad con los derechos fundamentales y las del mínimo vital, que se han proyectado en materia de protección de los derechos a la salud, a la seguridad social y a la remuneración mínima, vital y móvil ${ }^{127}$.

\footnotetext{
126 ORTIZ GUTIERREZ, Julio. Los derechos fundamentales en el ordenamiento constitucional de Colombia: Una aproximación a la jurisprudencia de la Corte Constitucional. Citado por: TEROL BECERRA, Javier. Derecho Constitucional para el siglo XX. Madrid.: Aranzadi, 2006. p. 51

127 Ibíd. p.52.
} 
Dado que el Estado Social de Derecho surge para garantizar los derechos fundamentales, estos son definidos por la doctrina como derechos humanos positivizados por los Estados ${ }^{128}$. En este sentido, en la jurisprudencia colombiana, la sentencia T-227 de 2003 expresa un cambio radical sobre el concepto de derecho fundamental, el cual se define de la siguiente manera:

[...] será fundamental todo derecho constitucional que funcionalmente esté dirigido a lograr la dignidad humana y sea traducible en un derecho subjetivo. Es decir, en la medida en que resulte necesario para lograr la libertad de elección de un plan de vida concreto y la posibilidad de funcionar en sociedad y desarrollar un papel activo en ella. Tal necesidad no está determinada de manera apriorística, sino que se define a partir de los consensos (dogmática del derecho constitucional) existentes sobre la naturaleza funcionalmente necesaria de cierta prestación o abstención (traducibilidad en derecho subjetivo), así como de las circunstancias particulares de cada caso (tópica) $^{129}$.

Tal como ha sido expuesto, la consideración de la fundamentalidad de un derecho resulta compleja y, por tanto, exige un análisis pormenorizado de su naturaleza desde el punto de vista de la teoría jurídica, sus titulares, obligados y su evolución en materia de consideración de derechos económicos, sociales y culturales

El concepto de limitación del poder absoluto del monarca y de la existencia de garantías que se anteponen a la existencia del Estado germina en Inglaterra con la suscripción del Bill of Rights. Más tarde, en Francia, a partir de la revolución burguesa y a la luz de las teorías contractualistas, tiene lugar la Declaración de los Derechos del Hombre y del Ciudadano de 1789. Este concepto alcanza posteriormente especial relieve en países como Alemania con la Ley fundamental de Bonn, en donde bajo el manto de los Grundrechte (en alemán: derechos fundamentales), se articula el sistema que media entre el individuo y el Estado.

De acuerdo con lo dicho, solo son fundamentales los derechos que participan de la fundamentalidad de la norma del ordenamiento jurídico: La Constitución que:

128 PRADO HERRERA, Gerardo Gianni. Los der échos Fundamentals y la application en la justifia constitutionnel. Buenos Aires.: El Cid Editor, 2009. p. 3.

129 COLOMBIA. CORTE CONSTITUCIONAL DE COLOMBIA. Sentencia T-227 de 2003. M.P: José Gregorio Hernández. Bogotá. p.1. 
Como fuente jurídica directamente aplicable, establece esos derechos y los dota de una disponibilidad por su titular potencialmente inmediata, y, como fuente de las demás fuentes del ordenamiento, preserva a los derechos fundamentales de su alteración o vulneración por normas infraconstitucionales (y en algunos casos incluso constitucionales), y los hace indisponibles por el legislador (e incluso por el órgano de reforma constitucional) ${ }^{130}$.

De lo anterior, puede inferirse que el contenido esencial del Estado Social de Derecho y su caracterización retrata la evolución de los derechos sociales en la historia contemporánea y, con ello, crea los cimientos conceptuales que permiten el reconocimiento de derechos fundamentales como es el caso de la salud, objeto de estudio de este análisis.

Lo anterior sucede, por ejemplo, en el supuesto de la manifestación de voluntad paterna, emitida en nombre de un menor, autorizando a un centro médico la práctica de una intervención quirúrgica necesaria para salvaguardar su vida. Por el contrario,

Deben quedar excluidos aquellos otros supuestos en los que no sea posible satisfacer el interés del titular representado. Se presenta esta situación, por ejemplo, en la facultad natural de deambular libremente o de expresarse, pues dicho interés consiste precisamente en la realización de la conducta de autodeterminación volitiva"131.

Los derechos subjetivos humanos fundamentales de la persona física jurídica no pueden ser separados de su titular, dado que constituyen un elemento indispensable e inherente a la persona misma y de ahí su carácter fundamental. En este sentido, como lo afirma Ferrajoli, son Derechos universales porque su respeto implica que a todos por igual se le deben de atribuir, y son fundamentales porque son necesarios para el adecuado funcionamiento del Estado de Derecho, ya que son la piedra angular del mismo ${ }^{132}$.

130 BASTIDA FREIJEDO, Francisco J. Op. Cit. pág. 6-7.

131 BASTIDA FREIJEDO, Francisco. Teoría General de los Derechos Fundamentales en la Constitución Española de 1978: Los Sujetos de los Derechos Fundamentales. Madrid: Tecnos, 2004. Pág. 86.

132 GIL RENDÓN, Raymundo. Los Derechos Fundamentales y la Impartición de Justicia (en línea). http://www.tfffa.gob.mx/investigaciones/pdf/losderechosfundamentalesylaimparticiondejusticia.pdf (citado 20 junio 2013). Pág. 3. 


\subsubsection{Obligados a la garantía de los derechos fundamentales.}

1.2.1.1 El Estado. El mandato de las normas internacionales con relación a la protección de los derechos fundamentales es claro. Los artículos 8, de la Declaración universal de derechos humanos, 18, de la Declaración americana de derechos humanos y 25, de la Convención Americana de Derechos Humanos, obligan a la incorporación de "un recurso efectivo y rápido ante los tribunales nacionales competentes, que los amparen contra actos que violen sus derechos fundamentales reconocidos por la constitución o por la ley"133. En ese sentido,

[...] ante una violación de un derecho fundamental cualquiera sea este, el Estado debe actuar de manera inmediata y al individuo se le debe abrir la jurisdicción constitucional para que la misma compulse debidamente y repare el derecho violado al efecto [...]. Es sabido por toda la doctrina que, para acceder en este caso a la jurisdicción y justicia constitucional, es necesario que se agoten todas las vías existentes, lo cual desnaturaliza el mandato de las normas internacionales con relación a la tutela de los derechos humanos ${ }^{134}$.

La incidencia de los derechos fundamentales no se produce en tanto derechos subjetivos opuestos a los particulares, sino apelando a su dimensión objetiva, cuya irradiación se traduce en pautas de interpretación aplicables a cualquier controversia entre individuos. Por el contrario, en el modelo de la eficacia inmediata se entiende que los derechos fundamentales sí pueden hacerse valer frente a los particulares como auténticos derechos subjetivos accionables jurisdiccionalmente. En este sentido, es la jurisdicción ordinaria el lugar apropiado para resolver los conflictos derivados de la eficacia de los derechos entre particulares, de tal manera que no es el acceso a un procedimiento de jurisdicción constitucional (como podría ser el amparo o algún otro equivalente) lo que condiciona dicha eficacia ${ }^{135}$.

De otra parte, Fix-Zamudio sistematiza la jurisprudencia de la Corte Interamericana de Derechos Humanos CIDH y advierte sobre la eficacia de los derechos fundamentales frente a particulares. Así, identifica tres etapas sucesivas donde se aprecia la evolución jurisprudencial sobre este tema:

\footnotetext{
133 PRADO HERRERA, Gerardo Gianni. Op. Cit. p. 8.

134 PRADO HERRERA, Gerardo Gianni. Op. Cit. pág. 8.

135 MIJANGOS GONZÁLEZ, Javier. Los derechos fundamentales en las relaciones entre particulares. 1를 Edición. México.: Porrúa, 2004. p. 595.
} 
En una primera etapa que se inicia en los años ochenta, la CIDH se adhiere a un modelo de la eficacia mediata y sostiene posiciones muy cercanas a la doctrina estadounidense de la state action: cuyo análisis se centra en la obligación de respeto y vigilancia de los derechos fundamentales a cargo de los Estados prevista en el artículo 1.1 de la $\mathrm{CADH}$. En una segunda etapa, ya en la década de los noventa, se considera la idea de que los derechos fundamentales previstos en la CADH constituyen obligaciones erga omnes que se imponen no sólo a los Estados sino también a los particulares. Finalmente, se desarrolla una tercera etapa que marca la consolidación de dicha doctrina a partir de la opinión consultiva 18/03 solicitada por México en relación a la condición jurídica de los inmigrantes, donde la $\mathrm{CIDH}$ reconoce de forma inequívoca la eficacia directa de los derechos fundamentales en las relaciones privadas ${ }^{136}$.

Por otro lado, el artículo 86 de la Constitución Colombiana determinó que:

La Ley establecerá los casos en que la acción de tutela procede contra particulares encargados de la prestación de un servicio público o cuya conducta afecte grave o directamente el interés colectivo, o respecto de quienes el solicitante se halle en estado de subordinación o de indefensión"137.

Al efecto, la Ley reglamentaria desarrolla el precepto y al comenzar su aplicación, la Corte Constitucional asume que la enunciación era taxativa y circunscribe la acción de tutela ante los particulares solo a los casos legalmente admitidos. El criterio jurisprudencial cambia poco después, ${ }^{138}$ cuando la Corte resuelve:

Resulta un contrasentido que el legislador, desconociendo el espíritu del Constituyente y uno de los propósitos del nuevo ordenamiento constitucional colombiano, pretenda limitar el radio de la acción de tutela, al señalar en forma taxativa aquellos derechos fundamentales que, a su juicio, puedan ser amparados cuando la conducta nociva provenga de un particular... No era atribución de la Ley, so pretexto de dar protección a un mandato constitucional, determinar los

\footnotetext{
136 Ibíd. p. 599.

137 COLOMBIA. Constitución Política de Colombia. Artículo 86 [Título II]. 35a Ed. Bogotá.: Legis, 2016.

138 ESTRADA, Alexei Julio. La eficacia de los derechos fundamentales entre particulares. Bogotá, Universidad Externado de Colombia, 2000. p. 232.
} 
derechos fundamentales que pueden ser invocados por el solicitante cuando el sujeto pasivo de la tutela es un particular, pues conviene señalarlo, los derechos fundamentales son la base, el sustento de toda legislación, y no su efecto. Si la acción de tutela procede para proteger los derechos fundamentales de las personas, entonces no resulta lógico realizar una diferenciación respecto de cuales derechos pueden ser amparados y cuáles no"139.

La fundamentalidad de los derechos posee una escala de categorías determinada por la preeminencia de los derechos. Así, a mayor o menor fundamentalidad dependerá el grado de preponderancia en el ejercicio de su garantía, con base en el análisis de la Constitución, como norma fundamental y fuente directa de relaciones jurídicas, lo cual, condiciona al sistema constitucional para que sean considerados en mayor medida los derechos fundamentales que otros, y en este sentido, se les garantizará una efectividad más inmediata, permitiendo un ejercicio directo de los mismos o vinculando estrechamente al legislador ${ }^{140}$.

De esta forma, el Estado no solo debe garantizar los derechos fundamentales frente a lo público sino también frente a lo privado, incluyendo los derechos sociales y el marco del derecho internacional, para así combatir la crisis del constitucionalismo frente a una globalización sin reglas ni controles que acentúa las diferencias entre las personas ${ }^{141}$. Siendo ello así, los derechos fundamentales no han de obedecer a criterios de inspiración fijos, ni se han de limitar al establecimiento de normas escritas que los consagren como tales, sino que su fundamentalidad debe corresponderse con la existencia de parámetros flexibles dirigidos a satisfacer las exigencias de una sociedad en constante evolución.

En este sentido, "El núcleo esencial de un derecho fundamental es la esencia de la persona que determina los bienes inherentes a ella. En otras palabras, el núcleo esencial del derecho fundamental es el mínimun de la dignidad racional, sin cuyo reconocimiento el hombre no puede vivir o desarrollarse como ser humano" 142 . Corolario, válido es concluir que la aplicación y protección de estos derechos no requiere de la existencia de normas o de su positivización en instrumentos jurídicos, toda vez que ha de ser suficiente su invocación para lograr su efectividad.

\footnotetext{
139 VALADÉS, Diego. Op. Cit. p. 604.

140 BASTIDA FREIJEDO, Francisco. Op. Cit. p. 56.

141 FERRAJOLI, Luigi. Op. Cit. Pág. 1

142 COLOMBIA. CORTE CONSTITUCIONAL DE COLOMBIA. Sentencia T-336 de1995. M.P: Vladimiro Naranjo Meza.
} 
Sin duda, "un derecho no es fundamental ni deja de serlo por ser reconocido en determinado artículo o título de la Constitución, sino por su contenido material, sus características, y los hechos circunstanciales del caso en cuestión"143. Bajo esta línea de argumentación:

Los derechos constitucionales fundamentales incluyen, además de derechos subjetivos y garantías constitucionales a través de los cuales el individuo se defiende frente a las actuaciones de las autoridades públicas, deberes positivos que vinculan a todas las ramas del poder público, pues no sólo existe la obligación negativa por parte del Estado de no lesionar la esfera individual, sino la también la obligación positiva de contribuir a la realización efectiva de tales derechos $^{144}$.

\subsection{TEORIAS DE LOS DERECHOS FUNDAMENTALES}

El concepto sobre derecho fundamental deviene de una lucha histórica en un contexto marcado por grandes problemas, guerras y víctimas. El resultado de su reconocimiento, ejercicio y protección está estrechamente atado al concepto de dignidad: por ello su respeto y pleno ejercicio permite consolidar la existencia de un verdadero Estado social de derecho, según Robert Alexy (alexy, 2014) nos dice:

"Los derechos fundamentales son posiciones tan importantes que su otorgamiento o no otorgamiento no puede quedar en manos de la simple mayoría parlamentaria"

Frente a esta concisa explicación de derechos fundamentales, se le han recogido muchas posiciones críticas positivas, como Rodolfo Arango (Arango 2005) explica:

Esta definición de los derechos fundamentales posee muchas ventajas. Su brevedad y grado de generalidad garantizan un amplio acuerdo. Por otro lado, la definición asocia directamente el concepto

\footnotetext{
143 ORTIZ GUTIERREZ, Julio. Los derechos fundamentales en el ordenamiento constitucional de Colombia: Una aproximación a la jurisprudencia de la Corte Constitucional. En: Derecho Constitucional para el siglo XXI: actas VIII Congreso Iberoamericano de Derecho Constitucional. Vol. 1, 2006, ISBN 84-9767. Pág.56.

144 Ibíd. Pág. 52.
} 
del derecho fundamental al concepto de la democracia, ${ }^{145}$ con los que los derechos fundamentales se anclan a la teoría política.

La evolución y el enfoque social de la concepción de los derechos fundamentales como atributos propios de las personas se han trabajado desde ópticas diferentes. Es por eso que al considerarse un derecho fundamental como atributo debe interpretarse como norma jurídica. Pero los tratadistas para llegar a esta conclusión han propuesto varias teorías, con el fin de darle viabilidad e importancia jurídica a estos atributos.

A partir de que la Constitución dejó de ser entendida como un sistema de garantías, para convertirse en un sistema de valores fundamentales con principios de justicia social y derechos económicos y sociales, se dio lugar al desarrollo de una rica jurisprudencia de los tribunales constitucionales europeos, y en particular el alemán, sobre el contenido concreto de los derechos fundamentales, el cual ha estado alimentado por teorías constitucionales viejas y nuevas, que han incidido en el fortalecimiento del Estado constitucional. En tal sentido, se pueden clasificar las principales teorías de los derechos fundamentales en seis grupos: ${ }^{146}$

1.3.1 Teoría Liberal. La primera de las categorías a trabajar sobre las teorías de los derechos fundamentales será la "teoría liberal", la cual implica que los derechos fundamentales son libertades de los individuos frente al Estado, es decir, el derecho de defensa. Se muestra en sentido clásico la libertad personal, tal como se indica en el artículo 4 de la declaración de los Derechos del hombre y ciudadano:

La libertad consiste en hacer todo lo que no perturbe a los otros: en consecuencia, el ejercicio de los derechos naturales de cada hombre sólo tiene los límites que aseguren a los otros miembros de la

\footnotetext{
145 C.R. Sunstein, constitutions and Democracies: an Epilogue, en: J. Elster/R. Slagstad, Consttuionalism and Democracy, Cambridge 1988, pp. 327, 338.

146 Böckenförde, Ernst-Wolfgang, "Grundrechstheorie und Grundrechtsinterpretation", idem, pp. 115 y ss. (se trabaja con la versión española de Escritos sobre..., cit., nota 11, pp. 44 y ss.); Alexy, Robert, Theorie der Grundrechte, Baden-Baden, Nomos Verlgasgesellschaft, 1985, pp. 100 y ss., hay versión en castellano: Teoría de los derechos fundamentales, Madrid, CEC, 1997; Häberle, Peter, "Recientes aportes sobre los derechos fundamentales en Alemania", Pensamiento Constitucional, Lima, Pontificia Universidad Católica del Perú-Maestría en Derecho Constitucional, s. a., s. n., 1994, pp. 45 y ss.; Kröger, Klaus Grundrechsteorie als Verfassungsproblem, Baden-Baden, Nomos VerlagsgeseIlschaft, 1978, pp. 13-30; asimismo, Pérez Luño, Antonio, Derechos humanos, Estado de derecho y Constitución, Madrid, Tecnos, 1991, pp. 295-316
} 
sociedad el disfrute de los mismos derechos. Esos límites no pueden estar determinados en la ley. ${ }^{147}$

Como un análisis más claro sobre el artículo anterior, puedo acotar lo siguiente del tratadista Manuel Media: (medina, 1997)

La libertad es garantizada sin condición material alguna, es decir, no está sometida al cumplimiento de determinados objetivos o funciones del poder, porque la autonomía de la voluntad no es objeto de formación, sino en la medida que sea compatible con el marco general, abstracto y formal de la ley. Por ello se han dado garantías tales como: "nadie está obligado a hacer lo que la ley no manda, ni impedido de hacer lo que ella no prohíbe" y la prohibición de la retroactividad de la ley. ${ }^{148}$ En ese sentido, se puede decir que la defensa de la libertad humana se convierte en el fin supremo de la sociedad y del Estado; actuando como principio delimitador de los derechos fundamentales, así como soporte del modelo constitucional liberal. ${ }^{149}$

En virtud de ello, los derechos fundamentales producen efectos privados de defensa de la persona y efectos públicos de contención de la autoridad. Pero, en caso de colisión no siempre se resuelve con el individuo por la búsqueda de libertad, sino a través del principio de proporcionalidad de los derechos fundamentales, que supone integrar la libertad y la autoridad, sin afectar el núcleo duro de los derechos fundamentales, mediante el principio de armonización y proporcionalidad.

Aunque hablamos de libertad de los individuos en reclamar la defensa de sus derechos frente al Estado, estos solo son los que el mismo Estado ha diseñado y/o formado para disfrute de todos, ya que estos son los límites del individuo y es el desarrollo de las obligaciones de hacer del Estado.

\footnotetext{
147 Vecchio, Giorgio. La Declaración de los Derechos del hombre y el ciudadano. Revolución Francesa, Roma, Edicion Fundacion Europea, 1968, p. 39.

148 BURDEAU, Georges, Les libertés publiques, París, LGDJ, 1972, pp. 129 y ss.; asimismo, Rivero, Jean, Les libertés publiques, t. 1, París, Presses Universitaires de France, 1981, pp. 145-152

149 SCHMITT, Carl, Verfassungslehre..., cit., nota 15, pp. 36 y ss.
} 
1.3.2 Teoría axiológica. Los derechos fundamentales desde su reconocimiento siempre han sido los representantes de todos los sistemas de valores, que resume la vida estatal contenida en las constituciones de cada ordenamiento jurídico, y es el pilar en que debe apoyarse toda interpretación de los derechos fundamentales. Al existir derechos fundamentales o estar contenidos en cartas políticas, esto genera legitimidad al Estado que está formado por la comunidad, que por lo general es diversa culturalmente, y siempre tendrán de presente la defensa que les ofrecerá cada sistema jurídico positivo de sus derechos, ya que siempre los derechos fundamentales serán concebidos como normas éticas objetivas, fiel expresión del orden valorativo de la sociedad que se va expresando en normas legales y sentencias.

Esta teoría podría resumirse de forma más práctica a la luz del escrito del tratadista alemán Ernst- Wolfgang (Ernst-Wolfgang, 1993), quien dice:

La teoría de los valores subordina el método jurídico a los contenidos axiológicos de la sociedad sobre los derechos fundamentales, con lo cual deja abierta la pregunta acerca de cómo identificar los valores supremos o superiores de la comunidad. Al parecer, corresponde aplicar el método de las ciencias del espíritu para conocer la jerarquía de la conciencia valorativa de la comunidad, que es alcanzable como una evidencia preferentemente intuitiva Vorzugsevidenz, o mediante el juicio de valor cultural y moral del momento, que no está exento de un juicio de valor superior frente a otro inferior.

Someter los derechos fundamentales a la valoración intuitiva o al estado de conciencia social, en etapas de rápidas transformaciones y cambios, permite suponer el cambio o la afectación de los valores supremos y eternos de una sociedad, en donde el carácter preexistente y vinculante de los principios y valores que dan sentido a la unidad de una comunidad no permanezcan estables 0 inmodificables. En este sentido, los derechos fundamentales se relativizan a su tiempo y espacio, revaluándose o devaluándose según las circunstancias del estado de conciencia o del espíritu del momento Zeitgeist. ${ }^{150}$

Es común que esta teoría termine convirtiendo a las minorías sociales en bárbaros, donde quieran hacer auto control o un exagerado reclamo de sus derechos, al

150 BÖCKENFÖRDE, Ernst-Wolfgang, Escritos sobre..., cit., nota 11, pp. 59 y ss 
apartarse de las mayorías sociales, con lo cual se crea un descontrol de percepción y se deja de lado el control ya objetivado en la norma positiva.

1.3.3 Teoría asociativa Los cambios económicos, sociales y políticos a veces son olvidados en la enmarcación de los llamados derechos objetivos absolutos o derechos subjetivos individuales, ya que estos no responden a las considerables demandas del desarrollo de nuestro ordenamiento jurídico, y el más importante, su aspecto social. De ahí que esta teoría institucional incluye en su marco teórico el desarrollo de temas tanto políticos como económicos utilizados en el Estado constitucional.

Para asimilar un concepto más propicio de esta teoría, veremos las posiciones de dos autores. Para Hauriou (Hauriou, 1965) los derechos fundamentales siempre deben ir vinculados en una doble faceta: los derechos fundamentales personales y el orden institucional. Esto lo expreso así:

"Los derechos individuales son a la vez instituciones jurídicas objetivas y derechos subjetivos"151

Esto solo le da fuerza a las teorías que dicen que con el paso transitorio de muchos procesos gubernamentales, y procesos legislativos donde impliquen modificaciones judiciales, los derechos puedan llegar a ser desconocidos, desvirtuados o vaciados de contenido.

Pero Hauriou no es el único que ha aportado al trabajo de desarrollar esta teoría, Schmitt (Schmitt, 1981) en uno de sus trabajos levantó un muro divisorio para así dejar de un lado a los derechos de libertad y la garantía institucional del otro, para que el legislador no vulnere los derechos de libertad. Schmitt defiende su teoría en la objetividad de siempre hacer esta diferenciación, sin embargo:

"la garantía institucional no es un derecho fundamental en sentido auténtico, pero significa una protección constitucional contra la

\footnotetext{
151 HAURIOU, Maurice, Précis de Droit Constitutionnel, reimpresión del CNRS, París, Sirey, 1965 (primeras ediciones: 1910, 1923 y 1929), p. 612, así como pp. 618 y ss.; asimismo revisar: Kaufmann, Erick, Das Wesen des Völkerrechts und die clasula rebus sic stantibus (Neudruck der Ausgabe Tübingen, 1911), Aaalen, Scientia Verlag, 1964, pp. 128 y ss.; y Häberle, Peter, La libertad fundamental..., cit., nota 3, pp. 163 y ss.
} 
supresión legislativa, según es característica de la garantía institucional" ${ }^{152}$

Siempre será pertinente explicar que lo subjetivo de los derechos fundamentales siempre irá de lado a un carácter objetivo, ya que estos requieren ciertas actuaciones del Estado para la protección y el desarrollo de la libertad. Así se configura el doble carácter de los derechos fundamentales, ya que los límites de la institución en cabeza del legislador regularán el contenido esencial y dará el valor a cada derecho fundamental.

A la luz del pensamiento institucional de los derechos fundamentales (Lopez, 1992),

Es posible identificar el contenido esencial del mismo, a partir de la idea de la libertad como instituto, es decir, como un dato objetivo que se realiza y despliega en la sociedad abierta, pero que encuentra en los conceptos jurídicos diversos elementos que inciden directa o indirectamente en la formación, proceso y resultado de la norma constitucional. En ese sentido, "el contenido y los límites de los derechos fundamentales deben determinarse partiendo de la totalidad del sistema constitucional de los valores al que hace en su esencia, referencia todo derecho fundamental". Por ello, se puede hablar de una teoría absoluta que indaga sobre el mínimo intangible de un derecho fundamental, y de una teoría relativa que busca otros valores y bienes constitucionales que justifiquen limitar los derechos fundamentales. En esa tarea de integración propia del desarrollo dinámico de los derechos fundamentales se trata de ponderar diversos bienes jurídicos Güterabwägung, en el marco de la totalidad de los valores y bienes jurídicos constitucionales. ${ }^{153}$

152 SCHMITT, Carl, Verfassungslehre..., cit., nota 15, pp. 170; Schmidt-Jortzig, Edzard, Die Eirichtungsgarantien der Verfassung. Dogmatischer Gehalt und Sicherungskraft einer umstrittenen Figur, 1979, pp. 63 y ss.; y Parejo, Luciano, Garantía institucional y autonomía local, Madrid, IEAL, 1981 , pp. 23 y ss.

153 LÓPEZ Pina, Antonio, La garantía constitucional de los derechos fundamentales. Alemania, España, Francia e Italia, Madrid, Civitas, 1992; Häberle, Peter, El legislador de los derechos fundamentales, ponencia, pp. 120 y ss. Müller, Friedrich, Normstruktur und Normativität. Zum Verhältniss von Recht und Wirklichkeit in der juristischen Hermeneutik, entwickelt an Fragen der Verfassungsinterpretation, Berlín, Duncker \& Humblot, 1966, pp. 207 y ss.; asimismo, Häberle, Peter, La libertad fundamental..., cit., nota 3, pp. 95 y ss., así como 127 y ss. 
Esto significa que el ejercicio de los derechos fundamentales sólo adquiere vistos de realidad como libertades sociales, cuando el bien común como objetivo humano reclama de la acción del Estado acciones concretas. En ese sentido

Los derechos fundamentales no son únicamente algo dado, organizado, institucional, y de tal modo objetivado como status; sino que ellos, en cuanto institutos, justamente a consecuencia del obrar humano, devienen en realidad vital, y como tal, se entiende el derecho como género ${ }^{154}$

1.3.4 Teoria práctica (Schmitt, Teoria de los derechos fundamentales, 1932) Se parte de concebir a los derechos de la persona en función de los objetivos o funciones públicas y del Estado constitucional, en el marco de una democracia deliberativa. De allí que "no hay legitimidad del derecho sin democracia y no hay democracia sin legitimidad del derecho". Es decir, que se pondera el carácter cívico de los derechos fundamentales como elementos constitutivos y participativos de la democracia estatal.

Desde esta perspectiva social y ciudadana, se puede plantear que hay derechos fundamentales, pero también deberes y obligaciones fundamentales con el Estado democrático-constitucional. En este último sentido, los derechos fundamentales no son bienes jurídicos de libre disposición, sino que presentan límites, en tanto los ciudadanos de una comunidad democrática tienen los límites y el deber de fomentar el interés público. ${ }^{155}$

La idea de que los derechos fundamentales deben asegurar el fortalecimiento del Estado constitucional se ha visto expresada en el desarrollo de los derechos a la libertad de opinión, libertad de prensa y libertad de reunión y asociación, como bases necesarias para el funcionamiento de la democracia.

Esta tesis de la democracia-funcional, de los derechos fundamentales, no deja de presentar interrogantes acerca de la posible presión social contra la aparición de nuevos derechos que se originan en los valores periféricos del consenso democrático existente. Es el caso de libertad de expresión o derecho electoral,

154 HÄBERLE, Peter, La libertad fundamental..., cit., nota 3, p. 199; Zippelius, Reinhold, Rechts und gerechtigkeit in der offenen Gesellschaft, Berlín, 1994, Duncker \& Humblot, pp. 67 y ss.

155 SCHMITT, Carl, Grundrechte und Grundphlichten (1932) (Verfassungsrechtliche Aufsätze aus den Jahren 1924-1954. Materialen zu einer Verfassungslehre: así, en el compendio del autor), Berlín, Duncker \& Humblot, 1973, pp. 181 y ss. 
entendidos como derechos fundamentales absolutos que pueden dar lugar a la transmisión de ideas y programas políticos, cuestionables desde una posición democrática -no funcionalista ni avalorativa-, lo cual abre un debate acerca de los límites y diferencias de los derechos fundamentales, sobre todo cuando aportan una carga político-social. ${ }^{156}$

1.3.5 Teoría social El punto de partida de esta teoría de los derechos fundamentales es la insuficiencia no sólo de la deshumanizada teoría individualista de los derechos, sino también la insuficiencia de una concepci ón meramente positivista de los derechos económicos y sociales, entendida como la norma programática sujeta a la reserva de ley, o abstracta delimitación de la libertad por la igualdad y la justicia.

Frente a esta perspectiva subyacen dos cosas: la primera es la obligación del Estado, derivada de los singulares derechos fundamentales de procurar los presupuestos sociales necesarios para la realización de la libertad de los derechos fundamentales, una especie de posición de garante para la aplicación de la libertad en la realidad constitucional; ${ }^{157}$ y la segunda es el procesamiento de pretensiones de derechos fundamental a tales prestaciones estatales, o, en su caso, a la participación en instituciones estatales o procuradas por el Estado que sirven a la realización de la libertad de los derechos fundamentales". 158

Es así que se contemplan derechos económicos y sociales en el mismo grado de importancia que en lo inherente al desarrollo del ser humano en su ambiente, ya que esto va de la mano del gran crecimiento económico de cada Estado, sin embargo:

En tal sentido, los presupuestos sociales de esta concepción de los derechos económicos y sociales son constituyentes del carácter jurídico de los mismos, en la medida que el origen y el fin de su carácter normativo reposa en el concreto ambiente económico y social necesario para su eficacia social, sin perjuicio del rol orientador y de fomento del Estado hacia una sociedad económica basada en la justicia distributiva. ${ }^{159}$ En consecuencia, el desarrollo económico y social es una premisa necesaria, aunque no suficiente, de la legitimidad de los derechos socioeconómicos, debido a que los derechos sociales podrán cumplir su función social,

156 KRÜGER, Herbert, Allgemeine Staatslehre, Stuttgart, Kohlhammer Verlag, 1966, pp. 543 y ss.

157 Así, la formulación en la sentencia del Tribunal Federal Administrativo 27, 360 (362); en sentido afirmativo Häberle, Peter, Grundrechte im Leistungsstaat... cit., nota 50, pp. 70 y ss.

158 Böckenförde, Ernst-Wolfgang, Escritos sobre..., cit., nota 11, p. 64

${ }^{159}$ Rawls, John, A theory of justice, Massachussetts, Harvard University Press, 1973, pp. 525 y ss. 
sólo en la medida en que su proyección normativa sepa desarrollar los elementos jurídico-sociales, que no dejen vacía o sin realización a la norma constitucional de los derechos sociales. ${ }^{160}$

Corolario de esta teoría tiene una falencia que radica en la dependencia de la vigencia de los derechos sociales de la situación de bienestar económico del Estado. Por ello si bien los derechos sociales son norma de cumplimiento obligatorio diferido del Estado, la exigencia judicial de la aplicación de las mismas sólo es factible de realizarse en la medida en que el legislativo y el gobierno hayan presupuestado el cumplimiento de las mismas.

1.3.6 Teoría de la protección legal. La teoría según la cual los derechos fundamentales son garantías procesales proviene del interés de otorgar eficacia en la aplicación y protección concreta de los derechos humanos, pero solo al profundizar y avanzar más allá del status activus processualis planteado por Häberle. ${ }^{161}$

Es claro que los derechos fundamentales son importantes, ya que estos prestan garantías procesales que nos permiten accionar no solo contra el aria judicial, sino la misma ejecutiva. La defensa de los derechos mediante tutela lleva necesariamente a dos cosas: (i) asegurar que la tutela judicial sea efectiva y garantista hacia los ciudadanos y (ii) que se garantice el debido procesal y sea permisible redundar que este sea tanto material como formal.

De esta manera, la tutela judicial y el debido proceso se incorporan al contenido esencial de los derechos fundamentales como elementos del núcleo duro de los mismos. Permitiendo de esta manera que a un derecho corresponda siempre una acción y que una acción suponga siempre un derecho.

A consecuencia de lo anterior, Pedro de Vega asume esta posición (Vega, 1997):

Las garantías de los derechos fundamentales dan la oportunidad material de ejercer el derecho contra el Legislativo, Ejecutivo y Judicial, no sólo en una idea formal. En este entendido, los derechos fundamentales como garantías procesales están vinculados con una amplia concepción del proceso.

160 HÄBERLE, Peter, Grundrechte im Leistungsstaat..., cit., nota 50, pp. 69 y ss
161 HÄBERLE, Peter, La libertad fundamental..., cit., nota 3, pp. 289 y ss. 
En consecuencia, diseñar los derechos fundamentales como garantías procesales materiales o reales admite reconstruir las garantías procesales, con el fin de resguardar los mismos derechos fundamentales. No obstante, esto no admite fundar una disposición organizacional explícita, en punto que ya está el Tribunal Constitucional, los tribunales comunes e incluso los tribunales administrativos, que además previenen espacios de los derechos fundamentales, sino transferir adecuadamente estudios, elementos y nociones del derecho procesal a los procesos constitucionales. En tal forma, los derechos fundamentales, como refuerzos procesales, se cristalizan punto en derechos subjetivos como en derechos objetivos fundamentales.

Esta de la teoría de la protección legal no se sujeta a los métodos constitucionales, judiciales y administrativos, sino que además se explaya al proceso legislativo. Pues la seguridad procesal de las partes y del proceso son bienes fundamentales en el amparo de los derechos humanos, éstas lograrán toda su fuerza en la elaboración de las propias reglas procesales del legislador democrático, quien en el proceso legislativo también debe respetarla, incorporándola a la práctica constituyente, como una garantía procesal y como un respaldo democrático de los derechos fundamentales de la cooperación de las minorías políticas y de la obstrucción parlamentaria. ${ }^{162}$

Para condensar este análisis de las teorías sobre los derechos fundamentales, partiendo, de que estas se han construido desde corrientes como la historica, la práctica y la sociológica, es significativo determinar que las numerosas teorías de los derechos fundamentales componen aportes apropiados para el progreso de los derechos de libertad en sus contextos, asi mismo develan los casos para solucionar por sí mismos los inconvenientes actuales de la falta de ejecución de los derechos fundamentales en los diferentes países y culturas disímiles. Es por ello, que partiendo del estudio de las anteriores teorías sobre los derechos fundamentales, se torna imperioso realizar en esta labor investigativa, un análisis sobre la interpretación de los derechos fundamentales, empezando por exponer su problematica, al momento de solucionar el conflicto o colisión de los derechos fundamentales.

162 VEGA, Pedro de, "Neoliberalismo y Estado", Pensamiento Constitucional, Lima, Pontificia Universidad Católica del Perú, Maestría en Derecho Constitucional, Fondo Editorial, año IV, núm. 4, 1997, pp. 31 y ss. 


\subsection{LA INTERPRETACIÓN DE LOS DERECHOS FUNDAMENTALES}

La problemática a la hora de interpretar los derechos fundamentales no es la cantidad de teorías que han surgido frente a esto, sino la errada interpretación de la Constitución, que va vinculada con los derechos fundamentales. Después de todo, los derechos fundamentales son protagonistas con más trascendencia y consulta de la Ley fundamental.

El desarrollo judicial de la Constitución, es pues, una profusa y complicada labor de lo que a, prima face, se podría entender, dado que el derecho y la justicia se han convertido en temas atrayentes, cambiantes, no obstante espinosos y complejos.

Desde la aparición de la Constitución, como una Ley fundamental, esta llega como un poder jurídico innegable y de mayor jerarquía frente a los otros productos jurídicos. Es la portadora del sustrato de valores y principios fundantes de una comunidad política y jurídica, y cómo dejar de lado que uno de los elementos más importante de esta comunidad contemporánea y política son los derechos fundamentales.

La interpretación que ha definido en gran magnitud la época actual jurídica, ha sido Isabel Linfante Vidal (Vidal, 2009), quien afirma que:

La interpretación del texto constitucional difiere de la interpretación de la ley, porque, como se ha sostenido, el contenido de la Constitución y su finalidad son distintos de los de la ley. En consecuencia, los principios que guían la interpretación legal no son suficientes para realizar la interpretación de la Constitución. Por esta razón, se han desarrollado métodos más adecuados e idóneos para la interpretación del texto constitucional. En razón de este cambio fundamental de paradigma jurídico hacia un paradigma constitucional, Lifante sostiene que "la interpretación del Derecho ha de ser vista fundamentalmente como una actividad reconstructiva, y no sólo como una mera precisión del significado de las palabras de una determinada disposición legislativa". ${ }^{163}$

163 LIFANTE Vidal, Isabel, "La interpretación jurídica y el paradigma constitucionalista", anuario de Filosofía del Derecho, núm. 25, 2008-2009, p. 269. 
Desde la perspectiva de la Constitución material, estos parámetros podrían estar definidos por su supremacía, lo que se entiende y justifica "por su contenido, en la medida que la Constitución expresa jurídicamente los contenidos esenciales que integran a dicha comunidad, es decir, los derechos fundamentales y la organización y limitación del poder político". ${ }^{164}$ Estos parámetros son esenciales en el ámbito de la protección de los derechos fundamentales, frente a un "lenguaje normativo que no tiene significaciones unívocas". ${ }^{165}$ En este contexto, Lifante defiende, correctamente a nuestro parecer, una teoría de la interpretación jurídica que se caracterizaría por primar la referencia a los valores o principios del derecho, "sobre sus aspectos autoritativos; por ver al derecho más como una práctica social que como un mero conjunto de textos...".

Ahora el problema de la interpretación constitucional, "se encuentra hoy en el centro no sólo de la teoría constitucional sino de la teoría jurídica en general. Esto sucede no sólo en Colombia, sino en la mayoría de los países en donde existe justicia constitucional, y existen al menos dos razones que explican esa importancia creciente de las discusiones sobre hermenéutica constitucional a pesar de esta centralidad de la interpretación constitucional, lo cierto es que en los países latinoamericanos, y en especial en Colombia, la literatura académica sobre el tema es bastante reducida ${ }^{166 "}$

En estas mismas líneas discursivas señala Dworkin, "el Derecho es una práctica social que se compone tanto de un conjunto de reglas, como de una serie de valores que dichas reglas pretenden desarrollar". ${ }^{167}$ Por eso, según Dworkin, la interpretación jurídica es por mucho un arte. ${ }^{168}$ Dado que:

164 LANDA, César, "La fuerza normativa constitucional de los derechos fundamentales", en Bazán, Víctor y Nash, Claudio (ed.), Justicia constitucional y derechos fundamentales. Fuerza normativa de la Constitución, Montevideo, KAS, 2011, pp. 17-42, especialmente p. 24.

165 NOGUEIRA Alcalá, Humberto, Lineamientos de interpretación constitucional y del bloque constitucional de derechos, Santiago, Librotecnia, 2006, p. 26; "Es cierto que en este terreno existe una situación particular, que deriva de la indeterminación de las garantías textuales de la mayoría de los derechos fundamentales". Grote, Rainer, "El desarrollo dinámico de la preceptiva constitucional por el juez constitucional en Alemania", anuario de Derecho Constitucional Latinoamericano, t. I, 2004, pp. 139-156, especialmente p. 147.

166 UPRIMNY YEPES, Rodrigo, “El dilema de la interpretación constitucional”, cit., p.455.

167 LIFANTE Vidal, Isabel, “La interpretación jurídica y el paradigma constitucionalista”, cit., p. 272.

168 "Soy un jurista y, para mí, las relaciones más importantes son las compenetraciones interpretativas del derecho y las otras disciplinas reconocidas por este Premio. El derecho es concebido algunas veces, particularmente por quienes no son abogados, como un oficio casi mecánico: los abogados son personas que saben en qué libros se debe buscar para encontrar las respuestas a los problemas que les plantean sus clientes, y cuales libros citarles a los jueces que están decidiendo el destino de sus clientes. El Premio Holberg corrige ese error al situar el derecho en el contexto correcto, es decir, 
...la interpretación es una actividad basada en valores, cuyo objetivo es presentar el objeto interpretado bajo su mejor ángulo; es decir, desarrollar al máximo los valores propios de su género. La actividad interpretativa implica llevar a cabo un proceso reconstructivo de los materiales jurídicos en el cual se establezcan los valores y objetivos perseguidos por ese derecho y se determine qué interpretación los desarrolla en mayor medida. La evolución que ha sufrido el tema de la interpretación jurídica, pasando a situarse en el núcleo de la teoría del Derecho, va de la mano con el cambio en el paradigma jurídico. ${ }^{169}$

De otro lado, "la justicia constitucional radicaliza las dificultades de la interpretación jurídica en general y conduce al siguiente dilema: por sus características, el texto constitucional parece muy difícil de ser sometido a reglas hermenéuticas rigurosas y está entonces sujeto a una gran libertad interpretativa, a tal punto que ningún funcionario judicial parece gozar de tanta discrecionalidad hermenéutica como el juez constitucional" 170 es por ello que la función que ejerce el tribunal constitucional y su enorme poder jurídico y político, parece necesario reducir la discrecionalidad de estos jueces, pues en una democracia ningún funcionario debería estar más limitado normativamente que el juez constitucional." 171

Colorario sobre el dilema en la interpretación de los derechos, debe soportar una voluntad necesaria, de parte del juez constitucional, que responda al desarrollo, aplicación y protección de los derechos fundamentales, partiendo de unos esfuerzos de ponderación sobre las máximas constitucionales.

Bajo los anteriores argumentos es importante estudiar los derechos sociales, los caules se incorporan al ordenamiento jurídico dentro del catalogo de derecho fundamentales, precisamente partiendo de una labor interpretativa de los mismos.

no sólo en el contexto de las ciencias sociales sino en el de las humanidades en general, reconociendo que la interpretación jurídica es por mucho un arte, valiéndose de todas las tradiciones de las humanidades, tal como sucede con la interpretación literaria, la histórica o la teológica". Palabras de Ronald Dworkin en la ceremonia de condecoración del Premio Internacional Ludvig Holberg. Professor Ronald Dworkin, Bergen, Noruega, noviembre 28 de 2007.

169 LIFANTE Vidal, Isabel, "La interpretación jurídica y el paradigma constitucionalista", cit., p. 277.

170 UPRIMNY YEPES, Rodrigo, "El dilema de la interpretación constitucional”, cit., p. 464.

${ }^{171}$ Ibedem. 


\subsection{LOS DERECHOS SOCIALES}

Resulta de trascendental importancia dilucidar si los derechos sociales y económicos, que se incorporan al ordenamiento jurídico a partir del modelo del Estado Social de Derecho, pueden ser considerados dentro de la categoría de derechos fundamentales, de los cuales surgen obligaciones positivas y encaminadas al logro de la equidad; esto permite determinar el alcance y eficacia del derecho prestacional a la salud en nuestro ordenamiento jurídico. De la consideración jurídica de los derechos sociales o de prestación descritos en la Constitución dependerá su imputación subjetiva social como plenos derechos con fuerza vinculante, derechos subjetivos de aplicación directa o simplemente como postulados normativos. Determinar dicha consideración frente a los derechos sociales, en especial el de la salud, es de gran importancia para este estudio.

En consecuencia, el problema que se plantea es si la naturaleza fundamental del derecho a la salud en Colombia tiene un origen exclusivamente jurídico en la Constituyente de 1991 o la misma obedece a un sistema de significaciones sociales construidas históricamente, las cuales se incorporan en el imaginario social bajo una estructura de principios y valores que finalmente asume el Estado, entendiendo este derecho como esencial para la existencia de los individuos.

La evolución histórica de las cláusulas constitucionales, que consagran derechos sociales de prestación, son producto de la activa exigencia de los diversos colectivos sociales que, a su vez, comparten e interiorizan los aportes que de la misma constitución emanan. Esta condición determina su naturaleza esencial y subjetiva. Bajo tal entendido:

Los DESC [derechos económicos, sociales y culturales] han avanzado por razones que tienen que ver poco con lo jurídico, y entre ellas merecen ser citadas tres. En primer lugar, el desarrollo tecnológico que ha proporcionado medios para satisfacer las necesidades de grandes conglomerados de población. En segundo lugar, la evolución de la política económica de los Estados y, en especial, del llamado Estado benefactor que, por desprestigiado que esté, hizo mucho por los derechos. Finalmente, los DESC se han desarrollado por causa de las luchas sociales y políticas, porque los derechos sociales son conquistas peleadas y logradas por la gente. Es necesario tener esto en cuenta porque lo que ocurre en el ámbito 
jurídico constituye una dimensión importante, pero no la principal, de la realización práctica de los derechos ${ }^{172}$.

Como se podrá observar a lo largo del presente capitulo, el logro de la consagración de un catálogo amplio de derechos prestacionales en la Constitución de 1991, obedece al giro en la concepción de la dignidad que atañe al ser humano y que es órbita del actuar del Estado, tanto para garantizar deberes de abstención propios de los derechos de tercera generación, como para la formulación y realización de actos que implican políticas positivas de efectividad de los derechos económicos, sociales y culturales, considerando que "sólo puede realizarse el ideal del ser humano libre, exento del temor y de la miseria, si se crean condiciones que permitan a cada persona gozar de sus derechos económicos, sociales y culturales, tanto como de sus derechos civiles y políticos"173.

El derecho a la salud ha de contar con medidas de protección y garantía que proporcionen un nivel de vida adecuado y mínimo para el ejercicio del conjunto de derechos del cual es titular una persona en el marco jurídico establecido para el Estado Social de Derecho. De esta forma:

La realización plena de los derechos económicos, sociales y culturales es una aspiración de toda la sociedad. Así como los derechos están interrelacionados, las acciones gubernamentales que los deben proteger y garantizar provienen de múltiples instancias complementarias. Por ejemplo, la realización plena del derecho a la salud no se agota en los beneficios de la ley ${ }^{174}$.

Sino que atañe de manera transversal a todo el entramado jurídico, administrativo y social que ha de actuar en procura de su realización mediante el acceso, el servicio y la calidad de los programas de atención en salud.

Así las cosas, en el cuerpo de esta disertación, se explicitan los alcances conceptuales y la estructura de los derechos sociales dentro del ámbito de la dogmática jurídica, partiendo de su fundamentación histórica, para lo cual se estudiará la teoría de los derechos sociales, sus titulares y obligados.

172 DE ROUX, Carlos Vicente y RAMÍREZ, Juan carlos. Derechos económicos, sociales y culturales, economía y democracia. Bogotá.: Serie estudios y perspectiva, 2004. p. 18

${ }^{173}$ COLOMBIA. CORTE CONSTITUCIONAL DE COLOMBIA. Sentencia SU-624-1999. M.P Alejandro Martínez Caballero. p. 20.

174 FUNDACIÓN MENONITA COLOMBIANA PARA EL DESARROLLO MENCOLDES. Mesa de trabajo de Bogotá sobre desplazamiento interno. En:_Boletín No. 13. (Sept, 2005). Pág. 41 
1.5.1. Fundamentación y perspectiva histórica. Para abordar la naturaleza de los derechos sociales, resulta importante mencionar su génesis desde la dogmática, así como los diferentes postulados jurídicos que los sustentan. La historia evolutiva de los derechos humanos plantea que los derechos sociales surgen como una respuesta a las exigencias de tutela estatal de los sectores más vulnerables de la sociedad, quienes sufrían las consecuencias del establecimiento de un Estado liberal-individualista, fruto de las Revoluciones liberales del siglo XVIIII75.

En el marco del constitucionalismo clásico liberal se gestaron enormes manifestaciones ciudadanas que propendieron por la reivindicación de los derechos individuales, con el fin de hacer de estos hechos reales y no solo formulaciones abstractas. Esta nueva perspectiva fue "la expresión legal del triunfo de las revoluciones burguesas que a diferencia de los sistemas legales anteriores establecieron la igualdad formal del hombre ante la ley"176. Sin embargo, la consagración de estos derechos individuales no fue suficiente; su protección y garantía sigue estando ligado a la movilización y presión social que se desarrolle al respecto. En este sentido, "pese a la igualdad formal del hombre ante la ley, surgió el Constitucionalismo Social en las propias sociedades capitalistas, tendientes a atenuar esas desigualdades sociales, aunque sin alterar las relaciones de producción capitalistas vigentes"177 La contradicción de la naturaleza del Estado capitalista con el trabajador fomenta la inequidad, razón por la cual la igual formal solo puede revestir de características reales si está presionada por la movilización social. De hecho, las libertades individuales proponen un ideal social que presupone unas condiciones previas de bienestar general para que los derechos individuales sean disfrutados por todos en igualdad de condiciones. Sin embargo, como se ha expuesto anteriormente, la antítesis del modelo económico en beneficio de unas minorías con respecto a los sectores vulnerables le exige a la teoría jurídica una reinterpretación de los derechos ubicando a los de carácter social en un lugar privilegiado por su fundamentalidad para la disminución de las brechas de inequidad social.

Las manifestaciones sociales acaecidas en el siglo XIX y comienzos del siglo XX fueron el producto de la inaplicabilidad de los derechos conseguidos en las revoluciones burguesas en un modelo que sustenta la inequidad, por ello el papel de la presión social es crucial, en la medida en que reconfigura al Estado, lo que,

175 AGUILERA PORTALES, Rafael y ESPINO TAPIA, Diana. Fundamento, garantías y naturaleza jurídica de los derechos sociales ante la crisis del Estado Social de Derecho. En: Revista Telemática de Filosofía del Derecho. № 10 (2006/2007); Pág. 111-139. ISSN 1575-7382.

176 TORRES MOLINA, Ramón. Cátedra II Historia Constitucional. Facultad de Ciencias Jurídicas y Sociales. Universidad Nacional de La Plata (en línea). En: https://historiaconstitucional.wordpress.com/2013/04/19/la-reforma-de-la-constitucion-y-el-constitucionalismo-social/ (Citado 15 de diciembre de 2016).

177 lbíd. Par. 2. 
además, fue el sustento práctico que enriquece los nuevos planteamientos teóricos del derecho "orientándose al reconocimiento de su cada vez mayor intervención en la vida social"178. Hecho que desencadenó "fuertes limitaciones a los clásicos derechos individuales en aras del bienestar colectivo en una gran tentativa de racionalización de la vida pública"179. Esto, teniendo en cuenta que el liberalismo clásico está basado en las libertades burguesas que benefician en particular a los dueños del capital y no a la clase obrera.

Al culminar la Primer Guerra Mundial, las protestas sociales de la clase obrera mundial gestaron procesos de transformación constitucional, prueba piloto de ello es "la Constitución mexicana de 1917, pero que adquiere resonancia universal con la promulgación de la Constitución rusa de 1918 y especialmente con la alemana de Weimar de 1919"180. Estos procesos constitucionales estuvieron precedidos por antecedentes de tensión social significativos. El aumento desmedido de las riquezas y su acumulación por parte de la clase burgués, agudizó la inequidad social y con ello la contradicción con el proletariado. Las clases trabajadoras sufrieron las consecuencias de la aceleración de los procesos industriales, la falta de empleos bien remunerados, la inestabilidad laboral, la imposibilidad de acceso a servicios de salud, entre otras situaciones, que se agravaron al pasar el tiempo. Estos hechos motivaron enormes huelgas de trabajadores en todo el mundo, las cuales presionaron a los gobiernos de turno y a la sociedad en general, con el propósito de reconfigurar la acción del Estado en la sociedad. El intervencionismo estatal fue el resultado de estas fuertes confrontaciones, las exigencias de las clases trabajadoras y de los más desfavorecidos condicionaron una nueva forma de participación ciudadana en las esferas del poder. El Estado ante el enorme abstencionismo, reconoció la necesidad de garantizar derechos exclusivamente sociales.

Como consecuencia de las luchas sociales emergentes, los procesos revolucionarios adquirieron mayor fuerza. La revolución mexicana se gestó en medio de un ambiente de protesta social y de enormes desigualdades entre clases. Por otra parte, estas insurrecciones crearon las condiciones materiales para que la sociedad comenzara a replantear su ordenamiento jurídico, por ejemplo, la constitución de Querétaro que fue producto de la revolución mexicana. En Alemania, en esta misma época, la clase trabajadora sufrió el empeoramiento de sus condiciones laborales, los proletarios desprovistos de seguridad social se organizaron en asociaciones sindicales y luego en partidos políticos social demócratas que hicieron "volver la mirada hacia los grupos y las clases; desconoce

178 SÁNCHEZ VÁSQUEZ, Rafael. La trascendencia del constitucionalismo social en América Latina (Caso México) En: Cuestiones Constitucionales. №.27 (Julio - Diciembre, 2012). p. 251-309.

179 lbíd. p. 272.

180 lbíd. p. 272. 
el primado de la autonomía de la voluntad, para abrazar el control social de la libertad; cercena los derechos absolutos, para reorientarlos en sentido social"181 Estas reivindicaciones sociales favorecieron a la clase trabajadora, pero permearon y se extendieron por su naturaleza a la sociedad en general. Aparecieron las distinciones especiales en cuanto al género, la edad, y, además, no solo se hablaba de beneficios laborales, sino también de educación, seguridad social, y en especial al caso de la salud, políticas en el tema agrario y la intervención permanente del Estado en escenarios económicos y sociales.

En tanto, la precisa respuesta a dichas exigencias, fue la creación del Estado Democrático y Social de Derecho,

El cual propugna por unos mínimos sociales que, junto a los derechos de libertad, pertenecen a todas las personas, son previos al propio contrato social y, por lo tanto, resultan indisponibles tanto para el Estado como para el mercado. Esos derechos sociales básicos no se oponen a los derechos de libertad, sino que constituyen su natural correspondencia cuando ésta última se concibe no sólo en su dimensión negativa, como no intromisión, sino también en su faceta positiva, como libertad-poder ${ }^{182}$.

Empero, en tal época y bajo tales postulados, nació el Estado Liberal justificado en el no reconocimiento ni aplicación de los derechos sociales como fundamentales, al considerar que solo "los individuales son "inherentes de la persona humana", lo cual enjaula, como diría Joaquín Herrera, los derechos humanos en una dimensión individual asocial y excluyente, que no aplica el principio universal de la integralidad de los derechos humanos"183. No obstante, algunos desarrollos que adelante se referenciarán, infringe de forma grave el Derecho Internacional de los Derechos Humanos (DIDH), por lo cual debió ser objeto de reformulaciones políticonormativas.

La infravaloración o valoración desigual de los derechos humanos fue estudiada por Abramovich-Courtis, quien adujo sobre lo previsto por la ONU en la Observación General №3 de 1966 y la obligatoriedad de adoptar medidas efectivas para hacer real este tipo de derechos a través de recursos idóneos y efectivos en caso de

181 SÁNCHEZ VÁSQUEZ, Rafael. Op.Cit. p. 266.

182 PISARELLO, Gerardo. Los derechos sociales en el constitucionalismo democrático. En: Boletín Mexicano de Derecho Comparado. № 92 (2006, México).

183 PERDOMO CASTAÑO, Carlos Alberto. Derechos fundamentales a medias e integralidad de derechos. Bogotá.: Defensoría del Pueblo, 2011. 
violación, que la fuerza vinculante y obligaciones de los DESC en el Pacto Internacional eran eminentemente declarativas y programáticas, ubicadas entre lo prejurídico y el derecho: en el tránsito del deber ser, que determina el principio o "mandato de optimización" de normas jurídicas que no obligan coactivamente a los Estados comprometidos, pero que no obstante son deseables.

La indebida acumulación de las riquezas y la falta de una apropiada distribución de las mismas es la causa de la injusticia social, lo que imposibilita el acceso equitativo a los bienes y servicios básicos por parte de las grandes mayorías. Esta situación de insatisfacción material en el marco de un Estado Social de Derecho es una contradicción de principio.

La injusticia social del sistema capitalista es descrita con criterio científico por el filósofo y economista alemán Karl Marx. Cuatro situaciones son esenciales en el análisis marxista que están relacionados con la evolución del derecho fundamental a la salud: la distribución de la riqueza, el acceso a los bienes y servicios básicos, la paz y la seguridad. Estas cuatro condiciones enmarcan la estabilidad de un Estado social.

Ahora bien, el contenido y la forma de las luchas sociales están relacionadas con las dinámicas particulares de determinadas épocas de la historia. Sus exigencias responden a la evolución de la conciencia frente a las dificultades materiales que se le presenten a determinada clase social en relación con la naturaleza y las demás clases sociales. La lucha de clases es el resultado de una contradicción frente al dominio de las riquezas producto del trabajo. La distribución y acumulación de estas riquezas representa uno de los pilares del mundo capitalista. Este sistema concentra el poder adquisitivo y con ello, la clase burguesa y sus ramificaciones en la sociedad actual tienen el privilegio de disfrutar de derechos consagrados por la ley de manera efectiva a diferencia de las clases dominadas, quienes por su condición económica no reciben las mismas garantías.

De otra parte, paralelo al Manifiesto Comunista, narra Aguilera,

[...] se produce en Europa otra tentativa de reconocimiento constitucional de esta "nueva generación" de derechos a través de la Constitución Francesa de 1848, en la cual se consignó como deber del Estado, la protección al trabajo y la instrucción. 
El Manifiesto Comunista de 1848, y el primigenio intento de la Constitución francesa del mismo año de incluir las nuevas exigencias sociales, "no son más que los antecedentes próximos del reconocimiento constitucional de los derechos sociales, a través del surgimiento del constitucionalismo social, y por ende, del Estado Social de Derecho ${ }^{184}$.

El desarrollo industrial de finales del siglo XIX estuvo acompañado por la expedición de documentos oficiales religiosos que manifestaban un giro hacia el compromiso social de la iglesia con las comunidades. Las encíclicas papales, pastorales de conferencias episcopales y concilios ecuménicos, conformaron lo que, con el paso de los años, se denominó como la doctrina social de la iglesia que manifiesta un viraje hacia la consolidación de una posición política de la iglesia católica tendente al respeto de los derechos sociales, influencia que fue en términos culturales determinante, teniendo en cuenta el poder del catolicismo en las bases sociales de la época. Hacia el año de 1891 con la rúbrica del papa León XIII, se expidió la encíclica Rerum Novarum, considerada como el primer gran documento de la doctrina social de la iglesia, si bien, como lo explica José Sols Lucía "ninguno de los papas que publicó encíclicas sociales tenía interés alguno en diseñar un nuevo modelo económico" 185 , los postulados preceptuados en las encíclicas papales de finales del siglo XIX y principios del siglo XX contienen acérrimas críticas a los modelos económicos, tanto al modelo liberal capitalista como al modelo que propugna por la dictadura del proletariado mediante la revolución.

El Rerum Novarum de León XIII planteó un sistema intermedio entre el capitalismo y el socialismo. "León XIII quiso situar esta posición intermedia entre la dictadura del mercado - capitalismo - y la dictadura del Estado — socialismo - al defender que el Estado puede y debe intervenir en asuntos económicos en determinados casos, pero no siempre"186. De esta manera, se puede apreciar la inclinación ideológica de la iglesia católica respeto a la función del Estado como garante de los derechos de los ciudadanos, haciendo énfasis especial en los sectores vulnerables.

La tendencia mencionada que marca la iglesia católica con relación a las funciones del Estado y su relación con la ciudadanía siguió manteniendo el mismo rumbo. Prueba de ello son las encíclicas papales que expidieron los papas de turno, como es el caso de la encíclica Centesimus Annus, proferida por Juan Pablo II, a propósito de los 100 años de la Rerum Novarum, su férrea oposición al uso de la violencia al

\footnotetext{
184 AGUILERA PORTALES, Rafael y ESPINO TAPIA, Diana. Op. Cit. p. 117.

185 SOLS LUCÍA, José. Cinco lecciones de pensamiento social cristiano. Madrid.: Editorial Trotta, S.A., 2013. p. 85.

186 Ibíd. p. 65.
} 
consagrar en su texto "¡Ojalá los hombres aprendan a luchar por la justicia sin violencia, renunciando a la lucha de clases en las controversias internas, así como a la guerra en las internacionales!"187 En razón de lo anterior, la Rerum Novarum y la manceba doctrina social de la iglesia, con ocasión del crecimiento y la adopción de modelos socialistas y de la imposibilidad de comportarse ajenos de la situación obrera, León XIII en su encíclica papal hace que ante esta situación coyuntural "se aporten pistas para afrontar la cuestión social, que suponen el rechazo frontal del socialismo de su época, pero también profundas correcciones al modelo vigente inspirado por el liberalismo"188, con base en su crítica a su modo de interpretar la libertad.

Las encíclicas mencionadas abordan el tema de las difíciles condiciones laborales de la época, asumen un papel mediador entre el dueño del capital y el obrero, por esta razón, estos textos no insistan a redefinir el statu quo, sino a mejorar las condiciones de trabajo en el marco del sistema capitalista, por ejemplo:

Se ha de mirar por ello que la jornada diaria no se prolongue más horas de las que permitan las fuerzas. Ahora bien: cuánto deba ser el intervalo dedicado al descanso, lo determinarán la clase de trabajo, las circunstancias de tiempo y lugar y la condición misma de los operarios. La dureza del trabajo de los que se ocupan ensacar piedras en las canteras o en minas de hierro, cobre y otras cosas de esta índole, ha de ser compensada con la brevedad de la duración, pues requiere mucho más esfuerzo que otros y es peligroso para la salud $^{189}$.

Por otra parte, estas encíclicas abordan el tema de la salud de manera especial y de esta forma inciden en la transformación de la idea del Estado Social de Derecho.

En la encíclica Quadragesimo Anno, 40 años después de la expedición de la encíclica papal de 1891, el Papa Pio XI defiende "que tanto el capital como el trabajo son necesarios para la actividad económica: de nada sirve que uno se imponga sobre el otro; deben vivir en armonía"190. Consecuente con el comentario contenido en la encíclica precedente de León XIII, que exhorta a los proletarios y obreros de

\footnotetext{
187 JUAN PABLO II. Encíclica Centesimus Annus (1 de mayo de 1991).

188 CAMACHO LARAÑA, Ildefonso. Doctrina social de la Iglesia: quince claves para su comprensión. Bilbao.: Editorial Desclée de Brouwer, 2009. p. 25.

189 LEÓN XIII. Encíclica Rerum Novarum (05 de mayo de 1891).

190 PIO XI. Encíclica Quadragesimo Anno (15 de mayo de 1931).
} 
"abstenerse de toda violencia al defender sus derechos y no promover sediciones"191

Los temas de las encíclicas papales evolucionaron. La llegada de un nuevo Obispo a Roma determinó su cambio, la discusión sobre los aspectos relacionados con los derechos sociales y la crítica a los modelos económicos se transformó en una idea sobre el problema de la relación entre el mundo desarrollado y el subdesarrollado, pues:

Si en la primera etapa la atención se concentra en los problemas típicos de las sociedades industrializadas (conflicto capital-trabajo, confrontación de los dos grandes sistemas socioeconómicos), en la segunda el horizonte se abre para atender al problema Norte-Sur (el subdesarrollo frente al desarrollo, sus mutuas relaciones) ${ }^{192}$.

Más adelante, el Papa Juan XXIII, hacia los años 1961 y 1963 expidió las encíclicas Mater et Magistra y Pacem In Terris respectivamente. En este periodo liderado por Juan XXIII "[...] aparece ya un estilo nuevo, no de confrontación, sino de diálogo"193. La primera de estas es de especial consideración en el escrutinio de los documentos oficiales proferidos en el marco de la Doctrina Social de la Iglesia con ocasión de los derechos sociales y en particular el derecho a la salud.

En Mater et Magistra "se manifiesta ya un cambio de sensibilidad para captar las nuevas dimensiones de la cuestión social, el problema multiforme de las desigualdades económicas y sociales en sus diferentes niveles de expresión"194. La denominada "cuestión social" es el bastión de la doctrina social de la iglesia que justifica volcar los esfuerzos del pontífice para expedir un documento para referirse a las problemáticas que aquejan a la sociedad. En mérito de lo anterior, Velasco Criado considera a esta como "[...] la encíclica que reconoce los derechos sociales, aunque continúe afirmando el carácter natural del derecho de propiedad privada" ${ }^{195}$.

En tanto lo anterior, es pertinente transcribir un extracto de la Mater et Magistra (1961) que permite avizorar el reconocimiento de los derechos sociales, de los cuales hace referencia Velasco Criado:

191 LEÓN XIII. Encíclica Rerum Novarum (05 de mayo de 1891).

192 CAMACHO LARAÑA, Ildefonso. Op. Cit. p. 23.

193 lbíd. p. 27.

194 Ibíd. p. 27.

195 VELASCO CRIADO, Demetrio. Derechos humanos y doctrina social de la lglesia: del anatema al diálogo. Bilbao.: Publicaciones de la Universidad De Deusto, 2000. p. 33. 
Es indudable que este progreso de las relaciones sociales acarrea numerosas ventajas y beneficios. En efecto, permite que se satisfagan mejor muchos derechos de la persona humana, sobre todo los llamados económico-sociales, los cuales atienden fundamentalmente a las exigencias de la vida humana: el cuidado de la salud, una instrucción básica más profunda y extensa, una formación profesional más completa, la vivienda, el trabajo, el descanso conveniente y una honesta recreación ${ }^{196}$.

Es importante tener en cuenta que los planteamientos de la iglesia hicieron parte de una serie de manifestaciones intelectuales sobre la pertinencia de un nuevo sistema estatal, es decir, el paradigma social se reconfiguró a partir de las nuevas necesidades de los ciudadanos y por ende las instituciones que los representa cambiaron o atendieron a ser transformadas. El Estado Social de Derecho ya contaba con adherentes, el denominado constitucionalismo social paralelamente hacía lo propio con su tendencia por salvaguardar más allá de los denominados derechos de primera generación, de tal manera que la doctrina social de la iglesia fungía como un insumo más que propendía por la constitucionalización de los derechos del orden social, entre ellos, el paladín del presente trabajo de investigación, el derecho a la salud.

Las encíclicas papales tienen el papel de representar dos situaciones importantes para la evolución de los derechos sociales. La primera, es la de presentarse como una expresión crítica y, a la vez, institucional del sistema; la representatividad de la iglesia católica en el mundo occidental es indudable, por ello sus afirmaciones pueden ser determinantes. La segunda, es la de manifestarse del lado de los más vulnerables, lo que es un hecho significativo teniendo en cuenta que a lo largo de la historia la iglesia ha jugado del lado de los que gobiernan en ocasiones y también de quienes son mal gobernados en otros momentos. La postura de la iglesia impulsa la transformación del Estado, pero esta no deja de ser crítica, como se expresa en la siguiente cita: "[...] la Doctrina Social nace y se desarrolla durante décadas hasta pasada la mitad del siglo XX, en estrecha vinculación al mundo occidental industrializado; los problemas específicos del resto del planeta, por su parte, están fuera de su horizonte de preocupaciones"197. Más allá de las críticas sobre la estrechez de la Doctrina Social, es claro que la iglesia fue determinante en esta reconfiguración del paradigma político, jurídico y social.

Por tanto, a nuestro entender la constitucionalización de los derechos sociales se concretiza a principios del siglo XX, posterior a la Primera Guerra mundial, cuando

196 JUAN XXII. Encíclica Mater et Magistra (15 de mayo de 1961).

197 CAMACHO LARAÑA. Op. Cit. Pág. 18. 
se produce un desarrollo nuevo en el constitucionalismo, "Los movimientos sociales del siglo XIX y el crecimiento acelerado que se produce en los primeros años del siglo XX, obligan a replantear la razón de ser del Estado, orientándose al reconocimiento de una cada vez mayor intervención en la vida social. Junto al fortalecimiento de las libertades individuales, surge entonces el establecimiento de las libertades-participación"198, las cuales obligan a un Estado-protector a intervenir en la vida social y política. Así, los derechos sociales son reconocidos y garantizados por el nuevo Estado protector, el cual "[...] no solo participa como árbitro en las relaciones capital-trabajo, sino que además planifica y regula la cultura y la familia, imprimiendo fuertes restricciones a los clásicos derechos liberales en pro del bienestar social" 199 .

Uno de los vestigios que dejó la Primera Guerra Mundial, fue la promulgación del Tratado de Versalles, firmado el 28 de junio de 1919 entre los Países Aliados y Alemania, cuya entrada en vigor fue el 10 de enero de 1920. Por medio de este, se pretendió poner fin a la confrontación bélica, garantizando la paz y la seguridad mundial. Las condiciones de vida de los habitantes de Europa para aquella época, en general, no eran óptimas, la Gran Guerra había deteriorado gravemente el tejido social y las instituciones estatales, las consecuencias de la guerra eran evidentes, tuvieron que pasar muchos años para que los países confrontados pudieran recuperarse.

Uno de los sectores más afectados con la guerra fue el de los trabajadores. Quienes vivieron las secuelas de esta gigantesca confrontación bélica y además, el retorno acelerado de la industrialización. La exigencia de mayor mano de obra, para la época, fue directamente proporcional a la cantidad de mercancías que el Estado necesita para mantener a flote su economía. Las condiciones de trabajo empeoraron, no hubo nuevos contratos para la exigencia que demandaba la aceleración industrial, sino que los dueños de las fábricas y los gobiernos de turno recurrieron a la sobreexplotación con el aumento indiscriminado de horas en la jornada laboral. Las exigencias fueron cada vez mayores para los trabajadores y sus garantías mínimas, esto exacerbó la contradicción de los proletarios con los dueños de las fábricas y los dirigentes del gobierno, por ende, la organización sindical se fortaleció y recobró importancia la discusión sobre un Estado basado en derechos de carácter social.

Lo anterior, da cuenta de la indefectible necesidad que existía en los trabajadores de contar con un instrumento normativo en el que se consagraran unos mínimos de

${ }^{198}$ DUVERGER, Maurice, Institutions politiques et droit constitutionnel. Paris.: Presses Universitaires de France, 1963. p. 201.

199 AGUILERA PORTALES. Op. Cit. Pág. 111-139. 
respecto, igualdad y protección frente a las labores que estos desempeñaban. Ello propició debates y discusiones alrededor de cuál fuera la forma más pertinente para asegurar las interpelaciones laborales de la clase proletaria, aquella que al mismo tiempo era responsable de sostener la economía de tales Estados.

En el marco de estas discusiones, alrededor del tema laboral y con ánimo de eliminar las condiciones paupérrimas de los obreros, nació el Tratado de Versalles, cuyo objetivo central era dar por terminadas las devastadoras consecuencias de esta Guerra, así como de todos los conflictos y situaciones que por causa de ella se encontraran vigentes, en un intento por promover la defensa y protección de los derechos humanos en sus distintos escenarios, puntualmente en el campo laboral. No se trató pues de una mera declaración, sino de un instrumento que reconoció derechos efectivos, en procura de condiciones integrales de bienestar para los trabajadores.

Con el fin de materializar las consignas mencionadas, la Sociedad de Naciones determinó mediante el Tratado de Versalles, la creación de la Organización Internacional del Trabajo, OIT, con las siguientes consideraciones como fundamento de su decisión:

Visto que existen condiciones de trabajo que implican para un gran número de personas la injusticia, la miseria y las privaciones, lo que engendra un tal descontento que la paz y la armonía universales son puestas en peligro, $y$ atento que es urgente mejorar esas condiciones: por ejemplo, en lo que concierne a la reglamentación de las horas de trabajo, a la fijación de una duración máxima de la jornada y de la semana de trabajo, al reclutamiento de la mano de obra, la lucha contra la desocupación, la garantía de un salario que asegure condiciones de existencia convenientes, la protección de los trabajadores contra las enfermedades generales o profesionales y los accidentes resultantes del trabajo, la protección de los niños, de los adolescentes y de las mujeres, las pensiones de vejez y de invalidez, la defensa de los intereses de los trabajadores ocupados en el extranjero, la afirmación del principio de la libertad sindical, la organización de la enseñanza profesional y técnica y a otras medidas análogas; Visto que la no adopción de un régimen de trabajo realmente humano es un obstáculo puesto a los esfuerzos de las demás naciones deseosas de mejorar la suerte de los trabajadores en sus propios países $[\ldots]^{200}$.

200 Tratado de Versalles (1919) (en línea) http://www.dipublico.org/1729/tratado-de-paz-de-versalles1919-en-espanol/ (citado 16 de diciembre de 2016). 
Saltan a la vista las razones por las cuales se hizo necesario crear un organismo internacional que hiciera las veces de garante frente a los derechos inherentes a la condición de trabajador y los mínimos necesarios para ejercer su profesión con dignidad y decoro. Limitaciones sobre la cantidad de horas laborables, el inminente pago de prestaciones sociales, la salubridad e incluso la vigilancia, control y protección en materia de accidentes laborales, que hoy son tan comunes, encuentran sus antecedentes en épocas tan recientes como los últimos años del siglo XX.

Como la mayoría de las luchas que han tenido lugar en la consecución y establecimiento de los derechos sociales, el Tratado de Versalles propendía por garantizar la paz y la seguridad, tal como reza el preámbulo del Pacto; empero, ello era inconcebible sin justicia social y era este el fin último del nacimiento de la OIT. Es, por tanto, una de las conquistas institucionales más sobresalientes del siglo anterior y marcó la llegada de un nuevo periodo en el que los trabajadores son dignificados y empoderados en los derechos que, per se, les pertenecen.

En conclusión, es mediante el reconocimiento constitucional que se les otorga a los ideales gestados en las luchas sociales una categorización, obteniéndose así "el reconocimiento de las nuevas aspiraciones que los Estados deben proteger, garantizando la institucionalización de nuevas obligaciones a nivel constitucional, de respeto integral de la dignidad humana"201. Todo lo anterior, "dentro del desarrollo e implementación del denominado constitucionalismo social, cuya ideología hace que se consoliden los derechos sociales, entre ellos la seguridad social y los derechos asistenciales prestacionales a cargo del Estado, verbigracia la salud"202.

La referida movilización social se concibe desde un escenario en el que circunscriben las expresiones contestatarias de la sociedad, que acarrean consigo un componente sociológico, las cuales no pueden interpretarse aisladamente del contexto social gestante. Ahora bien, desde su reconocimiento hasta su consagración en las cartas políticas del siglo XX, se debe a una tendencia denominada por Boaventura de Sousa como de "transformación social progresista" donde se supera el debate de la detentación del poder y, en lugar de ello, "elabora conceptos y metodologías destinadas a fundar una nueva racionalidad social que

\footnotetext{
201 lbíd. Pág. 111-139.

202 LÓPEZ OLIVA, José. La constitución de Weimar y los derechos sociales. La influencia en el contexto constitucional y legal colombiano a la luz de los derechos sociales asistenciales a la seguridad social en salud. En: Prolegómenos - Derechos y Valores. Volumen XIII, No. 26 (Jul - Dic, 2010). p. 236.
} 
ponga las bases para el establecimiento de un modelo social alternativo"203. El cual, desde luego, debe propender por ampliar cada vez más las prerrogativas sociales de las clases vulneradas.

De esta manera, la postura del sociólogo portugués, basado en una transformación progresista, pertenece a un modelo que define como "racionalidad cosmopolita", la cual, teniendo en cuenta las experiencias de los grupos sociales que a lo largo de la historia han estado en una posición de indefensión y desprotección estatal "pretende valorar la experiencia social de los grupos explotados y oprimidos poniendo el énfasis en la recuperación de los valores de la solidaridad y la emancipación social"204. Lo anterior, de acuerdo a su teoría, lo consigue mediante el reconocimiento reciproco de alteridad y la creación consecuente de escenarios que propicien relaciones sociales amparadas en un orden justo, igualitario y libre.

En virtud de lo anterior, la trasformación del papel del Estado es un hecho crucial en el desarrollo de los sucesos anteriormente expresados. El paradigma de un Estado abstencionista cambia a un Estado interventor y con ello la relación entre el ciudadano y el Estado se fortalece. En cuanto a esa nueva correspondencia de sujetos que antes era exigua, casi nula, debido al carácter negativo de los derechos, ahora pasa a ser una determinante en la búsqueda de la satisfacción de estos derechos que tutelan la dignidad humana del conglomerado social.

Según las anteriores consideraciones, el Estado es una organización política y jurídica que a través de sus instituciones y organismos busca afianzar el ejercicio de los derechos de sus ciudadanos, garantizando el desarrollo holístico de estos. El abandono del estado natural planteado por Hobbes es, pues, tan solo el comienzo del camino hacia el establecimiento de unas máximas que promuevan la completitud del hombre. En este sentido, el fin del Estado tendrá que ver con el mantenimiento de la paz, la cual será posible solo bajo estrictos lineamientos que se convierten en principios para los ciudadanos.

El mantenimiento de la paz, que antiguamente predicara Hobbes como el fin del Estado, comprende diferentes etapas y momentos, en el que se hacen necesarias las reivindicaciones sociales que conduzcan al reconocimiento incluso con rango constitucional de las prerrogativas inherentes al ser humano. Generalmente, la ratificación de derechos, por parte de un grupo social o una determinada

${ }^{203}$ AGUILÓ BONET, Antoni Jesús. Los Derechos Humanos como campo de luchas por la diversidad humana: Un análisis desde la sociología crítica de Boaventura de Sousa Santos. En: Universitas humanística. N 68 (jul-dic, 2009). p. 183.

204 AGUILÓ BONET, Antoni Jesús. Op. Cit. p. 183. 
colectividad, ha devenido de fases con un intenso contenido de belicosidad, entendida esta como el enfrentamiento de clases, posiciones y grupos dominantes y dominados que, a modo de pugna, han confrontado sus ideales hasta obtener un resultado acorde a las consignas esgrimidas.

En este proceso de cambio, el Estado reviste nuevas formas que se acomodan a la dinámica de la lucha social, en la medida en que el choque entre las esferas del poder y los movimientos de reivindicación comienza a dirimirse a través de acuerdos entre las dos partes. Las reivindicaciones sociales inciden en la metamorfosis del Estado, el cual asume un papel más garantista frente a la protección de los derechos de sus ciudadanos. De este modo, el derecho a la salud, y todo lo que ello implica, es progresivo. La adopción de normativa frente al tema y la consagración constitucional de este derecho han sido influenciadas por distintos factores políticos, religiosos, culturales, económicos y, por supuesto, sociales.

Frente al factor social, la sociología jurídica, entendida como la rama de la sociología que estudia la inter influencia de los aspectos sociales jurídicos, plantea que el Derecho no es una ciencia autónoma o independiente, sino que está en constante dinamismo debido a su interdependencia con la sociedad y con el hombre mismo.

De esta manera, la acción social repercute en la configuración del Estado, siendo impensable que este exista sin tener en cuenta las interacciones entre las dinámicas sociales y las institucionales que, como se mencionó anteriormente, pasan a convertirse en reivindicaciones propias de un grupo social específico.

En este sentido, desde la teoría de la sociología jurídica, es importante ahondar la característica de lo social en el derecho a la salud y en la consolidación del Estado Social de Derecho. Por supuesto, no es un debate sencillo, puesto que hay diversas concepciones sociológico-jurídicas como teóricas. Mas, para la presente investigación, se toma como referente, como ya se mencionó, al sociólogo Boaventura de Sousa, puntualmente en lo que respecta a las luchas sociales que devienen de los procesos de globalización y su consecuente influencia en la universalización de los derechos humanos.

El debate sobre el concepto de universalidad de los derechos encuentra su principal opositor en el sociólogo portugués Boaventura de Sousa, quien elabora una crítica sobre la manera como la universalidad de los derechos puede convertirse en una manifestación de la globalización que "puede llevar a toda una gama de resultados 'desviados', tales como la adopción oportunista de políticas de derechos humanos 
con el fin de complacer a las potencias hegemónicas"205. Desde esta perspectiva, el reconocimiento de los derechos fundamentales no consiste en hechos aislados, sino en un trinomio de causas que, al fusionarse, abocan progresos que determinan la evolución de los mismos. Este trinomio lo conforman los tópicos cultural, político y económico. Este conjunto reacciona y genera resultados que son palpables a nivel social y que, sin duda, ejercen una influencia vasta sobre las decisiones jurídicas de un Estado. Resulta interesante aterrizar el pensamiento de Sousa al respecto, especialmente cuando se refiere a los tipos de globalización, la cual puede darse desde arriba o desde abajo. A esta última es a la que el sociólogo le brinda todo su brazo fuerte, aludiendo al cosmopolitismo.

Para comprender lo anterior, es necesario retomar la idea de que toda globalización es un conjunto de luchas entre los estamentos sociales opuestos; así, las fuerzas sociales que están abajo se enfrentarán con las que están arriba, como si dominados y dominantes se encontraran en un constante proceso dialéctico de contradicción. La historia de la consolidación del derecho fundamental a la salud se desarrolla a partir de esta tensión entre los de arriba y los de abajo. Las luchas entre diversos sectores, en especial, las manifestaciones del proletariado son las instigadoras de los procesos de transformación jurídica que cambian las normativas constitucionales.

Según la concepción del pensador portugués Sousa, la universalidad de los derechos humanos, que en este caso se consideran fundamentales, debe generarse a través de una globalización determinada desde abajo. El cosmopolitismo es protagonista en la consolidación de un ambiente multiculturalmente garantista, pues, como expone el autor "su tarea consiste en construir un discurso contra-hegemónico que se oponga a aquel que a lo largo de la historia ha legitimado el derecho moderno a merced de los universales que el liberalismo propugna"206

La evolución del derecho a la salud es un proceso dialéctico en el que las clases dominadas, ya sea con la movilización social o con transformaciones de carácter revolucionario radical, se han convertido en su gestor principal. Cada una de las luchas sociales y jurídicas que se narran a lo largo de esta investigación, son prueba indiscutible del poder que se ha impreso "desde abajo" por parte de quienes han reclamado el reconocimiento generoso de sus derechos. No obstante, el progreso

205 CASTRO BUITRAGO, Erika; RESTREPO YEPES, Olga y GARCÍA MATAMOROS, Laura. Historia, concepto y estructura de los derechos económicos, sociales y culturales. En: Revista Estudios Socio-Jurídicos. Vol. 9, núm. (abril, 2007). p. 103.

206 URZOLA GUTIÉRREZ, Daniela. Boaventura de Sousa Santos y la reconstrucción intercultural de los derechos humanos. En: Revista Jurídicas. 9(2). (jul-dic, 2012). p. 82. 
de los derechos fundamentales, como es el caso de la salud, proviene de múltiples dificultades, pero es precisamente este camino difícil el que permite la consolidación de síntesis políticas que redundan en los procesos de democratización social, para lograr desembocar, finalmente, en la emancipación de la cual habla Boaventura, deshaciendo las relaciones de poder controlador y virándolas en verdadera cooperación y "autoridad compartida" 207.

Por otra parte, el formalismo derivado de la positivización de los derechos sociales en los ordenamientos jurídicos y la adquisición con esto del nomen derechos fundamentales no está dentro de su radio de interés; a esta ciencia social más que a su consagración, le interesa su implementación en "el análisis del conjunto de decisiones, actuaciones y medidas ejecutivas realizadas por los diversos organismos, operadores jurídicos y grupos de presión, que intervienen en el proceso de producción, interpretación, aplicación y ejecución de las normas jurídicas"208. De este modo, se deduce la importancia de las políticas que se adoptan en favor de la materialización del derecho a la salud, con supeditación a la sostenibilidad fiscal del Estado. Esto representa en la sociología un reto frente a la implementación de estas políticas en Estados subdesarrollados, en los que la desigualdad y la pobreza representan obstáculos en favor de su ejecución.

A partir del Estado Social de Derecho y del reconocimiento de los derechos fundamentales, se están implementando acciones y pensándose alternativas a fin de incorporar los llamados "derechos sociales" y las garantías para su cumplimiento. Desde esta perspectiva, el Estado debe tomar el rol de promotor de estos derechos, logrando que los principios de libertad e igualdad, no sean meras aspiraciones políticas, sino "fórmulas de cumplimiento efectivo, removiendo los obstáculos para su cumplimiento, y facilitando la participación de los ciudadanos en la vida política, económica, social y cultural"209.

1.5.2. El estado frente a los derechos sociales. El establecimiento de derechos sociales supone durante una época fuertemente influenciada por las ideas liberales, una participación activa del Estado en el sentido de "adoptar medidas que permitan el mejoramiento de los estándares de vida de los asociados, contradiciendo, por lo tanto, el pensamiento liberal que pedía del Estado una abstención o un no hacer"210.

207 AGUILÓ BONET, Antoni Jesús. Op. Cit. p. 201.

208 FARIÑAS DULCE, María José. Los derechos humanos: desde la perspectiva sociológico-jurídica a la actitud posmoderna. 2a. ed. Madrid.: Dykinson, 2006. Pág. 51.

209 AGUILERA PORTALES Op. Cit. p. 139.

210 CASTRO BUITRAGO, Erika; RESTREPO YEPES, Olga y GARCÍA MATAMOROS, Laura. Op. Cit. p. 81. 
En el contexto de los derechos sociales se plantea la necesidad de su concreción normativa, no solo para determinar el alcance concreto del contenido prescriptivo del derecho, es decir, las acciones que debe realizar el poder público como destinatario de los derechos sociales "sino también determinar sus deberes positivos para proteger y dotar de eficacia en los casos concretos al objeto de dichos derechos"211.

Los derechos sociales son inseparables de competencias, es decir, que un contenido objetivo interrelacionado hasta el punto de su dimensión subjetiva depende de su intermediación. En este sentido, es más fácil que este tipo de derechos pueda ser objeto de descentralización política, ya que consiente establecer medidas diferentes al permitir que los poderes públicos articulen diferenciaciones de contenido concreto en función de los distintos territorios y de las diferentes necesidades en ellos. Por el contrario, los derechos de defensa en tanto son límites de la actividad de los poderes públicos, funcionan de un modo plano e idéntico con independencia de las medidas de poder a las que afectan desde un punto de vista territorial.

Los derechos sociales no poseen intrínsecamente una caracterización que les permita diferenciarse y deducir que no poseen a priori el mismo contenido objetivo que el resto de las normas constitucionales, es decir, se debe comprobar su concreto grado de vinculación de conformidad con las propias reglas constitucionales que son las únicas que pueden autorizar una diferente intensidad de graduación en su efectividad y eficacia, pero "no por ello van a perder su carácter de normas jurídicas vinculantes para sus destinatarios; simplemente conlleva a determinar su eficacia en función del contexto constitucional y de su significado concreto"212.

1.5.3. Caracterización de los derechos sociales. Dentro de este marco, se caracterizan los derechos sociales bajo la propuesta del profesor Cascajo Castro, quien los define como "derechos de cualquier ciudadano a una directa o indirecta prestación positiva por parte de los poderes públicos, en función de la participación en los beneficios de la vida en sociedad o de la actuación del principio de igualdad"213. Igualmente, el catedrático de filosofía Prieto Sanchís afirma que en las actuales declaraciones de derechos aparecen consagradas nuevas prestaciones a

\footnotetext{
211 lbíd. 104.

212 lbid. Pág. 95.

${ }^{213}$ CASCAJO CASTRO, Jose Luis. DirittiSociali. Enciclopedia del Diritto, Vol. XII. Milán.: Giuffré. p. 48.
} 
cargo del Estado, lo cual obliga la ampliación del catálogo clásico de derechos y libertades, incluyendo dentro de los mismos los derechos sociales ${ }^{214}$.

De la misma manera, el jurista y profesor alemán, Robert Alexi propone la inclusión de los derechos de prestación "en sentido estricto" dentro del catálogo de los derechos fundamentales, llegando incluso a referirse a ellos como "derechos sociales fundamentales" 215 . No obstante, el profesor afirma que existe una dificultad para la consideración de los derechos sociales como derechos plenos por ser difícilmente justiciables $y$, también, porque suponen un esfuerzo económico cuantioso que choca con la escasez, que es una realidad en la que se encuentran todas las sociedades. En todo caso, esas dificultades no diluyen el mandato radical de la Constitución de remover los obstáculos y promover las condiciones para que la libertad y la igualdad puedan ser reales y efectivas para todos, aunque sí obligan a distinguir entre los derechos sociales distintas categorías ${ }^{216}$.

Por su parte, Rodolfo Arango establece que los derechos sociales fundamentales "no tienen como título de adquisición el texto expreso de la constitución [sino que] tiene como única fuente posible normas adscritas de derecho fundamental"217. Así las cosas, es a través de la interpretación y la argumentación jurídica que los derechos sociales cobran fuerza, fundamentando su exigibilidad y teniendo como base todo el entramado normativo que consagra la Carta Política. Es por esto que aunque los derechos sociales no consagren un medio para alcanzar su justiciabilidad, pueden ser traducidos a derechos subjetivos, por cuanto cumplen con las tres características del derecho subjetivo: una norma jurídica, una obligación jurídica y una posición jurídica ${ }^{218}$.

Para continuar el desarrollo de la hipótesis ante el problema de la naturaleza del derecho a la salud, se incorpora el análisis de la obra del profesor José Luis Cascajo, quien afirma que los derechos de prestación consagrados en la Constitución son derechos exigibles ante los poderes públicos por parte de cualquier ciudadano, en

214 PRIETO SANCHÍS, Luis. Estudios sobre derechos fundamentales. Madrid.: Editorial Debate, 1990. p. 45-46.

215 ALEXY, Robert. Teoría de los derechos fundamentales. Madrid.: Centro de Estudios Políticos y Constitucionales, 2003. p. 482.

216 PECES-BARBA, Gregorio. Reflexiones sobre los derechos sociales. En: coord. GARCIA MANRIQUE Ricardo. Derechos sociales y ponderación. 6 Ed. Madrid.: Fundación Coloquio Jurídico Europeo, 2009. pp. 85-102.

217 ARANGO, Rodolfo. El Concept de los derechos sociales Fundamentals. Bogotá.: Legis, 2005. p. 24.

218 lbid. p. 21. 
tanto que han sido concebidos como un certificado de garantía de los ciudadanos frente a la administración ${ }^{219}$.

Resulta evidente el condicionamiento economicista que debilita la efectividad de los derechos sociales, económicos y culturales, toda vez que como se ha insistido en el presente artículo, estos derechos reclaman más actuaciones de parte del Estado, lo que implica mayores erogaciones económicas, las cuales se supeditan, no a la autoridad judicial, sino en su mayoría, a decisiones de tipo político; "con base en esto, se sostiene que los enunciados constitucionales que recogen tales derechos no pueden ser objeto de decisiones judiciales hasta tanto el Congreso no haya expedido la legislación necesaria para aplicarlos; de lo contrario, se dice, el juez estaría ocupando terrenos que no le corresponden de acuerdo con la doctrina de la separación de los poderes"220.

Sobre el particular, debe resaltarse que como bien señala la jurisprudencia en cita:

Esta fue la solución que la doctrina colombiana e internacional dio al asunto mencionado, a la luz de los postulados del Estado de Derecho liberal clásico. Sin embargo, los nuevos postulados del Estado social y las nuevas relaciones jurídicas derivadas del Estado bienestar imponen un cuestionamiento de esta solución. 221

De esta forma, la reorientación del Estado colombiano como Estado Social de Derecho, tiene hondas implicaciones en la realización de los derechos económicos, sociales y culturales, ya que debe considerarse que estos últimos son la garantía, los mínimos necesarios para la efectividad de los derechos de libertad e igualdad formal, así como también le atañe al Estado Colombiano la formulación de políticas afirmativas por las que se generen mecanismos ciertos y reales para satisfacer las necesidades de orden económico, social y cultural de sus ciudadanos. Al respecto y en punto de la fundamentalidad del derecho a la salud, la misma ha de ser considerada dentro de la teoría jurídica como un significativo avance cuyo propósito no es otro que el de logar un equilibrio entre los que tienen más y los que tienen menos, a fin de permitir a toda la realización de sus derechos de todo orden: sociales, económicos y culturales, ora de libertad e igualdad formal.

219 CASCAJO, José Luis. Op. cit. p. 77.

220 COLOMBIA. CORTE CONSTITUCIONAL DE COLOMBIA. Sentencia T-406 de1992. M.P. Ciro Angarita Barón. Bogotá.

221 lbíd. 
Debe hacerse en tanto énfasis en la protección de los derechos sociales sin importar su nomen sino su contenido, creando garantías "previstas por el ordenamiento para reducir la distancia estructural entre normatividad y efectividad, $y$, por tanto, permitir la máxima eficacia de los derechos fundamentales en coherencia con su formulación constitucional, orientadas a asegurar la tutela de los derechos sociales"222.

A pesar de que al analizar las obligaciones estatales respecto a los derechos sociales surge notoriamente que en muchos eventos tales derechos han sido derechos politizados, tal circunstancia debe ser superada concibiéndose a los mismos como verdaderos derechos exigibles en un sin número de eventos, atendiendo la obligación constitucional que impone la cláusula "Estado Social de Derecho", a partir de la cual los derechos sociales constituyen verdaderos derechos fundamentales y fundamentadores, por lo cual es deber del Estado garantizarlos; ello "otorgando a sus ciudadanos armas para afrontar la actual situación mundial, y protegiéndolos de cualquier circunstancia que pueda mermar sus derechos y ser contrarios a su dignidad humana"223.

En este orden de ideas, el reconocimiento ius fundamental que hace de manera coherente la Corte Constitucional de los derechos sociales, transforma la concepción de estos, pues "pasan de ser derechos por conexidad, a ser disposiciones fundamentales que merecen protección reforzada y autónoma por mandato expreso de la Constitución"224. Esto porque de tales derechos, tal y como quedó demostrado, se pueden predicar todos los elementos que comporta un derecho subjetivo: un titular determinado, es decir, todo miembro de la especie humana que se encuentre en una situación en la cual no pueda satisfacer por sí mismo sus necesidades; unos sujetos obligados, que son el Estado y los particulares, y un objeto identificable: obligaciones de proteger, respetar y cumplir. Por ello, los derechos económicos, sociales y culturales merecen también ser susceptibles de protección ${ }^{225}$, incluso por medio de la acción de tutela, pues no existe ningún argumento que justifique la no exigibilidad judicial de los derechos.

Los resultados que arroja el análisis de la literatura presentada, el estudio de la línea jurisprudencial trazada por la Corte desde sus primeros pronunciamientos sobre la materia, el análisis de los instrumentos internacionales que versan sobre este derecho y el estudio de la recientemente promulgada Ley 1751 de 2015, son la base teórica de este trabajo de investigación, el cual tiene la finalidad de avanzar más

\footnotetext{
222 AGUILERA PORTALES, Rafael y ESPINO TAPIA, Diana. Op. Cit. p. 129.

${ }^{223}$ AGUILERA PORTALES, Rafael y ESPINO TAPIA, Diana. Op. Cit. p. 133.

${ }^{224}$ RIVEROS PARDO, Daniel Felipe. Op. Cit. p. 42.

${ }^{225}$ RIVEROS PARDO, Daniel Felipe. Op. Cit. p. 42.
} 
allá de la previsión jurídica de los derechos subjetivos y abordar los elementos de significación histórica que son las base de los principios y valores sociales que determinan el concepto de fundamental del derecho a la salud. Luego de esta conceptualización teórica, resulta evidente en este análisis, que adoptar una posición frente al problema plateado conlleva una diferente solución para la exigibilidad de los derechos considerados fundamentales. En el caso del derecho a la salud, este trabajo ofrece una explicación analítico-descriptiva del porqué de la problemática de su exigibilidad entre el sistema de justicia y la necesidad de su consagración constitucional y significación histórica que son las base de los principios y valores sociales que determinan el concepto de fundamental del derecho a la salud. 


\section{ANÁLISIS DE LA IUSFUNDAMENTALIDAD DEL DERECHO A LA SALUD}

\subsection{CONSIDERACIONES PREVIAS}

Hacer un análisis sobre la naturaleza fundamental del derecho a la salud, dentro de la órbita de la teoría jurídica, resulta relevante de cara al giro que la definición de este derecho ha tenido gracias a la evolución jurisprudencial, evidencia de notables avances en la implementación de las garantías propias del Estado Social de Derecho y de la gran acogida de los postulados provenientes de la orilla doctrinal.

Sin duda, la jurisprudencia ha permitido desarrollar el derecho a la salud más allá del plano de las clasificaciones históricas de los derechos, hoy en desuso por la afectación que las mismas representan a su contenido esencial, concediéndole de este modo su reconocimiento como garantía fundamental para el ejercicio del catálogo de derechos consagrados en la Constitución de 1991.

Hoy, tal y como lo ha considerado la Corte Constitucional en reiterada jurisprudencia, "La salud es un concepto que guarda íntima relación con el bienestar del ser humano, el cual, dentro del marco del Estado social, al convertirse en derecho, se constituye en un postulado fundamental del bienestar ciudadano"226. Ello institucionalizado mediante la ley estatutaria de la salud como derecho fundamental, que con el aval de la Corte Constitucional establece:

El derecho fundamental a la salud es autónomo e irrenunciable en lo individual y en lo colectivo. Comprende el acceso a los servicios de salud de manera oportuna, eficaz y con calidad para la preservación, el mejoramiento y la promoción de la salud. El Estado adoptará políticas para asegurar la igualdad de trato y oportunidades en el acceso a las actividades de promoción, prevención, diagnóstico, tratamiento, rehabilitación y paliación para todas las personas ${ }^{227}$.

${ }^{226}$ COLOMBIA. CORTE CONSTITUCIONAL DE COLOMBIA. Sentencia T-204 de 2000. M.P.: Fabio Morón Díaz. p. 1.

227 COLOMBIA. CONGRESO DE LA REPÚBLICA DE COLOMBIA. Ley 1751 (16, febrero, 2015). Por medio de la cual se regula el derecho fundamental a la salud y se dictan otras disposiciones. Diario Oficial, Bogotá D.C. 2015. № 49427. p. 1. 
Situados en esta nueva concepción, se hace necesario delimitar conceptualmente los cambios institucionales y de legislación que implica la consideración de la salud como un derecho fundamental, con base en, por una parte, el fundamento jurídicolegal cimentado en normas, leyes, convenios internacionales y mecanismos e instancias encargadas de su cumplimiento, y en segunda medida, el fundamento moral, aquel conjunto de principios éticos que lo sustentan, independientemente de que exista o no una ley que lo respalde. Esto porque a partir del sustento legal y moral debe estructurarse un nuevo paradigma que permee no solo el emporio Estatal, sino también social, el cual facilite imprimir cambios de todo orden para que el reconocimiento de este derecho no sea considerado como una mera prerrogativa que concede el Estado a sus asociados, sino un deber que impele su cumplimiento en beneficio de la plenitud de garantías que con su negación o afectación podrían ser conculcadas.

Asimismo y bajo tal línea de argumentación, resulta pertinente documentar la nueva concepción de dicho derecho, que redunde no solo en el mejoramiento del sistema en punto de la legalidad e institucionalidad, sino también, y no menos importante, en el del ideario social y la interpretación judicial, toda vez que en la realidad fáctica se conoce que un sinnúmero de casos requieren de la intervención de un juez para lograr la efectividad de este derecho en términos del acceso a los servicios requeridos de tal modo que si se avanza en la concepción del derecho a la salud y en consecuencia, en el rediseño la estructura del sistema de seguridad social en salud, será posible lograr un avance en la descongestión judicial y en el cumplimiento de los fines y la esencia del modelo de Estado Social de Derecho.

\subsection{EL DERECHO A LA SALUD}

2.2.1 Evolución histórica del derecho a la salud Visto en precedencia como es que nacen los derechos fundamentales, y en particular los derechos sociales, se hace necesario adentrarse en la historia y desarrollo del derecho que se configura en objeto de este estudio, a la salud, el cual, de la mano de los demás derechos sociales, es de reciente inclusión, en albores de los siglos XIX y XX, enraizado su nacimiento con las diferentes revoluciones sociales que en dicho periodo tuvieron lugar. No obstante, solo se formula la salud como derecho a partir de los condicionamientos sociales.

En primera medida, se tiene que, en Inglaterra hacia finales del siglo XIX, cobró importancia el estado de salud de los pobres, lo que sin duda repercutió en la salubridad pública. De esta manera, se plantearon medidas contra dicha población en el Report of the poor Law Comission, que fue antecedente significativo del Comité de Beveridge, otrora aludido, que postularía en el social insurance and allied 
services el mecanismo de cooperación entre Estado e individuos en aras de lograr un Sistema de Seguridad Social. En Alemania, en el siglo XIX, se empezó a pensar en la necesidad proporcionar "alguna asistencia médica y algún seguro para accidentes laborales, enfermedades, invalidez e incluso vejez" 228 . Este modelo pensado para hacer frente a las contingencias de la vida, conocido como el modelo de Bismark, es el inspirador del primigenio sistema de seguridad social que se incorporó en la república de Weimar, el cual se fundó, primero en la garantía de protección a los sujetos especiales de protección; y en segunda medida, en los aportes de los trabajadores. Posteriormente, se empezó a hablar de la salud como un derecho que debía estar soportado en un sistema e inició el curso de su positivización, a partir del cual empezó verdaderamente a cobrar importancia el mismo.

En ese sentido, se establece en el artículo 161 de la Constitución de Weimar lo siguiente:

Para atender a la conservación de la salud y de la capacidad para el trabajo, a la protección de la maternidad y a la previsión de las consecuencias económicas de la vejez, la enfermedad y las vicisitudes de la vida, el Imperio creará un amplio sistema de seguros, con el concurso efectivo de los interesados ${ }^{229}$.

En México, a la vanguardia de la constitucionalización de la salud, se consignó en la Constitución de Querétaro lo siguiente:

ARTICULO 8. Todo individuo tiene derecho al trabajo, a la salud y a disfrutar de vivienda digna y decorosa. El Gobierno del Estado y los gobiernos municipales promoverán la construcción de viviendas e inducirán a los sectores privado y social hacia este objeto, de conformidad con las disposiciones legales aplicables.

A título seguido, la Constitución Francesa, la Constitución Portuguesa, la Constitución Sudafricana de 1996 y la Constitución Española de 1978, entre otras, han incorporado tal derecho en su texto. Y si bien en tales textos no se pensaba la salud como un derecho, sino más bien como un servicio público importante, la

228 LEMA AÑÓN, Carlos. apogeo y crisis de la salud: Historia del derecho a la salud en el siglo XX. Madrid: Dykinson, Instituto de Derechos Humanos Bartolomé de las Casas, 2010. Pág. 30.

${ }^{229}$ ALEMANIA. CONSTITUCIÓN DEL IMPERIO (REICH) ALEMÁN. En: Textos Constitucionales españoles y extranjeros. Zaragoza.: Editorial Athenaeum, 1930. p. 23. 
positivización en los textos constitucionales fue el hito para que a nivel internacional se empezara a desarrollar tal derecho, impulsando así mismo a la evolución del concepto en garantía de la dignidad humana.

La incorporación del derecho a la salud en diferentes instrumentos internacionales ha determinado la esfera de efectividad del derecho a la salud en tanto ha intentado determinar, a partir del ordenamiento jurídico universal, el reconocimiento y garantía del derecho en el orden interno, logrando la exigibilidad en dicho ámbito. Son múltiples los instrumentos que han jaloneado dicho proceso, determinando hoy el reconocimiento del derecho a la salud como un derecho fundamental.

Luego de su internacionalización, se empezó a hablar de la salud como derecho fundamental, con antecedente en la Conferencia Internacional sobre Atención Primaria de Salud, que en el párrafo I de la Declaración de Alma Ata, de septiembre de 1978, señaló:

La Conferencia reitera firmemente que la salud, estado de completo bienestar físico, mental y social, y no solamente la ausencia de afecciones o enfermedades, es un derecho humano fundamental y que el logro del grado más alto posible de salud es un objetivo social sumamente importante en todo el mundo, cuya realización exige la intervención de muchos otros sectores sociales y económicos, además del de la salud ${ }^{230}$.

Tal contenido en demasía garantista, es impositivo de obligaciones por parte del Estado frente a la protección del "más alto nivel de salud", nivel que exige no solo medidas sanitarias, sino también sociales frente a los factores externos que afectan dicha condición y, así mismo, los factores económicos que tienen incidencia. Así en el numeral $\vee$ de dichos instrumentos se señala:

Los gobiernos tienen la responsabilidad de la salud de sus poblaciones, que puede ser conseguida sólo mediante la provisión de unas medidas sanitarias y sociales adecuadas. Un objetivo social principal de los gobiernos, organizaciones internacionales y el total de la comunidad mundial para las próximas décadas, debería ser la promoción, para todos los habitantes del mundo, en el año 2000, de

230 CONFERENCIA INTERNACIONAL SOBRE ATENCIÓN PRIMARIA DE SALUD. Declaración de Alma-Ata. URSS, 1978. p. 1. (en línea). ttp://www.paho.org/hq/index.php?option=com_docman\&task=doc_view\&gid $=19004 \&$ Itemid=2518. 
un nivel de salud que les permitiera llevar a cabo una vida productiva social y económicamente. La atención primaria de salud es la clave para conseguir este objetivo como parte del espíritu de justicia social del desarrollo231.

Colombia no ha sido ajena a este proceso, pues a partir de la Constitución de 1991 normativizó en el texto político la salud como derecho; si bien tal reconocimiento no se dio como de aplicación inmediata, sino reconocido más como un servicio público esencial, sin duda fue base para su ubérrimo y posterior desarrollo que, al compás de los instrumentos internacionales, se haría vía jurisprudencial. Luego de positivado, a partir de los pronunciamientos de la Corte Constitucional como máxima guardiana de la Constitución, se empezó a hablar de la salud como derecho fundamental como más adelante se verá a partir de la sentencia T-760 de 2008, que cambió la noción del derecho, antes protegido solo mediante la teoría de la conexidad, para dar paso al reconocimiento de un derecho fundamental autónomo, per se exigible.

Como se estudiará a profundidad en el abordaje jurisprudencial, en el interregno 2008 a la fecha, los pronunciamientos de la Corte Constitucional, aunque en ocasiones variopintos, siempre se han ubicado en la misma noción que tanto demanda del Estado y del Sistema de Seguridad Social. Dicho desarrollo pretende ser regulado como tal, de manera pionera en el mundo, pues hoy en el estudio del derecho fundamental a la salud en Colombia debe hacerse necesaria referencia a la Ley estatutaria del derecho fundamental a la salud, que por lo menos en el texto, plantea un reconocimiento legislativo a las medidas que tal derecho exige en virtud de su naturaleza fundamental; si bien dicha norma apenas se encuentra en trámite, fue declarada exequible aunque con condicionamientos por la Corte Constitucional.

Tal como lo exponen Nereida Rojo y Rosario García:

[...] la salud deviene como un fenómeno estrechamente ligado a las condiciones de vida de la población, que sólo puede ser explicado por medio de un enfoque integral y sistémico. Es un proceso inmerso en la dinámica social donde se pueden identificar seis grandes

231 CONFERENCIA INTERNACIONAL SOBRE ATENCIÓN PRIMARIA DE SALUD. Declaración de Alma-Ata. URSS, 1978. p. 1. (en línea). ttp://www.paho.org/hq/index.php?option=com_docman\&task=doc_view\&gid $=19004 \&$ Itemid=2518. 
dimensiones: biológica, ecológica, sociológica, psicológica, económica y de los servicios de salud ${ }^{232}$.

Este planteamiento fortalece la concepción que se ha instaurado en el Estado Colombiano, pues permite ver el derecho a la salud más allá que como un derecho autónomo, como un derecho que ampara toda la amalgama de esferas que lo comprenden y que arrogan su protección. Tan así es que la misma Corte Constitucional ha expuesto la importancia de garantizar el derecho a la salud aun cuando sus ciudadanos no cuenten con los recursos para acceder a los servicios de salud, caso en el cual el Estado social será responsable por la prestación del servicio, en desarrollo de sus fines esenciales.

Como se ve, el derecho a la salud en su génesis se ha desarrollado de manera acelerada sobre todo en Colombia. No obstante, de inusitada importancia hay que hacer ver que a pesar de los avances en el camino de su reconocimiento como derecho fundamental, hace falta recorrer un vasto camino a efecto de lograr su total exigibilidad y materialidad.

2.2.1.1. Referente internacional. El derecho a la salud ha tenido un amplio desarrollo en la normatividad internacional y busca homogeneizar las legislaciones del mundo en punto del principio pro homine tratándose de derechos fundamentales como el que se estudia. Así, una primera y necesaria alusión debe hacerse a la Declaración Americana de Derechos y Deberes del Hombre de 1948, la cual incorpora al sistema interamericano un conjunto de derechos sociales, económicos y culturales, dentro de los cuales se reconoce el derecho a la salud al siguiente tenor: Toda persona tiene derecho a que su salud sea preservada "i) por medidas sanitarias y sociales, relativas a la alimentación, el vestido, la vivienda y la asistencia médica, ii) correspondientes al nivel que permitan los recursos públicos y los de la comunidad"233. Se desprende de la interpretación de la norma que si bien la misma se encamina a garantizar la salud del individuo en el marco de la protección inclusive de los factores externos que determinan su condición, verbigracia, alimentación, etc., la misma es tímida en su alcance, pues de manera enfática limita el mismo a la existencia de recursos, los cuales no son exclusivamente provenientes del Estado, sino también de la comunidad que, en cumplimiento de su deber de solidaridad, debe sufragar la atención en salud.

232 ROJO PÉREZ, Nereida, GARCÍA GONZÁLEZ, Rosario. Sociología y salud. Reflexiones para la acción. En: Red Revista Cubana de Salud Pública. vol.26, n.2. (2006). p. 94.

233 Novena Conferencia Internacional Americana. Declaración Americana de los Derechos y Deberes del Hombre. Bogotá, 1948. p. 3. (en línea). http://www.hchr.org.co/documentoseinformes/documentos/carceles/2_Interamericanos/1_Instrumentos/1_Generales_DH/2111_Decla_Ameri-

cana_DS_Deb_H.pdf. 
A título seguido, la Declaración Universal de Derechos Humanos, proclamada en el mismo año por la Asamblea General de Naciones Unidas, incluyó así mismo el derecho a la salud en su artículo 25 al siguiente tenor:

Toda persona tiene derecho a un nivel de vida adecuado que le asegure, a sí mismo como a su familia, la salud y el bienestar, y en especial la alimentación, el vestido, la vivienda, la asistencia médica y los servicios sociales necesarios ${ }^{234}$.

En esta normatividad, el concepto del derecho es amplio y se extiende más allá de la asistencia médica o la atención sanitaria, sin reducirse al estar sano, sino a gozar del máximo nivel de vida adecuado frente a todas las condiciones de vida.

Posteriormente, los Convenios de Ginebra de 1949, anclados al Derecho Internacional Humanitario, se enfocaron en brindar protección al derecho a la salud en el contexto de los conflictos armados, por lo cual, bajo la pretensión de humanizar la guerra, se protegieron de manera expresa y clara algunos de sus componentes, reconocidos en dicho ámbito como irrenunciables e impostergables. Así se deduce de las siguientes normas:

- Convenio de Ginebra para aliviar la suerte que corren los heridos y los enfermos de las fuerzas armadas en campaña (Convenio I, 1949) 235 , el cual consagra en su artículo 3, que cuando el conflicto armado no sea de índole internacional y que surja en el territorio de una de las Altas Partes Contratantes, cada combatiente tiene obligaciones frente a la salud de los heridos y enfermos, tanto de quienes participan en las hostilidades, como con la de aquellos que no.

- Convenio de Ginebra relativo al trato debido a los prisioneros de guerra (Convenio III, 1949) ${ }^{236}$, el cual establece en su artículo 7 la protección de la salud a todo prisionero de guerra.

234 ORGANIZACIÓN DE LAS NACIONES UNIDAS. Declaración Universal de los Derechos Humanos, United Nations. 2008. (en línea) http://www.un.org/es/documents/udhr/index_print.shtml.

235 CONFERENCIA DIPLOMÁTICA PARA ELABORAR CONVENIOS INTERNACIONALES. Convenio de Ginebra para aliviar la suerte que corren los heridos y los enfermos de las fuerzas armadas en campaña. Ginebra, 1949. (en línea). https://www.icrc.org/spa/resources/documents/treaty/treatygc-2-5tdkwc.htm.

${ }^{236}$ CONFERENCIA DIPLOMÁTICA PARA ELABORAR CONVENIOS INTERNACIONALES. Convenio de Ginebra relativo al trato debido a los prisioneros de guerra. Ginebra, 1949. (en línea). https://www.icrc.org/spa/resources/documents/treaty/treaty-gc-3-5tdkwx.htm 
- Convenio de Ginebra relativo a la protección debida a las personas civiles en tiempo de guerra (Convenio IV, 1949)237, establece la obligación de brindar tratamiento médico y asistencia hospitalaria a los extranjeros que se encuentren en el territorio de una parte del conflicto cuando así lo requieran.

Posteriormente, en el año 1959, se suscribe la Declaración de los Derechos del Niño ${ }^{238}$, que enfatiza en el interés superior del menor, reconociendo que los menores son acreedores de protección y cuidados especiales en materia de salud, la cual ha de brindarse de manera automática.

Luego, en 1965, surgió la Convención Internacional sobre la Eliminación de todas las Formas de Discriminación Racial de Naciones Unidas, instrumento en el cual se establece que en pro del derecho de la igualdad en el disfrute de los derechos humanos y las libertades fundamentales. Los Estados deben adoptar medidas "[...] especiales y concretas, en las esferas social, económica, cultural y en otras esferas para asegurar el adecuado desenvolvimiento y protección de ciertos grupos raciales o de personas pertenecientes a estos grupos" 239 , en particular frente al "[...] derecho a la salud pública, la asistencia médica, la seguridad social y los servicios sociales"240.

En 1966, se suscriben los Pactos Internacionales de Derechos Humanos en desarrollo de la Convención de derechos humanos de 1948. En primera medida, tuvo lugar el Pacto Internacional de Derechos Civiles y Políticos (PIDCP) y, luego, el Pacto Internacional de Derechos Económicos, Sociales y Culturales (PIDESC); en este último, suscrito con base en los fines en mayor medida programáticos ante la imposibilidad real de su goce efectivo, se incluyó el derecho a la salud como un derecho de carácter social, incluido en artículo 12 de la normativa como el derecho al disfrute del más alto nivel posible de salud física y mental a saber:

237 CONFERENCIA DIPLOMÁTICA PARA ELABORAR CONVENIOS INTERNACIONALES. Convenio de Ginebra relativo a la protección debida a las personas civiles en tiempo de guerra. Ginebra, 1949. (en línea). https://www.icrc.org/spa/resources/documents/treaty/treaty-gc-4-5tdkyk.htm.

238 ASAMBLEA GENERAL DE LAS NACIONES UNIDAS. Declaración de los Derechos del Niño, 1959. (en línea). http://www.humanium.org/es/wp-content/uploads/2013/09/Declaraci\%C3\%B3n-delos-Derechos-del-Ni\%C3\%B101.pdf.

239 ASAMBLEA GENERAL DE LAS NACIONES UNIDAS. Convención Internacional sobre la Eliminación de todas las Formas de Discriminación Racial. 1965. (en línea). http://www.ohchr.org/SP/Professionallnterest/Pages/CERD.aspx.

${ }^{240}$ ASAMBLEA GENERAL DE LAS NACIONES UNIDAS. Op. Cit. 


\section{Artículo 12.}

1. Los Estados Partes en el presente Pacto reconocen el derecho de toda persona al disfrute del más alto nivel posible de salud física y mental.

2. Entre las medidas que deberán adoptar los Estados Partes en el Pacto a fin de asegurar la plena efectividad de este derecho, figurarán las necesarias para:

a) La reducción de la mortinatalidad y de la mortalidad infantil, y el sano desarrollo de los niños;

b) El mejoramiento en todos sus aspectos de la higiene del trabajo y del medio ambiente;

c) La prevención y el tratamiento de las enfermedades epidémicas, endémicas, profesionales y de otra índole, y la lucha contra ellas;

d) La creación de condiciones que aseguren a todos asistencia médica y servicios médicos en caso de enfermedad ${ }^{241}$.

En los términos del pacto, no solo se contempla la amplia definición acogida por la Declaración Universal de Derechos Humanos, sino que se habla de otro componente de la salud, por ejemplo, la salud mental. De la misma manera, se asocian al Estado un conjunto de medidas encaminadas a su protección; no obstante, lo anterior debe hacer énfasis en el carácter programático que dicho instrumento otorga a tal derecho, desprovisto totalmente de exigibilidad inmediata, lo que implica, por un lado, que el ámbito de protección no está previamente establecido de forma precisa, pues depende del nivel de recursos disponibles y, por otro, que la exigibilidad vía judicial del mismo no es plena, ya que se plantea como un futuro deber ser.

A continuación, en el año 1968, la Proclamación de Teherán, resaltó la importancia de dotar de exigibilidad a los derechos económicos, sociales y culturales, señalando que "la realización de los derechos civiles y políticos sin el goce de los derechos económicos, sociales y culturales resulta imposible"242, razón por la cual se exhorta

241 ASAMBLEA GENERAL DE LAS NACIONES UNIDAS. Pacto Internacional de Derechos Económicos, Sociales y Culturales. 1966. (en línea). http://www.ohchr.org/SP/Professionallnterest/Pages/CESCR.aspx.

242 CONFERENCIA INTERNACIONAL DE DERECHOS HUMANOS. Proclamación de Teherán. 1968, (en línea). http://hrlibrary.umn.edu/instree/spanish/sl2ptichr.html. 
a los pueblos y los gobiernos del mundo a redoblar sus esfuerzos para ofrecer a todo ser humano un estado de bienestar físico, mental, social y espiritual.

En Europa para el año 1970, se adoptó la Carta Social Europea, la cual estableció en su artículo 11 que toda persona "[...] tiene derecho a beneficiarse de cuantas medidas le permitan gozar del mejor estado de salud que pueda alcanzar" 243 . A título seguido, la Declaración sobre el Progreso y el Desarrollo en lo Social de 1969, en el marco de las Naciones Unidas, se señaló dentro de sus objetivos principales "[...] el logro de los más altos niveles de salud y la prestación de servicios de protección sanitaria para toda la población, de ser posible en forma gratuita"244. En el artículo 19 de dicha declaración también se señaló, con relación al derecho a la salud, el deber de adoptar medidas para "(i) proporcionar gratuitamente servicios sanitarios a toda la población, y (ii) asegurar instalaciones y servicios preventivos y curativos adecuados y servicios médicos de bienestar social accesibles a todos" 245 . El alcance de tales disposiciones resulta significativo, en tanto incluyen un componente adicional a los presupuestos de la salud como servicio y este es el componente de gratuidad.

Otro hito en cuanto al referente internacional, tiene lugar con la Declaración de Alma Ata ${ }^{246}$, a partir de la cual empezó a pensarse la salud, no solo como derecho, sino como derecho fundamental. A partir de esta significación, se dota a nivel internacional al derecho a la salud de una naturaleza incita al ser humano en condiciones de dignidad, que exige esfuerzos verdaderos y constantes por parte de las esferas sociales.

Para el año 1982, el Comité de derechos Humanos de la ONU adoptó la Observación General sobre derecho a la vida ${ }^{247}$, contemplando el derecho a la salud a partir de la interdependencia entre este y el derecho a la vida. Sobre el particular, se incluyó como obligación del Estado incorporar medidas para disminuir la mortalidad infantil y aumentar la esperanza de vida; así mismo, se dispuso que las medidas en materia de salud no serían suspendidas ni siquiera en casos de emergencia pública o social.

243 CONSEJO DE EUROPA. Carta Social Europea. Turín, 1961. (en línea). http://hrlibrary.umn.edu/euro/spanish/Sz31escch.html.

244 ASAMBLEA GENERAL DE LAS NACIONES UNIDAS. Declaración sobre el progreso y el desarrollo en lo social. Washington, 1969. (en línea). http://www.ohchr.org/SP/Professionallnterest/Pages/ProgressAndDevelopment.aspx.

245 lbíd.

${ }^{246}$ CONFERENCIA INTERNACIONAL SOBRE ATENCIÓN PRIMARIA DE SALUD. Op. Cit.

247 ASAMBLEA GENERAL DE LAS NACIONES UNIDAS. Observaciones generales aprobadas por el Comité de Derechos Humanos. (en línea). http://www.derechos.org/nizkor/ley/doc/obgen2.html\#Prohibicion. 
En el mismo año, se adoptaron por parte de la Asamblea General de las Naciones Unidas los Principios de ética médica aplicables a la función del personal de salud, especialmente los médicos, en la protección de personas presas y detenidas contra la tortura y otros tratos o penas crueles, inhumanas o degradantes, en los cuales se determinó el deber de brindar protección a la salud física y mental, en especial a las personas presas o detenidas sin importar su condición. En el artículo 3 de dicho instrumento, se fija:

el límite que existe en la relación profesional entre el personal de salud y las personas detenidas o presas, al señalar que constituye una violación de la ética médica, en particular de los médicos, cualquier relación cuya sola finalidad no sea evaluar, proteger o mejorar la salud física y mental de éstos, o discriminativas ${ }^{248}$.

Sobre la misma materia, en 1988, el Conjunto de Principios para la protección de todas las personas sometidas a cualquier forma de detención o prisión ${ }^{249}$ contempló en su artículo 22 que ninguna persona detenida o presa será sometida, ni siquiera con su consentimiento, a experimentos médicos o científicos que puedan ser perjudiciales para su salud.

Abordando nuevamente el interés superior del menor, en 1989, se proclamó la Convención sobre los Derechos del Niño, en la cual se estableció que la infancia tiene derecho a cuidados y asistencia especiales conexas a la vida, a la dignidad, al medio ambiente sano, a la recreación, familia, salud, supervivencia y sano desarrollo; en ese sentido se obligan los Estados a reconocer al niño (i) "El disfrute del más alto nivel posible de salud" $250 \mathrm{y}$, (ii) "[...] servicios para el tratamiento de las enfermedades y la rehabilitación de la salud" 251 , resaltando en punto de que los Estados "[...] se esforzarán por asegurar que ningún niño sea privado de su derecho al disfrute de esos servicios sanitarios" 252 .

248 ASAMBLEA GENERAL DE LAS NACIONES UNIDAS. Principios de ética médica aplicables a la función del personal de salud, especialmente los médicos, en la protección de personas presas y detenidas contra la tortura y otros tratos o penas crueles, inhumanas o degradantes. 1982. (en línea). http://www.cidh.org/privadas/principiosdeetica.htm.

${ }^{249}$ ASAMBLEA GENERAL DE LAS NACIONES UNIDAS. Conjunto de Principios para la protección de todas las personas sometidas a cualquier forma de detención o prisión. 1988. (en línea). http://www.ohchr.org/SP/Professionallnterest/Pages/DetentionOrlmprisonment.aspx.

250 ASAMBLEA GENERAL DE LAS NACIONES UNIDAS. Convención sobre los Derechos del Niño. 1989. (en línea). http://www.ohchr.org/SP/Professionallnterest/Pages/CRC.aspx.

251 lbíd.

252 lbíd. 
Frente a la salud de la población indígena, tema neural de cara a la cosmovisión especial que se reconoce a tal población a la luz del pluralismo que irradia nuestra Carta política, se proclamó el Convenio № 169 sobre Pueblos Indígenas y Tribales en Países Independientes en 1989, el cual, basado en la Recomendación sobre Poblaciones Indígenas y Tribales de 1957, preceptuó frente al derecho a la salud de dichos grupos lo siguiente:

El mejoramiento de las condiciones de vida y de trabajo y del nivel de salud y educación de los pueblos interesados, con su participación y cooperación, deberá ser prioritario en los planes de desarrollo económico global de las regiones donde habitan. Los proyectos especiales de desarrollo para estas regiones deberán también elaborarse de modo que promuevan dicho mejoramiento ${ }^{253}$.

En aras de evitar cualquier tipo de discriminación en la prestación del servicio de salud, pero así mismo garantizar a tales pueblos la autonomía con génesis en su raigambre cultural, se consagró:

1. Los gobiernos deberán velar por que se pongan a disposición de los pueblos interesados servicios de salud adecuados o proporcionar a dichos pueblos los medios que les permitan organizar y prestar tales servicios bajo su propia responsabilidad y control, a fin de que puedan gozar del máximo nivel posible de salud física y mental.

2. Los servicios de salud deberán organizarse, en la medida de lo posible, a nivel comunitario. Estos servicios deberán planearse y administrarse en cooperación con los pueblos interesados y tener en cuenta sus condiciones económicas, geográficas, sociales y culturales, así como sus métodos de prevención, prácticas curativas y medicamentos tradicionales.

3. El sistema de asistencia sanitaria deberá dar la preferencia a la formación y al empleo de personal sanitario de la comunidad local y centrarse en los cuidados primarios de salud, manteniendo al mismo tiempo estrechos vínculos con los demás niveles de asistencia sanitaria.

253 CONFERENCIA GENERAL DE LA ORGANIZACIÓN INTERNACIONAL DEL TRABAJO. Convenio sobre pueblos indígenas y tribales. 1989. (en línea). http://www.ilo.org/wcmsp5/groups/public/@ed_norm/@normes/documents/publication/wcms_100910.pdf. 
4. La prestación de tales servicios de salud deberá coordinarse con las demás medidas sociales, económicas y culturales que se tomen en el país" 254 .

Las disposiciones aludidas se encaminan, como se colige visiblemente, a obligar al Estado a suministrar los recursos y bienes necesarios a efectos de que las diferentes comunidades organicen de manera interna y autónoma su servicio de salud, sin quedar así desamparados a causa de su cosmogonía.

Posteriormente, y ya de manera universal, el Protocolo Adicional a la Convención Americana sobre Derechos Humanos en materia de Derechos Económicos, Sociales y Culturales, el Protocolo de San Salvador ${ }^{255}$, de 1988, obliga a los Estados americanos a comprometerse a cumplir cinco tipos de obligaciones con relación a los derechos económicos sociales y culturales, las cuales son: (i) Adoptar medidas necesarias, hasta el máximo de los recursos disponibles, para lograr progresivamente su plena efectividad. (ii) Adoptar disposiciones legislativas o de otro carácter que fueren necesarias para hacerlos efectivos. (iii) Garantizar su ejercicio sin discriminación. (iv) No restringir derechos específicamente reconocidos nacional o internacionalmente, y $(\mathrm{v})$ solo restringir y limitar los derechos reconocidos en el Protocolo mediante leyes que tengan por fin proteger el bienestar general en una sociedad democrática.

Lo anterior, hasta el máximo de los recursos disponibles, y tomando en cuenta su grado de desarrollo, a fin de lograr progresivamente, y de conformidad con la legislación interna, la plena efectividad de los derechos reconocidos, entre los que se encuentra la salud. En el mismo sentido, en su artículo 10, el protocolo determina que el derecho a la salud de toda persona, entendido como "[...] el disfrute del más alto nivel de bienestar físico, mental y social”256 es un bien público.

Además de tales disposiciones, otras disposiciones incluidas dentro de dicho instrumento son de gran importancia para este objeto de estudio, ejemplo:

Artículo 2. Obligación de Adoptar Disposiciones de Derecho Interno. Si el ejercicio de los derechos establecidos en el presente Protocolo

${ }^{254}$ CONFERENCIA GENERAL DE LA ORGANIZACIÓN INTERNACIONAL DEL TRABAJO. Op. Cit. p. 8-9.

255 CONVENCIÓN AMERICANA SOBRE DERECHOS HUMANOS. Protocolo de San Salvador. 1988. (en línea). http://www.hchr.org.co/documentoseinformes/documentos/html/pactos/protocolo_san_salvador.html.

${ }^{256}$ CONVENCIÓN AMERICANA SOBRE DERECHOS HUMANOS. Op. Cit. 
no estuviera ya garantizado por disposiciones legislativas o de otro carácter, los Estados partes se comprometen a adoptar, con arreglo a sus procedimientos constitucionales y a las disposiciones de este Protocolo, las medidas legislativas o de otro carácter que fueren necesarias para hacer efectivos tales derechos ${ }^{257}$.

En este sentido, se dispone que el contenido y alcance del instrumento no es meramente un canto a la bandera ni un discurso teórico con elegante toque de filantropía, sino una norma que impele a los Estados a trasformar el ordenamiento interno a la luz del internacional, en garantía de los derechos reconocidos.

En cuanto al derecho a la salud en concreto, el mismo se desarrolló de manera amplia como sigue:

Artículo 9. Derecho a la Seguridad Social:

1. Toda persona tiene derecho a la seguridad social que la proteja contra las consecuencias de la vejez y de la incapacidad que la imposibilite física o mentalmente para obtener los medios para llevar una vida digna y decorosa. En caso de muerte del beneficiario, las prestaciones de seguridad social serán aplicadas a sus dependientes.

2. Cuando se trate de personas que se encuentran trabajando, el derecho a la seguridad social cubrirá al menos la atención médica y el subsidio o jubilación en casos de accidentes de trabajo o de enfermedad profesional y, cuando se trate de mujeres, licencia retribuida por maternidad antes y después del parto ${ }^{258}$.

$\mathrm{Y}$,

Artículo 10. Derecho a la Salud.

1. Toda persona tiene derecho a la salud, entendida como el disfrute del más alto nivel de bienestar físico, mental y social.

2. Con el fin de hacer efectivo el derecho a la salud los Estados partes se comprometen a reconocer la salud como un bien público y

257 lbíd.

${ }^{258}$ CONVENCIÓN AMERICANA SOBRE DERECHOS HUMANOS. Op. Cit. 
particularmente a adoptar las siguientes medidas para garantizar este derecho:

a. la atención primaria de la salud, entendiendo como tal la asistencia sanitaria esencial puesta al alcance de todos los individuos y familiares de la comunidad;

b. la extensión de los beneficios de los servicios de salud a todos los individuos sujetos a la jurisdicción del Estado;

c. la total inmunización contra las principales enfermedades infecciosas;

d. la prevención y el tratamiento de las enfermedades endémicas, profesionales y de otra índole;

e. la educación de la población sobre la prevención y tratamiento de los problemas de salud, y

f. la satisfacción de las necesidades de salud de los grupos de más alto riesgo y que por sus condiciones de pobreza sean más vulnerables ${ }^{259}$.

Este instrumento de marcada importancia, incorporó la protección de una población poco aludida en el orden internacional, los adultos mayores, quienes a partir del mismo se reconocen acreedores de una protección reforzada, precisamente por su condición de vulnerabilidad y sus especiales requerimientos en materia de salud a causa de la vejez.

Artículo 17. Protección de los Ancianos. Toda persona tiene derecho a protección especial durante su ancianidad. En tal cometido, los Estados partes se comprometen a adoptar de manera progresiva las medidas necesarias a fin de llevar este derecho a la práctica y en particular a:

a. Proporcionar instalaciones adecuadas, así como alimentación y atención médica especializada, a las personas de edad avanzada que carezcan de ella y no se encuentren en condiciones de proporcionársela por sí mismas; $[\ldots]^{260}$.

${ }^{259}$ CONVENCIÓN AMERICANA SOBRE DERECHOS HUMANOS. Op. Cit.

260 lbíd. 
Hasta este momento, los esfuerzos de los organismos internacionales se centraron en la preparación de documentos internacionales suscritos entre los diferentes Estados, esfuerzos que posteriormente y ya para los años 90 , se concentraron en definir e interpretar el alcance de los textos existentes, por parte de las autoridades competentes. El primer instrumento que se produjo después de esta época, fue la Convención internacional sobre la protección de los derechos de todos los trabajadores migratorios y de sus familiares de 1990, la cual fue emitida por la Asamblea General de las Naciones Unidas. En esta Convención que reiteró la estrecha relación entre el derecho a la salud y la dignidad humana, se señaló en su artículo 28 que:

Los trabajadores migratorios y sus familiares tendrán derecho a recibir cualquier tipo de atención médica urgente que resulte necesaria para preservar su vida o para evitar daños irreparables a su salud en condiciones de igualdad de trato con los nacionales del Estado de que se trate 261 .

En 1993, la Declaración y Programa de acción de Viena adoptada en la Conferencia Mundial de Derechos Humanos, reconoció, entre otras cosas, la importancia del disfrute por la mujer del más alto nivel de salud física y mental durante toda su vida, concretamente su derecho "[...] a tener acceso a una atención de salud adecuada y a la más amplia gama de servicios de planificación familiar"262.

Otro instrumento de especial significación en este inventario de normatividad reguladora al derecho a la salud, fue la Convención sobre los derechos de las personas con discapacidad adoptada en el marco de la Asamblea General de las Naciones Unidas el 13 de diciembre de 2006, aprobada en Colombia mediante Ley 1346 de julio 31 de 2009 y, avalada en su constitucionalidad la Corte Constitucional en sentencia C- 293 de 2010. Sobre la referencia se establece:

Artículo 25. Salud. Los Estados Partes reconocen que las personas con discapacidad tienen derecho a gozar del más alto nivel posible de salud sin discriminación por motivos de discapacidad. Los Estados Partes adoptarán las medidas pertinentes para asegurar el acceso de las personas con discapacidad a servicios de salud que tengan en

${ }^{261}$ ASAMBLEA GENERAL DE LAS NACIONES UNIDAS. Convención internacional sobre la protección de los derechos de todos los trabajadores migratorios y de sus familiares. 1990. (en línea). http://www.ohchr.org/SP/Professionallnterest/Pages/CMW.aspx.

262 CONFERENCIA MUNDIAL DE DERECHOS HUMANOS. Declaración y Programa de acción de Viena. 1993. (en línea). http://www.ohchr.org/Documents/Events/OHCHR20/VDPA_booklet_Spanish.pdf. 
cuenta las cuestiones de género, incluida la rehabilitación relacionada con la salud. En particular, los Estados Partes:

a). Proporcionarán a las personas con discapacidad programas y atención de la salud gratuitos o a precios asequibles de la misma variedad y calidad que a las demás personas, incluso en el ámbito de la salud sexual y reproductiva, y programas de salud pública dirigidos a la población;

b). Proporcionarán los servicios de salud que necesiten las personas con discapacidad específicamente como consecuencia de su discapacidad, incluidas la pronta detección e intervención, cuando proceda, y servicios destinados a prevenir y reducir al máximo la aparición de nuevas discapacidades, incluidos los niños y las niñas y las personas mayores;

c). Proporcionarán esos servicios lo más cerca posible de las comunidades de las personas con discapacidad, incluso en las zonas rurales;

d). Exigirán a los profesionales de la salud que presten a las personas con discapacidad atención de la misma calidad que a las demás personas sobre la base de un consentimiento libre e informado, entre otras formas mediante la sensibilización respecto de los derechos humanos, la dignidad, la autonomía y las necesidades de las personas con discapacidad a través de la capacitación y la promulgación de normas éticas para la atención de la salud en los ámbitos público y privado;

e). Prohibirán la discriminación contra las personas con discapacidad en la prestación de seguros de salud y de vida cuando estos estén permitidos en la legislación nacional, y velarán por que esos seguros se presten de manera justa y razonable;

f). Impedirán que se nieguen, de manera discriminatoria, servicios de salud o de atención de la salud o alimentos sólidos o líquidos por motivos de discapacidad ${ }^{263}$.

La normativa anterior, se tornó en la Política Pública de discapacidad que impera en nuestro país, la cual pretende de manera completa e integral proporcionar todos

263 ASAMBLEA GENERAL DE LAS NACIONES UNIDAS. Convención sobre los derechos de las personas con discapacidad. 2006. (en línea). http://www.un.org/esa/socdev/enable/documents/tccconvs.pdf. 
los servicios de atención en salud a la población discapacitada, con fines de discriminación positiva que garantice la igualdad de tales individuos más allá de sus limitaciones.

Por otro lado, se encuentran las Observaciones del Comité de Derechos Económicos, Sociales y Culturales que, a partir del año 1989, empezó a proferir observaciones generales acerca del Pacto Internacional de Derechos Económicos, Sociales y Culturales de 1966, en aras de la correcta aplicación, implementación y cumplimiento del Pacto por los Estados Partes. Dentro de sus observaciones, el Comité reconoce que los Estados tienen tres tipos de obligaciones frente al derecho a la salud, las cuales son de respetar, proteger y garantizar. Frente a dichas obligaciones, se establecen los consecuentes imperativos de: (i) facilitar: "requiere en particular que los Estados adopten medidas positivas que permitan y ayuden a los particulares y las comunidades a disfrutar del derecho a la salud"264. (ii) Proporcionar un derecho específico enunciado en el Pacto "[...] en los casos en que los particulares o los grupos no están en condiciones, por razones ajenas a su voluntad, de ejercer por sí mismos ese derecho con ayuda de los medios a su disposición"265 y (iii) promover: "[...] requiere que los Estados emprendan actividades para promover, mantener y restablecer la salud de la población"266.

Esta observación es un aporte de capital trascendencia para definir el alcance de los preceptos del Pacto de Derechos Económicos, Sociales y Culturales. Dicho instrumento ha irradiado la jurisprudencia constitucional y el cambio de paradigma en el caso colombiano, especialmente el que tuvo lugar mediante la Sentencia T760 de 2008. La capital importancia del instrumento, tiene origen en que, mediante el mismo, se exalta que "[...] la salud es un derecho humano fundamental e indispensable para el ejercicio de los demás derechos humanos"267.

En este sentido, de acuerdo con la Corte Constitucional,

[...] el Comité exaltó la vinculación y la dependencia del derecho a la salud con otros derechos humanos, dentro de los que cita particularmente el derecho a la alimentación, a la vivienda, al trabajo, a la educación, a la dignidad humana, a la vida, a la no discriminación, a la igualdad, a no ser sometido a torturas, a la vida privada, al acceso

264 Aplicación del Pacto Internacional de los Derechos Económicos, Sociales y Culturales. Observación general 14. El derecho al disfrute del más alto nivel posible de salud. 2000. (en línea). http://hrlibrary.umn.edu/gencomm/epcomm14s.htm.

265 lbíd.

266 Ibíd.

267 lbíd. 
a la información y a la libertad de asociación, reunión y circulación, que desde una visión integral hacen parte del derecho a la salud ${ }^{268}$.

En ese entendido "el Estado no está obligado a garantizar que toda persona goce, en efecto, de 'buena salud', sino a garantizar toda una gama de facilidades, bienes y servicios" que aseguren el más alto nivel posible de salud"269.

Además de lo anterior, el derecho a la salud se aborda desde un punto de vista complejo, pues se vinculan al mismo factor básico determinante de la salud, como lo son:

[...] el acceso al agua limpia potable y a condiciones sanitarias adecuadas, el suministro apropiado de alimentos sanos, una nutrición adecuada, una vivienda adecuada, condiciones sanas en el trabajo y el medio ambiente y acceso a la educación e información sobre cuestiones relacionadas con la salud, incluida la salud sexual y reproductiva ${ }^{270}$.

En dicha observación, al igual que el proyecto de ley estatutaria que está en curso en la actualidad en el Congreso de la República de Colombia, se establece que el derecho a la salud debe gozar siquiera de los elementos de disponibilidad, accesibilidad, aceptabilidad y calidad; ello dado que:

(i) Cada Estado debe tener disponibles un número suficiente de establecimientos, bienes y servicios públicos de salud y centros de atención, así como programas; (ii) Los establecimientos, bienes y servicios de salud deben ser accesibles a todos, sin discriminación alguna, en cuatro dimensiones superpuestas: (a) no discriminación; (b) accesibilidad física; (c) accesibilidad económica; y (d) acceso a la información'; (iii) Los establecimientos, bienes y servicios de salud deberán ser aceptables respetuosos de la ética médica y culturalmente apropiados, es decir respetuosos de la cultura de las personas, las minorías, los pueblos y las comunidades, a la par que sensibles a los requisitos del género y el ciclo de vida, y deberán estar concebidos para respetar la confidencialidad y mejorar el estado de

268 COLOMBIA. CORTE CONSTITUCIONAL DE COLOMBIA. Sentencia C-313/14. M. P. Gabriel Eduardo Mendoza Martelo. Bogotá. p. 215.

269 COLOMBIA. CORTE CONSTITUCIONAL DE COLOMBIA. Op. Cit. p. 215.

270 Aplicación del Pacto Internacional de los Derechos Económicos, Sociales y Culturales. Op. Cit. 
salud de las personas de que se trate, y; (iv) deberán ser también de buena calidad, apropiados desde el punto de vista científico y médico ${ }^{271}$.

De igual forma, se incorpora en dicho instrumento la obligación de no adoptar deliberadamente medidas regresivas o a justificar las mismas de manera minuciosa el examen de todas las alternativas posibles, justificando su implementación con miras a las normas internacionales de derechos humanos, y su compatibilidad con la naturaleza de los derechos amparados por el Pacto.

Ahora bien, en cuanto a las violaciones de las obligaciones, el Comité advierte que un Estado viola las obligaciones derivadas del derecho a la salud, en caso de que no utilice el máximo de los recursos de que disponga para dar efectividad al derecho. No sucede lo propio en el supuesto de que el Estado tenga una limitación de recursos para cumplir, en cuyo caso "tendrá que justificar, no obstante, que se ha hecho todo lo posible por utilizar todos los recursos de que dispone para satisfacer, como cuestión de prioridad, las obligaciones"272 derivadas del derecho a la salud. No obstante, el Estado "no puede nunca ni en ninguna circunstancia justificar su incumplimiento de las obligaciones básicas"273 antes mencionadas, las cuales son inderogables.

Además de establecer el concepto, obligaciones y demás con asidero en el derecho a la salud, en aras de que el amplio desarrollo dado al mismo no quede en el texto normativo, sino que traspase barreras, se exhorta a los Estados a crear políticas de abordaje, en las cuales esté garantizada la participación de las personas, especialmente de aquellas que resulten afectadas por el derecho fundamental. Esto con el objeto de, (i) fijar prioridades, (ii) adoptar decisiones, (iii) la planificar (iv) la aplicación y (v) evaluar las estrategias destinadas a mejorar la salud; todo con un propósito progresivo y medible en resultados ${ }^{274}$.

Por último, se encuentra la Declaración Política y Plan de Acción Internacional de Madrid sobre el Envejecimiento, suscrita en Madrid entre el 8 y el 12 de abril del año 2002, en la cual se adoptaron dos disposiciones a saber, La Declaración Política y Plan de Acción Internacional de Madrid sobre el Envejecimiento, las cuales se enfocan en tres ámbitos principales como son: "las personas de edad y el desarrollo, el fomento a la salud y el bienestar de la vejez; y la creación de un entorno propicio

271 COLOMBIA. CORTE CONSTITUCIONAL DE COLOMBIA. Op. Cit. p. 217.

272 Aplicación del Pacto Internacional de los Derechos Económicos, Sociales y Culturales. Op. Cit.

273 Ibíd.

274 Ibíd. 
y favorable"275. En lo atinente a la Declaración Política, se encuentra, en cuanto al derecho a la salud, el artículo 14 en el que se incluyen aspectos como la progresividad, la necesidad de adoptar medidas para efectivizar el derecho, así como la universalidad, la igualdad, el requerimiento de políticas públicas, la promoción de medios de vida saludables, entornos propicios, y la independencia y participación de las personas de edad en todos los aspectos de la sociedad. En el Plan de Acción, se incluyen recomendaciones encaminadas al fomento de la salud y el bienestar en la vejez, pues se evidencia a la salud como un elemento base para el aspecto económico de un sistema y, por ende para su sostenibilidad, pues se estima que, si un país cuida de la buena salud de sus habitantes, su sistema financiero tiene una mayor probabilidad de progresividad.

Bajo estos lineamientos, se exhorta a adoptar políticas pertinentes que propicien la salud durante toda la vida:

Incluidas las de promoción de la salud y la prevención de las enfermedades, la tecnología de asistencia, los cuidados para la rehabilitación [...], los servicios de salud mental, la promoción de los modos de vida saludables y los entornos propicios pueden reducir los niveles de discapacidad asociados con la vejez y permitir obtener economías presupuestarias ${ }^{276}$.

Hecho este breve esbozo sobre los instrumentos internacionales que en pro de una vida más digna han normatizado las diferentes facetas del derecho a la salud y su connotación, generando así obligaciones horizontales y verticales en la garantía del mismo desde todos los ejes y dimensiones posibles, es necesario concluir que la regulación internacional ha sido el puente indispensable para que hoy el derecho a la salud pueda pensarse, por lo menos, en el ordenamiento jurídico colombiano, como fundamental y autónomo. La implementación de dichos instrumentos, hasta la fecha, solo fue posible a partir de los pronunciamientos de los jueces constitucionales, en particular de la Corte Constitucional, corporación que dio alcance y exigibilidad a este derecho antiguamente consagrado en el texto constituciona como un servicio público, de carácter obligatorio, el cual se desarrollaba bajo la sujecion de los principios constitucionales, Por ello, su inusitada importancia resulta referir, a título seguido, los principios constitucionales, que acompasaban la obligatoriedad de la prestación del servicio publico esencial de la salud por parte del Estado como garante de su asistencia.

275 ASAMBLEA GENERAL DE LAS NACIONES UNIDAS. Declaración Política y Plan de Acción Internacional de Madrid sobre el Envejecimiento. 2002. (en línea). https://social.un.org/ageing-workinggroup/documents/mipaa-sp.pdf.

276 lbíd. 


\subsubsection{Principios del derecho a la salud}

2.2.2.1. Principio de universalidad. El acceso a la seguridad social es un Derecho Fundamental en razón a que se concibe como inherente al ser humano, así mismo, la seguridad social en salud se concibe como un servicio público inherente a la finalidad social del Estado Colombiano, por ende, y según lo manifestado por la Corte Constitucional, su prestación se debe llevar a cabo con fundamento en el principio de la universalidad. Este principio no obliga a que los titulares de los derechos sociales sean todos los individuos de la especie humana, sino que parte de la premisa de que cuando algún sujeto se encuentra en una situación de desequilibrio, el ordenamiento jurídico pueda proporcionar la asistencia necesaria. Uno de los ejemplos más utilizados para explicar lo anterior, sucede cuando una persona se encuentra en desequilibrio por falta de capacidad económica y es allí cuando el ordenamiento jurídico debe proporcionar la asistencia al respecto ${ }^{277}$.

La Constitución Política de 1991 en su artículo 49 consagra:

La atención de la salud y el saneamiento ambiental son servicios públicos a cargo del Estado. Se garantiza a todas las personas el acceso a los servicios de promoción, protección y recuperación de la salud. Corresponde al Estado organizar, dirigir y reglamentar la prestación de servicios de salud a los habitantes y de saneamiento ambiental conforme a los principios de eficiencia, universalidad y solidaridad ${ }^{278}$.

Por lo cual la ley 1751 de 2015, por medio de la cual se regula el derecho fundamental a la salud, en el literal a del artículo 6 establece el principio de la universalidad frente al derecho fundamental a la salud: "Los residentes en el territorio colombiano gozarán efectivamente del derecho fundamental a la salud en todas las etapas de la vida"279. Dicho principio contempla que:

[...] la cobertura en la protección de los riesgos inherentes a la seguridad social debe amparar a todas las personas residentes en Colombia, en cualquiera de las etapas de su vida, sin discriminación

\footnotetext{
277 RIVEROS PARDO, Daniel Felipe. Los derechos económicos, sociales y culturales como derechos subjetivos: una visión estructural. En: Revista Derecho del Estado. № 24 (Jul, 2010). p. 35. ${ }^{278}$ COLOMBIA. Constitución Política de Colombia. Op. Cit. Artículo 49 [Título II]. 279 COLOMBIA. CONGRESO DE LA REPÚBLICA DE COLOMBIA. Ley 1751. Op. Cit. p. 3.
} 
alguna por razones de sexo, edad, raza, origen nacional o familiar, lengua, religión, opinión política o filosófica, etc. ${ }^{280}$.

Con todo, la Corte Constitucional en Sentencia C-463 de 2008 aclara que este principio tiene una doble connotación. La primera, con relación al sujeto a quien se le garantiza la seguridad social en salud, así pues y de acuerdo al principio de universalidad, todas las personas habitantes del territorio nacional deben estar cubiertas, amparadas o protegidas en materia de salud; $Y$ la segunda, respecto del objeto, lo que significa la prestación de los servicio en salud general, "[...] este principio implica que todos los servicios de salud, bien sea para la prevención o promoción de la salud, o bien para la protección o la recuperación de la misma; razón por la cual deben estar cubiertos todos estos servicios dentro de los riesgos derivados del aseguramiento en salud"281.

La Corte Constitucional en Sentencia C-463 de 2008 señala;

Del principio de universalidad en materia de salud se deriva primordialmente el entendimiento de esta Corte del derecho a la salud como un derecho fundamental, en cuanto el rasgo primordial de la fundamentabilidad de un derecho es su exigencia de universalidad, esto es, el ser un derecho predicable y reconocido para todas las personas sin excepción, en su calidad de seres humanos con dignidad. En virtud del entendimiento del derecho a la salud como un derecho constitucional con vocación de universalidad y por tanto de fundamentabilidad, esta Corte en su jurisprudencia, ha resaltado la importancia que adquiere la protección del derecho fundamental a la salud en el marco del estado social de derecho, en cuanto afecta directamente la calidad de vida ${ }^{282}$.

Es claro que el principio de Universalidad resalta el carácter de fundamental del derecho a la Salud, ya que da la posibilidad de ser atribuible, predicable y reconocido para todas las personas sin excepción alguna, en razón a su calidad de seres humanos y de su dignidad, destacándose como principal rasgo de la fundamentalidad de dicho derecho.

280 COLOMBIA. CORTE CONSTITUCIONAL DE COLOMBIA. Sentencia C-623-04. M.P.: Rodrigo Escobar Gil. Bogotá. p. 1.

${ }^{281}$ COLOMBIA. CORTE CONSTITUCIONAL DE COLOMBIA. Sentencia C-603-98 M.P.: Jaime Araujo Rentería. Bogotá. p. 37.

${ }^{282}$ COLOMBIA. CORTE CONSTITUCIONAL DE COLOMBIA. Sentencia C-463 de 2008. Op Cit. p. 2. 
2.2.2.2. Principio de eficiencia. La eficiencia es entendida como "[...] procura por el mejor uso social y económico de los recursos, servicios y tecnologías en aras de garantizar el derecho a la salud para toda la población"283. Lo anterior, con base en el artículo 365 de la Constitución Política de $1991^{284}$, donde se establece que es deber del Estado asegurar la prestación eficiente de los servicios públicos a los habitantes del territorio, contemplándose dentro de estos el servicio de salud. Para la Corte Constitucional el principio de la eficiencia "[...] tiene como destinatario a los propios organismos responsables de la prestación del servicio público de la seguridad social -el Estado y los particulares-. Ella es reiterada por el artículo 209 de la Carta como principio rector de la gestión administrativa"285. Así mismo, es menester que el Estado realice un control de los resultados del servicio, siendo por tanto un deber del Estado para la garantía del derecho fundamental a la seguridad social en salud.

Con respecto a la amplia definición que otorga la Carta Política de 1991 de este principio, la Ley 100 de 1993 lo define de una manera mucho más clara en su artículo segundo: "Es la mejor utilización social y económica de los recursos administrativos, técnicos y financieros disponibles para que los beneficios a que da derecho la seguridad social sean prestados en forma adecuada, oportuna y suficiente"286.

En este orden de ideas, en materia de salud el principio de eficiencia tiene estricta relación con "[...] al arte de la mejor utilización y maximización de los recursos financieros disponibles para lograr y asegurar la mejor prestación de los servicios de salud a toda la población a que da derecho la seguridad social en salud"287, la naturaleza del derecho y los principios que lo conforman han sido los argumentos principales para determinar la salud como derecho fundamental. Por tanto, con respecto a la eficiencia como principio fundamental en la prestación del servicio de salud y la garantía del derecho fundamental a la salud, es importante resaltar la definición hecha por la Corte Constitucional en el año 2013: "Eficiencia: Este principio busca que los trámites administrativos a los que está sujeto el paciente sean razonables, no demoren excesivamente el acceso y no impongan al interesado una carga que no le corresponde asumir"288.

${ }^{283}$ COLOMBIA. CORTE CONSTITUCIONAL DE COLOMBIA. Sentencia C-313 de 2014. Op. Cit. p. 37.

${ }^{284}$ COLOMBIA. Constitución Política de Colombia. Op. Cit. Artículo 365 [Título XII].

${ }^{285}$ COLOMBIA. CORTE CONSTITUCIONAL DE COLOMBIA. Sentencia T-116 de 1993. Op. Cit. p. 1,2 .

${ }^{286}$ COLOMBIA. CONGRESO DE LA REPÚBLICA. Ley 100. (23, diciembre, 1993). Op. Cit. p. 2.

287 COLOMBIA. CORTE CONSTITUCIONAL DE COLOMBIA. Sentencia C-463 de 2008. Op Cit. p. 1.

${ }^{288}$ COLOMBIA. CORTE CONSTITUCIONAL DE COLOMBIA. Sentencia T-745 de 2013. M.P.: Jorge Iván Palacio. Bogotá. p. 17. 
De esta manera, la Corte Constitucional ha vinculado el principio de eficiencia a otros, como lo son el de continuidad en el goce del derecho y al principio de oportunidad;

[...] esta Corporación ha defendido que la eficiencia en la prestación de los servicios de salud, y las condiciones oportunas y continuas de su suministro, guardan estrecha relación con la orientación que se le dé al usuario, pues solo así quien pretende acceder a determinado beneficio del Sistema de Salud, sabrá qué diligencias son necesarias para obtener la autorización de un servicio médico por parte de su Entidad Promotora de Salud ${ }^{289}$.

El principio de Eficiencia hace parte de los pilares esenciales del derecho fundamental a la salud y del servicio público de seguridad social en salud. La Ley 1751 en su artículo 6, lo define como: "Eficiencia. El sistema de salud debe procurar por la mejor utilización social y económica de los recursos, servicios y tecnologías disponibles para garantizar el derecho a la salud de toda la población"290. Al utilizar el verbo "procurar" la Corte Constitucional hace una precisión en torno a que este debe armonizar con el principio de la progresividad, esto es evidenciar la existencia de unas obligaciones de inmediato cumplimiento que comprometen de modo inmediato a los responsables, mientras que existen otras que requieren recursos a tiempo:

Para la Corte, con la incorporación del Principio, se torna en inmediatamente exigible la obligación de trazar las políticas públicas pertinentes y darle aplicación a lo que ya se había expuesto en la Sentencia T-760 de 2008, cuando se dijo, en materia de condiciones básicas a observar por toda política pública, que, en primer lugar, la política efectivamente debe existir, en segundo lugar, debe tener como finalidad y prioridad la garantía del goce efectivo del derecho y, en tercer lugar, debe permitir la participación democrática en el proceso de decisión, elaboración y evaluación de dicha política ${ }^{291}$.

Es claro que este principio no tiene únicamente relación con la fundamentalidad del derecho a la salud, sino que sumerge sus raíces en el la naturaleza económica y administrativa expresada a lo largo de la Constitución política, sumado a esto, es

289 COLOMBIA. CORTE CONSTITUCIONAL DE COLOMBIA. Sentencia T-234 de 2013. M.P.: Luis Guillermo Guerrero Pérez. Bogotá. p. 15.

290 COLOMBIA. CONGRESO DE LA REPÚBLICA DE COLOMBIA. Ley 1751. Op. Cit. p. 4.

${ }^{291}$ COLOMBIA. CORTE CONSTITUCIONAL DE COLOMBIA. Sentencia C-313 de 2014. Op. Cit. 359. 
claro que este principio tiene un carácter polivalente, es decir, que no solo tiene su aplicación en casos particulares, sino que puede o más bien debe ampliarse hasta la planificación de políticas públicas especialmente en lo que respecta al sistema de seguridad social en salud.

2.2.2.3. Principio de solidaridad. La solidaridad no solo se consagra como principio del Estado Social de Derecho, tal como se establece en la Constitución Política de $1991^{292}$ en su artículo primero, donde la república de Colombia se cimienta en el respeto de la dignidad humana, en el trabajo y en la solidaridad de las personas que la integran, sino también se concibe como un principio básico de la seguridad social en salud.

[...] su comprensión se da en dos sentidos: una solidaridad general en virtud de la cual todos los miembros de la sociedad prestan su colaboración al bien común, aportando los medios necesarios para el suministro de las prestaciones a quienes necesiten y con independencia del interés particular en la obtención de un beneficio y una solidaridad entre generaciones, según la cual cada generación activa debe proveer la tutela de las generaciones pasivas ${ }^{293}$.

También, el artículo 48 de la Carta Política de 1991 establece la seguridad social como servicio público de carácter obligatorio. La prestación de este servicio se debe hacer conforme los principios de universalidad, solidaridad y eficacia, convirtiendo al principio de solidaridad en un pilar básico para la realización del derecho a la seguridad social, en razón a que este principio impone un deber sustancial tanto al Estado como a los empleadores. Igualmente, el artículo 6 de la Ley 1751 de 2015, en su literal $j$ consagra: "El sistema está basado en el mutuo apoyo entre las personas, generaciones, los sectores económicos, las regiones y las comunidades" 294 .

Para la Corte Constitucional, al concebirse la seguridad social como un servicio público, este se convierte en una manifestación integral y completa del principio constitucional de la solidaridad, entendiéndose que la seguridad social está destinada al cumplimiento de este principio:

292 COLOMBIA. Constitución Política de Colombia. Op. Cit. Artículo 1 [Título I].

293 DUQUE QUINTERO, Sandra; GOMEZ RÚA, Natalia \& RIVERA AGUIRRE, Christian. Sobre la materialización del principio de solidaridad en el sistema general de salud colombiano. En: Revista CES DERECHO. Vol. 4, No.2 (Julio-diciembre, 2013). p. 60.

${ }^{294}$ COLOMBIA. CONGRESO DE LA REPÚBLICA DE COLOMBIA. Ley 1751. Op. Cit. p. 4. 
La seguridad social como esfuerzo mancomunado y colectivo, como propósito común en el que la protección de las contingencias individuales se logra de mejor manera con el aporte y la participación de todos los miembros de la comunidad. En un sistema de seguridad social, aquellos siniestros que generan un riesgo que amenaza el mínimo vital (la falta de ingresos en la vejez o en la invalidez, el súbito desempleo, la ausencia imprevista de un generador de ingresos en el hogar, una enfermedad catastrófica no anticipada), y que no pueden ser cubiertos o atenuados a través de un simple esfuerzo individual o familiar, se atienden o cubren por la vía de la suma de muchos esfuerzos individuales, esto es, de un esfuerzo colectivo 295 .

Así mismo, con respecto al derecho fundamental a la salud, la Corte Constitucional señala en Sentencia T-618 de 2000 que:

El primer encargado de su salud es la propia persona y si es mayor de edad con mayor razón. Sin embargo, el Estado, la familia y la sociedad solidariamente deben contribuir a un eficiente cubrimiento universal en salud. En materia de salud la solidaridad tiene como una de sus manifestaciones el cubrimiento de quienes la ley considera como beneficiarios del servicio. La solidaridad también aparece dentro de los deberes constitucionales ${ }^{296}$.

La Corte Constitucional en Sentencia 623 de 2004 establece respecto del principio de la solidaridad como máxima constitucional lo siguiente: "[...] exige la ayuda mutua entre las personas afiliadas, vinculadas y beneficiarias, independientemente del sector económico al cual pertenezcan, y sin importar el estricto orden generacional en el cual se encuentren"297. Por lo cual fija dos sub-reglas para su aplicación. La primera se refiere a la imposición de un deber que recae sobre los sectores con mayores recursos económicos, el cual consiste en ayudar con el financiamiento de la seguridad social de aquellas personas que no cuentan con los recursos económicos suficientes, esto por medio de "[...] aportes adicionales destinados a subsidiar las subcuentas de solidaridad y subsistencia del sistema integral de seguridad social en pensiones, cuando los altos ingresos del cotizante

295 COLOMBIA. CORTE CONSTITUCIONAL DE COLOMBIA. Sentencia C-529 de 2010 M.P.: Mauricio González Cuervo. Bogotá. p. 1.

${ }^{296}$ COLOMBIA. CORTE CONSTITUCIONAL DE COLOMBIA. Sentencia T-618 DE 2000. M.P.: Alejandro Martínez Caballero. Bogotá. p.1.

${ }^{297}$ COLOMBIA. CORTE CONSTITUCIONAL DEL COLOMBIA. Sentencia C-623 de 2004. Op. Cit. p. 2. 
así lo permiten"298. Y la segunda, que contempla la obligación de toda la sociedad, o alguna parte de ella, de contribuir en la protección de la seguridad social de las personas que se encuentran imposibilitadas para procurar su sustento y el de sus familias.

Como ya se ha esbozado con anterioridad, el principio de solidaridad podría entenderse como el fundamento de la seguridad social y por ende es quien resulta determinando su finalidad y sus propósitos. Cabe resaltar que en este caso se habla de un concepto axiológico con alto contenido filosófico y político, debido a eso es inmensamente complicado definirlo de forma precisa, pero lo que sí se puede decir es que dicho principio tiene indudablemente una relación con la esencia misma de la humanidad y que se evidencia en las relaciones entre individuos y grupos de individuos.

2.2.2.4. Principio de corresponsabilidad. El principio de corresponsabilidad: se empieza a hablar de la corresponsabilidad como principio rector del sistema de salud, a partir del año 2011, en donde la ley 1438 en su artículo 3. 3.17 es expresado de la siguiente manera:

Toda persona debe propender por su autocuidado, por el cuidado de la salud de su familia y de la comunidad, un ambiente sano, el uso racional y adecuado de los recursos el Sistema General de Seguridad Social en Salud y cumplir con los deberes de solidaridad, participación y colaboración. Las instituciones públicas y privadas promoverán la apropiación y el cumplimiento de este principio. ${ }^{299}$

Resulta transcendente la inserción de este principio en el texto normativo, toda vez que ello avizora la posibilidad de construir una política pública, que permita mitigar la problemática en la prestación de los servicios de salud a toda la población colombiana, que se encuentre vinculada en el sistema de seguridad social. Ello refiere en la medida en que, como lo menciona la norma, debe existir una responsabilidad compartida, es decir, que todos los actores del sistema de salud deben ser responsables tanto de su salud, como de la propia sostenibilidad financiera. Es decir, que la responsabilidad no debe estar solo en cabeza del Estado y de las Instituciones que prestan el servicio, sino del usuario del sistema, quien debe procurar su auto-cuidado, dado que no solo debe ser un sujeto pasivo del mismo, y convertirse en solo un reclamador y peticionario del sistema, sino

298 COLOMBIA. CORTE CONSTITUCIONAL DE COLOMBIA. Sentencia C-111/06. M.P.: Rodrigo Escobar Gil. Bogotá. p. 1.

299 Ley 1438 de 2011 artículo 3. 3.17 
convertirse en un actor dinámico que genere acciones que procuren su autocuidado, el de su familia y el de la comunidad. En ello favorecería el uso racional de los servicios y la sostenibilidad fiscal del mismo.

Para facilitar el desarrollo de este principio, sería importante que el sistema concediera estímulos a los afiliados, que mantenga el autocuidado de su salud, y la de su familia, el cual se mediría a través de su perfil epidemiológico, con ello no solo se cuidaría la salud del afiliado, sino que se cuidan los recursos del sistema.

Estos estímulos pueden traducirse en beneficios tanto para el afiliado como para su familia.

De ser así, la corresponsabilidad de los afiliados al sistema salud, resultaría de gran significación, en la medida en que permite su continuidad, su sostenibilidad, su progresividad, garantizándose de esta manera este derecho fundamental a la salud en Colombia.

De lo anterior podemos señalar que los principios constitiuconles, concurrieron en el marco de la evolución jurisprudencial, en la medida que la Corte Constitucional, conecta e incopora directamente una serie de principios al momento de adoptar sus decisiones, es sin duda a partir de la principialistica de nuestro texto constitucional y de la importante función de que se dotó al juez de tutela.

2.2.3. Evolución jurisprudencial. Para profundizar en la evolución jurisprudencial del derecho a la salud en Colombia, se debe, en principio, hacer un pequeño esbozo jurisprudencial sobre el Estado Social de Derecho en Colombia, pues es con el advenimiento de este modelo de Estado que los derechos y su importancia cobran sentido más allá de la mera consagración en instrumentos legales, materializándose por vía de mecanismos que generan un cambio institucional revolucionario en garantías. Sin duda el carácter esencial de esta fórmula de Estado "ya no solo tiene que ver con la organización entre poderes y la producción y aplicación del derecho, sino también y de manera especial, con el compromiso por la defensa de contenidos jurídicos materiales" 300 .

Más allá de la mera enunciación constitucional, tempranamente la jurisprudencia también concedió dicho alcance a la fórmula del Estado Social de Derecho, al

300 COLOMBIA. CORTE CONSTITUCIONAL DE COLOMBIA. Sentencia T-406-1992. MP: Ciro Angarita Baron. p. 9. 
considerar en la sentencia T-406 del año 1992 que el concepto clave de la misma puede ser resumido de la siguiente manera: "pérdida de la importancia sacramental del texto legal entendido como emanación de la voluntad popular, y mayor preocupación por la justicia material y el logro de soluciones que consulten la especificidad de los hechos"301. Así las cosas:

[...] la fórmula del artículo primero de la Constitución, ampliada y respaldada a través de todo el texto fundamental, según la cual Colombia se define como un Estado Social de Derecho, es de una importancia sin precedentes en el contexto del constitucionalismo colombiano. El término "social", ahora agregado a la clásica fórmula del Estado de Derecho, no debe ser entendido como una simple muletilla retórica que proporciona un elegante toque de filantropía a la idea tradicional del derecho y del Estado. Una larga historia de transformaciones institucionales en las principales democracias constitucionales del mundo, está presente para dar testimonio de la trascendencia de este concepto ${ }^{302}$.

Las implicaciones del termino Estado social que irradia el contenido de todos los derechos, no son menos importantes en materia del derecho a la salud, por el contrario, al depender del mismo, el desenvolvimiento de muchos de los aspectos que concretan la vida del individuo en condiciones de dignidad se incrementa de manera exponencial su protección, siempre buscando la interpretación más garantista de un derecho que en condiciones iniciales estaba concebido como un servicio, limitado por la cobertura y la disponibilidad presupuestal del sistema. Solo a la luz del Estado Social cuya filosofía es "el respeto por los derechos humanos, de un lado, y el acatamiento de unos principios rectores de la actuación estatal, por otro"303. Así, se vislumbra la necesidad de diseñar un modelo de Sistema de seguridad social en salud que tenga en la dignidad del ser humano su punto de fusión.

Este nuevo diseño que se pretende exponer a partir de cada una de las pinceladas dadas a tal derecho por la Corte Constitucional en el emanar de su jurisprudencia, solo ha sido posible sin duda a partir de la principialistica de nuestro texto constitucional y de la importante función de que se dotó al juez de tutela, cuyo papel va más allá de ser el brazo de la ley, para ser modulador de la interpretación de los

\footnotetext{
${ }^{301}$ COLOMBIA. CORTE CONSTITUCIONAL DE COLOMBIA. Op. Cit. p. 8.

302 lbíd. p. 7.

303 COLOMBIA. CORTE CONSTITUCIONAL DE COLOMBIA. Sentencia C-449 de 1992. M.P: Alejandro Martínez Caballero.
} 
derechos. En consecuencia, se ha superado esa prohibición categórica contenida en la sentencia T-406 de 1992 en la cual se expuso:

Para que un derecho constitucional pueda ser considerado como fundamental, debe además ser el resultado de una aplicación directa del texto constitucional; por lo tanto, en normas que poseen una textura abierta, a partir de la cual el legislador entra a fijar el sentido del texto, no podrían presentarse la garantía de la tutela. Está claro que no puede ser fundamental un derecho cuya eficacia depende de decisiones políticas eventuales ${ }^{304}$.

Tampoco es posible predicar la efectividad de derechos de contenido prestacional. Para una mejor comprensión se plantea de manera gráfica dicha evolución y su alcance (Figura 1).

La sentencia T-402 de 1992 es la fundante que intenta por vez primera abordar la protección del derecho a la salud por vía constitucional. Dicha jurisprudencia, que sienta las bases de la materialidad de los derechos fundamentales, excluye de forma rotunda la naturaleza fundamental del derecho a la salud, puesto que aclara que:

Los derechos sociales, económicos y culturales de contenido difuso, cuya aplicación está encomendada al legislador para que fije el sentido del texto constitucional, no pueden ser considerados como fundamentales, salvo aquellas situaciones en las cuales, en un caso específico, sea evidente su conexidad con un principio o con un derecho fundamental ${ }^{305}$.

304 COLOMBIA. CORTE CONSTITUCIONAL DE COLOMBIA. Sentencia T-406 de1992. MP: Ciro Angarita Barón. Bogotá.

305 COLOMBIA. CORTE CONSTITUCIONAL DE COLOMBIA. Sentencia T-402 de1992. MP: Ciro Angarita Barón. Bogotá. p. 19. 
Figura 1. Naturaleza y evolución del derecho a la salud en Colombia

\begin{tabular}{|c|c|c|}
\hline $\begin{array}{l}\text { NO es un derecho } \\
\text { fundamental }\end{array}$ & $\begin{array}{l}\text { ES un derecho fundamental } \\
\text { por conexidad }\end{array}$ & $\begin{array}{c}\text { ES un derecho fundamental } \\
\text { Autónomo }\end{array}$ \\
\hline Ley $100 / 1993$ & 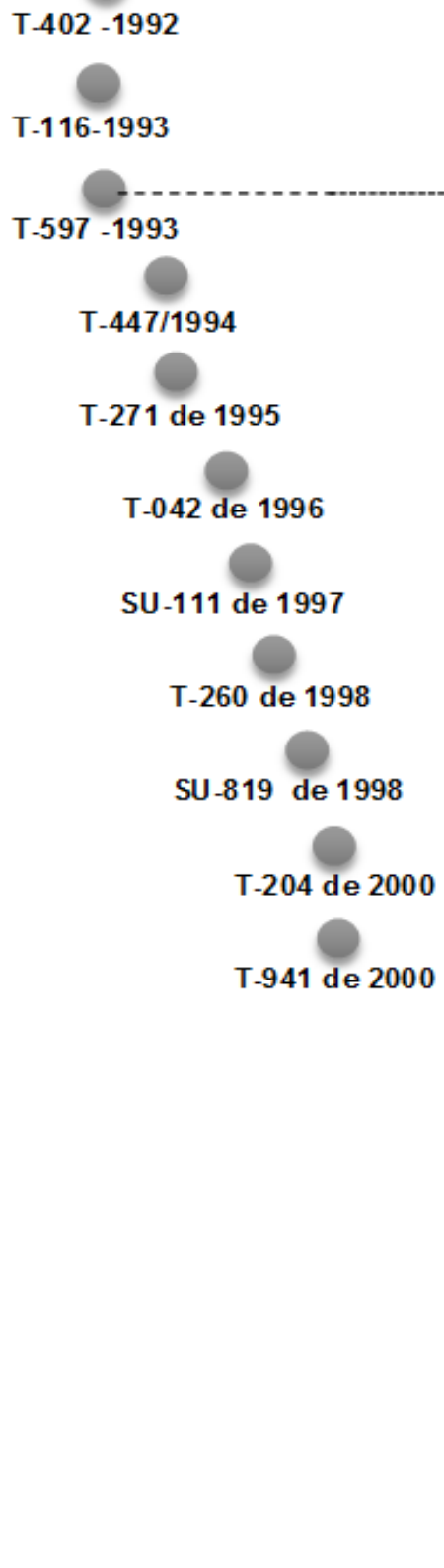 & T-760 de 2008 \\
\hline
\end{tabular}

De tal forma, desde un primer momento se deja en claro por la jurisprudencia que la salud no es un derecho fundamental, pero puede llegar a convertirse en tal en 
determinados casos como lo son: cuando tiene una evidente conexidad con un principio o derecho fundamental o cuando se trata de la salud de los niños ${ }^{306}$. Sobre este último se dijo que:

Algunos derechos, por ser inherentes a la persona humana son fundamentales (v. gr. derecho a la vida, libertad de locomoción etc.); otros no son fundamentales para algunas personas, pero sí para otras que se encuentran en circunstancias específicas u ostentan determinada condición: es el caso del derecho a la salud que, no siendo inherente a la persona, tampoco es derecho fundamental ni tiene aplicación inmediata, pero que, tratándose de los niños, sí adquiere carácter fundamental ${ }^{307}$.

En esta línea argumentativa, según la cual el derecho a la salud adquiere estatus de derecho fundamental por su relación directa con otros derechos que sí ostentan dicho carácter, tales como la vida y la integridad física, se incorpora más claramente en la sentencia T-406 de 1992, en la cual la Corte reconoció la procedibilidad de la Tutela para proteger la salud, preceptuando que:

La seguridad social se considera derecho fundamental sólo sobre la base de los siguientes supuestos: primero, que opere en conexión con otro derecho fundamental; segundo, entendida como la asistencia pública que debe prestarse ante una calamidad que requiera, de manera urgente, la protección del Estado y de la sociedad, por afectar de manera grave e inminente la vida humana o la salud; tercero, ante casos de extrema necesidad, y cuarto, que se pueda prestar de acuerdo con las posibilidades reales de protección de que disponga el Estado para el caso concreto ${ }^{308}$.

Cuando no se estaba frente a dichos supuestos, inevitable se hacía conceptuar la salud como un servicio público, sin otra connotación, como se señala en la sentencia T-484 de 1992, a saber:

[...] la salud es un servicio público a cargo del Estado, garantizándose en el a todas las personas el acceso al mismo, para la promoción,

\footnotetext{
${ }^{306}$ COLOMBIA. CORTE CONSTITUCIONAL DE COLOMBIA. Sentencia T-402 de1992. Op. Cit. 307 lbíd. p.1.

308 COLOMBIA. CORTE CONSTITUCIONAL DE COLOMBIA. T-406 de 1992. M.P.: Vladimiro Naranjo Mesa. p.1.
} 
protección y recuperación de este derecho. Se agrega que corresponde al poder público organizar, dirigir, reglamentar, establecer políticas para que las personas privadas presten ese servicio, y definir las competencias a cargo de los distintos órdenes, nacional, de las entidades territoriales y de los particulares, con el fin de que se haga de manera descentralizada y participativa ${ }^{309}$.

El mecanismo de protección del derecho fundamental a la salud, a partir de la teoría de la conexidad, empezó a desarrollarse a profundidad mediante la sentencia T 116 de 1993, tal y como será reconocida desde dicho periodo y hasta aproximadamente el año 2008, en el entendido de que los derechos fundamentales no son solo aquellos consagrados en el Capítulo 1, Titulo II de la Constitución, sino que los mismos también adquieren dicha connotación por conexidad, es decir:

\begin{abstract}
[...] aquellos derechos que, no siendo denominados como tales en el texto constitucional, les es comunicada esta calificación en virtud de la íntima e inescindible relación con otros derechos fundamentales, de forma que, si no fueran protegidos en forma inmediata los primeros, se ocasionaría la vulneración o amenaza de los segundos ${ }^{310}$.
\end{abstract}

En el particular de la salud se expuso que "no siendo en principio derecho fundamental, tal adquiere dicha categoría cuando la desatención del enfermo amenaza con poner en peligro su derecho a la vida"311.

A continuación, la sentencia T-597 de 1993 sigue la línea de que el derecho a la salud no es fundamental de manera absoluta, puesto que "los derechos de prestación no pueden ser protegidos a través de la acción de tutela" ${ }^{312}$. No obstante, tal planteamiento no se torna absoluto, pues se reitera que "la vulneración del derecho a la salud puede ser tutelable en ciertos casos en los cuales se viola igualmente un derecho fundamental de aplicación inmediata"313, situación frente a la cual el juez de tutela debe realizar un estudio acucioso de la conexidad con otros derechos fundamentales, interpretando de manera sistemática las normas constitucionales en juego en el caso detallado y sus implicaciones, para decidir si

309 COLOMBIA. CORTE CONSTITUCIONAL DE COLOMBIA. T-484 de 1992. M.P.: Fabio Moron Diaz. p.4.

${ }^{310}$ COLOMBIA. CORTE CONSTITUCIONAL DE COLOMBIA. Sentencia T-116 de 1993. M.P.: Hernando herrera Vergara. p. 1.

311 lbíd. p. 1.

312 COLOMBIA. CORTE CONSTITUCIONAL DE COLOMBIA. Sentencia T-597 de 1993. M.P.: Eduardo Cifuentes Muñoz. p. 1.

${ }^{313}$ Ibíd. p. 1. 
es menester darle al mismo protección. Es importante referir que en esta providencia nuevamente se resalta el carácter fundamental del derecho a la salud tratándose de niños, sin otro tipo de consideración. De tal forma, se sentó precedente de que cuando se trata de menores, el derecho a la salud:

No sólo es fundamental sino prevalente, en el sentido de su respeto incondicional y universal. [...]. De ahí que lo tutele cuando se lesiona o amenace en forma grave, ya que contra el derecho a la salud de un niño no puede haber argumentación válida alguna ${ }^{314}$.

La Corte Constitucional avanzando en esta línea, dio diferentes pinceladas con la sentencia T-447 de 1994, en la cual refirió, contrario a la postura negativista de los derechos prestacionales, que "[...] el derecho a la salud es inherente al ser del hombre, $\mathrm{y}$, por tanto, se le puede considerar perfectamente como uno de los derechos fundamentales de la persona humana" 315 , ello porque:

Es derivado del derecho a la vida que tiene toda persona desde el momento de la concepción hasta su muerte, que implica conservar la plenitud de sus facultades físicas, mentales y espirituales, y poner todos los medios ordinarios al alcance para la prevención de las enfermedades, así como para la recuperación ${ }^{316}$.

No obstante, la anterior sentencia continúa supeditando la exigibilidad del derecho a la existencia de recursos para darle trámite, y de suyo, a la conexidad con el derecho a la vida.

En el año 1994, la tesis de la fundamentalidad del derecho a la salud por conexidad mantuvo su vigor, sosteniéndose nuevamente en pronunciamientos del alto tribunal constitucional, que "La salud reviste la naturaleza de derecho fundamental merced a su relación inescindible con el derecho a la vida y al mínimo vital”317. De esta manera, se reiteró la tesis sostenida por la Corte Constitucional en el sentido de que a pesar de que la salud no representa un derecho fundamental, según el supuesto fáctico que avoque el juez de tutela se le puede dar tal connotación, siempre que se esté frente a la posibilidad de una transgresión grave a principios

314 Ibíd. p. 1.

${ }^{315}$ COLOMBIA. CORTE CONSTITUCIONAL DE COLOMBIA. Sentencia T-447 de 1994. M.P.: Vladimiro Naranjo Meza. p. 10.

${ }^{316}$ Ibíd. p. 10.

317 COLOMBIA. CORTE CONSTITUCIONAL DE COLOMBIA. Sentencia T-271-1995. M.P.: Alejandro Martínez Caballero. p. 1. 
fundamentales de aplicación inmediata como la vida y el mínimo vital. En este orden de ideas, "la posibilidad de exigir un derecho de prestación es apreciable sólo en el caso concreto y dependiendo del tipo de derecho" ${ }^{318 .}$

Los lineamientos jurisprudenciales continuaron sosteniendo esta posición, siendo la relación directa entre el derecho a la salud como derecho prestacional y el derecho a la vida como derecho fundamental. El argumento base para conceder fundamentalidad al primero lo cimentó en este sentido la Corte Constitucional en sentencia T-042 de 1996 en la que expuso: "[...] dentro de los derechos prestacionales económicos, de salud y de servicios complementarios que conforman el derecho a la seguridad social, el derecho a la salud está íntimamente ligado al derecho a la vida"319. Así:

Cuando se habla del derecho a la salud, no se está haciendo cosa distinta a identificar un objeto jurídico concreto del derecho a la vida, y lo mismo ocurre cuando se refiere al derecho a la integridad física. Es decir, se trata de concreciones del derecho a la vida, mas no de bienes jurídicos desligados de la vida humana, porque su conexidad próxima es inminente ${ }^{320}$.

En el año 1998, la Corte Constitucional continuó resaltando este planteamiento, ampliando a la postre su reconocimiento por vía de tutela, no solo en los eventos en los cuales se pone en peligro el derecho a la vida, sino también a aquellos en los que cualquier derecho, sin importar su entidad, estaba en peligro de ser vulnerado. En ese orden de ideas se refirió:

Existe necesidad de tutelar el derecho a la salud cuando haya certeza sobre la vulneración o amenaza de derechos constitucionales con carácter fundamental en cualquier grado y no solamente cuando la vulneración o amenaza de tales derechos sea muy grave; es decir, no debe esperarse a estar al borde de una negación completa de los derechos vinculados con el derecho a la salud, para que su tutela proceda $^{321}$.

318 COLOMBIA. CORTE CONSTITUCIONAL DE COLOMBIA. Sentencia T-207-1995. M.P.: José Gregório Hernández Galindo. p. 8.

319 COLOMBIA. CORTE CONSTITUCIONAL DE COLOMBIA. SentenciaT-042 de 1996. M.P.: Carlos Gaviria Díaz. p. 8.

${ }^{320}$ COLOMBIA. CORTE CONSTITUCIONAL DE COLOMBIA. Sentencia T-494 de 1993. M.P.: Vladimiro Naranjo Mesa.

${ }^{321}$ CORTE CONSTITUCIONAL DE COLOMBIA. Sentencia T-260-1998. M.P.: Fabio Morón Díaz. p. 1. 
Demás está decir que en virtud de esta línea de interpretación se elimina una talanquera adicional en el reconocimiento del derecho a la salud, esta es, que se encontrara en conexión con la vida o la integridad personal y que la afectación fuera de naturaleza grave.

A título seguido mediante la sentencia SU- 819 de 1999, se eliminó de manera definitiva uno de los argumentos en virtud de los cuales se había negado la procedencia de la protección del derecho a la salud, este era el que esbozaba de conformidad con la sentencia T-406 de 1992, su imposible concreción por ser de contenido abierto y prestacional, y requerir de una norma para su desarrollo. Frente a ello, sentó la alta Corporación con miras a unificar su jurisprudencia, que a pesar de tratarse el mismo de un derecho social, todas las medidas e interpretaciones abonadas desde la jurisprudencia para fijar su alcance restaban su indeterminación, haciéndolo concreto y exigible siempre que se esté frente a una situación definitivamente ajustada al precedente. A partir de ello, el derecho a la salud pasa a "convertirse, entonces, en un verdadero derecho subjetivo cuya protección puede solicitarse, entre otras instancias, ante los estrados judiciales" ${ }^{322 .}$

Además de los términos anteriormente referidos de significativo alcance, en tal sentencia de unificación se deja en claro que la salud puede ser concebida como un derecho fundamental cuando se cumplen cuatro presupuestos, estos son:

[...] primero, que opere en conexión con otro derecho fundamental; segundo, entendida como la asistencia pública que debe prestarse ante una calamidad que requiera, de manera grave e inminente la vida humana o la salud; tercero, ante casos de extrema necesidad, y cuarto, que se pueda prestar de acuerdo con las posibilidades reales de protección de que disponga el Estado para el caso concreto ${ }^{323}$.

Lo anterior, tratándose de la salud de adultos, puesto que como anteriormente se había expuesto, el derecho a la salud de los menores no sólo tiene carácter fundamental, sino también prevalente.

Ahora, si bien el derecho a la salud no es en sí mismo un derecho fundamental, sí puede llegar a ser efectivamente protegido, cuando la inescindibilidad entre el derecho a la salud y el derecho a la vida hagan necesario garantizar este último a

322 COLOMBIA. CORTE CONSTITUCIONAL DE COLOMBIA. Sentencia SU-819 de 1999. M.P.: Álvaro Tafur Galvis.

323 Ibíd. p. 1. 
través de la recuperación del primero, a fin de asegurar el amparo de las personas y de su dignidad. De ahí que el derecho a la salud sea un derecho protegido constitucionalmente en los eventos en que, por conexidad, su perturbación pone en peligro o acarrea la vulneración de la vida u otros derechos fundamentales de las personas $^{324}$.

Esta línea de pensamiento también se sustenta en la sentencia T-204-2000, en la cual se señaló:

en relación con la protección constitucional del derecho a la salud, esta Corte a lo largo de su jurisprudencia ha distinguido dos connotaciones: de una parte, la salud adquiere el rango de fundamental cuando está en riesgo el derecho a la vida u otro derecho fundamental, por ende susceptible de amparo a través de la tutela, y de otro lado, cuando no está en conexidad con otros derechos adquiere el carácter de prestacional, y puede ser exigible a través de otros medios de defensa diferentes a la tutela ${ }^{325}$.

Recapitulando, a pesar de encontrarse consagrado el derecho a la salud como un derecho económico, social y cultural (DESC), él mismo puede ser considerado como fundamental y así lo ha expresado la Corte Constitucional, bajo tres criterios básicos:

- Cuando tiene conexidad con otros derechos fundamentales: el derecho a la salud adquiere su condición de fundamental por la estrecha relación que tiene con otros derechos fundamentales, de manera que si no fuera protegido, se vería seriamente afectado el derecho fundamental al que se encuentra ligado, por ejemplo, cuando la desatención de un enfermo pone en peligro su vida.

- Cuando se está frente a sujetos de especial protección, verbigracia, la Constitución Política de Colombia en su artículo 44 ha concedido una especial protección a los niños y las niñas, y la corte Constitucional ha afirmado que las personas con discapacidad y los adultos mayores también requieren de protección especial y prevalente.

${ }^{324}$ COLOMBIA. CORTE CONSTITUCIONAL DE COLOMBIA. Sentencia T-941 del 24 de julio de 2000. M.P Alejandro Martínez Caballero. p. 6.

325 CORTE CONSTITUCIONAL DE COLOMBIA. Sentencia T-204-2000. M.P: Fabio Morón Díaz. Pág. 4. 
- Por su contenido, tal como se expuso en el capítulo anterior, la Corte Constitucional (Sentencia C-859-2003), ha considerado que el derecho a la salud puede ser un derecho fundamental, toda vez que,

Al adoptarse internamente un sistema de salud [...] en el cual se identifican los factores de riesgo, las enfermedades, males, medicamentos, procedimientos y, en general, los factores que el sistema va a atender para lograr la recuperación y el disfrute del máximo nivel posible de salud en un momento histórico determinado, se supera la instancia de indeterminación que impide que el propósito funcional del derecho se traduzca en un derecho subjetivo ${ }^{326}$.

Para dar cumplimiento a dicha posibilidad, se establece la necesidad de adopción de un plan de salud, una legislación complementaria a dicho plan y la asignación de recursos, pues tal y como se tuvo dicho en la sentencia SU-111 de 1997, "la efectividad del derecho a la salud, como de otros derechos que tienen clara naturaleza prestacional, depende de una actividad del Estado, que se enmarca en una serie de políticas públicas, adoptadas democráticamente"327. De ahí que a la luz de este último evento, solo fuese plausible su reclamación ante la negación de un bien o servicio incluido en el Plan Obligatorio de Salud.

Posteriormente, se avanzó en el reconocimiento del derecho más allá de las situaciones de conexión con la vida en peligro inminente, ello porque el tema de la conexidad debió hacerse cada vez más fluido por estar la salud no solo conectada íntimamente con tal derecho, sino también con otros muchos que dependen de ella para su materialización. Así, en otras decisiones la calificación del derecho como autónomo fue expresa y no implicó alusiones a la conexidad. Muestra de esta forma de estimar el derecho a la salud es lo indicado en las sentencias:

- T-1081 de 2001, en la que se dispuso la naturaleza fundamental del derecho a la salud de manera autónoma frente a adultos mayores, así: "El derecho a la salud de los adultos mayores es un derecho fundamental autónomo, dadas las características de especial vulnerabilidad de este grupo poblacional y su particular conexidad con el derecho a la vida y a la dignidad humana" ${ }^{28}$.

326 COLOMBIA. COLOMBIA. CORTE CONSTITUCIONAL DE COLOMBIA. Sentencia T-859 de 2003. M.P.: Eduardo Montealegre Lyneth. p. 7,8.

327 lbíd.

${ }^{328}$ COLOMBIA. CORTE CONSTITUCIONAL DE COLOMBIA. Sentencia T-1081/01. M.P.: Marco Gerardo Monroy Cabra. p. 1. 
- T-111 de 2003, en la que se señaló: "Es tal la vulnerabilidad y desprotección de este grupo poblacional que, en algunas ocasiones, la jurisprudencia de esta Corporación ha llegado a considera la salud de las personas de la tercera edad como derecho fundamental autónomo"329.

Para el caso de los niños, la calificación de fundamental resultó menos compleja, dado que por virtud de lo dispuesto en el citado art. 44 de la Carta, tratándose de estos sujetos de especial protección, el derecho en consideración se estima como fundamental. No fueron pocas las oportunidades en las cuales la Corte Constitucional por vía de revisión se pronunció sobre el carácter automático de la exigibilidad del derecho a la salud en menores. A modo de ejemplo se puede referir lo señalado en la sentencia T-754 de 2005, a saber:

La Constitución Colombiana, establece que la salud es un derecho y un servicio público cuyo acceso debe ser regulado a través de la ley. Es así como, de acuerdo con su artículo 49, el Estado debe garantizar a todas las personas "el acceso a los servicios de promoción, protección y recuperación de la salud". De igual manera, a la luz del artículo 44 de la Constitución, el derecho a la salud y las prestaciones que comprende adquieren un carácter fundamental por sí mismas en relación con la infancia, la cual es un grupo de especial protección constitucional.

A partir del artículo 44, la Corte Constitucional ha explicado que el derecho a la salud de los menores es objeto de una protección constitucional reforzada. Igualmente, que la fundamentalidad del derecho a la salud, cuando se trata de población infantil, conlleva el deber de otorgar de manera pronta, eficiente y eficaz la atención médica requerida ${ }^{330}$.

De igual forma, se reconoció en sentencia T- 573 de 2005, que "se puede considerar que el derecho a la salud es un derecho fundamental cuya efectiva realización depende, como suele suceder con otros muchos derechos fundamentales, de condiciones jurídicas, económicas y fácticas, así como de las circunstancias del caso concreto" 331 .

${ }^{329}$ COLOMBIA. CORTE CONSTITUCIONAL DE COLOMBIA. Sentencia T-111/03. M.P.: Marco Gerardo Monroy Cabra. p. 7.

330 COLOMBIA. CORTE CONSTITUCIONAL DE COLOMBIA. Sentencia t-754/05. M.P.: Jaime Araújo Rentería. p. 10.

331 COLOMBIA. CORTE CONSTITUCIONAL DE COLOMBIA. Sentencia T-573/05. M.P.: Humberto Sierra Porto. p. 11. 
Avanzando de forma más enérgica en la posición hasta ahora sostenida, el máximo tribunal constitucional de nuestro país en el año 2007 profirió sobre la naturaleza fundamental del derecho a la salud un magnífico pronunciamiento condensado en la sentencia T-060-2007, en el cual se destacó:

[...] el mencionado derecho a la salud, no es un derecho cuya protección se pueda solicitar prima facie por vía de tutela. Su carácter de derecho prestacional obliga al Estado a racionalizar, por un lado, la asignación de inversión suficiente para que su garantía tenga un alcance integral frente a la necesidad de sostenimiento que tiene también la garantía de otros derechos. En este escenario, por otro lado, debe igualmente por ello racionalizar su prestación satisfactoria a cargo del Estado sólo en casos en que su falta de reconocimiento: (i) afecte directamente y de manera conexa los derechos fundamentales de la persona, (ii) se pregone de un sujeto de especial protección constitucional y/o (iii) no dé cuenta de su contenido esencial para satisfacer la carga mínima que implica garantizar tanto la dignidad de las personas como sus necesidades básicas en salud ${ }^{332}$.

En dicho pronunciamiento, se resaltó nuevamente que el derecho a la salud resultaba fundamental por conexidad, pues otros derechos definidos por la Constitución como fundamentales resultarían vulnerados si no fuera garantizada su prestación de forma inmediata. No obstante, se dejó abierta la posibilidad de entender la salud como un derecho fundamental autónomo en sujetos de especial protección constitucional, por ejemplo, la población infantil, los discapacitados y los adultos mayores, pues frente a ellos la salvaguardia del mismo es reforzada debido a su grado de vulnerabilidad:

El derecho a la salud puede adquirir lo que la Corte Constitucional ha denominado carácter de derecho fundamental autónomo. Esto en atención a que la Constitución Política establece cláusulas que identifican sujetos de especial protección constitucional, y frente a ellos la protección del derecho a la salud es reforzada debido al grado de vulnerabilidad que en ocasiones deben afrontar ${ }^{333}$.

332 COLOMBIA. CORTE CONSTITUCIONAL DE COLOMBIA. Sentencia T-060-2007. M.P.: Humberto Antonio Sierra Porto. $p$.

${ }^{333}$ COLOMBIA. CORTE CONSTITUCIONAL DE COLOMBIA. Sentencia T-060-2007. Op. Cit. p. 7. 
La Corte consideró que dicha connotación se hacía posible solo funcionalmente dirigida a lograr la dignidad humana. Esta concepción se fue enraizando en la jurisprudencia constitucional, profiriéndose pronunciamientos como el siguiente:

[...] la salud es un derecho fundamental 'de manera autónoma', cuando se puede concretar en una garantía subjetiva derivada de las normas que rigen el derecho a la salud, advirtiendo que algunas de estas se encuentran en la Constitución misma, otras en el bloque de constitucionalidad, y la mayoría, finalmente, en las leyes y demás normas que crean y estructuran el Sistema Nacional de Salud, y definen los servicios específicos a los que las personas tienen derecho ${ }^{334}$.

Posteriormente, la Corte asumió la condición de fundamental del derecho a la salud como autónomo y, sin aludir puntualmente a la titularidad en cabeza de algún sujeto de especial protección. Al igual que cualquier derecho de los denominados individuales, este, originado en el contexto de las revoluciones sociales, alcanzó un estatus que lo hace protegible por el mecanismo de la acción de tutela y cuyo contenido esencial no está a disposición del principio mayoritario. De tal forma, se extiende el sentido y alcance del anterior pronunciamiento, y en tanto, el reconocimiento del derecho fundamental a la salud mediante la sentencia T-463 del año 2008 , un pronunciamiento académico y muy sustancioso, en el cual se estudian un sinnúmero de casos que tienen que ver con diferentes prestaciones atenientes al derecho a la salud y la organización y regulación del Sistema en garantía del derecho fundamental, ello para derivar del fallo las diferentes reglas de protección del derecho de manera autónoma. Se preceptuó en tanto:

Del principio de universalidad en materia de salud se deriva primordialmente el entendimiento de esta Corte del derecho a la salud como un derecho fundamental, en cuanto el rasgo primordial de la fundamentabilidad de un derecho es su exigencia de universalidad, esto es, el ser un derecho predicable y reconocido para todas las personas sin excepción, en su calidad de seres humanos con dignidad. En virtud del entendimiento del derecho a la salud como un derecho constitucional con vocación de universalidad y por tanto de fundamentabilidad, esta Corte en su jurisprudencia, ha resaltado la importancia que adquiere la protección del derecho fundamental a la

334 lbíd. p. 9. 
salud en el marco del estado social de derecho, en cuanto afecta directamente la calidad de vida ${ }^{335}$.

Sin lugar a dudas, esta jurisprudencia es un hito en materia de salud en Colombia, pues no solo estudia en conjunto un gran número de casos, sino que se toma la vocería en analizar las actuaciones y omisiones de los administradores del Sistema de Salud, los entes reguladores y en la veeduría y control por parte del Estado, para así impartir ordenes de toda naturaleza, y hacer posible la exigencia de los mínimos alcances del derecho jurisprudencialmente reconocidos. De tal forma, se ordena, por ejemplo, la reducción del número de estadísticas de tutelas en la materia, como condición para el cumplimiento de la sentencia. Tal es la contundencia del Tribunal Constitucional en la calificación del derecho a la salud como autónomo, que desde 2007 se ha calificado como "artificioso" acudir a la conexidad para predicar el carácter fundamental del derecho.

Para lograr dicho alcance, la jurisprudencia parte de la consideración de que:

El reconocimiento de la salud como un derecho fundamental en el contexto constitucional colombiano, coincide con la evolución de su protección en el ámbito internacional: en efecto, la génesis y desenvolvimiento del derecho a la salud, tanto en el ámbito internacional como en el ámbito regional, evidencia la fundamentalidad de esta garantía ${ }^{336}$.

Las exigencias internacionales propugnan que,

El derecho a la salud entraña libertades y derechos', señala el Comité, indicando como ejemplo de las libertades 'el derecho a controlar su salud y su cuerpo' o 'el derecho a no ser sometido a torturas ni a tratamientos y experimentos médicos no consensuales'. Entre los derechos, se presenta como ejemplo 'el relativo a un sistema de protección de la salud que brinde a las personas oportunidades iguales para disfrutar del más alto nivel posible de salud ${ }^{337}$.

335 COLOMBIA. CORTE CONSTITUCIONAL DE COLOMBIA. Sentencia C-463/08. M.P.: Jaime Araújo Rentería. p. 2.

${ }^{336}$ COLOMBIA. CORTE CONSTITUCIONAL DE COLOMBIA. SentenciaT-760 de 2008. M.P.: Manuel José Cepeda Espinosa. p. 31.

337 Ibíd. p. 53. 
Aunque lo anterior no significa que deba hacerse el mismo exigible de manera impensada en todos los casos, pues la exigibilidad es diferente de la fundamentalidad y obedece a reglas de urgencia, necesidad, entre otras. Es claro que el Estado no puede de manera permanente excusarse en términos presupuestales para negar prestaciones en materia de salud, pues su carácter progresivo debe ser verificable. Sobre dicha referencia se dijo:

[...] no poder garantizar de manera instantánea el contenido prestacional del derecho es entendible por las razones expuestas, pero carecer de un programa que de forma razonable y adecuada conduzca a garantizar los derechos en cuestión, es inadmisible constitucionalmente. El carácter progresivo de la prestación no puede ser invocado para justificar la inacción continuada, ni mucho menos absoluta, del Estado ${ }^{338}$.

Ahora bien, superada la primera década del siglo XXI, la jurisprudencia de la Corte Constitucional en punto de la consideración fundamental del derecho a la salud ha continuado su desarrollo y mediante la sentencia T-1024 del año 2010 resaltó:

La salud fue consagrada por el Constituyente de 1991 en el artículo 49 de la Carta Política como un concepto que goza de una doble connotación: como derecho fundamental y como servicio público. [...]. En tanto derecho fundamental, calidad que no deriva de forma expresa de la categorización trazada en el texto de la Carta, su designación ha resultado de la evolución jurisprudencial que, a la par de la doctrina y los instrumentos internacionales en la materia, ha conducido a la superación de la clasificación que en antaño se hacía respecto de los derechos -en derechos civiles y políticos de un lado y económicos, sociales y culturales- y a la correspondiente variación de la perspectiva que se tiene sobre los medios para su exigibilidad 339 .

Dicha jurisprudencia en tales términos no solo reconoce la fundamentalidad del derecho a la salud, sino que además resalta el abandono en su consideración como derecho económico, social y cultural y pone de presente las implicaciones de tal interpretación al momento del uso de los mecanismos judiciales previstos para esta clase de derechos. En consecuencia:

\footnotetext{
338 Ibíd. p. 42.

339 COLOMBIA. CORTE CONSTITUCIONAL DE COLOMBIA. Sentencia T-1024-2010. M.P.: Humberto Antonio Sierra Porto. p. 10,11.
} 
Hoy se muestra artificioso predicar la exigencia de conexidad respecto de derechos fundamentales los cuales tienen todos - unos más que otros - una connotación prestacional innegable. Ese requerimiento debe entenderse, en otros términos, es decir, en tanto enlace estrecho entre un conjunto de circunstancias que se presentan en el caso concreto y la necesidad de acudir a la acción de tutela en cuanto vía para hacer efectivo el derecho fundamental. Así, a propósito del derecho fundamental a la salud puede decirse que respecto de las prestaciones excluidas de las categorías legales y reglamentarias únicamente podrá acudirse al amparo por vía de acción de tutela en aquellos eventos en los cuales logre demostrarse que la falta de reconocimiento del derecho fundamental a la salud (i) significa a un mismo tiempo lesionar de manera seria y directa la dignidad humana de la persona afectada con la vulneración del derecho; (ii) se pregona de un sujeto de especial protección constitucional y/o (iii) implica poner a la persona afectada en una condición de indefensión por su falta de capacidad de pago para hacer valer ese derecho ${ }^{340}$.

Recientemente mediante sentencia T-174 del año 2013, se señaló que:

La fundamentalidad del derecho a la salud se hace efectiva a partir del desarrollo de los principios y postulados consagrados en la Carta de derechos de 1991, los cuales han dejado atrás su indeterminación en virtud del desarrollo legislativo y la adhesión a diversos cuerpos normativos, legales y supra constitucionales entre los que se destacan la Ley 100 de 1993, los Decretos que la reglamentan, el Acuerdo 29 de 2011 de la CRES y el Protocolo de Derechos Económicos Sociales y Culturales ${ }^{341}$.

Por último, resulta fructífero finalizar este estudio de evolución jurisprudencial haciendo mención a la reciente jurisprudencia del alto tribunal constitucional, sentencia C-313 de 2014, mediante la cual se analizó de forma previa, de fondo y de forma el proyecto de ley estatutaria del derecho fundamental a la salud, que culminó con la expedición de la Ley 1751 de 2015. Dicha jurisprudencia haciendo un análisis de fondo del derecho a la salud, entendido este en sus facetas positiva y negativa, declaró la exequibilidad del proyecto en comento, siempre bajo el entendido de que no es aceptable la incorporación de políticas regresivas que

${ }^{340}$ COLOMBIA. CORTE CONSTITUCIONAL DE COLOMBIA. Sentencia T-016/07. M.P.: Humberto Antonio Sierra Porto. p. 18.

${ }^{341}$ COLOMBIA. CORTE CONSTITUCIONAL DE COLOMBIA. Sentencia T-174-2013. M.P.: Jorge Iván Palacio. p. 7. 
menoscaben el derecho, que descarten o dificulten la acción de tutela como mecanismo para hacer exigible su garantía, o que supedite al mismo al principio de sostenibilidad fiscal que de ninguna manera puede ser talanquera en la prestación del servicio, su continuidad y su calidad ${ }^{342}$.

Esto en aras de aprobar "una reforma estructural que limite el lucro basado en la enfermedad y priorice el garantizar un derecho humano fundamental y no la rentabilidad de un negocio"343. En dicha providencia, sin duda se plantea el análisis de una norma, a partir del precedente configurado por la Corte a partir de sus pronunciamientos y a la luz del Bloque de Constitucionalidad. En ese entendido, se avaló el contenido del proyecto, siempre bajo el condicionamiento de no regresión, de progresividad, y de exigibilidad inmediata en los eventos en los que hay lugar a ella.

Estos pronunciamientos hasta aquí resumidos, recapitulan un avance que es del todo observable en el panorama constitucional implementado por la Corte Constitucional de Colombia, la cual ha reconocido la fundamentalidad del derecho y le ha otorgado su jerarquía en la clasificación de los mismos antes de que el legislativo pretendiera institucionalizarlo, optando por la realización de los fines del Estado colombiano como social de derecho.

Resaltada la línea jurisprudencial sobre la materia, conviene por último resaltar que, si bien los conjuntos de pronunciamientos generaron un significativo progreso en la concepción de este derecho humano, también fueron notoriamente tardíos. Valga para ello traer a juicio la Observación General $\mathrm{N}^{\circ} 14^{344}$, anteriormente citada, en la que de manera clara y categórica ya se había establecido desde tal fecha, que la salud es un derecho humano fundamental e indispensable para el ejercicio de los demás derechos humanos. Al respecto, el Comité insistía desde antes en la indivisibilidad e interdependencia del derecho a la salud en tanto estrechamente vinculado con el ejercicio de otros derechos humanos, de forma específica los de alimentación, vivienda, trabajo, educación, dignidad humana, la vida, la no discriminación, la igualdad, etc.

342 COLOMBIA. CORTE CONSTITUCIONAL DE COLOMBIA. Sentencia C-313/14. M.P.: Gabriel Eduardo Mendoza Martelo.

343 Ibíd. p. 237.

${ }^{344}$ Aplicación del Pacto Internacional de los Derechos Económicos, Sociales y Culturales. Observación general 14. Op. Cit. 
Desde ese precedente, huelga anotar finalmente el alcance dado al mismo por el Relator Especial de la Organización Mundial de la Salud, de la Oficina del Alto Comisionado de las Naciones Unidas para los derechos humanos, al punto que:

[...] un sistema de salud nacional debe tener varios componentes: un sistema adecuado para recopilar datos que permitan hacer un seguimiento de la realización del derecho a la salud; datos desglosados por factores como el sexo, la edad y las zonas urbanas/rurales, capacidad nacional para producir un número suficiente de trabajadores sanitarios competentes que disfruten de buenas condiciones de empleo, un proceso para la preparación de evaluaciones del impacto en el derecho a la salud antes de dar el toque final a las principales políticas relacionadas con la salud, disposiciones que garanticen la participación en la formulación de las políticas de salud, y mecanismos efectivos, transparentes y accesibles de rendición de cuentas ${ }^{345}$

2.2.3.1. Análisis dinámico de la evolución jurisprudencial. De acuerdo con lo anterior, es preciso resaltar que la fundamentalidad del derecho a la salud en Colombia (Figura 2) ha sido una conquista lograda a partir de la jurisprudencia, la cual se ha encargado de dar pasos en dirección al logro de los contenidos materiales del Estado Social de Derecho, así como de poner en el plano de la legalidad nacional los avances realizados en el orden internacional.

En un inicio, la interpretación de la jurisprudencia constitucional de manera categórica enfatizaba en la naturaleza prestacional del derecho a la salud, motivo por el cual no había cabida para la acción de tutela a fin de solicitar el amparo de este derecho. Bajo este entendido se enfiló la jurisprudencia durante los años 1992 y 1993. Posteriormente, en 1994, la Corte aceptó la fundamentalidad del derecho en los casos en que existía conexidad con derechos fundamentales propiamente consagrados en la Constitución de 1991, como es el caso de la vida, el mínimo vital y la integridad física. Dicha jurisprudencia se mantuvo vigente hasta finalizar la última década del siglo XX, no sin advertir ligeras variaciones particularmente hacia el año 1998, año en el cual se señaló que la afectación del derecho fundamental invocado en conexidad con el derecho a la salud no tenía que ser plenamente catalogada como grave, toda vez que ante el riesgo de su conculcación debían ponerse en marcha los mecanismos judiciales necesarios para evitar un daño.

\footnotetext{
${ }^{345}$ NACIONES UNIDAS Y ORGANIZACIÓN MUNDIAL DE LA SALUD. El derecho a la salud. Folleto informativo № 31. (en línea). http://www.ohchr.org/Documents/Publications/Factsheet31sp.pdf. p. $40,41$.
} 


\section{Figura 2. Análisis dinámico del derecho a la salud en Colombia}

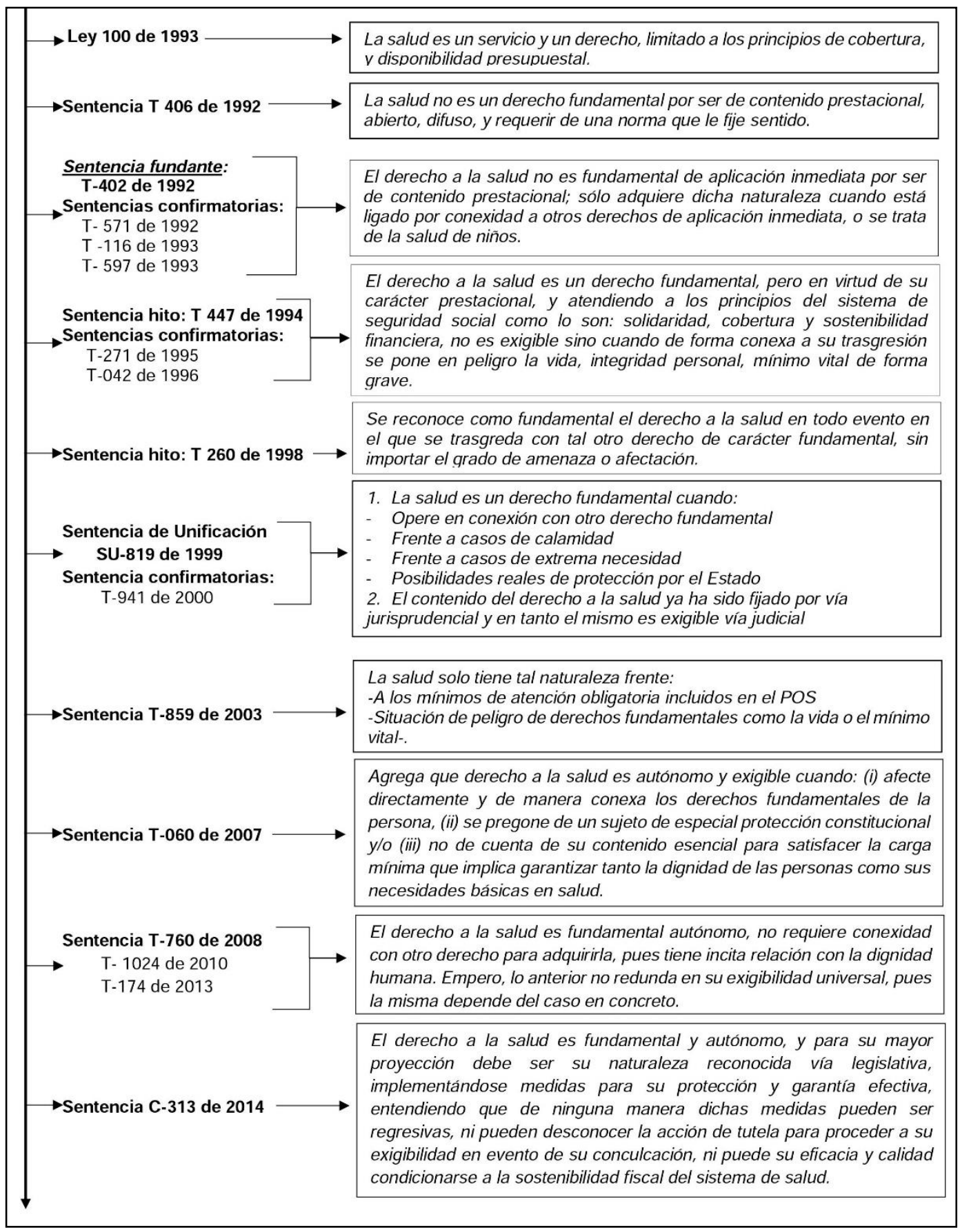

Advenido el siglo XXI, durante la primera década, se reconoció la salud como un derecho fundamental autónomo, lo que de punta le habilitaba para solicitar su amparo sin necesidad de conexidad con otro derecho. Así, se estableció la dimensión positiva y negativa de este particular derecho: 
El derecho a la salud tiene una marcada dimensión positiva, aunque también tiene dimensiones negativas. La jurisprudencia constitucional ha reconocido desde un inicio, que el Estado, o las personas, pueden violar el derecho a la salud, bien sea por una omisión al dejar de prestar un servicio de salud, o bien por una acción, cuando realizan una conducta cuyo resultado es deteriorar la salud de una persona. En lo que respecta a las dimensiones negativas del derecho a la salud, de las cuales no se deriva la obligación de realizar una acción positiva, sino más bien, obligaciones de abstención, en tanto no suponen que el Estado haga algo, sino que lo deje de hacer, no hay razón alguna para que sean obligaciones cuyo cumplimiento sea pospuesto hasta que el Estado entidad o persona cuente con los recursos suficientes y la capacidad administrativa adecuada ${ }^{346}$.

Asimismo, se reconoció su fundamentalidad autónoma para el caso de sujetos de especial protección como la población infantil, las personas con discapacidad y los adultos mayores, entre otros. Demás está decir, que a lo largo del siglo XXI y sus casi dos décadas, los compromisos del Estado colombiano en materia internacional han centrado su atención en el derecho a la salud, así, se tiene que:

[...] el derecho a la salud y el derecho a la atención médica, está reconocido por lo menos en 115 constituciones. Otras seis, por lo menos, imponen deberes con respecto a la salud, por ejemplo, el deber del Estado de desarrollar los servicios de salud o de asignarles un presupuesto concreto ${ }^{347}$.

Lo anterior en el marco del reconocimiento de que "La salud puede ser para las personas que viven en condiciones de pobreza el único activo del que disponen para ejercer otros derechos económicos y sociales, como el derecho al trabajo o el derecho a la educación"348.

En suma, el derecho a la salud, como se ha expuesto, tiene diversas connotaciones por tratarse de un derecho humano y por ello al Estado el deber de "[...] prestar una atención específica a las distintas personas y grupos de personas de la sociedad, en particular los que viven en situaciones vulnerables"349.

346 COLOMBIA. CORTE CONSTITUCIONAL DE COLOMBIA. Sentencia T-760 de 2008. M.P.: Manuel José Cepeda Espinosa. Op Cit. p. 36,37.

347 NACIONES UNIDAS Y ORGANIZACIÓN MUNDIAL DE LA SALUD. Op. Cit. p. 22.

348 lbíd. p. 15.

${ }^{349}$ NACIONES UNIDAS Y ORGANIZACIÓN MUNDIAL DE LA SALUD. Op. Cit. p. 23. 
Como podemos apreciar el concepto de la salud, ha tenido una considerable evolución jurisprudencial, "pues inició como un derecho de desarrollo progresivo, que era amparable por vía de la acción de tutela cuando quiera que el mismo estuviese en conexidad con el derecho a la vida"350 Empero, el desarrollo jurisprudencial de los diferentes pronunciamientos de la Corte Constitucional "advirtió que la fundamentalidad de un derecho no podía depender de la manera en que éste se pudiese materializar" 351 considerando de este modo, la salud como un derecho fundamental autónomo.

Luego en sentencia T-760 de 2008, es la misma Corte quien denota la presencia "de fallas estructurales en la regulación del Sistema de Seguridad Social en Salud, en donde "en lo que respecta a un ámbito básico, el cual coincide con los servicios contemplados por la Constitución, la ley y los planes obligatorios de salud, con las extensiones necesarias para proteger una vida digna". Con este progreso jurisprudencial se pone fin a la interpretación restrictiva de la naturaleza del derecho a la salud como derecho conexo a otros, y se pasó a la interpretación actual como un derecho fundamental nato"352, es por ello, que a partir del año 2008 la evolución jurisprudencial marca un enorme impacto en sistema de salud, dado que dicha sentencia hito, la cual recopila un numero significativo de decisiónes de la corte sobre la salud, "buscaba incrementar la igualdad en el acceso a la salud y mejorar el funcionamiento del sistema de salud, para reducir así el enorme número de demandas judiciales. En dicha sentencia, la Corte examinó los problemas estructurales de dicho sistema y ordenó una reestructuración importante de la política pública en salud a partir de un enfoque basado en los derechos ${ }^{353}$.

Esta corporación considera la salud como un derecho fundamental "que aunque es de desarrollo progresivo, impone a las autoridades estatales obligaciones específicas inmediatas" 354 . Es de advertir que la corte constitucional mediante la sentencia T760 de 2008 "evidencia plenamente que el derecho a la salud, tanto en los tratados de derechos humanos como en la Constitución Política de 1991, impone al Estado colombiano una serie de obligaciones, destinadas a lograr la plena realización de ese derecho" 355

\footnotetext{
350 Sentencia T-579/17

351 lbídem

352 T-760 de 2008

353 lbídem

354 Higuera Jiménez, Diego Mauricio; Alonso Niño, Edwin Hernando Derechos Sociales Fundamentales, problemática hermenéutica en el derecho a la salud en Colombia Revista VIA IURIS, núm. 12, enero-junio, 2012, pp. Fundación Universitaria Los Libertadores Bogotá, Colombia

355 lbídem
} 
Consecuencialmente la corte constitucional después de hacer un prolijo análisis en la sentencia T760 de 2008 sobre la salud, siguió advirtiendo que la salud es un derecho fundamental autónomo, esto lo desarrollo mediante las sentencia de tutela T-893/10, recordando que "La jurisprudencia de la Corte Constitucional ha señalado que el derecho a la salud de las niñas y los niños es fundamental, cuenta con un carácter prevalente frente a los derechos de los demás y corresponde a la familia, el Estado y la sociedad garantizarles su desarrollo armónico e integral", la sentencia T-845/11, en relación a la "especial Protección a las personas en situación de discapacidad. Sentencia T-073/13 "Al definirse los contenidos precisos del derecho a la salud, se genera un derecho subjetivo a favor de los beneficiarios del sistema de salud. Por lo tanto, cuando las entidades prestadoras de los servicios de salud, se niegan a suministrar tratamientos, medicamentos o procedimientos incluidos en el POS o POS-S, vulneran el derecho a la salud, el cual como se ha reiterado adquiere la condición de derecho fundamental autónomo y éste puede ser protegido por la acción de tutela" sentencia T-161/13, Al definirse los contenidos precisos del derecho a la salud, se genera un derecho subjetivo a favor de los beneficiarios del sistema de salud. Por lo tanto, cuando las entidades prestadoras de los servicios de salud, se niegan a suministrar tratamientos, medicamentos o procedimientos incluidos en el POS o POS-S, vulneran el derecho a la salud, el cual como se ha reiterado adquiere la condición de derecho fundamental autónomo y éste puede ser protegido por la acción de tutela. Sentencia T-180/13 Derecho a la salud de las personas de la tercera edad es fundamental autónomo. Sentencia T-408/13 Derecho fundamental a la salud en especial de las personas de la tercera edad y de los niños, niñas y adolescentes. Sentencia T-539/13 Obligación de las EPS de autorizar de manera inmediata servicios de salud y/o medicamentos excluidos del POS sin someter su suministro a previa autorización del Comité Técnico Científico, cuando se requiera de forma urgente para salvaguardar la vida e integridad del paciente, sentencia T-563/13 La Constitución Política y la jurisprudencia constitucional han reconocido a la salud como un derecho fundamental autónomo. De acuerdo con los tratados internacionales ratificados por Colombia, se han radicado en cabeza del Estado la obligación de garantizar la atención médica que las personas requieran, establecido los elementos esenciales del contenido del derecho a la salud, como son: la disponibilidad, la accesibilidad, la aceptabilidad, la calidad y la prohibición de discriminación de los bienes y servicios de salud. Tal como lo ha establecido la jurisprudencia constitucional e internacional, el derecho a la salud implica el disfrute del más alto nivel de salud física y mental posible, razón por lo cual, no solo implica la prevención de la enfermedad, sino también el tratamiento, la recuperación y la rehabilitación de la misma. Sentencia T-153/14 La Corte Constitucional ha reconocido a través de numerosos fallos que el derecho a la salud es un derecho fundamental autónomo en virtud del cual se pretende asegurar "'un estado completo de bienestar físico, mental y social' dentro del nivel posible de salud para una persona". En principio es obligación del Estado velar por la prestación oportuna del servicio de salud a todos sus habitantes, buscando prevenir futuras afectaciones el bienestar físico o psicológico de los mismos. Ahora bien, en los casos en que la acción u omisión de las entidades prestadoras de estos 
servicios consoliden un perjuicio grave, los sujetos afectados se convierten en acreedores de la acción positiva del Estado, encaminada a corregir las desigualdades que los afectan en razón a su incapacidad. Sentencia T-599/15 I principio de integralidad implica que el derecho a la salud se protege cuando se suministran todas las prestaciones requeridas para que una persona se recupere de la patología que sufre. De esta manera, esta Corporación ha expuesto que la integralidad hace referencia al "cuidado, suministro de medicamentos, intervenciones quirúrgicas, prácticas de rehabilitación, exámenes para el diagnóstico y el seguimiento, así como todo otro componente que el médico tratante valore como necesario para el pleno restablecimiento de la salud del paciente 0 para mitigar las dolencias que le impiden llevar su vida en mejores condiciones; y en tal dimensión, debe ser proporcionada a sus afiliados por las entidades encargadas de prestar el servicio público de la seguridad social en salud". Cabe resaltar que el derecho fundamental a la salud incluye el reconocimiento de la prestación del servicio que se requiere (POS y no POS) y el acceso oportuno, eficiente además de calidad de aquél. Sentencia T-609/15 En relación con la agencia oficiosa, la Corte ha señalado que resulta procedente que un tercero interponga acción de tutela en nombre de otra persona cuando ella no puede ejercer su propia defensa, situación que se debe manifestar en la demanda de amparo. Con base en ello, la Corte ha reiterado los elementos para que proceda la agencia oficiosa en materia de tutela, a saber: "(i) la necesidad de que el agente oficioso manifieste explícitamente que está actuando como tal, y (ii) que el titular de los derechos invocados no se encuentre en condiciones para instaurar la acción de tutela a nombre propio". Sentencia T-002/16 En virtud del principio de integralidad del servicio de salud, la Corte Constitucional ha sido enfática en señalar que el tratamiento que se debe proporcionar para garantizar el derecho a la salud, no tiene como único objetivo obtener la curación. Este, debe estar encaminado a superar todas las afecciones que pongan en peligro la vida, la integridad y la dignidad de la persona, por tal razón se deben orientar todos los esfuerzos para que, de manera pronta, efectiva y eficaz reciba todos los cuidados médicos tendientes a proporcionarle el mayor bienestar posible. Sentencia T-115/16 El carácter fundamental y autónomo del derecho a la salud, ha sido ratificada por la Ley Estatutaria de la Salud, la Ley 1751 de 2015, sometida a control previo y automático de constitucionalidad por parte de esta Corporación, mediante la Sentencia C- 313 de 2014. Precisamente, dicho ordenamiento, a través de los artículos $1^{\circ}$ y $2^{\circ} \circ$, al definir el objeto, naturaleza y contenido de la ley, se refiere a la salud como un "derecho fundamental", "autónomo e irrenunciable en lo individual y en lo colectivo", el cual comprende, entre otros elementos, la prestación del servicio de manera "oportuna, eficaz y con calidad para la preservación, el mejoramiento y la promoción de la salud". " ejercicio de los deberes constitucionales que adquiere el Estado colombiano, de crear un sistema que permita la cobertura del derecho a la salud a toda la población, se han estructurado dos tipos de destinatarios: por un lado, los afiliados a los regímenes contributivo y subsidiado que se diferencian entre ellos de acuerdo a la capacidad de pago para cotizar al interior del Sistema de Seguridad Social en Salud; y por otro, la figura del participante vinculado, constituido con el 
objetivo de cubrir aquellas personas que, si bien no se encuentran afiliados al régimen subsidiado, se les debe garantizar la prestación del servicio a través de las Instituciones públicas o privadas que tengan contrato con el Estado por no contar con la capacidad económica necesaria para cotizar en el sistema, no obstante teniendo a su cargo, la asunción de parte de los costos de servicio, de acuerdo con las normas sobre cuotas de recuperación. Sentencia T-507/17 La solicitud de amparo constitucional se torna, en general, improcedente para solucionar las controversias que se originan en los contratos de planes adicionales, voluntarios 0 complementarios de atención en salud, debido a que sus normas especiales tienen mecanismos propios y acciones de resolución. No obstante, atendiendo que los mismos tienen como objeto la prestación de servicios de salud y que pueden ser trasgredidos los derechos fundamentales de los usuarios, la acción de amparo procederá excepcionalmente bajo las condiciones establecidas en la jurisprudencia constitucional, así como en atención a la calidad del sujeto de especial protección constitucional que reclama la protección de sus derechos fundamentales. T-579/17 El derecho fundamental a la salud es un derecho de contenido cambiante, que exige del Estado una labor de permanente de actualización, ampliación y modernización en su cobertura, por lo que no es aceptable considerar que ya se ha alcanzado un grado de satisfacción respecto de su garantía. Para ello, es fundamental que el Estado garantice que los elementos esenciales del derecho a la salud como son (i) la disponibilidad, (ii) la aceptabilidad, (iii) la accesibilidad y (iv) la calidad e idoneidad profesional, siempre estén interrelacionados y que su presencia sea concomitante pues, a pesar de la independencia teórica que cada uno representa, la sola afectación de uno de estos elementos esenciales es suficiente para comprometer el cumplimiento de los otros y afectar en forma negativa la protección del derecho a la salud.

Finalmente conviene destacar, que la corte constitucional sigue insistiendo en reiterada jurisprudencia la fundamentalidad autónoma del derecho a la salud, esta corporación también ha determinado que el antedicho derecho "se compone de unos elementos esenciales que delimitan su contenido dinámico, que fijan límites para su regulación y que le otorgan su razón de ser. Estos elementos se encuentran previstos en el artículo 6 de la Ley 1751 de 2015, en los que se vincula su goce pleno y efectivo con el deber del Estado de garantizar su (i) disponibilidad, (ii) aceptabilidad, (iii) accesibilidad y (iv) calidad e idoneidad profesional" ${ }^{356}$.

Bajo los lineamientos de la evolución jurisprudencial, resulta importante de cara a esta labor investigativa, realizar igualmente un estudio sobre concepto del derecho a la salud, teniendo en cuenta los consiguientes presupuestos.

${ }^{356}$ Sentencia T-092/18 
2.2.4. Evolución conceptual del derecho a la salud. Sin dubitación, hoy se plantea la salud como un derecho fundamental por estar estrechamente ligado al avance en la concepción de la vida del ser humano en términos de dignidad y de justicia, de forma tal que de la realización del mismo pende necesariamente la posibilidad de gozar de otros que forman parte de sus componentes integrales en una más completa noción. Así, por ejemplo, de manera clara y categórica, la Observación General №14 (2000), citada en la sentencia T-760-2008, establece que:

[...] la salud es un derecho humano fundamental e indispensable para el ejercicio de los demás derechos humanos". Al respecto, se insiste en la indivisibilidad e interdependencia del derecho a la salud en tanto está estrechamente vinculado con el ejercicio de otros derechos humanos y depende de esos derechos ${ }^{357}$.

Esta posición es de recibo por parte de la doctrina, al considerar que: "Es una categoría que abarca también el acceso a una alimentación adecuada, a condiciones de trabajo sanas y seguras y a servicios de apoyo para el cuidado de la salud." 358

Como ha sido expuesto, el derecho a la salud es hoy parte fundamental de los derechos humanos y de lo que entendemos por una vida digna. No obstante, ser esto para nosotros una novedad, el derecho a disfrutar del nivel más alto posible de salud física y mental, por decirlo con todas las palabras, ino es nuevo!, ello porque en el plano internacional ya se había proclamado por primera vez en la Constitución de la Organización Mundial de la Salud (OMS) de 1946, en cuyo preámbulo se definió a la salud como un "[...] estado de completo bienestar físico, mental y social y no solamente la ausencia de afecciones y enfermedades" 359 . Afirmándose, también, en la disposición normativa en comento, que el goce del grado máximo de salud que se pueda lograr es uno de los derechos fundamentales de todo ser humano, sin distinción de raza, religión, ideología política o condición económica o social. Sin embargo, esta definición solo logra acogida posterior a muchos enfrentamientos legales, jurisprudenciales y doctrinales luego de que teorías económicas del derecho a la salud, y otras tantas temerosas de asignarle significancia constitucional fueran vencidas por el entendimiento de que tal garantía es la piedra angular de otros derechos sin los cuales se imposibilita la existencia

${ }^{357}$ CORTE CONSTITUCIONAL DE COLOMBIA. Sentencia T-760-2008. Op. Cit. p. 46.

358 ÁLVAREZ CASTAÑO, Luz Stella. El derecho a la salud en Colombia: una propuesta para su fundamentación moral. En: Revista Panamericana de Salud Pública.18 (2) (2005). p. 3.

359 NACIONES UNIDAS Y ORGANIZACIÓN MUNDIAL DE LA SALUD. Op. Cit. p. 8. 
del ser humano en condiciones dignas y justas. En virtud de ello, y atendiendo a los criterios de nuestra Carta Política,

[...] el ámbito del derecho fundamental a la salud está delimitado por la dogmática constitucional que reconoce los contenidos garantizados a las personas en virtud del mismo, por tanto, el ámbito de protección no está delimitado por el plan obligatorio de salud, pues puede existir un servicio de salud no incluido en el plan, que se requiera con necesidad, y que comprometa de forma grave la vida digna de la persona o su integridad personal ${ }^{360}$.

Desde este enfoque, se han ampliado los horizontes en materia de la fundamentalidad del derecho a la salud, toda vez que se reconoce su trascendencia aún por encima de los contenidos legales que contienen las garantías y cobertura de la prestación del servicio de salud. Surge entonces que uno es el derecho y otra su prestación, delimitada conceptualmente por la Corte Constitucional bajo el denominado principio de continuidad en la prestación de los servicios de salud, el cual "[...] responde, no solo a la necesidad de los usuarios de recibir tales servicios, sino también a los postulados del principio de buena fe y de confianza legítima contemplados en el artículo 83 de la Constitución Política de 1991"361. Dicho esto, es posible que la prestación en materia de salud traspase las fronteras de los planes de salud.

De líneas anteriores, salta a la luz que esta concepción actual, que se ha matizado de cara a la consideración del ser humano desde su máxima estimación de dignidad, es la que plantea una visión más garantista del derecho en cuestión; sin embargo, para arribar al perfeccionamiento de la misma se transitó, como se dijo, necesariamente por la incorporación de varias teorías sobre tal derecho, teniendo en cuenta que nuestra Carta no fue clara en determinar si la salud se trataba de un derecho fundamental o de un servicio público. Así las cosas, dichas teorías básicas serán planteadas a continuación, con miras a profundizar de acuerdo con los fines propios de esta investigación, sobre los aportes que cada una de ellas dejó en materia.

${ }^{360}$ COLOMBIA. CORTE CONSTITUCIONAL DE COLOMBIA. Sentencia T-073 de 2007. Op. Cit. p. 29.

361 COLOMBIA. CORTE CONSTITUCIONAL DE COLOMBIA. Sentencia T-214-2013, M.P.: Luis Ernesto Vargas Silva. p. 1. 
2.2.4.1. Noción de la salud como un servicio. Nuestro texto constitucional reza en su artículo 49: "La atención de la salud y el saneamiento ambiental son servicios públicos a cargo del Estado" ${ }^{62}$. Por su parte, la Ley 100 determina que:

ART. 3o: El Estado garantiza a todos los habitantes del territorio nacional, el derecho irrenunciable a la seguridad social.

Este servicio será prestado por el sistema de seguridad social integral, en orden a la ampliación progresiva de la cobertura a todos los sectores de la población, en los términos establecidos por la presente Ley.

ART. 4-- Del servicio público de seguridad social. La seguridad social es un servicio público obligatorio, cuya dirección, coordinación y control está a cargo del Estado y que será prestado por las entidades públicas o privadas en los términos y condiciones establecidos en la presente ley ${ }^{363}$.

Así mismo, la jurisprudencia en un primer momento señaló, verbigracia, en sentencia C- 408 de 1994:

[...] la interpretación integradora de distintos elementos concurrentes en determinadas realidades constitucionales, permite afirmar que la seguridad social es un derecho de la persona que se materializa mediante la prestación de un servicio público de carácter obligatorio.

Desde el artículo 10., la Carta aborda el derecho a la seguridad social, al organizar la República como un Estado Social de Derecho. Esta forma del Estado trae implícito el comentado derecho a la seguridad social. Comprende la solidaridad colectiva que hace resaltar la obligación del poder público, de la Sociedad y del propio hombre, de asistir a los ciudadanos a fin de procurarles una mejor forma de vivir $[\ldots]$.

362 COLOMBIA. Constitución Política de Colombia. Op. Cit. Artículo 49 [Titulo II].

363 COLOMBIA. CONGRESO DE LA REPÚBLICA. Ley 100. (23, diciembre, 1993). Por la cual se crea el sistema de seguridad social integral y se dictan otras disposiciones. Diario Oficial. Bogotá, D.C., 1993. No. 41148. p. 1-168. 
La Carta adopta pues, un concepto ampliado de la seguridad social que incluye el mayor número de servicios, auxilios, asistencias y prestaciones en general, diferenciándose de la escuela que la limita a lo básico. Un conjunto de derechos cuya eficacia compromete al Estado, la sociedad, la familia y la persona, gradualmente deben quedar comprendidos en la seguridad social. También muestra la norma superior con claridad el derecho de los particulares en la realización de la seguridad social. Sin perjuicio de que la tarea superior en la dirección, coordinación, reglamentación y vigilancia, corresponde al Estado, los particulares tienen el derecho y el deber concomitante de participar en la ampliación de la cobertura y en la ejecución de las prestaciones que les son propias.

El servicio público se prestará, por mandato superior, con sujeción a los principios de eficiencia, universalidad, solidaridad, integralidad, unidad y participación $[\ldots]^{364}$.

Se colige de dicha regulación que los términos en los cuales se consagró el derecho a la salud en nuestro país son de una ambigüedad franca: a veces se enuncia como derecho, en otras como servicio y en otras como un derecho fundamental que se materializa a partir de la prestación de un servicio público. A pesar de ello, estas connotaciones de suyo excluyentes por distar su centro de atención: como un derecho, el foco es el ser humano, como servicio.

Aventajados por tal falta de claridad, el Estado y en particular los operadores privados de la salud en Colombia optaron por entenderla como un servicio, esto aunque de su naturaleza como derecho humano deviene que "[...] exista para todas las personas aunque el Estado no lo haya transformado en derecho "positivo" 365 . La superación de esta teoría liberal que ancla sus bases en el pragmatismo y la utilidad, solo ha sido posible mediante el activismo judicial: los jueces a través de su providencia, y en consonancia con los acuerdos internacionales, han dotado de prevalencia a tal derecho fundamental. Sin embargo, resulta de gran importancia rememorar las bases de dicha concepción.

El fundamento ideológico y moral del entendimiento de la salud como un servicio tiene asidero en la teoría liberal negativista, que privilegia el respeto a derechos como la vida, la integridad física, la libertad, la propiedad privada y el voto, en

364 COLOMBIA. CORTE CONSTITUCIONAL DE COLOMBIA. Sentencia C- 408 de 1994. M.P.: EDUARDO CIFUENTES MUÑOZ. p. 154.

365 ÁLVAREZ CASTAÑO, Luz Stella. Op. Cit. p. 2 
consideración a que el único presupuesto de su eficacia es la abstención. Conforme a este pensamiento, solo se contemplan los derechos civiles y políticos como de obligación perfecta, es decir, aquellos que generan deberes para los demás, mientras que las prerrogativas sociales y culturales, dentro de las que se incluye la salud, se contemplan como de obligación imperfecta, pues no generan la obligación del Estado o de los demás miembros de la sociedad ${ }^{366}$. Siendo ello así y de acuerdo con el pensamiento liberal:

[...] existe un derecho negativo a la salud entendida como el derecho de las personas a exigir que su vida e integridad física sean respetadas, pero no como un derecho positivo a la asistencia sanitaria que implique un papel activo del Estado. En conclusión, según el liberalismo, el cuidado de la salud no es un derecho humano fundamental ${ }^{367}$.

Así mismo, esta última conclusión se acrecienta si se tiene en cuenta que la salud se ubica dentro de los denominados derechos económicos, sociales y culturales, frente a los cuales se ha dado una amplia discusión doctrinal que se resume así:

Básicamente, existen dos orientaciones: una, considera que los DESC son simples aspiraciones o ideales, ya que no resultan exigibles, por cuanto no existen recursos jurídicos para su cumplimiento efectivo y que no pueden anclarse en los principios imperativos de Derecho internacional, por cuanto el artículo 53 de la Convención de Viena sobre el Derecho de los Tratados de 1969, exige para ello el acuerdo del conjunto de la comunidad internacional para configurar el carácter de jus cogens. [...]. La otra posición estima que se trata de verdaderos derechos, reconocidos como tales por los Estados tanto en su propia normativa interna como al suscribir acuerdos internacionales. Sin embargo, a diferencia de los derechos civiles y políticos que han sido objeto de mayor atención, codificación legislativa e interpretación y aplicación judicial, los DESC aparecen como de segunda clase, inaplicables, carentes de juridicidad, es decir, de imposible sometimiento a los tribunales y pasibles de una realización progresiva sin mayor especificación ${ }^{368}$.

\footnotetext{
366 lbíd. p. 2

367 Ibíd. p. 3

368 ARTIGRAS, Carmen; FRANCO, Rolando y FRANCO GUZMAN, Carmen. Derechos económicos, sociales y culturales en América Latina: su situación actual. En: Anales de la Cátedra Francisco Suárez. 35 (2001) p. 62.
} 
Aterrizando esta apreciación en el contexto particular colombiano, se tiene que el derecho a la salud no se contempló en el capítulo primero del título II de los denominados derechos fundamentales, sino en el capítulo segundo titulado de los derechos sociales, económicos y culturales, que para el caso colombiano son un mero catalogo axiológico inaplicable y carente de juridicidad, primando la concepción de los mismos como servicios a cargo del Estado, lo cual se manifiesta por ejemplo, en las disposiciones en la Ley 100 de $1993^{369}$ que establece, como uno de los objetivos del sistema general de seguridad social en salud, crear condiciones de acceso al servicio para toda la población, condiciones que al ser incitas al ser humano no deberían ser creadas: jexisten por naturaleza!. Así, lejos de incurrir en las altas erogaciones que representan para la institucionalidad reconocer por toda la salud como derecho fundamental, se prefiere dejar al libre juego del mercado el bienestar de los ciudadanos.

En suma, como ha de verse, se desprenden de la salud como servicio las siguientes consecuencias:

- Se condiciona su efectividad a la existencia de recursos para proceder a su plena satisfacción, tal y como lo contempla el artículo 2 del Pacto de la ONU ${ }^{370}$, que sujeta dicha efectividad a la disponibilidad de recursos económicos por los Estados.

Esta consecuencia, que surge al identificarse tal derecho dentro de las previsiones de orden constitucional de forma exclusiva como parte de los derechos económicos, sociales y culturales, es decir, prestacionales, es la principal y en virtud de la cual giran otros efectos adversos de dicha concepción, toda vez que parte de una idea errónea del ser humano no como sujeto de derechos, sino como sujeto de la prestación de servicios, previo pago de unos emolumentos. Al dejar de ser el ser humano en su concepción ontológica el centro activo del quehacer del Estado, para pasar a ser quien patrocina y da rentabilidad a una empresa: ipara acceder a un servicio, hay que pagar!; de manera tal, empieza a ser el factor económico el determinante en el goce de un servicio a la salud acorde con mínimas condiciones de bienestar. La salud en estos términos, termina siendo un negocio en el cual prima la renta antes que la calidad: el usufructo antes que la vida. Definir el sistema organizacional de la salud como un servicio, es pensar en ganancias, en negocios, en rentabilidad y utilidades.

369 COLOMBIA. CONGRESO DE LA REPÚBLICA. Ley 100. (23, diciembre, 1993). Op. Cit.

370 ASAMBLEA GENERAL DE LAS NACIONES UNIDAS. Pacto Internacional de Derechos Económicos, Sociales y Culturales. Op. Cit. 
Sin duda la concepción de la salud como un servicio, en el caso de Colombia, ha sido la causa de que se pauperrimice el mismo, pues como bien se ha dicho por los críticos, "La salud en Colombia tiene en su corazón y en su cerebro varios tumores cancerosos, cuya patología se halla en la lucha de intereses que genera todo negocio mercantil" 371 . Lastimosamente, nuestro sistema de salud es la viva experiencia de la noción mercantil, servil y liberal del derecho a la salud; hoy en crisis por la presencia de intermediarios privados como lo son las E.P.S de alta connotación política, que buscan obtener el máximo de utilidades a costa de millares de pacientes víctimas de los llamados mercaderes de la muerte.

- La salud como un servicio deja de ser reconocida como un derecho natural y fundamental, por ello la relación altruista con el mismo no es garantizar su efectividad para todos, sino que se limita en orden a ampliar progresivamente la cobertura a todos los sectores de la población. En sentido estricto, no se puede ampliar ni crear lo que ya está creado y reconocido por naturaleza y, en tanto, debería ser reconocido a toda persona en pie de igualdad.

Es por lo mismo, que la exigencia de tal derecho no puede hacerse ipso jure por mandato natural, sino que la misma deviene de la afiliación efectiva a un Sistema de Seguridad Social en salud que, como parte del sector asegurador, busca amparar riesgos mínimos, y apartarse frente complejas patologías que le impliquen altos costos.

- Otra de las vastas consecuencias de concebir la salud como un servicio, y como un derecho económico y social, es la ausencia de medios para invocar su exigibilidad; no hay procedimientos establecidos, acciones propias y ordinarias para solicitarlo, menos aún se enuncian los sujetos de quien debe pregonarse tal respeto.

- Además de ello, se aparta de forma directa el uso de la acción de tutela, toda vez que, si se tiene en cuenta lo establecido en el artículo 86 de la Carta, en el inciso primero:

Toda persona tendrá acción de tutela para reclamar ante los jueces, en todo momento y lugar, mediante un procedimiento preferente y sumario, por sí misma o por quien actué a su nombre, la protección inmediata de sus derechos constitucionales fundamentales, cuando

371 BALLEN, Rafael. El negocio de la Salud. En: Revista Semana. edición 20 de febrero de 2012. Sección de Opinión. 
quiera que resulten vulnerados o amenazados por la acción o la omisión de cualquier autoridad pública ${ }^{372}$.

Resulta ostensible que la acción de tutela desde un punto de vista plenamente formal no ampararía la protección del derecho a la salud por considerársele un derecho de naturaleza social, y no -como es requerido para la procedencia de la acción de tutela- fundamental.

Estos principales efectos como se decía con anterioridad, solo empezaron a ser superados a través del emanar de las providencias judiciales, ante la presión de Organismos Multilaterales, en especial protectores de derechos humanos; no obstante, esta evolución ha sido paulatina y progresiva y de ningún modo completa.

2.2.4.2. Noción de fundamentalidad por conexidad. La evolución de la salud hacia la teoría del derecho fundamental autónomo no fue inmediata, y en tanto en su curso, encontramos un acercamiento a través de la teoría de la conexidad, fundamentada moralmente en la dependencia a la salud de la eficacia de derechos como la vida y otros de gran trascendencia; así se pregonó:

Es cierto que la salud y la integridad física son objetos jurídicos identificables, pero nunca desligados de la vida humana que los abarca de manera directa. Por ello cuando se habla del derecho a la vida se comprenden necesariamente los derechos a la salud e integridad física, porque lo que se predica del género cobija a cada una de las especies que lo integran. Es un contrasentido manifestar que el derecho a la vida es un bien fundamental, y dar a entender que sus partes -derecho a la salud y derecho a la integridad física- no lo son 373 .

En concreto, que el derecho a la salud resulte fundamental "por conexidad significó en la jurisprudencia de la Corte Constitucional, que otros derechos que la misma Constitución había definido como fundamentales, resultaran vulnerados si no se garantizaba la prestación del servicio de salud de forma inmediata" ${ }^{374}$.

372 COLOMBIA. Constitución Política de Colombia. Op. Cit. Artículo 86 [Titulo II].

373 COLOMBIA. CORTE CONSTITUCIONAL DE COLOMBIA. Sentencia T-494/93. M.P.: Vladimiro Naranjo Mesa. p. 1.

374 Ibíd. 
De tal suerte, la superada concepción de la salud como un derecho fundamental por conexidad devenía de la necesaria atención de aquellos casos en los que existía compromiso directo entre un derecho fundamental y el derecho a la salud, ámbito en el cual, de no procederse a la inmediata protección del último, habría vulneraciones para el primero. Así lo entendió la Corte Constitucional señalando al respecto que:

En relación con la protección constitucional del derecho a la salud, ésta Corte, a lo largo de su jurisprudencia ha distinguido dos connotaciones; de una parte, la salud adquiere el rango de fundamental cuando está en riesgo el derecho a la vida u otro derecho fundamental, por ende, susceptible de amparo a través de la tutela, y de otro lado, cuando no está en conexidad con otros derechos, adquiere el carácter de prestacional y puede ser exigible a través de otros medios de defensa, diferentes a la tutela ${ }^{375}$.

Bajo tal argumentación, se hacía posible concluir que una vez relacionado un derecho fundamental con el derecho a la salud, y existiendo riesgo de conculcación del primero, se habilitaba la exigibilidad, reservada para los derechos fundamentales propiamente considerados por la Constitución, por vía tutela, evento en el cual la salud adquiría rango de derecho fundamental. Así no sucedía cuando no se relacionaba a la salud con uno de estos exclusivos derechos, caso en el que no tendría más connotación fundamental, sino que descendería a su consideración como derecho prestacional, para cuya exigencia el ciudadano debía limitarse a la existencia de recursos y determinación de medios legales.

Acentuando esta última afirmación enunciaba la Corte Constitucional:

Si bien la jurisprudencia constitucional ha reconocido amparo de tutela al derecho a la salud en virtud de su conexidad con el derecho a la vida y la integridad de la persona en eventos en que deslindar salud y vida es imposible y se hace necesario asegurar y proteger al hombre y su dignidad, no por esta razón el derecho a la salud puede ser considerado en sí mismo como un derecho autónomo y fundamental, pues deriva su protección inmediata del vínculo inescindible con el derecho a la vida ${ }^{376}$.

375 COLOMBIA. CORTE CONSTITUCIONAL DE COLOMBIA. Sentencia T-204-2000. M.P.: Fabio Morón Díaz. p. 1.

${ }^{376}$ COLOMBIA. CORTE CONSTITUCIONAL DE COLOMBIA. Sentencia T-490 de 2006. M.P.: Marco Gerardo Monroy Cabra.. 
Así las cosas, bajo el amparo de esta teoría el derecho a la salud no podría reclamarse prima facie por vía de tutela. En cuanto a la exigibilidad directa frente al Estado, se tenía que,

Por su carácter de derecho prestacional, al Estado correspondían sólo dos obligaciones: racionalizar, por un lado, la asignación de inversión suficiente para que su garantía tuviera un alcance integral, de cara a la necesidad de sostenimiento que tiene también la garantía de otros derechos, y por otro lado, racionalizar su prestación sólo en casos en que su falta de reconocimiento, afectara directamente y de manera conexa los derechos fundamentales de la persona ${ }^{377}$.

De lo anterior, se tiene que desde esta nueva perspectiva ya no se habla de la salud como un derecho meramente negativo, pues se deja por sentando

[...] que los derechos civiles y políticos, así como los derechos sociales, económicos y culturales son derechos fundamentales que implican obligaciones de carácter negativo como de índole positiva. El Estado ha de abstenerse de realizar acciones orientadas a desconocer estos derechos (deberes negativos del Estado) y con el fin de lograr la plena realización en la práctica de todos estos derechos - políticos, civiles, sociales, económicos y culturales - es preciso, también, que el Estado adopte un conjunto de medidas y despliegue actividades que implican exigencias de orden prestacional (deberes positivos del Estado) $)^{378}$.

Sin duda, esta noción fue en su momento un avance significativo, toda vez que abrió la puerta a la exigibilidad de este derecho, en especial mediante la acción de tutela, frente a la cual en lo atinente al derecho a la salud se había pronunciado un no rotundo. No obstante, esta interpretación limitó, aunque en menor medida, su eficacia, obviando reconocer el derecho a la salud como un derecho humano, tal y como lo haría posteriormente la noción del mismo como derecho autónomo.

La última y más reciente teoría, que se ampliará a continuación, surge de la interpretación de la Corte Constitucional que enuncia la salud como un derecho

377 COLOMBIA. CORTE CONSTITUCIONAL DE COLOMBIA. Sentencia T-060-2007. M.P.: Humberto Sierra Porto.

378 COLOMBIA. CORTE CONSTITUCIONAL DE COLOMBIA. Sentencia T-016-07. M.P.: Humberto Sierra Porto. p. 16. 
fundamental que debe ser garantizado a todos los seres humanos, igualmente dignos, por el Estado y las autoridades que intervienen en su prestación, ello porque "[...] no hacerlo conduce a que se presente un déficit de protección constitucionalmente inadmisible" 379 . A su vez, dicha protección debe ser automática en los determinados supuestos reglados, sin lugar a consideración alguna en punto de su conexidad con otros derechos.

2.2.5 La salud como derecho fundamental. Hoy sería artificioso predicar la exigencia de conexidad del derecho a la salud como presupuesto de su eficacia, dada su connotación de derecho fundamental autónomo, que surge al considerar que el mismo:

a) es inherente a la persona humana al constituir parte integral de su ser, y ser condición de la calidad de vida; b) Es un derecho derivado del derecho a la vida, tiene efecto vital pues ayuda a vivir en mejores condiciones de bienestar físico, mental y espiritual; c) Es un derecho que se tiene desde el momento de la concepción hasta la muerte por ser inherente a la persona humana, se predica en la totalidad de la existencia del hombre, en todo tiempo y en todo lugar; d) No es una contingencia jurídica, sino un derecho que deviene de la naturaleza humana; e) Es de carácter complejo, e implica no solo la atención en salud sino todos los medios ordinarios al alcance para la prevención de las enfermedades, así como para recuperarse y gozar de una mejor calidad de vida ${ }^{380}$.

Hablar de la salud en dichos términos y a la luz de tal fundamento implica, en primera medida, la superación de la doctrina histórica que le atribuía naturaleza social o prestacional a tal derecho y por ello, de suyo eliminaba toda exigibilidad autónoma, a menos de la existencia de conexidad con el derecho a la vida, a la integridad personal o a la dignidad humana. Sin duda, tal superación progresiva ha sido un hecho, puesto que los múltiples fallos proferidos sobre la materia han procurado dejar en claro que, si bien inicialmente el derecho a la salud era carente de regulación que fijara su contenido, en la actualidad el mismo está bastamente reglado por la Constitución, la ley y el sinnúmero de pronunciamientos de las altas Cortes, en especial la Corte Constitucional, corporación que ha establecido las reglas jurisprudenciales para su aplicación. En consecuencia, a pesar de las implicaciones del carácter prestacional de tal derecho, hoy se contempla al mismo como fundamental autónomo por tener entidad propia y por no requerir conexidad con otros para adquirir tal categoría.

${ }^{379}$ COLOMBIA. CORTE CONSTITUCIONAL DE COLOMBIA. Sentencia T-760-2008. Op. Cit. p. 30. 380 COLOMBIA. CORTE CONSTITUCIONAL DE COLOMBIA. Sentencia T-760-2008. Op. Cit. p. 30. 
Hechos los esbozos precedentes, resulta pertinente estudiar los fundamentos en virtud de los cuales tiene asidero el reconocimiento de la naturaleza fundamental autónoma del derecho a la salud en Colombia. Para proceder, debe en primera medida entenderse, sin pretender generalizar sobre los criterios de identificación o delimitación de los derechos fundamentales, tema sobre cual la controversia está latente, que los derechos fundamentales se catalogan como tal no por estar contemplados dentro de un capitulo en específico de la Constitución, sino por partir de un elemento central que los caracteriza en su conjunto. Esto es su relación intrínseca con la dignidad humana; de tal forma, se refirió "[...] no todos los derechos están consagrados expresamente en el texto, pues no pueden negarse como derechos aquellos que 'siendo inherentes a la persona humana', no estén enunciados en la Carta"381.

De tal forma, se cimentó estructuralmente el reconocimiento del derecho fundamental autónomo a la salud, en la incita relación con la dignidad como valor, principio y derecho en nuestro Estado Social de Derecho, término que no es "[...] un recurso literario u oratorio, ni un adorno para la exposición jurídica, sino un principio constitucional elevado al nivel de fundamento de Estado, base del ordenamiento y de la actividad de las autoridades públicas"382. Ello por el hecho incontrovertible de que el ser humano es, en cuanto tal, único en relación con los otros seres vivos, y por ello "un fin en sí mismo", lo que descarta toda actitud despectiva frente a sus necesidades corporales y espirituales que merecen atención en el Estado Social de Derecho al ser la razón de su existencia y la base y justificación del sistema jurídico. En consecuencia, es la dignidad humana definida como la "[...] libertad de elección de un plan de vida concreto en el marco de las condiciones sociales en las que el individuo se desarrolle" 383 y con la posibilidad real y efectiva "de gozar de ciertos bienes y de ciertos servicios que le permiten a todo ser humano funcionar en la sociedad según sus especiales condiciones y calidades, bajo la lógica de la inclusión y de la posibilidad de desarrollar un papel activo en la sociedad" 384 , en la que se centra el eje rector de la salud como derecho fundamental, ello porque "en este orden de ideas, será fundamental todo derecho constitucional que funcionalmente esté dirigido a lograr la dignidad humana y sea traducible en un derecho subjetivo", pues de no brindarse protección, verbigracia a la salud, se omite el contenido axiológico de la Carta Constitucional, direccionada a materializar la dignidad.

381 COLOMBIA. CORTE CONSTITUCIONAL DE COLOMBIA. Sentencia T-760-2008. Op. Cit. p. 13. 382 COLOMBIA. CORTE CONSTITUCIONAL DE COLOMBIA. Sentencia T-556/98. M.P.: Jose Gregorio Hernández Galindo. Bogotá. p. 1.

${ }^{383}$ COLOMBIA. CORTE CONSTITUCIONAL DE COLOMBIA. Sentencia T-227 de 2003. Op. Cit. p. 2.

384 Ibíd. p. 2. 
Consecuencialmente, preestablecido el primer y más importante requisito, resulta enriquecedor alimentar el fundamento moral y principal en virtud del cual se predica la salud como un derecho fundamental autónomo, para dotarlo de una validez axiológica ${ }^{385}$, fundada en su valor intrínseco que le confiere mérito para ser digno de obediencia. Para tal fin, en primera medida se referencian los argumentos de la paradigmática sentencia T-760 de 2008, que se basa en los siguientes criterios para determinar el carácter fundamental de un derecho: "[...] son fundamentales: (i) aquellos derechos respecto de los cuales existe consenso sobre su naturaleza fundamental y (ii) todo derecho constitucional que funcionalmente esté dirigido a lograr la dignidad humana y sea traducible en un derecho subjetivo"386. En desarrollo de los anteriores presupuestos, explaya que la Corte desde siempre ha protegido diferentes esferas del mismo, en tanto socialmente se reclama su garantía deseable para todos los seres humanos en igualdad de condiciones. De esta manera, existe consenso sobre la naturaleza, la importancia, la trascendencia y el alcance del derecho a la salud socialmente: la sociedad no justifica en ningún evento la no protección a dicha condición.

Por otra parte, arguye que aproximadamente desde el año 2003 se ha venido desarrollando la teoría de que el derecho a la salud es un derecho fundamental 'de manera autónoma', siempre que se pueda concretar en una garantía subjetiva derivada de las normas que rigen el derecho a la salud. Dicha concreción hoy es factible con sustento en la Constitución misma, el bloque de constitucionalidad, las leyes y demás normas que crean y estructuran el Sistema Nacional de Salud, y definen los servicios específicos a los que las personas tienen derecho.

En cuanto al cumplimiento de los demás criterios de fundamentación axiológica, el derecho a la salud cumple de la misma manera con los requisitos señalados en la sentencia T -406 de 1992, los cuales son: "1) Conexión directa con los principios constitucionales; 2) Eficacia directa y 3) Contenido esencial"387. De lo anterior, es claro, en primera medida, que la salud tiene conexión directa con dos principios constitucionales en particular, estos son: el respeto a la dignidad humana y la solidaridad, los cuales son la base axiológico-jurídica sin la cual cambiaría la naturaleza misma de la Constitución y la organización del Estado perdería su significado y su razón de ser, ya que no es posible predicar vida en condiciones de salud, frente a falencias o dolores que impiden el normal ejercicio del hombre en sociedad. Frente al segundo componente, sin duda, la eficacia de la salud ha sido el talón de Aquiles para su reconocimiento como derecho fundamental, por las

385 VERNENGO, Roberto. Legalidad y legitimidad: fundamentos morales del derecho. En: Revista de Estudios Políticos. Centro de Estudios Constitucionales. No. 77 (1992). p. 269.

${ }^{386}$ COLOMBIA. CORTE CONSTITUCIONAL DE COLOMBIA. Sentencia T-760 de 2008. Op Cit. p. 29.

${ }^{387}$ COLOMBIA. CORTE CONSTITUCIONAL DE COLOMBIA. Sentencia T-406-1992. Op. Cit. p. 1. 
implicaciones presupuestales que contiene; empero, la Corte Constitucional ha determinado que la misma no se debe predicar en abstracto, sino en casos concretos, puesto que es ostensible la existencia de supuestos en los cuales debe de manera inmediata procederse a su materialización por las especiales características. Así las cosas, aunque el derecho a la salud no es exigible de forma deliberada, existen determinadas circunstancias frente a las cuales es predicable su exigibilidad directa, y su eficacia. Por último, y si bien se tiene que el derecho a la salud no es anterior a su positivización, pues se requiere de un prestador de servicios para su garantía, del mismo en determinados casos depende la materialización de la vida, la integridad personal y la dignidad humana, derechos que no solo existen con anterioridad al derecho positivo, sino que además le dan razón de ser al mismo.

En referencia a los elementos axiológicos que doctrinalmente califican a un derecho como fundamental, debe resaltarse de entrada que se encuentran cumplidos en su totalidad, puesto que, en primera medida, se trata de un derecho esencial para el ser humano; en segunda medida, su naturaleza fundamental deviene del ser del individuo, del ser humano y no del deber ser de la norma constitucional; seguidamente, se tiene que el mismo está radicado exclusivamente en la esfera social; en cuarto lugar, se trata de una libertad privada y personal sin dimensión política de relación con el poder público; en quinto lugar, tanto su validez como existencia jurídica se ubican por encima de la Constitución; y finalmente, la merma de positividad para configurar los derechos fundamentales desde y por la Constitución, mantiene a estos derechos en la esfera social y los preserva de injerencias estatales ${ }^{388}$.

Además del cumplimiento de los parámetros básicos en virtud de los cuales se entiende a la salud como un derecho fundamental autónomo, su reconocimiento sin duda no hubiese sido posible de no ser por los pronunciamientos de los organismos internaciones sobre dicha materia, que han llamado la atención del amplio contenido de prestaciones que con el derecho a la salud se deben reconocer. De esta manera, se inicia una carrera por entender la salud de una forma más amplia y garantista, que se acompasa con los postulados de la Organización Mundial de la Salud, la cual estableció:

La salud es un estado de completo bienestar físico, mental y social y no solamente la ausencia de afecciones o enfermedades. El goce del grado máximo de salud que se pueda lograr es uno de los derechos

${ }^{388}$ BASTIDA FREIJEDO, Francisco José. El fundamento de los derechos fundamentales. En: Revista electrónica del Departamento de Derecho de la Universidad de La Rioja. № 3 (2005). p. 5. 
fundamentales de todo ser humano sin distinción de raza, religión, ideología política o condición económica o social ${ }^{389}$.

Según la OMS:

El derecho a la salud significa que los gobiernos deben crear las condiciones que permitan a todas las personas vivir lo más saludablemente posible. Esas condiciones incluyen las disponibilidades garantizadas de servicios de salud, condiciones de trabajo saludables y seguras, vivienda adecuada y alimentos nutritivos. El derecho a la salud no debe entenderse como el derecho a estar sano ${ }^{390}$,

Pues por su concepción, como por la diversidad de obligaciones que de él se derivan y por la magnitud y variedad de acciones y omisiones que sus cumplimientos demandan del Estado y de la sociedad en general, se define como un derecho complejo. El anterior contenido programático, sin hesitación tiene un férreo respaldo en normas constitucionales que por bloque de constitucionalidad se han incorporado en nuestro ordenamiento jurídico, como lo son:

- La Declaración Universal de Derechos Humanos, que dispone en su artículo 25 que "Toda persona tiene derecho a un nivel de vida adecuado que le asegure, así como a su familia, la salud y el bienestar, y en especial la alimentación, el vestido, la vivienda, la asistencia médica y los servicios sociales necesarios" ${ }^{391}$.

- El Pacto Internacional de Derechos Económicos Sociales y Culturales, que contiene en su artículo 12 una de las disposiciones más completas y exhaustivas sobre el derecho a la salud, determinando en su párrafo $1^{\circ}$ que los Estados partes reconocen, "[...] el derecho de toda persona al disfrute del más alto nivel posible de salud física y mental"392; mientras que en el párrafo 2 del artículo 12 indica, a título de ejemplo, diversas "[...] medidas que deberán adoptar los Estados Partes a fin de asegurar la plena efectividad de este derecho"393 .

389 ASAMBLEA MUNDIAL DE LA SALUD. Constitución de la Organización Mundial de la salud. Nueva York (1946). Documentos básicos, suplemento de la 45a edición (2006). (en línea) http://www.who.int/governance/eb/who_constitution_sp.pdf. p. 1.

390 ORGANIZACIÓN MUNDIAL DE LA SALUD. El derecho a la salud. Nota Descriptiva № 323 noviembre de 2013. (en línea) http://www.maternoinfantil.org/archivos/smi_D494.pdf. p. 1.

${ }^{391}$ Organización de las Naciones Unidas. Declaración Universal de los Derechos Humanos. Op. Cit. 392 ASAMBLEA GENERAL DE LAS NACIONES UNIDAS. Pacto Internacional de Derechos Económicos, Sociales y Culturales. Op. Cit.

393 lbíd. 
- La Observación General 14 del Comité de Naciones Unidas sobre Derechos Económicos, Sociales y Culturales, determinó que: "La salud es un derecho humano fundamental e indispensable para el ejercicio de los demás derechos humanos. Todo ser humano tiene derecho al disfrute del más alto nivel posible de salud que le permita vivir dignamente"394.

De todos los anteriores fundamentos se colige, en definitiva, que se está frente a un derecho fundamental cuya actual naturaleza autónoma deviene de la interpretación jurisprudencial fundada en el Bloque de Constitucional, los postulados constitucionales y el estudio de los elementos axiológicos y requisitos de dicho derecho en particular. Para dar desarrollo a la precedente afirmación, pertinente resulta exponer el contenido, efectos, implicaciones y limites a dicha naturaleza.

2.2.6. Alcance del derecho fundamental a la salud. Sobre el alcance de la naturaleza fundamental del derecho a la salud, es preciso advertir de entrada que la misma no trae como consecuencia que sea exigible en todos los casos.

La Corte Constitucional, como máximo intérprete de la Constitución, ha dejado por sentado que la salud es un derecho fundamental autónomo, pues para que se haga efectivo no requiere, como antes, de la trasgresión de otros derechos fundamentales, como el derecho a la vida, sino que su protección y garantía es independiente de cualquier otro. De esta manera, se abole la teoría de la conexidad, que había sido la utilizada como único mecanismo para dar protección al derecho a la salud. Así, se positivizó, a partir de la Ley 1751 de $2015^{395}$, en la cual se estableció la naturaleza del mismo como derecho fundamental. No obstante, aun cuando dicha enunciación es del todo revolucionaria, pues de su lectura a primera vista se creería que en Colombia el derecho a la salud constitucionalmente es aguardado por encima de toda regla presupuestal, debe señalarse de manera previa que su alcance no trae consigo las implicaciones deseadas, ya que tiene un gran contenido simbólico y no hay garantías económicas serias que lo respalde.

De la definición del derecho a la salud como fundamental autónomo, se pensaría que el papel del Estado es exclusivamente prestacional, un hacer continuo, un autorizar de todo medicamento o servicio requerido, sin consideración presupuestal o administrativa alguna. Sin embargo, la realidad fáctica es que el derecho a la salud, por su carácter social, contiene múltiples facetas tanto negativas como positivas, la primera de ellas, el deber de abstención del Estado que es exigible de

394 COMITÉ DE DERECHOS ECONÓMICOS, SOCIALES Y CULTURALES DE NACIONES UNIDAS. Observación general 14. p. 1.

${ }^{395}$ COLOMBIA. CONGRESO DE LA REPÚBLICA DE COLOMBIA. Ley 1751. Op. Cit. 
manera autónoma e inmediata sin consideración de cobertura o presupuesto, y la positiva, que bajo aplicación de los principios de equidad, solidaridad, subsidiariedad y eficiencia, propugna que el Estado está en obligación de ejecutar una prestación a favor de una persona; son estas últimas prestaciones las que están sometidas a una protección gradual y progresiva.

Algunas de las obligaciones que se derivan de dicha faceta positiva son, en ocasiones, de cumplimiento inmediato, ya que se trata de acciones simples del Estado que no involucra recursos, tales como brindar información, y otras son progresivas, por la complejidad de las acciones y los recursos que se requieren para garantizar efectivamente su goce efectivo. Surge así. Una conclusión en el sentido de que el derecho a la salud tiene diversas facetas que requieren acciones variadas, simples y complejas por parte del Estado, por lo cual este derecho, aunque autónomo y fundamental, no es exigible en todos los casos, pues en determinadas situaciones priman condiciones de conveniencia, sostenibilidad y cobertura. De tal manera, compete a las autoridades constitucionalmente, en el particular mediante la regulación de la Ley 1751 de 2015, decidir cuáles serán las acciones y medidas necesarias para su garantía, bajo reglas que irradien el ejercicio del poder público y determinen sus funciones principales en un Estado Social de Derecho.

Bajo el anterior razonamiento, surge la dicotomía entre los conceptos de fundamentalidad y exigibilidad, que redundan necesariamente en que el alcance del mismo no se extienda, sino en determinados casos concretos, más allá del texto constitucional a la práctica. En esta línea, es preciso anunciar que la Corte Constitucional siempre ha dejado establecido que:

El carácter de fundamental no coincide con el de aplicación inmediata. Siendo así, es necesario distinguir entre derechos fundamentales de aplicación inmediata y derechos fundamentales que no son de aplicación inmediata. Ante esta dificultad, corresponde a la jurisprudencia, y en especial a la Corte Constitucional, la definición de la naturaleza y alcance de los derechos fundamentales que no son de aplicación inmediata ${ }^{396}$.

Como corolario del contenido real de la nueva concepción del derecho a la salud, se tiene que su fundamentalidad, con génesis legal y jurisprudencial, no es sustento en todos los casos para hacerlo exigible y menos aún para hacerlo por vía tutela. Esto, precisamente, porque,

${ }^{396}$ COLOMBIA. CORTE CONSTITUCIONAL DE COLOMBIA. Sentencia T-406 de 1992. Op. Cit. p.2. 
[...] uno de los aspectos en los que la jurisprudencia constitucional ha avanzado, es en el de señalar que, reconocer la fundamentalidad de un derecho, no implica, necesariamente, que todos los aspectos cobijados por éste son exigibles; primero, porque los derechos constitucionales no son absolutos, es decir, pueden ser limitados de conformidad con los criterios de razonabilidad y proporcionalidad que ha fijado la jurisprudencia constitucional. Segundo, porque la posibilidad de exigir el cumplimiento de las obligaciones derivadas de un derecho fundamental y la procedencia de hacerlo por medio de la acción de tutela, son cuestiones diferentes y separables ${ }^{397}$.

De esa forma, entendiendo que es dependiendo del caso en concreto que este derecho fundamental se reviste de exigibilidad, es menester reconocer las implicaciones prácticas del mismo que más adelante se expondrán, dejando desde ya en claro, como la Corporación lo ha precisado, que la misma en ninguna medida se restringe a los medicamentos y servicios incluidos dentro de un plan de beneficios, ni se restringe por las exclusiones del mismo contenidas en el nuevo sistema de exclusiones dispuesto por la Ley Estatutaria.

2.2.7 Enfoques diferenciados. La exigibilidad del derecho a la salud tiene un enfoque diferenciado frente a diferentes circunstancias dispuestas en el artículo 13 de la Constitución ${ }^{398}$ y el Bloque de Constitucionalidad, que han demarcado la debilidad manifiesta de determinados sujetos especiales de protección, y su reconocimiento como foco de acciones afirmativas. En esta línea dispuso el artículo 11 de la Ley Estatutaria del Derecho a la salud que:

[...] los niños, niñas y adolescentes, mujeres en estado de embarazo, desplazados, víctimas de violencia y del conflicto armado, población adulta mayor, personas que sufren de enfermedades huérfanas y personas en condición de discapacidad, gozarán de especial protección por parte del Estado. Su atención en salud no estará limitada por ningún tipo de restricción administrativa o económica ${ }^{399}$.

Para materializar dicha protección, las instituciones del sector salud adquirieron la obligación de definir procesos de atención intersectoriales e interdisciplinarios que les garanticen las mejores condiciones de atención prioritaria. A continuación, se

397 COLOMBIA. CORTE CONSTITUCIONAL DE COLOMBIA. Sentencia T-760 de 2008. Op. cit. p. 32.

398 COLOMBIA. Constitución Política de Colombia. Op. Cit. Artículo 13 [Título II].

399 COLOMBIA. CONGRESO DE LA REPÚBLICA DE COLOMBIA. Ley 1751. Op. Cit. p. 7 
hará una breve enunciación de las mismas como acciones afirmativas, a efectos de precisar el alcance del derecho según las circunstancias del sujeto:

2.2.7.1. Enfoque de género. El derecho a la salud, al igual que todo el ámbito social, ha estado permeado por un enfoque de género tendiente a la reivindicación de los derechos de la mujer, bajo la observancia de normas internacionales incorporadas al bloque de constitucionalidad, tales como la Convención sobre la eliminación de todas las formas de discriminación contra la mujer ${ }^{400}$, CEDAW, de 1979, en la que Colombia como Estado parte se comprometió a eliminar toda distinción, exclusión o restricción basada en el sexo, adoptando todas las medidas apropiadas para eliminar la discriminación de la mujer en la esfera médica, asegurándole así el "acceso" en condiciones de igualdad.

El Comité para la Eliminación de la Discriminación contra la Mujer, en observancia de la Convención y de presente su atribución de realizar "[...] sugerencias y recomendaciones de carácter general basados en el examen de los informes y de los datos transmitidos por los Estados Partes"401, incorporó de importancia la Recomendación General № 15 de $1990^{402}$ sobre la necesidad de evitar la discriminación contra la mujer en las estrategias nacionales de acción preventiva y lucha contra el síndrome de inmunodeficiencia adquirida (SIDA). Así mismo, la Recomendación General № $19^{403}$ (1992) en la que, teniendo como tema principal la violencia contra la mujer, recomienda a los Estados adoptar medidas para poner fin a estas prácticas y tengan en cuenta las recomendaciones del Comité sobre la circuncisión femenina. En tratándose particularmente de las mujeres discapacitadas, en la Recomendación General № $18^{404}$, se puso de presente a los Estados Partes la necesidad de incluir en sus informes periódicos información sobre las mujeres discapacitadas, y sobre las medidas adoptadas para hacer frente a su situación particular, persuadiendo la inclusión de medidas especiales en materia de servicios de salud y seguridad social, que aseguren su participación en todos los aspectos de la vida social y cultural.

400 ASAMBLEA GENERAL DE LAS NACIONES UNIDAS. Convención sobre la eliminación de todas las formas de discriminación contra la mujer (CEDAW). 1997. (en línea) http://www.humanium.org/es/wp-content/uploads/2013/10/Convenci\%C3\%B3n-Discriminaci\%C3\%B3n-Racial.pdf.

401 ASAMBLEA GENERAL DE LAS NACIONES UNIDAS. Convención sobre la eliminación de todas las formas de discriminación contra la mujer (CEDAW). Op. Cit. p. 6.

402 COMITÉ PARA LA ELIMINACIÓN DE LA DISCRIMINACIÓN CONTRA LA MUJER. Recomendaciones Generales. Recomendación General № 15. 1990. (en línea). http://www.un.org/womenwatch/daw/cedaw/recommendations/recomm-sp.htm.

403 COMITÉ PARA LA ELIMINACIÓN DE LA DISCRIMINACIÓN CONTRA LA MUJER. Recomendaciones Generales. Recomendación General № 19. 1991. (en línea). http://www.un.org/womenwatch/daw/cedaw/recommendations/recomm-sp.htm.

404 COMITÉ PARA LA ELIMINACIÓN DE LA DISCRIMINACIÓN CONTRA LA MUJER. Recomendaciones Generales. Recomendación General № 18. 1990. (en línea). http://www.un.org/womenwatch/daw/cedaw/recommendations/recomm-sp.htm. 
Por otra parte, en la Declaración y Programa de acción de Viena de 1993, adoptada por la Conferencia Mundial de Derechos Humanos, se reconoció entre otras cosas la "[...] importancia del disfrute por la mujer del más alto nivel de salud física y mental durante toda su vida" 405 , concretamente su derecho "[...] a tener acceso a una atención en salud adecuada, y a la más amplia gama de servicios de planificación familiar $[\ldots]^{\prime \prime 06}$. Corolario, la mujer ha tenido tratamiento diferenciado particularmente cuando a su condición se acompañan circunstancias especialísimas como la maternidad, o cuando la misma ha sido objeto de vejámenes sexuales o tratamientos crueles o degradantes, siendo en dichos eventos sujeto especial de protección de manera automática y prioritaria, y en tanto objeto de medidas afirmativas tendientes a su reivindicación.

2.2.7.2. Niñez y adolescencia. Por mandato Constitucional contenido en el artículo $44^{407}$ de la Carta, el derecho a la salud de los niños goza de prevalencia, siendo los menores sujetos especiales de protección dada su condición de debilidad, prevaleciendo sus derechos sobre los de los demás. Por lo anterior, la Corte, de manera expresa atendiendo al carácter de fundamental del derecho, ha señalado que la acción de tutela procede directamente para salvaguardarlo sin tener que demostrar su conexidad con otra garantía, incluso en los casos en los que los servicios requeridos no estén incluidos en el Plan de Beneficios. Igualmente, ha sostenido que cuando se vislumbra su vulneración o amenaza, el juez constitucional debe exigir su protección inmediata y prioritaria a través de medidas provisionales.

A la luz de nuestro ordenamiento interno, y del Bloque de Constitucionalidad, haciendo referencia a la Convención Internacional sobre los Derechos del Niño ${ }^{408}$, se tiene entonces que los menores requieren de una atención en salud idónea, oportuna y prevalente, respecto de la cual toda entidad pública o privada tiene la obligación de garantizar su acceso efectivo a los servicios y tecnologías en salud, en concordancia con los principios legales de protección integral e interés superior de los niños y niñas.

2.2.7.3. Adultos mayores. La jurisprudencia ha sido enfática en la consigna de que el derecho a la salud, tratándose de adultos mayores, se convierte en fundamental y autónomo, y su exigibilidad se hace inmediata con miras a precaver perjuicios irremediables; esto de cara a instrumentos internaciones como el Protocolo

405 CONFERENCIA MUNDIAL DE DERECHOS HUMANOS. Declaración y Programa de acción de Viena. Op. Cit. p. 43.

406 CONFERENCIA MUNDIAL DE DERECHOS HUMANOS. Declaración y Programa de acción de Viena. Op. Cit. p. 43.

407 COLOMBIA. Constitución Política de Colombia. Op. Cit. Artículo 44 [Título II].

408 ASAMBLEA GENERAL DE LAS NACIONES UNIDAS. Convención sobre los Derechos del Niño. Op. Cit. 
Adicional a la Convención Americana sobre Derechos Humanos en materia de Derechos Económicos, Sociales y Culturales, Protocolo de San Salvador de $1988^{409}$, en cuyo artículo 17 se establece el derecho de Protección de los Ancianos, el cual propugna que toda persona tiene derecho a protección especial durante su ancianidad, y en tal cometido los Estados partes deben adoptar de manera progresiva las medidas necesarias como proporcionar instalaciones adecuadas, alimentación, y atención médica especializada, a fin de llevar este derecho a la práctica.

Un amplio margen de protección ha sentado sobre este tema en particular la Corte Constitucional, en el sentido de invertir la carga de la prueba frente a la capacidad económica de los adultos mayores y flexibilizar el principio de solidaridad del núcleo familiar cuando el mismo requiere con urgencia medidas tendientes no sólo a su salud sino a su dignidad, por ejemplo, la tutela del derecho para la entrega de pañales, del servicios de enfermería u otros, que si bien en principio fueron excluidos del plan por considerarse suntuosos, fueron concedidos vía jurisprudencial al prever que dignifican la calidad de vida del paciente.

2.2.7.4. Discapacidad. Mediante la Ley 1346 del 31 de julio de $2009^{410}$ se incorpora a nuestra legislación la Convención sobre los derechos de las personas con discapacidad, adoptada por la Asamblea General de las Naciones Unidas el 13 de diciembre de 2006, cuya constitucionalidad de cara a la protección de la condición de discapacidad fue avalada mediante Sentencia C- 293 de 2010. A partir de su vigencia Colombia reconoce el derecho a gozar del más alto nivel posible de salud sin discriminación por motivos de discapacidad, y se obligó a adoptar medidas pertinentes para asegurar el acceso de las personas con discapacidad a servicios de salud en aras de su rehabilitación. A partir de ello, corresponde al Estado proporcionar a las personas con discapacidad, los programas y servicios de salud requeridos como consecuencia de su condición, incluida la pronta detección e intervención, cuando proceda, y servicios destinados a prevenir y reducir al máximo la aparición de nuevas discapacidades.

La Corte Constitucional en salvaguardia de los derechos de las personas con discapacidad y con miras a su recuperación efectiva, ha ampliado la exigibilidad de las prestaciones requeridas para su tratamiento y rehabilitación, reforzando el

409 CONVENCIÓN AMERICANA SOBRE DERECHOS HUMANOS. Protocolo de San Salvador. 1988. Op. Cit.

410 COLOMBIA. CONGRESO DE LA REPÚBLICA DE COLOMBIA. Ley 1346. (31, julio, 2009) Por medio de la cual se aprueba la "CONVENCIÓN SOBRE LOS DERECHOS DE LASPERSONASCON DISCAPACIDAD", adoptada por la Asamblea General de la Naciones Unidas el 13 de diciembre de 2006. Diario Oficial. Bogotá, D.C. 2009. № No. 47.427. 
alcance del derecho a la salud frente a estos sujetos de protección de manera diferencial.

2.2.8 Obligaciones del estado frente al derecho a la salud. El Comité de Derechos Económicos, Sociales y Culturales en la Observación General № 14 de año 2000 establece que la salud es un derecho humano fundamental e indispensable para el ejercicio de los demás derechos humanos y, por tanto, supone obligaciones de tres tipos: (i) respeto, (ii) protección y (iii) cumplimiento (denominadas también de garantizar). Sobre el alcance de cada una de dichas obligaciones, el Comité indicó que la obligación de respetar exige que los Estados se abstengan de injerir directa o indirectamente en el disfrute del derecho a la salud, ello es:

[...] abstenerse de denegar o limitar el acceso igual de todas las personas, incluidos los presos o detenidos, los representantes de las minorías, los solicitantes de asilo o los inmigrantes ilegales, a los servicios de salud preventivos, curativos y paliativos; abstenerse de imponer prácticas discriminatorias como política de Estado, y de imponer prácticas discriminatorias en relación con el estado de salud y las necesidades de la mujer ${ }^{411}$.

Las obligaciones de respetar también incluyen la obligación del Estado de abstenerse de prohibir o impedir los cuidados preventivos, las prácticas curativas y las medicinas tradicionales, comercializar medicamentos peligrosos y aplicar tratamientos médicos coercitivos, salvo en casos excepcionales, para el tratamiento de enfermedades mentales, o la prevención de enfermedades transmisibles y la lucha contra ellas.

De otro lado, el cumplimiento de la obligación de protección requiere que los Estados adopten medidas para impedir que terceros interfieran en la aplicación de las garantías previstas en el artículo 12 del Pacto Internacional de Derechos Económicos, Sociales y Culturales; de acuerdo con la Observación General №14 (2000),

Las obligaciones de proteger incluyen, entre otras, las obligaciones de los Estados de adoptar leyes u otras medidas para velar por el acceso igual a la atención de la salud y los servicios relacionados con la salud

411 Aaplicación del Pacto Internacional de los Derechos Económicos, Sociales y Culturales. Observaciónn general 14. Op. Cit. p. 9,10. 
proporcionados por terceros; velar porque la privatización del sector de la salud no represente una amenaza para la disponibilidad, accesibilidad, aceptabilidad y calidad de los servicios de atención de la salud; controlar la comercialización de equipo médico y medicamentos por terceros, y asegurar que los facultativos y otros profesionales de la salud reúnan las condiciones necesarias de educación, experiencia y deontología. Los Estados también tienen la obligación de velar porque las prácticas sociales o tradicionales nocivas no afecten el acceso a la atención anterior y posterior al parto ni a la planificación de la familia; impedir que terceros induzcan a la mujer a someterse a prácticas tradicionales, por ejemplo a la mutilación de los órganos genitales femeninos; y de adoptar medidas para proteger a todos los grupos vulnerables o marginados de la sociedad, en particular las mujeres, los niños, los adolescentes y las personas mayores, teniendo en cuenta los actos de violencia desde la perspectiva de género. Los Estados deben velar asimismo porque terceros no limiten el acceso de las personas a la información y los servicios relacionados con la salud ${ }^{412}$.

Para el caso de Colombia, desde 1988, el Estado adquiere la obligación frente a la garantía del derecho a la salud mediante la suscripción del Protocolo Adicional a la Convención Americana sobre Derechos Humanos en materia de Derechos Económicos, Sociales y Culturales, Protocolo de San Salvador de $1988^{413}$, al respecto de los compromisos de respeto y protección, reconociendo así un carácter progresivo de los derechos económicos, sociales y culturales bajo el compromiso de: (i) adoptar medidas necesarias, hasta el máximo de los recursos disponibles, para lograr progresivamente su plena efectividad (artículo 1), (ii) adoptar disposiciones legislativas o de otro carácter necesarias para hacerlos efectivos (artículo 2), (iii) garantizar su ejercicio sin discriminación (artículo 3), (iv) no restringir derechos específicamente reconocidos nacional o internacionalmente (artículo 4) y, (v) solo restringir y limitar los derechos reconocidos en el Protocolo mediante leyes que tengan por fin proteger el bienestar general en una sociedad democrática (artículo 5). Así se cifran dichas disposiciones:

Artículo 1: Obligación de Adoptar Medidas. Los Estados partes en el presente Protocolo Adicional a la Convención Americana sobre Derechos Humanos se comprometen a adoptar las medidas necesarias tanto de orden interno como mediante la cooperación entre los Estados, especialmente económica y técnica, hasta el

\footnotetext{
412 lbíd. p. 10.

413 CONVENCIÓN AMERICANA SOBRE DERECHOS HUMANOS. Protocolo de San Salvador. 1988. Op. Cit.
} 
máximo de los recursos disponibles y tomando en cuenta su grado de desarrollo, a fin de lograr progresivamente, y de conformidad con la legislación interna, la plena efectividad de los derechos que se reconocen en el presente Protocolo.

Artículo 2: Obligación de Adoptar Disposiciones de Derecho Interno. $\mathrm{Si}$ el ejercicio de los derechos establecidos en el presente Protocolo no estuviera ya garantizado por disposiciones legislativas o de otro carácter, los Estados partes se comprometen a adoptar, con arreglo a sus procedimientos constitucionales y a las disposiciones de este Protocolo, las medidas legislativas o de otro carácter que fueren necesarias para hacer efectivos tales derechos.

Artículo 3: Obligación de no Discriminación. Los Estados partes en el presente Protocolo se comprometen a garantizar el ejercicio de los derechos que en él se enuncian, sin discriminación alguna por motivos de raza, color, sexo, idioma, religión, opiniones políticas o de cualquier otra índole, origen nacional o social, posición económica, nacimiento o cualquier otra condición social.

Artículo 4: No Admisión de Restricciones. No podrá restringirse o menoscabarse ninguno de los derechos reconocidos o vigentes en un Estado en virtud de su legislación interna o de convenciones internacionales, a pretexto de que el presente Protocolo no los reconoce o los reconoce en menor grado.

Artículo 5: Alcance de las Restricciones y Limitaciones. Los Estados partes sólo podrán establecer restricciones y limitaciones al goce y ejercicio de los derechos establecidos en el presente Protocolo mediante leyes promulgadas con el objeto de preservar el bienestar general dentro de una sociedad democrática, en la medida que no contradigan el propósito y razón de los mismos ${ }^{414}$.

Así mismo, en Colombia se dio por vía legal y jurisprudencial acatamiento a las obligaciones de protección y abstención del Estado, no obstante, frente a la obligación de cumplir, garantizar, o satisfacer, antes de la aprobación de la Ley Estatutaria del Derecho a la salud, se cernieron todo tipo de debates doctrinales y

414 CONVENCIÓN AMERICANA SOBRE DERECHOS HUMANOS. Protocolo de San Salvador. 1988. Op. Cit. 
jurisprudenciales por la complejidad de la misma, pues se requería que "[...] los Estados adopten medidas apropiadas de carácter legislativo, administrativo, presupuestario, judicial y de otra índole para dar plena efectividad al derecho a la salud"415. La Corte Constitucional fue pionera en propugnar, a pesar de que las autoridades gubernamentales y administrativas exponían que dichas obligaciones de garantía eran costosas y en tanto debían limitarse a su carácter progresivo, que es posible en determinados eventos, mediante la intervención del juez constitucional, ordenar que se dé garantía al derecho fundamental por encima de cualquier consideración presupuestal, removiendo las barreras que obstaculizan su goce efectivo; no obstante, tal garantía no es suplicable de manera general, sino dependiendo de las connotaciones de los determinados casos en concreto.

Sin duda en los términos de la Ley 1751 de 2015, este conjunto de obligaciones se amplía necesariamente, en aras de dar garantía al derecho fundamental a la salud, teniendo en cuenta, las tres obligaciones básicas dispuestas en la observación No 14; las mismas se cifran así:

Artículo $5^{\circ}$. El Estado es responsable de respetar, proteger y garantizar el goce efectivo del derecho fundamental a la salud; para ello deberá:

a) Abstenerse de afectar directa o indirectamente en el disfrute del derecho fundamental a la salud, de adoptar decisiones que lleven al deterioro de la salud de la población y de realizar cualquier acción u omisión que pueda resultar en un daño en la salud de las personas;

b) Formular y adoptar políticas de salud dirigidas a garantizar el goce efectivo del derecho en igualdad de trato y oportunidades para toda la población, asegurando para ello la coordinación armónica de las acciones de todos los agentes del Sistema;

c) Formular y adoptar políticas que propendan por la promoción de la salud, prevención y atención de la enfermedad y rehabilitación de sus secuelas, mediante acciones colectivas e individuales;

d) Establecer mecanismos para evitar la violación del derecho fundamental a la salud y determinar su régimen sancionatorio;

415 Aplicación del Pacto Internacional de los Derechos Económicos, Sociales y Culturales. Observación general 14. Op. Cit. p. 14. 
e) Ejercer una adecuada inspección, vigilancia y control mediante un órgano y/o las entidades especializadas que se determinen para el efecto;

f) Velar por el cumplimiento de los principios del derecho fundamental a la salud en todo el territorio nacional, según las necesidades de salud de la población;

g) Realizar el seguimiento continuo de la evolución de las condiciones de salud de la población a lo largo del ciclo de vida de las personas;

h) Realizar evaluaciones sobre los resultados de goce efectivo del derecho fundamental a la salud, en función de sus principios y sobre la forma como el Sistema avanza de manera razonable y progresiva en la garantía al derecho fundamental de salud;

i) Adoptar la regulación y las políticas indispensables para financiar de manera sostenible los servicios de salud y garantizar el flujo de los recursos para atender de manera oportuna y suficiente las necesidades en salud de la población;

j) Intervenir el mercado de medicamentos, dispositivos médicos e insumos en salud con el fin de optimizar su utilización, evitar las inequidades en el acceso, asegurar la calidad de los mismos o en general cuando pueda derivarse una grave afectación de la prestación del servicio. ${ }^{416}$

Estos preceptos adoptados por el legislador deben contener una interpretación amplia del derecho objeto de regulación, por tanto, no es correcta la lectura según la cual las aludidas responsabilidades son exclusivas, ya que hacen parte de un conjunto de obligaciones abiertas y orientadas por la Observación $\mathrm{N}^{\circ} 14$, acorde con los principios de progresividad y no regresividad, propios de derechos analizados.

2.2.9 Acciones para materializar el derecho fundamental a la salud. De forma infortunada, hay anomia también en las acciones o vías por las cuales debe darse protección al derecho fundamental a la salud, que a priori, debería ser garantizado de manera inmediata por las empresas prestadoras del servicio de salud, sin lugar a medio coercitivo alguno. Empero, la negativa de dichas empresas frente a los servicios ya reconocidos como viables y los múltiples requerimientos y órdenes jurisprudenciales ha sido una constante, razón por la cual la tutela se ha tornado el

${ }^{416}$ COLOMBIA. CONGRESO DE LA REPÚBLICA DE COLOMBIA. Ley 1751. Op. Cit. p. 2. 
único mecanismo para dar exigibilidad, útil para unificar criterios de los mínimos servicios exigidos.

A la vanguardia de la existencia de la tutela, dichas entidades optaron erróneamente por considerarla como el procedimiento idóneo antes de dar garantía al derecho, lo que sin duda desnaturaliza el mecanismo preferente y sumario. Esta fue la razón por la que en sentencia T-760 de 2008, la Corte Constitucional ordenó al Estado dar cumplimiento a la protección del derecho a la salud sin necesidad de que el paciente hubiere impetrado la acción; para ello condiciona el cumplimiento del proveído a la reducción de las estadísticas de tutelas en materia de salud.

Trigésimo. - Ordenar al Ministerio de Protección Social que presente anualmente un informe a la Sala Segunda de Revisión de la Corte Constitucional, a la Procuraduría General de la Nación y a la Defensoría del Pueblo, en el que mida el número de acciones de tutela que resuelven los problemas jurídicos mencionados en esta sentencia $y$, de no haber disminuido, explique las razones de ello. El primer informe deberá ser presentado antes del $1^{\circ}$ de febrero de $2009^{417}$.

A pesar de que la jurisprudencia constitucional señala tempranamente que la acción de tutela es el medio judicial idóneo para defender el derecho a la salud, no puede entenderse de ninguna manera que es una etapa previa para poder acceder a su garantía, de ser así, la existencia del mecanismo constitucional sería la primera barrera para acceder su protección. De otra parte, menesteroso es referir que mediante la tutela es posible pedir la protección del derecho a la salud, tanto para exigir las prestaciones incluidas en el POS, como no incluidas en él. No obstante, las primeras deberían ser automáticas, puesto que el Estado ya cuenta con recursos para darle garantía y por ello, están contempladas en un plan. Sin embargo, en contraposición a lo mencionado en el 2013 se reportó 418 que el $88,30 \%$ de los tratamientos, el $35,4 \%$ de los medicamentos, y el $94,47 \%$ de las citas exigidas vía tutela, corresponden a los incluidos dentro del Plan Obligatorio de Salud, lo cual destaca un panorama absolutamente desalentador.

Vale recordar sobre los servicios incluidos en el POS, que la Superintendencia Nacional de Salud en virtud de la Ley 1122 de $2007^{419}$, cuenta también con facultades judiciales frente a las EPS para decretar la protección del derecho a la

417 COLOMBIA. CORTE CONSTITUCIONAL DE COLOMBIA. Sentencia T-760-2008. Op. Cit. p. 286. 418 DEFENSORIA DEL PUEBLO COLOMBIA. Informe: La tutela y el derecho a la Salud. 2012.

419 COLOMBIA. CONGRESO DE LA REPÚBLICA DE COLOMBIA. Ley 1122 de 2007 (9, enero, 2007). Diario Oficial. Bogotá, D.C. 2007. No. 46.506. 
salud, sin que ello signifique que la acción de tutela deja de ser un medio judicial idóneo para reclamar la protección de este derecho. Por tanto, frente a los servicios y medicamentos incluidos en el POS se cuenta con dos mecanismos de protección, los cuales, aunque relacionadas, difieren en su alcance: en uno, se garantiza directamente el goce efectivo del servicio al paciente y, en otro, se sanciona a los administradores del sistema por la mala prestación. De otra parte, en cuanto a los medicamentos y servicios no incluidos dentro del POS, sin lugar a dudas la Tutela se ha convertido en el único mecanismo que estudia de fondo el caso concreto de un paciente, al evaluar si debe o no brindársele protección, de conformidad con las reglas y sub-reglas que ha delimitado para dicho efecto.

2.2.10 Amenazas y barreras a la efectividad del derecho a la salud. La salud como derecho fundamental autónomo, encuentra en el interregno entre su reconocimiento y efectividad, un sinnúmero de barreras y amenazas que reducen el impacto del trabajo hasta la fecha realizado por la Corte Constitucional. Dichas barreras están inspiradas principalmente en su otrora naturaleza de derecho prestacional, que no entiende que, aunque

[...] la salud deba ser un objetivo programático tangible no significa que no se deriven de él obligaciones inmediatas para los Estados. En efecto, éstos deben hacer todo lo posible, dentro de los límites de los recursos disponibles, para hacer efectivo el derecho a la salud, y adoptar medidas en ese sentido sin demora ${ }^{420}$.

Consecuente a dicha incomprensión, se supedita la materialización del mismo a la estructura organizacional, a la disponibilidad de recursos que tenga previstos el Estado dentro de sus arcas para sostener el sistema, entre otros términos que reducen la efectividad del mismo, impidiendo coincidir su diseño y promulgación con la garantía que debemos tener todas las personas como fundamento de la existencia del Estado Social de Derecho, dentro de cuyos fines se cuenta el de lograr el bienestar de sus asociados y propiciar condiciones favorables que permitan la realización de un ideal de vida. Siendo coherente con el alcance de los pronunciamientos de la Corte y el modelo de Estado en el que vivimos, se debería adoptar la acepción más completa del derecho a la salud y su garantía, no como la ausencia de enfermedades, sino como "[...] la facultad de mantener la normalidad orgánica funcional, tanto física como en el plano de la operatividad mental, y de restablecerse cuando se presente una perturbación en la estabilidad orgánica y

420 NACIONES UNIDAS Y ORGANIZACIÓN MUNDIAL DE LA SALUD. El derecho a la salud. Op. Cit. p. 6. 
funcional de su ser, implicando por tanto, una acción de conservación y otra de restablecimiento" 421 .

Concluyendo, la salud se trata de "[...] un estado variable susceptible de afectaciones múltiples, que inciden en mayor o menor medida en la vida del individuo"422, cuya garantía depende de medidas adoptadas por parte del poder público, la sociedad, la familia y el individuo. El derecho a la salud es un derecho que protege múltiples ámbitos de la vida humana, desde diferentes perspectivas, por lo cual:

[...] es un derecho complejo, tanto por su concepción, como por la diversidad de obligaciones que de él se derivan, y la magnitud y variedad de acciones y omisiones que su cumplimiento demanda del Estado y de la sociedad en general. La complejidad de este derecho, implica que la plena garantía del goce efectivo del mismo, esté supeditada en parte a los recursos materiales e institucionales disponibles ${ }^{423}$.

De esta manera y dada la naturaleza asistencial de este derecho, se encuentra que existen obligaciones a las que se comprometen los Estados que no pueden ser evadidas de modo alguno por falta de recursos. Así, se plantea desde la Organización Mundial de la Salud que: "[...] ningún Estado puede justificar el incumplimiento de sus obligaciones por falta de recursos. Los Estados deben garantizar el derecho a la salud en la mayor medida posible con arreglo a los recursos disponibles, incluso cuando éstos sean escasos" ${ }^{424}$. No obstante, debe resaltarse que las medidas que están obligados los Estados a cumplir de forma inmediata, son las relacionadas con el respeto, protección y realización.

El fundamento de lo anterior, es una premisa que queda más que clara en el desarrollo constitucional: el derecho a la salud es fundamentalmente autónomo, pero no es absoluto e ilimitable, razón por la cual la protección del mismo, si bien no se reduce a un Plan Obligatorio de Salud, es exigible a partir de mínimos de protección, intrínsecamente relacionados con la vida en condiciones de dignidad ${ }^{425}$.

${ }^{421}$ COLOMBIA. CORTE CONSTITUCIONAL DE COLOMBIA. Sentencia T-597 de 1993. Op. Cit.

422 lbíd. p. 6.

423 lbíd. p. 33.

424 NACIONES UNIDAS Y ORGANIZACIÓN MUNDIAL DE LA SALUD. EI derecho a la salud. Op. Cit. p. 7.

425 FRANCO, Rolando; ARTIGAS, Carmen y FRANCO GUZMAN, Carmen. Derechos económicos, sociales y culturales en América Latina: su situación actual. En: Anales de la Cátedra Francisco Suárez. 35 (2001). p. 17. 
Ello porque se está frente a un sistema que debe ser sostenible a efectos de garantizar el derecho a la salud de todos los que a él están afiliados y que en tanto debe funcionar a la luz de los criterios de universalidad, solidaridad, sostenibilidad y cobertura.

Por lo anterior, y como anticipadamente se resaltó, la efectividad del derecho a la salud implica necesariamente el advenimiento de cambios de todo orden, legal, institucional, judicial y social de manera progresiva para hacerlo cada vez más inclusivo, teniendo en cuenta que la salud es el presupuesto esencial para el ejercicio de otros derechos. Por esta razón, todo plan de salud que se formule en el marco de la reelaboración de un sistema integral de salud en Colombia, debe contener como lo señaló el relator especial de la Organización Mundial de la Salud,

[...] un sistema adecuado para recopilar datos que permitan hacer un seguimiento de la realización del derecho a la salud; datos desglosados por factores como el sexo, la edad y las zonas urbanas/rurales; capacidad nacional parar producir un número suficiente de trabajadores sanitarios competentes que disfruten de buenas condiciones de empleo; un proceso para la preparación de evaluaciones del impacto en el derecho a la salud antes de dar el toque final a las principales políticas relacionadas con la salud; disposiciones que garanticen la participación en la formulación de las políticas de salud; y mecanismos efectivos, transparentes y accesibles de rendición de cuentas ${ }^{426}$.

Precisamente estas amenazas y barreras a la efectividad del derecho a la salud, han venido siendo superadas por principios normas y valores que, sin presentarsen explícitamente en la carta politica, son esgrimidos como medidas del control constitucional en las legislación, en tanto que, han sido integrados a la Constitución Politica, entre ellos tenemos el bloque de constitucionalidad.

Aunado a lo anterior resulta de alta significación el estudio, de la figura del Estado de cosas inconstitucionales forjada jurisprudencialmente como mecanismo por la corte constitucional, con el propósito de proteger los derechos fundamentales, igualmente definiendo en estas líneas lo correspondiente al bloque de consrtitucionalidad y control de convencionalidad, finalizano este apartado con la figura jurídica de la responsabilidad por omison en salud, ante la constante conculcación de el derecho fundamental a la salud.

${ }^{426}$ ORGANIZACIÓN MUNDIAL DE LA SALUD. Op. Cit. p. 40,41. 


\subsection{ESTADO DE COSAS INCONSTITUCIONALES}

La figura del Estado de cosas inconstitucionales puede ser definida como un mecanismo o técnica jurídica creada por la Corte Constitucional, mediante la cual declara que ciertos hechos resultan abiertamente contrarios a la Constitución, por vulnerar de manera masiva derechos y principios consagrados en la misma, en consecuencia insta a las autoridades competentes, para que en el marco de sus funciones y dentro de un término razonable, adopten las medidas necesarias para corregir o superar tal estado de cosas.

En la sentencia T-025 de 2004, la Corte enumera los factores que se deben tener en cuenta para determinar cuando existe un estado de cosas inconstitucional:

1) La vulneración masiva y generalizada de varios derechos constitucionales que afecta a un número significativo de personas.

2) La prolongada omisión de las autoridades en el cumplimiento de sus obligaciones para garantizar los derechos.

3) La adopción de prácticas inconstitucionales, como la incorporación de la acción de tutela como parte del procedimiento para garantizar el derecho conculcado.

4) La no expedición de medidas legislativas, administrativas o presupuestales necesarias para evitar la vulneración de los derechos.

5) La existencia de un problema social cuya solución compromete la intervención de varias entidades, requiere la adopción de un conjunto complejo y coordinado de acciones y exige un nivel de recursos que demanda un esfuerzo presupuestal adicional importante.

6) El hecho de que si todas las personas afectadas por el mismo problema acudieran a la acción de tutela para obtener la protección de sus derechos, se produciría una mayor congestión judicial.

Estos seis elementos, pueden ser resumidos en dos factores principales que son denominados por 5 el doctor Cesar Rodríguez Garavito, como condiciones de proceso (fallas estructurales de las políticas públicas en el país) y condiciones de resultado (violación masiva y sistematizada de los derechos fundamentales de un número indeterminado de personas). Y un tercer factor sería la necesidad imperiosa 
del trabajo en conjunto de diversas autoridades públicas para la modificación de una realidad que resulta contraria a la Constitución. ${ }^{427}$

Esta forma no deja de ser polemica, en tanto que, rompe con los diseños usuales de los efectos inter-partes que definen los fallos de tutela, asumiendo que en el sello de la declaración de un estado de cosas antitético a la Constitución, la Corte ocupa un lugar más arduo con la sociedad y ante todo con los sectores más sensibles de la sociedad, en razón, a que se da a la labor de indagar medidas decisivas a los inconvenientes de entorno organizado que se ostentan en el país, y arrogando disposiciones que cambian el caso concreto, y exigiendo el labor en conjunto de otras atribuciones públicas, con el proposito de cambiar una situación que rastra explícitamente contraria a los principios constitucionales de un Estado Social de Derecho.

El surgimiento de la figura del ECI se presentó con la sentencia SU-559 del 6 de noviembre de 1997, en la cual la Corte declaró un estado de cosas contrario a la Constitución, por la omisión de dos municipios de Bolívar de afiliar a sus docentes al Fondo Nacional de Prestaciones del Magisterio, a pesar de que se estaban haciendo los correspondientes descuentos de los salarios devengados.

Posteriormente la Corte, declaró un Estado de cosas inconstitucionales en diversas ocasiones: por la mora habitual de la Caja Nacional de Previsión en resolver las peticiones presentadas por jubilados (sentencia T-068 de 1998), por la falta de convocatoria al concurso para el nombramiento de notarios (sentencias T-1695 de 2000 y SU-250 de 1998).

Así mismo, mediante sentencias T-153 de 1998 y T-606 de 1998 se declaró el estado de cosas inconstitucionales en el sistema carcelario en Colombia y sobre el derecho a la salud de las personas privadas de la libertad, en centros de reclusión. En la Sentencia T-590 de 1998, se declaró el estado de cosas inconstitucionales por la omisión del Estado de adoptar medidas para garantizar los derechos de los defensores de derechos humanos. Finalmente, la más reciente declaratoria de un Estado de cosas inconstitucionales se hizo en la sentencia T-025 de 2004, por la violación de los derechos de la población desplazada en Colombia.

427 La Corte en la misma sentencia T-025 de 2004 señaló los elementos imprescindibles para declarar la existencia del ECI: (1) "cuando se constata la vulneración repetida y constante de derechos fundamentales que afectan a multitud de personas, y (2) cuya solución requiere la intervención de distintas entidades para atender (3) problemas de orden estructural, esta corporación ha declarado la existencia de un estado de cosas inconstitucional". (Subrayadas y números, fuera del texto) 
Consecuencialmente, nos preguntamos porque el estado de cosas inconstitucionales en salud? para ello partiremos de lo expuesto en el texto titulado "Ley 100: Quo Vadis?"428 En donde se sintetiza el problema del sistema de salud colombiano a través de una válida metáfora. Dice que el sistema de salud pudiera pensarse como un engranaje de piñones de distinto material. Un piñón -el más grande- es el de las EPS -que es de metal- (son negocios que administran servicios y tiene la fortaleza económica de dominar el mercado). Un segundo piñón es el de las IPS -que es de corcho- (son intermediarios que prestan un servicio a través de planes de beneficios que funcionan como paquetes de salud que el usuario compra para suplir sus enfermedades). Y un tercer y último piñón es el del usuario -que es de caucho- (es el ciudadano, el enfermo, el más vulnerable). Según el artículo, con el tiempo, el piñón de acero daña el de corcho, y el de caucho se desestabiliza. Así, los resultados del sistema no pueden ser buenos.

Además, Esta lógica estructural parte de la separación entre los servicios individuales y los servicios colectivos en salud, para dejar los primeros en manos del mercado con "competencia regulada" y, los segundos, a cargo del Estado ${ }^{429}$. Lo crítico es concebir un esquema de salud como un esquema de negocios. Pues, los derechos deben ser universales y cuando este se transforma en un producto del mercado se debe reconocer que existen ciudadanos que no pueden adquirirlos. Por ende, para ellos no existe ni siquiera el servicio prestacional de salud. El profesor Antonio Parra ${ }^{430}$ diría, "si los colombianos no tienen garantizados derechos fundamentales como el derecho a la vida y el derecho al trabajo, vulnerados en Colombia de manera permanente, mucho menos tendrán acceso al sistema de salud o más exactamente a la atención en salud "jesto es una barbaridad!. Recordemos algunas palabras del jurista Rodolfo Arango "la negación de un nivel mínimo de asistencia médica y de medicamentos puede ser contraria a la vida digna de un individuo." 431

Entonces, el debate se centra en comprender que la responsabilidad de tener este sistema precario de salud radica en el hecho de concebir la salud como una

428 ECHEVERRI, Oscar. Mercantilización de los servicios de salud para el desarrollo: el caso de Colombia. En: Revista Panamericana de Salud Pública, 2008. vol. 24, p. 213.

429 ÁLVAREZ, Mario Hernández. Op Cit. p. 129

430 YEPES PARRA, Antonio. El derecho a la salud: La necesidad de repensar los derechos sociales. En: Revista cubana de salud pública, 1999. vol. 25, p. 119.

${ }^{431}$ Arango, Rodolfo. El concepto de derechos sociales fundamentales. Prólogo de Robert Alexy. Universidad Nacional de Colombia- Legis. Bogotá, 2005. Citado por: ORDÓÑEZ, Jorge R.; JORGE, R. El derecho a la salud en la jurisprudencia de la Corte Constitucional de Colombia. Apuntes para la definición de un contenido esencial de ese derecho en la jurisprudencia mexicana. Ferrer MacGregor, Eduardo y Zaldívar Lelo de Larrea, Arturo (coords.), op. cit, 2006. p. 599. 
mercancía cualquiera, que se debe comprar obligatoriamente mediante un seguro, y que debe dejar un margen de ganancia suficiente para las EPS. ${ }^{432}$

La corte constitucional ha intervenido ante la inoperancia de los gobiernos nacionales tratando de solucionar la crisis que deja la conculcación sistemática del derecho a la salud de los colombianos. Esta Corte ha entrado a precisar su definición, las formas de acceso y protección, así como la calidad del servicio. "ejerciendo un fuerte control de la formulación y ejecución de políticas públicas". La realidad del sistema ha ocasionado que transcurridos diez años de la ley 100 , más de un tercio de las acciones de tutela interpuestas en el país corresponden a vulneración al derecho a la salud, de las cuales el $87 \%$ son resueltas a favor del accionante y de las denegadas, un buen número corresponde a muerte de quien la interpuso o a hechos superados al haberse subsanado la violación por parte de la entidad aseguradora. ${ }^{433}$ Para el año 2016, la cuarta parte de las tutelas que se interponen en el país reclaman el derecho a la salud ${ }^{434}$. Esto, alrededor de problemas cruciales tales como, el acceso, la calidad del servicio prestado, y la protección de grupos poblacionales de especial tratamiento.

A través de su desarrollo jurisprudencial, la corte constitucional empezó a trabajar alrededor de un término jurídico denominado "Estado de cosas inconstitucional" que al parecer es consecuencia de la ausencia del Estado, entendida como vulneración efectiva a derechos fundamentales a partir de la inoperancia del Estado ${ }^{435}$. Es decir, la Ausencia de Estado, se entiende como la omisión o el olvido del deber constitucional por parte del Estado Colombiano con sus habitantes, al no cumplir con sus deberes de protección y cubrimiento de sus necesidades fundamentales dando lugar a la vulneración de derechos constitucionales ${ }^{436}$. Así. El objetivo principal de la Corte Constitucional es ordenar mejoras y tutelar derechos a través de la introducción de medidas de prevención, de atención, de promoción y de estabilización para los ciudadanos, para poder mantener el estado de bienestar ${ }^{437}$.

\footnotetext{
432 ECHEVERRI, Oscar. Mercantilización de los servicios de salud para el desarrollo: el caso de Colombia. En: Revista Panamericana de Salud Pública, 2008. vol. 24, p. 214.

433 BARBOSA, Jiménez; GIOVANNI, Wilson. Op Cit. p. 115.

434 CARACOL RADIO. La cuarta parte de las tutelas en Colombia reclaman el derecho a la salud. 21/04/2017. Salud. [en línea] http://caracol.com.co/radio/2017/04/21/salud/1492800196_111047.html

435 ZAMBRANO, Sonia Patricia Cortés. Poder discrecional de la Corte Constitucional en el Estado de Cosas Inconstitucional. En: Via Inveniendi Et Iudicandi, 2012. vol. 7, no 2, p. 5.

436 Ibíd. p. 21

437 Ibíd. p. 26
} 
El tratamiento jurídico del "Estado de cosas inconstitucional" se dio por primera vez en la sentencia SU-559 de $1997^{438}$, pero fue en la providencia T-025 de $2004^{439}$ la que determino la razón fundamental de atender y construir este concepto. Dice la corte que se constituye un "estado de cosas inconstitucional" cuando, "se presenta una repetida violación de derechos fundamentales de muchas personas que pueden entonces recurrir a la acción de tutela para obtener la defensa de sus derechos y colmar así los despachos judiciales y cuando la causa de esa vulneración no es imputable únicamente a la autoridad demandada, sino que reposa en factores estructurales" ${ }^{440}$. Es decir, que en varias situaciones la solución no obedece únicamente de la autoridad demandada, sino que su solución es por la acción de distintas autoridades ${ }^{441}$.

Esta figura ha impactado de manera indirecta la forma en que se debe prestar el servicio. Por ejemplo, en la sentencia T-153 de 1998 la corte constitucional levanto el velo del sistema carcelario, mostrando que estos establecimientos eran un factor de constante vulneración a los derechos fundamentales de las personas privadas de su libertad. En la sentencia T-606 de 1998 se dejó claro que la protección del derecho a la salud a los detenidos o condenados que están en las cárceles es una obligación que el estado tiene y debe proteger en conexidad con los artículos 11 y 12 de la constitución política. Esto con un fin común, velar por la vida digna del recluso. La corte en su momento se refirió al caso en concreto con un razonamiento sustancialmente útil para la idea de este escrito, "no es menester hacer un examen exhaustivo de los elementos que configuran el estado de salud actual del actor para concluir que, en virtud de la prolongada omisión de los funcionarios encargados de los aspectos médicos en el establecimiento de reclusión, la persona ha venido siendo desamparada y corre los riesgos consiguientes por una falta de información

${ }^{438}$ COLOMBIA. CORTE CONSTITUCIONAL. Sentencia SU-559 de 1997. M.P Dr. Eduardo Cifuentes Muñoz

${ }^{439}$ COLOMBIA. CORTE CONSTITUCIONAL. Sentencia T-025 de 2004. M.P Dr. Manuel José Cepeda Espinosa

${ }^{*} 440$ [...] La Corte Constitucional colombiana, ha decretado en siete ocasiones la existencia de un estado de cosas inconstitucional. La primera, lo hizo ante la omisión de dos municipios en afiliar a docentes a su cargo al Fondo Nacional de Prestaciones Sociales del Magisterio, a pesar de los descuentos realizados para prestaciones y pensiones sociales. (Sentencia SU 559 de 1997), posteriormente declaró la figura por la situación de violación continua de los derechos de los sindicados y procesados detenidos en las diferentes cárceles del país (Sentencia T 153 de 1998); la tercera vez, fue por la falta de un sistema de seguridad social en salud para los sindicados y reclusos (sentencia T- 606 y T-607 de 1998); la cuarta situación fue por la mora habitual en el pago de mesadas pensionales, durante un período prolongado de tiempo, en los departamentos de Bolívar (Sentencia T-525 de 1999) y de Chocó (Sentencia SU -090 de 2000); la sexta circunstancia, por omisiones en la protección de la vida de defensores de derechos humanos frente a las amenazas permanentes contra la vida de estas personas (Sentencia T-590 de 1998) y la última situación fue por la omisión en la convocatoria de un concurso de méritos para el nombramiento de notarios (Sentencia SU 250 de 1998 y Sentencia T-1695 de 2000). ZAMBRANO, Sonia Patricia Cortés. Op Cit. p. 6.

${ }^{441}$ COLOMBIA. CORTE CONSTITUCIONAL. Sentencia T-153 de 1998. M.P Dr. Eduardo Cifuentes Muñoz 
elemental con miras a sus cuidados médicos." Además, enfatizó en decir que la causa sustancial de la desorganización en el sistema de salud se debe a "la presencia ya inevitable de enfermedades que amenazan palmariamente la vida del interno, postergando indefinidamente los cuidados indispensables para el mantenimiento de una salud regular y aun aquellos que resultan imperativos para controlar un dolor persistente, aunque no sea grave". Es decir, la base sustancial del problema radica primero, en la ausencia de una real infraestructura que preste el servicio y segundo, en la filosofía prestacional no preventiva que existe en lo que hay de servicio. Lo anterior fue motivación de insistencia por parte de la Corte para decir en la providencia T-607 del mismo año que, "El Estado debe hacerse responsable de la salud de los internos" y resaltó algo muy categórico y admirable, "para preservar adecuadamente tales derechos se debe proteger con eficiencia la vida digna del interno. El fallo no debe limitase a ordenar, como se hará, la práctica de los posteriores procedimientos médicos que conforme a ella se hagan indispensables, sino también debe contemplar acerca de las ostensibles deficiencias que presenta el sistema general de salud". en esta idea resuelve decisiones como la siguiente, "debe existir la contratación de un sistema global que cobije a todos los reclusos trasladando los riesgos a las empresas prestadoras de salud que el Estado escoja o al sistema de seguridad social que cree con tal objeto, garantizando a los asegurados -los internos- una permanente cobertura, la seguridad de su atención médica, quirúrgica, hospitalaria y de drogas y tratamientos, y simultáneamente evitando el constante apremio a las autoridades carcelarias y la recurrente tensión entre los siniestros ya creados, cuyos gastos resultan inevitables y urgentes, y la escasez de los recursos económicos disponibles y manejados por cada establecimiento o por el Instituto Nacional Penitenciario y Carcelario."

Ahora, no debemos olvidar que la Corte constitucional utiliza la figura del Estado de cosas inconstitucional para evitar la vulneración de derechos fundamentales generados a partir de la omisión o la actuación ineficiente del Estado, exigiendo la toma de medidas oportunas y eficaces por parte de las distintas ramas del poder y sus órganos, para la atención y solución inmediata con miras al cese de la amenaza o vulneración ${ }^{442}$. No se debe perder de vista que para configurar tal figura se debe demostrar que el derecho vulnerado presenta las siguientes características ${ }^{443 * 444}$

442 ZAMBRANO, Sonia Patricia Cortés. Op Cit. p. 7

443 COLOMBIA. CORTE CONSTITUCIONAL. Sentencia T-025 de 2004. M.P Dr. Manuel José Cepeda Espinosa

${ }^{*} 444$ [....] El estado de cosas contrario a la Constitución fue explicada por la Sala Plena de la Corte Constitucional de la siguiente manera: Se pregunta la Corte si, desde ahora, de verificarse que el comportamiento omisivo indicado viola la Constitución Política, es posible que la Corporación, en razón de sus funciones, pueda emitir una orden a las autoridades públicas competentes, con el objeto de que a la mayor brevedad adopten las medidas conducentes a fin de eliminar los factores que inciden en generar un estado de cosas que resulta abiertamente inconstitucional. La Corte considera que debe responder de manera afirmativa este interrogante, por las siguientes razones: (1) La Corte 
a) la vulneración masiva y generalizada de varios derechos constitucionales que afecta a un número significativo de personas.

b) la prolongada omisión de las autoridades en el cumplimiento de sus obligaciones para garantizar los derechos.

c) la adopción de prácticas inconstitucionales, como la acción de tutela como parte del procedimiento para garantizar el derecho conculcado. (Si todas las personas afectadas por el mismo problema acudieran a la acción de tutela para obtener la protección de sus derechos, se produciría una mayor congestión judicial).

d) la no expedición de medidas legislativas, administrativas o presupuestales necesarias para evitar la vulneración de los derechos.

e) la existencia de un problema social cuya solución compromete la intervención de varias entidades, requiere la adopción de un conjunto complejo y coordinado de acciones que exige un nivel de recursos que demanda un esfuerzo presupuestal adicional importante.

Según lo anterior un fallo de estado de cosas inconstitucionales del derecho a la salud debe estructurarse e ir dirigido al diseño de políticas, planes o programas que garanticen de manera adecuada los derechos afectados, que se adapten los recursos suficientes para garantizar la garantía de dichos derechos; que se modifiquen las fallas de organización y de procedimiento que sean violatorias a la Constitución Política; que se modifique el marco jurídico cuyas falencias han ayudado al estado de cosas inconstitucionales y por último que se realicen los trámites administrativos, presupuestales y de contratación que sean indispensables para superar la vulneración de los derechos fundamentales ${ }^{445}$.

En la naturaleza fundamental del derecho a la salud, Decir que existe un estado de cosas inconstitucional, genera un impacto que gira alrededor de garantizar su protección y permite crear condiciones necesarias para que el derecho social pueda

Constitucional tiene el deber de colaborar de manera armónica con los restantes órganos del Estado para la realización de sus fines (C. P., art. 113). Del mismo modo que debe comunicarse a la autoridad competente la noticia relativa a la comisión de un delito, no se ve por qué deba omitirse la notificación de que un determinado estado de cosas resulta violatorio de la Constitución Política. (2) El deber de colaboración se torna imperativo si el remedio administrativo oportuno puede evitar la excesiva utilización de la acción de tutela. Los recursos con que cuenta la administración de justicia son escasos. Si instar al cumplimiento diligente de las obligaciones constitucionales que pesan sobre una determinada autoridad contribuye a reducir el número de causas constitucionales, que de otro modo inexorablemente se presentarían, dicha acción se erige también en medio legítimo a través del cual la Corte realiza su función de guardiana de la integridad de la Constitución y de la efectividad de sus mandatos. TOLE MARTÍNEZ, Julián. Op Cit. p. 303

445 ZAMBRANO, Sonia Patricia Cortés. Op Cit. 
ser. Donde se categorice su condición real y sustancial de derecho fundamental. Esto permitiría presionar al estado para que materialice las acciones positivas que está obligado a realizar para satisfacer la salud de cada uno de los ciudadanos y también incentive métodos de prevención que están dentro de sus obligaciones (negativas) de no dañar la salud. Este actuar del estado representa un tratamiento nuevo con la protección del derecho y una atención verdadera frente a los problemas de naturaleza estructural que sufre la prestación del derecho a la salud en Colombia.

\subsection{BLOQUE DE CONSTITUCIONALIDAD Y EL CONTROL DE CONVENCIONALIDAD}

EL bloque de constitucionaliadad entendido como el conjunto de medidas internacionales, que yuxtapuesto a la Constitución de 1991, tiene como objetivo, determinar libertades y garantías de los individuos en la sociedad, normas a saber: los Derechos Humanos y el Derecho Internacional Humanitario.

2.4.1 Control de convencionalidad del derecho a la salud en Colombia. La constitución política de Colombia no es "un catálogo cerrado" 446 de normas instituidas en un único documento jurídico. Su diseño normativo se sustenta en dos mandatos del constituyente primario fundados en los artículos 4 y 93 de la ley fundamental dando categoría de mayor jerarquía jurídica a lo que se denominará "bloque de constitucionalidad ${ }^{447 "}$ que ante duda alguna de interpretación, en el año 93 el magistrado Carlos Gaviria Díaz definió brillantemente; "Es aquella unidad jurídica compuesta por normas y principios que, sin aparecer formalmente en el

446 HIGUERA, Diego Mauricio. RELECTURA ESTRUCTURAL DEL BLOQUE DE CONSTITUCIONALIDAD EN COLOMBIA: ELEMENTOS CRÍTICOS PARA APLICACIÓN DEL CONTROL DE CONSTITUCIONALIDAD. En: Principia luri. 2014. vol. 15, no 15. P. 99.

447 [...] de conformidad con Uprimny, 26 la construcción del bloque de constitucionalidad ha atravesado cinco etapas. Inicialmente bajo la Constitución de 1886 no tuvo lugar la figura, por lo que hubo necesidad de esperar a la expedición de la Carta de 1991 y las primeras sentencias de la Corte Constitucional, donde se precisarían las normas que sirven de fundamento al Bloque de constitucionalidad (los artículos 53, 93 y 214 de la Constitución). Igualmente, comienzan a ser usados los tratados públicos como variables normativas en las decisiones. El tercer momento acontece con la jurisprudencia del año 1995, que empieza a usar la expresión "Bloque de constitucionalidad", a construir una dogmática alrededor de ella y a referir fenómenos de integración con normas provenientes del Derecho Internacional de los Derechos Humanos y del Derecho Internacional Humanitario. El año 1997 da inicio a una nueva etapa, en la que la figura gana consistencia en tres aspectos centrales: se precisan los componentes de la remisión expresa; se especifica que no todos los tratados públicos hacen parte del bloque de constitucionalidad; y se introduce la distinción entre bloque de constitucionalidad en sentido estricto y en sentido amplio. Finalmente, y desde 1999, el Bloque de constitucionalidad consolida sus componentes dogmáticos y se erige en una institución decisiva en el ejercicio del control constitucional, en los casos complejos que involucran el compromiso de los derechos humanos. 
articulado del texto constitucional, son utilizados como parámetros del control de constitucionalidad de las leyes, por cuanto han sido normativamente integradas a la constitución"448.

La sentencia C-582 de 1999, manifiesta de conformidad con el artículo 93 de la Carta Política, que no todos los tratados internacionales son per se parte del bloque de constitucionalidad pues "solo constituyen parámetros de control constitucional aquellos tratados y convenios internacionales que reconocen derechos humanos y, que prohíben su limitación en estados de excepción. Es por ello que integran el bloque de constitucionalidad, entre otros, los tratados del derecho internacional humanitario, tales como los Convenios de Ginebra, los Protocolos I y II y ciertas normas del Pacto de San José de Costa Rica"449. Es decir, los tratados sobre derechos humanos ratificados por Colombia, tienen prevalencia en el orden interno y las reglas del derecho internacional humanitario tienen vigencia irrestricta a nivel nacional, pues hacen parte del bloque de constitucionalidad. ${ }^{450}$ Entonces, Podemos decir que la constitución colombiana no se agota con el conteo de los artículos registrados en el texto constitucional, sino se extiende abarcando otros componentes, en especial de derecho internacional "que pasan a ser también normas constitucionales" 451 . Esto nos permite comprender que el Bloque de constitucionalidad ha sido construido y usado exclusivamente para hacer control de constitucionalidad, desde normas internacionales de aplicación directa (control estricto) o desde normas internacionales que sirven como criterio de interpretación en el ejercicio del control constitucional (control amplio) ${ }^{452}$. Ahora, desde la doctrina y la jurisprudencia colombiana, el Estado colombiano debe cumplir a cabalidad el principio "pacta sunt servanda" ratificado en la convención de Viena de 1969. ${ }^{453} \mathrm{Su}$ aplicación se deriva de lo que se llamará "Control de convencionalidad" -figura que se ha venido introduciendo gradual y paulatinamente en el país ${ }^{454}$ - que precisamente es consecuencia directa del deber de los Estados de tomar todas las medidas que sean necesarias para que los tratados internacionales que han firmado se apliquen cabalmente. Es menester precisar dos rasgos teóricos en base a lo expuesto:

\footnotetext{
448 COLOMBIA. CORTE CONSTITUCIONAL. Sentencia C-225 de 1993. M.P Carlos Gaviria Díaz. 449 HIGUERA, Diego Mauricio. Op Cit. p. 105.

450 VELANDIA SÁNCHEZ, Arcenio. Justicia nacional o jurisdicción interamericana: el control de convencionalidad en relación con el bloque y control de constitucionalidad colombianos. 1 ed. Bogota: Universidad la Gran Colombia. 2014. P. 152.

451 RAMÍREZ, Manuel Fernando Quinche; FERNANDO, Manuel. El control de convencionalidad y el sistema colombiano. En: Revista Iberoamericana de Derecho Procesal Constitucional. 2009, vol. 163, p. 169.

452 lbíd. p. 171.

453 VELANDIA SÁNCHEZ, Arcenio. Op Cit. P 189.

454 DURANGO ÁLVAREZ, Gerardo A.; GARAY HERAZO, Kennier José. EL CONTROL DE CONSTITUCIONALIDAD Y CONVENCIONALIDAD EN COLOMBIA. En: Prolegómenos. Derechos y Valores. 2015, vol. 18, no 36. P. 110.
} 
1. El Poder Judicial debe ejercer una especie de 'control de convencionalidad' entre las normas jurídicas internas, que aplican a los casos concretos y la Convención Americana sobre Derechos Humanos. En esta tarea el Poder Judicial debe tener en cuenta no solamente el Tratado sino también la interpretación que del mismo ha hecho la corte internacional. Por ejemplo, la Corte IDH, intérprete última de la Convención Americana"455

2. Si los tribunales constitucionales controlan la 'constitucionalidad', el tribunal internacional de derechos humanos resuelve acerca de la 'convencionalidad' de esos actos. 456

Al rasgo uno, es necesario señalar lo dicho por el profesor Eduardo Ferrer - que me permito citar como "deber ser" para el ordenamiento jurídico colombiano- "Los jueces (de los estados partes -por ejemplo- de la convención americana) no son simples aplicadores de la ley nacional, sino que tienen además una obligación de realizar una "interpretación convencional" verificando si dichas leyes que aplicarán a un caso particular resultan compatibles con la CADH. De lo contrario, su proceder sería contrario al artículo 1.1 de dicho tratado, produciendo una violación internacional, ya que la aplicación de una ley inconvencional produce por sí misma una responsabilidad de Estado." 457 además, se debe partir de que, si bien el tribunal internacional -de nuevo como ejemplo la $\mathrm{CIDH}$ - es consiente que los jueces y tribunales internos están sometidos al imperio de la ley que los obligan a aplicar las disposiciones vigentes en el ordenamiento jurídico, no se debe olvidar que cuando un Estado ha ratificado un tratado internacional-como la convención americana- el poder judicial debe tener en cuenta no solamente el tratado, sino también la interpretación que del mismo ha hecho la corte internacional -en este caso la corte interamericana que es interprete ultima de la convención- (lo que llaman control de convencionalidad ex officio) ${ }^{458459}$ Es decir, los jueces nacionales en aplicación del principio de subsidiariedad, bajo un método conflictual deben solucionar el problema de derechos humanos consultando su propio derecho, pero comparándolo con la convención internacional, pues como se sabe, una parte no puede invocar las disposiciones de su derecho interno como justificación del incumplimiento de un tratado. 460

\footnotetext{
455 HITTERS, Juan Carlos. Control de constitucionalidad y control de convencionalidad. Comparación (Criterios fijados por la Corte Interamericana de Derechos Humanos). En: Estudios constitucionales. 2009, vol. 7, no 2, p. 115.

456 Ibíd. p. 113.

457 CARBONELL, Miguel. El ABC de los derechos humanos y del control de convencionalidad. México. Editorial Porrúa. 2015. P. 178

458 Op Cit. P. 177

459 SAGÜÉS, Néstor Pedro. El control de convencionalidad. En particular sobre las Constituciones Nacionales. En: La Ley, 2009, vol. 73, no 35.

460 Convención de Viena de 1969, articulo 27.
} 
En cuanto al segundo rasgo el control de convencionalidad tiene como función garantizar en ultimas que los estados comprometidos en este instrumento internacional, cumplan sus compromisos internacionales, de buena fe, dada su posición de garante y en caso de no hacerlo -también con criterios de subsidiariedad-pueda la corte internacional -por ejemplo la corte interamericana de derechos humanos-, compelerlos al cumplimiento, con la correspondiente responsabilidad ante la comunidad interamericana. ${ }^{461} \mathrm{La}$ corte interamericana puede emitir sentencias y la jurisprudencia que de ellas emane, implica un auténtico pronunciamiento jurisdiccional de control constitucional al estado demandado. ${ }^{462}$ Recordemos que la responsabilidad internacional de los Estados surge en el momento de la violación de las obligaciones generales de la $\mathrm{CIDH}$, de carácter erga omnes, de respetar y hacer respetar las normas de protección y de asegurar los derechos allí consagrados en toda circunstancia y respecto de toda persona, concentrado en los artículos 1.1 y 2 de dicho tratado. Dichas obligaciones derivan deberes especiales, determinables en función de las particulares necesidades de protección del sujeto de derecho. ${ }^{463}$ En esta idea continua el profesor Ignacio Herrerías al plantear en síntesis que "no existe impedimento alguno para aplicar directa e inmediatamente las normas internacionales, siempre y cuando las obligaciones que nacen de dichas normas sean exigibles ante autoridad pública por el titular del derecho". Es decir, la función jurisdiccional de la corte se concreta en analizar los hechos a la luz de las disposiciones aplicables y determinar si las personas que han solicitado la intervención de las instancias del Sistema Interamericano son víctimas de las violaciones alegadas y, en su caso, si el estado debe adoptar determinadas medidas de reparación ${ }^{464}$. En conclusión, después de lo expuesto, es claro que si puede existir una sanción por parte de un organismo jurisdiccional a través del ejercicio del control de convencionalidad sobre la violación de derechos fundamentales. Esto, Con todas sus posibilidades y mecanismos.

Respecto del derecho fundamental a la salud sometido a control convencional por parte de una jurisdicción internacional, debe darse principalmente con el criterio de ser aplicado a un caso en concreto y a raíz de ello desarrollar el proceso para luego sancionar e incluso de exigir adaptaciones del estado demandado si se encuentra responsable o a raíz de un precepto legal interno -aplicado o no- vigilado por la corte internacional hacia un Estado podría suceder que aquella le ordena al país el deber de inmediatamente 'adaptar' la legislación interna. ${ }^{465}$

461 VELANDIA SÁNCHEZ, Arcenio. Op Cit. P. 228.

462 HERRERÍAS CUEVAS, Ignacio. CONTROL DE CONVENCIONALIDAD Y EFECTOS DE LAS SENTENCIAS. México. Ubijus, 2012. P. 132.

463 lbíd. P. 72.

${ }^{464}$ RAMÍREZ, Manuel Fernando Quinche. Op Cit. p. 164.

465 HITTERS, Juan Carlos. Op Cit. p. 125. 


\subsection{LA RESPONSABILIDAD POR OMISIÓN EN SALUD}

La responsabilidad por omisión según el tratadista Cassage corresponde a "una responsabilidad objetiva, extracontractual, y se le aplican los requisitos generales de la responsabilidad por acción del Estado" 466

Conforme se encuentra en el diccionario de la Real Academia de la Lengua Española, la responsabilidad es la: "Deuda u obligación de reparar y satisfacer, por sí o por otra persona, a consecuencia de un delito, de una culpa o de otra causa legal". Con esto puede entenderse, entonces, que el concepto anteriormente definido se entiende, de manera general, como la producción de efectos jurídicos mediante un actuar que incide directamente en una persona desde otra, -de forma patrimonial o extra patrimonial, y que genera la obligación de esta última de resarcir los perjuicios que hayan sido irrogados a la víctima con la acción o la omisión que dio lugar a los efectos jurídicos en mención.

Dada esta amplia conceptualización del término "responsabilidad", dentro de sus categorías especificas al aplicarse su accionar en las ciencias jurídicas, es posible dilucidar límites entre éstas tales como la responsabilidad extra contractual y contractual, la responsabilidad estatal y aquella de índole privado, la responsabilidad penal o fiscal y las demás formas de organización en que, mediante el ordenamiento jurídico, se ha establecido el régimen de responsabilidad.

Teniendo en cuenta la relevancia del ejercicio de las profesiones liberales en el sistema estructural de la sociedad occidental, se encuentra que la actividad medica no escapa a las anteriormente mencionadas categorías de la responsabilidad, determinando así lo que se denomina responsabilidad médica, que se presenta producto del ejercicio de dicha profesión, y de los riesgos que en ella se asumen.

La normatividad colombiana no contempla en alguno de sus apartes una definición precisa para el acto médico, como si lo hace por ejemplo la legislación peruana, concretamente en el denominado Código de Ética y Deontología del Colegio Médico de Perú, que en su título 2, artículo 12, puntualiza que: "Acto médico es toda acción o disposición que realiza el médico en el ejercicio de la profesión médica. Han de entenderse por tal, los actos de diagnóstico, terapéutica y pronóstico que realiza el médico, en la atención integral de pacientes, así como los que se deriven directamente de éstos. Los actos médicos mencionados son de exclusivo ejercicio del profesional médico". A pesar de tratarse de una norma plasmada en una

${ }^{466}$ Cassagne Juan Carlos, Derecho Administrativo, tomo 1, Editorial Abeledo Perrot, 1998. 
legislación ajena a la colombiana, puede afirmarse que el acto médico, entonces, es cualquier actuación que es llevada a cabo por un profesional del campo de la medicina en el ejercicio de su misma profesión.

Con las conceptualizaciones de la responsabilidad médica y el acto médico en sí, es notable la ausencia de una correlación directa entre estas dos; es decir, cómo presentándose normalmente un acto médico, las actividades que en el realice un profesional de la salud pudieran desembocar en un caso de responsabilidad médica y, con él, su intrínseca propiedad resarcitoria hacia el sujeto afectado; la respuesta a este planteamiento solo se da a partir del título de imputación denominado falla médica.

2.5.1 La falla médica La falla médica, que es aquel actuar de un profesional de la salud o de una entidad prestadora de este servicio que causa una afectación a quien es objeto de dicho accionar, puede ligarse entonces, junto a la responsabilidad médica, con la responsabilidad estatal; esto es que, teniendo los elementos que configuren la primera, pueda imputarse al Estado.

Como demarca el artículo 90 de la Constitución Política Colombiana, "El Estado responderá patrimonialmente por los daños antijurídicos que le sean imputables, causados por la acción o la omisión de las autoridades públicas'467'. Este daño antijurídico es definido por la Corte Constitucional en sentencia C-333 de 1996 como "el perjuicio que es provocado a una persona que no tiene el deber jurídico de soportarlo", con lo que se entiende que si la administración causa dicho daño, se configura entonces la responsabilidad del Estado, aspecto también aplicable en el ámbito de la salud.

2.5.2 Obligaciones de medio y de resultado incorporadas en la actividad médica La determinación de la naturaleza de la actividad médica, y de las obligaciones que de la misma surgen, es importante para definir la forma en la que se puede dar cumplimiento al compromiso asumido por el médico tratante, así como para comprender adecuadamente los requisitos exigibles en materia de responsabilidad.

Para este fin resulta de inusitada importancia acudir a la génesis de la distinción entre obligaciones de medio y de resultado que se incorporaron en el ordenamiento jurídico colombiano, cuyas raíz francesa tiene lugar a partir de los términos

${ }^{467}$ Constitución Política Colombiana, articulo 90. 
"moyens" y "résultent", utilizados por el francés René Demogue en su obra "Traite des obligations", de 1925, en la cual definió la clasificación.

Según la teoría originalmente planteada, la obligación medica era de medios, y por tanto en ningún caso el médico tratante podía comprometerse a la curación del paciente. Así fue como desde la sentencia de 5 de marzo de 1940, la Corte Suprema de Justicia, partiendo de la distinción entre obligaciones de medio y de resultado, estimó que el médico no se obliga a sanar al enfermo, sino a ejecutar correctamente el acto o serie de actos que, según los principios de su profesión, de ordinario deben ejecutarse para conseguir el resultado, siendo la disposición de sus medios con arreglo a la ciencia y a la técnica, el pago de su obligación.

En este sentido señaló también la doctrina, que al galeno correspondía "desplegar todos los medios necesarios en procura de un resultado sin tener la obligación de obtenerlo (...) la obligación del médico es una sola, y es realizar su actividad de la mejor manera posible, de acuerdo a los conocimientos adquiridos y actualizados y conforme las técnicas y usos existentes aceptados por las autoridades médicas, con miras a que el resultado sea el que normal y ordinariamente debe producirse" 468 . En la misma línea el Dr. Carlos Ignacio Jaramillo esbozó que "el médico únicamente se compromete a brindarle al paciente una diligente y cuidadosa atención médica, en un todo de acuerdo con los avances y los cánones de la ciencia médica, sin que se vea obligado a asegurar un resultado, pues el mismo no depende meramente de su actuación, intervención o actividad, sino de una suerte de circunstancias e imponderables que trascienden su querer $y$, por contera, le son enteramente ajenos '”'469. En estos términos y según lo manifiesto por el doctrinante, la obligación médica es definida como una simple obligación de diligencia, "dado que se agota con una actuación prudente, al margen de lo que pueda acaecer ulteriormente como respuesta a numerosos e imponderables factores que se anidan en la periferia del acto médico"470.

La justificación se condensa de manera completa en la obra titulada "Derecho Médico Colombiano", en la cual se sostiene que a pesar de los esfuerzos del médico por lograr diligentemente prever un resultado determinado, "nunca se sabrá en forma rotunda el comportamiento final sino cuando éste ya se haya producido, por cuanto el elemento "alea" está siempre presente en la actividad médica, y, en ese

468 SERRANO ESCOBAR, Luis Guillermo. Nuevos conceptos de la responsabilidad médica. Bogotá: Ediciones Doctrina y Ley, 2001. Pág. 113

469 JARAMILLO, Carlos Ignacio. Responsabilidad Civil Médica. La relación médico-paciente: análisis doctrinal y jurisprudencial. Bogotá: Universidad Javeriana, 2008. Pág. 297.

470 Ibíd. Pág. 335. 
sentido, "esa dosis de incertidumbre que envuelve todavía a la ciencia médica, impide que el galeno garantice un resultado concreto" 471 .

No obstante el arraigo de esta teoría que explica la obligación medica atendiendo al carácter aleatorio del resultado, y las implicaciones humanísticas que le son inherentes, la misma empezó a ser rebatida posteriormente, en tanto no en todas las ramas de la medicina se predica una obligación de medios, sin que sea posible asegurar un resultado, haciéndose necesario repensar según algunos críticos, la naturaleza y alcance de la obligación médica. Fue así como una corriente doctrinal se inclinó a reconocer obligaciones de resultado para ciertas ramas de la medicina o procedimientos médicos concretos, sin lograr a la fecha una acogida doctrinal ni jurisprudencial definitiva.

En fallo del 30 de enero de 2001, la Corte Suprema de Justicia refirió que la determinación de las obligaciones del médico tratante se verificaban teniendo en cuenta las características particulares del caso: autor, profesionalidad, estado de la técnica, complejidad de la intervención, medios disponibles, estado del paciente y otras circunstancias exógenas, como el tiempo y el lugar del ejercicio, pues no de otra manera, con justicia y equidad, se podría determinar la corrección del acto médico (lex artis).

A la luz de este criterio, se tiene que por regla general los médicos se obligan a realizar su actividad con la diligencia debida, esto es, a poner todos sus conocimientos, habilidades y destrezas profesionales, así como todo su empeño, en el propósito de obtener la curación del paciente, o, en un sentido más amplio, a que éste consiga en relación con su salud o con su cuerpo el cometido que persigue o anhela, sin que, por lo tanto queden vinculados al logro efectivo de la recuperación de la salud o su curación, pues su deber de prestación se circunscribe, particularmente, a la realización de la actividad o comportamiento debido, con la diligencia exigible a este tipo de profesionales. No obstante lo anterior, en desarrollo del principio de autonomía privada puede presentarse casos en los cuales se adquiera una obligación de tal categoría.

Además de la taxatividad contractual, se ha intentado reconocer obligaciones de resultado para ciertas ramas de la medicina o procedimientos médicos concretos como la cirugía plástica con fines estéticos o de embellecimiento, y otras actuaciones médicas como la colocación de un aparato ortopédico, la inmovilización de una extremidad, el implante de un mecanismo anticonceptivo, labores médicas

471 FRANCO DELGADILLO, E.; SAAVEDRA ROJAS, E., \& GUZMÁN MORA, F. La obstetricia como obligación de medio y no de resultado. Medellín: Biblioteca Jurídica Diké, 2004. Pág. 497. 
de certificación o los análisis de laboratorio, entre otras, en las cuales la finalidad perseguida se puede obtener con la ejecución de la conducta convenida, y en las que la presencia de elementos contingentes es mínima, lo que conduce a que se generen obligaciones de resultado. Dentro de dicha categoría se pretendió incluir la actividad médica en el marco de la gineco-obstetricia, en tanto se predicaba que ante un proceso de gestación normal, el curso del alumbramiento debía ser perfecto sin contratiempo alguno; no obstante lo anterior, esta tesis fue refutada en tanto en medicina aún no cuenta con las suficientes bases para prever y corregir situaciones inesperadas como la integridad física del feto y la tolerancia de la madre dentro del trabajo de parto, no siendo dable hablar en la actualidad de responsabilidad objetiva para esta práctica, pues ello "atentaría contra la propia naturaleza de la medicina, que no es otra que la de ser una ciencia inexacta que cuenta con un factor aleatorio"472; de ahí que no obstante los intentos, no se hayan logrado resultados generalizados dada la especial naturaleza de la ciencia médica.

En tanto, con miras a establecer la eventual responsabilidad del profesional de la salud y su alcance, es indispensable entrar a reparar, en cada caso específico, sobre la naturaleza y contenido de la relación sustancial que lo vincula al paciente; pues sólo así resulta factible dilucidar cuáles son las prestaciones a cargo médico y de suyo sus obligaciones. Hecho este análisis, ha de arribarse a la imposibilidad de sentar reglas absolutas en materia de las obligaciones surgidas en la actividad médica, de cara a los componentes especiales que en cada caso en concreto determinan el régimen aplicable.

2.5.3 Particularidades de la carga de la prueba. Hasta el inicio de la década de los noventa, en los casos de responsabilidad administrativa por la actividad médica, era imperativo que quien demandaba aportara las pruebas para acreditar la falla del servicio en el acto médico, con el fin de que sus pretensiones salieran avante; esta situación implicaba que en muchas ocasiones las demandas fueran infructuosas por la imposible consecución de la prueba, en tanto escapaba de la esfera de conocimiento del paciente. Posteriormente el Consejo de Estado cambió su postura mediante sentencia del 24 de Octubre de $1990^{473}$, en la cual determinó que en tratándose de responsabilidad médica, la carga de la prueba correspondía al demandado, esto era, al médico tratante.

Esta teoría que invertía la carga de la prueba con cargo al demandado, a quien correspondía de manera férrea probar la diligencia y cuidado empleada en el procedimiento bajo la teoría de la Falla presunta, estuvo en vigencia

472 FRANCO DELGADILLO, E. Óp. cit. Pág. 1208.

473 CONSEJO DE ESTADO. Sección Tercera. C.P. Gustavo de Greiff Restrepo. Bogotá, D.C., 24 de octubre de 1990. Expediente $N^{\circ} 5902$. 
aproximadamente diez años hasta el año 2000, cuando se empieza a reconocer la teoría de la carga dinámica de la prueba, regla que permite al juez en el caso concreto "determinar cuál de las partes debe aportar la prueba de un determinado hecho, en virtud de que le resulta más fácil suministrarla"474.

Así es como mediante sentencia del 10 de Febrero de $2000^{475}$, C.P. Alier Eduardo Hernández Enríquez, se reconoce esta regla que no tiene como objeto invertir dicha carga de manera inmutable o asignarla de manera definitiva a uno de los sujetos procesales, sino ponerla a disposición del juez, quien tiene un papel activo en la repartición de las cargas probatorias, para determinar quién está en mejor condición de probar; ello concretando su aplicabilidad según las particularidades del caso y de las partes.

Esta teoría es nuevamente reevaluada en el año $2006^{476}$, bajo el argumento de que la determinación de la responsabilidad médica debía ser probada como regla general por el demandante, no obstante, dentro de dicha actividad probatoria se tendrían en cuenta los indicios que aportaran "un grado suficiente de probabilidad"477 del vínculo causal entre el hecho y el daño, construidos a partir de las reglas de experiencia de carácter científico, objetivo o estadístico, a efectos de imputar responsabilidad a la entidad.

La adopción y declinamiento de esta regla ha tenido especial curso en determinados supuestos facticos, con el propósito de morigerar la tradicional carga de la prueba, y en tanto facilitar el acceso a la tutela e indemnización por la conculcación del derecho a los sujetos especiales de protección, siendo este el caso de la especialidad de Ginecobstetricia, cuyo desarrollo jurisprudencial ha partido del reconocimiento de la condición especial de la maternidad, y el amplio margen de protección de las mujeres en estado de gravidez y la población recién nacida, a la luz de los Pactos internacionales. La responsabilidad médica en materia de Ginecobstetricia ha sido objeto de un tratamiento diferenciado por parte de la jurisprudencia, no sólo en punto de la determinación de las obligaciones que surgen al médico tratante, sino también en la asignación de la carga probatoria.

474 BERMÚDEZ MUÑOZ, Martín. El futuro de la carga de la prueba en materia de responsabilidad. En: Revista Temas Jurídicos. № 11 (1995). Pág. 16.

475 CONSEJO DE ESTADO. Sección Tercera. C. P. Alier Eduardo Hernández Enríquez. Sentencia del 10 de febrero de 2000. Expediente $N^{\circ} 11878$.

476 CONSEJO DE ESTADO. Sección Tercera. C.P. Ruth Stella Correa Palacio. Sentencia del 31 de agosto de 2006. Expediente $N^{\circ} 15772$.

477 CONSEJO DE ESTADO. Sección Tercera. Ruth Stella Correa Palacio. Sentencia del 14 de julio de 2005. Expediente. 15.276.. 
En un primer momento el Consejo de Estado puntualizó ${ }^{478}$ en el campo de la Ginecobstetricia, definida como 'la rama de la medicina que se ocupa principalmente del embarazo, parto y los fenómenos posteriores al alumbramiento, hasta la involución completa del útero', que dicha responsabilidad médica tiende a ser objetiva, cuando ab initio el proceso de embarazo se presenta normal, es decir, sin dificultades o complicaciones científicamente evidentes o previsibles.

Durante este periodo se insistió en que la imputación de la responsabilidad patrimonial debía hacerse a título objetivo, pero siempre que desde el inicio el proceso de gestación fuera normal, es decir, sin dificultades evidentes o previsibles, eventos en los cuales era de esperarse que el embarazo culminara con un parto normal. Se señalaba así:

"Es cierto que, en forma pacífica, se ha aceptado la tesis según la cual, por regla general, en la actividad médica la obligación es de medio, no de resultado; se ha dicho que el compromiso profesional asumido en dicha actividad tiende a la consecución de un resultado, pero sin asegurarlo (...)Sin embargo, en el campo de la obstetricia, definida como 'la rama de la medicina que se ocupa principalmente del embarazo, parto y los fenómenos posteriores al alumbramiento, hasta la involución completa del útero', la responsabilidad médica tiende a ser objetiva, cuando ab initio el proceso de embarazo se presentaba normal".

"En casos como éstos, parte de la doctrina se inclina por encontrar una obligación de resultado, puesto que lo que se espera de la actividad médica materno-infantil, es que se produzca un parto normal, que es precisamente la culminación esperada y satisfactoria de un proceso dispuesto por la naturaleza, en donde la ciencia médica acude a apoyarlo o a prever y tratar de corregir cualquier disfuncionalidad que obstaculice su desarrollo normal o ponga en riesgo a la madre o al que está por nacer. Lo especial y particular de la obstetricia es que tiene que ver con un proceso normal y natural y no con una patología". 479

\footnotetext{
478 CONSEJO DE ESTADO, Sección Tercera. C.P. Ruth Stella Correa Palacio. Sentencia del 13 de mayo de 2009. Expediente 15.033.

${ }^{479}$ CONSEJO DE ESTADO. Sección Tercera. C.P: Alier Hernández Enríquez. Sentencia de 17 de agosto de 2000. Expediente 12.123.
} 
Sobre el particular puntualizó el doctrinante CARLOS ALBERTO GHERSI:

(...) más allá de los riesgos inherentes a todo embarazo y parto -o a pesar de ellos- lo cierto es que el resultado final lógico de un proceso de gestación que, debidamente asistido y controlado por el médico obstetra, se presenta como normal, habrá de ser el nacimiento de una criatura sana, por ello, ante la frustración de dicho resultado, corresponderá al galeno la acreditación de las circunstancias exculpatorias. Éstas deberán reunir, a dichos fines, las características de imprevisibilidad o irresistibilidad propias del caso fortuito. 480

En posteriores providencias se recogió dicho criterio para considerar que en materia de responsabilidad médica por el servicio de obstetricia, no podía predicarse un régimen objetivo de responsabilidad, y por tanto, que la parte demandante no quedaba relevada de probar la falla del servicio sólo por el hecho de que la evolución del embarazo hubiera sido normal, pero el proceso del alumbramiento no hubiera sido satisfactorio, puesto que la obligación probatoria persistía, no obstante tal suceso constituía un indicio de dicha falla ${ }^{481}$. En tal línea se expuso posteriormente la misma el Consejo de Estado ${ }^{482}$ :

"Debe precisarse, en esta oportunidad, que las observaciones efectuadas por la doctrina, que pueden considerarse válidas en cuanto se refieren a la naturaleza especial y particular de la obstetricia, como rama de la medicina que tiene por objeto la atención de un proceso normal y natural, y no de una patología, (...) No existe, sin embargo, fundamento normativo para considerar que, en tales eventos, la parte demandante pueda ser exonerada de probar la existencia del citado elemento de la responsabilidad. Y más exigente será, en todo caso, la demostración del mismo, cuando se trate de un embarazo riesgoso o acompañado de alguna patología”.

Bajo el abrigo de esta tesis, corresponde al paciente por regla general probar: (i) el daño, (ii) la falla en el acto obstétrico y (iii) el nexo causal, mediante cualquier medio probatorio, siendo el indicio la prueba por excelencia ante la falta de una evidencia directa de la responsabilidad, dadas las especiales condiciones en que se

${ }^{480}$ CARLOS ALBERTO GHERSI. Responsabilidad Profesional. Buenos Aires: Ed. Astrea, 1998. Pág. 114.

${ }^{481}$ CONSEJO DE ESTADO. Sección Tercera. C.P. Enrique Gil Botero. Sentencia de 7 de diciembre de 2004. Exp: 14.767.

${ }^{482}$ CONSEJO DE ESTADO. Sentencia del 14 de julio de 2005 Exp. No. 15.276. 
encuentra el paciente frente a quienes realizan los actos médicos; la presencia de un daño en el momento del parto cuando el embarazo se desarrolló en condiciones normales, constituye un indicio de la presencia de una falla en el acto obstétrico, así como de la relación causal entre el acto y el daño.

De esta forma se tiene que en la actualidad en el marco de la falla en el servicio que deviene de la actividad medico obstetra, no se invierte automáticamente la carga de la prueba para dejarla a la entidad hospitalaria de la cual se demanda la responsabilidad, sino que dicha entidad debe demostrar la inexistencia de una falla en el acto obstétrico, o la falta de relación causal con el daño causado, rebatiendo el indicio de un embarazo normal y un proceso de alumbramiento insatisfactorio; ello por regla general, en tanto el Consejo de Estado ha admitido la posibilidad de continuar empleando los sistemas de aligeramiento probatorio de res ipsa loquitur (las cosas hablan por sí solas) o culpa virtual (faute virtuelle), en aquellos eventos en los que la elocuencia de los hechos releva al juez de un análisis de recorrido causal y de falla del servicio, dada la connotación del daño antijurídico ${ }^{483}$, esto es, cuando el daño padecido es de grandes proporciones, o se producen circunstancias particulares que acortan el recorrido causal y la culpa se entiende probada.

De esta forma se vislumbra que frente a la carga probatoria no se han sentado reglas probatorias absolutas con independencia del caso concreto, pues habrá caso en los cuales el onus probandi permanezca inmodificable con el objeto de rebatir el indicio, o donde sea dable la inclusión de presunciones judiciales en las cuales cobre vigencia el carácter dinámico de la carga de la prueba, para exigir de cada una de las partes dentro de un marco de lealtad y colaboración, y dadas las circunstancias de hecho, la prueba de los supuestos configurantes del tema de decisión.

De lo anterior se colige que, si bien es cierto no se han unificado criterios absolutos que deban ser acogidos en el análisis de este tipo de actuaciones profesionales, tales pronunciamientos jurisprudenciales dan cuenta de un cierto grado de "discrecionalidad" en la evaluación de los elementos de juicio del caso, de una manera que se acompasa con la legalidad, pero sobre todo con las circunstancias particulares del mismo, en aras de las protección de la parte vulnerable: el paciente.

De esta manera se pone de presente que en materia de la actividad médico obstetra, y en aras de la protección de sujetos especiales como lo son las madres gestantes y los neonatos, se presentan tendencia conciliatorias tendientes a

483 ÁLVAREZ, Pedro. La prueba por presunciones. Particular referencia a su aplicación judicial en supuestos de responsabilidad extracontractual. España: Ed. Comares, 2007. Pág. 80. 
flexibilizar el procedimiento probatorio común de la culpa, evitando así que el sistema se erija como una probatio diabólica que revictimiza y obstaculiza el derecho fundamental a la salud de los pacientes, y el acceso a una indemnización a causa de su conculcación.

\subsection{PERJUICIOS INDEMNIZABLES: PRINCIPIO DE PÉRDIDA DE LA OPORTUNIDAD}

El Consejo de Estado desde vieja data definió un tipo de perjuicio autónomo, que no deviene de la concreción de un daño material propiamente dicho como la muerte, esto es la Perdida de Oportunidad, indemnizable cuando se cercena la posibilidad de recuperar la salud y de tratar de sobrevivir, esto es, cuando una intervención más oportuna y un manejo más racional, suficiente y expedito por parte del sistema médico, hubiera permitido otro resultado final.

Este principio tiene aplicación cuando de haber dado cumplimiento a todos los procedimientos médicos en salud de manera diligente, no hubiese ocurrido la pérdida del "chance" o la oportunidad de recuperación de la salud.

En sentencia dictada el día 26 de abril de $1999^{484}$, la Sala Tercera del Consejo de Estado fundamentó esta teoría en un caso en el cual encontró que el retardo de una entidad prestadora de servicios, restó al paciente la oportunidad de sobrevivir; bajo este derrotero configuró el principio de 'pérdida de una oportunidad' impulsada por la teoría francesa "perte d'une chance", bajo los siguientes elementos: i). La culpa de un agente, ii). Una ocasión u oportunidad perdida que se configura en un perjuicio, y iii). La ausencia de prueba de la relación de causalidad entre la pérdida de la ocasión y la culpa, porque por definición la ocasión era aleatoria. La ocasión u oportunidad a la que se hace referencia, sólo tiene trascendencia cuando es virtual y atribuible a un incidente, en tanto si es apenas eventual no es reparable; solo cuando se demuestra clínicamente que las posibilidades de curación de un paciente hubiesen sido más grandes si el médico le hubiera dispensado cuidados más atentos, hay lugar a la indemnización de perjuicios por dicho concepto.

Más adelante mediante sentencia del 14 de marzo de $2013^{485}$, el Consejo de Estado reforzó lo expuesto sobre los requisitos en comento, estableciendo para la

${ }^{484}$ CONSEJO DE ESTADO. Sección Tercera. C.P Dr. Ricardo Hoyos Duque. Sentencia del 26 de abril de 1999. Expediente No 10.755.

485 CONSEJO DE ESTADO. Sección Tercera. C.P. Mauricio Fajardo. Sentencia del 14 de marzo de 2013. 
configuración de este perjuicio "la necesidad de cuantificar científica y estadísticamente la probabilidad de acceder a una ventaja o de evitar un perjuicio que desapareció como consecuencia de la acción o de la omisión del demandado, especialmente, la insoslayable exigencia de que entre el hecho dañino y la pérdida de chance como daño a reparar se acredite-como no podría ser de otro modo- la existencia del correspondiente ligamen causal, por manera que si dicha relación entre la falla del servicio y la pérdida de oportunidad cuya reparación se procura no queda debidamente probada, deben denegarse las pretensiones de la demanda".

Como ha de verse, el principio de "pérdida de una oportunidad" a pesar de su simple formulación y loable objeto, exige de fondo un contenido probatorio y sustancial estricto para su configuración, puesto que la perdida de oportunidad no puede ser una mera especulación, siendo necesario que de manera científica quede establecida cuál era la posibilidad real del paciente de recuperar su salud o preservar su vida, y que esa expectativa real haya sido frustrada por omisiones o erradas actuaciones médica. De tal suerte no bastan las especulaciones sin la prueba directa o indiciaria que acredite que el paciente tenía posibilidades reales de recuperar su salud, en tanto tiene que ser notoria la evidencia de posibilidades, y la determinación de las mismas de manera porcentual y concreta" 486 .

A la luz de los requisitos señalados por la jurisprudencia, es posible predicar la conculcación del derecho a la salud por la omisión que genera la perdida virtual del chance de recuperación, accediendo a la indemnización de perjuicios ha lugar.

Dentro de esta categoría general de responsabilidad denominada Falla médica, encontramos que de manera genérica las obligaciones de los galenos es de medio, es decir, los mismos deben adelantar toda gestión humanamente necesaria, y realizar el procedimiento médico conforme a la lex artis, con el objeto de proveer posibilidades de curación a un paciente, no siendo en tanto, por regla general, la curación propiamente dicha su obligación.

No obstante lo anterior y según las fijaciones del caso en concreto, es posible que el mismo adquiera obligaciones de resultado, verbigracia, frente a procedimientos médicos estéticos en donde el fin último es el logro de un producto final: el cambio de imagen.

${ }^{486}$ CONSEJO DE ESTADO. Sección Tercera. C.P. Mauricio Fajardo Gómez. Sentencia del 7 de julio de 2011. Expediente 20.139. 
Según la obligación surgida para el médico tratante y la entidad prestadora de servicios, se determina el régimen de responsabilidad aplicable, y las cargas procesales que a las partes corresponden, reglas que se derivan no sólo de las circunstancias del caso en concreto, sino también de los sujetos que en las mismas se involucran, por ejemplo, la carga de la prueba como se expuso a lo largo del capítulo, tiene una consideración especial en tratándose de la actividad médico obstetricia, dadas las connotaciones de los sujetos de la intervención, una madre gestante, y un neonato.

Del somero abordaje dado a las figuras, ha de verse que sobre las mismas no existen criterios absolutos, no obstante que su finalidad ha permitido la interpretación extensiva y la flexibilización de su aplicación en cada caso, con miras a facilitar el acceso a la indemnización de perjuicios a las personas víctimas de daños ocasionados por el sistema de salud y los médicos tratantes.

Estudiadas las anteriores figuras juridicas, desde sus distintas perspectivas, se torna necesario hacer una exposición normativa del sistema general de seguridad social en salud.

\subsection{SISTEMA COLOMBIANO DE SEGURIDAD SOCIAL EN SALUD}

La necesidad de un Sistema de Seguridad Social que actúe en procura del bienestar de las personas no es un concepto del todo nuevo. El asistencialismo del Estado en la materia hace parte esencial de la fórmula del Estado Social de Derecho, pues.

La sociedad no se presenta más como una entidad absolutamente independiente y autoregulada, dotada de un orden inmanente ajeno a toda regulación estatal que no fuera puramente adaptativa y promulgada en momentos de crisis. La experiencia histórica ha demostrado la necesidad de que el Estado tenga una decidida presencia existencial y regulativa en las dimensiones más importantes de la vida social y económica, con el objeto de corregir sus disfuncionalidades y racionalizar su actividad, lo que llevado a la práctica ha contribuido a difuminar - hasta cierto punto - las fronteras entre lo estatal y lo social, reemplazándolas por una constante, fluida e interactiva relación entre lo público y lo privado ${ }^{487}$.

${ }^{487}$ COLOMBIA. CORTE CONSTITUCIONAL DE COLOMBIA. Sentencia C-566 de 1995. Op. Cit. p. 10. 
En este contexto,

[...] el derecho fundamental a la salud es el enfoque teórico y político que se ha contrapuesto a la hegemonía neoliberal-utilitarista. Por derecho a la salud se entiende el acceso a los servicios de promoción de la salud, de prevención y curación de enfermedades y de rehabilitación en los casos de deterioro ${ }^{488}$.

En otras palabras, la salud deja de ser identificada con la construcción de hospitales y prevención sanitaria y pasa a ser un objetivo programático de los Estados del cual se derivan obligaciones a cargo de estos y a favor de los ciudadanos, tal como lo es la regulación y procura de efectividad del Sistema de Seguridad Social en salud y su consideración dentro del catálogo fundamental de los derechos, de modo tal que:

El derecho a la seguridad social, en la medida en que es de importancia fundamental para garantizar a todas las personas su dignidad humana, es un verdadero derecho fundamental cuyo desarrollo, si bien ha sido confiado a entidades específicas que participan en el sistema general de seguridad social fundado por la Ley 100 de 1993, encuentra una configuración normativa preestablecida en el texto constitucional (artículo 49 superior) y en los tratados internacionales que hacen parte del bloque de constitucionalidad; cuerpos normativos que dan cuenta de una categoría iusfundamental íntimamente arraigada al principio de dignidad humana, razón por la cual su especificación en el nivel legislativo se encuentra sometida a contenidos sustanciales preestablecidos $^{489}$.

Con estos antecedentes es de vital importancia recabar en el diseño, estructura y evolución del Sistema de Seguridad Social en Colombia y su impacto en la materialización de los pronunciamientos de la Corte Constitucional, puesto que tal concepción de manera definitiva necesita una fuerte infraestructura en su materialidad; además, de hacer una breve alusión a dichas disposiciones, recobra gran importancia aludir las falencias que determinan su crisis. Con dicho fin es necesario esbozar de entrada que, en Colombia, la salud se ha definido como un derecho que es garantizado a través de la prestación de un servicio público

488 ÁLVAREZ CASTAÑO, Luz Stella. Op. Cit. p. 3.

489 COLOMBIA. CORTE CONSTITUCIONAL DE COLOMBIA. Sentencia T-032-2012. M.P.: Jorge Ignacio Pretelt Chaljub. p. 1. 
esencial; de esta forma, el artículo 49 de la Constitución Política 490 establece que, la salud es en favor de todos los habitantes del territorio Nacional tanto un derecho como un servicio público. Por ello, surge la obligación del Estado de "[...] organizar, dirigir, reglamentar y garantizar su prestación de conformidad con los principios de eficiencia, universalidad y solidaridad" 491 .

La Ley 1751 de 2015 enfatiza el carácter fundamental autónomo de dicho derecho, como ya la máxima Corporación de lo Constitucional lo había hecho; seguramente en aras del alcance práctico de los preceptos de la Ley, la regulación de la misma comportara cambios fundamentales frente al contenido de la Ley 100 de 1993. La estructura legal del Sistema está contenida en el libro segundo de la Ley 100 de 1993, artículos 152 a 248, en los cuales se desarrolla la salud como un servicio público esencial, entendido este como aquel compuesto por actividades que:

[...] contribuyen de modo directo y concreto a la protección de bienes, la satisfacción de intereses, o la realización de valores ligados con el respeto, vigencia, ejercicio y efectividad de los derechos y libertades fundamentales. Ello es así, en razón de la preeminencia que se reconoce a los derechos fundamentales de la persona y de las garantías dispuestas para su amparo, con el fin de asegurar su respeto y efectividad ${ }^{492}$.

Dicho servicio está basado en las siguientes disposiciones:

De acuerdo con el tenor literal del artículo 157 de la Ley 100 de $1993^{493}$, existen dos regímenes de afiliación, por una parte, el contributivo que fue creado para las personas vinculadas mediante contrato de trabajo, servidores públicos, trabajadores independientes, jubilados y pensionados, el cual exige el pago de una cotización o aporte económico financiado directamente por el afiliado o en concurrencia con su empleador, en una proporción del 12.5\% del ingreso base de cotización, siendo administrado por las Empresas Promotoras de Salud, y por otra, el régimen subsidiado, pensado para las personas incapaces de cubrir el monto de la cotización al sistema y su grupo familiar, en consideración a su condición de pobreza y vulnerabilidad que los clasifica como beneficiarios de este régimen. La administración del mismo está a cargo de las direcciones locales, distritales o

\footnotetext{
490 COLOMBIA. Constitución Política de Colombia. Op. Cit. Artículo 49 [Titulo II].

491 COLOMBIA. CORTE CONSTITUCIONAL DE COLOMBIA. Sentencia T-060-2007. Op. Cit. p. 6.

492 COLOMBIA. CORTE CONSTITUCIONAL DE COLOMBIA. Sentencia C-075-1997. M.P.: Hernando Herrera Vergara. Bogotá. p. 14,15.

493 COLOMBIA. CONGRESO DE LA REPÚBLICA. Ley 100. (23, diciembre, 1993). Op. Cit.
} 
departamentales de salud, quienes deben suscribir contratos de administración del subsidio con las E.P.S, siendo financiados con los recursos del fondo de solidaridad y garantía y el sector oficial salud. "En Colombia los recursos financieros que se obtienen mediante cotizaciones y aportes representan cerca del $70 \%$ del total, mientras que más del $50 \%$ de los afiliados se encuentran en el régimen subsidiado"494. Adicionalmente, se encuentran las personas vinculadas temporalmente al sistema bajo la denominación de "participantes vinculados", categoría en la cual se asegura la atención en salud a las personas mientras logran afiliarse al régimen subsidiado.

Con estas disposiciones de entrada se caracteriza el sistema como una mezcla público-privada, cuyas principales fuentes de financiamiento son las cotizaciones de empleados y empleadores del régimen contributivo y los recursos fiscales obtenidos por medio de impuestos generales que financian el régimen subsidiado. De inusitada importancia resulta advertir que, aunque existe una diferente financiación de cada régimen, el plan de beneficios fue unificado bajo el principio de igualdad. Dicha mixtura surge del principio socialdemócrata en virtud del cual "quien tiene más recursos paga más" y con relación a la solidaridad, en el sentido de que los impuestos de todos se direccionan a sostener el sistema, en ninguna medida afecta como se ha dicho por algunos críticos la materialización del derecho a la salud.

La libertad de acceso a cualquiera de estos regímenes debe ser obligatoria en aras de la cobertura que propugna la norma, no obstante, ello se queda en una consideración meramente escrita, puesto que en la práctica se evidencia el sinnúmero de talanqueras interpuesta por las aseguradoras para dar efectividad a una afiliación; no es soslayada la negligencia de dichas empresas con miras a entrabar a como dé lugar la afiliación, máxime de pacientes con enfermedades catastróficas o con familiares en dicha condición. Ello, sin duda, afecta el derecho a la salud, pues no se garantiza de manera pronta la debida organización y prestación del servicio público, la atención en urgencias, la libertad de escogencia de EPS, entre otras cosas. Una vez adquirida la condición de afiliado tampoco cesan las talanqueras para el acceso al servicio, tal y como lo denunció la Defensoría del Pueblo ${ }^{495}$ en el marco de la celebración del Día Mundial de la Salud, en donde señala que en últimos cinco años el número de acciones de tutela que reclaman derechos relacionados con los servicios de salud en Colombia se

494 AGUDEL CALDERON, Carlos Alberto y otros. Sistema de salud en Colombia: 20 años de logros y problemas. En: Ciencia y Salud colectiva, Instituto de Salud Pública. Universidad Nacional de Colombia. 16(6) 2011. p. 2818.

495 UNIVERSIDAD DEL VALLE. Tutelas en salud siguen aumentando: Defensoría del Pueblo. En: http://salud.univalle.edu.co/comunicandosalud/wp-content/uploads/2015/04/08.04.2015-Tutelas-ensalud-siguen-aumentando-Defensor\%C3\%ADa-del-Pueblo.-p\%C3\%A1g-8.pdf 
incrementó en 25,2 por ciento, indicando que solo en 2014 se interpusieron más de 118 mil recursos de amparo, muy superior a los 94.502 de 2010.

Los afiliados clasificados en la mecánica del Sistema, suscriben con su afiliación un contrato mediante el cual aseguran sus riesgos de salud en el marco de un plan de beneficios contenido en un "Plan Obligatorio de Salud", el cual solo en la teoría permite la protección integral de las familias, la maternidad y enfermedad general, incluyendo la provisión de medicamentos esenciales en la presentación genérica de los mismos. En dicho plan como disposición especial, se exige a todas las EPS reasegurar los riesgos derivados de la atención a pacientes con enfermedades catalogadas como de alto costo. A renglón seguido, se plasma la atención básica cuya prestación será gratuita y obligatoria y la financiación de parte del Gobierno Nacional complementada con recursos de los entes territoriales.

El plan de beneficios contenido en el Plan Obligatorio de Salud, cuya estructuración se ve paradigmáticamente modificada a partir de la Ley 1751 de 2015, contentiva de un plan de beneficios configurado a partir de exclusiones, es y ha sido en nuestro criterio una de las primeras fallas del Sistema, no por su existencia en sí mismo, puesto que se hace imperativa a efectos de la sostenibilidad, sino porque para que dicha sostenibilidad no ponga en jaque el derecho fundamental a la salud, mínimamente debería gozar de legitimidad, condición que no se adquiere con la mera negociación del mismo por un estamento gubernamental sino por la misma sociedad.

Sin duda alguna, es el plan de beneficios una de las herramientas más fuertes para garantizar el reconocimiento del derecho a la salud como fundamental y enfatizar en la dignidad del paciente sin recurrir al mecanismo de la tutela; si el mismo fuese fruto de un consenso, verbigracia, con las fundaciones encargadas del trabajo con enfermos terminales, voceros de pacientes, entre otras, y así se priorizaran las prestaciones y se asignaran de entrada recursos para aquellas enfermedades catastróficas, la situación de la salud en Colombia mejoraría ostensiblemente. No obstante, el plan es negociado a las espaldas de los pacientes, de forma absolutamente limitante y con una interpretación restrictiva, cuyo fin pretendido se encamina a la garantía de lucro para las administradoras de salud.

Además de ilegitimo, el POS se ha tornado ineficaz, pues, aunque se supone que el recurso para su financiación ya está sufragado, según reciente informe de la Defensoría del Pueblo 7 de cada 10 tutelas que se interponen en el país, es decir, el $70,93 \%$, son para reclamar procedimientos, medicamentos y tratamientos que están contenidos en el POS, pero que a falta de recursos no son entregados. Visto que en "859 de los 1.123 municipios que tiene el país, sus pobladores recurrieron 
a la tutela con este propósito" 496 , es ostensible que en Colombia son negados a los pacientes los derechos exigibles consagrados en el plan a pesar de que están cubiertos económicamente por el Sistema.

Por otra parte, teniendo en cuenta que según el mismo informe ocho de cada diez tutelas son interpuestas contra las entidades promotoras de servicios de salud, puede argüirse que otro de los principales problemas que surgen en el reconocimiento de esta condición como derecho fundamental autónomo, es la existencia de las EPS, y de suyo, la consideración mercantilista de las mismas. Desafortunadamente, sobre esta disposición la Ley 1751 de $2015^{497}$ no introdujo cambios trascendentes, en tanto permitió que el Sistema en futuro continúe siendo operado tanto por entidades públicas, privadas como mixtas.

Si bien se estableció que el Sistema de Seguridad Social en Salud en nuestro país se encuentra bajo la orientación, regulación, supervisión, vigilancia y control del Gobierno Nacional y del Ministerio de Salud, quienes para tal propósito tienen funciones de inspección y vigilancia, y además se creó el Consejo Nacional de Seguridad Social en Salud adscrito al último, como organismo de dirección del Sistema que desempeña funciones con carácter permanente, dichas disposiciones han quedado en letra muerta, pues las atribuciones de dirección y control han cedido ante el enorme poder adquirido por las Empresas Promotoras de Salud. Estas entidades están reguladas por el Capítulo I del Título II de la Ley $100^{498}$, definidas como las responsables de la afiliación y registro de los afiliados y del recaudo de sus cotizaciones. En estos términos, la función básica de estas entidades es la de organizar y garantizar la prestación del plan de salud obligatorio del que se ocupa el capítulo III del título I de la Ley 100 de 1993, prestando sus servicios de manera directa o indirecta, mediante la contratación de servicios de salud con las Instituciones prestadoras (IPS).

La Ley ${ }^{499}$ dispuso que las EPS pueden ser de naturaleza pública, privada o mixta y pueden ser conformadas como Instituto de Seguros Sociales, Cajas, Fondos, Empresas de Previsión del sector público, Entidades de Medicina Prepagada, EPS creadas por los departamentos, distritos y municipios, Organismos creados por empresas públicas o privadas para prestar servicios de salud y Entidades privadas, solidarias o públicas creadas con el propósito específico de funcionar como EPS, previa autorización de la Superintendencia Nacional de Salud; empero, la amplia

496 REDACCIÓN SALUD. Cada cinco minutos hay una nueva tutela en el País. (4 de septiembre de 2013). (en línea). http://www.eltiempo.com/archivo/documento/CMS-13045163. (citado el 04 de septiembre de 2013).

497 COLOMBIA. CONGRESO DE LA REPÚBLICA DE COLOMBIA. Ley 1751. Op. Cit.

498 COLOMBIA. CONGRESO DE LA REPÚBLICA. Ley 100. (23, diciembre, 1993). Op. Cit. 499 lbíd. 
gama de posibilidades, en Colombia, las EPS privadas han ganado el mayor terreno en la administración del Sistema desde la noción empresarial.

Esta es una de las grandes barreras en la garantía del derecho fundamental a la salud, pues como lo ha mostrado la experiencia, las mismas se tornan políticamente muy poderosas dentro de desarrollo mercantil y consiguen frenar esfuerzos para su control y regulación. Es un equívoco permitir la inclusión de empresas meramente privadas para la administración de los recursos públicos de la salud, pues las mismas no carecen de ánimo de lucro, sino que es en el mismo en el que centran sus esfuerzos, generando su perdida en casos tan sonados como el de Saludcoop, para reseñar tan sólo un caso de intervención, empresa que desvió recursos de la salud por astronáuticas sumas de dinero. Es preciso aludir la información suministrada por la Contralora de la Republica Sandra Morelli al periódico El Espectador, responsabilizando a la EPS Saludcoop, en cabeza del expresidente de la EPS, Carlos Gustavo Palacino, del desvío y detrimento patrimonial de $\$ 3$ billones de pesos en recursos de la salud ${ }^{500}$.

Es evidente el poder que tienen en Colombia las EPS, apalancadas desde las altas esferas del poder, así mismo, lo es la dificultad de volver atrás una vez creadas, por lo cual resultan imperativas las políticas de regulación y control, así como la creación de mecanismos que hagan efectiva la exigibilidad de prestaciones frente a las mismas, sin acudir para tal fin a la tutela. De la misma manera, sería conveniente apoyar desde las políticas gubernamentales la competencia entre dichas empresas a partir de la creación, por ejemplo, de una administradora de salud sin ánimo de lucro, con beneficios tributarios, con financiamiento estatal, con la participación administrativa de las fundaciones, asociaciones y vocerías de pacientes, con miras a que, enfrentadas a tales costos, las EPS de carácter privado sean obligadas a disminuir sus costos.

La crisis del Sistema de salud que hoy presenta el país y la vulneración de tal derecho a los afiliados es en gran parte producto del desborde de poder de las EPS, que de suyo tienen sumidas en dificultades financieras a las Empresas Sociales del Estado o ESE; en el año 2014 La Superintendencia Nacional de Salud "anunció la apertura de 16 procesos administrativos sancionatorios contra igual número de EPS del régimen subsidiado, que acumulan 1 billón 126 mil millones de pesos en deudas con clínicas y hospitales que han prestado servicios a sus afiliados" 501 . Dicha crisis

500 REDACCIÓN VIVIR. El caso Saludcoop según la Contraloría (en línea) En: EL ESPECTADOR. Sección salud. (7 Nov 2013). (En línea). http://www.elespectador.com/noticias/salud/el-casosaludcoop-segun-contraloria-articulo-457191 (citado 05 de julio de 2015).

501 ESTILO DE VIDA. Bajo lupa, 16 EPS del régimen subsidiado que les deben a hospitales. En: EI Tiempo. (24 de junio de 2014). (En línea). http://www.eltiempo.com/estilo-de-vida/salud/supersaludinvestiga-a-16-eps-del-regimen subsidiado-por-deudas-/14162615. (Citado el 07 de junio de 2015). 
ha estado ahondada por las falencias en la vigilancia y control de los organismos gubernamentales, Superintendencia Nacional de Salud y Ministerio de Protección Social, que se han abstenido de utilizar las herramientas coercitivas frente a señaladas instituciones, como la imposición de multas a favor de la subcuenta de solidaridad del fondo de solidaridad y garantía y a cargo de las entidades que violen lo previsto en la Ley 100.

Adicionalmente, el Sistema carece de fuerte control social y veeduría ciudadana que impulse el control social en temas de cobertura, eficiencia y calidad de los servicios. Solo a partir del empoderamiento social es posible la exigencia de un servicio de calidad, frenar la pérdida de recursos y lograr que las cuotas moderadoras no se conviertan en una barrera que impida el acceso a los servicios de salud cuando quienes lo requieren son las personas más pobres y vulnerables. Dichas veedurías deberían tener como objetivo racionalizar desde las dos orillas las prestaciones y el uso de los servicios del sistema, en pro de un buen servicio y de su sostenibilidad y permanencia.

Como se señaló a lo largo del texto, la estructura de este Sistema no varía de manera contundente con la incorporación de la Ley 1751 de 2015 ${ }^{502}$, Ley Estatutaria del Derecho a la Salud, la cual reconoce el derecho a la salud como fundamental y autónomo y en su garantía define el Sistema de Salud como un conjunto articulado y armónico de principios y normas; políticas públicas; instituciones; competencias y procedimientos; facultades, obligaciones, derechos y deberes; financiamiento; controles; información y evaluación, dispuestas por el Estado para la garantía y materialización del derecho fundamental; este Sistema así descrito es indeterminado y carece de concreción, por lo cual sus alcances serán conocidos solo de cara a su posterior regulación.

Agotados en los términos anteriores los principales aspectos de la regulación del Sistema de salud en Colombia, vale advertir nuevamente como se hizo a lo largo del texto, la necesidad de replanteamiento de los temas conflictivos a partir de la regulación de la Ley Estatutaria del Derecho a la Salud, con miras a que se empiece a cerrar la brecha existente entre la prestación del servicio esencial y la garantía del derecho fundamental autónomo. El avance en la consideración del derecho a la salud como derecho fundamental, exige desafíos legales, prácticos y de ejecución que deben ponerse en obra para alcanzar la materialidad y efectiva garantía del mismo.

502 COLOMBIA. CONGRESO DE LA REPÚBLICA DE COLOMBIA. Ley 1751. Op. Cit. 
2.7.1 Diseño del sistema de seguridad social en salud. El Sistema de Salud contemplado en la Ley 100 de $1993^{503}$ y normas posteriores, está pensado y formulado para la buena prestación de un servicio y no para la efectividad de un derecho fundamental, careciendo así de vías para dar exigencia al mismo, por lo que los usuarios se han visto abocados a tutelar siempre que requieren hacer exigible su derecho. Este tema sin duda representa gran importancia para arribar a un aporte final, que merece un posterior y más amplio desarrollo.

Huelga resaltar, que si bien la teoría plasmada en el texto de la Ley 100 de 1993 consagra la salud como un servicio y contiene principios rectores garantistas como el de cobertura, eficiencia, "[...] universalidad y equidad, mediante los cuales se busca la prestación a todos los habitantes sin discriminación alguna y la igual calidad de los servicios a todos los beneficiarios"504, tal Sistema dista del contenido filosófico de este tema concreto en la realidad, debido a la inclusión de múltiples disposiciones adecuadas con fines económicos para garantizar más que la sostenibilidad del Sistema y el lucro de las Empresas Promotoras de Salud de carácter privado, las cuales lejos de abanderar los derechos en salud, buscan establecer barreras para aumentar sus rendimientos económicos a pesar de tratarse en un gran porcentaje de dineros públicos. Todo ello aunado a la falta de presupuesto e inversión incluso para sostener los mínimos plasmados en el Plan Obligatorio de Salud y la escasa cobertura de los planes cuyo incremento progresivo se ha quedado en el papel, lo que evidencia la forma como se han creado barreras para la garantía del derecho a la salud. Todo lo anterior, motiva la búsqueda de mejores condiciones por vía de los medios judiciales como la tutela.

A partir de dichos pronunciamientos jurisprudenciales emanados por diversas tutelas que han plasmado en cada caso en concreto las reglas sobre la concesión de prestaciones, medicamentos, diagnósticos, entre otros, se ha desarrollado la fundamentalidad del derecho a la salud, fijando el alcance de dicho derecho ante los vacíos normativos y la falta de implementación de políticas para hacer efectivo lo que constitucionalmente se predica. En estos pronunciamientos se ha redireccionado el Sistema en aras de cerrar la brecha existente entre la connotación jurisprudencial del derecho a la salud y la estructura legal creada para su prestación; no obstante, se hace imposible desde la jurisdicción emanar decisiones de mayor trascendencia, por no ser de su resorte. Por lo anterior, resulta de vital trascendencia que los organismos gubernamentales encargados de la dirección, vigilancia y control de la salud en Colombia incorporen las disposiciones constitucionales en la actividad diaria y misional de cada ente administrador del Sistema y replanteen la estructura del mismo a fin de lograr su eficacia y capacidad

503 COLOMBIA. CONGRESO DE LA REPÚBLICA. Ley 100. (23, diciembre, 1993). Op. Cit.

504 MESA DE TRABAJO DE BOGOTÁ SOBRE DESPLAZAMIENTO INTERNO. Boletín No. 13. septiembre de 2005. p. 12. 
para armonizarse con el alcance constitucional dado a tal derecho, en el entendido de que es fundamental, y de que del mismo se desprende la garantía de otros derechos naturalmente fundamentales para el desarrollo de la persona.

\subsubsection{Ley estatutaria de la salud como derecho fundamental}

2.7.2.1. Perspectiva diacrónica. La evidente crisis del Sistema de Salud en Colombia, manifestada en la desatención de las necesidades y requerimientos básicos de bienestar de la población, suscitó diversas reacciones intentando buscar un camino idóneo a través del cual rediseñar el modelo instituido a partir de las previsiones de la Ley 100 de 1993, dando aplicación a lo señalado y ordenado por la Corte Constitucional en cuanto a los mínimos de satisfacción de este derecho. La gravedad de la situación del Sistema de salud ameritaba una reforma significativa que se introdujera respetando los principios democráticos que sustentan el Estado Social de Derecho, siendo en este afán presentado al Senado en el año 2013 el proyecto de ley ordinaria ${ }^{505}$ por el cual se redefinía el Sistema General de Seguridad Social en Salud, proyecto del cual llamaba la atención el entendimiento de la salud como servicio. Sin duda, el mismo no sugería avance alguno en la consideración de la salud como un derecho fundamental autónomo, pues no contemplaba variaciones en la organización, dirección, coordinación y control sobre dicho servicio ni proponía una solución estructural a las desavenencias del sistema, al continuar contemplado los recobros desmesurados, la intermediación financiera, el sistema de contribuciones a través de copagos y cuotas moderadoras, entre otros. Dicha iniciativa, mantenía una perspectiva abiertamente económica, puesto que no descartaba la posibilidad de adjudicar los cargos de dirección de las Empresas Sociales del Estado según conveniencias políticas, que como es sabido someten a su albedrio el desarrollo y gestión de las entidades administradas, augurando así la continuidad del estado de crisis del Sistema.

En este sentido se pronunciaron sobre la reforma la Comisión de Seguimiento a la Sentencia T-760 de 2008 y de Reforma Estructural del Sistema de Salud, CSR, y las organizaciones sociales, quienes consideraron que el problema del Sistema es de estructura y organización, que no de financiamiento ni de regulación, aspectos que en nada se solucionaban con la propuesta del gobierno que de manera clara mantenía bajo diferente denominación la lógica del sistema: aseguramiento con competencia regulada y subsidio a la demanda. Desde la óptica constitucional, y a tono con los desarrollos jurisprudenciales en punto de la naturaleza fundamental del derecho a la salud, el Proyecto de Ley presentado no solo resultaba inadecuado,

505 COLOMBIA. CONGRESO DE LA REPÚBLICA DE COLOMBIA. Proyecto De Ley No.210 De 2013. Por medio de la cual se redefine el sistema general de seguridad Social en salud y se dictan otras disposiciones. Bogotá, D.C. 
sino insuficiente, dada la necesidad de una reforma de fondo que garantizara el derecho más allá de su carácter prestacional, modificando en ese entendido la estructura sustancial del Sistema, en lo ateniente a la Empresas Promotoras de Salud.

Ante la insuficiencia del conjunto de proyectos hasta ahí presentados, los Decretos de Emergencia Social y el precario proyecto de Ley ordinaria en comento, el Gobierno presentó el proyecto de Ley Estatutaria No. 209 de $2013^{506}$ del senado por medio de la cual se regula el Derecho Fundamental a la Salud y 267 de la Cámara, el cual mediante un breve articulado propuso garantizar tal derecho fundamental, regularlo y establecer sus mecanismos de protección. En el proyecto saltaba a la vista en primera medida la consideración de la salud no como servicio, sino como derecho fundamental, autónomo e irrenunciable, tanto en lo individual como en lo colectivo; así, diferencia entre la naturaleza de la salud como derecho, y su efectividad a través su prestación como servicio público esencial obligatorio, ejecutado bajo la indelegable dirección, supervisión, organización, regulación, coordinación y control del Estado.

De manera novedosa respecto al proyecto de Ley ordinaria, esta iniciativa incorporó elementos esenciales que se entendían determinantes en la fundamentalidad del derecho a la salud, tales como507: aceptabilidad, referida al respeto de la ética médica y el pluralismo; accesibilidad, tanto física como económica, relativa a los servicios prestados en condiciones de igualdad y sin discriminación, aspecto sobre el cual se impone un deber al Estado consistente en garantizar la disponibilidad de los servicios de salud para toda la población en el territorio nacional, en especial, en las zonas marginadas o de baja densidad poblacional, advirtiendo que la extensión de la red pública hospitalaria no depende de la rentabilidad económica, sino de la rentabilidad social; calidad de las tecnologías y servicios ofrecidos, e idoneidad profesional del personal educado, capacitado y evaluado de manera oportuna. Mediante la enunciación de este conjunto de elementos, el proyecto no se limitaba, en teoría, a realizar una lista única de principios, sino que definía las características vitales para la consideración fundamental de este derecho, imponiendo la obligación de evaluación de sus elementos esenciales por parte de los agentes del sistema, con el propósito de diseñar e implementar políticas públicas tendientes a mejorar las condiciones de salud de la población.

506 COLOMBIA. CONGRESO DE LA REPÚBLICA DE COLOMBIA. Proyecto de Lley Estatutaria 209 de 2013 Senado. Por medio de la cual se regula el derecho fundamental a la salud y se dictan otras disposiciones. Gaceta del congreso. Bogotá, D.C. № 116. 2013.

507 COLOMBIA. CONGRESO DE LA REPÚBLICA DE COLOMBIA. Proyecto de Lley Estatutaria 209 de 2013 Senado. Op. Cit. 
Asimismo, contempló derechos y deberes para las personas relacionadas con el derecho fundamental a la salud $y$, en consecuencia, estableció que tal fundamentalidad comprendía el derecho de participación en las decisiones adoptadas por los agentes del Sistema de salud, disponiendo mecanismos de veeduría y seguimiento para lograr la concreción de la mencionada participación. Este proyecto discutido es el que finalmente se aprueba como Ley Estatutaria No 1751 del 16 de febrero de 2015, previas algunas modificaciones incorporadas a partir del análisis previo de constitucionalidad realizado por la Corte Constitucional mediante sentencia No. 313 del 09 de mayo de 2014, con ponencia del magistrado Gabriel Eduardo Mendoza Martelo.

2.7.2.2. Análisis de constitucionalidad. La Corte en el particular realizó un análisis previo de constitucionalidad tanto de forma como de fondo ${ }^{508}$ del contenido de los 26 artículos de la norma, a efectos de verificar que dicho proyecto final se tramitara en correspondencia con el procedimiento riguroso señalado para las leyes estatutarias en nuestra Constitución. En el primer análisis, se determinó que se hicieran las publicaciones de rigor y que la aprobación del texto contará con la participación del quorum reglamentario. En el mismo sentido, se concluyó la no transgresión de la unidad de materia sinónimo de coherencia de la norma. Igualmente, se observó que no se hacía preciso realizar consulta previa, dado que las disposiciones del proyecto eran de carácter general y no suponían una afectación directa y específica a las minorías. Por otra parte, en el análisis de fondo se estudiaron cada una de las disposiciones de la norma a la luz de la Constitución y del bloque de constitucionalidad, dando como resultado el análisis de la Sentencia C-313 de 2014509, que en cortas líneas se esboza a continuación:

- El artículo $1^{\circ}$ del proyecto ${ }^{510}$, que preceptúa su objeto encaminado a garantizar el derecho fundamental a la salud y a establecer sus mecanismos de protección, se analiza constitucional en el entendido que los mecanismos creados a partir de la expedición de la ley no pueden modificar ni menoscabar el mecanismo constitucional de la acción de tutela, tal como está regulado en las disposiciones constitucionales y legales correspondientes. Bajo dicho alcance se condicionó la exequibilidad de la norma.

- En relación con el artículo $2^{511}$, se estimó que la naturaleza y contenido dado al derecho fundamental son acordes a los postulados constitucionales

508 COLOMBIA. CORTE CONSTITUCIONAL DE COLOMBIA. Sentencia C-313/14. M.P.: GABRIEL EDUARDO MENDOZA MARTELO. Bogotá, D.C. p. 66.

509 lbíd.

510 lbíd. p. 547.

511 lbíd. p. 548. 
reiteradamente expuestos por la Corte Constitucional. Dicha Corporación no presentó reparos frente a los elementos incluidos por el legislador al momento de caracterizar el derecho a la salud a la luz de una definición amplia del mismo que abarca su acceso con miras a la promoción, prevención, diagnóstico, tratamiento, rehabilitación y paliación; no obstante, hizo preciso incluir a dicho listado de actividades en salud la recuperación, así como el acceso a todas las facilidades, establecimientos, bienes y condiciones necesarios para alcanzar el más alto nivel de salud de manera oportuna, eficaz y con calidad.

- En cuanto al ámbito de aplicación, artículo $3^{512}$, la Corte dispuso que la misma, en tanto su contenido general, debía aplicarse a toda categoría de agentes y usuarios del sistema en los más amplios términos, esto es, a todos los que intervengan de manera directa o indirecta en la garantía del derecho fundamental a la salud. Si bien se criticó por etéreo o indeterminado el alcance de esta disposición, se avaló su constitucionalidad en tratándose de una lista abierta que irá alcanzando su concreción en la medida en que la afectación y/o la relación con el derecho lo vayan poniendo de presente, sin poner ello en riesgo la garantía del derecho; esta interpretación contiene una fuerte razón de ser que es hacer extensivos los mandatos de la Ley a los diversos sujetos que participan e inciden en el sistema de salud, incluso antes de su perfecta delimitación.

- En cuanto al artículo $4^{513}$, que define el Sistema de Salud como un conjunto articulado y armónico de principios y normas, políticas públicas, instituciones, competencias y procedimientos, facultades, obligaciones, derechos y deberes, financiamiento, controles, información y evaluación, que el Estado disponga para la garantía y materialización del derecho fundamental de la salud, la Corte resolvió declararlo exequible, advirtiendo que la expresión "que el Estado disponga "no podrá entenderse como facultad alguna para disminuir los factores existentes que configuran el sistema de salud ni retroceder en cuanto a garantías, resultando en dicho sentido inaceptable el adelgazamiento del volumen de recursos orientados a la garantía del derecho, pues ello implicaría un detrimento para su materialización. Bajo este entendido, se advierte que el paradigma de irreductibilidad del punto de partida, para la consecución del derecho, y de no regresividad, que se predica de derechos fundamentales como el que está en estudio, debe orientar el significado de la presente disposición.

- A título seguido, el artículo $5^{514}$ contentivo de las obligaciones del Estado fue declarado exequible en el entendido de que no solo le asisten al mismo las de

512 COLOMBIA. CORTE CONSTITUCIONAL DE COLOMBIA. Sentencia C-313/14. Op. Cit. p. 548 513 Ibíd. p. 548, 549.

${ }^{514}$ COLOMBIA. CORTE CONSTITUCIONAL DE COLOMBIA. Sentencia C-313/14. Op. Cit. 548, 549. 
respetar, proteger y garantizar el goce efectivo del derecho, sino también toda clase de obligaciones en materia de salud faltantes, que se acompasen con la Carta y con la Observación 14.

En relación con los deberes contenidos en los literales a), e), f), g), h) y j), la Corte los encontró ajustados a la Constitución sin ningún reparo, ello en tanto ${ }^{515}$ : a), es importante la inclusión de conductas de no hacer como censurables cuando causan daño a la salud, justificándose la obligación de respeto, u abstención preceptuada en este literal; el literal e) es expresión del deber de vigilancia y supervisión del servicio de salud en cabeza del Estado. El literal f) es exequible en tanto está orientado a lograr la efectividad del derecho. El literal $g$ ) comporta actividades relevantes para el establecimiento de políticas en salud, tales como el seguimiento continuo a la evolución de las condiciones de salud de los pacientes. El literal $h$ ), que preceptúa la realización de evaluaciones sobre los resultados del goce efectivo del derecho y eficacia del Sistema de Salud, fue declarado exequible, pues, se advirtió que presentaba finalidades similares a la del literal $g$ ). El literal $j$ ) también se encontró ajustado a la Constitución en la medida en que se entiende como necesaria la intervención del Estado en el mercado de los medicamentos, dispositivos médicos e insumos a efectos de la real efectividad del derecho a la salud.

Por su parte se condicionó la interpretación de los deberes contenidos en el literal b), c), d) y i $)^{516}$. En esta línea, la Corte declaró exequible el literal b) que asigna como deber al Estado el de formular y adoptar políticas de salud dirigidas a garantizar el goce efectivo del derecho en igualdad de trato, en el entendido de que se deben continuar aplicando medidas de discriminación positiva que reivindiquen los derechos de los grupos vulnerables, discriminados 0 marginados. El literal c) fue declarado exequible, pues resulta ajustado a la constitución el deber de formular y adoptar políticas en materia de promoción, prevención atención y rehabilitación en salud. A estas actividades se deben incorporar también las destinadas a la recuperación y la paliación de la enfermedad. Por su parte, el literal $d$ ), que impone la obligación de establecer mecanismos para evitar la violación del derecho a la salud y definir su régimen sancionatorio, se analizó exequible en el entendido dado al artículo primero de la norma, esto es, en cuanto a la prohibición de expedir normas que menoscaben el mecanismo de protección de los derechos fundamentales. Dicho de otro modo, la inclusión de mecanismos de protección del derecho se hace sin perjuicio de las garantías protectoras de los derechos fundamentales. Por último, el literal i) fue declarado exequible dada la importancia de la sostenibilidad financiera para la realización del derecho, advirtiéndose como otrora se había

515 lbíd. p. 549.

516 lbíd. p 549, 550. 
hecho vía jurisprudencia, que "[...] la sostenibilidad financiera no puede comprender la negación a prestar eficiente y oportunamente todos los servicios de salud debidos a cualquier usuario"517. En tal sentido, la falta de recursos no puede ser óbice para desconocer las obligaciones que asisten al Estado en la efectiva materialización del derecho a la salud, puesto que la sostenibilidad fiscal del Sistema debe necesariamente ceder en aras de la garantía que predica la norma y que la Corte ha definido a través de sus pronunciamientos.

- Frente a los elementos y principios contenidos en el artículo $6{ }^{518}$, esto es los elementos de a). Disponibilidad; b). Aceptabilidad; c). Accesibilidad; d). Calidad, y principios de: a). Universalidad; b). Pro homine; c). Equidad; e). Oportunidad; f). Prevalencia de derechos; g). Progresividad del derecho; h). Libre elección; i). Sostenibilidad; j). Solidaridad; k). Eficiencia; I). Interculturalidad; m). Protección a los pueblos indígenas; $n$ ). Protección pueblos y comunidades indígenas, ROM y negras, afrocolombianas, raciales y palanqueras, señaló la Corte la necesidad de acompasarlos con los señalados en la Observación No 14, pues si bien muchos de ellos están allí contenidos, tal norma carece de demás elementos incluidos en la Observación No 14.

Así se señaló que el elemento de Disponibilidad contenido en el literal a) del inciso $1^{519}$, debía comprender programas de salud y personal médico profesional competente, así como medicamentos esenciales definidos en el programa de acción sobre medicamentos de la OMS y demás factores determinantes básicos de la salud como el agua potable y las condiciones sanitarias adecuadas entre otros, garantizando no solo la existencia de servicios tecnologías e instituciones, sino también de facilidades, establecimientos, bienes, servicios, tecnologías y condiciones necesarias para alcanzar el más alto nivel de salud. En cuanto a la aceptabilidad $^{520}$ no se formularon reparos. En punto de la accesibilidad ${ }^{521}$ se advirtió que debía entenderse en consonancia con las varias formas de accesibilidad que prescribe la observación 14, extendiendo el concepto al conjunto de componentes que señala dicha observación como adecuados para realizar el servicio, esto es, no solo la existencia de servicios tecnologías e instituciones, sino la de facilidades, establecimientos, bienes, servicios, tecnologías y condiciones necesarios para alcanzar el más alto nivel de salud. Para el caso de la calidad ${ }^{522}$, sinónimo de idoneidad médica y científica, se extiende dicho elemento más allá de los servicios y tecnologías, a los demás medios ya referidos en los otros elementos esenciales del derecho.

517 COLOMBIA. CORTE CONSTITUCIONAL DE COLOMBIA. Sentencia C-313/14. Op. Cit. 550.

518 lbíd. p. 550-552

519 COLOMBIA. CORTE CONSTITUCIONAL DE COLOMBIA. Sentencia C-313/14. Op. Cit. 550.

520 lbíd. p. 550.

521 lbíd. p. 550.

522 Ibíd. p. 550. 
En referencia a los principios, se examina que el de universalidad tiene asidero constitucional en el artículo 49 de la Carta; el principio pro homine fue declarado exequible dada su relevancia como cláusula hermenéutica para la interpretación de los derechos fundamentales. Frente al principio de equidad se explayó su asidero constitucional y si entendimiento en punto de que el "[...] mejoramiento de salud de las personas de escasos recursos, de los grupos vulnerables y de los sujetos de especial protección"523, implica una medida afirmativa del Estado en la adopción de políticas públicas dirigidas a mejorar la prestación del servicio en todas sus etapas de promoción, prevención, diagnóstico, curación, rehabilitación, paliación y recuperación. De otra parte, el principio de Continuidad fue declarado exequible, pero la Corte excluyó las expresiones de manera intempestiva y arbitraria que calificaban la interrupción del servicio, pues con ellas se disponían elementos que conducían a cercenar el goce del derecho. El principio de oportunidad contenido en el literal e), inciso 2 se declaró exequible en tanto su coherencia con la Constitución. No obstante, la Corte proscribió las expresiones que se requieran con necesidad y que puedan agravar la condición de salud de las personas, pues en criterio de la misma implicaban una restricción al goce del derecho y al elemento accesibilidad.

La prevalencia de los derechos del menor ${ }^{524}$, dada la copiosa jurisprudencia sobre la materia y su status de primacía contemplado en el artículo 44 de la norma superior, se consideró exequible sin condicionamientos. El principio de progresividad ${ }^{525}$ fue estudiado por conforme el precedente, destacándose, en primera medida, que el mismo no es óbice para el desconocimiento del derecho, puesto que de suyo implica la exigibilidad inmediata de ciertas obligaciones que recaen en el Estado, así mismo, se explayó que el mismo va de la mano con la prohibición de regresividad, desconociendo una lectura distinta el goce efectivo del derecho. Subsiguiente, el principio de la libre elección ${ }^{526}$ se encontró ajustado a los preceptos constitucionales, siendo luego del mismo analizado uno con alto contenido y alcance. La sostenibilidad ${ }^{527}$, cuyo alcance fue fijado de cara a la sentencia C-288 de 2012 y el artículo 334 de la Carta Superior, como un mero criterio orientador que no tiene la calidad de principio, siendo en virtud del mismo improcedente desconocer las garantías del derecho fundamental a la salud, en tanto los recursos económicos de ninguna manera pueden ser talanquera para la exigibilidad de la garantía del derecho, tal y como se explayó frente a tal obligación encargada al Estado.

${ }^{523}$ COLOMBIA. CORTE CONSTITUCIONAL DE COLOMBIA. Sentencia C-313/14. Op. Cit. 551.

524 lbíd. p. 551.

525 Ibíd. p. 551.

526 lbíd. p. 551.

527 Ibíd. p. 551. 
Por su parte, el principio de solidaridad ${ }^{528}$ se encontró ajustado al preámbulo de la Constitución y a la razón de ser del Estado Social de Derecho; la eficiencia como principio fue declarada exequible dada su expresa consagración constitucional para el derecho a salud, precisándose la necesidad de leer de manera amplia la expresión "recursos, servicios y tecnologías", haciéndola extensiva a otros medios. Los literales I) y $\mathrm{m})^{529}$ fueron declarados constitucionales, pues, comportan disposiciones concordes con el respeto a las minorías que se preceptúa en el artículo 13 de la Constitución, en el cual se dispone el trato discriminatorio positivo reivindicador de derechos. Por último, en cuanto a la principialistica, el literal $n{ }^{530}$ contentivo del principio de Protección de pueblos y comunidades indígenas, ROM y negras, afrocolombianas, raizales y palanqueras, fue declarado exequible por las mismas razones que los literales I) y m), advirtiéndose que la expresión "aplicará" no excluye a las otras facetas del derecho, particularmente "la creación" del mismo, pues, allí también debe operar la concertación.

- En cuanto al artículo $7^{531}$ que preceptuaba la acción de evaluación anual de indicadores de goce efectivo como herramienta de trazabilidad en cabeza del Ministerio de salud y protección Social, en aras del diseño e implementación de políticas públicas tendientes para mejorar las condiciones del derecho a la salud y fomentar la participación y veeduría ciudadana sobre los resultados del sistema, la Corte determinó su exequibilidad.

- El artículo $8^{532}$, que señala el principio de integralidad, se examinó exequible en tanto su inclusión resulta trascendente para la realización efectiva del derecho mandada por los artículos 2 y 49 de la Carta. Sin embargo, se señaló al igual que lo hecho para la misma expresión en todo lo largo del texto, que los términos servicios y tecnológicos", debía ser leídos desde la Constitución, y por ende, incluir los otros elementos faltantes para la real y completa prestación del servicio. El inciso 2 que por su parte dispone la interpretación favorable en caso de duda sobre el alcance del servicio, debe entenderse según el máximo Tribunal Constitucional a la luz del principio pro homine, en garantía de la dignidad del ser humano; ello en tanto quien espera un servicio o tecnología en salud se encuentra frecuentemente en una situación de vulnerabilidad, que exige máximos de protección. En cuanto a la disposición contenida en el parágrafo que restringía el acceso a las tecnologías o servicios de salud directamente

\footnotetext{
${ }^{528}$ COLOMBIA. CORTE CONSTITUCIONAL DE COLOMBIA. Sentencia C-313/14. Op. Cit. 551, 552.

529 lbíd. p. 552.

530 lbíd. p. 552.

531 lbíd. p. 552.

${ }^{532}$ COLOMBIA. CORTE CONSTITUCIONAL DE COLOMBIA. Sentencia C-313/14. Op. Cit. 553.
} 
relacionados con el tratamiento ${ }^{533}$, la Corte determinó que los conceptos de "vinculación directa" y "vinculación indirecta" condicionan la inclusión o exclusión de la prestación del servicio, siendo una limitación injustificada que hacía imperativo excluir tal parágrafo del ordenamiento, declarándose en consecuencia su inexequibilidad.

- El artículo $9^{534}$, que versa sobre los determinantes sociales en salud y establece el deber estatal de adoptar políticas públicas con miras a reducir las desigualdades sociales, el goce efectivo del derecho, promover el mejoramiento de la salud, así como crear mecanismos que permitan reconocer cuáles sectores impactan directamente la salud y determinar los procesos de participación en la toma de decisiones conducentes a la mejora de los resultados en salud, fue analizado constitucional, en tanto la búsqueda de la igualdad es acorde a los preceptos de Carta, máxime si con las mismas se pretende favorecer de manera positiva a las poblaciones vulnerables en el acceso al derecho fundamental. Tampoco encontró la Corte desajustado a la Constitución el mandato según el cual los factores sociales determinantes de la salud, sean financiados con recursos diferentes a los destinados para el cubrimiento de los servicios y tecnologías en salud, ello en tanto dicha definición se hace en virtud de la libertad de configuración legislativa que asiste al legislador.

- En el artículo $10^{535}$ a título seguido se realizó un análisis de los derechos y deberes de las personas en relación con la prestación de los servicios de salud, dejando en primera medida en claro que los allí contenidos son meramente enunciativos y que en tanto el catálogo de derechos está abierto y cobija también todos aquellos requeridos para garantía del mismo. Los derechos contenidos en los literales a), b) e) i) ${ }^{536}$, (esto es, de acceder a los servicios y tecnologías en salud, recibir la atención de urgencias requerida sin la exigencia de un carnet o documento, a recibir prestaciones en salud en las condiciones y términos prescritos en la ley, así como el acceso oportuno a los servicios de salud), fueron declarados constitucionales sin reparo alguno, en tanto manifestación del elemento de accesibilidad del derecho, y en el entendido de que es improcedente la negación de un servicio bajo el pretexto de que un procedimiento no hace parte del correspondiente plan de beneficios. Por su parte y también como derivación del elemento de accesibilidad, se encontró que el literal q) que contemplaba como derecho "Agotar las posibilidades razonables de tratamiento efectivo para la superación de su enfermedad" ${ }^{537}$, dadas las

533 lbíd. 553.

534 Ibíd. 553, 665.

535 COLOMBIA. CORTE CONSTITUCIONAL DE COLOMBIA. Sentencia C-313/14. Op. Cit. 554-556.

536 lbíd. p. 555.

537 Ibíd. p. 555. 
expresiones "razonables" y "efectivamente", restringía de manera indeterminada el acceso al servicio, dando lugar eventualmente a una inadmisible limitación del derecho a la salud, razón por la cual los dos vocablos fueron retirados del ordenamiento jurídico.

Los derechos contenidos en los literales c), d), g) I), m) y n) ${ }^{538}$, a mantener una comunicación plena con profesional tratante, obtener información clara y apropiada para adoptar decisiones libres y conscientes, a que la historia clínica sea tratada de manera confidencial, a conocer los canales de reclamación, a solicitar y recibir reclamaciones y rendición de cuentas, y a que se respete su voluntad de aceptación o negación de donación, fueron declarados exequibles al estimarse expresiones del elemento de acceso a la información. Precisó la Sala que en tales casos se debían continuar acatando las subreglas sentadas en la jurisprudencia constitucional, a efectos de dar alcance a cada una de las disposiciones. En cuanto a los literales h) y j) ${ }^{539}$, contentivos del derecho a la prestación de los servicios de salud por parte de personal autorizado, y el de recibirlo en condiciones de higiene y seguridad, se predicó así mismo la constitucionalidad como consecuentes del elemento de calidad del servicio. De igual forma el derecho a la intimidad, a no ser sometidos a trato cruel o degradante, y a que no se trasladen cargas administrativas o burocráticas al paciente, fueron declarados exequibles a la luz de los principios de confidencialidad y eficiencia.

En materia de deberes ${ }^{540}$, la Corte consideró que los definidos en la norma, como lo son el autocuidado y el de la familia, atender oportunamente las recomendaciones formuladas, actuar de manera solidaria frente a situaciones de peligro, cumplir las normas del sistema de salud, actuar de buena fe ante el mismo, respetar al personal responsable del servicio de salud, y usar de manera adecuada las prestaciones ofrecidas, son manifestaciones de específicos deberes constitucionales, y en tanto se les declaró exequibles. El deber contenido en el literal e), esto es el uso "adecuado y racional" de las prestaciones ofrecidas, es exequible en el entendido de que cuando el legislador establezca las consecuencias por el incumplimiento de los deberes, deberá cuidar lo que permita definir las expresiones "adecuada y racionalmente", pues tal como están indeterminadas podrían constituirse en un obstáculo para el goce del derecho. Así mismo el deber contenido en el literal i), que dispone el deber de "[...] contribuir solidariamente al financiamiento de los gastos que demande la atención en salud y la seguridad social, de acuerdo con su capacidad de

538 COLOMBIA. CORTE CONSTITUCIONAL DE COLOMBIA. Sentencia C-313/14. Op. Cit. 555.

539 lbíd. p. 555.

540 lbíd. p. 556. 
pago" 541 , se previó acorde al principio constitucional de numeral 9 del artículo 95 de la Carta, y con la apreciación que del principio de solidaridad ha hecho la Corte. Respecto del parágrafo 1 del inciso 2 del artículo $10^{542}$, la Corte excluyó la expresión "con necesidad", pues implicaba una restricción sin justificación del alcance del principio de oportunidad en la prestación del servicio. El restante contenido fue declarado exequible junto con el parágrafo 2.

- La Corte coligió del análisis del artículo 11 relativo a los sujetos especiales de protección, que dicha norma se encuentra en consonancia con los artículos 13 y 49 Superiores y con la Observación General Número 14, toda vez que "[...] i) es una materialización de la protección reforzada reconocida tanto por la normatividad internacional como nacional, ii) propugna por la erradicación de la discriminación y iii) constituye una medida que el Estado adopta en favor de los sujetos especiales" 543 . Nuevamente y en punto del conjunto de derechos que la ley asigna a estos grupos vulnerables, la Corte señaló que se trata de una lista enunciativa, que no de una taxativa restrictiva de otros derechos a lugar para su protección. En cuanto a la atención de la madre gestante señaló que las medidas para la garantía de sus derechos tienen lugar en todo momento, y no cuando se requieran con necesidad, como otrora señalaba el proyecto. Así mismo, se hizo extensivo el tratamiento integral a cualquier víctima de delitos sexuales según sus necesidades, sin restringir el mismo al sicológico y siquiátrico.

- Frente al artículo 12, denominado participación en las decisiones del sistema de salud, la Sala señaló que la definición de las "[...] decisiones adoptadas por los agentes del sistema de salud que la afectan o interesan" ${ }^{44}$ no son de ninguna manera taxativa o meramente enunciativa de garantías en favor de dicha participación. La Sala estimó que la participación debe comprender, además, las decisiones que se adoptarán por los agentes del sistema de salud, de modo que tal participación en el marco del modelo democrático pueda ser efectiva, continua, activa y propositiva, permitiendo la formulación de políticas de salud y planes para su implementación, fijando prioridades, evaluando resultados, participando en las decisiones sobre exclusión de servicios y tecnologías y en aquellas que implican una limitación o restricción en las condiciones de acceso a establecimientos de salud. Estas acciones de participación no pueden restringirse a una lista taxativa, dado el amplio espectro expansivo y universal del principio democrático y el derecho de participación.

${ }^{541}$ COLOMBIA. CORTE CONSTITUCIONAL DE COLOMBIA. Sentencia C-313/14. Op. Cit. 556.

542 lbíd. p. 556.

543 lbíd. p. 557.

${ }^{544}$ COLOMBIA. CORTE CONSTITUCIONAL DE COLOMBIA. Sentencia C-313/14. Op. Cit. 557. 
- En cuanto a la organización del sistema de salud en redes integrales de servicios de salud que pueden conformarse por entidades de naturaleza pública, privada o mixta, tal y como se contempla en el artículo $13^{545}$ del proyecto examinado, la Corte considera que el modelo que propone el legislador estatutario se aviene a los preceptos de la Constitución, por cuanto contribuye a evitar la fragmentación en la prestación del servicio de salud, al incorporar en este el concepto de integralidad, lo cual supone la promoción de los principios de eficiencia, universalidad y solidaridad, e implica la cobertura global de las contingencias derivadas del derecho a la salud a través de una misma estructura organizacional. Por otra parte, y en contravía a las prolifera críticas extendidas por la participación de particulares en la organización del Sistema, la Corte concluyó que la misma no contraría la Carta Política por cuanto en la misma se contempla dicha posibilidad.

- El artículo 14 del proyecto ${ }^{546}$, que advierte que para acceder a servicios y tecnologías en salud no se requerirá ningún tipo de autorización administrativa entre el prestador de servicios y la entidad que cumpla la función de gestión del servicio para efectos de la atención inicial de urgencia, fue declarado exequible a la luz del criterio de asignación de cargas administrativas en el Estado, no obstante, el término "inicial" fue retirado del ordenamiento jurídico en tanto la Corte consideró que el mismo podría conducir a la pérdida de derechos fundamentales irrecuperables, bajo la excusa de que no es el periodo inicial de urgencias el que se atiende. En cuanto al término "[...] en aquellas circunstancias que determine el Ministerio de Salud y Protección Social'547, la Corte determino su inexequibilidad, toda vez que se difiere al Ejecutivo una tarea propia del legislador estatutario, consistente en establecerle límites al derecho fundamental, dejando indeterminada o abierta una disposición que permite la posibilidad de imponer cargas administrativas a la prestación del mismo en materia de urgencias. En cuanto a la disposición de sanciones penales y disciplinarias para quienes incurran en casos de negación del servicio, la Corte no encuentra reparos, en tanto la disposición hace parte de la libre configuración legislativa del congreso, para expedir normas en materia sancionatoria. En cuanto a la imposibilidad de modificación de la acción de tutela, dicho mandato se acompasa con la efectividad del derecho y la imposibilidad de modificación de los mecanismos de protección de derechos fundamentales, en primera medida, la acción de tutela.

\footnotetext{
545 lbíd. p. 557.

${ }^{546}$ COLOMBIA. CORTE CONSTITUCIONAL DE COLOMBIA. Sentencia C-313/14. Op. Cit. 559, 560. 547 Ibíd. p. 560.
} 
- En lo que respecta al artículo $15^{548}$, la Corporación halló concordantes con la Constitución los incisos 1, 2 y 3, que señalan:

El Sistema garantizará el derecho fundamental a la salud a través de la prestación de servicios y tecnologías, estructurados sobre una concepción integral de la salud, que incluya su promoción, la prevención, la paliación, la atención de la enfermedad y rehabilitación de sus secuelas. En todo caso, los recursos públicos asignados a la salud no podrán destinarse a financiar servicios y tecnologías en los que se advierta alguno de los siguientes criterios ${ }^{549}$.

Advirtiendo en relación con los literales del inciso 2 que las exclusiones de servicios y tecnologías operan, siempre y cuando dada las particularidades del caso concreto, no se trate de situaciones que reúnan los requisitos establecidos y que establezca la jurisprudencia de esta Corporación para excepcionar lo dispuesto por el legislador. En cuanto a las exclusiones, todas se encontraron ajustadas a la Constitución, en tanto es válido negar servicios de salud cuando los mismos tienen fines cosméticos, no hay evidencia científica sobre su efectividad y eficacia clínica, su uso no haya sido autorizado por la autoridad competente, se encuentre en fase de experimentación o deba ser prestados en el exterior; sobre los mismos, se señaló aplican las sub-reglas jurisprudenciales sentadas por la Corte a lo largo de los años a efectos de conceder tales servicios excluidos de manera general cuando se está frente a circunstancias especialísimas, es decir, debe ser develada su eventual inaplicación en casos concretos acorde con los lineamientos trazados jurisprudencialmente.

De otra parte, y en cuanto al procedimiento de exclusión y su definición como mecanismo técnico-científico, de carácter público, colectivo, participativo y transparente, la Corte encontró la Constitucionalidad de la disposición, siempre que mediante el mismo se definan las exclusiones y no los beneficios, que se entienden incluidos siempre que no se excluyan taxativamente según el régimen taxativo de exclusiones incorporado por la norma. En cuanto a los 3 parágrafos del enunciado legal ${ }^{550}$, la Sala estimó que se avienen a la Carta, pero, en el caso del parágrafo 2 , que se refiere a la acción de tutela, su exequibilidad debe condicionarse al entendimiento de que dicho mandato no puede dar lugar a menoscabar el mecanismo de protección de los derechos fundamentales.

548 COLOMBIA. CORTE CONSTITUCIONAL DE COLOMBIA. Sentencia C-313/14. Op. Cit. 560, 563. 549 lbíd. p. 580.

550 COLOMBIA. CORTE CONSTITUCIONAL DE COLOMBIA. Sentencia C-313/14. Op. Cit. 561. 
- El precepto, que consagra el procedimiento de resolución de conflictos por parte de los profesionales de la salud contenido en el Artículo $16^{551}$, fue encontrado vago e indeterminado, sujeto a la posibilidad de que, por su grado de indeterminación, conduzca a un ejercicio hermenéutico que se oponga a los postulados decantados respecto del derecho fundamental a la salud. La corte advirtió que mediante dicho mecanismo se deja desamparado al paciente, en tanto se controvierten las alternativas terapéuticas prescritas por el médico tratante, sin existir para dicho efecto delimitación alguna frente a lo que puede y no ser controvertido. Sin la existencia de parámetros mínimos ni criterios de razonabilidad científica como pautas decisorias, quedaría abandonada la garantía del derecho fundamental a la salud a la subjetividad del legislador, sin ningún límite. Por lo anterior, se precisó que el procedimiento de resolución de conflictos por parte de los profesionales de la salud no se debe oponer a la Constitución, principalmente, a los principios de oportunidad, eficiencia y acceso efectivo que caracterizan al derecho fundamental a la salud, para lo cual es menester que el mismo, acorde con el precedente sentado por el Tribunal Constitucional, no opere cuando del diagnóstico y/o terapia de recuperación se advierta cualquier riesgo para la vida o integridad del paciente y que su resolución no exceda de 7 días.

- Por su parte los artículos 17 y $18^{552}$, derivaciones del elemento de autonomía e idoneidad profesional, fueron encontrados ajustados a la carta, en tanto representan la garantía no solo del derecho al libre desarrollo de la profesión que al personal médico asiste, sino que el mismo redunda en la garantía del derecho fundamental a la salud. Así mismo, se encontró concordante el artículo $18^{553}$, que consagra el respeto a los profesionales y trabajadores de la salud, quienes deben laborar bajo unas condiciones justas y dignas, al igual que todo trabajador en Colombia, lo cual es consonante con los artículos $1^{\circ}, 2^{\circ}, 25,53$ y 54 de la Constitución. Según se revisó, estas normas no comprometen ninguno de los derechos laborales de los profesionales de la salud, los cuales se preservan en su integridad.

- Los artículos 19 y 21 del proyecto ${ }^{554}$, relativos a la política para el manejo de la información en salud y la divulgación de información sobre progresos científicos, respectivamente, fueron revisados de manera conjunta, encontrándose acordes al derecho de acceso a la información. La disposición contenida en el artículo $20^{555}$ que establece una obligación para el Gobierno Nacional consistente en

\footnotetext{
551 lbíd. 561-564.

552 COLOMBIA. CORTE CONSTITUCIONAL DE COLOMBIA. Sentencia C-313/14. Op. Cit. 564, 565.

553 lbíd. 565.

554 Ibíd. 565, 566.

555 lbíd. 566.
} 
implementar una política social de Estado que permita la articulación entre los diferentes sectores administrativos con el propósito de garantizar los componentes esenciales del derecho a la salud y afectar de manera positiva sus determinantes sociales, en aras de propender por la promoción de la salud, prevención de la enfermedad y su atención integral, se determinó ajustado al principio constitucional de colaboración armónica, que implica relaciones de cooperación interinstitucional en aras de la garantía de los derechos. No obstante, se precisó que además de las actividades en salud relacionadas, debían integrarse las de diagnóstico, tratamiento y paliación de las enfermedades, así como las acciones para la recuperación de la salud de las personas, con miras a una descripción más completa del alcance del mismo.

- Los artículos 22 y $23^{556}$, que establecen la creación de una Política de Innovación, Ciencia y Tecnología en Salud, así como una Política Farmacéutica Nacional, a efectos de incentivar la investigación y generación de nuevos conocimientos en salud, y regular la financiación, adquisición, almacenamiento, producción, compra y distribución de medicamentos, se encontraron exequibles en tanto se encaminan a salvaguardar la accesibilidad al derecho; no obstante, la Corte encontró que no resulta aceptable dejar únicamente a las leyes del mercado los costos de los fármacos, en tanto ello podría conllevar a poner en riesgo la garantía de la efectividad del derecho a la salud. En cuanto a la obligación de garantía del derecho en zonas marginadas a través de medidas razonables y eficaces, progresivas y continuas para que los habitantes de las zonas dispersas accedan oportunamente a los servicios de salud que requieran con necesidad, se determina la pertinencia constitucional, en el entendido de que se trata de una medida necesaria en aras de garantizar la universalización del derecho.

E

n cuanto a las características asignadas a los recursos mediante los cuales se financian los servicios de salud, esto es, públicos, inembargables, y de destinación específica, la Corte dejó por sentada su constitucionalidad, explayando la necesidad de que los mismos estén destinados al único fin de dar garantía al derecho, así como de dotar de inembargabilidad a los mismos; empero, frente a esta última precisión, se observó que la inembargabilidad no opera como una regla, sino como un principio, y por ende, no tiene carácter absoluto, debiendo entonces atenderse al momento de la aplicación del precepto las excepciones definidas por la Corte. Por último, y en cuanto la vigencia de las disposiciones, no se encontró reparo alguno.

${ }^{556}$ COLOMBIA. CORTE CONSTITUCIONAL DE COLOMBIA. Sentencia C-313/14. Op. Cit. 567. 
2.7.2.3. Contenido de la Ley 1751 de 2015. Bajo estas consideraciones fue aprobada el 16 de febrero la Ley 1751 de 2015, motivada como una reforma estructural que pretende limitar el lucro basado en la enfermedad y priorizar la garantía de este derecho humano fundamental a través de su definición y su regulación, en aras de la sostenibilidad en el financiamiento, su calidad en términos de acceso, continuidad y progresividad, y la incorporación de mecanismos para incentivar corresponsabilidad en el cuidado de la salud de los afiliados al Sistema de salud. Así, se contempló como objeto de la ley "[...] garantizar el derecho fundamental a la salud, regularlo y establecer sus mecanismos de protección" 557 , entendiendo que estos últimos no pueden menoscabar la acción de tutela.

La norma caracteriza el derecho fundamental a la salud como autónomo e irrenunciable, tanto en lo individual como en lo colectivo, comprendiendo la prestación de los servicios de salud de manera oportuna, eficaz y con calidad para la preservación, el mejoramiento y la promoción de la salud ${ }^{558}$. De otra parte, radica en cabeza del Estado el deber de adoptar políticas que aseguren:

[...] la igualdad de trato y oportunidades en el acceso a las actividades de promoción, prevención, diagnóstico, tratamiento, rehabilitación y paliación para todas las personas. [...] su prestación como servicio público esencial obligatorio, se ejecuta bajo la indelegable dirección, supervisión, organización, regulación, coordinación y control del Estado 559 .

Por otra parte, la definición del derecho a la salud como fundamental se basa en los elementos de: disponibilidad, como garantía de la existencia de servicios, tecnologías e instituciones de salud; aceptabilidad, en el sentido de que todos los agentes del sistema deben ser respetuosos de la ética médica, así como las diversas culturas; accesibilidad, a los servicios y tecnologías en salud; y calidad e idoneidad profesional, bajo los estándares de calidad aceptados por las comunidades científicas ${ }^{560}$. De estos elementos, se derivan los principios de universalidad, interpretación pro homine, equidad, continuidad, oportunidad, prevalencia de los derechos de los niños, niña y adolescentes, progresividad, entre otros $^{561}$.

${ }^{557}$ COLOMBIA. CONGRESO DE LA REPÚBLICA DE COLOMBIA. Ley 1751. Op. Cit. p. 1.

558 lbíd. p. 1.

559 lbíd. p. 1.

560 COLOMBIA. CONGRESO DE LA REPÚBLICA DE COLOMBIA. Ley 1751. Op. Cit. p. $2,3$.

561 Ibíd. p. 3, 4. 
Así mismo, se enuncia un listado de derechos y deberes de las personas, relacionado con la prestación de los servicios de salud, a saber 17 derechos y 9 deberes ${ }^{562}$ que se acompasan con los parámetros constitucionales. En garantía de estos derecho se establece el principio de integralidad, el cual señala que los servicios y tecnologías de salud deben ser suministradas de manera completa para prevenir, paliar o curar las enfermedades, con independencia de su origen 0 condición de salud, sin posibilidad de fragmentar la responsabilidad en la prestación de un servicio en desmedro de la salud del usuario ${ }^{563}$, siendo estos aspectos con los cuales se avanza en la concepción del derecho a la salud más allá de la ausencia de enfermedades, aproximándose a los estándares internacionales que asimilan la salud a un estado de completo bienestar físico, mental y social.

Por su parte, el plan de beneficios ${ }^{564}$ se definió como de exclusiones, esto es, que todo servicio o tecnología en salud se entiende incluida hasta tanto no se excluya mediante un procedimiento técnico-científico y siempre que la misma se catalogue dentro de una de las causales de la norma, esto es, que tenga naturaleza cosmética, que carezca de eficacia o efectividad médica, que su uso esté prohibido por las autoridades, que se encuentre en fase experimental, o que deba practicarse en el exterior, en el entendido de que estos criterios se hacen inaplicables en algunos eventos y nunca pueden afectar el acceso a tratamientos para las personas que sufren enfermedades raras o huérfanas ${ }^{565}$. La definición del procedimiento de exclusiones de servicios y medicamentos cuenta con un término de hasta dos años.

Por otra parte, se da amplia importancia a la autonomía profesional ${ }^{566}$ frente a la adopción de decisiones sobre el diagnóstico y tratamiento de los pacientes, ejercida en el marco de esquemas de autorregulación, ética, racionalidad y evidencia científica, prohibiendo en ese sentido todo constreñimiento, presión, o restricción en su ejercicio profesional, que atente contra la autonomía de los profesionales de la salud, o contra la seguridad del paciente. En lo referido a la organización del sistema de salud, el proyecto de Ley estatutaria previó redes integrales de servicios de salud de diferente naturaleza, pública, privada o mixta ${ }^{567}$, proponiéndose de esa forma la implementación de una política social de Estado que permite la articulación intersectorial con el propósito de garantizar los componentes esenciales del derecho, afectando de manera positiva los determinantes sociales de la salud pública.

\footnotetext{
562 lbíd. p. 5 - 7.

563 lbíd. p. 5.

564 lbíd. p. 9.

565 COLOMBIA. CONGRESO DE LA REPÚBLICA DE COLOMBIA. Ley 1751. Op. Cit. p. 9, 10.

566 lbíd. p. 10.

567 lbíd. p. 8.
} 
Puestas las presentes disposiciones de la Ley Estatutaria, conviene poner sobre la palestra las dificultades tanto conceptuales como de aplicación que la misma reviste. En primer lugar, respecto al sostenimiento de los aportes y cuotas que deben cancelar los usuarios para acceder a los servicios, continúa incardinando el derecho fundamental a la salud a una sostenibilidad fiscal y financiera, lo cual coarta la propugnada igualdad y no discriminación en materia de prestación del servicio. Seguidamente, se encuentra dificultad en cuanto a la administración y destinación de los recursos del sistema que seguramente quedarán a merced de los intermediarios y no en procura de la atención de los usuarios, ante la persistencia del factor privado en el manejo de recursos.

Dicho sea de paso, que la pretensión de materializar los principios contenidos en la norma, no se acompasa con un cambio fundamental o paradigmático en la estructura del sistema, puesto que la misma es etérea y en muchos casos indeterminada, y carece de instrumentos de exigibilidad o coerción, lo que genera el riesgo de que la misma sea considerada una carta programática sin ningún tipo de instrumento para su concreción. En ese entendido, persiste la ausencia de control, vigilancia y regulación, así como la existencia de zonas grises que dan lugar a interpretaciones desajustadas a la pretensión misma de la Ley. Esta tampoco cumple un papel claro en punto de la regulación económica para la realización efectiva del derecho a la salud a partir de un flujo de recursos económicos adecuado, y su uso eficaz y eficiente, persistiendo uno de los evidentes obstáculos para la accesibilidad, esto es, la ejecución real y efectiva de acciones necesarias para que los servicios de salud no se desvíen, y recuperar los apropiados ilegítimamente. A pesar de las desavenencias que en su conjunto instrumentalizan la naturaleza fundamental del derecho a la salud, ha de reconocerse el gran avance que esta ley bajo la interpretación dada por la Corte Constitucional trae consigo al positivizar los avances jurisprudenciales, sin embargo, es importante resaltar que una verdadera reforma más allá de la inclusión de principios, debió regular de fondo los problemas de la salud, esto es, la existencia de vacíos normativos, la carencia de medios de control efectivos en el manejo de los recursos y la ausencia de mecanismos para invocar de manera satisfactoria su efectividad.

Las múltiples fallas estructurales en el modelo de Seguridad social de salud en Colombia, han hecho evidente la necesidad de cambios de fondo que den garantía a la realización del derecho a la salud como derecho fundamental, para lo cual resulta conveniente tener en cuenta que bajo esta acepción, la salud trasciende los límites de su componente prestacional que lo ubica como un derecho económico, social y cultural, y se erige en una garantía primaria que condiciona el ejercicio de un sinnúmero de derechos, sin la cual no podrían materializarse con acierto los propósitos del Estado Social de Derecho. Así entendida, la salud es uno de los derechos fundamentales de todo ser humano sin distinción de raza, religión, ideología política o condición económica o social, debiendo cimentarse su 
consideración en la construcción de un sistema igualitario como ha sido estudiado en la doctrina por

Gosepath [quien] propone basar los derechos sociales (educación, salud y trabajo, entre otros) en el mismo principio moral en que se fundamentan los derechos humanos, es decir, en el respeto igualitario que merecen todos los seres humanos. Este es el principio rector de todas las corrientes políticas de la sociedad moderna. Según Gosepath, del respeto igualitario se puede derivar una propuesta de distribución igualitaria de todos los bienes de que se disponga en la sociedad, lo que puede servir de fundamentación de los derechos sociales ${ }^{568}$.

En búsqueda de dicho sistema igualitario y de la eficacia del derecho a la salud, se impele el ajuste de políticas en la materia y el redireccionamiento del Sistema hacia un esquema que propicie la igualdad, y solucione los problemas de accesibilidad, contando con una distribución y aseguramiento de los recursos efectiva a fin de evitar la desviación de los mismos en detrimento de los usuarios, a quienes no ha de condicionarse por su capacidad de aportar o pagar por el servicio. En cumplimiento de tal obligación, los entes gubernamentales plantearon propuestas legislativas para dar una solución de fondo a la situación de la salud en Colombia, alejada de la noción meramente mercantilista de la misma y bajo criterios que se estancan en la promoción, prevención, atención y rehabilitación de un paquete de servicios que son tan solo una extremidad de lo que es el derecho fundamental a la salud. En varias oportunidades, dichas iniciativas fueron ineficaces, en tanto se tramitaron de manera indebida o su contenido no era acorde a la Carta fundamental, no obstante, este impulso se materializó a través del Proyecto de Ley Estatutaria 209 de 2013 del Senado y 267 de 2013 Cámara por medio de la cual se regula el derecho fundamental a la salud y se dictan otras disposiciones, el cual luego del respectivo análisis constitucional se sancionó como Ley Estatutaria No. 1751 de 2015.

Dicha norma, hoy en vigencia a la espera de regulación, sin duda alguna representa un avance de cara a la concepción y carácter fundamental que se da al derecho a la salud, reconociéndose el camino ya abonado por la Corte Constitucional bajo el paradigma de que la salud es un derecho fundamental que se garantiza a través de un servicio público esencial. Sin embargo, el reto persiste en tanto el mismo no soluciona de fondo las talanqueras que se le han impuesto, siendo su desarrollo legal determinante en la fijación de su alcance, pues la generalidad de la norma actual permite que persista su indefinición, carencia de control y veeduría, así como

${ }^{568}$ ÁLVAREZ CASTAÑO, Luz Stella. Op. Cit. p. 4. 
ausencia de mecanismos coercitivos que vislumbren no solo sanciones morales, sino también legales frente a su conculcación.

Ahora bien, conluyendo que el sistema de seguridad social en salud, regulado por la ley 100 de 1993, como lo acabamos de exponer, y ubicada a su vez la salud en el abanico de los Derechos Economicos Sociales y Culturales de la carta política colombiana, logró una evolución importante, dado que la Corte Constitucional, desarrollo un número significativo de sentencias relacionadas con la protección de los derechos económicos sociales y culturales, entre ellas la protección del derecho a la salud.

\subsection{LOS DERECHOS ECONÓMICOS SOCIALES Y CULTURALES: DERECHO A LA SALUD.}

Los derechos económicos, sociales y culturales son considerados derechos fundamentales, los cuales tienen una estrecha relación con los derechos humanos, toda vez que se refieren a las condiciones básicas, esenciales y necesarias que requiere una persona para llevar una vida acorde a la dignidad humana, que es un pilar fundamental en un estado social de derecho. De allí que algunos tratadistas consideren que los derechos fundamentales en un estado social de derecho "dejan de ser meros límites de la actuación estatal para transformarse en instrumentos jurídicos de control de su actividad positiva, que debe estar orientada a posibilitar la participación de los individuos y los grupos en el ejercicio del poder. ${ }^{569}$

Por tanto, los derechos económicos sociales y culturales deben incluirse en ese abanico de derechos fundamentales, como derechos justiciables y no como simplemente supuestos programáticos.

Las teorías doctrinales estudiadas sobre la naturaleza jurídica de los derechos económicos, sociales y culturales coinciden en disentir que no es posible un constructo dogmático perfecto, desde el punto de vista de su estructura jurídica, en donde son derechos, en sentido estricto.

Únicamente desde la figura de su contenido, podrían distinguirse los derechos económicos sociales y culturales, pero no a partir de la disposición de una diversa naturaleza, como derechos de prestación en oposición a los tradicionales derechos

${ }^{569}$ A.E. Pérez Luño, Derecho Humanos. Estado de Derecho y Constitución. Cit. Pág. 228 
de libertad, dado que esta condición reviste parcialmente al catálogo constitucional de derechos sociales.

Por consiguiente, el esfuerzo de construir como única categoría los derechos económicos, sociales y culturales, como derechos de prestación, no brinda ventaja alguna al sistema tradicional de los derechos fundamentales. También entre esta amalgama existen derechos económicos, sociales y culturales. Se trata por tanto de criterios que los cataloga, más no de dos formas estructurales de derechos.

En este sentido, Alexy expresa que "la polémica sobre los derechos a prestaciones está caracterizada por diferencias de opinión sobre el carácter y tareas del estado, del derecho y de la constitución, inclusive los derechos fundamentales" 570 , discrepancias que se extienden a las valoraciones generales de tipo político o de tipo práctico sobre la situación social, que con frecuencia se solapan con los razonamientos jurídicos" 571 .

Esta discusión doctrinal sobre la naturaleza de los derechos sociales se estructura en una polémica mucho más profunda, que corresponde a la distinción de la noción individualista de los derechos y el abandono de las condiciones tradicionales, de allí deriva su estructura.

\subsubsection{Estructura de los derechos económicos sociales y culturales}

2.8.1.1. Titulares Cuando se trata de la titularidad de los derechos sociales, partimos del hecho de que corresponden a grupos sociales o colectividades humanas, es decir, grupos con una dimensión social constitutiva, protegidas por el derecho, por lo que protege el derecho es la propia necesidad del grupo. De acuerdo a ello, Benda expresa que "la protección del Estado se dirige en la actualidad no ya a los trabajadores, sino a quienes no son organizables en grupos de interés, grupos socialmente infradotados que precisan especial atención y asistencia"572. Desde este punto de vista, los derechos sociales se reconocen como garantía de la participación del individuo en la vida social y sobre la correlativa socialización de la libertad"573.

570 R Alexy, Teoría de los derechos fundamentales, pág. 426.

571 lbídem.

572 E. BENDA, El Estado Social de Derecho, en E.BENDA/W.MAIHOFER/H.J VOGEL/K. HESSE/W, HEY, Manual de Derecho Constitucional, Madrid, 1996, pág. 524

573 G. CICALA, OP. CIT., Pág. 31 
Para Pérez Luño, los derechos sociales en su sentido estricto "se refieren a aquellos derechos fundamentales dirigidos a tutelar la actividad del homo faber, o sea, al ser humano trabajador." 574 Esta caracterización expresada por Pérez Luño sobre los derechos sociales, en cuanto "definen las líneas básicas del status laboral"575, dejaría por fuera o excluiría de este contexto de derechos a un colectivo social, es decir, a favor de todos los ciudadanos, dado que considera que los derechos sociales son propios de los trabajadores.

De lo anterior se colige que no podemos considerar la titularidad colectiva de los derechos económicos sociales y culturales como una de sus características distintivas, sino como una acotación que puede predicarse, con particularidades en relación sobre algunos de ellos, pero que no sirve para determinar los derechos sociales con una condición específica.

Consecuencialmente, los derechos económicos sociales y culturales no se arrogan únicamente determinadas clases de sujetos, en contraste con sus titulares una misma finalidad: lograr el goce efectivo de las libertades civiles políticas, de manera que elimine así las desigualdades sociales, y las circunstancias básicas de la existencia. Esta finalidad se proyecta en el espacio de regulación estos derechos, y en los supuestos materiales para su eficacia.

2.8.1.2. Objeto El objeto fundamental de los derechos económicos, sociales y culturales es garantizar el bienestar económico, el acceso al trabajo, a la educación, etc., de tal manera que respondan a las necesidades esenciales y el desarrollo de los seres humanos.

En el análisis de elementos objetivos, resulta de inusitada importancia determinar cuáles son los contenidos económicos sociales y culturales que la constitución acoge: la existencia o no de un contenido mínimo o esencial de los derechos positivizados como principios rectores.

Para Torres del Moral, "en todo texto fundamental, al menos en el constitucionalismo más reciente, coexisten una constitución política, una constitución económica, social y una constitución cultural”576

${ }^{574}$ A.E. PEREZ LUÑO, Los derechos fundamentales, 5a․ Ed. Madrid, pág. 192.

575 lbídem.

${ }^{576}$ A.TORRES DEL MORAL, Comentarios al as leyes políticas, Edersa, 1984, Pag.210 
La Constitución política de 1991 ubica en su capítulo segundo los Derechos económicos sociales y culturales, cuyo objetivo principal es el desarrollo y garantía de las necesidades esenciales de la persona y de la sociedad.

El artículo 1 de la carta política establece que "Colombia es un Estado social de derecho, organizado en forma de República unitaria, descentralizada, con autonomía de sus entidades territoriales, democrática, participativa y pluralista, fundada en el respeto de la dignidad humana, en el trabajo y la solidaridad de las personas que la integran y en la prevalencia del interés general. ${ }^{577}$

Estos principios considerados los pilares del Estado colombiano han postulado los elementos de las decisiones de la Corte Constitucional, con el objetivo de proteger los derechos económicos sociales y culturales.

\subsection{LOS DERECHOS ECONÓMICOS SOCIALES Y CULTURALES: EL DERECHO A LA SALUD}

La Corte Constitucional ha desarrollado un número significativo de sentencias relacionadas con la protección de los derechos económicos sociales y culturales, entre ellas la protección del derecho a la salud.

Para Jaime León Gañán, el "derecho a la salud se encuentra conectado directamente con los principios constitucionales colombianos por varias razones: por ser Colombia un Estado social de derecho, por contribuir a la materialización de la dignidad humana, por ser un derecho inalienable que en consecuencia goza de primacía, sin discriminación alguna, por ser la Constitución norma de normas y ser el derecho a la salud una disposición constitucional"578.

Bajo estas premisas podemos afirmar que el derecho a la salud, si bien es cierto goza de una amplia protección y garantía constitucional, "La vulneración, en su conjunto, de los principios citados, hace que el Estado colombiano, como garante del derecho fundamental a la salud de toda su población, subsidiada o contributiva, vulnere, a su vez, los perentorios mandatos de protección, de cumplimiento y de respeto por los derechos de esencia social. Con ello, se incumple con los fines

577 Constitución Política Colombia, art 1

578 Jaime León Gañán Echavarría, De la naturaleza jurídica del derecho a la salud en Colombia, Superintendencia Nacional de Salud, 2013. 
esenciales del Estado social y se permite que cada vez haya más muertos de Ley $100 " 579$.

Por tanto, la ineficacia del sistema de salud colombiano conlleva a la vulneración constante del derecho fundamental a la salud, toda vez que no se respetan los mínimos de protección, que le permiten a la población su goce efectivo.

Como corolario ante la consecuente vulneración del derecho fundamental a la salud, "corresponde al Estado organizar, dirigir y reglamentar la prestación de servicios de salud a los habitantes y de saneamiento ambiental conforme a los principios de eficiencia, universalidad y solidaridad. También, establecer las políticas para la prestación de servicios de salud por entidades privadas, y ejercer su vigilancia y control"580.

2.9.1 Derecho a la salud a la luz de los derechos económicos sociales y culturales. No está de más recordar que el Estado colombiano ha ratificado el Pacto Internacional de Derechos Económicos, Sociales y Culturales (PIDESEC), el cual en su artículo 12 numeral primero dice lo siguiente: "Los Estados Partes en el presente Pacto reconocen el derecho de toda persona al disfrute del más alto nivel posible de salud física y mental"581. La observación No $14^{582}$ con la cual se amplía el artículo 12 de la PIDESC inicia afirmando que la salud es un derecho humano fundamental e indispensable para el ejercicio de los demás derechos humanos. También, la interpretación que el comité realiza acerca del derecho a la salud reúne desde la atención de salud oportuna y apropiada hasta factores determinantes de la misma, como lo son el acceso al agua limpia y potable, condiciones sanitarias adecuadas, suministro adecuado de alimentos sanos, condiciones sanas en el trabajo y medio ambiente, entre otros, además contempla el acceso a la educación e información sobre cuestiones relacionadas a la salud, incluida la salud sexual y reproductiva. Así mismo, resalta que, en el proceso de adopción de decisiones sobre las cuestiones relacionadas con la salud, que se encuentran circunscritos a los planos comunitarios nacional e internacional, deben contar con la participación de la población a la que hace referencia.

579 Jaime León Gañán Echavarría, Los muertos de la ley 100, Universidad de Antioquia, 2013, pág. 253.

580 Alexandra Salazar Salazar, La Instrumentalización Del Derecho Fundamental A La Salud A Través De La Prestación Del Servicio Público. Universidad Nuestra Señora del Rosario, 2014, pág. 242 581 ASAMBLEA GENERAL DE LAS NACIONES UNIDAS. Pacto Internacional de Derechos Económicos, Sociales y Culturales. Op. Cit.

582 Aplicación del Pacto Internacional de los Derechos Económicos, Sociales y Culturales. Observación general 14. Op. Cit. 
De acuerdo con la Observación No 14583, los elementos esenciales e interrelacionados del derecho a la salud, en todas sus formas y a todos sus niveles, son:

- La disponibilidad ${ }^{584}$, dispone contar con un número suficiente de establecimientos, bienes, servicios y centros de atención en salud, lo anterior dependiendo del nivel particular de desarrollo del Estado parte.

- La accesibilidad ${ }^{585}$, dichos establecimientos bienes, servicios de salud, deben ser accesibles a todos dentro de la jurisdicción del Estado parte, dicha accesibilidad, contiene cuatro dimensiones ${ }^{586}$. La primera, se refiere a la no discriminación, lo que implica que deben ser accesibles de hecho y de derecho sin discriminación alguna; la segunda, accesibilidad física, referente al alcance geográfico de todos los sectores de la población en espacial los grupo vulnerables, a los establecimientos, bienes y servicios de salud, incluidos los servicios médicos y los factores determinantes básicos de la salud, como el agua potable y servicios sanitarios básicos; la tercera, la accesibilidad económica, que hace referencia a que los pagos por servicios de atención de la salud deberán estar basados en el principio de la equidad sin importar si son públicos 0 privados, dicha equidad exige que sobre los hogares más pobres no recaiga una carga desproporcionada en comparación con los hogares más ricos; y la cuarta, acceso a la información, la cual comprende el derecho de solicitar, recibir y difundir información e ideas sobre cuestiones relacionadas con la salud, lo anterior sin menoscabar el derecho a la confidencialidad.

- La aceptabilidad ${ }^{587}$, elemento que conlleva al respeto de la ética médica y de la cultura de las personas, minorías, pueblos y comunidades por parte de todos los establecimientos, bienes y servicios de salud que se presten estando concebidos para el respeto de la confidencialidad y el mejoramiento del estado de salud de las personas.

- La calidad ${ }^{588}$, los establecimientos bienes y servicios deben ser apropiados desde el punto de vista científico y médico, así mismo requieren de personal médico capacitado, medicamentos y equipo hospitalario en buen estado y

\footnotetext{
${ }^{583}$ Aplicación del Pacto Internacional de los Derechos Económicos, Sociales y Culturales. observación general 14. Op. Cit.

584 lbíd. p. 3, 4.

585 lbíd. p. 4.

586 Ibíd. p. 4.

587 Aplicación del Pacto Internacional de los Derechos Económicos, Sociales y Culturales. observación general 14. Op. Cit. p. 4.

588 lbíd. p. 4.
} 
científicamente aprobados, agua limpia y potable junto con condiciones sanitarias para que de ellos se predique una buena calidad.

EI PIDESC reconoce los obstáculos que se presentan debido a los limitados recursos disponibles en los Estados parte, estableciendo la aplicación progresiva del artículo 12 y observando unas obligaciones de efecto inmediato, que están relacionadas con el derecho a la salud, como por ejemplo, el ejercicio del derecho sin discriminación alguna y la obligación de adoptar medidas tendientes a la realización del artículo 12, medidas que deben ser deliberadas, concretas y se deben dirigir a la realización plena del derecho a la salud, lo que implica que los Estados tienen la obligación concreta y constante de avanzar lo más expedita y eficazmente posible, dichas obligaciones son denominadas como legales de carácter general.

El derecho a la salud impone tres tipos de obligaciones ${ }^{589}$ específicas a los Estados parte:

- La obligación de respetar ${ }^{590}$, donde el Estado parte debe abstenerse de ingerir directa o indirectamente en el disfrute del derecho a la salud; "absteniéndose de denegar o limitar el acceso a los servicios de salud preventivos, curativos y paliativos, en condiciones igualitarias de todas las personas, entre ellas los presos o detenidos, los representantes de las minorías, los solicitantes de asilo o inmigrantes ilegales $[\ldots]^{591}$. Así mismo debe "[...] abstenerse de imponer prácticas discriminatorias como política de Estado; y abstenerse de imponer medidas discriminatorias en relación con el estado de salud y necesidades de la mujer"592.

- La obligación de proteger ${ }^{593}$, donde el Estado debe adoptar medidas que impidan la interferencia de terceros, en la aplicación de las garantías que prevé el artículo 12. Dichas medidas deben estar encaminadas al acceso igualitario en atención en salud y los servicios relacionados con la salud que sean proporcionados por terceros, esto incluye velar por que la privatización del sector salud no constituya una amenaza para la disponibilidad, accesibilidad, aceptabilidad y calidad de los servicios de atención ${ }^{594}$.

\footnotetext{
589 lbíd. p. 9.

590 Aaplicación del Pacto Internacional de los Derechos Económicos, Sociales y Culturales. observaciónn general 14. Op. Cit. p. 9.

591 lbíd. p. 9, 10.

592 lbíd. p. 10.

593 lbíd. p. 9.

594 Ibíd. p. 10.
} 
- La obligación de cumplir: la cual exige "[...] que los Estados adopten medidas apropiadas de carácter legislativo, administrativo, presupuestario, judicial o de otra índole para dar plena efectividad al derecho a la salud"595. Lo anterior hace referencia al reconocimiento del derecho a la salud en los sistemas políticos y ordenamientos jurídicos nacionales de los Estados parte, garantizando la atención de la salud en particular con el establecimiento de programas de inmunización contra las principales enfermedades infecciosas ${ }^{596}$. Así mismo, el Estado parte debe velar por el acceso igualitario a todos los factores determinantes básicos de la salud, estos hacen referencia a los alimentos nutritivos sanos y agua potable, servicios básicos de saneamiento y vivienda junto con unas condiciones de vida adecuadas ${ }^{597}$. Con lo anterior, los Estados Partes deben tener en cuenta que la obligación de cumplir hacer referencia a tres obligaciones más: facilitar, proporcionar y promover.

Por su parte, el Protocolo Adicional a la Convención Americana sobre Derechos Humanos en materia de Derechos Económicos, Sociales y Culturales, Protocolo de San Salvador ${ }^{598}$, enuncia que todas las personas tienen derecho a la salud, la cual debe ser entendida como el disfrute del más alto nivel de bienestar físico, mental y social; comprometiendo a los Estados Partes a reconocer la salud como un bien público y particularmente a adoptar medidas para garantizar dicho derecho, entre las que se encuentran: la atención primaria en salud; la extensión de los servicios de salud a todos los individuos; la total inmunización contra las principales enfermedades infecciosas.

Podemos inferir entonces que, los Derechos Económicos Sociales y Culturales (DESC), representan indudables derechos humanos, refieren estos, las condiciones económicas y sociales esenciales de cada individuo, con el propósito de alcanzar una calidad de vida acorde a la dignidad humana, pilar fundamental de un Estado Social del Derecho, dentro de esta clase de derechos encontramos el derecho a la seguridad social, a la salud, al trabajo entre otros, ellos proveen un catálogo de normas, las cuales constituyen unas obligaciones del Estado, como garante de la efectiva protección de los mismo.

Tenemos entonces, que los Derechos Económicos Sociales y Culturales (DESC), representan indudablemente derechos humanos, que refieren no solamente a las

\footnotetext{
595 lbíd. p. 9.

596 lbíd. p. 10.

597 Aplicación del Pacto Internacional de los Derechos Económicos, Sociales y Culturales. observación general 14. Op. Cit. p. 10.

598 CONVENCIÓN AMERICANA SOBRE DERECHOS HUMANOS. Protocolo de San Salvador. 1988. Op. Cit.
} 
condiciones sociales, sino a condiciones económicas, en este estudio abordaremos la economía en el sistema de salud colombiano. 


\section{ESTUDIO DE LA ECONOMÍA EN EL SISTEMA DE SALUD.}

\subsection{GENERALIDADES:}

En nuestro país, el progreso de la economía en salud se expresa de manera significativa con la reforma del Sistema de Salud, es decir, con la entrada en vigor de la Ley 100 de 1993. Esto estableció que un grupo nutrido de economistas y académicos se interesara por el desarrollo de las teorías económicas en salud.

Para dar inicio a este tema abordaremos de manera general qué estudia la economía política y la política económica y cómo se emprende el tema globalmente. La economía es una ciencia muy específica. Los problemas y las controversias aparecen apenas se da el primer paso en esta rama del conocimiento, apenas se plantea la pregunta fundamental: de qué trata esta ciencia ${ }^{599}$. Es así como en el libro de fundamentos de la economía política Manual y libro de lectura para hombres de empresa y estudiantes, publicada en 1854, se describe que por ciencia de la economía nacional o política entendemos aquella ciencia que trata las leyes del desarrollo de la economía de una nación, o de su vida económica nacional. ${ }^{600}$

La economía política tiene como la rama que nos expone el estado de esta economía, o sea, las normas mediante las cuales una sociedad genera su tesoro a través de su trabajo, asi mismo la aumenta, las reparte entre los personas en sociedad, y finalmente la consume. "Ha de ser pues la vida económica de un pueblo entero lo que constituye el objeto de la investigación, a diferencia de la economía privada o economía individual, cualquiera sea el significado que estas últimas puedan tener. Una vez confirmado aparentemente este concepto, la obra del inglés Adam Smith, llamado el padre de la economía política, aparecida en 1776 y que hizo época, lleva precisamente el título de La riqueza de las naciones. ${ }^{601}$

La falta de la Economía política habitual en una serie de normas "autónomas ha tenido a veces un componente ligado a lo que ha dado en llamarse la "sociología del mundo científico", donde los distintos grupos de especialistas tienden a constituirse en colectivos que intentan definir, con mejor o peor fortuna, las fronteras de su especialidad. Pero en general, en este caso, como en el de otras ciencias, la

599 LUXEMBURG, Rosa. Introducción a la economía política. Edición internacionals Sedov. Nucleo en defensa del marxismo.

$600 \mathrm{lbid}$

$601 \mathrm{lbid}$ 
especialización ha sido una necesidad, producto de la conveniencia científica, aunque "quizás ello no sea una virtud», como señaló agudamente J. K. Galbraith, al criticar la falta de visión global de muchos economistas contemporáneos. J. A. Schumpeter sitúa el inicio de la etapa moderna del desarrollo de la Economía como ciencia en la escuela fisiocrática, que como se sabe tuvo una enorme influencia en Adam Smith, quien todavía la consideraba una rama de la Filosofía moral. Las aportaciones de A. Smith, D. Ricardo, R. Malthus y J. Stuart Mill, entre otros, permitieron que la Economía política reuniera en buena medida las condiciones que Nagel establece para la existencia de una ciencia social: cierto grado de formalización, búsqueda de leyes, universalidad de las leyes propuestas, explicación causal de los hechos, contrastación de las hipótesis formuladas y capacidad de predicción. ${ }^{602}$

Igualmente existe la definición de economía como: "el concepto de políticas económicas, como aquellas que tienen como objetivo la obtención del óptimo económico para el Estado, y para dar cumplimiento a dicho objetivo aplica las medidas que considera necesarias para su logro. Los objetivos de la Política económica generalmente están influidos por las teorías vigentes sobre la realidad económica y por la oportunidad de la acción del Estado en este terreno. Asimismo lo están otras exigencias, como la competencia internacional, la presión de los grupos económicos y sociales, etc. ${ }^{603}$

De igual manera "La Política económica es un fenómeno que coincide con la existencia de un poder estatal y es una de las formas en que se ejerce dicho poder. Esta depende de la ciencia histórica y no puede ser enriquecida más que por la introducción de una filosofía de la historia económica de los estados y de la acción de los poderes públicos. La historia de los estados muestra distintos ejemplos de la misma: en la Edad Media, época de relajamiento de la autoridad del Estado, la delegación del poder del Estado estuvo en manos de las corporaciones. Durante el siglo XII, restaurados los poderes del Estado se establece la política mercantilista, nacional y dirigista. Posteriormente, la Política económica liberal que permite un gran desarrollo industrial ha sido importante porque el Estado en éste período no intervino en la producción, el consumo y los precios, sino que se limitó al campo legal y reglamentario sin utilizar la política presupuestaria o monetaria. ${ }^{604}$

La expresión política económica se designa habitualmente a la aplicación de categóricas medidas, que efectúan para conseguir unos determinados propósitos

602 CUADRADO, Roura, Juan. Política Economica elaboración, objetivos e instrumentos. Aravaca Madrid. 2006

603 RICCIARDI, Darío Omar. Repasemos la teoría económica, la política económica. Ensayo. P. 2 ${ }^{604}$ RICCIARDI, Darío Omar. Repasemos la teoría económica, la política económica. Ensayo. P. 2 
esenciales, por ello. "La política económica, en cuanto «praxis», ha sido definida de distintas formas, aunque si se comparan las definiciones más conocidas, es posible advertir en ellas bastantes coincidencias. Se afirma que la política económica es siempre el resultado de una decisión de la autoridad, la cual puede definirse con carácter más o menos amplio: desde el gobierno hasta otros niveles inferiores, la «Teoría» de la Política económica y los estudios de Política económica enlazaron pronto con las principales escuelas y corrientes. J. Tinbergen afirmó que «la política económica consiste en la variación deliberada de los medios para alcanzar ciertos objetivos; La Política económica, en cuanto disciplina integrada al «Sistema de Ciencias Económicas», se considera dentro del grupo de materias que ordinariamente se califican como Economía Aplicada. Es preciso distinguir pues, claramente, los dos significados que pueden atribuirse al término «política económica». Por un lado, este suele aplicarse a las medidas y actuaciones de las autoridades en el terreno económico, orientadas a conseguir determinados fines. Por otro, dicho término designa también el tratamiento y análisis científico de las acciones llevadas a cabo por los gobiernos y otras instituciones. En el primer sentido, la política económica se concibe desde el punto de vista de la praxis, mientras que en el segundo, se considera desde una perspectiva científico-analítica: como disciplina autónoma dentro del campo general de la Ciencia económica. ${ }^{605}$

Finalmente, podemos decir que "se ha afirmado con frecuencia que las políticas económicas practicadas por los gobiernos son «políticas» por el nombre y «económicas» por el apellido. En cuanto política, cualquier política económica forma parte de lo que el profesor norteamericano D. S. Watson calificaba hace años como Política pública, que no es sino un variado conjunto de distintas políticas (políticas sociales, políticas económicas, política exterior, de defensa...) desarrolladas por los gobiernos, y que están claramente interrelacionadas entre sí606.

Es evidente que para la realización de proyectos en Colombia es necesaria la inversión económica, ya que el manejo de los recursos económicos da movilidad y participación a los proyectos que integran los planes de desarrollo en el área de la salud.

La última obra legislativa de nuestro ordenamiento jurídico ha dado un cambio de trecientos sesenta grados a nuestro sistema integral de seguridad social, en especial al área de salud donde se enmarca nuevas formas de financiación y de manejo de recursos.

605 CUADRADO, Roura, Juan. Política Economica elaboración, objetivos e instrumentos. Aravaca Madrid. 2006

606 CUADRADO, Roura, Juan. Política Economica elaboración, objetivos e instrumentos. Aravaca Madrid. 2006 
Para procurar una posición más crítica sobre lo que fue la reforma al sistema, traeré a colación uno de los apartados del libro de los doctrinantes Juan Luis Londoño y Julio Frenk (y, Londoño, \& Frenk, 1997):

La implantación de la Ley 100 de 1993 representó uno de los cambios más radicales que se han llevado a cabo en los sistemas de salud para países en desarrollo. ${ }^{607}$ Sus objetivos principales fueron la universalización de los servicios de salud y el logro de la equidad en el acceso entre grupos sociales. El marco de referencia que la soportó impulsó un modelo inédito, que implicaba una nueva estructura institucional para los sistemas de salud. Esta aproximación teórica acuñó el término de pluralismo estructurado, bajo el cual se buscaba evolucionar el modelo de sistema de salud segmentado que se había impuesto durante la mitad del siglo XX en América Latina y otros países en desarrollo

Las reformas estuvieron originadas por cuestiones de indole social, "que en realidad no fueron favorables. Esta reforma se enfatizó en que el modelo anterior segmentado de seguridad social no cubría más del $25 \%$ de la población ${ }^{608}$ y que eran considerables las inequidades entre ricos y pobres, así como entre área urbana y rural, o diferentes regiones geográficas del país. ${ }^{609}$

Este contexto se podría resumir en que hay tanto buenas noticias como malas: las cifras de personas afiliadas al sistema de salud han aumentado significativamente, aunque las conclusiones frente a la prestación de este servicio no son las mejores.

Esto lo expresan cifras donde se muestra un antes y un después de lo que es la situación del sistema de salud después de la publicación y puesta en camino de la Ley 100 de 1993.

Es importante expresar que hace unos años la poca cobertura de protección era el desafío del Sistema General de Seguridad Social en Salud (SGSSS). "En 1993 sólo una cuarta parte de la población tenía algún tipo de protección, mientras que el aseguramiento de la población más pobre y en las zonas rurales era incipiente. Una

607 Musgrove, P. (2010). Colombia: Approaching Uni

608 Velandia, F., Corral, L., Talero, R., Valencia, A., \& Serna, E. (1990). Financiamiento. En F. Yepes, La Salud en Colombia. Estudio Sectorial de Salud (Vol. II, págs. 81-259). Bogotá, Colombia: Ministerio de Salud - Departamento Nacional de Planeación.

609 Pabón, H. L. (1986). Evaluación de Servicios de Salud Modelo Prides. Grupo Salud Comunidad (2da Edición). 
mayor cobertura amplía el acceso a los servicios de salud de los colombianos más pobres, contribuye al cierre de las brechas sociales y protege financieramente a millones de hogares. En la actualidad, se estima que el $97 \%$ de la población (más de 46 millones de colombianos) se encuentran asegurados en salud, cifra histórica para ese indicador y considerada como una cobertura prácticamente universal. En el régimen subsidiado, el número de afiliados supera los 23 millones de personas. El régimen contributivo se acerca a los 21 millones de afiliados y existe un estimado de más de 2 millones de personas ubicadas en los regímenes exceptuados. Es importante destacar que sólo en estos últimos doce meses se registraron 1'213.000 nuevos afiliados, de los cuales 355.000 corresponden al régimen subsidiado y 858.000, al contributivo. ${ }^{610}$

Esto conlleva también un esfuerzo en inversión para garantizar mejores Entidades Promotoras de Salud y una lista más amplia en lo ofrecido en el Plan Obligatorio de Salud.

En cuanto a este logro, hay que resaltar el inmenso esfuerzo en inversión que ello implica, no solo como consecuencia del crecimiento de la población colombiana, sino también de la actualización anual del valor de la Unidad de Pago por Capitación (UPC) que se reconoce por cada afiliado a las Entidades Promotoras de Salud (EPS), para garantizar los servicios de salud incluidos en el Plan Obligatorio de Salud (POS). "Para la UPC promedio que rige en 2015, este incremento fue de 6,06 $\%$, decisión adoptada mediante el Decreto 1664 de 2014 y que, acompañada de ajustes adicionales por reconocimiento de mayores costos para la atención de poblaciones especiales, como la carcelaria, la indígena y la raizal de San Andrés, se constituye en un paso más hacia la equidad en Colombia. ${ }^{611}$

Colombia en la ejecución de su Plan de Ordenamiento Territorial ha estructurado que un poco más de $7 \%$ de su producto interno bruto sea invertido en salud, lo cual la llevaría a ser uno de los países latinoamericanos con mayor inversión en esta área. Este título, aunque importante, no deja de lado que para el año 1997 el país estaba invirtiendo un poco más del $8,5 \%$ de su producto interno bruto, como lo muestra la siguiente gráfica tomada de la página del Banco Mundial (ver gráfica 1).

610 Oficina Asesora de Planeacion y Estudios Sectoriales. Sector administrativo de Salud y Proteccion Social. Informe 2014-2015.

611 Oficina Asesora de Planeacion y Estudios Sectoriales. Sector administrativo de Salud y Proteccion Social. Informe 2014-2015. 
Figura 3. Balance del PIB colombia del año 1995 hasta el año 2014

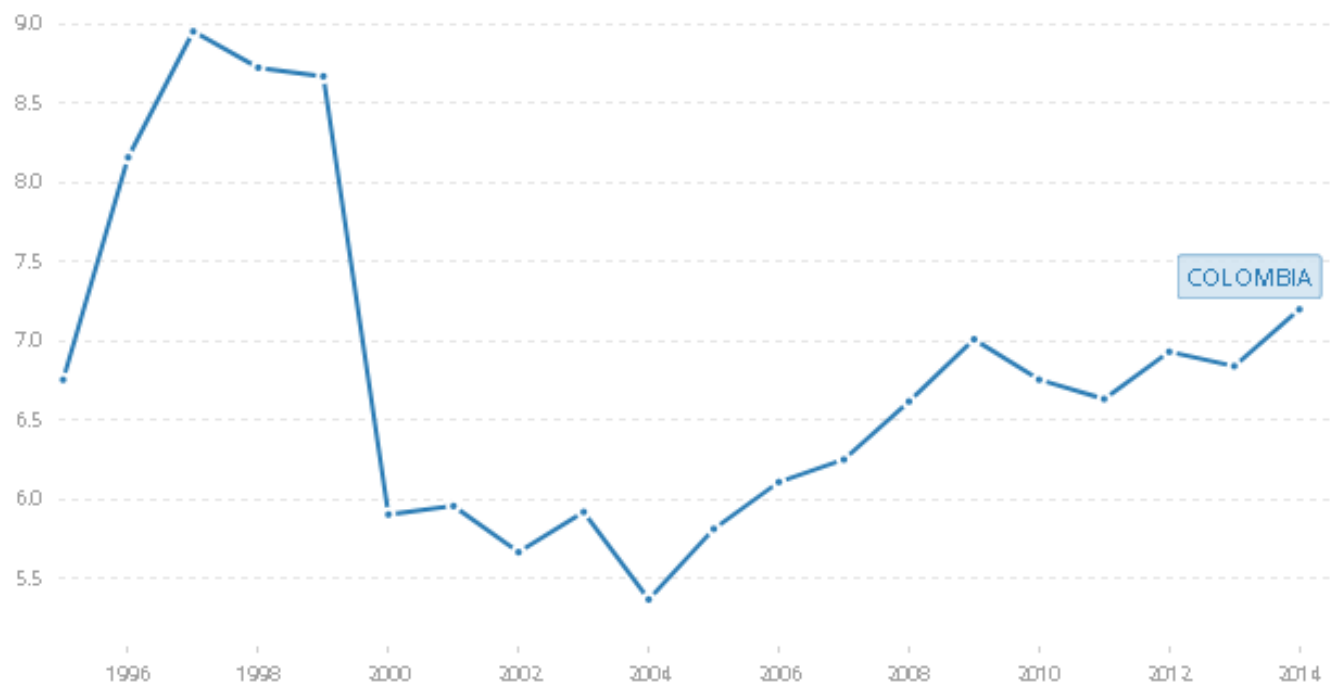

(Ver: https://datos.bancomundial.org/indicador/SH.XPD.TOTL.ZS?locations=CO )

"En la actualidad, Colombia invierte cerca de siete puntos porcentuales del PIB en salud, donde el $75 \%$ es invertido por el sector público. Eso ubica a Colombia como uno de los países latinoamericanos con mayor gasto público sectorial y donde las familias invierten una menor proporción de recursos en salud.

Hay que rescatar que en Colombia se financia desde una forma descentralizada y el presupuesto que hasta el 2012 había de inversión en el área de salud era de 9.061.166.432.119, según los datos obtenidos por el DNP hasta el año 2012. https://colaboracion.dnp.gov.co/CDT/Desarrollo\%20Social/fuentes\%20de\%20finan ciacion\%20por\%20departamento\%202000-2012.xls

Frente al documento anterior agregado veremos las fuentes de financiación de salud por departamentos hasta el año 2012, y en la parte general, la financiación total dada por el país y los entes externos que ayudan a su financiación.

Frente a ingresos y gastos al año 2012, se habría autorizado un capital general de ingresos por 20.728.466.833.614,00, y hubo un gasto generalizado por pagos acumulados de 5.823.264.273.727,09. Esta información fue debidamente obtenida de la página del departamento nacional de planeación 
https://colaboracion.dnp.gov.co/CDT/Desarrollo\%20Social/Ing\%20y\%20gastos\%2 Ofosyga.xls.

Como pudimos ver anteriormente, el sistema de salud en Colombia tiene muchos ingresos de distintos rubros adquiridos por procesos legislativos en el desarrollo de nuestro ordenamiento jurídico. "Pero con todas estas financiaciones siempre hay riesgos en cuanto a la prestación de servicio, infraestructura y contratación. Es por eso que el Ministerio de Salud y la Protección Social en su resolución 02090 de 2014 efectúa la categorización del riesgo de las Empresas Sociales del Estado del nivel territorial para la vigencia 2014 y dicta otras disposiciones, donde ha dado una perspectiva hasta este momento de un alto riesgo en la prestación del servicio salud, por la indebida movilidad de los recursos y la contratación, pero prevé una forma de ejecución de recursos y de medición de riesgo, con el fin de que haya una disminución de riesgo importante para los años siguientes, y así garantizar una mejor prestación del servicio. ${ }^{612}$

\subsection{DEFINICION:}

Para definir la economía de la salud o economía y salud, es importante primero ver dichos conceptos por separado, así poder entender sus apropiaciones individuales, con miras a obtener un resultado desde el enfoque colectivo.

Es importante definir que la economía según la rae, es definida como un conjunto de bienes y actividades que integran la riqueza de una colectividad o individuo, y a este mismo se acota, que es una ciencia que estudia los métodos más eficaces para satisfacer las necesidades humanas materiales, mediante el empleo de bienes escasos. (Española) $)^{613}$.

El segundo concepto es el de salud, este definido por la rae como un conjunto de condiciones físicas en que se encuentra un organismo en un momento determinado, y un conjunto de condiciones mínimas de salubridad de una población determinada, que los poderes públicos tienen la obligación de garantizar y proteger. (Española)614 El concepto salud ha tenido diferentes interpretaciones,

612https://colaboracion.dnp.gov.co/CDT/Desarrollo\%20Social/Reso-

luci\%C3\%B3n\%202090\%20de\%202014\%20riesgo\%202014.PDF

613 Información obtenida en sitio web (fecha de la búsqueda: 22/05/18), búsqueda en el sitio web de la Academia Real de la Lengua Española, URL: http://dle.rae.es/?id=ELVW605.

614 Información obtenida en sitio web (fecha de la búsqueda: 22/05/18), búsqueda en el sitio web de la Academia Real de la Lengua Española, URL: http://dle.rae.es/srv/fetch?id=X7MRZku 
estas jurídicas, doctrinales como jurisprudenciales. Entre esas interpretaciones, la Ley 1751 de 2015, en su artículo 4, ha definido el sistema de salud como:

Es el conjunto articulado y armónico de principios y normas; políticas públicas; instituciones; competencias y procedimientos; facultades, obligaciones, derechos y deberes; financiamiento; controles; información y evaluación, que el Estado disponga para la garantías y materialización del derecho fundamental a la salud ${ }^{615}$

La corte constitucional, ha dado un concepto de salud mucho más amplio y garantista, este entendido como un atributo fundamental de las personas, y conexo al derecho a la vida, esta corporación ha dicho que este tiene una doble connotación al ser un derecho fundamental y un servicio público.

Ahora bien, "la salud tiene dos facetas distintas, que se encuentran estrechamente ligadas: por una parte, se trata de un servicio público vigilado por el Estado; mientras que, por la otra, se configura en un derecho que ha sido reconocido por el legislador estatutario como fundamental, de lo que se predica, entre otras, su carácter de irrenunciable. Además de dicha condición, se desprende el acceso oportuno y de calidad a los servicios que se requieran para alcanzar el mejor nivel de salud posible. (Constitucional, 2015) ${ }^{616}$

Importante mencionar el principio de integralidad, en la prestación del servicio de salud, en el que se entiende que, el servicio de salud debe ser oportuno, eficiente y de calidad.

Es pues asi que: "el derecho a la salud implica el acceso oportuno, eficaz, de calidad y en igualdad de condiciones a todos los servicios, facilidades, establecimientos y bienes que se requieran para garantizarlo. De igual manera, comprende la satisfacción de otros derechos vinculados con su realización efectiva, como ocurre con el saneamiento básico, el agua potable y la alimentación adecuada. Por ello, según el legislador estatutario, el sistema de salud: Es el conjunto articulado y armónico de principios y normas; políticas públicas; instituciones; competencias y procedimientos; facultades, obligaciones, derechos y deberes; financiamiento;

615 COLOMBIIA. CONGRESO DE LA REPUBLICA. Ley 1715. (6, febrero, 2015). Por la cual se regula el derecho fundamental a la salud y se dictan otras disposiciones. Diario Oficial, Bogotá, D.C., 2015. No. 49427.

616 CORTE CONSTITUCIONAL. Magistrado Ponente: Luis Guillermo Guerrero Pérez. T-121-15. 2015 
controles; información y evaluación, que el Estado disponga para la garantía y materialización del derecho fundamental de la salud. (Constitucional, 2015) (17 $^{61}$

El estado asume la responsabilidad de implementar políticas, para que la prestación del servicio de salud sea de alta calidad, y a esto crea un complejo de estructuras tanto políticas, sociales y económicas; esta última como se dijo anteriormente, estipula el conjunto de bienes y servicios que va a estructurar un sistema de salud que cubra la demanda y garantice un óptimo servicio. Es esto que hay una intervención del estado en la economía, y con esta intervención se crean sistemas de valores para sustentar y propiciar el máximo desarrollo de los servicios a cargo del estado en su función pública. La intervención del estado en la economía tiene un propósito, y este ha sido desarrollado por la corte constitucional así:

La intervención del Estado en la economía tiene como propósito armonizar los intereses privados de los particulares con el interés general, "por ello, en las normas de intervención que así expide el legislador, está presente la tensión entre la libertad de empresa y la prevalencia del interés general". En consecuencia, la intervención en la economía se constituye en un mandato constitucional que adquiere aún mayor relevancia cuando se trata de la prestación de servicios públicos. (Constitucional, 2017)618

Pero como entender que el estado interviene en el mercado y que oferta un derecho fundamental como la salud, que la economía estudiara los criterios de calidad para el servicio de salud y que todo queda en una oferta y demanda de un servicio público que se expresa en un mercado de productos en salud. Intentando conectar los vocablos salud y economía habitualmente se piensa en:

La salud es el bien más preciado. Con el fin de mantenerse en buen estado de salud cualquier cosa es válida.

La atención sanitaria está en crisis. Si los costes continúan creciendo con las tasas actuales, el bien salud se tomara inalcanzable para muchos ciudadanos.

617 CORTE CONSTITUCIONAL. Magistrado Ponente: Luis Guillermo Guerrero Pérez. T-121-15. 2015.

618 CORTE CONSTITUCIONAL. Magistrado Ponente: Iván Humberto Escruceria Mayolo. C-284-17. 2017. 
Aunque las dos frases pueden parecer contradictorias, existe cierto acuerdo entre ambas, puesto que presentan a la salud como un bien sin precio (la salud no tiene precio), tanto desde el punto de vista ético, inestimable, como desde el punto de vista económico, muy caro. (Gisbert i Gelonch, 2002). En la posición de muchas personas, es que el Estado siga destinando recursos a la sanidad. Sin embargo, el producto interno bruto (PIB) siempre se ve fracturado por la necesidad de una industrialización de otros bienes y servicios, y el crecimiento descontrolado del gasto sanitario, estaría dedicado solo a sanidad en el actual tiempo. Es por esto, que el estudio de la economía en salud es decidir es en que escala o aproximarse, sería aceptable que cada sociedad considere apropiada y, para ayudar a decidir esta escala, no debe olvidarse que depende de las necesidades de asistencia sanitaria de la población, pero también del resto de necesidades, se concluye entonces que el análisis económico puede llegar a ser útil.

\subsection{CARACTERISTICAS:}

Tenemos entonces como característica importante, que mediante la intervención del estado crea una especialidad, dentro de los estudios de economía, llamada economía de la salud, dedicada a la investigación, el estudio de los métodos de medición y los sistemas de análisis de las actividades relacionadas con la regulación, la financiación, la producción, la distribución y el consumo de los bienes y servicios que satisfacen necesidades sanitarias y de salud, bajo los principios normativos de la eficiencia, compatibles con el respeto a otras consideraciones esenciales, tales como la ética, la calidad, la utilidad y la equidad. (Gimeno, y otros, 2012)619 La finalidad general de esta área que, en cuanto a sus conocimientos, hace una aproximación de cuáles son los elementos constitutivos y las características funcionales del sector sanitario, esto fundamentado en los comportamientos racionales de los individuos en función de la oferta, demanda, financiación, el aseguramiento y la organización del mercado sanitario, y ajustado a las peculiaridades de estos servicios. Dicha área de conocimiento tiene una vertiente normativa, y esta es:

En su vertiente normativa, la economía de la salud sugiere acciones para el mejoramiento de la eficiencia del sector, ocupándose de temas tales como: la objetivizacion de necesidades, la planificación de los servicios, las políticas de incentivos, la reingeniería de procesos, el desarrollo aplicado de las disciplinas

619 GIMENO, Juan Antonio. TAMAYO LORENZO, Pedro. ECONOMIA DE LA SALUD: INISTRUMENTOS. Ediciones Díaz de Santos. P. 496. 2012. 
concernientes con la gestión y control de los recursos, y la evaluación económica de programas y tecnologías sanitarias. (Gimeno, y otros, 2012)620

Por tanto, la disciplina de la economía, pretende desplegar su posicion social en este plano de dinamismo, estableciendo claros los razonamientos en los que se basan sus disposiciones, reemplazando reflexiones de coste subjetivos por demostraciones razonables desarrollando la claridad y la eficacia en la prestación de un insuperable servicio en salud.

Pero como se garantiza esa transparencia y calidad en el servicio de salud, principal función de que los estudios económicos se enfoquen en esta determinada área, pues investigando y coadyuvándose de algunas áreas como la política, el entendimiento de producto ofertado y/o demandado, en este caso salud y la sociedad que se beneficia de la estructuración de ese sistema de valores que va a regular los bienes y servicios en salud.

Para los estudios económicos en el área de salud, es importante abordar el terreno de la política, y con esta en especial, a aquella que es determinante en salud. Mediante el uso de políticas sanitarias se proyectan, y se asientan en mercados algunas formas de producir salud y las mismas políticas de salud que regulan las instituciones y fijan parámetros para su funcionamiento, es decir, reglan el sistema de salud y dan un equilibrio entre Estado, mercado y normas, esto en el experimento que esta área dirima conflictos específicos entre eficiencia y equidad en la determinación de la composición y cuantiad de los servicios en salud, y en este sentido las políticas de sus métodos de financiación.

\subsection{ELEMENTO:}

Entonces como elemento, la política debe entenderse, como una apolítica publica, que permite estudiar e interpretar el proceso de construcción y ejecución de una determinada área en los ordenamientos jurídicos. Como indica Roth (Roth, 2010)621 "tal como para cualquier objeto de estudio, para analizar las políticas públicas es necesario disponer de un marco teórico y conceptual y de herramientas que nos sirvan como lente o tamiz para orientar la labor investigativa". Son estos los

620 GIMENO, Juan Antonio. TAMAYO LORENZO, Pedro. ECONOMIA DE LA SALUD: INISTRUMENTOS. Ediciones

Díaz de Santos. P. 496. 2012.

621 ROTH, A. N. LAS POLITICAS PÚBLICAS Y SUS PRINCIPALES ENFOQUES ANALITICOS. Universidad Nacional de Colombia. Pp. 17. Bogotá. 2010. 
enfoques los que hacen fácil elaborar una explicación de este objeto de estudio y tener un mejor conocimiento de los elementos que inciden en el proceso de una política pública. Es evidente que para garantizar un desarrollo económico en salud, en especial la salud pública, ya que en la atención y prestación de servicio es un resultado de la proyección económica, haciendo síntesis a los antecedentes de los sistemas de salud diseñados mediante el uso de políticas públicas.

De entrada no parece fácil entender que mediante políticas hagan que la salud solo sea adquirida en mercado, lo que si puede adquirirse son los servicios para su mantenimiento y mejora es decir, la regulación de políticas que confeccionen una asistencia de sanitaria de calidad, y que esta pueda estar a disposición de la sociedad, pero se justifica la economía en la salud, en cuanto a las cifras relativas propias de este sector alcanzaron costas importantes para el PIB. En realidad, dos peculiaridades, por encima de otras, de la atención sanitaria atraen la atención del economista, y estas son (Gisbert i Gelonch, 2002):

Tamaño del sector. El sector sanitario constituye una industria considerable significación. Su participación en el PIB se acerca al 10\% en muchos países, en Colombia ya es el $12 \%$, Esto implica, por otra parte, que muchas personas consiguen su renta trabajando en el sector. Para los economistas esta es una razón de suficiente peso para incrementar el conocimiento y el análisis del sector.

Intervención pública en muchos países. La financiación de la atención sanitaria se realiza a través de impuestos, o mediante cuotas obligatorias a sistemas de Seguridad Social. Al estar fuera del mercado se plantea la cuestión de cómo conseguir una asignación de los recursos escasos.

Entonces la economía de la salud, es:

Un campo de investigación, cuyo objeto de estudio es el uso óptimo de los recursos para la atención de la enfermedad y la promoción de la salud. Su tarea consiste en estimar la eficiencia de la organización de los servicios de salud y sugerir formas para mejorar esta organización. (Hacia una definicion de la economia de la salud, 1999)

Ahora como es el análisis de la economía de la salud en Colombia, se debería iniciar por un recuento histórico del tema y su relación con la reforma del sistema de seguridad social en salud, y el sistema nacional de ciencia y tecnología, reformas que buscaban introducir eficiencia sobre la manera como organizaba la provisión 
de servicios de salud. (Williams, 1989) La emergencia social trae 2 conjuntos de medidas sobre los que debe conducirse el debate desde la perspectiva de la economía de la salud: la financiación y sostenibilidad del sistema y su institucionalidad. ACOES considera apropiado y conveniente para el país que en primera instancia se brinde claridad sobre el tipo de gastos en que están representados los casi $\$ 2$ billones destinados al pago de prestaciones No- POS. El principal reto que enfrenta el país en materia de salud se refiere al establecimiento de criterios para garantizar que los recursos existentes generen el mayor impacto en el estado de salud y la calidad de vida de la población, y que enfrentan los estudios de la economía de la salud en Colombia, enfrenta una crisis de legitimidad y de liquidez, con incertidumbre sobre su sostenibilidad financiera"622. En el supuesto y en la cuestión política está presente el pensamiento de el sistema salud se encuentra acabado, con lo cual no reconoce a las posibilidades y necesidades de los afiliados, y que es necasario originar una transformación en el sistema que prescinda las EPS.

El gobierno está atrapado por la visión fatalista y genera mayor incertidumbre al poner en marcha una "reforma a pedazos", como lo inició hace dos años, sin mostrar coherencia ni una visión integral sobre lo que se propone; tres ejemplos:

Ley 1438 , en silencio sobre sus alcances y posibilidades.

Liquidación cuestionada de la CRES: se pierde tradición de gobierno y regulación del sistema de seguridad social.

Reforma tributaria: sustitución parcial de cotizaciones por impuestos generales.

Nueva organización industrial en el régimen subsidiado -vs- unificación del POS.

En resumen la economía de la salud puede abordarse a partir de la relación entre economía y salud, dicha relación entendida como, la salud como componente del bienestar y la salud como sector económico.

La salud como componente de bienestar: La salud no sólo es la ausencia de enfermedad sino también la capacidad de las personas para desarrollar todo su

622 RESTREPO ZEA Jairo Humberto, Retos y perspectivas de la economía de la salud en Colombia: desarrollo académico y evolución del sistema de salud, cit. 
potencial a lo largo de su vida (estado de salud o capital salud). La relación entre salud y desarrollo es en doble dirección: (i) Un mayor desarrollo económico permite a la población obtener una mejor salud. (ii) Un mejor estado de salud es un promotor de mayor desarrollo económico (salud, 2001)623

\subsection{PRINCIPIO DE LIBERTAD ECONÓMICA EN SALUD}

Es necesario ahondar en el principio de la libertad económica y analizar su definición concreta y su relación con el derecho a la salud, a la luz del modelo económico colombiano expresado en la constitución política.

Alexei Julio624 afirma que la constitución de 1886 en su artículo 31 garantiza los derechos adquiridos con justo título con arreglo a las leyes civiles, de los que afirma que hace parte del derecho de propiedad, haciendo un barrido por los artículos constitucionales que tienen relación con los derechos de propiedad, entre los que destacan, la propiedad literaria o artística, el aseguramiento de la economía de mercado y, finalmente, enuncia el Acto Legislativo 3 de 1910 que según el autor obliga al Estado a la indemnización de particulares en caso de afectación a causa del establecimiento de un monopolio estatal. Más adelante, el autor afirma que:

[...] la imposición del modelo centralizador consagrado por la constitución de 1886, que permite la consolidación de una unidad política, junto con el desarrollo económico que se comienza a experimentar desde principios de siglo, conducen finalmente a una ruptura definitiva con la herencia colonial y a la progresiva adopción de un sistema económico liberal ${ }^{625}$.

De lo anterior, se puede evidenciar la relevancia que va tomando el principio de la libertad económica aun antes de la entrada en vigencia de la Constitución Política de 1991.

623 WHO Commission on Macroeconomics and Health \& World Health Organization. (2001). Macroeconomía y salud: invertir en salud en pro del desarrollo económico: informe de la Comisión sobre Macroeconomía y Salud: sinopsis. Ginebra: Organización Mundial da la Salud.

${ }^{624}$ ALEXEI ESTRADA, Julio. Economía y Ordenamiento Constitucional. En: Homero Cuevas et al. Teorías Jurídicas y Económicas del Estado. 1aㅡ ed. Bogotá.: Universidad Externado de Colombia, 2002. p. 180.

${ }^{625}$ ALEXEI ESTRADA, Julio. Op. Cit. p. 181. 
Alexei Julio ha definido una serie de principios que caracterizan la visión económica de la Constitución del 91, entre los que se encuentran:

El Estado, para propiciar la efectividad de los derechos fundamentales, económicos, sociales y culturales, está obligado a elaborar una política económica que potencie tales libertades.

El Estado garantiza la propiedad privada, asociativa y solidaria, pero se establece que tiene una función social y económica.

La calidad de los bienes y servicios ofrecidos y prestados a la comunidad debe ser objeto de regulación legal y de vigilancia pública.

El manejo y aprovechamiento de los recursos naturales, lo mismo que el ambiente sano, son elementos que integran el núcleo de derechos colectivos y se convierten por tanto en materia de regulación e intensa protección.

Las políticas económicas, sociales y ambientales se articulan a través de los planes de desarrollo, que deben ajustarse al concepto de "desarrollo sostenible".

Se garantiza la libertad económica y la iniciativa privada, dentro de los límites del bien común, el ambiente y el patrimonio cultural de la nación.

Se promueve el correcto y transparente funcionamiento de los mercados como garantía y presupuesto de la libertad económica y del eficiente funcionamiento de la economía, para lo cual el Estado debe controlar los abusos que se comentan y que distorsionen sus mecanismos.

Se ordena al Estado estimular y mantener altos niveles de productividad y competitividad [...]. 
Es deber del Estado asegurar la prestación de los servicios públicos a todos los habitantes del territorio nacional.

Se considera que es objetivo fundamental de la actividad del Estado solucionar las necesidades insatisfechas de salud, educación, saneamiento ambiental y agua potable, entre otras ${ }^{626}$.

Asimismo, el autor expone, al abordar el tema del modelo económico propuesto por la constitución de 1991, que este es difícil de determinar, debido a que se mezclan elementos de naturaleza liberal con otros relacionados con una economía dirigida, característica del Estado Social, por lo que opta por definirlo como un modelo mixto, aclarando que se trata de un sistema complejo donde concurren diversos elementos que cumplen distintas funciones de la siguiente manera:

Por una parte, las libertades económicas clásicas ponen límites a la actuación de los poderes públicos; los valores y principios, de otro lado, además de ese papel cumplen la función de mandatos informadores de la actividad de las instancias estatales con competencias en materia, al establecer el sentido de cómo deben utilizar los diversos instrumentos de intervención en la economía ${ }^{627}$.

Sin embargo, este autor se contradice al afirmar que los fallos de la Corte Constitucional se encuentran errados, puesto que no se trata de una económica social del mercado, aun cuando resalta que el mercado continúa siendo "[...] un elemento central de la Constitución económica, que conserva por tanto un rasgo marcadamente liberal" 628 . Por otro lado, Contreras Bautista ${ }^{629}$ plantea que el mercado posee una condición especial de autoregulación y que, en este sentido, la primera perspectiva económica clásica liberal expresada en la constitución tiene sus propios medios para resolver sus necesidades. Contreras además considera que esta autoregulación surge mediante los precios del mercado, lo cual resulta garantizando la mejor forma asignación de recursos. Para sustentar esto, el autor hace referencia a la doctrina de Laissez-Faire 630 la cual, según él, pregona la libertad total del mercado, esto es, sin intervención del Estado.

${ }^{626}$ ALEXEI ESTRADA, Julio. Op. Cit. p. 189-191.

627 lbíd. p. 192.

628 Ibíd. p. 195.

${ }^{629}$ CONTRERAS BAUTISTA, Juan Darío. Derecho y Economía de la Salud en Colombia. Bogotá.: Librería Ediciones del Profesional, 2009. p. 44.

630 CONTRERAS BAUTISTA, Juan Darío. Op. Cit. p. 44. 
De acuerdo con Contreras Bautista, esa posición tiene su fundamento en la relación directa de la economía clásica con las revoluciones burguesas. Es claro que, como consecuencia de dichos cambios económicos, el nuevo sistema rechaza tajantemente cualquier acción pública encaminada a intervenir de algún modo en el mercado, reduciéndose su papel a "[...] la defensa nacional, la preservación del orden público y a garantizar el cumplimiento de la ley"631. Sin embargo, debido a acontecimientos como la Primera Guerra Mundial, la Revolución Rusa, y la Gran Depresión ${ }^{632}$, fue cambiada la percepción del Estado, ya que estos eventos desestabilizaron tanto el mercado que fue evidente la necesidad de intervención del Estado. El sistema de economía mixta tiene como uno de los principales objetivos alcanzar el mayor grado de eficiencia económica y para dar cumplimiento a dicho objetivo es necesario que el Estado garantice la libre competencia, lo que se logra por medio de la apertura de mercados, teniendo en cuenta, como se dijo anteriormente, que se debe intervenir en el mismo, con la intención de corregir las fallas del mercado toda vez que estas impidan la asignación eficiente de los recursos y la distribución del ingreso. Este autor, manifiesta que los servicios públicos han sido criticados por carecer de eficiencia en los casos de prestación directa por parte del Estado, por lo afirma que "[...] el mercado ha reclamado su participación en la oferta de los mismos" 633 .

En Colombia, según Contreras, en materia de servicios públicos existe una económica mixta, de esta forma, la actividad económica y de empresa se rige por el principio de la libre competencia, la cual se ve elevada a categoría de derecho, resaltando que el concepto de propiedad privada dentro de nuestro ordenamiento jurídico se ve impactado por la obligación del cumplimiento de función social de la misma, lo que en ultimas se puede interpretar como intervención estatal en la economía de mercado. El autor dice lo siguiente "[...] premisas que legitiman la intervención del Estado en la economía con fines de preservación y mejoramiento de la eficacia económica y redistribución del ingreso" 634 . Agregando que esto se ve sustentado en los artículos constitucionales 333 y 334, que se deben entender en consonancia con los artículos 58 y 78 del mismo rango:

Artículo 333. La actividad económica y la iniciativa privada son libres, dentro de los límites del bien común. Para su ejercicio, nadie podrá exigir permisos previos ni requisitos, sin autorización de la ley. La libre competencia económica es un derecho de todos que supone responsabilidades. La empresa, como base del desarrollo, tiene una función social que implica obligaciones. El Estado fortalecerá las

\footnotetext{
631 Ibíd. p. 44.

632 lbíd. p. 44.

633 Ibíd. p. 48.

${ }^{634}$ CONTRERAS BAUTISTA, Juan Darío. Op. Cit. p. 49.
} 
organizaciones solidarias y estimulará el desarrollo empresarial. El Estado, por mandato de la ley, impedirá que se obstruya o se restrinja la libertad económica y evitará o controlará cualquier abuso que personas o empresas hagan de su posición dominante en el mercado nacional. La ley delimitará el alcance de la libertad económica cuando así lo exijan el interés social, el ambiente y el patrimonio cultural de la Nación ${ }^{635}$.

Artículo 58. Se garantizan la propiedad privada y los demás derechos adquiridos con arreglo a las leyes civiles, los cuales no pueden ser desconocidos ni vulnerados por leyes posteriores. Cuando de la aplicación de una ley expedida por motivos de utilidad pública o interés social, resultaren en conflicto los derechos de los particulares con la necesidad por ella reconocida, el interés privado deberá ceder al interés público o social. La propiedad es una función social que implica obligaciones. Como tal, le es inherente una función ecológica. El Estado protegerá y promoverá las formas asociativas y solidarias de propiedad. Por motivos de utilidad pública o de interés social definidos por el legislador, podrá haber expropiación mediante sentencia judicial e indemnización previa. Esta se fijará consultando los intereses de la comunidad y del afectado. En los casos que determine el legislador, dicha expropiación podrá adelantarse por vía administrativa, sujeta a posterior acción contenciosa-administrativa, incluso respecto del precio ${ }^{636}$.

Desde este momento, se encuentran la posibles colisiones entre el derecho fundamental a la salud y el principio de la libertad económica, precisamente, por la mixtura del sistema económico constitucional colombiano; por una parte, se manifiestan principios netamente liberales como el de la empresa como base del desarrollo, el Estado como garante de la no obstrucción o restricción de la libertad económica y, por el otro, principios intervencionistas como el de la función social de la de la empresa y la examen del interés social, y el patrimonio cultural de la país.

Ahora, en el artículo 334 se plantea,

Artículo 334. La dirección general de la economía estará a cargo del Estado. Este intervendrá, por mandato de la ley, en la explotación de

${ }^{635}$ COLOMBIA. Constitución Política de Colombia. Op. Cit. Artículo 333 [Título XII].

636 Ibíd. Artículo 58 [Título II]. 
los recursos naturales, en el uso del suelo, en la producción, distribución, utilización y consumo de los bienes, y en los servicios públicos y privados, para racionalizar la economía con el fin de conseguir en el plano nacional y territorial, en un marco de sostenibilidad fiscal, el mejoramiento de la calidad de vida de los habitantes, la distribución equitativa de las oportunidades y los beneficios del desarrollo y la preservación de un ambiente sano. Dicho marco de sostenibilidad fiscal deberá fungir como instrumento para alcanzar de manera progresiva los objetivos del Estado Social de Derecho. En cualquier caso, el gasto público social será prioritario.

El Estado, de manera especial, intervendrá para dar pleno empleo a los recursos humanos y asegurar, de manera progresiva, que todas las personas, en particular las de menores ingresos, tengan acceso efectivo al conjunto de los bienes y servicios básicos. También para promover la productividad y competitividad y el desarrollo armónico de las regiones.

La sostenibilidad fiscal debe orientar a las Ramas y Órganos del Poder Público, dentro de sus competencias, en un marco de colaboración armónica.

El Procurador General de la Nación o uno de los Ministros del Gobierno, una vez proferida la sentencia por cualquiera de las máximas corporaciones judiciales, podrán solicitar la apertura de un Incidente de Impacto Fiscal, cuyo trámite será obligatorio. Se oirán las explicaciones de los proponentes sobre las consecuencias de la sentencia en las finanzas públicas, así como el plan concreto para su cumplimiento y se decidirá si procede modular, modificar o diferir los efectos de la misma, con el objeto de evitar alteraciones serias de la sostenibilidad fiscal. En ningún caso se afectará el núcleo esencial de los derechos fundamentales.

Parágrafo. Al interpretar el presente artículo, bajo ninguna circunstancia, autoridad alguna de naturaleza administrativa, legislativa o judicial, podrá invocar la sostenibilidad fiscal para menoscabar Los derechos fundamentales, restringir su alcance o negar su protección efectiva ${ }^{637}$.

${ }^{637}$ COLOMBIA. Constitución Política de Colombia. Op. Cit. Artículo 334 [Título XII]. 
Es evidente como el papel del Estado intervencionista se manifiesta en el texto constitucional al ordenar que es el Estado el director de la economía nacional, y es una continuación que a su vez sirve como sustento para entender como la libertad de empresa también se ve intervenida por el artículo 78 que dice lo siguiente:

Artículo 78. La ley regulará el control de calidad de bienes y servicios ofrecidos y prestados a la comunidad, así como la información que debe suministrarse al público en su comercialización. Serán responsables, de acuerdo con la ley, quienes en la producción y en la comercialización de bienes y servicios, atenten contra la salud, la seguridad y el adecuado aprovisionamiento a consumidores y usuarios. El Estado garantizará la participación de las organizaciones de consumidores y usuarios en el estudio de las disposiciones que les conciernen. Para gozar de este derecho las organizaciones deben ser representativas y observar procedimientos democráticos internos ${ }^{638}$.

Ahora, en materia de prestación de servicios, el artículo $365^{639}$ aclara que estos son inherentes a la finalidad del Estado y que es deber del mismo asegurar que su prestación sea de forma eficiente; además, asegura que dicho control se llevará por medio de la ley y que estos pueden ser prestados por el Estado o por los particulares. Adicionalmente, el artículo $366^{640}$, también el caracter constitucional, consigna que el bienestar de las personas, y la calidad de vida acorde a la dignidad humana, son propósitos del Estado, constituyendo necesidades y calificando en primera disposición a la salud.

3.5.1. La salud y el principio de la libertad económica. Debido a que los particulares se encuentran habilitados por la constitución para prestar servicios públicos, se hace necesario abordar el tema de la salud como una actividad del mercado, recordando que la Corte Constitucional en sentencia C-974 del año 2002, ha diferenciado la capacidad de racionalización de la inversión cuando en tratándose de empresas públicas o privadas diciendo lo siguiente:

La opción por un modelo que, dentro del ámbito de regulación y control propio de los servicios públicos y en particular de los servicios de salud, se desenvuelve en un ambiente de libertad económica es congruente con los citados principios constitucionales de

638 Ibíd. Artículo 78 [Título II].

639 Ibíd. Artículo 335 [Título XII].

640 Ibíd. Artículo 336 [Título XII]. 
universalidad, solidaridad y eficiencia, en la medida en que se orienta, precisamente, a lograr que la iniciativa privada se canalice hacia objetivos de interés social y que las ventajas de la libre competencia y la racionalidad en la asignación de los recursos propia de un esquema de libre empresa, se traduzcan en ampliación de la cobertura y mejoramiento en la calidad de los servicios ${ }^{641}$.

También, la corte constitucional de alguna manera ha abordado la contradicción entre el control Estatal y la libertad económica en sentencia C-615 del año 2002, que dice lo siguiente:

Esta desproporción en la medida de intervención, a juicio de la Corte pervierte la finalidad constitucional de racionalizar la oferta de servicios de salud perseguida por el legislador. Ciertamente, dentro de la axiología constitucional la libertad de empresa y de competencia se reconoce, como se dijo, por razones de interés general pues se la estima motora del desarrollo. En el presente caso, se presenta un ejemplo claro de cómo la eliminación de estas garantías y del esquema de mercado libre, trunca la posibilidad social de acceder a mejores ofertas de bienes y servicios. Al impedir la oferta libre de servicios, la ley produce un estancamiento de la ampliación de las redes en lo referente a infraestructura, equipos y servicios, y en la mejora de su calidad, con grave detrimento del interés general y de la garantía de la satisfacción de necesidades básicas y de derechos fundamentales. Lo anterior porque, aunque se ajusta a la Carta la planificación de la oferta de servicios públicos y su control y vigilancia a efectos de lograr la atención de las necesidades de la población en todos los niveles, el exceso de la reglamentación anula los beneficios del modelo legal vigente, con grave deterioro del interés colectivo ${ }^{642}$.

La corte resulta poniendo una cota a la intervención del Estado en los asuntos de las empresas privadas prestadoras de servicios de salud, aludiendo que la libertad de empresa constituye un motor de desarrollo y que el exceso de reglamentación anula los beneficios del modelo legal vigente para Colombia, lo que implica que se está haciendo alusión al sistema de economía mixta del que se hablaba con anterioridad. Al respecto, la honorable Corte Constitucional en sentencia C-228 del año 2010 dijo lo siguiente:

${ }^{641}$ COLOMBIA. CORTE CONSTITUCIONAL DE COLOMBIA. Sentencia C-974 de 2002. M.P.: Rodrigo Escobar Gil. Bogotá, D.C. p. 17.

642 COLOMBIA. CORTE CONSTITUCIONAL DE COLOMBIA. Sentencia C-615 de 2002. M.P.: Marco Gerardo Monroy Cabra. Bogotá, D.C. p. 30. 
[...] el Estado Constitucional colombiano es incompatible tanto con un modelo del liberalismo económico clásico, en el que se proscribe la intervención estatal, como con modalidades de economía de planificación centralizada en las que el Estado es el único agente relevante del mercado y la producción de bienes y servicios es un monopolio público. En contrario, la Carta adopta un modelo de economía social de mercado, que reconoce a la empresa y, en general, a la iniciativa privada, la condición de motor de la economía, pero que limita razonable y proporcionalmente la libertad de empresa y la libre competencia económica, con el único propósito de cumplir fines constitucionalmente valiosos, destinados a la protección del interés general643.

La Corte Constitucional en Sentencia C-615 del año 2002 señala la capacidad que tiene el legislador de influir en el diseño del sistema de seguridad social en salud, pero hace la salvedad que esta configuración no es absoluta toda vez que debe encontrarse enmarcada en los límites especificados por la norma constitucional y principalmente su relación con los derechos fundamentales:

Ahora bien, a la hora de definir lo anterior, es decir en el diseño del sistema de seguridad social en salud, el legislador tiene una amplia libertad de configuración legislativa y sólo se encuentra sometido a los límites que imponen ciertas normas constitucionales. Dentro de estas normas limitativas de su capacidad de acción en esta materia, en primer lugar, se encuentran aquellas que consagran derechos fundamentales. En este orden de ideas, por ejemplo, no sería constitucional una reglamentación del servicio público de salud que fuera discriminatoria y excluyente de algún sector de la población, o que tolerara una amenaza seria del derecho a la vida o a la intimidad de las personas. De otro lado, el legislador debe regular la prestación del servicio público de salud respetando lo dispuesto por los principios de eficiencia, universalidad y solidaridad a que se refiere el artículo 49 superior. Por ello, dentro de las variadas formas de regulación que caben dentro del marco de su libertad de configuración, debe garantizar que toda la población el acceso a los bienes y servicios que satisfagan adecuadamente sus necesidades en materia de salud ${ }^{644}$.

${ }^{643}$ COLOMBIA. CORTE CONSTITUCIONAL DE COLOMBIA. Sentencia C-228/10. M.P.: Luis Ernesto Vargas Silva. Bogotá, D.C. p. 24.

${ }^{644}$ COLOMBIA. CORTE CONSTITUCIONAL DE COLOMBIA. Sentencia C-615 de 2002. Op. Cit. p. 13. 
3.5.2 Conflicto entre el derecho a la salud y el principio de la libertad económica. La plena garantía del reconocimiento del derecho fundamental a la salud parece encontrar límites, principalmente, con respecto al principio de la libertad económica, recordando que los dos tienen rango constitucional, razón por la cual es menester abordar la discusión acerca de cómo estos dos (principio y derecho) colisionan frecuentemente; esto, posiblemente, por la mixtura del sistema económico colombiano, que tiene su raíz en la promulgación de la Constitución Política. Para dichos fines, es necesario abordar el tema desde los pronunciamientos de la Corte Constitucional colombiana sobre el mismo, exponer los límites del principio a la libertad económica, el principio de la sostenibilidad fiscal, y los limites jurisprudenciales entre otros temas.

3.5.2.1 Planteamientos de la Corte Constitucional de Colombia en relación con el derecho a la salud y el principio de la libertad económica. Para iniciar con este apartado, es necesario aclarar que en la mayoría de los casos abordados, que son tomados de sentencias de la honorable Corte Constitucional colombiana para ilustrar la colisión entre el derecho fundamental a la salud y el principio de la libertad económica, no solamente se deben entender bajo el crisol del modelo económico, el cual, como se expuso anteriormente tiene un carácter mixto, influenciado fuertemente por el respeto de los derechos fundamentales, sino que además hay que entender que en estos casos específicos de discusiones relacionadas con la salud de los asociados al Estado Social de Derecho, ya sea por necesidad de medicamentos, procedimientos o tratamientos médicos se hará un énfasis en los ordenados por lo médicos tratantes vinculados a la Entidades Promotoras de Salud. Además, se tomarán casos donde existan conflictos relacionados con la necesidad económica de los pacientes y donde se vean comprometidas la vida digna e integridad físicas de los mismos, puesto que es sobre estos escenarios donde la corte constitucional ha erigido reglas y condiciones con la intención de salvaguardar el equilibrio entre el sistema económico colombiano y la garantía de los derechos fundamentales.

De ese desarrollo jurisprudencial, producido a partir de la providencia T-760 de 2008 de la Corte Constitucional, surge un principio que fue nombrado "requerir con necesidad"645, lo que constituye el primer paso en la entrega de medicamentos, tratamientos, o procedimientos que se encuentran por fuer del POS. Uno de los casos emblemáticos de ejercicio del principio de "requerir con necesidad" es el tratado en la sentencia T-1024 del año $2010^{646}$ donde se procede a ordenar una silla de ruedas y otros suministros a una señora de avanzada edad, utilizando como

645 COLOMBIA. CORTE CONSTITUCIONAL DE COLOMBIA. Sentencia T-760 de 2008. Op Cit. p. 87.

646 COLOMBIA. CORTE CONSTITUCIONAL DE COLOMBIA. Sentencia T-1024 de 2010. M.P.: Humberto Antônio Sierra Porto. Bogotá, D.C. 
principal argumento que, si bien lo requerido por la paciente no se encontraba dentro del POS, sí se encontraba en un estado de necesidad debido a la falta de capacidad demostrada por la ciudadana. Con relación a la necesidad y al requerimiento, la Corte constitucional en sentencia T-323 del año 2013 dijo lo siguiente:

En ese orden de ideas se concluye, que toda persona tiene el derecho a que se le garantice el acceso a los servicios de salud que requiera, y que no es posible que se aplique de manera restrictiva la reglamentación, y se excluya la práctica de procedimientos o intervenciones, toda vez que no es constitucionalmente admisible que dicha reglamentación restrictiva tenga prelación sobre la debida protección y garantía de los derechos fundamentales ${ }^{647}$.

Aun cuando se evidencia que los servicios de salud son necesarios para la personas per se, el ordenamiento jurídico cuando se trata de casos especiales como el abordado por la sentencia T-361/14 ${ }^{648}$ de la Corte Constitucional, donde se estudia el caso de un paciente que debe ser tratado en el exterior, hace la salvedad de que dichos tratamientos implican costos muy elevados y que los recursos del Estado en salud son limitados, por tanto, dicha corporación recuerda que en la Ley 508 de $1999^{649}$, se establecieron unos requisitos que son de obligatorio cumplimiento para acceder a los servicios de salud del POS, y recuerda que dichos requisitos y situaciones deben ser observadas a la luz de los principios constitucionales de la seguridad la prevalencia del interés general y de los principios propios del sistema de salud, los cuales son la eficiencia, universalidad y solidaridad.

El factor económico tiene dos formas de ser tomado por la jurisprudencia de la Corte Constitucional, toda vez que es uno de los requisitos fundamentales cuando se trata de reconocimiento de costos de procedimientos, intervenciones y medicinas del POS llegando a establecer reglas para demostrar dichas incapacidades económicas por parte de los pacientes y sus familias. De las reglas se resalta la siguiente: "[...] (ii) ante la afirmación de ausencia de recursos económicos por parte del actor (negación indefinida), se invierte la carga de la prueba correspondiendo en ese caso

647 COLOMBIA. CORTE CONSTITUCIONAL DE COLOMBIA. sentencia T-323-13. M.P.: Jorge Ignacio Pretelt Chaljub. Bogotá, D.C. p. 22.

${ }^{648}$ COLOMBIA. CORTE CONSTITUCIONAL DE COLOMBIA. sentencia T-361/14. M.P.: Jorge Ignacio Pretelt Chaljub. Bogotá, D.C.

649 COLOMBIA. CONGRESO DE LA REPÚBLICA DE COLOMBIA. Ley 508 de 1999 (29, julio, 1999). Por la cual se expide el Plan Nacional de Desarrollo para los años de 1999-2002. Diario Oficial, Bogotá D.C. 1999. № 43.651. 
a la entidad demandada demostrar lo contrario [...]" ${ }^{650}$. Como una de las principales razones para justificar las negaciones de la prestación de los servicios de salud, la Corte Constitucional ha justificado alegando que se trata de una forma para salvaguardar el equilibrio financiero ${ }^{651}$ del sistema de seguridad social en salud, alegando que en dicho sistema no solamente no se cuenta con recursos ilimitados, sino, más que eso, los recursos del sistema son escasos:

[...] la Corte Constitucional ha fijado en materia de derechos sociales, según el cual, es el individuo el primer llamado a proveerse lo necesario para suplir sus necesidades básicas y que, sólo frente a la imposibilidad de los agentes de concretar este mandato social, derivado de la obligatoriedad del trabajo, emana el deber del Estado de desplegar su actividad para procurarle a las personas ese mínimo en la satisfacción de sus necesidades. Lo anterior, en aras de salvaguardar el equilibrio financiero del Sistema de Seguridad Social en Salud, habida cuenta que este parte de recursos escasos para la provisión de los servicios que contempla ${ }^{652}$.

Cabe resaltar que las situaciones particulares de salud o de condiciones de existencia de las personas deben ser evaluadas a la luz de los principios constitucionales y derechos fundamentes teniendo como pilar el reconocimiento de la dignidad humana. Es por esto, que en sentencia T-099 de 1999 la Corte Constitucional decidió amparar los derechos de una persona de avanzada edad que se encontraba en condiciones indignas de existencia ordenando el suministro de pañales desechables por parte de la Entidad Promotora de Salud:

En este caso específico, es claro que la omisión de Capresub en otorgar los pañales a la actora, vuelve indigna su existencia, puesto que no le permite gozar de la óptima calidad de vida que merece y, por consiguiente, le impide desarrollarse plenamente. La inhabilidad para controlar los esfínteres, su avanzada edad (80 años), la situación económica que no le permite acudir a métodos más sofisticados para la solución de su problema, la disfunción cerebral que originó dicha anomalía y el riesgo de infecciones en la zona (heridas, llagas, hongos) no le permiten una vida normal, ni llevar a buen término sus actividades diarias, a menos que se le proporcionen en alguna

650 COLOMBIA. CORTE CONSTITUCIONAL DE COLOMBIA. Sentencia T-683 de 2003. M.P.: Eduardo Montealegre Lynett. Bogotá, D.C. p. 1.

651 COLOMBIA. CORTE CONSTITUCIONAL DE COLOMBIA. Sentencia T-073/13. M.P.: Jorge Ignacio Pretelt Chaljub. Bogotá, D.C.

652 COLOMBIA. CORTE CONSTITUCIONAL DE COLOMBIA. Sentencia T-712/07. M.P.: Rodrigo Escobar Gil. Bogotá, D.C. p. 10. 
medida, las condiciones que le faciliten vivir con la dignidad que demanda la existencia. Recuérdese además que en tratándose de personas de la tercera edad el derecho a la seguridad social se erige en fundamental y su protección se torna insoslayable en casos como el presente ${ }^{653}$.

Así las cosas, la Corte estableció a lo largo de reiterada jurisprudencia los siguientes criterios sobre la regla de acceso a los servicios de salud que se requerían y no están incluidos en el plan obligatorio:

a) la falta del medicamento o tratamiento excluido por la reglamentación legal o administrativa, debe amenazar los derechos constitucionales fundamentales a la vida o a la integridad personal del interesado; b) debe tratarse de un medicamento o tratamiento que no pueda ser sustituido por uno de los contemplados en el Plan Obligatorio de Salud o que, pudiendo sustituirse, el sustituto no obtenga el mismo nivel de efectividad que el excluido del plan, siempre y cuando ese nivel de efectividad sea el necesario para proteger el mínimo vital del paciente; c) que el paciente realmente no pueda sufragar el costo del medicamento o tratamiento requerido, y que no pueda acceder a él por ningún otro sistema o plan de salud (el prestado a sus trabajadores por ciertas empresas, planes complementarios prepagados, etc.) ; y finalmente, d) que el medicamento o tratamiento haya sido prescrito por un médico adscrito a la Empresa Promotora de Salud a la cual se halle afiliado el demandante ${ }^{654}$

Lo que se puede ver como una posición tajante con relación al requerimiento, el cual puede ser entendido más bien como una necesidad, donde la corporación es clara al afirmar que la reglamentación restrictiva no puede tener una prelación sobre la protección y garantía de los derechos fundamentales. Las colisiones entre el derecho fundamental a la salud y la libertad económica únicamente no tienen relación con el suministro de medicamentos, la práctica de procedimientos 0 tratamientos médicos, sino que se ha expandido en materia legal y jurisprudencial a situaciones como el reconocimiento de servicios de transporte cuando estos se encuentren relacionados con la recuperación del paciente. Para esto, la corte constitucional en sentencia T-346 de 2009 ha impertido las siguientes reglas:

653 COLOMBIA. CORTE CONSTITUCIONAL DE COLOMBIA. Sentencia T-099/99. M.P.: Alfredo Beltrán Sierra. Bogotá, D.C. p. 4.

654 COLOMBIA. CORTE CONSTITUCIONAL DE COLOMBIA. Sentencia T-180/13. M.P.: Jorge Ignacio Pretelt Chaljub. Bogotá, D.C. p. 16. 
[...] (i) ni el paciente ni sus familiares cercanos tienen los recursos económicos suficientes para pagar el valor del traslado y (ii) de no efectuarse la remisión se pone en riesgo la vida, la integridad física o el estado de salud del usuario ${ }^{655}$.

De igual forma, citó que en algunas oportunidades se ha ordenado la prestación del transporte, junto con un acompañante, cuando el paciente:

[...] (i) El paciente sea totalmente dependiente de un tercero para su desplazamiento, (ii) requiera atención permanente para garantizar su integridad física y el ejercicio adecuado de sus labores cotidianas y (iii) ni él ni su núcleo familiar cuenten con los recursos suficientes para financiar el traslado ${ }^{656}$.

Con relación a la naturaleza o la obligatoriedad de los Comités Técnico Científicos, la Corte ha dicho ese sentido en sentencia T-298 de $2008^{657}$ que sus conceptos no son indispensables para un paciente sea otorgado, toda vez que es suficiente en primera medida el concepto del médico tratante, aclarando que dicho comité "[...] no puede considerarse como una instancia más entre los usuarios y las Entidades Promotoras de Salud" 658 , debido a que no se pueden imponer dichas cargas a los pacientes.

3.5.2 Fines de la libertad económica. La Corte Constitucional en Sentencia C-228 de $2010^{659}$ señala que la intervención del Estado en materia de libertad económica se encuentra justificada en la intención de corrección de desigualdades, inequidades y demás comportamientos que sean lesivos en materia de garantías constitucionales:

De otro lado, los límites a la libertad económica justifican la intervención estatal en el mercado, de modo que el Estado esté habilitado para ejercer "labores de regulación, vigilancia y control, a través de una serie de instrumentos de intervención con los cuales se

655 COLOMBIA. CORTE CONSTITUCIONAL DE COLOMBIA. Sentencia T-346 de 2009. M.P.: María Victoria Calle Correa. Bogotá, D.C. p. 1.

656 COLOMBIA. CORTE CONSTITUCIONAL DE COLOMBIA. Sentencia T-346 de 2009. Op. Cit. p. 1.

657 COLOMBIA. CORTE CONSTITUCIONAL DE COLOMBIA. Sentencia T-298 de 2008. M.P.: Jaime Córdoba Triviño. Bogotá, D.C.

658 lbíd. p. 11.

659 COLOMBIA. CORTE CONSTITUCIONAL DE COLOMBIA. Sentencia C-228 de 2010. Op. Cit. 
controlan y limitan los abusos y deficiencias del mercado. Dicha intervención es mucho más intensa precisamente cuando se abre la posibilidad de que a la prestación de los servicios públicos concurran los particulares". Nótese que la intervención del Estado en la economía apunta a la corrección de desigualdades, inequidades y demás comportamientos lesivos en términos de satisfacción de garantías constitucionales. Por ende, dicha actividad estatal se enmarca no solo en la corrección de conductas, sino también en la participación pública en el mercado, destinada a la satisfacción de los derechos constitucionales de sus participantes, en especial de los consumidores $^{660}$.

La corte Constitucional en la sentencia C-615 del año 2002 ha enunciado unas reglas de intervención por parte del Estado como en virtud de las limitaciones de la libertad de empresa, haciendo la salvedad que dicha intervención no puede desconocer la libertad y debe estar sustentada en los criterios de razonabilidad y proporcionalidad:

Al respecto, ha indicado que tal intervención: i) necesariamente debe llevarse a cabo por ministerio de la ley; ii) no puede afectar el núcleo esencial de la libertad de empresa; iii) debe obedecer a motivos adecuados y suficientes que justifiquen la limitación de la referida garantía; iv) debe obedecer al principio de solidaridad; y v) debe responder a criterios de razonabilidad y proporcionalidad ${ }^{661}$.

Lo anterior, en consonancia con lo expuesto anteriormente por la Corte en sentencia SU-157/99662 donde la corporación dejó claro que la limitación de las libertades económicas aun cuando no sean derechos por si mismos tampoco pueden ser restringidos arbitrariamente:

Si bien las libertades económicas no son derechos fundamentales per se y que, además, pueden ser limitados ampliamente por el Legislador, no es posible restringirlos arbitrariamente ni es factible impedir el ejercicio, en igualdad de condiciones, de todas las personas que se encuentren en condiciones fácticamente similares. Es viable

\footnotetext{
${ }^{660}$ COLOMBIA. CORTE CONSTITUCIONAL DE COLOMBIA. Sentencia C-228 de 2010. Op. Cit. p.2. ${ }^{661}$ COLOMBIA. CORTE CONSTITUCIONAL DE COLOMBIA. Sentencia C-615 de 2002. Op. Cit. p.1. 662 COLOMBIA. CORTE CONSTITUCIONAL DE COLOMBIA. Sentencia SU-157 de 1999. M.P.: Alejandro Martínez Caballero. Bogotá, D.C.
} 
predicar la ius fundamentalidad de estos derechos cuando se encuentren en conexidad con un derecho fundamental ${ }^{663}$.

De lo anterior, se puede colegir que el principio de la libertad económica no es absoluto, precisamente, debido a la mixtura en razón al sistema económico adoptado por Colombia desde la proclamación de la Constitución Política. No obstante, las imposiciones de limitantes al principio deben tener asidero en el mismo ordenamiento constitucional, resaltando que en momentos específicos la libertad económica puede ser entendida desde un punto de vista ius fundamental como cuando se encuentre en conexidad con un derecho fundamental664.

\subsection{PRINCIPIO DE SOSTENIBILIDAD FISCAL}

Establecido en el marco normativo como un principio orientador de la actividad de todas las ramas del poder público, y pensado para alcanzar por su vía y de manera progresiva y programática los objetivos del Estado Social de Derecho, el principio de sostenibilidad fiscal constituye en los términos en que se ha previsto, un límite para la satisfacción del derecho a la salud, toda vez que se busca por medio del mismo garantizar para el Estado la existencia de recursos presentes que no inhiban el gasto en inversiones futuras.

El principio objeto de esbozo es un mandato de actuación coordinada entre todas las entidades del Estado, que determina la vigencia del reconocimiento de los derechos, ya que los avances en materia de educación, salud, vivienda, entre otros, dependen de la viabilidad económica del Estado665. De acuerdo con el magistrado Humberto Sierra ${ }^{66}$, un Estado es sostenible fiscalmente cuando tiene condiciones de, en primer lugar, asumir su deuda pública, en segundo lugar, cuenta con la disponibilidad de recursos para garantizar su crecimiento en el largo plazo, y finalmente, posee estabilidad macroeconómica, términos todos coincidentes con el tema de la economía que encuentran su interrelación con el tema de los derechos, en punto de que la satisfacción de los mismos se supedita a lo precedentemente expuesto.

\footnotetext{
663 lbíd. p. 2.

${ }^{664}$ COLOMBIA. CORTE CONSTITUCIONAL DE COLOMBIA. Sentencia SU-157 de 1999. Op. Cit. ${ }^{665}$ COLOMBIA. CORTE CONSTITUCIONAL DE COLOMBIA. Sentencia C-132 de 2012. M.P.: Humberto Antonio Sierra Porto. Bogotá, D.C.

666 lbíd.
} 
Huelga decir que este principio, así entendido y en punto de la naturaleza fundamental del derecho a la salud, ha establecido una limitación, pues inevitablemente una economía sostenible reduce esfuerzos en la protección de derechos fundamentales y asistencialismo, y limita la suficiencia de recursos que, en un país subdesarrollado como Colombia, es una utopía. No obstante, por lo anterior no debe entenderse la imposibilidad de coexistencia del reconocimiento del derecho a la salud con el principio de Sostenibilidad fiscal, pues en el más sano de los supuestos, la relación de los mismos debe ser interpretada de manera armónica, mientras se da el progresivo incremento de recursos y ampliación de cobertura. Necesariamente, frente a dicha relación armónica, la sostenibilidad fiscal, como instrumento para alcanzar de manera progresiva los objetivos del Estado Social de Derecho, se debe incardinar dentro de los postulados de este último, pues en ningún evento la ausencia de recursos es aceptable para que el Estado se exonere de "[...] la plena realización de los derechos, pues la escasez de recursos no lo exime de ciertas obligaciones mínimas esenciales en la aplicación de los derechos económicos, sociales y culturales"667.

Sin duda alguna, a la luz del entendimiento de la salud dentro los DESC, la sostenibilidad fiscal fue uno de los más fuertes principios ponderados por la Corte para proceder a su reconocimiento de fundamentalidad y autonomía, sin embargo, para tenerlo en cuenta decidió desarrollar una línea jurisprudencial universal del derecho a la salud, y esto no es por causa diferente a que con el mismo se protegen mínimos ínsitamente relacionados con la vida, la dignidad y la integridad personal que sería prohibido soslayar. Tal como se preceptúa en el artículo 334 de la Constitución, "[...] bajo ninguna circunstancia, autoridad alguna de naturaleza administrativa, legislativa o judicial, podrá invocar la aplicación del principio de sostenibilidad fiscal para menoscabar los derechos fundamentales"668.

Así las cosas, se observa con claridad que la consideración de la salud como derecho fundamental lleva consigo no solo el compromiso de las personas y las familias, sino también del Estado, que debe encaminar su actividad a la realización del derecho por vías que trascienden el deber de abstención y tocan la disponibilidad de recursos, la no interpretación restrictiva del principio de sostenibilidad fiscal, el replanteamiento del sistema de seguridad social en salud y el diseño de políticas efectivas y contundentes para poder materializar lo que desde la interpretación constitucional se ha logrado de manera tan garantista, superando así las barreras legales que surgen de camino a su efectividad.

667 COLOMBIA. CORTE CONSTITUCIONAL DE COLOMBIA. Sentencia C-132 de 2012. Op. Cit. p. 125.

${ }^{668}$ COLOMBIA. Constitución Política de Colombia. Op. Cit. Artículo 334 [Título XII]. 
La Corte Constitucional ${ }^{669}$ planteó que la reglamentación de una ley Estatutaria de ninguna manera puede retroceder en cuanto a la garantía del derecho, ni frente a pronunciamientos o reglas jurisprudenciales de protección sentadas vía constitucional. Así mismo, advirtió que no puede ponerse obstáculos a la acción de tutela como mecanismo preferente y sumario ante la conculcación del derecho, incluso ante la creación de otros mecanismos de protección. Por último, y con gran alcance, estableció que el principio de sostenibilidad fiscal no puede ser talanquera para la eficiente prestación de un servicio de salud de calidad, puesto que corresponde al Estado garantizar la existencia de recursos para su protección.

3.6.1 Decisiones artificiosas de carácter legislativo y administrativo. La administración privada del sistema de seguridad social en salud bajo la permisión de la configuración legislativa ha buscado por todos los medios jurídicos resguardar la rentabilidad del negocio de la salud, para lo cual se ha valido, verbigracia, en principio, del gran número de lagunas de regulación del sistema, que hacen tan factible el desconocimiento del derecho con base en los supuestos desregulados. Posteriormente, dado cuenta de los continuos pronunciamientos jurisprudenciales que dieron contenido y alcance a los aspectos carentes de regulación, se inició una carrera de estipulación taxativa de prohibiciones y limitaciones que sin duda también atentaron contra la garantía del derecho. Desde dicho momento, se ha intentado por tal vía soslayar el derecho fundamental a la salud a través de la promulgación de diversos instrumentos jurídicos, verbigracia, leyes ordinarias, actos administrativos, leyes estatutarias, e incluso Decretos con fuerza de ley.

El ejemplo vivo del alcance de lo precedente, es que durante los años 2009 y 2010 , el gobierno de turno por vía de un paquete nutrido de decretos pretendió reformar aspectos estructurales de la salud en Colombia, verbigracia, en el Decreto número 128 de $2010^{670}$ que incluía un conjunto de "micos" que soslayaban de manera trascendental cualquier garantía del derecho a la salud, verbigracia, se le cambiaba el nombre a los servicios no POS por el de "prestaciones excepcionales en salud", que debían ser financiadas total o parcialmente por los afiliados y para cuya autorización se requería del estudio por parte del Comité Técnico Científico que creaba la norma, y dentro cuya competencia, estaba el estudio de los ingresos y patrimonio individual y familiar de quien necesitaba un servicio. Sin duda, el alcance negativo de este instrumento legal era de amplias magnitudes, pues, verbigracia, comprometía para el pago de dichas prestaciones excepcionales las cesantías, los ahorros pensionales e incluso préstamos bancarios, siendo la solidaridad del Estado

669 COLOMBIA. CORTE CONSTITUCIONAL DE COLOMBIA. Sentencia C-313/14. Op. Cit. 670 COLOMBIA. CONGRESO DE LA REPÚBLICA DE COLOMBIA. Decreto 128 DE 2010 (21, enero, 2010). Declarado INEXEQUIBLE por la Corte Constitucional mediante Sentencia C-258 de 2010. Por medio del cual se regulan las prestaciones excepcionales en salud y se dictan otras disposiciones. Diario Oficial, Bogotá D.C. 2010. № 47.599. 
casi nula; afortunadamente, los decretos en comento surtieron su trámite en la Corte Constitucional, en donde se resolvió su inexequibilidad aunque bajo un análisis meramente formal.

Visto de tal forma, es ostensible que el actuar encaminado a dar rentabilidad al sistema es una de las mayores barreras en la efectividad del servicio a la salud, razón por la cual se deben crear y fortalecer los controles del Estado, a efectos de que el bienestar ciudadano en la materia no sea supeditado al juego del mercado.

\subsection{PRESUPUESTOS PARA EL RECONOCIMIENTO DEL DERECHO A LA SALUD.}

La materialidad del derecho objeto de estudio, como es claro, requiere de unos mínimos presupuestos que son:

1. La existencia de un Sistema de Seguridad Social ${ }^{671}$ en salud a cargo del Estado y regulado por el mismo, compuesto por un conjunto de personas e instituciones que presten servicios y tecnologías en el área medico quirúrgica, cuya prioridad sea la de garantizar en condiciones de universalidad el goce efectivo del derecho. Mediante la Ley Estatutaria ${ }^{672}$ del derecho a la salud, este Sistema se organiza a través de redes integrales de servicios, con la participación de entidades públicas, privadas o mixtas, según se determine en su momento.

2. Que el Estado ejecute de manera indelegable las siguientes obligaciones:

[...] (i) Organizar, (ii) dirigir y (iii) regular la prestación de los servicios de salud; (iv) establecer las políticas para la prestación de los servicios por parte de entidades privadas, y ejercer (v) su vigilancia y (vi) control; (viii) establecer las competencias de la Nación, las entidades territoriales y los particulares, y (ix) determinar los aportes a su cargo en los términos y condiciones señalados en la ley. Así pues, es obligación del Estado establecer el Sistema; definir qué entidades y personas lo pueden integrar, y qué labores puede desempeñar cada uno; cómo pueden los particulares participar en la prestación de los servicios y en qué términos; así como también, establecer quiénes

671 COLOMBIA. CONGRESO DE LA REPÚBLICA. Ley 100. (23, diciembre, 1993). Op. Cit. 672 COLOMBIA. CONGRESO DE LA REPÚBLICA DE COLOMBIA. Ley 1751. Op. Cit. 
aportan al Sistema y en qué cantidades, esto es, definir el flujo de recursos del Sistema ${ }^{673}$.

3. La vinculación al Sistema de usuarios del servicio de salud independientemente de su calidad, ya sean contribuyentes 0 afiliados del régimen contributivo 0 subsidiado, o participantes vinculados, que a su vez requieran asegurar el riesgo de enfermedad, y sus necesidades sean sujetas a la solidaridad de los otros usuarios del sistema. El Estado tiene la obligación de respetar el derecho a la salud de toda persona, permitiendo que acceda sin discriminación alguna al Sistema de Salud ${ }^{674}$.

4. "El conocimiento de la información adecuada y necesaria para acceder a los servicios de salud con libertad y autonomía"675, a fin de que el paciente pueda elegir la opción que satisface de mejor manera su derecho; de ahí que se debe permitir al usuario conocer todas las condiciones de aseguramiento, así como brindar información inteligible, y leal sobre el servicio de salud que requiere, sus probabilidades de éxito y riesgos.

5. Garantía por parte de las entidades responsables del sistema de los máximos estándares de calidad, eficacia, y oportunidad ${ }^{676}$, en la prestación de los mínimos servicios de salud a los que una persona tiene derecho de acceder.

6. Existencia de recursos que mantengan el equilibrio económico. La financiación sin lugar a dudas es un condicionamiento determinante de la garantía del derecho a la salud, toda vez que en el mismo se fundamentan sus limitaciones. Dicha financiación debe ser en lo posible sostenible puesto que además del flujo permanente de recursos que requiere el servicio público esencial para su mantenimiento, oportuna y adecuada prestación, el equilibrio financiero permite garantizar la viabilidad del sistema de salud, y su permanencia en el tiempo ${ }^{677}$. En esta materia se ciernen las principales controversias frente al derecho a la salud, toda vez que la Corte como guardiana de la Constitución no ha permitido que las políticas y regulación incorporadas para financiar de manera sostenible el sistema de salud, lesionen los derechos de los usuarios del sistema y, desconozcan la jurisprudencia sobre sus límites, en el entendido de que la protección del derecho no puede ser sacrificada con pretexto de la sostenibilidad financiera. Corolario, la

673 COLOMBIA. CORTE CONSTITUCIONAL DE COLOMBIA. Sentencia C-197/12. M.P.: Jorge Ignacio Pretelt Chaljub. Bogotá, D.C. p. 2.

${ }^{674}$ CORTE CONSTITUCIONAL DE COLOMBIA. Sentencia T-760-2008. Op. Cit. p. 68.

675 lbíd. p. 75.

676 Ibíd. p. 78.

677 COLOMBIA. CORTE CONSTITUCIONAL DE COLOMBIA. Sentencia C-252/10. M.P.: Jorge Iván Palacio. Bogotá, D.C. p. 10. 
sostenibilidad financiera no puede comprender la negación a prestar eficiente y oportunamente todos los servicios de salud debidos a cualquier usuario.

7. Trámite administrativo. El artículo 14 de la Ley 1751 de $2015^{678}$, prohíbe la negación de la prestación de servicios con fundamento en requerimientos de autorización administrativa entre el prestador de servicios y la entidad que cumpla la función de gestión de servicios, siempre y cuando se trate de atención de urgencias. En dicha situación opera con todo vigor el criterio de la imposibilidad de cargas administrativas como barreras frente al derecho a la salud. Así señaló la Corte en la sentencia T-760 de 2008 que, "Toda persona tiene derecho a acceder a los servicios de salud sin que las EPS puedan imponer como requisito de acceso a un servicio de salud el cumplimiento de cargas administrativas propias de la entidad"679. En tal sentido, cuando una EPS niega servicios de salud a una persona que tiene derecho a ellos, porque no realizó un trámite que le corresponde realizar a la propia entidad, irrespeta su derecho a la salud, puesto que crea una barrera para acceder al servicio. En ese sentido se puede afirmar que hay ciertas cargas administrativas que debe afrontar el paciente, no obstante, hay situaciones en las cuales las mismas no son aceptadas como razones para negar la prestación de un servicio de salud, no importando si este servicio es el diagnóstico, intervención quirúrgica, suministro de medicamentos o cualquier otro requerido para hacer efectivo el derecho, tal es el caso de las urgencias y los trámites del resorte interno de la entidad.

\subsection{COBERTURA, EXCLUSIONES, Y REGLAS JURISPRUDENCIALES APLICABLES}

La recientemente promulgada Ley Estatutaria del derecho a la salud instituye un Sistema de beneficios basado en exclusiones, y no en inclusiones como históricamente se configuraba el Plan Obligatorio de Salud. De ahí que según el artículo 15 de la norma, toda prestación, servicio o tecnología en salud, será autorizada siempre que la misma no esté expresamente excluida luego de un procedimiento técnico científico creado para dicho efecto, bajo el fundamento de uno de los criterios enunciados en la norma. Así se dispone en el artículo 15:

El Sistema garantizará el derecho fundamental a la salud a través de la prestación de servicios y tecnologías estructurados sobre una concepción integral de la salud, que incluya su promoción, la

678 COLOMBIA. CONGRESO DE LA REPÚBLICA DE COLOMBIA. Ley 1751. Op. Cit. p. 8. 679 COLOMBIA. CORTE CONSTITUCIONAL DE COLOMBIA. Sentencia T-760 de 2008. Op Cit. p. 265. 
prevención, la paliación, la atención de la enfermedad y rehabilitación de sus secuelas. En todo caso, los recursos públicos asignados a la salud no podrán destinarse a financiar servicios y tecnologías en los que se advierta alguno de los siguientes criterios:

a) Que tengan como finalidad principal un propósito cosmético o suntuario no relacionado con la recuperación o mantenimiento de la capacidad funcional o vital de las personas;

b) Que no exista evidencia científica sobre su seguridad y eficacia clínica;

c) Que no exista evidencia científica sobre su efectividad clínica;

d) Que su uso no haya sido autorizado por la autoridad competente;

e) Que se encuentren en fase de experimentación;

f) Que tengan que ser prestados en el exterior 680 .

Frente a la primera exclusión, la Corte Constitucional planteó que el "[...] concepto de salud debe interpretarse en un sentido amplio, abarcando no sólo el aspecto funcional o físico de la persona sino también sus condiciones psíquicas, emocionales y sociales" 681 . Bajo este presupuesto, es viable conceder servicios o tecnologías en salud con fines estéticos cuando los mismos son determinantes para dignificar la vida de un paciente afectado psíquica y emocionalmente por su aspecto físico, siendo imperativo conceder la tutela frente a los asuntos que trascienden lo meramente cosmético, y llegan a comprometer la dignidad humana de un paciente.

En este sentido, debe comprenderse el alcance de la exclusión en dichas situaciones en las cuales no se advierte por parte de un prestador del servicio un requerimiento relacionado la salud, pero de fondo el mismo incide de manera significativa en el goce efectivo del derecho, por ejemplo, en materia de salud oral cuando enfermedades bucales impiden el consumo de alimentos, el bypass gástrico cuando permite mejorar la vida del paciente, entre otros múltiples ejemplos. Solo bajo esta lectura, dicha exclusión puede catalogarse como constitucional, siempre y cuando dada las particularidades del caso concreto, no se trate de situaciones que reúnan los requisitos establecidos por la jurisprudencia para excepcionar lo dispuesto por el legislador.

680 COLOMBIA. CONGRESO DE LA REPÚBLICA DE COLOMBIA. Ley 1751. Op. Cit. p. 9.

681 COLOMBIA. CORTE CONSTITUCIONAL DE COLOMBIA. Sentencia T-933/13. M.P.: Jorge Ignacio Pretelt Chaljub. Bogotá, D.C. p. 30. 
Por otra parte, están excluidos los servicios respecto de los cuales no existe evidencia científica sobre su efectividad clínica ${ }^{682}$, entendiendo que el hecho de que un medicamento no haya sido aprobado por el INVIMA para ser comercializado nacionalmente, no implica que el mismo tenga carácter experimental y carezca de dicha evidencia. Si un medicamento tiene o no tal condición, no depende de los procedimientos administrativos que se estén adelantando, sino de la mejor evidencia con que cuente la comunidad médica y científica al respecto. De esta manera, la disposición debe leerse a la luz de la Sentencia T-539 de 2013, M.P. Pretelt Chaljub, en la cual se concluyó que:

(i) toda persona tiene el derecho constitucional a acceder a los servicios que requiera; (ii) el conocimiento científico, aplicado al caso concreto del paciente, son los criterios mínimos para establecer si un servicio de salud se requiere; (iii) cuando el servicio de salud que se requiera es un medicamento, este deber ser ordenado de acuerdo con su principio activo, salvo casos excepcionales y (iv) los medicamentos que aún no han sido autorizados por el INVIMA deben ser suministrados cuando se requieran, con base en la mejor evidencia científica disponible ${ }^{683}$.

Así pues, la excepción es constitucional siempre y cuando no tenga lugar la aplicación de las reglas trazadas por la Corte para excepcionar la restricción del acceso al servicio de salud y no se afecte la dignidad humana de quien presenta el padecimiento. En el mismo sentido, debe entenderse el literal $c$ de la norma ${ }^{684}$, en la cual se excluyen los servicios respecto de los cuales no se tiene evidencia científica sobre su efectividad clínica.

Respecto a las restricciones enunciadas en los literales $d$ y e de la norma ${ }^{685}$, que consagran la exclusión de aquellos servicios o tecnologías cuyo uso no ha sido autorizado por autoridad competente, o se encuentren en fase de experimentación, la Corte señaló que el alcance del registro del INVIMA no puede interpretarse como un criterio excluyente sobre la idoneidad de los medicamentos, pues sobre dicha idoneidad decide también el personal médico. Por ello, no resulta una justificación suficiente que un medicamento prescrito por el médico tratante, no se suministre al paciente carecer de registro del INVIMA, pues ello sería "[...] desconocer la competencia normativa otorgada a los médicos en relación con la posibilidad y el

682 COLOMBIA. CONGRESO DE LA REPÚBLICA DE COLOMBIA. Ley 1751. Op. Cit. p. 9. ${ }^{683}$ COLOMBIA. CORTE CONSTITUCIONAL DE COLOMBIA. Sentencia T-539/13. M.P.: Jorge Ignacio Pretelt Chaljub. Bogotá, D.C. p. 49.

684 COLOMBIA. CONGRESO DE LA REPÚBLICA DE COLOMBIA. Ley 1751. Op. Cit. p. 9. 685 Ibíd. p. 9. 
deber de prescribir medicación y tratamientos necesarios y adecuados según el estado de salud de sus pacientes" 686 . Es viable según el criterio del médico tratante y bajo fundamentación científica realizar algunas excepciones frente a medicamentos o servicios requeridos en enfermedades raras o huérfanas, siempre que estén agotadas las posibilidades internas; por ende, no se desconoce la Constitución y cabe la exclusión, siempre que además de la ausencia de permiso INVIMA, o el carácter experimental del bien o servicio, existan razones de peso sobre la conveniencia de conceder el medicamente, bajo la condición de que no se afecte la dignidad humana de quien presenta el padecimiento.

En cuanto al literal 6687 , que consagra la exclusión de los servicios o tecnologías que tengan que ser prestados en el exterior, la Corte señaló en sentencia T-1018 de 2001 que esta regla puede ser inaplicada cuando se cumplen los siguientes requisitos:

a) La situación de riesgo inminente para la vida del afiliado.

b) Cuando se trate de procedimientos a practicar en el exterior, la existencia de un procedimiento cuya eficacia esté científicamente acreditada; que exista aprobación y concepto técnico-científico favorable del médico tratante; que no se practique en el país y sea viable practicarlo al afiliado dadas sus condiciones particulares de salud. Se deben descartar, por ende, los tratamientos y procedimientos experimentales $[\ldots]^{688}$.

A la luz del precepto, la exclusión establecida es aplicable siempre y cuando no tenga lugar la aplicación de las reglas trazadas por la Corte para excepcionarla y no se afecte la dignidad del paciente. Como ha de verse, las exclusiones enunciadas en la norma resultaron concordantes con el concepto del servicio de salud, en el cual la inclusión de todos los servicios, tecnologías y demás se constituye en regla y las exclusiones en la excepción. Si bien este sistema propugna que el derecho a la salud implica el acceso a todos los elementos necesarios para lograr el más alto nivel de salud posible, y las limitaciones son expresas y taxativas, las mismas no pueden entenderse absolutas, tal y como lo señaló la Corte mediante sentencia C313 de $2014^{689}$, en la cual determinó que debían continuarse aplicando las sub-

${ }^{686}$ COLOMBIA. CORTE CONSTITUCIONAL DE COLOMBIA. Sentencia T-1214/08. M.P.: Humberto Antonio Sierra Porto. Bogotá, D.C. p. 2.

${ }^{687}$ COLOMBIA. CONGRESO DE LA REPÚBLICA DE COLOMBIA. Ley 1751. Op. Cit. p. 9.

${ }^{688}$ COLOMBIA. CORTE CONSTITUCIONAL DE COLOMBIA. Sentencia T-180/13. Op. Cit. p. 22.

689 COLOMBIA. CORTE CONSTITUCIONAL DE COLOMBIA. Sentencia C-313/14. Op. Cit. 
reglas constitucionales de protección del derecho a la luz del principio de no regresividad que permea la materia.

La garantía constitucional de toda persona a acceder a los servicios de promoción, protección y recuperación de la salud contemplados en la Constitución, sin duda tiene un prolifero desarrollo jurisprudencial desde antaño, el cual conviene exponer en aras de determinar en qué eventos el derecho es exigible por encima de toda disposición en contrario, incluso de un plan de beneficios aprobado en aras de su sostenibilidad.

Así, en primera medida, se tiene lo preceptuado en la Sentencia T-237 de 2003, en la cual se señala que bajo algunos presupuestos el juez de tutela puede inaplicar las normas del sistema y ordenar el suministro del procedimiento o fármaco correspondiente a pesar de que el mismo no esté incluido o esté expresamente excluido del plan de beneficios; estas condiciones son:

a. Que la ausencia del fármaco o procedimiento médico lleve a la amenaza o vulneración de los derechos a la vida o la integridad física del paciente, bien sea porque se pone en riesgo su existencia o se ocasione un deterioro del estado de salud que impida que ésta se desarrolle en condiciones dignas.

b. Que no exista dentro del plan obligatorio de salud otro medicamento o tratamiento que supla al excluido con el mismo nivel de efectividad para garantizar el mínimo vital del afiliado o beneficiario.

c. Que el paciente carezca de los recursos económicos suficientes para sufragar el costo del fármaco o procedimiento y carezca de posibilidad alguna de lograr su suministro a través de planes complementarios de salud, medicina prepagada o programas de atención suministrados por algunos empleadores.

d. Que el medicamento o tratamiento excluido del plan obligatorio haya sido ordenado por el médico tratante del afiliado o beneficiario, profesional que debe estar adscrito a la entidad prestadora de salud a la que se solicita el suministro690.

690 COLOMBIA. CORTE CONSTITUCIONAL DE COLOMBIA. Sentencia T-237/03. M.P.: Jaime Córdoba Triviño. Bogotá, D. C. p. 5,6. 
De tal forma, se colige que la inclusión en un plan no es el único evento en que el derecho a la salud es fundamental y tutelable, pues también lo es siempre que:

[...] logre demostrarse que la falta de reconocimiento del mismo (i) significa lesionar de manera seria y directa la dignidad humana de la persona afectada con la vulneración del derecho; (ii) se pregona de un sujeto de especial protección constitucional y/o (iii) implica poner a la persona afectada en una condición de indefensión por su falta de capacidad de pago para hacer valer ese derecho ${ }^{691}$.

Visto lo anterior, para conocer las implicaciones prácticas de este derecho y las características de los escenarios en los que se puede tutelar y proteger, conviene partir del neural pronunciamiento T-760 de 2008, mediante el cual la Corte Constitucional se pronunció frente a una acumulación de casos que involucraba el acceso a servicios de salud que fueron negados, ello con el fin de analizar sus diferentes facetas. Vale la pena ahondar en el estudio de dicha jurisprudencia, toda vez que inicia una línea paradigmática de la naturaleza y exigibilidad del mismo, lo cual permite fundamentar de manera general y universal algunas de sus implicaciones y alcances ${ }^{692}$ :

¿Se trasgrede el derecho a la salud de una persona frente a la negativa de entrega de medicamentos y servicios incluidos en el Plan de beneficios?693

Toda persona tiene el derecho constitucional a que se le garantice el acceso efectivo a los servicios que requiera, esto es, servicios indispensables para conservar su salud, cuando se encuentre comprometida gravemente su vida, su integridad personal, o su dignidad. En desarrollo de lo anterior, se tiene en claro que la mínima garantía de salud a que tiene derecho un usuario del Sistema en el marco del Estado Social de Derecho, es a la prestación de los bienes y servicios médicos incluidos en el Plan de beneficios; por ello ha dicho la Corte que "No brindar los medicamentos previstos en cualquiera de los planes obligatorios de salud, o no permitir la realización de las cirugías amparadas por el plan, constituye una vulneración al derecho fundamental a la salud" 694 .

691 COLOMBIA. CORTE CONSTITUCIONAL DE COLOMBIA. Sentencia T-760 de 2008. Op Cit. p. $35,36$.

692 COLOMBIA. CORTE CONSTITUCIONAL DE COLOMBIA. Sentencia T-760 de 2008. Op. Cit. p. 693 lbíd.

694 COLOMBIA. CORTE CONSTITUCIONAL DE COLOMBIA. Sentencia T-736 de 2004. M.P.: Clara Inés Vargas Hernández. Bogotá, D.C. p. 8. 
Sobre dicho particular, también se dijo, "[...] algunos de los servicios contemplados en el plan obligatorio de salud pueden estar sometidos a pagos moderadores, pero en ningún caso estos se pueden convertir en barreras de acceso de la persona que carezcan de recursos"695.

Concretamente, en respuesta a este primer planteamiento, se deriva de la anterior jurisprudencia que el acceso a los servicios de salud que se requieran contemplados en los planes obligatorios de salud, son un derecho fundamental autónomo y hacen parte de la mínima garantía que debe brindarse a una persona, incluso sin condicionar su efectividad al pago de cuota moderadora alguna, en aquellos eventos de incapacidad de pago del necesitado. No obstante, para que dicha prestación sea efectiva debe darse cumplimiento a las siguientes reglas:

(i) que la prestación esté contemplada por el Plan Obligatorio de Salud [hoy Plan de beneficios]; (ii) que haya sido ordenada por su médico tratante adscrito a la entidad prestadora del servicio de salud correspondiente, (iii) que sea necesario para conservar su salud, su vida, su dignidad, su integridad, o algún otro derecho fundamental ${ }^{696}$.

¿Se trasgrede el derecho a la salud cuando se niegan medicamentos o servicios que están excluidos del Plan de beneficios a un paciente que los requiere, pero es incapaz de sufragarlos?697

En esta línea, la Corte fija una regla jurisprudencial que establece que es deber del Estado garantizar el derecho a la salud en todos aquellos eventos en los cuales un usuario del Sistema de Seguridad Social requiere de un servicio que no se encuentra incluido en el POS y el mismo no cuenta con la capacidad económica para sufragarlo. De ser negada la autorización de un servicio o medicamento por una Entidad Prestadora de Salud, a pesar de la manifestación del paciente de su incapacidad de costear el mismo y con fundamento en la mera exclusión del plan, se configura una violación del derecho fundamental a la salud, sin otro tipo de consideración de conexidad frente a otros derechos. Así se sintetizó en palabras de la alta Corporación:

695 COLOMBIA. CORTE CONSTITUCIONAL DE COLOMBIA. Sentencia T-970/08. M.P.: Marco Gerardo Monroy Cabra. Bogotá, D.C. p. 13.

696 COLOMBIA. CORTE CONSTITUCIONAL DE COLOMBIA. Sentencia T-760 de 2008. Op. Cit. p. 78.

697 lbíd. 
Toda persona tiene el derecho constitucional a acceder a los servicios de salud que requiera con necesidad, es decir, que hayan sido ordenados por el médico tratante que ha valorado científicamente la necesidad del mismo y que el interesado no tiene para costearlo por sí mismo, es decir, capacidad económica (porque su costo es impagable por el interesado dado su nivel de ingreso o le impone una carga desproporcionada para él ${ }^{698}$.

A efecto de clarificar el componente de incapacidad de pago, es necesario enunciar que se entiende que una persona carece de tal capacidad cuando no tiene, cuantitativamente, recursos para sufragar cierto costo, comprometiendo, de hacerlo, su mínimo vital.

Para la entrega de estos medicamentos y la prestación de los servicios excluidos del Plan, también se fijaron, por la jurisprudencia en mención, un conjunto de requisitos en virtud, de los cuales es procedente dar cumplimiento a los mismos. Estos son:

(i) que la falta del servicio médico vulnere o amenace los derechos a la vida y a la integridad personal de quien lo requiere; (ii) que el servicio no pueda ser sustituido por otro que se encuentre incluido en el plan obligatorio; (iii) que el interesado no pueda directamente costearlo, y no puede acceder al servicio por otro plan distinto que lo beneficie; y (iv) que el servicio médico haya sido ordenado por un médico adscrito a la entidad encargada de garantizar la prestación del servicio a quien está solicitándolo699.

Imperativo es aclarar que estas reglas fueron de creación jurisprudencial, toda vez que, en materia de medicamentos y servicios no incluidos en el plan de beneficios, la ley aguarda una laguna o zona gris, siendo tal omisión la primera barrera existente para poder obtenerlos.

${ }^{698}$ COLOMBIA. CORTE CONSTITUCIONAL DE COLOMBIA. Sentencia T-760 de 2008. Op. Cit. p. 91.

699 COLOMBIA. CORTE CONSTITUCIONAL DE COLOMBIA. Sentencia T-650/13. M.P.: Alberto Rojas Ríos. Bogotá, D.C. p. 1. 
¿Se trasgrede el derecho a la salud de un paciente cuando se le niegan medicamentos o servicios argumentando la no realización del trámite debido ante el Comité Técnico Científico de la EPS?700

En primera medida y coherente con lo dicho con anterioridad, las reglas y procedimientos para el acceso a servicios y medicamentos no contemplados en el Plan, no están concebidos en ninguna normatividad, por ello, se ha venido utilizando, conforme a lo resuelto por la Comisión de Regulación en Salud, CRES, y el estudio por parte de un Comité Técnico Científico para su autorización. Empero, el estudio por parte de dicho Comité es un trámite administrativo de la entidad que no puede configurarse como una barrera de acceso a los mismos, siendo en consecuencia afirmativa la respuesta a este cuestionamiento, ya que de su temática se establece una regla jurisprudencial garantista que se concreta en que:

[...] una EPS viola el derecho a la salud de una persona cuando le niega el acceso al servicio con base en el argumento de que no ha presentado la solicitud al Comité Técnico Científico; ello porque 'Las EPS no pueden imponer como requisito de acceso a un servicio de salud el cumplimiento de cargas administrativas propias de la entidad $^{701}$.

Teniendo en cuenta que es al médico tratante a quien compete solicitar la autorización de dichos servicios frente al Comité. De allí, que en virtud de esta regla se haga exigible el derecho a la salud en los eventos en los cuales se niega un servicio o medicamento a un paciente bajo argumentos de orden administrativo, que trasladan la carga de gestión de la entidad a un paciente, las más de las veces en estado de indefensión.

¿Desconoce la mínima protección del derecho a la salud que el Comité Técnico Científico de una EPS se niegue a autorizar los medicamentos ordenados por un médico externo?702

Sobre este particular, la máxima Corporación encargada de fijar el alcance de los derechos fundamentales afirmó que:

700 COLOMBIA. CORTE CONSTITUCIONAL DE COLOMBIA. Sentencia T-760 de 2008. Op. Cit. p. 701 COLOMBIA. CORTE CONSTITUCIONAL DE COLOMBIA. Sentencia T-760 de 2008. Op. Cit. p. 14.

702 COLOMBIA. CORTE CONSTITUCIONAL DE COLOMBIA. Sentencia T-760 de 2008. Op. Cit. p. 
[...] mientras no se establezca un procedimiento expedito para resolver con base en criterios claros los conflictos entre el médico tratante y Comité Técnico Científico de una EPS, la decisión de un médico tratante de ordenar una droga excluida del POS por considerarla necesaria para salvaguardar los derechos de un paciente, prevalece y debe ser respetada, salvo que el Comité Técnico Científico, basado en (i) conceptos médicos de especialistas en el campo en cuestión, y (ii) en un conocimiento completo y suficiente del caso específico bajo discusión, considere lo contrario ${ }^{703}$.

De lo anterior y a pesar de entender que el derecho a la salud no es ilimitado, pues el Comité Técnico Científico no está obligado a autorizar de manera automática cada solicitud del médico tratante, verbigracia, si la misma alude a un tratamiento estético, a un asunto dental o a otros razonablemente excluidos del POS, se concluye que el Comité sí tiene una fuerte carga argumentativa para subordinar el criterio del médico tratante al del Comité, limitada a aquellos casos en que se fundamente en estrictos términos médicos aplicables a un diagnostico en referencia, o que un medicamento o servicio no satisface las necesidades corporales de un paciente.

¿Transgrede el derecho a la salud la no autorización de un servicio con fundamento en el no pago de una cuota moderadora cuando la persona carece de la capacidad económica para hacerlo? ${ }^{704}$

Frente a este interrogante, nuevamente, se da una respuesta afirmativa, advirtiéndose que de manera efectiva se trasgrede el derecho a la salud cuando una EPS se deslinda del principio de solidaridad que rige el Sistema y abandona a su suerte el estado de salud de un paciente por su mera incapacidad de pago de los bienes y servicios que requiere para mejorar su condición de salud. Sobre dicha referencia, se dijo en concreto:

[...] la sala reitera que una entidad encargada de garantizar la prestación de los servicios de salud a una persona irrespeta su derecho a acceder a éstos, si le exige como condición previa que cancele un pago moderador al interesado que no tiene la capacidad económica de asumir ${ }^{705}$.

\footnotetext{
703 lbíd. p. 94.

704 Ibíd.

705 COLOMBIA. CORTE CONSTITUCIONAL DE COLOMBIA. Sentencia T-760 de 2008. Op. Cit. p. 15.
} 
Esto porque el pago no puede constituir una barrera de acceso al servicio cuando un paciente lo requiere con necesidad y no tiene capacidad parcial, total, temporal o definitiva de costearlo de manera directa. Si bien el legislador estableció el pago de cuotas moderadoras en aras de la sostenibilidad del sistema, los principios rectores del mismo con asidero constitucional como lo son, la eficiencia, universalidad y solidaridad, impelen a que el mismo no puede ser excluido de prestaciones por el no pago de sumas de dinero, lo que de suyo sería una situación constitutiva de discriminación.

¿Trasgrede el derecho a la salud la imposición de periodos mínimos de cotización para la prestación de servicios de alto costo?706

Desde temprano, la jurisprudencia dejó por sentado que en situaciones de urgencia no es posible oponer períodos mínimos de cotización, "pues su exigencia violaría los derechos a la salud y a la vida de las personas que, padeciendo de una enfermedad que requiere tratamiento de 'alto costo', necesiten de atención médica y hospitalaria en forma inmediata"707. Sin duda, exigir periodos de cotización en dichos eventos constituye un riesgo para la salud, y pone en peligro la vida de los usuarios.

Empero, es una garantía para situaciones de urgencia, toda vez que cuando no se está frente a dicho evento, la imposición de periodos mínimos de cotización es procedente, pues no limita el acceso al servicio, sino que difiere su atención al momento en que el afiliado cumple con un número de semanas o cancela ciertos emolumentos de acuerdo con su capacidad económica. En tanto, en los casos de urgencias no se pueden oponerse períodos mínimos de cotización, máxime si se compromete la vida o integridad de un paciente en alto estado de vulnerabilidad.

¿Trasgrede el derecho fundamental a salud la no prestación de los servicios excluidos del POS que son requeridos por un menor que no tiene capacidad de costearlo, porque dicho bien o servicio no condiciona su vida o integridad personal? ${ }^{708}$

La jurisprudencia desde sus primeros pronunciamientos, incluso desde aquellos que negaban de forma rotunda la posibilidad de proteger vía tutela el derecho prestacional a la salud, dejó en claro que tal derecho en menores no solo se hacía

706 lbíd.

707 lbíd. p. 107.

708 COLOMBIA. CORTE CONSTITUCIONAL DE COLOMBIA. Sentencia T-760 de 2008. Op. Cit. 
fundamental y exigible en todos los casos, sino también prevalente por la supremacía de los derechos del niño. Se fundamentaba en tanto que el derecho a la salud,

[...] adquiere mayor importancia, frente a las circunstancias del caso revisado si el afectado con la decisión de la entidad prestadora de servicios de salud es un menor de edad, pues para su caso, el derecho a la salud es de naturaleza fundamental y, por tanto, es procedente su protección a través del amparo constitucional no sólo en los eventos en que se afecten de forma grave los derechos a la vida y a la integridad física, sino también cuando se compruebe que, a raíz de la falta de atención médica, se impide el mantenimiento de adecuadas condiciones biológicas o psíquicas del niño ${ }^{709}$.

Así las cosas, teniendo en cuenta que la garantía del derecho a la salud del menor es reforzada, la respuesta al anterior cuestionamiento necesariamente es afirmativa, en tanto se promulga una regla jurisprudencial aplicable que establece que no es necesario que un menor se encuentre en peligro latente o frente a un perjuicio irremediable en su salud para que proceda la protección a su derecho, puesto que dicha protección es automática y prevalente para ellos en todo evento, incluso a pesar de no estar en riesgo su vida o integridad personal; ello máxime cuando sus responsables no cuentan con los recursos para costearle un bien o servicio del que tiene necesidad, o para su mayor bienestar. De tal forma la regla resume en que, el derecho a la salud se viola especialmente, cuando el servicio requerido con necesidad es negado a una niña o a un niño, sujeto de especial protección constitucional.

¿Trasgrede una EPS el derecho a la salud de un paciente cuando se niega a autorizarle un bien o servicio excluido del POS ordenado por un médico no adscrito a la misma pero que es experto en la materia? ${ }^{710}$

Este interrogante fija una regla en el sentido de que una EPS no puede negar la autorización de un bien o servicio por haber sido ordenado por un médico no adscrito a la entidad, cuando este es: "(ii) que es un profesional reconocido que hace parte del Sistema de Salud y (iii) la entidad no ha desvirtuado dicho concepto, con base en razones científicas que consideren el caso específico del paciente"711. Vale la pena advertir que el concepto de un médico externo vincula a la EPS, en el

\footnotetext{
709 lbíd. p. 108.

710 COLOMBIA. CORTE CONSTITUCIONAL DE COLOMBIA. Sentencia T-760 de 2008. Op. Cit.

711 lbíd. p. 15.
} 
sentido de obligarla a confirmarlo, descartarlo o modificarlo con base en consideraciones de carácter técnico; el fundamento para negarse a su prestación, deber ser fundada en la historia clínica del paciente, cuando este se valora inadecuadamente, o no se somete siquiera a consideración de los especialistas internos.

De ahí que en aquellos eventos en los cuales la entidad no procede a someter a evaluación médica interna al paciente en cuestión para desvirtuar el concepto del médico externo, debe entonces atender y cumplir lo que este manda; es solo entonces en los casos de incumplimiento, y los de especial urgencia, aquellos en los que es exigible directamente a la entidad encargada que garantice el acceso al servicio de salud ordenado, sin dar oportunidad a que el servicio sea avalado por algún profesional de la entidad: si la entidad tiene noticia de la opinión médica que se quiere hacer valer, y no la descartó con base en información científica, tiene que darle cumplimiento. Así mismo, la jurisprudencia ha ampliado la prestación del servicio más allá del aval y del carácter de urgencia, a la ausencia de valoración médica por los profesionales correspondientes ${ }^{712}$, la mala prestación del servicio ${ }^{713}$, y a los que en el pasado se hubieren valorado y aceptado conceptos del 'médico tratante $\mathrm{T}^{714}$.

¿Es procedente mediante la tutela del derecho fundamental a la salud ordenar el pago de incapacidades médicas cuando el motivo de la negativa es la no cancelación oportuna de los aportes? ${ }^{715}$

La Corte Constitucional ha decidido que solo en casos excepcionales puede tutelarse el derecho fundamental a la salud en eventos de no pago de prestaciones sociales; ello bajo los condicionamientos de que, por una parte, la prestación sea transcendental para la garantía de los derechos fundamentales al mínimo vital, a la salud y a la dignidad humana, y por otra, que la entidad promotora de salud no haya hecho uso de los diferentes mecanismos de cobro que se encuentran a su alcance para lograr el pago efectivo de los aportes atrasados. Así, cuando la EPS se allana a la mora "[...] no puede fundamentar el no reconocimiento de una incapacidad laboral en la falta de pago o la cancelación extemporánea de las cotizaciones"716.

712 COLOMBIA. CORTE CONSTITUCIONAL DE COLOMBIA, Sentencia T-083 de 2008. M.P.: Mauricio González Cuervo. Bogotá, D.C.

713 COLOMBIA. CORTE CONSTITUCIONAL DE COLOMBIA, Sentencia T-1041 de 2005. M.P.: Humberto Antonio Sierra Porto. Bogotá, D.C.

714 COLOMBIA. CORTE CONSTITUCIONAL DE COLOMBIA, Sentencia T-1138 de 2005. M.P.: Rodrigo Escobar Gil. Bogotá, D.C.

715 COLOMBIA. CORTE CONSTITUCIONAL DE COLOMBIA. Sentencia T-760 de 2008. Op. Cit.

716 COLOMBIA. CORTE CONSTITUCIONAL DE COLOMBIA. Sentencia T-760 de 2008. Op. Cit. 162. 
Corolario, para que se predique transgredido el derecho fundamental a la salud, de contera debe haber una necesidad del usuario del sistema que comprometa su mínimo vital, y una negligente omisión por parte de la EPS que le arrebata la posibilidad de alegar su propia torpeza para abstenerse de reconocer una prestación social.

¿Desconoce una EPS el derecho a la salud de una persona al interrumpirle el suministro de servicios y medicamentos por haber dejado de cotizar en razón a su condición de desempleado? 717

A partir del referido problema jurídico, la Corte Constitucional fija una línea en la cual advierte que el acceso al servicio de salud debe ser continuo, y no puede ser interrumpido súbitamente antes de que este haya sido efectivamente asumido por otro prestador, en especial, si se trata de un sujeto de especial protección en salud por padecer una enfermedad catastrófica o de alto costo, caso en el cual, adicionalmente, no puede cobrársele copagos. Con asidero en el principio de solidaridad, que rige el Sistema de seguridad social en salud, debe garantizarse a los menos favorecidos el acceso a básicas condiciones de salud, cuando están en una mayor condición de vulnerabilidad, ello en virtud del principio de continuidad del servicio.

¿Es en adultos mayores automática la protección del derecho a la salud?718

En definitiva, en adultos mayores, así como en niños, el derecho a la salud es fundamental dadas las características de especial vulnerabilidad de este grupo poblacional, y su particular conexidad con el derecho a la vida y a la dignidad humana.

¿Es necesario en reconocimiento del derecho fundamental a la salud brindar a un paciente aportes para transporte y estadía para acceder a un servicio cuando el mismo requiere desplazamiento? ${ }^{719}$

Sobre esta referencia la Corte ha establecido, que el transporte y hospedaje de un paciente, si bien no son servicios médicos, hacen parte integral del derecho a la salud en ciertos eventos en los cuales recibir la atención requerida depende de que

717 lbíd.

718 COLOMBIA. CORTE CONSTITUCIONAL DE COLOMBIA. Sentencia T-760 de 2008. Op. Cit.

719 lbíd. 
al paciente le sean sufragados dichos costos, ello por su incapacidad de pago. La jurisprudencia constitucional ha reconocido el derecho a obtener el pago del transporte necesario para acceder al servicio de salud requerido, e incluso a la manutención, cuando el desplazamiento es a un domicilio diferente al de la residencia, estableciendo como condiciones las siguientes:

(i) ni el paciente ni sus familiares cercanos tienen los recursos económicos suficientes para pagar el valor del traslado y (ii) de no efectuarse la remisión se pone en riesgo la vida, la integridad física o el estado de salud del usuario Cumplidos los criterios precedentes, debe el Estado proceder a la protección sin otra consideración ${ }^{720}$.

De acuerdo con la jurisprudencia expresada de manera precedente, se desprende que toda persona cuenta, entre otros, con el derecho fundamental a la salud que cobija mínimamente los siguientes componentes, así los mismos estén o no abarcados en un Plan de beneficios:

(i) Acceso a servicios. Toda persona tiene derecho a que la entidad encargada de garantizarle la prestación de los servicios de salud, EPS, ${ }^{721}$ autorice el acceso a los servicios que requiere y aquellos que requiere con necesidad, incluso si no se encuentran en el plan obligatorio de salud; obstaculizar el acceso en tales casos implica irrespetar el derecho a la salud de la persona. El acceso a los servicios debe ser oportuno, de calidad y eficiente.

(ii) Protección especial a niños y niñas. Los derechos a acceder a un servicio de salud que requiere un niño o una niña para conservar su vida, su dignidad, y su integridad, así como para desarrollarse armónica e integralmente, está especialmente protegido; cuando una EPS obstaculiza el acceso a servicios de salud, incluidos aquellos que atienden las necesidades específicas de los menores, irrespeta gravemente su derecho a la salud.

(iii) Concepto del médico adscrito y externo. Por regla general, el médico que puede prescribir un servicio de salud es el médico adscrito a la EPS. El usuario puede acudir a otros médicos, pero su concepto no obliga a la EPS a autorizar lo que éste prescribió, sino a remitir al usuario a un médico adscrito a la correspondiente EPS (al respecto,

\footnotetext{
720 lbíd. p. 120.

721 En el actual régimen legal, las entidades encargadas de garantizar la prestación del servicio de salud a las personas son denominadas 'Entidades Promotoras de Salud', EPS.
} 
ver apartado 4.4.2.). Toda persona tiene derecho a que su EPS valore científica y técnicamente el concepto de un médico reconocido y vinculado al Sistema de Salud que considera que la persona requiere un servicio de salud. Este médico es el médico adscrito a la EPS y a él debe acudir el interesado. No obstante, en el evento excepcional de que el interesado acuda a un médico externo - no adscrito a la red de prestadores de la correspondiente EPS- la EPS tiene una carga de valoración del concepto de dicho médico. El concepto del médico externo no podrá ser automáticamente descartado por la EPS, sino que es necesario una valoración de su idoneidad por parte de un médico adscrito a la EPS (de manera directa o mediante remisión del interesado) o del Comité Técnico Científico, según lo determine la propia EPS.

(iv) Acceso sin obstáculos por pagos. 'Los pagos moderadores no pueden constituir barreras al acceso a los servicios de salud para las personas que no tienen la capacidad económica de soportar el pago del mismo'.

(v) Acceso al diagnóstico. Toda persona tiene derecho a acceder a las pruebas y exámenes diagnósticos indispensables para determinar si requiere o no un servicio de salud.

(vi) Allanamiento a la mora. Cuando una EPS no ha hecho uso de los diferentes mecanismos de cobro que se encuentran a su alcance para lograr el pago de los aportes atrasados, se allana a la mora y, por ende, no puede fundamentar el no reconocimiento de una incapacidad laboral en la falta de pago o en la cancelación extemporánea de las cotizaciones.

(vii) Protección a las enfermedades catastróficas y de alto costo. El acceso a los servicios de salud oportunos es especialmente garantizado cuando se trata de una persona con una enfermedad catastrófica o de alto costo; no se les puede dejar de atender 'bajo ningún pretexto', ni pueden cobrársele copagos.

(viii) Acceso con continuidad a la salud. El acceso a un servicio de salud debe ser continuo, no puede ser interrumpido súbitamente; irrespeta el derecho a la salud una EPS que suspende un servicio de salud que se requiere, antes de que éste haya sido efectivamente asumido por otro prestador.

(ix) Información, acompañamiento y seguimiento. Toda persona tiene derecho a que las EPS o autoridades públicas no obligadas a autorizar el servicio de salud pedido, adopten las medidas adecuadas para, por 
lo menos, (1) suministrar la información que requería para saber cómo funciona el sistema de salud y cuáles son sus derechos, (2) indicar específicamente cuál era la institución prestadora de servicios de salud que tiene la obligación de realizar las pruebas diagnósticas que requiere y una cita con un especialista, y (3) la acompañar durante el proceso de solicitud del servicio, con el fin de asegurar el goce efectivo de sus derechos.

(x) Prohibición de trasladarle a los usuarios cargas administrativas y burocráticas que le corresponde asumir a la EPS. Toda persona tiene derecho a acceder a los servicios de salud sin que las EPS puedan imponer como requisito de acceso a un servicio de salud el cumplimiento de cargas administrativas propias de la entidad. En especial, toda persona tiene derecho a que su EPS autorice y tramite internamente los servicios de salud ordenados por su médico tratante; una EPS irrespeta el derecho a la salud de una persona cuando le obstaculiza el acceso al servicio, con base en el argumento de que la persona no ha presentado la solicitud al Comité Técnico Científico. El médico tratante tiene la carga de iniciar dicho trámite.

(XI) Acceso a los servicios de acuerdo al principio de integralidad. Toda persona tiene derecho a acceder integralmente a los servicios de salud que requiera. En tal sentido, toda persona tiene derecho, entre otras cosas, a que se remuevan las barreras y obstáculos que impidan a una persona acceder integralmente a los servicios de salud que requiere con necesidad, como ocurre, por ejemplo, cuando el acceso implica el desplazamiento a un lugar distinto al de residencia, debido a que en su territorio no existen instituciones en capacidad de prestarlo, y la persona no puede asumir los costos de dicho traslado. En el mismo sentido, las inclusiones y exclusiones del POS deben ser interpretadas conforme a un criterio finalista, relacionado con la recuperación de la salud del interesado y el principio de integralidad ${ }^{722}$.

Para concluir lo anterior, de tan solo algunos de los eventos en los que se ha dado protección al derecho a la salud más allá del Plan, es menester referir que la mayoría de estas reglas jurisprudenciales no se lograron de forma exclusiva a partir de la providencia en cuestión, sino que las mismas son una construcción histórica desde la promulgación de la Carta de 1991 y la expedición de la Ley 100 de 1993, con miras a fijar su contenido pragmático. De tal forma, además de los servicios y tecnologías no excluidos expresamente del Plan de beneficios creado para la

722 COLOMBIA. CORTE CONSTITUCIONAL DE COLOMBIA. Sentencia T-760 de 2008. Op. Cit. p. 264-266. 
garantía del derecho a la salud, debe entenderse exigible cualquier tipo de prestación que se derive de las reglas jurisprudenciales anteriormente enunciadas, sin reparo de que en cada caso en concreto y con fundamento en sus particularidades, pueda darse protección al derecho, o surja una nueva regla de aplicación.

\subsection{LÍMITES JURISPRUDENCIALES A LOS SERVICIOS Y TECNOLOGÍAS EN SALUD}

Analizados los casos en los cuales la Corte Constitucional ha brindado protección al derecho a la salud por encima de toda consideración sobre el Plan de beneficios, es preciso rememorar aquellos eventos en los cuales dicha Corporación dio un no rotundo frente a la tutela de prestaciones, para avizorar de cara a la indeterminación actual de la Ley 1751 de 2015 que no ha sido objeto de regulación, en qué eventos podría mantenerse dicha negativa. Conociendo que el Sistema circunscribe su protección a cubrir las necesidades y a establecer prioridades de manera estratégica a efectos de dar garantía al derecho a la salud en un amplio marco de cobertura y necesidad, conviene hacer un esbozo de aquellos eventos y su negativa, de conformidad con los citado en la sentencia T-760 de 2008 y otros pronunciamientos posteriores:

(i) Cirugía refractiva de ojos: según ha dicho la corte, este se trata de un límite razonable a las prestaciones derivadas del derecho, porque si bien es funcional también es estética y por ello debe ser sufragada por el paciente al no comprometer la vida; así, en sentencia T-409 de $1995^{723}$ se negó una cirugía refractiva para corregir problemas visuales a un hombre que padecía de miopía y astigmatismo y se negaba a usar gafas por la incomodidad y mal aspecto físico que le producía su uso.

(ii) Tratamientos de fertilidad: se dijo sobre este tema que no es obligación del Estado garantizar la procreación a través de dichos planes; de tal forma, a partir de la sentencia T-752 de $2007^{724}$ se niega la fertilización in-vitro a una mujer beneficiaria del régimen subsidiado que tenía complicaciones para quedar embarazada.

723 COLOMBIA. CORTE CONSTITUCIONAL DE COLOMBIA. Sentencia No. T-409/95. M.P.: Antonio Barrera Carbonell. Bogotá, D.C.

724 COLOMBIA. CORTE CONSTITUCIONAL DE COLOMBIA. Sentencia T-752/07. M.P.: Clara Inés Vargas Hernández. Bogotá, D.C. 
(iii) Tratamiento de desintoxicación: sobre el particular la jurisprudencia ha sido ambivalente, pues en principio establecía irrestrictamente que los tratamientos integrales prescritos para tratar enfermedades relacionadas con adicciones no era exigible por vía tutela, sin embargo, con posterioridad a partir de la sentencia T438-09725 se empezó a tutelar el derecho fundamental a la salud ordenando la prestación de tales tratamientos, precisamente por su relación ínsita con la vida en condiciones de dignidad.

(iv) Bypass gástrico: la Corte en sentencia T-229 de $2012^{726}$ clarificó que el procedimiento de Bypass gástrico debe entenderse como incluido en el POS, siempre y cuando no tenga un fin estético o de embellecimiento para quien lo requiera, sino que, por el contrario, del mismo dependa la vida e integridad personal del paciente.

(v) Servicios de odontología ${ }^{727}$ : sobre esta materia también se ha pronunciado la jurisprudencia en la misma línea, esto es, los servicios odontológicos no hacen parte del derecho fundamental a la salud, a menos de que concurran los requisitos para ordenarlos a pesar de su no inclusión dentro del POS, comprometan la vida en condiciones de dignidad y exista incapacidad del paciente para costearlos.

Estos son algunos de los límites prácticos que se han trazado a efectos de la garantía del derecho fundamental.

\subsection{CONTRADICCIONES ENTRE DERECHOS DE PRESTACIÓN Y LIBERTAD DE COMERCIO}

Los derechos de prestación y la libertad de comercio representan una contradicción que desde mediados del siglo $X X$ se viene configurando alrededor de la consolidación del statu quo mundial. Esta paradoja se logra ver como una contradicción sociológica, jurídica y estatal. Hablar de Derechos de prestación y libertad de comercio significa sustancialmente pensar en Derechos e Intereses ${ }^{728}$. La dicotomía es lógicamente sencilla aunque conserva sus variables complejas:

725 COLOMBIA. CORTE CONSTITUCIONAL DE COLOMBIA. Sentencia T-438/09. M.P.: Gabriel Eduardo Mendoza Martelo. Bogotá, D.C.

726 COLOMBIA. CORTE CONSTITUCIONAL DE COLOMBIA. Sentencia T-229/12. M.P.: Gabriel Eduardo Mendoza Martelo. Bogotá, D.C.

727 COLOMBIA. CORTE CONSTITUCIONAL DE COLOMBIA. Sentencia T-760 de 2008. Op. Cit

728 J. FORRAS. Nadales. Derechos e Intereses. Problemas de Tercera Generación. En: Revista del Centro de Estudios Constitucionales. Madrid. Septiembre/diciembre 1991, no. 10,. P. 222. ISBN: 840214618-X- 
mientras la sustancia de los derechos prestacionales busca un crecimiento de la intervención del Estado para proteger el cumplimiento de los derechos ${ }^{729}$ del colectivo social -entre ellos el individuo-, la sustancia de la libertad de comercio es buscar el crecimiento de la no intervención del mercado para proteger el cumplimiento de intereses individuales -donde no prima la noción de colectivo social-.

Además, dentro de las contradicciones vemos que ideológicamente los contenidos estatales de los derechos de prestación se enmarcan en idearios constitucionales o neoconstitucionales que adopta la figura de Estado "social" de derecho, mientras que la libertad de comercio o libre mercado tiene unos contenidos estatales enmarcados en idearios neoliberales ${ }^{730}$ donde el Estado se concibe como Estado mínimo, no intervencionista, desregulado, privatizado y mercantilista. Es por eso que temas como la salud, la educación y el trabajo deben pertenecer a la visión del mundo, de lo privado o de la beneficencia ${ }^{731}$.

Siguiendo esta tendencia, encontramos que jurídicamente los derechos prestacionales devienen de antecedentes esporádicos en la formación del bloque de los derechos económicos y sociales plasmados en las constituciones de México (1917), Rusia (1918) y Weimar (1919), donde su fin principal es la satisfacción de las necesidades colectivas ${ }^{732}$, fundamentadas en lógicas de instituir un sector público que obedezca a unos criterios de solidaridad. Esta concepción tomó fuerza con la aparición de las constituciones portuguesa (1976) y española (1978), fundamentadas en la filosofía jurídica de los derechos fundamentales de Robert Alexy. ${ }^{733}$

${ }^{729}$ NOTA: Puede interpretarse también como intereses, pero desde una perspectiva social que prima sobre el individualismo.

730 MATÍAS, S.R. y ESTUPIÑAN, L. Contradicciones del Constitucionalismo Colombiano Contemporáneo. En: Revista Republicana. Bogotá D.C. Julio - diciembre de 2014. No. 17, p. 43 y 62. ISSN $1909-4450$

731 FARIÑAS DULCE, María José. "Globalización, Ciudadanía y Derechos Humanos". Cuadernos Bartolomé de las Casas. Editorial Dykinson. Madrid. 2000, p. 11. En: VARGAS, Rodolfo Andrés Correa. Globalización y derechos humanos. Ratio Juris, 2017, vol. 1, no 3, p 112.

732 CITA: "Éstos implican ya una acción positiva del Estado, el cual debe tomar determina das medidas, emprender determinadas obras y realizar determinadas acciones para satisfacer las necesidades a que esos derechos responden". 4 Ref. MAGARIÑOS DE MELO, MATEO J., "Derechos humanos y medio ambiente", Hector Gros Espiell, amicorum liber, 1997, vol. 1, p. 753. En: WITKER, Jorge. Los derechos económicos y sociales en el contexto del Área de Libre Comercio de las Américas. En Derecho internacional de los derechos humanos, Memoria del VII Congreso Iberoamericano de Derecho Constitucional. 2002. P 821.

733 CANOTILHO, José Joaquim Gomes. Tomemos en serio los derechos económicos, sociales y culturales. Revista del Centro de Estudios Constitucionales, 1988, no 1, p 248. 
Esa visión jurídica de la concepción de los derechos prestacionales se enfrenta a aquella de instaurar una serie de instituciones y acuerdos, promovida por algunos países victoriosos después de la segunda guerra mundial, quienes pretendían direccionar la economía mundial e impulsar el desarrollo de los pueblos, . Fue así como surgió la Organización Mundial del Comercio, que concibió alcanzar el desarrollo a través de la liberalización del comercio y la acumulación de capital a escala planetaria ${ }^{734}$.

Así, guarda como bloque jurídico todos los acuerdos comerciales que surgen de negociaciones, tratados de libre comercio bilaterales o regionales y de las reuniones y conferencias ministeriales que realizan después de la supresión del Acuerdo General de Comercio y Tarifas (GATT, por su nombre en inglés) en 1994735. Evidentemente, esta lectura permite observar cómo se busca revestir a una organización de comercio como si fuera una de derechos humanos. ${ }^{736}$

En las bases teóricas de la discusión, el profesor alemán Robert Alexy da un gran aporte cuando hace referencia a los derechos de prestación ${ }^{737}$, como aquellos derechos que requieren de acciones positivas por parte del Estado. Así, los derechos prestacionales no son las comunes acciones negativas 0 las exhortaciones a no hacer algo, o como el mismo profesor los llama, los derechos de defensa. Los derechos prestacionales en esta línea son derechos a protección social, de creación, de organización y de procedimiento.

Es fundamental sintetizar que los derechos de prestación también son identificados como derechos sociales ${ }^{738}$ o derechos sociales de prestación ${ }^{739}$, como el mismo

${ }^{734}$ FUNDACIÓN FRIEDRICH EBERT ARGENTINA y CLATE. Derechos Sociales Vs Libre Comercio. El gran debate detrás de la OMC. 2017. P 6.

735 lbíd. P 5.

736 LUMINA, Cephas. Free trade or just trade? The world trade organisation, human rights and development. Law, Democracy \& Development, 2010, vol. 14, no 1. P.190

737 NOTA: 'Leistungsrecht' es el término que utiliza en su obra Teoría de los derechos fundamentales. Ref.: ALEXY, R., Teoría de los derechos fundamentales, ob. cit., p. 189.

${ }_{738}$ CITA: "los derechos sociales no sólo suponen derechos de prestación, sino que tienen además el carácter de derechos de defensa y protección". Ref.: KRENNERICH, Michael; GÓNGORA, E. Los derechos sociales en América Latina. Desafíos en justicia, política y economía. Artículos del Centro de Derechos Humanos de Núremberg, 2006. P 4.

739 CITA: "El núcleo central de mi análisis sobre la relación entre derechos liberales y derechos sociales está en que los derechos humanos conforman una categoría unitaria en lo importante (en su carácter básico, asociado a la dignidad y la autonomía moral humana, que exige reconocimiento y garantías efectivas), aunque no unitaria en aspectos secundarios. Lo decisivo, sin embargo, es que, de una parte, en cuanto categoría unitaria, en lo esencial, los derechos humanos no se reducen a los derechos civiles y políticos, sino que comprenden también a los derechos económicos, sociales y culturales básicos". Ref. RUIZ MIGUEL, Alfonso. Derechos liberales y derechos sociales. 1994. P 655. 
profesor Robert Alexy hacía referencia. Y esto debido a que su naturaleza práctica exige el desempeño institucional y administrativo de los poderes públicos frente a las pretensiones necesarias de los ciudadanos que exigen su cumplimiento. ${ }^{740}$

El político ingles Thomas Paine, en un comentario a la Declaración de los Derechos del Hombre y del Ciudadano en 1789, dijo que "Una declaración de derechos es, también, recíprocamente, una declaración de deberes. Cualquiera que sea mi derecho como hombre, es también el derecho de otro, y es mi deber garantizarlo"741. Lo dicho por Paine es la contraposición a la noción de privilegio y la proclamación de una relación correlativa en donde el derecho corresponde a un deber. Esto, en relación con los derechos civiles y sociales, en ocasiones implica algunas discordancias, porque una cosa es afirmar la existencia de un derecho y otra muy distinta determinar cuáles son los modos y formas de protección de ese derecho. $Y$ aquí precisamente es donde encontramos las vicisitudes entre la noción liberal del Estado y la noción constitucional del mismo.

José Joaquim Gomes Canotilho, profesor de la Universidad de Coimbra en Portugal, analiza el bloque de derechos económicos, sociales y culturales de las constituciones española y portuguesa ${ }^{742}$ e indaga en una pregunta crucial para el tema abordado: "¿Los derechos de prestación son verdaderos derechos fundamentales?" Ya que una cosa es atribuir a cualquier prestación el significado de derecho subjetivo, por ser prestacional y estar en la constitución, y otra es delimitar y enfatizar cuáles pertenecen a esta esfera, como lo recomienda Lindahl al indicar el deber de "buscar los tipos básicos de las posiciones subjetivas de entre estas posiciones normativas básicas" ${ }^{\prime 43}$.

Por consiguiente, los derechos prestacionales pueden ser relativamente fundamentales en cuanto a su dependencia material en el desarrollo, relación y determinación con la dignidad y libertad del ser humano, es decir, alcanzarán el status de "fundamentales a prestaciones", bajo el sentido de tener que ser subjetivos y constitucionales ${ }^{744745}$. Por ejemplo, en Colombia, aunque en el debate jurídico aún

740 ECHAVARRÍA, Juan José Solozábal. Algunas cuestiones básicas de la teoría de los derechos fundamentales. Revista de estudios políticos, 1991, no 71, p. 90.

741 Los derechos del hombre (1791-1792), trad. cast. de Agustín Jiménez, Madrid, Doncel, 1977, pág. 101.

742 NOTA: - en este sentido el análisis comparado con la constitución colombiana es posible, ya que compartimos pilares homogéneos -.

743 CANOTILHO, José Joaquim Gomes. Tomemos en serio los derechos económicos, sociales y culturales. Revista del Centro de Estudios Constitucionales, 1988, no 1, p 246.

744 ibíd.

745 NOTA: Si un titular de un derecho fundamental (a) tiene un derecho frente al Estado (e) a que éste realice la acción positiva $h$, entonces, el Estado tiene frente a el deber de realizar $h$-esto, porque siendo fundamental la prestación y estando en la constitución el derecho, y las herramientas para 
se discute su naturaleza de fundamental, el Estado colombiano a través de sus altas cortes ha elaborado una aceptación clara alrededor de esta tesis ${ }^{746747}$.

Entonces, si el maestro Robert Alexy explica que el derecho de prestación se reduce a "el derecho de cualquier ciudadano a un acto positivo de los poderes públicos (Estado)", consecuentemente el profesor Canotilho tiene razón cuando dice que estamos ante un concepto ambiguo y amplio ${ }^{748}$. Ya que existe un espacio de discrecionalidad por parte de los poderes públicos en cuanto a la elección del medio para hacer efectivos tales derechos. Esto se utiliza para observar su cumplimiento con escepticismo, ya que el límite de los recursos lo muestra como una imposibilidad fáctica pero que en ocasiones, como lo indica el profesor Alfonso Ruiz ${ }^{749}$, pareciera con más claridad venir de "un presupuesto ideológico sobre cuánto y en qué es apropiado invertir y gastar".

En consecuencia, lo cierto es que los derechos de prestación tienen hoy en día garantías constitucionales y jurisprudenciales que amparan su cumplimiento.

Este pensamiento deviene de la visión globalizadora de la política mundial. Según las previsiones de la libertad de comercio, el fin es alcanzar un mayor crecimiento y

materializar el derecho, la noción de "deber" es más aceptable-. Ref. CUENCA, Encarnación Carmona. Los derechos sociales de prestación y el derecho a un mínimo vital. Nuevas Políticas Públicas: Anuario multidisciplinar para la modernización de las Administraciones Públicas, 2006, no 2, p. 177. ${ }^{746}$ CORTÉS NIETO, Johanna del Pilar, et al. La naturaleza jurídica de los derechos económicos, sociales y culturales en la jurisprudencia de la Corte Constitucional. Revista Estudios Socio-Jurídicos, 2007, vol. 9, no Esp. NOTA: En el trabajo de los estudiantes de la universidad Externado de Colombia se logra ver todo un relato que describe como el Estado Colombiano a través de sus altas cortes a definido una postura garantista frente a los derechos económicos, sociales y culturales, dando relativa protección como derechos fundamentales y exhortando a el gobierno público a una acción mas comprometida.

747 NOTA: Robert Alexy indica que los derechos sociales de prestación (al menos, algunos de ellos) pueden considerarse derechos fundamentales si están reconocidos en las Constituciones (o si pueden deducirse de otras normas constitucionales que enuncien derechos o principios), y este reconocimiento constitucional es susceptible de protección jurisdiccional frente a los poderes públicos (incluido el legislador) y, en algunos casos frente a los particulares. Ref. CUENCA, Encarnación Carmona. Los derechos sociales de prestación y el derecho a un mínimo vital. Nuevas Políticas Públicas: Anuario multidisciplinar para la modernización de las Administraciones Públicas, 2006, no 2, p. 179. 748 CITA: "Ya que puede consistir en 1) en el derecho del ciudadano a exigir del Estado protección frente a otros ciudadanos. 2) en el derecho a que el Estado atribuya a los ciudadanos una posición organizadora y procedimentalmente relevante para la defensa o el ejercicio de otros derechos (p. ej.: la participación en órganos colegiados, la participación en el procedimiento administrativo); 3) en el derecho a prestaciones fácticas (subvenciones, plazas en la Universidad, puestos de trabajo, servicios de salud), hablándose aquí de derecho de prestación en sentido estricto". Ref. CANOTILHO, José Joaquim Gomes. Tomemos en serio los derechos económicos, sociales y culturales. Revista del Centro de Estudios Constitucionales, 1988, no 1, p. 247.

749 RUIZ MIGUEL, Alfonso. Derechos liberales y derechos sociales. 1994. P 660. 
desarrollo de los pueblos, aunque algunos dirían que es un mito. ${ }^{750} \mathrm{Y}$ lo comentan en ocasiones como un mito porque en la práctica lo que realmente existe es una mera liberalización de mercado de capitales. Corolario, una liberalización de mercado de capitales implica una privatización del mismo, y así, un desentendimiento sobre tales sectores de la regulación o intervencionismo del Estado, o por lo menos en su mínima expresión.

Entonces, si la libertad de comercio busca limitar el poder del Estado con respecto a ámbitos de acción de los individuos, al observar la Organización Mundial del Comercio se puede concebir que la intervención del libre comercio funciona como un factor especial para incentivar algunos derechos y erosionar otros ${ }^{751}$.

El libre mercado, como lo explica el profesor Antonio J. Forras, se basa en dos principios: el principio dinámico de la competencia -horizontal- entre intereses individuales, con su lógica de riesgo inherente ${ }^{752}$. Es decir, el interés es su identidad, y la ambigüedad, en cuanto al cumplimiento de garantías hacia los demás, su comportamiento. Y el principio de protección en la esfera vertical, que implica implantar restricciones al Estado frente a posibles interferencias políticas en la esfera privada. Esta lógica busca eliminar la noción de barreras y proyectar la economía a la creación de regímenes internacionales y multilaterales donde se permita "facilitar el acceso de las mercancías nacionales a los mercados extranjeros, liberalizar el flujo de mercado internacional y regular su comportamiento de acuerdo a sus intereses ${ }^{\prime 753}$.

Pero también se dice, que el libre mercado no respeta aquel ideario de interéslibertad de todos los ciudadanos que dice defender, ya que eficazmente lo que ha logrado es una compleja construcción de oligopolios -interés de unos pocos-, que elimina las economías nacionales ${ }^{754}$, lo cual es, un autoritarismo económico.

750 CITA: "Abarcaría libre circulación de bienes, servicios y capitales, hasta la libre circulación de personas (capital humano). El objetivo último de cualquiera de estos procesos es que los países, y sus habitantes, accedan a mayores niveles de crecimiento y de desarrollo". Ref. WITKER, Jorge. Los derechos económicos y sociales en el contexto del Área de Libre Comercio de las Américas. En Derecho internacional de los derechos humanos, Memoria del VII Congreso Iberoamericano de Derecho Constitucional. 2002. P 830.

751 BURGOS, Germán. La OMC y los derechos humanos: ¿alguna relación? Colombia Internacional, 2012, no 76, p. 336.

752 J. FORRAS. Nadales. Derechos e Intereses. Problemas de Tercera Generación. En: Revista del Centro de Estudios Constitucionales. Madrid. Septiembre/diciembre 1991, no. 10, P. 223. ISBN: 840214618-X-

753 SCRIMIERI, Bruno Fernández. Derechos sociales y globalización: soluciones multilaterales. Información Comercial Española, ICE: Revista de economía, mayo-junio 2000, no 785, p. 71.

754 VARGAS, Rodolfo Andrés Correa. Globalización y derechos humanos. Ratio Juris, 2017, vol. 1, no $3, \mathrm{p} 114$. 
Además, en cuanto a su regulación, el libre comercio tiene sus propias figuras normativas que devienen de los acuerdos generales de comercio y tarifas GATT, impulsaos por el bloque de países capitalistas en vísperas de la guerra fría, ${ }^{755}$ que, como se dijo, buscaba la acumulación de capital a escala planetaria. Hoy en día quien direcciona las misiones y visiones del libre mercado mundial es la Organización Mundial del Comercio, de donde el $85 \%$ de los estados en el mundo sujetan su política económica. Esta alianza no ha logrado el desarrollo de los pueblos y mucho menos ha logrado una distribución social de la riqueza ${ }^{756}$. Es decir, el bloque jurídico del mayor ente del libre comercio dentro de sus fines solo ha logrado una fragmentación de los derechos sociales, por no decir enfrentamiento.

Una contradicción es una discrepancia entre dos proposiciones que al oponerse se invalidan: es el rasgo antagónico existente en dos ideas. Por esto, referirse a los derechos prestacionales y al libre comercio como dos nociones complementarias es un desatino pragmático de la política mundial.

Es claro que en el panorama ya expuesto existen derechos que consisten solo en meros permisos, tales como el derecho a competir, y este es el caso de los derechos que rodean al libre mercado. Pero los derechos prestacionales, además de meros permisos, exigen el acompañamiento por parte del Estado y el reconocimiento de otros componentes relacionables a los derechos fundamentales. Por ejemplo, cualquier derecho prestacional como la salud, la educación, o la vivienda, además de permitirle al ciudadano ser titular del derecho, requiere de la realización de un servicio como la asistencia en salud, la organización de un colegio público y los subsidios de vivienda, respectivamente ${ }^{757}$. Así, jurídicamente hablar de libre mercado exige concebir que la principal actividad del Estado es no hacer nada, o para ser más precisos, concentrarse en una serie de situaciones consideradas de "principal importancia" por parte de los protagonismos del mercado. En cambio, los derechos prestacionales naturalmente requieren de un Estado activo, interesado en los requerimientos de todos los ciudadanos y esto por definición es una contradicción en la concepción de los derechos por una u otra idea.

Una de las contradicciones que se les imputan a los derechos prestacionales es que su bloque de derechos puede ser muy extenso y por ende fácticamente se necesitan medios económicos ilimitados o muy abundantes ${ }^{758}$. Esto es doblemente antagónico bajo las siguientes consideraciones: primero, en una economía de

755 FUNDACIÓN FRIEDRICH EBERT ARGENTINA y CLATE. Derechos Sociales Vs Libre Comercio. El gran debate detrás de la OMC. 2017. P 5.

756 FUNDACIÓN FRIEDRICH EBERT ARGENTINA y CLATE. Derechos Sociales Vs Libre Comercio. El gran debate detrás de la OMC. 2017. P 15.

757 RUIZ MIGUEL, Alfonso. Derechos liberales y derechos sociales. 1994. P 669.

758 NOTA: Por ello se duda de la noción verdadera de derechos fundamentales. 
mercado los medios que son necesarios se tornan imposibles de conseguir, ya que el Estado dentro de esta noción -economía de mercado- debe evitar cualquier gasto no rentable ${ }^{759}$, como es el caso de los gastos en el cumplimiento de los derechos sociales. Hacerlo implicaría "un desequilibrio fiscal" dentro de sus nociones del lenguaje. Segundo, la afirmación de concebir a los derechos sociales concretamente los prestacionales-, como necesarios de medios económicos ilimitados, se enfrenta a la comprensión racional dentro del mismo lenguaje del libre mercado. Fijémonos en que el libre mercado basa su comportamiento en consignas como la libertad, que devienen de las nociones de derechos establecidas en la Revolución Francesa y la Declaración de los Derechos Humanos de 1948, y pensar en el contexto de una sociedad moderna, en la cual los únicos derechos que requieren de gasto público son los sociales de prestación, implica una sinrazón fáctica, por ejemplo en cuanto en el derecho a la libertad su cumplimiento también requiere facetas positivas del estado, es decir, prestacionales: "libertad de locomoción depende en gran medida del servicio público de transporte". ${ }^{760}$

Dentro de la contradicción anterior finamente podemos observar otra noción difícil de asimilar sobre los derechos de prestación: "El gasto social no es rentable". En la política del libre mercado se han ratificado algunos acuerdos que sorpresivamente aparecieron como beneficiadores del gasto social como lo que resultó de la Ronda celebrada en la ciudad de Qatar, Doha, que se enfrentó a la reciente reunión ministerial de Nairobi celebrada en 2015, que deja abierta la posibilidad de desechar lo alcanzado en Doha. Esto, en beneficio de "facilitación y protección de las inversiones, garantías para la libre competencia, compras gubernamentales y facilidades para el comercio"761. Teóricamente la causa de la sinrazón la explica la autora norteamericana Susan Aaronson 762

"el principal conflicto entre el derecho internacional de los derechos humanos y el libre comercio remite a las dificultades que este último plantea para permitir a los países llevar a cabo políticas intervencionistas favorables para la garantía de los derechos humanos. En concreto, se le endilga a la OMC que, mediante el Sistema de Solución de Diferencias, castiga aquellas políticas de

\footnotetext{
759 DE CURREA-LUGO, Víctor. La encrucijada del derecho a la salud en América Latina. Los derechos económicos, sociales y culturales: Del invento a la herramienta. Ciudad de México, México: Plaza y Valdes, 2006, p. 227.

760 CORTÉS NIETO, Johanna del Pilar, et al. La naturaleza jurídica de los derechos económicos, sociales y culturales en la jurisprudencia de la Corte Constitucional. Revista Estudios Socio-Jurídicos, 2007, vol. 9, no Esp. P 118.

${ }^{761}$ FUNDACIÓN FRIEDRICH EBERT ARGENTINA y CLATE. Derechos Sociales Vs Libre Comercio. El gran debate detrás de la OMC. 2017. P 6.

762 BURGOS, Germán. La OMC y los derechos humanos: ¿alguna relación? Colombia Internacional, 2012, no 76, p 335.
} 
subsidios, subvenciones $u$ otro tipo de restricciones al comercio defendibles a la luz de los derechos humanos, pero cuestionables según las normas del comercio internacional".

Y es contradictoria la afirmación sobre el gasto social, porque aquellas medidas que las normas del comercio internacional han abalado por medio del Fondo Monetario Internacional, y que se han implantado sobre los límites del intervencionismo estatal, lo único que han hecho es aumentar la crisis social de los estados en vía de desarrollo. Por ejemplo, "el recorte de subsidios a alimentos en Indonesia sólo aumentó la crisis y el que se hizo a los programas de salud en Tailandia significó el retroceso de una de las mejores medidas contra el SIDA en el mundo. En cambio, cuando se desobedecieron las recomendaciones del FMI de recortar los gastos sociales en Uganda y Jordania, hubo grandes beneficios sociales."763 Metafóricamente, Gabriel García Márquez diría que tal desobediencia nos permitiría evitar comer tierra como lo hacía Rebeca en Cien años de soledad.

A su vez, es una contradicción ubicar el bienestar social como un instrumento de cálculo racional de intereses y hacerlo compatible con el interés individual para que pertenezca así mismo a la esfera del egoísmo humano, que es incompatible con el esquema constitucional de un estado social de derecho y derechos ${ }^{764}$.

Ahora, el libre mercado, como vimos, utiliza como instrumento de justicia social el interés individual, mientras que los derechos de prestación, de acuerdo con Robert Alexy, exigen un protagonismo en la utilización de los soportes legales, constitucionales bien definidos. $Y$ aun así los derechos de prestación requieren actuaciones distintas al interés individual del libre mercado. Esto, por medio de mecanismos como los de control por omisión que pueden desarrollarse a través de la esfera judicial ${ }^{765}$.

763 DE CURREA-LUGO, Víctor. La encrucijada del derecho a la salud en América Latina. Los derechos económicos, sociales y culturales: Del invento a la herramienta. Ciudad de México, México: Plaza y Valdes, 2006, p. 232.

764 J. FORRAS. Nadales. Derechos e Intereses. Problemas de Tercera Generación. En: Revista del Centro de Estudios Constitucionales. Madrid. Septiembre/diciembre 1991, no. 10, P. 223. ISBN: 840214618-X-

765 CITA: "La jurisprudencia de los tribunales nacionales en los países de la región brinda ejemplos de algunas vías que ya han sido exploradas con éxito para exigir al Poder Judicial". Ref. ABRAMO$\mathrm{VICH}$, Víctor. La articulación de acciones legales y políticas en la demanda de derechos sociales. YAMIN, Alicia Ely. Los Derechos Económicos, Sociales y Culturales en América Latina: del invento a la herramienta. México: Centro Internacional de Investigaciones para el Desarrollo, 2006. P 150. 
Puede presentarse la situación en donde el modelo de Estado que acoja un pueblo sea al mismo tiempo neoliberal y neoconstitucional. Esto semánticamente presenta por sí mismo una contradicción: por un lado, aquel limita la intervención Estatal, y por otro, este plantea una mayor intervención Estatal ${ }^{766}$. Tal es el caso del Estado colombiano ${ }^{767}$, como diría el economista Jairo estrada: "Aquí se mantendrá la tesis sobre la funcionalidad del ordenamiento constitucional de 1991 para continuar, en lo esencial con el proceso de construcción de un ordenamiento neoliberal"768

Por tanto, si bien garantizar los derechos humanos, sociales y prestacionales permite alcanzar las bases primarias para el libre comercio como la propiedad privada, la libre contratación y el libre desplazamiento, lo máximo que puede plantear la lógica del libre mercado en el desarrollo de garantizar derechos de prestación es aplicar la lógica de vender al que puede comprar y dar a los más pobres de los pobres, agrego, lo que se pueda dar. Esto es aplicar una idea inicua del servicio social no inmerso en el deber ser de los derechos de prestación. Así, las necesidades fundamentales de los ciudadanos funcionan bajo las leyes de la oferta y la demanda y de lo poco prestacional que aplican funciona bajo la noción de privilegios y afortunados. Contradicción de la idea prestacional de la constitución colombiana.

Es por esto que en Colombia el funcionamiento de las políticas públicas se basa en disminuir lo máximo posible la inversión social en educación, salud, vivienda y seguridad social. Entonces, como consecuencia, se convierten en mercancías de libre circulación y precios ${ }^{769}$.

\footnotetext{
${ }^{766}$ CITA: "Dicho de otra manera, de estar fundada, esta tesis obligaría a reconocer que el heredero legítimo y coherente de los ideales del liberalismo clásico es antes el socialismo democrático que el

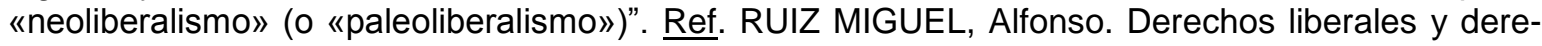
chos sociales. 1994. P 656.

767 MATÍAS, S.R. y ESTUPIÑAN, L. Contradicciones del Constitucionalismo Colombiano Contemporáneo. En: Revista Republicana. Bogotá D.C. Julio - diciembre de 2014. No. 17, p. 41-66. ISSN 1909 $-4450$

768 Este concepto proviene de la teoría constitucional alemana. Véase: REICH, Norbert. Mercado y derecho. Teoría y praxis del derecho económico en la República Federal de Alemania. Barcelona: Ariel, 1985. (Estrada J., 2004, p. 131).

769 CITA: "Este soporte neoliberal, tiene como estrategia maniqueísta el afán por desprestigiar lo público y generar así la masificación del deseo privatizador del Estado, bajo el sofisma de que lo público no funciona, de que los políticos son corruptos y que lo único eficiente y próspero es lo privado. Todo lo anterior, para desembocar en el éxito de sus principales postulados: la desregularización del sector financiero, la eliminación de los derechos sociales del catálogo de derechos humanos y la flexibilización absoluta de los derechos laborales, es decir, los denominados por esa corriente como derechos contrarios al mercado". Ref. VARGAS, Rodolfo Andrés Correa. Globalización y derechos humanos. Ratio Juris, 2017, vol. 1, no 3, p. 113.
} 
En consecuencia, los fines de las políticas del libre mercado no son los mismos a los de las políticas para materializar los derechos de prestación, y esto, por lógica humana, es la mayor causa para indicar que el libre mercado es el principal antagonista de los derechos de prestación. Ello nos deja como paradoja política existencial que la mayor contradicción entre estos dos conceptos en Colombia es el mismo Estado.

Jurídicamente, la salud se configura como un derecho y un valor universal. En teoría, debe estar inmersa en los programas de bienestar social de cada país, pues los servicios que devienen del derecho son una responsabilidad primaria de cada gobierno. Es por esto que idealmente no se debería pensar en tratar el derecho a la salud como un bien sujeto a los procesos simples de la comercialización. ${ }^{770}$

${ }^{771}$ Las alteraciones que ha tenido son aquellas que resultan del afán neoliberal por privatizar la responsabilidad de ejecutar el derecho por parte del Estado. La lógica natural de la salud como prestación exige comprender que a mayores recursos en la atención a la salud se dan mejores condiciones de vida. Se debe reconocer que la garantía del derecho exige profundizar en espacios que incentiven la educación, el cuidado del medio ambiente y el bienestar social. Hablar de alteraciones exige observar que todos los sujetos vinculados al área han sufrido un cambio. Por ejemplo, en México se observó a los cinco años del libre mercado con Canadá y EE. UU, que los pacientes, médicos, el gobierno y el mismo empresario median sus alteraciones en la medida de expectativas y temores.

Lo hecho en México sintetiza lo reproducido por la expansión de libre mercado en el resto del continente. En el área de la salud se buscaba "Mayor privatización de la medicina, presión en costos y precios, aumento en la competitividad entre aseguradoras, hospitales, laboratorios y gabinetes"772. Esto, con el fin de alcanzar un mayor beneficio social bajo la lógica de la competencia. Lo cierto es que los resultados alcanzados dejan ver que el acceso a la salud se configura bajo las dinámicas del acceso al mercado y su estancia depende de las posibilidades económicas de cada individuo eludiendo garantías de calidad, pues ante su exigencia se coloca la barrera del precio.

770 SPEZIALE, Arturo M. Terrés; ARTURO, M. El impacto del Tratado de Libre Comercio en los Servicios de Salud. Revista Mexicana de Patología Clínica, 1999, vol. 46, no 4. P 209

${ }^{771}$ GRAFICO: Ibíd. P 213. Cuadro V. Calidad en la atención médica sobre la base de las perspectivas de los protagonistas.

772 SPEZIALE, Arturo M. Terrés; ARTURO, M. El impacto del Tratado de Libre Comercio en los Servicios de Salud. Revista Mexicana de Patología Clínica, 1999, vol. 46, no 4. P 211. 
Lo anterior significa que en América Latina el libre mercado ha causado lo que indicó el profesor Víctor de Currea-Lugo: "una encrucijada al derecho a la salud". Pues como indica él mismo:

\begin{abstract}
"el sistema público transita entre su deber de garantizar un derecho constitucional y la necesidad de asegurar su supervivencia mediante procesos administrativos y financieros, en un contexto adverso por la reducción del gasto social, de búsqueda de autonomía administrativa de los hospitales y, en general, de disminución del papel del Estado social. Mientras se obliga al sector público a obedecer a unos criterios de solidaridad, esa obligatoriedad no tiene el mismo peso para el sector privado, cuya naturaleza es precisamente, más que la solidaridad, el lucro". ${ }^{773}$
\end{abstract}

Por ejemplo, en Colombia, a través de la ley 100 de 1993 se reforma el sistema del derecho a la salud. Que neoconstitucionalmente proclama una serie de principios tales como la eficiencia, la universalidad, la solidaridad, la integralidad, la unidad y la participación, pero que a su vez generó una crisis de la salud. Es decir, si bien se adopta un modelo bajo la hipótesis de la competencia moderada y de administración eficiente, un modelo que permite el crecimiento de recursos en el sistema, también se adopta un sistema costoso de intermediación que exhorta a funcionar bajo el fin de tener utilidades corporativas. Esto ha generado paradójicamente el cierre de instituciones prestadoras del servicio, poca importancia en cuanto a calidad que somete al acto médico a la infraestructura de la industria y al poder del mercado. Entonces el médico se convierte en un operario medianamente calificado que cumple una jornada laboral, responsable de generar los menores márgenes de costos y los mayores de ganancias. Así, el fin de la salud como disciplina intelectual prestadora de un servicio social se ve constituida en una institución lucrativa: en una empresa. Por eso el paciente ahora pasa a ser consumidor de un producto industrial administrado por intermediarios. El Estado transfiere su responsabilidad social a entidades comerciales y desaparece de la gobernación política "la ética médica, cuyo objetivo inefable es el bien social, es reemplazada por una todavía no bien definida 'ética corporativa', donde el costo-beneficio en términos de rendimiento financiero es el objetivo principal". 774

773 DE CURREA-LUGO, Víctor. La encrucijada del derecho a la salud en América Latina. Los derechos económicos, sociales y culturales: Del invento a la herramienta. Ciudad de México, México: Plaza y Valdes, 2006, p. 229.

774 PATIÑO, José Félix. Ley 100 de 1993: Reforma y Crisis de la Salud. Bogotá: Academia Nacional de Medicina de Colombia. Revista Medicina - Vol. 21 No. 1 (49). 1999. P 2. 
Son aún vigentes las apreciaciones hechas por el profesor Luis Ángel Villar, de la Escuela de Medicina de la Universidad Industrial de Santander, cuando explica 11 años después de la aplicación de la ley 100 , entre estadísticas y testimonios, que el resultado no puede sorprendernos ya que eso era lo que se esperaba luego de que se adoptara un modelo basado en convertir la salud en una mercancía, lo cual generaba que al tiempo que la salud se deterioraba la pobreza aumentaba, contradicción por sí sola para acceder al servicio. Y como dato curioso, en el año 2004 en la revista Semana número 1147/ 2004, SaludCoop, Coomeva, Colsánitas Medicina Prepagada, Susalud y SaludTotal estaban entre las 100 empresas más grandes de Colombia. Y esto se debe, según el profesor Villar, a modelos devastadores aun dentro de la economía de mercado donde bajo la permisibilidad gubernamental ${ }^{775}$,

\begin{abstract}
"las EPS privadas desarrollaron su llamado 'crecimiento vertical' con el que estas empresas de la salud se venden a sí mismas la atención en clínicas propias, aumentando sus jugosas ganancias a costa de 'abaratar costos de operación', poniendo en riesgo la red de clínicas privadas del país y organizando una estructura desde la cual aspiran a incursionar al área de la formación en salud creando sus propias Facultades de Medicina, en busca de un recurso humano 'ajustado a sus necesidades' y del aumento de sus ganancias." 776
\end{abstract}

Finalmente los académicos Cephas Lumina y Anita Pipan expresaban, "el libre comercio se ha previsto para potenciar los intereses de los más poderosos que en absolutamente nada favorece a los derechos humanos de los países en desarrollo". 777

Por tanto, el libre mercado y los derechos prestacionales forman parte de una contradicción semántica. En la geopolítica mundial la regulación del libre comercio es inversamente proporcional a los fines de los derechos económicos, sociales y culturales, y en especial, de los prestacionales.

Despues de un detallado estudio de la economía en salud desde susdiferentes perspectivas y contradicciones, y dada su complejidad, es importante hacer un análisis de las políticas publicas en salud, dado los disímiles desajustes

775 VILLAR, Luis A. La Ley 100: el fracaso estatal en la salud pública. Revista Deslinde, 2004, vol. 36.

776 lbíd. P 5.

777 BURGOS, Germán. La OMC y los derechos humanos: ¿alguna relación? Colombia Internacional, 2012, no 76, p. 334. 
microeconómicos en la relación entre los agentes del sistema quedesembocaron en rígidos problemas de flujos financieros, altos costos de transacciónes, riesgos a través de los recobros al sistema y de los servicios no incluidos en el plan de beneficios, entre otros, con miras a lograr un moderación en el sistema de salud, y a su vez alcanzar un equlibrio administrativo y financiero al interior del sistema de salud Colombiano, por ello resulta de alta significación analizar las políticas publicas en el sistema de salud colombiano. 


\section{POLITICAS PÚBLICAS EN EL SISTEMA DE SALUD COLOMBIANO}

\subsection{DEFINICION DE LAS POLITICAS PÚBLICAS}

Tenemos que los autores que han desarrollado el concepto de políticas públicas, parten, que estas se ofrecen para reorientar y apoyar las decisiones y actuaciones que el Estado ejecuta. El término política pública tiene un cimiento anglosajón denominado Policy Sciences, que fue formulado por Harold D. Lassawell, en el que él proponía que el gobierno tuviese gran conocimiento sobre aquellas decisiones públicas, es decir, que aquella decisión social tomada pueda involucrar no solamente al Estado como principal actor, sino también a un individuo o a una organización. En el mismo sentido, este concepto se puede entender desde dos perspectivas. La primera, desde la política pública entendida como estudio de los problemas que son considerados públicos, y aquellos procesos de toma de decisión por parte de las autoridades públicas. La segunda, como una política gubernamental o de alguna organización de la sociedad civil en una jurisdicción política. Generalmente, cuando se habla de políticas pública, esta es entendida como aquella función que tiene y que ejecuta el gobierno, a sabiendas de que asimismo puede considerarse en la diversidad de los problemas y situaciones que resuelve el gobierno ${ }^{778}$.

Otros autores como Yves Mény y Jean- Claude Thoening definen a las políticas públicas como aquella que se presentan bajo la forma de un programa de acción gubernamental en un sector de la sociedad o en un espacio geográfico. Esta definición se encuentra en relación con el planteamiento pragmático que es a menudo el de los analistas de políticas públicas. La ventaja de estas definiciones es permitir delimitar un objeto de investigación relativamente concreto, es decir, hacía qué parte de la sociedad se va a dirigir cierta política, por ejemplo, a los granjeros, a los trabajadores, etc. Se evidencia, entonces, la problemática acerca de la génesis social de las políticas públicas y eso ocasiona olvidar por completo que la creación de estas parte de un ámbito social, que necesita de una solución, es decir, la complementación de lo gubernamental con lo social ${ }^{779}$.

Según Lassawell, las políticas públicas tienen un sentido multidisciplinar, es decir, que estas tienen un componente en el cual se involucran las distintas áreas que

\footnotetext{
778 Nateras González, Martha Elisa Las políticas públicas: ¿discurso o realidad? Espacios Públicos, vol. 9, núm. 17, febrero, 2006, pp. 252-274 Universidad Autónoma del Estado de México Toluca, México.

779 Muller, Pierre. Les politiques publques, publicado en Collectión Quesais-je. Francia. Junio 2000
} 
normalmente se pueden evidenciar en la cotidianidad. Esta orientación está dirigida por aspectos políticos, económicos, administrativos, culturales y de derechos. Las políticas públicas en América Latina y, particularmente, en Colombia son consideradas objetos de estudio de la ciencia política, la economía y la administración pública, y poco a poco se incorporó el Derecho que ha ingresado a formar parte de este campo multidisciplinar. Con dependencia del enfoque y de la literatura que se analiza de las políticas públicas, estas pueden ser dirigidas por dos focos; el primero es el descriptivo, lo que significa entenderlas como una decisión expedida desde un ente gubernamental que actúa en un contexto legal. Un ejemplo de esto son las que se expiden para políticas de salud, de educación o comerciales; es así como se evidencia que vienen de una actividad gubernamental. También están aquellas normas que son expedidas o que ya existen para resolver una determinada problemática social, tales como las de medio ambiente y las de ecología. El segundo foco es el teórico, que consiste en entender que las políticas públicas son elaboradas a partir de la interacción entre el gobierno y los ciudadanos, y que en ellas se fortalecen aspectos como los objetivos públicos del Estado, los programas diseñados para cumplir con esos objetivos y el impacto que tienen estas en la sociedad ${ }^{780}$.

De esta manera, la política pública la podemos definir como aquel producto de una actividad gubernamental que involucra la relación entre el Estado y la sociedad, en la que, por consiguiente, se evidencia que la política pública es un elemento institucional, puesto que las decisiones son tomadas por una autoridad formada legalmente, dentro de un sistema político y jurídico en el que se ponen a consideración la relación de fines-medios y se observa la acción o inacción del mismo Estado. Todo esto con base en su campo de estudio; y es en la acción pública, por la que se genera esta política pública. Pero también es necesario explicar que una política pública también es una variable que se puede aplicar en una diversidad de casos o situaciones y que estas no son solo conceptos flotantes. Una política pública es en la medida en que se dimensione su fin y como se analice el mismo ${ }^{781}$.

Las políticas públicas pueden ser entendidas como una serie de decisiones o acciones intencionalmente coherentes, tomadas por diferentes actores públicos y a veces no públicos, con el fin de resolver, de manera puntual, un problema políticamente definido como colectivo. El estudio se justifica en la medida en que el concepto de política pública no es un término prescriptivo del que se conozca un

\footnotetext{
780 Nateras González, Martha Elisa Las políticas públicas: ¿discurso o realidad? Espacios Públicos, vol. 9, núm. 17, febrero, 2006, pp. 252-274 Universidad Autónoma del Estado de México Toluca, México 781 lbídem.
} 
único significado y uno solo uso posible. Por el contrario, su comprensión ha dependido, en parte, del lente disciplinar que se utilice ${ }^{782}$.

\subsection{CARACTERISTICAS DE LAS POLITICAS PÚBLICAS}

Para entender las políticas públicas es necesario que su construcción y ejecución comprendan un análisis de la actividad que van a desarrollar. Para esto es necesario que se parta de un marco teórico y conceptual, así como de herramientas que sirvan como guía para la labor investigativa. En ese sentido, se hace posible la elaboración del objeto de estudio que va a incidir en el proceso de creación de las políticas públicas ${ }^{783}$. Las características que distinguen a las políticas públicas para su creación y para la investigación de las mismas son: la orientación de dar solución a los problemas; estar dirigidas al mundo real; y, su reserva ante los estériles juegos de salón académicos. Estas se ocupan tanto de la prescripción como de la descripción. Por tanto, es necesario que se deje claro el compromiso con los valores particulares y evitar así la postura de "Neutralidad valorativa", que es aquella en la que se piensa que la rama de las ciencias sociales deben producir intelectualmente pensamientos objetivos en cuanto a las políticas públicas, postura que genera discordancia entre algunos pensadores, ya que estas políticas se concentran en asuntos particulares y claramente requieren un juicio de valor sobre su importancia ${ }^{784}$.

Por otro lado, una política pública debe estar sustentada en un corpus teórico (filosofía) que oriente los cursos de acción, así como la toma de decisiones, el establecimiento de prioridades y la asignación de recursos financieros en el ámbito público. Del mismo modo, la política debe crear los canales para transmitir flujos de información entre el Estado y la sociedad civil. Finalmente, este instrumento de trabajo debe señalar los objetivos, recursos, señales, límites y plazos para el cumplimiento de las alianzas o acuerdos y llevar a la práctica la propuesta de trabajo $^{785}$.

Al estar conformadas las políticas públicas por diversas disciplinas de las ciencias políticas, estas son sensibles a la amplia matriz social, en la que se formulan y

\footnotetext{
782 Subirats y Knoepfel, 2008, p. 38

${ }^{783}$ Cano, L. F. (2014). La narrativa de las políticas públicas en la jurisprudencia de la Corte Constitucional colombiana. Papel Político, 19(2). pp. 435-458. http://dx.doi. org/10.11144/Javeriana.PAPO19-2.npp.

784 Aguilar Villanueva, Luis F. El estudio de las Políticas Públicas- estudio introductorio y edición. México. Ediciones Miguel Ángel Porrúa. 1992. pg 186. ISBN 968-842-318-1.

785 Podestá, Juan. Políticas Públicas y regiones: Un Análisis crítico. En revista ciencias sociales 10. 2000. Pg 69. Chile.
} 
aplican las políticas con énfasis en el contexto y su articulan entre sí. Asegura Aguilar que este enfoque es sensible en los procesos dinámicos como la elaboración misma de las políticas, pues no adopta un punto de vista estático ni considera la decisión como acontecimiento de un solo momento. Además, presta atención a la conducta humana $y$, en vez de considerarla mecanicistamente determinada, hace suyo el principio "intencionalista" de que los esfuerzos individuales, por maximizar resultados considerados valiosos, suministran la base fundamental para comprender la conducta individual. El enfoque es científico, pero en el sentido general de buscar más conocimientos verificables que en el sentido específico y terriblemente limitante de buscar leyes generales ${ }^{786}$.

\subsection{OBJETIVO DE LAS POLITICAS PUBLICAS}

El objetivo con el que se crean las políticas públicas es alcanzar un bien común. Por consiguiente, de este se derivan transformaciones estructurales, resolución de problemas sectoriales o temáticos, asignación de recursos y optimización de situaciones. Es por esto que el marco teórico de una política pública debe intentar expresar en totalidad una visión de sociedad, como también expresar el planteamiento de la función que cumple el Estado frente a la sociedad. Esta debe originarse de manera sistemática y con coherencia, en el que el tema que se quiera apoyar sea adecuado tanto espacial como temporalmente, y también que tenga una viabilidad política y con soporte económico ${ }^{787}$.

\subsection{IMPACTO DE LAS POLITICAS PÚBLICAS}

Finalmente, el impacto que tienen las políticas públicas varía de acuerdo con el compromiso que esta política genere en la sociedad a la que le será benéfica. Entonces, es necesario mencionar que hay dos elementos relevantes para que una política pública genere conformidad o, mejor aún, la legitimen. La primera de ellas es que se cree una identificación con la misma. Una política pública debe ubicarse en una perspectiva de resolución de problemas que afectan a toda la población. En ese orden, se pretende que se evidencie el esfuerzo de esta política por acercar los dos extremos de la relación Estado-sociedad. La segunda es la asociada con la difusión, cuyo objetivo sea vincular al Estado con los ciudadanos en una dimensión no solo racional, sino también afectiva: relación en la que se reconozcan sus necesidades, hábitos, identidades, capacidades, para que, de esta manera, se

${ }^{786}$ Aguilar Villanueva, Luis F. El estudio de las Políticas Públicas- estudio introductorio y edición. México. Ediciones Miguel Ángel Porrúa. 1992. pg 186. ISBN 968-842-318-1.

787 Podestá, Juan. Políticas Públicas y regiones: Un Análisis crítico. En: Revista Ciencias Sociales 10. 2000. Pg. 70 Chile. 
pueda hablar de que la población legitima la política y la asume en igual proporción. Puesto que, generalmente, cuando una política se quiere difundir se hace estratégicamente para que se conozca su fin, sin explicar el sentido de la misma y su función en la sociedad, muchas veces con el olvido de la diferenciación regional y la utilización de un lenguaje técnico que para la población a la que se ejecutará carecerá de sentido ${ }^{788}$.

\subsection{GENERALIDADES DE LAS POLITICAS PÚBLICAS}

Las políticas públicas son aquellos mecanismos que se implementan para la satisfacción de necesidades colectivas, las cuales construyen la realidad social y generan un resultado. Según Jaime Torres Melo y Jairo Santander, en un estudio creado en conjunto con el Instituto de estudios del ministerio público de Colombia:

"La política pública se debe comprender como el resultado de una acción colectiva que se desarrolla en lo público y de una serie de transacciones políticas, en donde el Gobierno ya no tiene como único objetivo ejecutar lo planeado, sino también garantizar la coordinación y la cooperación de los actores claves"789.

Como existen diferentes conceptos de lo que es una política pública, tenemos también el de Pedro Medellín:

"La estructuración de las políticas debe ser comprendida como el producto de un intenso proceso político a través del cual emergen y toman forma los proyectos e intereses de agentes (individuos), agencias (instituciones) y discursos (síntesis de la interacción entre agentes y agencias) en pugna por imponer un determinado proyecto de dirección política y de dirección ideológica sobre la sociedad y el estado que son gobernados." 790

788 Podestá, Juan. Políticas Públicas y regiones: Un Análisis crítico. En: Revista Ciencias Sociales 10. 2000. Pg. 75 Chile.

789 TORRE, Jaime y SANTANDER, Jairo. Introducción a las políticas públicas: Conceptos y herramientas desde la relación entre estado y ciudadanía. Bogotá, D. C. noviembre 2013.

790 MEDELLIN, Pedro. La política de las políticas públicas: propuesta teórica y metodológica para el estudio de las políticas públicas en países de frágil institucionalidad. Chile. Serie: Políticas Sociales, núm. 93, CEPAL 
En este sentido, una política pública es aquella herramienta que utilizan las entidades públicas para desarrollar y ejecutar las leyes o normas que garantizan la creación y ejecución de las peticiones o necesidades de los ciudadanos, las cuales son totalmente relevantes en el momento.

De esta forma, también es necesario tener claro el objetivo de implementar políticas públicas, que consiste en buscar el bienestar colectivo y mirar cómo se lleva a cabo el desarrollo del estado y hacia dónde se dirige el mismo, pues las políticas públicas no simplemente se basan en la gestión documental y de presupuesto ${ }^{791}$. Por el contrario, ponen en acción el papel del Estado y más que todo el papel del Gobierno que esté en ejecución: aquel que protege al ciudadano y cumple con su plan de desarrollo elegido.

Se considera que las políticas públicas no son un fin en sí mismas, sino más bien un medio para dar respuesta a una problemática social específica. De ahí se desprende que en el núcleo del concepto de las políticas públicas se encuentre anclado el asunto que se quiere resolver, al que se le quiere dar respuesta, o sea, la presencia de un problema público. Es perentorio, entonces, iniciar el acercamiento a las políticas públicas desde la conceptualización de lo público y de un problema público ${ }^{792}$.

Para crear una política pública, se deben tener en cuenta 4 niveles o pasos a seguir. De acuerdo a la estructura creada por Fernández Ballesteros, "el primero de ellos es el nivel estratégico y en este se encuentran los principios y rutas fundamentales que orientarán el proceso para alcanzar los objetivos a los que se desea llegar; en el segundo nivel está el de planeación, en donde se organizan de forma coherente las metas, directrices y tácticas en tiempo y espacio, así como los instrumentos, mecanismos y acciones que se utilizarán para llegar a los fines deseados. El tercer nivel es el de programación. En este se crea un Conjunto homogéneo y organizado de actividades a realizar para alcanzar una o varias metas del plan, a cargo de una unidad responsable. Y un sub programa: componente del programa destinado a una población o zona específica, y finalmente el ultimo nivel es de la acciones políticas, que corresponde al ejercicio de aquellos instrumentos económicos, sociales, normativos y administrativos que utiliza y desarrolla el Gobierno para inducir determinados comportamientos de los actores con objeto de que hagan compatibles sus acciones con los propósitos del plan." 793

791 TORRE, Jaime y SANTANDER, Jairo. Introducción a las políticas públicas: Conceptos y herramientas desde la relación entre estado y ciudadanía. Bogotá, D. C. noviembre 2013.

792 MOLINA, Marin, Gloria y CABRERA, Gustavo. Políticas Públicas en salud: aproximación a un análisis. Grupo de investigación en gestión y políticas en salud. Facultad Nacional de salud pública Universidad de Antioquia.2008. p.7.

793 lbid. 
Como esta la base para entender qué comprende el tema de políticas públicas como eje central del escrito, pasaremos a explicar cuáles son las políticas públicas que actualmente desarrollan el sistema general de salud y cómo se ejecutan actualmente.

\subsection{POLITICAS PÚBLICAS EN SALUD: COLOMBIA}

Las políticas públicas en salud en Colombia y en el mundo en general son aquellos mecanismos que implementan la regulación que existe en los estados y buscan el bienestar de la colectividad en el derecho a la salud.

En Colombia, el sistema de salud pública actualmente se encuentra representado por la Ley 100 de 1993, la cual creó el sistema general de seguridad integral. Con esta ley se reforma la antigua regulación, la cual cambia de fondo lo administrativo y lo financiero en la salud y refleja la descentralización, la privatización, la autonomía de las entidades y la participación ciudadana. ${ }^{794}$ Dicho reflejo se transa desde el artículo primero de la Carta Política, en donde se estipula que Colombia es un Estado social de derecho, organizado en forma descentralizada $(\ldots)^{795}$. La ley marca 4 entes que se relacionan en el sistema: el estado como encargado de la organización, dirección y vigilancia, el cual actúa por medio del Ministerio de Salud y Protección social, y cuya función es elaborar políticas públicas en materia de Salud ${ }^{796}$. Otro ente son las entidades promotoras de salud, conocidas generalmente como EPS, cuya función se minimiza a la afiliación y recaudación de las cotizaciones que deben entregar los afiliados ${ }^{797}$. El tercer ente son las instituciones prestadoras del servicio de salud, llamadas IPS, las cuales prestan el servicio de salud a los usuarios. Por último, se encuentra el usuario, que representa a las personas que atienden cualquiera de los dos regímenes, el contributivo o el subsidiado. ${ }^{798}$

Seguido a esto, para que la ley sea implementada como se ha explicado en la parte general de políticas públicas, debe ir ejecutada y planeada por una política pública. Es así como en el año 2011 se actualiza el SGSSS por medio de la ley 1438 del mismo año, y como resultado de la actualización se crea el Plan decenal de salud pública PDSP 2012-2021, en la cual se formulan diferentes políticas públicas para

794 JARAMILLO, Ivan. El futuro de la salud en Colombia: La puesta en marcha de la ley 100. Bogota, D. C En: Fescol.1999.p.99

795 COLOMBIA. Constitución Politica de Colombia. Articulo 1. 1991

796 COLOMBIA. Superintendencia nacional de salud. Objetivos y funciones. Consultado 28 de enero 2018

797 CONGRESO DE LA REPUBLICA. Ley 100 de 1993.

798 Ibid. 
llevar a cabo la ley. Este plan centra su fin en la reducción de la desigualdad que existe cuando los ciudadanos ejercen su derecho a la salud, y mejora las condiciones de vida al minimizar la enfermedad que puede ser evitable.

Como se describe en el mismo plan:

"Uno de los mayores desafíos del Plan Decenal de Salud Pública, PDSP, 2012 - 2021, es afianzar el concepto de salud como el resultado de la interacción armónica de las condiciones biológicas, mentales, sociales y culturales del individuo, así como con su entorno y con la sociedad, a fin de poder acceder a un mejor nivel de bienestar como condición esencial para la vida. Como la salud pública es un compromiso de la sociedad con su ideal de salud, el Plan Decenal de Salud Pública, PDSP, $2012-2021$ es un pacto social y un mandato ciudadano que define la actuación articulada entre actores y sectores públicos, privados y comunitarios para crear condiciones que garanticen el bienestar integral y la calidad de vida en Colombia". ${ }^{799}$

En el plan se desarrollarán 2 dimensiones: una es la dimensión prioritaria, en donde se manejarán políticas públicas que se desarrollarán de manera intersectorial, con la participación de diferentes actores sociales, para materializar el derecho a un ambiente sano en el que se favorezca y se promueva la calidad de vida y la salud de la población de presentes y futuras generaciones, a través de la transformación positiva de los determinantes sociales, sanitarios, laborales, ocupacionales y ambientales ${ }^{800}$ La segunda dimensión será la transversal, en la cual se hablará de políticas públicas sobre la gestión diferencial de poblaciones vulnerables. Allí se orientará el proceso de formulación, implementación y evaluación de los planes territoriales de salud, en lo que se refiere a la atención integral de niños, niñas y adolescentes. Por otro lado, en esta misma dimensión se encuentra la gestión para el fortalecimiento institucional y de los servicios de salud. Se habla de una dimensión transversal porque son funciones indelegables del Estado, lideradas por la Nación a través del Ministerio de Salud y Protección Social, de aquellas instituciones adscritas y de los mecanismos de gestión. La gestión para el fortalecimiento institucional y de los servicios de salud promueve la corresponsabilidad de todos los sectores y actores para afectar positivamente los determinantes sociales y económicos de la salud, y propiciar condiciones de vida y desarrollo saludable y sostenible ${ }^{801}$.

799 MINSTERIO DE SALUD COLOMBIA. Plan decenal de salud publica. Bogota. Marzo 2013 800 MINSTERIO DE SALUD COLOMBIA. Plan decenal de salud pública. Bogotá. Marzo 2013 ${ }^{801}$ MINISTERIO DE SALUD COLOMBIA. Plan decenal de salud pública. Bogotá. Marzo 2013 
Para este punto de las políticas públicas en la salud, es necesario pensar que cuando se crean estas políticas se dista mucho de la investigación para crearla. Lo primero que hay que recalcar es la preparación de dichas políticas. La ciencia política en general ha aceptado con cautela la influencia de las investigaciones sobre las políticas públicas, por considerar que estas últimas son la expresión y resultado de complejos procesos de interacción política, en que la lógica de los razonamientos y la evidencia de los estudios sucumben a la evidencia de los intereses predominantes en la organización social ${ }^{802}$. La relación entre investigaciones y políticas puede entenderse como un proceso complejo y variable, cuyos resultados podrían depender de ciertos factores susceptibles de identificación e intervención. ${ }^{803}$

Los mutuos estereotipos interfieren negativamente en el aprovechamiento y la aplicación de las investigaciones. Los tomadores de decisiones pueden considerar que las investigaciones tardan mucho, que no son suficientemente aplicables o que no apuntan a problemas prioritarios, y suelen ver a los investigadores como tecnócratas insensibles y poco dispuestos a aceptar la complejidad e incertidumbre inherente a las decisiones, más interesados en la publicación de los hallazgos que en su aplicación. ${ }^{804}$

Los intereses predominantes en la sociedad se imponen a los investigadores, cuya producción estará condicionada por la influencia determinante que sobre ella ejercerán el sistema político, el clima político y las características del Estado. ${ }^{26} \mathrm{La}$ multiplicidad de combinaciones que pueden experimentar ambos contextos en el espacio y el tiempo introduce un alto grado de incertidumbre en la relación entre investigaciones y políticas, y los investigadores interesados en el tema deberían tener en cuenta estos aspectos al formular sus proyectos. La estabilidad de los sistemas políticos, la pertenencia de investigadores y tomadores de decisiones a la misma élite y la urgencia percibida alrededor de un problema de salud podrían propiciar la influencia de las investigaciones sobre las políticas, mientras el centralismo, la discontinuidad del Gobierno y las restricciones económicas podrían interferir desfavorablemente en ello. 805

Las políticas son el producto de intereses ideológica y políticamente determinados y los investigadores pueden verse tanto estimulados como restringidos por estos intereses. ${ }^{34}$ Las políticas internacionales y nacionales influyen tanto en la

802 GOMEZ, Ruben Dario. Políticas públicas y salud: relación entre investigación y decisión. Bogotá. En: Revisión. P.106.

${ }^{803}$ lbidi.

${ }^{804}$ GOMEZ, Ruben Dario. Políticas públicas y salud: relación entre investigación y decisión. Bogotá. En: Revisión. P.109.

805 lbid. 
generación de investigaciones como en su adopción por los tomadores de decisiones. El aumento de publicaciones sobre el tema de las reformas que se observa durante la década de los noventas podría constituir un ejemplo de influencia de las políticas vigentes sobre los intereses de investigación, más que en el sentido contrario. Durante la década de los noventa, los organismos internacionales mostraron un particular interés en la investigación en políticas de salud y, en especial, en el tema de las reformas. En 1990, la Asamblea Mundial de la Salud enfatizó la necesidad de desarrollar investigaciones en salud para fundamentar en ellas las políticas nacionales e impulsó la noción de investigación sanitaria nacional esencial; por su parte, en 1993, el informe del Banco Mundial, Invertir en salud, destacaba la importancia de la investigación para mejorar la salud. 806

Un estudio de la Ley 100 del 1993 indica que aumentó la cobertura de la salud y disminuyó la brecha entre ricos y pobres, brindó a la población un mejor acceso a los servicios de salud y aumentó la protección financiera de los usuarios. Esto se reflejó en mejoras en variables objetivas y subjetivas de salud. De esta forma, se podría concluir que para Colombia la descentralización trajo múltiples ventajas. Sin embargo, esta trajo consigo una serie de incentivos que han generado problemas al sistema. La reforma de 1993 ha sido una de las más radicales que se ha implementado en los sistemas de salud y sus objetivos primordiales fueron la universalización del aseguramiento social, la protección financiera de las familias frente al gasto catastrófico derivado de los riesgos de salud y la equidad en el acceso a los servicios de salud. La evidencia muestra que la mayor parte de esos objetivos se lograron en los pasados 20 años. ${ }^{807}$

Sin embargo, el desarrollo del modelo derivó en diferentes problemas, especialmente concentrados en la fragmentación del modelo de salud con incentivos de los agentes hacia la extracción de rentas en demerito de los objetivos de salud de la población. Como consecuencia, se generaron tres situaciones problemáticas: primero, un esquema de prestación de servicios orientado hacia la resolutividad en la alta complejidad, con baja capacidad de ejecución de acciones preventivas en un entorno de transición epidemiológica y elevadas cargas de enfermedad; segundo, un aseguramiento que se centró en el manejo financiero por encima del objetivo misional de gestión de los riesgos en salud; y tercero, resultados negativos que se manifiestan sobre los usuarios en la forma de barreras de acceso, en particular en la limitada resolutividad de aquellos procedimientos que involucran el acceso a tecnología en el entorno de los servicios de alta complejidad. ${ }^{808}$

806 GOMEZ, Rubén Darío. Políticas públicas y salud: relación entre investigación y decisión. Bogotá. En: Revisión. P.112.

807 PAEZ Nicolás. JARAMILLO Luis. FRANCO Camila. REGOCES Leonardo. Estudio sobre el modo de gestionar la salud en Colombia. Ministerio de salud y protección.

808 PAEZ Nicolás. JARAMILLO Luis. FRANCO Camila. REGOCES Leonardo. Estudio sobre el modo de gestionar la salud en Colombia. Ministerio de salud y protección 
Los diferentes desarreglos microeconómicos en la relación entre los agentes del sistema desembocaron en severos problemas en los flujos financieros, altos costos de transacción y ruptura de la mancomunación de riesgos a través de los recobros al sistema y de los servicios no incluidos en el plan de beneficios (No POS). El resultado en el contexto institucional y de muchos usuarios es la limitada legitimidad del sistema. Estos problemas han determinado una situación de crisis sistémica donde los diferentes intentos de resolución han encontrado que la capacidad de agenciamiento de intereses de los agentes se ha sobrepuesto a la capacidad regulatoria del Ministerio de Salud y Protección Social. Los esfuerzos legislativos a través de las Leyes 1122 de 2007 y 1438 de 2011 han ofrecido soluciones parciales que no han resuelto de manera estructural el problema de fragmentación, con lo cual han dejado al propio Ministerio de Salud y Protección Social con muy limitada capacidad de rectoría y débiles mecanismos regulatorios para efectuar una ordenación del sistema. ${ }^{809}$

Las barreras de acceso a los servicios de salud es un tema sensible para los usuarios, especialmente en los momentos en que se requiere atención por enfermedad, pero también en las acciones destinadas a la promoción de la salud y la prevención, cuya no realización oportuna genera mayores costos para la sociedad cuando no se realizan de manera adecuada y oportuna. Según la ECV de 2011, dentro de las razones de no uso de los servicios de consulta externa se destaca el mal servicio o la cita distanciada $(12,17 \%)$ y la falta de dinero para asistir $(6,97 \%)$. A pesar de que la cobertura del sistema de salud es casi universal, los problemas en el acceso siguen teniendo un papel importante en la crisis del sistema ${ }^{810}$.

Estos problemas de acceso se hacen más evidentes en la medida en que la complejidad y el costo esperado de la atención se incrementan. Las barreras que limitan el acceso se pueden clasificar en tres grupos: geográficas, de carácter financiero y administrativas. Las barreras geográficas son las que aparecen con la dispersión poblacional, la distancia a los centros poblados, la precariedad en las vías de comunicación o los altos costos de transporte y que tiene como resultado las inequidades en los resultados en salud. En estos municipios la población es rural y pertenece al régimen subsidiado. Para recibir atención, la población debe desplazarse a los centros de atención, donde habitualmente la distancia y los costos del traslado son altos. ${ }^{811}$

\footnotetext{
809 lbid.

810 PAEZ Nicolás. JARAMILLO Luis. FRANCO Camila. REGOCES Leonardo. Estudio sobre el modo de gestionar la salud en Colombia. Ministerio de salud y protección $811 \mathrm{lbid}$
} 
En este escenario, tanto las Empresas Promotoras de Salud (EPS) como las Instituciones Prestadoras de Servicios (IPS) obtienen un beneficio económico cuando la población afiliada no hace uso de los servicios. Dado que en estas zonas no existen condiciones de mercado ni una posibilidad de competencia, es preciso ajustar el funcionamiento del sistema en estas zonas. Existen barreras de carácter financiero en diferentes niveles del sistema. Existe evidencia de que el desarrollo del sistema condujo a la consolidación de condiciones ineficientes de competencia entre EPS e IPS ${ }^{812}$.

Esto condujo a la generación de monopolios bilaterales en los que tanto el asegurador como el prestador cuentan con poder de mercado. Este poder se incrementa progresivamente en el prestador a medida que el nivel de complejidad de los servicios crece. Esta situación puede reflejar desequilibrios en el sistema y algunos estudios muestran que los hospitales y clínicas privadas pueden estar generando mayores utilidades que los propios aseguradores. Por otra parte, bajo un esquema predominantemente de pago por servicios, el aumento en la demanda de servicios generó demoras en los pagos a los prestadores. Las deudas reportadas por los hospitales crecieron de manera preocupante. Este crecimiento afecta negativamente la calidad de la atención a los usuarios, debido a que las IPS no pueden costear los pagos a los proveedores o a que estas amenazan con el deterioro de la calidad para lograr el pago de las acreencias. De acuerdo con la Resolución 2509 de 2012, más del $40 \%$ de las IPS públicas fueron categorizadas en riesgo fiscal y financiero medio o alto. ${ }^{813}$

Como proyecto de ley sobre una política pública en salud, se encuentra en el Senado el proyecto de ley 142 de 2017, cuyo objeto es garantizar el ejercicio pleno del derecho a la salud mental a la población colombiana, con prioridad para los menores de edad y adultos mayores, mediante la promoción de la salud, la prevención del trastorno mental y la Atención Integral e Integrada en Salud Mental en el ámbito del Sistema General de Seguridad Social en Salud. De igual forma, se establecen los criterios de política para la reformulación, implementación y evaluación de la Política Pública Nacional de Salud Mental, con base en los enfoques de derechos territorial y poblacional por etapa del ciclo vital. ${ }^{814}$

Por otro lado, también se encuentra el proyecto de ley 046 de 2017en la cámara de representantes, el cual tiene por objeto garantizar y asegurar el ejercicio efectivo de

\footnotetext{
$812 \mathrm{lbid}$

813 PAEZ Nicolás. JARAMILLO Luis. FRANCO Camila. REGOCES Leonardo. Estudio sobre el modo de gestionar la salud en Colombia. Ministerio de salud y protección

814 CONGRESO DE LA RESPUBLICA DE COLOMBIA. Proyecto de ley 142 de 2017. Consultado 30 de enero de 2018.
} 
los derechos de las personas con Trastorno del Espectro Autista (TEA), en igualdad de condiciones que las personas en situación de discapacidad en Colombia, brindándoles los apoyos y ajustes razonables que requieran para una efectiva inclusión de conformidad con la normatividad vigente en nuestro país y con los tratados internacionales de los cuales Colombia hace parte. ${ }^{815}$

El proyecto de ley 72 de 2017 tiene por objeto reformar el Sistema General de Seguridad Social en Salud, con el propósito de garantizar el goce efectivo del derecho fundamental a la salud. Con esto mejorarían las condiciones de acceso de la población al servicio público de seguridad social en salud, en todos los niveles de atención: con calidad, oportunidad, continuidad y seguimiento de los servicios, y la sostenibilidad y el equilibrio financiero mediante el esquema de Administración Regulada. Para tal efecto, se redefinen las funciones de administración de recursos financieros del Sistema de aseguramiento y de prestación de servicios de salud, con el fin de garantizar el acceso a los servicios de salud, el oportuno y adecuado flujo de recursos que financian el mismo y su correcta destinación. Establece los principios del Sistema, los instrumentos para la gestión de la salud pública y la atención primaria en salud, el marco a partir del cual se regulan los beneficios en salud, la operación, gestión y administración de la prestación de los servicios, algunos procedimientos de inspección, vigilancia y control, el fortalecimiento de la gestión del talento humano en salud, el régimen laboral aplicable a los servidores públicos de las Empresas Sociales del Estado (ESE) y su fortalecimiento y un régimen de transición para la aplicación de lo dispuesto en la presente ley. ${ }^{816}$

Según la Organización Mundial de la Salud, en Colombia los aportes al PIB que se destinaron hacia el sistema de salud para el año 2014 correspondieron al 7,2\% del mismo ${ }^{817}$. Es claro mencionar que en Colombia el aumento ha sido también importante ya que el gasto total en salud pasó de representar el 5,9\% del PIB en el año 2000 a $6,5 \%$ en 2011 , lo cual representa una variación de más del $10 \%$. A pesar de que en Colombia los gastos en salud como porcentaje del PIB están aún por debajo de muchos de sus vecinos de América Latina, es interesante ver que el mayor esfuerzo en la financiación de este gasto proviene del Gobierno nacional. Por ejemplo, en Colombia, el sector público contribuye con el $75 \%$ del gasto total en salud, mientras que en promedio en el resto del continente americano este aporte no alcanza el $50 \%$ y el promedio mundial se acerca al $59 \%$. La única región del

815 CONGRESO DE LA REPUBLICA DE COLOMBIA. Proyecto de ley 046 de 2017 consultado 31 de enero de 2018.

816 CONGRESO DE LA REPUBLICA DE COLOMBIA. Proyecto de ley 72 de 2017 consultado el 29 de enero de 2018.

817 Organización Mundial de la Salud. Gasto total en salud del PIB. 2014. 
mundo que tiene alguna similitud con Colombia es Europa, en donde el sector público financia el $74 \%$ del gasto total en salud. ${ }^{818}$

Según los indicadores del gasto en salud 2004 - 2011, el gasto total en salud expresado como porcentaje con respecto al PIB representa el 6,3\% en promedio durante el período en cuestión, en el cual los valores relativos extremos obtenidos son de $5,4 \%$ para 2004 y 7,0 \% para 2009: el más alto del período. Los porcentajes de 2004 y 2005 inferiores a $6 \%$ se explican por la baja magnitud del gasto de bolsillo estimado mediante interpolación con base en el método Kriging universal para esos años; a partir de 2007 los porcentajes que expresan esa relación se localizan por encima del $6 \% .{ }^{819}$

Por su parte, el gasto del Gobierno general como porcentaje del PIB representa el $4,7 \%$ en promedio durante el período. Sobre este indicador cabría agregar que en relación con el financiamiento de dicho gasto, el 2,8 \% del PIB, en promedio, corresponde a gasto financiado con fondos de la seguridad social y $19 \%$ con fondos públicos $^{10}$. Asimismo, el gasto privado como porcentaje del PIB representa el 1,7\% también en promedio durante el período y el gasto de bolsillo $1,1 \%$, porcentaje que tiende a disminuir progresivamente desde 2008, año en el cual fue de 1,4\%, el más alto del período. ${ }^{820}$

De otro lado, con respecto al gasto total en salud (GTS), el gasto en seguridad social en salud (GSSS) representa el 59,4 \% en promedio durante el período, con lo que se ubica por encima del $60 \%$ durante los tres últimos años del período. ${ }^{821}$

El gasto del Gobierno general (GGG), por su parte, representa también una participación en promedio del $73,8 \%$ con respecto al GTS, aunque claramente dicha participación disminuyó continuamente entre 2004 y 2008. Y en cuanto a salud pública, gasto privado y gasto de bolsillo, los porcentajes obtenidos con respecto al GTS, como promedios durante el período de referencia, son $4,6 \%, 26,2 \%$ y $17.9 \%$, respectivamente ${ }^{822}$.

818 PEREZ, Javier y VALBUENA, Alejandro. Documentos de trabajo sobre Economía Regional. En: Banco de la Republica centro de estudios económicos regionales CREER. Cartagena. volumen 218. Abril. 2015.

819 MINISITERIO DE SALUD Y PROTECCIÓN SOCIAL. Cifras financieras del sector salud. Gasto en salud de Colombia. 2004-2011. Boletín bimestral. Enero- febrero 2014. P. 15

820 ibid

$821 \mathrm{lbid}$

$822 \mathrm{lbid}$ 
Las políticas públicas del sector salud resultan de gran importancia, puesto que garantizan la materialización de las consignas teóricas, en beneficio de la comunidad en general. Estas constituyen un progreso significativo en la cobertura universal y de la prestación de servicios en salud, por ello la promoción de buenas políticas públicas implica un compromiso social y por ende una mayor satisfacción y garantía en el sector salud.

La creación del Sistema de Salud Pública tiene sus bases en la Constitución Política de Colombia, dado que esta establece que Colombia es un Estado Social de Derecho, organizado de forma descentralizada, con autonomía de sus entidades territoriales, participativa y pluralista, fundada en el respeto de la dignidad humana y solidaria con las personas ${ }^{823}$. Posteriormente, con la expedición de la Ley 100 de 1993 se creó el Sistema General de Seguridad Integral y con esta ley hubo una transformación a nivel administrativo y financiero, reflejado en la descentralización, la privatización, la autonomía de las entidades y la participación ciudadana ${ }^{824}$, además dio una calidad de vida acorde con el principio de dignidad Humana y solidaridad.

Dicha Ley constituyó cuatro grandes actores dentro del Sistema de Salud.

- El Estado, encargado de la organización, dirección y vigilancia, el cual actúa por medio del Ministerio de Salud y Protección Social, dándole a este el poder de elaborar políticas públicas en materia de salud, salud pública, y promoción social en salud ${ }^{825} ; \mathrm{y}$, por medio de la Ley $1122 / 07$ en su artículo 41 , este da poder a la Superintendencia de Salud para que ejerza funciones de Inspección, vigilancia y control del aseguramiento en salud ${ }^{826}$.

- Las Entidades Promotoras de Salud, EPS, son entidades de naturaleza pública, privada o mixta, que se encargan de afiliar y recaudar la cotización de los afiliados, actúan como intermediarias y administradoras de los recursos que provee el Estado 827.

- Las Instituciones Prestadoras del Servicio de Salud -IPS-, son las instituciones públicas, privadas o mixtas que prestan directamente el servicio de salud a los

${ }^{823}$ COLOMBIA. Constitución Política de Colombia. Op. Cit. Artículo 1 [Título I].

824 JARAMILLO PÉREZ, Iván. El futuro de la salud en Colombia: la puesta en marcha de la ley 100. Bogotá, D.C.: Fescol, 1999. p.99.

825 COLOMBIA. MINISTERIO DE SALUD Y PROTECCIÓN SOCIAL. Objetivos y Funciones. [Sitio Web]. [Consulta: 30 de diciembre de 2016]. Disponible en: https://www.minsalud.gov.co/Ministerio/Institucional/Paginas/institucional-objetivos-funciones.aspx.

${ }^{826}$ COLOMBIA. SUPERINTENDENCIA NACIONAL DE SALUD. Objetivos y Funciones. [Sitio Web]. [Consulta: 30 de diciembre de 2016]. Disponible en: https://www.supersalud.gov.co/es-co/superintendencia/nuestra-entidad/objetivos-y-funciones.

${ }^{827}$ COLOMBIA. CONGRESO DE LA REPÚBLICA. Ley 100. (23, diciembre, 1993). Op. Cit. 
usuarios, como las clínicas, hospitales o laboratorios; estas instituciones se encuentran orientadas por los principios de eficiencia y calidad, y se caracterizan por tener autonomía administrativa, técnica y financiera ${ }^{828}$.

- Por último, los usuarios, los cuales están atendidos bajo dos regímenes: el contributivo y el subsidiado. Al primer régimen pertenecen todas las personas vinculadas laboralmente, los servidores públicos, los pensionados y los trabajadores independientes con capacidad de pago; el segundo régimen acoge a la población que no tiene capacidad de pago que le permita aportar al Sistema, así, quienes ingresan al SGSSS por este régimen reciben subsidios totales 0 parciales. En cuanto a su financiación, se da por dos fuentes de recursos fundamentales: las trasferencias de la Nación a los departamentos y municipios y el FOSYGA ${ }^{829}$. Existe también el Sistema de Selección de Beneficiarios Para Programas Sociales -SISBÉN-, es el sistema de información diseñado por el Gobierno Nacional para identificar a las familias potenciales beneficiarias de programas Sociales ${ }^{830}$.

Posteriormente, se implantaron diferentes leyes y decretos que establecieron cómo se debe aplicar dicho sistema y cuáles son los recursos económicos que el Estado debe designar para el mismo, entre estas se encuentran la Ley 715 de 2001, en la que se encuentran las diferentes disposiciones para organizar la prestación de los servicios de educación y salud, entre otros, y establece la obligatoriedad de la Nación y sus entidades territoriales para que sean priorizadas dichas acciones encaminadas a la protección de los servicios y a elaborar un Plan de Atención Básica, con la participación de la comunidad y bajo la dirección del Consejo Territorial de Seguridad Social en Salud; todo esto a partir de la situación de salud en el territorio y las necesidades básicas del ciudadano colombiano ${ }^{831}$.

Luego, se creó la Ley 1122 de 2007, señalando que

[...] el propósito fundamental es mejorar la prestación de servicios de salud a los usuarios, fortalecer los programas de salud pública, las

\footnotetext{
828 lbíd.

829 JIMÉNEZ, Natalia Cecilia. Análisis del Sistema de Salud colombiano desde la perspectiva de la nueva gerencia pública. Monografía de Grado Politóloga. Bogotá. Universidad Colegio Mayor Nuestra Señora del Rosario. Facultad de Ciencia Política y Gobierno. 2013. p. 9.

830 COLOMBIA. SISBÉN. ¿Qué es el SISBÉN? [Sitio Web]. [Consulta: 30 de diciembre de 2016]. Disponible en: https://www.sisben.gov.co/Informaci\%C3\%B3n/El-

Sisb\%C3\%A9n.aspx\#.WGYUjPI97IU.

831 COLOMBIA. MINISTERIO DE SALUD Y PROTECCIÓN SOCIAL. Plan Decenal de Salud Pública 2012-2021: La salud en Colombia la construyes tú. Bogotá, D.C.: Imprenta Nacional de Colombia, 2013.
} 
funciones de inspección, vigilancia y control, organizar el funcionamiento de las redes para la prestación de servicios de salud y hacer reformas en aspectos de dirección, universalización, financiación y equilibrio entre los actores del sistema, así como establecer los mecanismos para la evaluación a través de indicadores de gestión y resultados en salud y bienestar de todos los actores del Sistema ${ }^{832}$.

Todo lo anterior adquiere valor humano y fundamental con la Sentencia T-760/08, MP Dr. Manuel José Cepeda Espinosa, en la cual la honorable Corte Constitucional clasifica al Derecho a la Salud como un Derecho Fundamental eliminando la expresión "por conexidad" que se utilizaba para poder solicitar el amparo de tutela al Derecho a la Salud; para esto, la Corte toma lo ya mencionado en la sentencia T-227/03:

[...] elección de un plan de vida concreto en el marco de las condiciones sociales en las que el individuo se desarrolle" y de "la posibilidad real y efectiva de gozar de ciertos bienes y de ciertos servicios que le permiten a todo ser humano funcionar en la sociedad según sus especiales condiciones y calidades, bajo la lógica de la inclusión y de la posibilidad de desarrollar un papel activo en la sociedad", definen los contornos de lo que se considera esencial, inherente y, por lo mismo inalienable para la persona, razón por la cual se traduce en derechos subjetivos (entendidos como expectativas positivas (prestaciones) o negativas) cuyos contenidos esenciales están sustraídos de las mayorías transitorias ${ }^{833}$. [...] En este orden de ideas, será fundamental todo derecho constitucional que funcionalmente esté dirigido a lograr la dignidad humana y sea traducible en un derecho subjetivo ${ }^{834}$.

De esta forma, el Derecho a la Salud, siguiendo a la OMS, que se refiere a un estado completo de bienestar físico, mental y social de una persona, innegablemente afecta la vida digna de cualquier ser humano, y por ende, adquiere su carácter fundamental, sin importar que se encuentre o no establecido como tal en la Carta Magna.

\footnotetext{
832 lbíd. p. 14.

${ }^{833}$ COLOMBIA. CORTE CONSTITUCIONAL DE COLOMBIA. Sentencia T-227 de 2003. Op. Cit. p. 1.

834 Ibíd. p. 11.
} 
Algunos años después se expidió la Ley 1438 de 2011, por la cual se reformó el SGSSS fortaleciendo todas las acciones encaminadas a la prestación del Servicio Público a la Salud, con las cuales se busca brindar un ambiente sano y agradable a la población colombiana. los aporte más importante de la Ley 1438 de 2011 fueron la creación del Plan Decenal de Salud Pública, la cual debe realizarse por el Ministerio de Salud y protección social, a través de un proceso amplio de participación social, estableciendo que en el PDSP deben coincidir las políticas sectoriales para mejorar el estado de salud de la población, incluyendo la salud mental; así mismo, debe incluir los objetivos, las metas, las acciones, los recursos, los responsables, los indicadores de seguimiento y los mecanismos de evaluación $^{835}$. Otro aporte significativo de la ley 1438 de 2011, fue la inserción del principio de corresponsabilidad en el sistema de salud, Por último, se encuentra la Ley Estatutaria 1751 de 2015 por la cual se regula el Derecho Fundamental a la Salud y se dictan otras disposiciones ${ }^{836}$.

\title{
4.7 POLÍTICAS PÚBLICAS ESTABLECIDAS POR EL PLAN DECENAL DE SALUD PÚBLICA, PDSP
}

El último PDSP presentado por el Ministerio de Salud y Protección Social fue el 2012 - 2021 busca:

\begin{abstract}
"lograr la equidad en salud y el desarrollo humano" de todos los colombianos y colombianas mediante siete dimensiones prioritarias y dos transversales, que representan aquellos aspectos fundamentales que por su magnitud o importancia se deben intervenir, preservar o mejorar, para garantizar la salud y el bienestar de todos los colombianos, sin distinción de género, etnia, ciclo de vida, nivel socioeconómico o cualquier otra situación diferencial" 837 .
\end{abstract}

EI PDSP es por antonomasia la política de salud pública esencial del Estado, este reconoce y garantiza la salud como un derecho fundamental, dimensión central del desarrollo humano e instrumento indispensable para lograr la paz y la equidad social con bienestar integral y calidad de vida, a través de la acción de todos los sectores que están involucrados directamente con la determinación social de la

\footnotetext{
835 lbíd.

${ }^{836}$ COLOMBIA. CONGRESO DE LA REPÚBLICA DE COLOMBIA. Ley 1751. Op. Cit.

837 COLOMBIA. MINISTERIO DE SALUD Y PROTECCIÓN SOCIAL. Plan Decenal de Salud Pública 2012-2021: La salud en Colombia la construyes tú. Op. Cit.
} 
salud ${ }^{838}$; esto quiere decir que en dicho documento se encuentran las diferentes políticas públicas referentes a la salud que aplicará el Estado.

\subsection{DIMENSIONES TRASVERSALES}

EI PDSP propone dos dimensiones trasversales: la Gestión Diferencial de Poblaciones vulnerables y la Gestión para el Fortalecimiento Institucional y de los Servicios de Salud. La primera dimensión va encaminada al reconocimiento de los diferentes grupos poblacionales que se encuentran en un estado de vulneración constante y que son reconocidos por la Constitución política y por la Corte Constitucional como Personas de Especial Protección por parte del Estado colombiano*, para así poder aplicar medidas a favor de los grupos sociales que se presentan en desventaja y/o situación grave de vulnerabilidad ${ }^{839}$.

La segunda dimensión promueve la corresponsabilidad de todos los sectores y actores para afectar positivamente los determinantes sociales y económicos de la salud, y propiciar condiciones de vida y desarrollo saludable y sostenible. Se desarrolla a través del ejercicio de la planificación e integración de las acciones relacionadas con la producción social de la salud y con la promoción de la respuesta dentro y fuera del sector salud. Incluye la regulación, conducción, garantía del aseguramiento y provisión de los servicios, sostenibilidad financiera, fiscalización, movilización social y recursos y las acciones colectivas e individuales de salud pública que se definen en el Plan, al interior de las siete dimensiones prioritarias para la vida ${ }^{840}$.

A lo largo de este trabajo hemos pretendido dejar en claro que la Corte Constitucional ha establecido el Derecho a la Salud como un derecho fundamental

838 lbíd.

* La sentencia T-736 de 2013 MP Alberto Rojas Ríos establece que: "la Corte Constitucional ha señalado como sujetos de especial protección a los niños y niñas, a las madres cabeza de familia, a las personas en situación de discapacidad, a la población desplazada, a los adultos mayores, y todas aquellas personas que por su situación de debilidad manifiesta los ubican en una posición de desigualdad material con respecto al resto de la población; motivo por el cual considera que la pertenencia a estos grupos poblacionales tiene una incidencia directa en la intensidad de la evaluación del perjuicio, habida cuenta que las condiciones de debilidad manifiesta obligan a un tratamiento preferencial en términos de acceso a los mecanismos judiciales de protección de derechos, a fin de garantizar la igualdad material a través de discriminaciones afirmativas a favor de los grupos mencionados".

839 COLOMBIA. MINISTERIO DE SALUD Y PROTECCIÓN SOCIAL. Plan Decenal de Salud Pública 2012-2021: La salud en Colombia la construyes tú. Op. Cit.

840 COLOMBIA. MINISTERIO DE SALUD Y PROTECCIÓN SOCIAL. Plan Decenal de Salud Pública 2012-2021: La salud en Colombia la construyes tú. Op. Cit.p. 156, 157. 
por medio de sus jurisprudencias, pero no es sino hasta el año 2015 que el gobierno colombiano crea una ley que establezca esta verdad jurídica. La creación de la Ley Estatutaria 1751/15 regula el Derecho Fundamental a la Salud basándose en numerosos elementos (disponibilidad, aceptabilidad y accesibilidad) y principios (calidad e idoneidad profesional, universalidad, pro homine, equidad, continuidad, oportunidad, prevalencia de derechos, progresividad del derecho, libre elección, sostenibilidad, solidaridad, eficiencia, interculturalidad, protección a los pueblos indígenas y la Protección pueblos y comunidades indígenas, ROM y negras, afrocolombianas, raizales y palenqueras) ${ }^{841}$; de esta forma, la ley busca solucionar los problemas de la atención relacionados con la calidad, oportunidad y el acceso a los servicios de salud.

La Corte Constitucional definió dos años como periodo transicional para que la ley estatutaria pueda entrar en funcionamiento, ya que esta trae consigo cambios al sistema de salud como lo son:

1. Autonomía profesional: Autoriza al médico tratante a realizar el procedimiento médico necesario y recetar los medicamentos y procedimientos médicos necesarios (teniendo en cuenta los esquemas de autorregulación, la ética, la racionalidad y la evidencia científica) sin el constreñimiento que antes existía por parte de las instituciones prestadoras del servicio de salud ${ }^{842}$.

2. Cambio en el esquema de beneficios: El Plan Obligatorio de Salud -POSdesaparecerá; se creará un plan de beneficios basado en un régimen de exclusión, el cual le permitirá a los afiliados acceder a todo lo que los médicos le ordenen a excepción de: los cosmético y lo suntuario, lo experimental, lo que no tenga evidencia científica y los tratamientos en el exterior que puedan ser brindados en el país; estos tratamientos podrán ser solicitados por medio de un proceso individual ante las juntas médicas específicas ${ }^{843}$; dicho cambio no será una barrera, sino que pretende reconocer, de manera más clara, cuáles son los derechos de los usuarios y qué deben hacer si desean un tratamiento diferente a los ya permitidos por Colombia. Al hacer una lectura integral de la ley, se ve que establece un catálogo de derechos de las personas en materia de salud, que determinan unos deberes a las entidades prestadoras de salud y unos principios que consagran y materializan el derecho a la salud como un verdadero derecho fundamental.

841 COLOMBIA. CONGRESO DE LA REPÚBLICA DE COLOMBIA. Ley 1751. Op. Cit. 842 COLOMBIA. CONGRESO DE LA REPÚBLICA DE COLOMBIA. Ley 1751. Op. Cit. 843 lbíd. 
3. Atención integral en urgencias: Acabará el conocido "Carrusel de la Muerte", la verificación de requisitos y derechos en el sistema no podrán ser un impedimento a la hora de presta el servicio de salud de urgencias, así los usuarios no tendrán que esperar para ser atendidos debido a las barreras administrativas de las entidades prestadoras del servicio y la entidad encargada de la gestión del servicio. Tampoco se podrá negar el servicio de salud de urgencias porque el ciudadano no se encuentre afiliado al sistema ${ }^{844}$. Para la prestación del servicio de "Urgencias" no aplicará el periodo de 2 años para la implementación de la presente ley. De no prestar este servicio, las entidades prestadoras del Servicio de Salud incurrirán en la imposición de las sanciones y multas correspondientes. De ahí la importancia de políticas públicas más eficaces en salud, las cuales tiene como propósito promover y garantizar la salud de la población.

Como fin de las políticas públicas tenemos,

La atención primaria, el acceso universal y la protección social representan las principales respuestas a estas expectativas. Las personas esperan asimismo que sus gobiernos instauren una serie de políticas públicas cuyas disposiciones abarquen desde el nivel local hasta el supranacional y sin las cuales la atención primaria y la cobertura universal perderían gran parte de su impacto y su sentido. Comprenden las políticas necesarias para hacer que los sistemas sanitarios funcionen adecuadamente y emprender acciones de salud pública muy beneficiosas para todos ${ }^{845}$.

De igual manera, como objetivos del sistema de políticas públicas corresponde a

[...] comprender las políticas que puedan contribuir a la salud y a la sensación de seguridad y garanticen a la vez el correcto manejo de cuestiones como el desarrollo urbano, el cambio climático, la discriminación por razones de género o la estratificación social. Un primer grupo de políticas públicas fundamentales es el constituido por las políticas de los sistemas sanitarios (relacionadas con los medicamentos esenciales, la tecnología, el control de la calidad, los recursos humanos, la acreditación, etc.) de las que dependen la atención primaria y las reformas en pro de la cobertura universal ${ }^{846}$.

\footnotetext{
${ }^{844}$ Ibíd.

845 ORGANIZACIÓN MUNDIAL DE LA SALUD. Informe sobre la salud en el mundo 2008: La atención primaria de salud más necesaria que nunca Informe sobre la salud. Suiza, 2008. p. 66.

846 Ibíd. p. 69.
} 
Por ejemplo, sin unos sistemas de suministro y logística en buen estado de funcionamiento, una red de atención primaria no puede operar adecuadamente: cabe citar el caso de Kenya, donde los niños disfrutan de mayor protección contra la malaria gracias a que los servicios locales les han proporcionado mosquiteros tratados con insecticida. Esto ha sido posible únicamente porque las actividades de atención primaria recibieron el apoyo de una iniciativa nacional que contaba con un firme compromiso político, mercadotecnia social y respaldo nacional para el suministro y la logística ${ }^{847}$.

Ahora bien, finalmente y abordado el análisis de las políticas públicas, es de inusitada importancia, hacer un examen precisamente sobre la política pública en el sistema de salud colombiano, fundamentada en el principio de corresponsabilidad.

847 Ibíd. p. 66 


\section{EL PRINCIPIO DE CORRESPONSABILIDAD EN EL DERECHO A LA SALUD EN COLOMBIA}

El derecho a la salud en Colombia ha trasegado desde 1991 por un camino ambivalente en el que se ha auscultado su naturaleza jurídica por diversidad de intérpretes que lo han llevado a ser concebido en la actualidad como un derecho fundamental autónomo exigible por la totalidad de la población, fincado en una Ley Estatutaria nutrida por un activismo jurisprudencial encomiable que ha permitido mutar su definición, ampliar su espectro de acción y disminuir las cortapisas para su acceso en la búsqueda de su materialidad, permitiendo así, trascender de la mera formalidad del documento normativo que lo consagra. De esta manera, las mutaciones de las que ha sido objeto el derecho a la salud en Colombia desde la promulgación de la Constitución Política en el año de 1991, permiten entender que la concepción de este derecho no ha sido tarea fácil para el poder legislativo del país, pues es un derecho social, nominado como derecho de segunda generación, distinción ya superada, pero que representa para el Estado un reto adicional. Hoy, ya está relevada la concepción del derecho a la salud como un servicio público, asimismo, también la que lo concibió como un derecho fundamental, pero que condicionó predicarlo de tal si no ostentaba la conexidad con el derecho a la vida. A la fecha, se tiene como un derecho fundamental, pero con un ingrediente especial, objeto de tratamiento en el presente documento, su multilateralismo con relación a los sujetos.

En este orden de ideas, a propósito de la promulgación de la Ley 1751 de $2015^{848}$, la cual representa un hito acerca de la concepción del derecho a la salud, resulta pertinente hacer referencia a un tema poco tratado. Se tiene que el derecho a la salud se rige bajo ciertos principios, puntualmente, en esta Ley, con ocasión del análisis que se pretende desarrollar, se consagran como elementos esenciales e interrelacionados al derecho fundamental a la salud: la solidaridad, la eficiencia y la sostenibilidad, entre otros más, pero antes de hacer referencia puntualmente a estos, subsumimos estos elementos referidos con el plasmado en la Ley 1438 de $2011^{849}$, a saber, la corresponsabilidad.

Frente al particular, para iniciar un análisis tanto en materia legal como jurisprudencial, es oportuno citar la definición de este principio, contemplada en el

848 COLOMBIA. CONGRESO DE LA REPÚBLICA DE COLOMBIA. Ley 1751. Op. Cit.

849 COLOMBIA. CONGRESO DE LA REPÚBLICA DE COLOMBIA. Ley 1438 de 2011 (19, enero, 2011). Por medio de la cual se reforma el Sistema General de Seguridad Social en Salud y se dictan otras disposiciones. Diario Oficial, Bogotá D.C. 2011. º 47.957. 
artículo 3 inciso 17 de la Ley 1438 de 2011, el cual modificó el artículo 153 de la Ley 100 de 1993, a saber:

Artículo $3^{\circ}$. Principios del Sistema General de Seguridad Social en Salud. [...].

3.17 Corresponsabilidad. Toda persona debe propender por su autocuidado, por el cuidado de la salud de su familia y de la comunidad, un ambiente sano, el uso racional y adecuado de los recursos el Sistema General de Seguridad Social en Salud y cumplir con los deberes de solidaridad, participación y colaboración. Las instituciones públicas y privadas promoverán la apropiación y el cumplimiento de este principio ${ }^{850}$.

Así, se puede colegir de esta definición, que el principio de corresponsabilidad está compuesto por los deberes de solidaridad, participación y colaboración, recogidos en la referida disposición legal, que exhorta a que la comunidad, la familia y las personas en su esfera individual en un trabajo mancomunado con la instituciones públicas y privadas coadyuven en la aplicación de este principio que conlleva a la correlativa materialización del derecho a la salud, no visto como una garantía exclusivamente a cargo del Estado. Por el contrario, se requiere que esa solidaridad, esa participación y esa colaboración provenga de todo el entramado social que redunde en la efectividad, entendida como la sumatoria de la eficiencia y la eficacia, del derecho fundamental a la salud dentro del Sistema General de Seguridad Social en Salud, que, dicho sea de paso, entraría en consonancia con el bloque de constitucionalidad, consagrado en el artículo 93 de nuestra Carta Política. Con sujeción estricta a lo anterior, existen numerosos instrumentos internacionales que conforman el bloque de constitucionalidad; resulta oportuno señalar, a propósito del principio de eficiencia ${ }^{(*)}$ que el artículo 16 del Código lberoamericano señala: "Artículo 16. Los Estados ratificantes, cualquiera que sea el modelo organizativo e institucional adoptado propiciarán una gestión apoyada en los principios de eficacia y eficiencia, simplificación, transparencia, desconcentración, responsabilidad y participación social"851. Así entonces, con ocasión del mapeo normativo, se logra encontrar que postulados del principio de corresponsabilidad se hallan insertos dentro del marco de bloque de constitucionalidad, caso puntual la participación social, por tanto, puede predicarse que su inobservancia conlleva al

850 lbíd. p. 3.

(*) Consagrado como principio del SGSSS en la Ley 1438 de 2011 y elemento esencial del derecho fundamental a la salud en la Ley 1751 de 2015.

851 ORGANIZACIÓN IBEROAMERICANA DE SEGURIDAD SOCIAL. Código iberoamericano de seguridad Social. (en línea). http://www.oiss.org/IMG/pdf/CODIGO_IBEROAMERICANO2.pdf. p. 23. 
desconocimiento de disposiciones normativas ratificadas por el Congreso colombiano.

En sede jurisprudencial, el principio de corresponsabilidad no tiene una referencia autónoma, tanto así, que es con base en los deberes que lo integran que permite avizorar una referencia en este campo del derecho, que se llega a confundir como una noción más amplia del principio de solidaridad. Sin embargo, es con base en la conceptualización de esos deberes que se predican como insumos del principio de corresponsabilidad que se hace viable edificar una noción de este principio dentro del sistema de salud en Colombia.

Con sustento en la sentencia C-760 de 2008, la Corte Constitucional define el principio de solidaridad en los siguientes términos:

La solidaridad es la mutua ayuda entre las personas, las generaciones, los sectores económicos, las regiones y las comunidades bajo el principio de protección del más fuerte hacia el más débil; es deber del Estado garantizar la solidaridad en el régimen de seguridad social mediante su participación, control y dirección del mismo 852 .

A su turno, en esa misma sentencia de constitucionalidad la Corte define la participación como "[...] la intervención de la comunidad a través de los beneficios de la seguridad social en la organización, control, gestión y fiscalización de las instituciones y del sistema en su conjunto"853.

En este estado de las cosas, al abordar la aplicación que se le da al principio de corresponsabilidad por parte de los sujetos que intervienen en esta relación, es necesario tener en cuenta la ausencia de un conocimiento legible frente a este principio que, a toda luces, repercute en el nivel de satisfacción del derecho fundamental a la salud entendido como un "[...] estado de completo bienestar físico, mental y social" 854 , estado al que tiene derecho todo ser humano y se insiste: está condicionalmente supeditado a la aplicación de los deberes que materializan el

852 COLOMBIA. CORTE CONSTITUCIONAL DE COLOMBIA. Sentencia C-760/04. M.P.: Rodrigo Uprimny Yepes. Bogotá, D.C. p.1.

853 Ibíd. p. 1.

854 NACIONES UNIDAS Y ORGANIZACIÓN MUNDIAL DE LA SALUD. El derecho a la salud. Op. Cit. p. 1. 
principio de corresponsabilidad, principio novedoso y de desarrollo incipiente tanto legal, doctrinaria como jurisprudencialmente.

Precisamente, es el escaso tratamiento de este tema, el que imposibilita poder atribuir una sentencia como la fundante de este principio, a lo sumo, se acude a aquellos atisbos amplificados que hace la Corte Constitucional acerca del principio de solidaridad, en la que extiende su ámbito de aplicación a escenarios más concretos, por ello, vale la pena citar la sentencia C-126 de 2000, en la cual determinó que:

[...] el principio de solidaridad implica, que todos los partícipes de este sistema deben contribuir a su sostenibilidad, equidad y eficiencia, lo cual explica que sus miembros deban en general cotizar, no sólo para poder recibir los distintos beneficios, sino además para preservar el sistema en su conjunto ${ }^{855}$.

Aunado a lo anterior, expone que:

[...] es deber del Estado garantizar la solidaridad en el sistema de seguridad social mediante la participación, dirección y control del sistema, asegurando que los recursos públicos en dicho sistema se destinen de manera preferente a los sectores más vulnerables de la población $n^{856}$.

Con mérito de lo anterior, se toca otro tema que mucho tiene que ver con el principio de corresponsabilidad y es la sostenibilidad del sistema, que precedentemente se anunció como uno de los pilares plasmados tanto en la Ley 1438 de 2011 como en la Ley 1751 de 2015, del cual se desprende que los usuarios deben aportar en términos pecuniarios para el funcionamiento y su correlativa sostenibilidad, habida cuenta que el derecho fundamental a la salud tiene un componente de carácter económico, el denominado "condicionamiento economicista" que, según demuestra la experiencia, ha implicado una talanquera en la materialización de derechos del orden social, lo cual exige una posición no solo vigilante por parte del Estado, sino, a su vez, demanda que gestione y facilite erogaciones económicas que se destinen como respaldo financiero que sirvan de soporte a los servicios requeridos.

855 COLOMBIA. CORTE CONSTITUCIONAL DE COLOMBIA. Sentencia C- 126/00. M.P.: Carlos Arturo Martínez Caballero. Bogotá, D.C. p. 1.

${ }^{856}$ COLOMBIA. CORTE CONSTITUCIONAL DE COLOMBIA. Sentencia C-760/04. Op. Cit. p. 1. 
La Ley 1438 de 2011 acuña este principio en los siguientes términos:

[...] 3.13 Sostenibilidad. Las prestaciones que reconoce el sistema se financiarán con los recursos destinados por la ley para tal fin, los cuales deberán tener un flujo ágil y expedito. Las decisiones que se adopten en el marco del Sistema General de Seguridad Social en Salud deben consultar criterios de sostenibilidad fiscal. La administración de los fondos del sistema no podrá afectar el flujo de recursos del mismo ${ }^{857}$.

A pesar de que la Ley 1438 de 2011 no considera el principio de sostenibilidad como insumo del principio de corresponsabilidad, la relación de estos resulta bastante determinante, pues una concientización más profunda de la importancia de la aplicación de este principio de cara a políticas públicas que se implementan en este tema, verbigracia, la Atención Primaria en Salud (APS)* debe responde a esa multilateralidad referida precedentemente, que el individuo adquiera un papel más activo en lo que concierne a su salud, que los síntomas experimentados aunados a una atención temprana disminuyan la complejidad de las patologías que se presenten.

No obstante, que esta disminución no solo sea producto de una atención prioritaria, sino de un hábito de vida que permita reducir los riesgos atendiendo las recomendaciones de los profesionales de la salud, acrecentando así, los niveles de vida en condiciones dignas que incentiven la promoción de la atención integral enfocada más en la medicina preventiva que la paliativa, sin que implique desconocer esta última. Por su parte, la Ley 1751 de 2015 lo consagra así: "Sostenibilidad. El Estado dispondrá, por los medios que la ley estime apropiados, los recursos necesarios y suficientes para asegurar progresivamente el goce efectivo del derecho fundamental a la salud, de conformidad con las normas constitucionales de sostenibilidad fiscal" 858 .

857 COLOMBIA. CONGRESO DE LA REPÚBLICA DE COLOMBIA. Ley 1438 de 2011. Op. Cit. p. $2,3$.

* "La Atención Primaria en Salud es la estrategia de coordinación intersectorial que permite la atención integral e integrada, desde la salud pública la promoción de la salud, la prevención de la enfermedad, el diagnóstico, el tratamiento, la rehabilitación del paciente en todos los niveles de complejidad a fin de garantizar un mayor nivel de bienestar en los usuarios, sin perjuicio de las competencias legales de cada uno de los actores del Sistema General de Seguridad Social en Salud" (Artículo 12 de la Ley 1438 de 2001).

858 COLOMBIA. CONGRESO DE LA REPÚBLICA DE COLOMBIA. Ley 1751. Op. Cit. p. 4. 
A pesar de que la definición del principio de sostenibilidad es más austera en esta última disposición, no debe confundirse como de menor importancia, de hecho, la asunción del derecho a la salud como derecho fundamental hace que su protección asuma tintes de inmediatez, hecho tal que demanda del Sistema General de Seguridad Social en Salud una agilidad mayor que redunde en la eficiencia en el manejo de los recursos.

Continuando con el miraje jurisprudencial, se puede advertir otra expresión, tal vez más amplia, del principio de solidaridad que la Corte Constitucional invocó frente al tema, en cuanto al caso en particular, en sentencia T-154 de 2014 le dio una connotación que vale la pena citar: "[...] los familiares más próximos tienen deberes de solidaridad y apoyo recíproco, que han de subsistir más allá de las desavenencias personales" 859 , definiendo esto como una solidaridad familiar, que sin discriminación alguna la corporación establece que se le atribuye a los miembros de una sociedad el "[...] deber de ayudar, proteger y socorrer a sus parientes cuando se trata del goce de sus derechos fundamentales a la salud y a la vida digna" 860 .

Así, pues, rebosa la noción de solidaridad entendida como aquella acción de contribuir económicamente mediante la realización de aportes al sistema. Por el contrario, insta a que unos de los sujetos consagrados en el principio de corresponsabilidad, entre en la palestra asumiendo un rol preponderante y no tangencial, la familia, toda vez, que aún ante las posibles animadversiones que gravitan en el ámbito familiar, son los parientes más próximos a quienes se le endilga una responsabilidad de socorro, de ayuda y de protección con sus consanguíneos en virtud no solo de los lazos de sangre, sino de la cercanía afectiva con el paciente.

Con fundamento en esa misma sentencia de tutela, la Corte Constitucional plasma otra arista al principio de solidaridad, insumo del principio de corresponsabilidad, por medio de la cual, acuña el concepto de solidaridad social, entendida:

[...] como parte fundante del Estado Social de Derecho, según el cual es deber de todas las personas responder con acciones humanitarias ante situaciones que pongan en peligro la vida o la salud de las personas, y cuya primera manifestación, sin lugar a dudas, ha de

859 COLOMBIA. CORTE CONSTITUCIONAL DE COLOMBIA. Sentencia T-154/14. M.P.: Luis Guillermo Guerrero Pérez, D.C. p. 17.

860 lbíd. p. 17. 
darse entre los miembros de la familia, en caso de necesidad de uno de sus integrantes ${ }^{861}$.

Corolario a lo anterior, es viable aducir que ese otro sujeto, que se encuentra dentro de la definición del principio de corresponsabilidad, antes esbozado, también debe asumir una posición al respecto frente al derecho fundamental a la salud en el marco del sistema general de seguridad social. Es coherente advertir que este principio está orientado a brindar amparo al sistema mediante el cumplimiento de los principios que le son compatibles y, entre otras cosas, consagrados en mandatos legales, lo que conforme al diagnóstico referencial adelantado puede predicarse su inobservancia, lo cual incide en la inaplicación de estos elementos que resultan esenciales e interrelacionados, aunado a un incipiente tratamiento por parte de los operadores, tanto legal como jurisprudencialmente, lo que hace que no medie una coadyuvancia de la pluralidad de sujetos a los que se les puede arrogar una corresponsabilidad que permita optimizar en términos de efectividad y sostenibilidad el sistema.

Otra de las nociones que se extienden del principio de solidaridad, entendido también como autocuidado, involucra directamente al paciente, puesto que el afirmar que: "[...] los pacientes deben hacer esfuerzos para cumplir con el mandato constitucional de autocuidado de su salud y no limitarse a alegar su falta de disciplina para negarse a intentar los procedimientos previstos en el POS "862 implica que el comportamiento del afiliado no pude limitarse estrictamente a actuar como un sujeto pasivo, se exhorta, en virtud de este principio, que él mismo coadyuve a propiciar un ambiente más propicio que blinde de un deterioro paulatino su afección. Lo etéreo de este principio se traslada también a escasas referencias en disposiciones normativas dispersas, por ejemplo, en la Ley 1392 de 2010, la que en su artículo 4 preceptúa:

Artículo 4 Principios rectores: [...].

Corresponsabilidad: La familia, la sociedad y el Estado son corresponsables en la garantía de los derechos de los pacientes que padecen enfermedades huérfanas y propiciarán ambientes favorables para ellos, con el fin de generar las condiciones adecuadas, tanto en

${ }^{861}$ COLOMBIA. CORTE CONSTITUCIONAL DE COLOMBIA. Sentencia T-154/14. Op. Cit. p. 17. 862 COLOMBIA. CORTE CONSTITUCIONAL DE COLOMBIA. Sentencia T-1078/07. M.P.: Humberto Antonio Sierra Porto. Bogotá, D.C. p. 2. 
el ámbito público como privado, que permitan su incorporación, adaptación, interacción ante la sociedad ${ }^{863}$.

Asimismo, se puede encontrar en un acuerdo expedido por el Concejo Municipal de Bogotá, exactamente en el acuerdo 485 de 2011, el principio de corresponsabilidad, a saber:

Las entidades distritales encargadas de la protección de la infancia, promoverán periódicamente programas y políticas con el objetivo de sensibilizar a la sociedad frente al deber de proteger y preservar la dignidad humana de los niños, niñas y adolescentes, en aplicación del principio de corresponsabilidad concientizar sobre la existencia y posibilidad de propiciar mecanismos positivos de educación, distintos del castigo físico, humillante, denigrante y todo tipo de violencia ${ }^{864}$.

Es preciso resaltar que las dos últimas disposiciones esbozadas, la Ley 1392 de 2010 y el Acuerdo 485 de 2011, sí contemplan textualmente el principio objeto de análisis, a pesar de ello, se logra advertir que se adolece de una hilaridad congruente que permita un tratamiento legal escalonado de este principio, tan es así, que en la Ley 1752 de 2015 no se contempló, por tanto, no se puede predicar una coherencia que propicie el cumplimiento de los principios que contribuyan al mejoramiento del sistema de salud, de por sí, bastante desacreditado.

Finalmente, y como se ha venido insistiendo, el principio de corresponsabilidad del derecho a la salud, en el marco de un Sistema de Seguridad Social como el colombiano, se encuentra permeado de la idiosincrasia nacional, en donde no hay una mutualidad entre las entidades prestadoras, públicas o privadas, y los usuarios de los servicios, en consecuencia, el principio en mención parece no tener cabida. La ausencia de adherentes a él hace que los problemas de atención en salud respondan a múltiples causas, tan diversas una de otra que no se destila su origen. En Colombia, el Congreso colombiano expidió la Ley 1438 de 2011, disposición legal que funge como ópera prima de éste principio, de la que constantemente se

863 COLOMBIA. CONGRESO DE LA REPÚBLICA DE COLOMBIA. Ley 1392 de 2010 (2, julio, 2010). Por medio de la cual se reconocen las enfermedades huérfanas como de especial interés y se adoptan normas tendientes a garantizar la protección social por parte del Estado colombiano a la población que padece de enfermedades huérfanas y sus cuidadores. Diario Oficial, Bogotá D.C. 2010. № 47.758. p. 2.

864 COLOMBIA. CONCEJO MUNICIPAL DE BOGOTÁ D.C. Acuerdo 485 de 2011 (27, diciembre 2011). Por el cual se establecen medidas educativas encaminadas a la erradicación del castigo físico, humillante y denigrante en contra de los niños, niñas y adolescentes de Bogotá, D.C. Registro Distrital, Bogotá, D.C. 2011. № 4804. p. 1. 
ha hecho mención a lo largo de este escrito, en la cual, a su vez, se consagran postulados de Atención Primaria en Salud, sin embargo, con apego a doctrina internacional, en países como Venezuela y México también se ha intentado la implementación de este principio en políticas de Atención Primaria en Salud.

En México, "[...] las premisas que sustentan la estrategia de la atención primaria a la salud (APS) establecen, dentro de su base metodológica, la importancia de la participación"865, así, se evidencia la necesidad de una participación, pero no de cualquiera, sino de una participación intersectorial, en la que se ven implicados los entes territoriales, la comunidad y los afiliados. Frente a este último actor se demanda "[...] a intervención organizada y responsable de los individuos de una comunidad en el autocuidado de su salud a la que deben enfocar integralmente los aspectos de promoción, prevención curación y rehabilitación"866. De lo anterior, se desprende un tópico que resulta oportuno profundizar y es aquel que se refiere al autocuidado de la salud enfocado en la prevención, toda vez que la atención en salud se ciñe al "[...] paradigma centrado en la enfermedad, con la atención dirigida casi exclusivamente en el daño, cuando ya está instalado, con sus respectivas secuelas" 867 . Así, "[...] este énfasis ha traído como consecuencia la ignorancia o la minimización del enfoque preventivo dejando al margen el manejo especifico de los factores de riesgo" 868 , lo que permite colegir que llevado a escenarios puntuales genere desestabilización en el sistema, la agudización de problemas como las repercusiones atinentes a enfermedades huérfanas, la profundización del deterioro de la salud y su correlativa implicación en el sistema de previsión social, al acrecentarse, por ende, los reconocimientos de pensión de invalidez.

En Brasil, también en escenarios de atención primaria en salud, se propende porque que exista una relación más cercana en la que haya participación del usuario "El objetivo es crear un vínculo de corresponsabilidad entre estos equipos profesionales y la población para facilitar la identificación y la atención de enfermedades. Actualmente el Programa de Salud de la Familia cubre a cerca de $50 \%$ de la población ${ }^{869 "}$. De tal manera que se avizoran atisbos de corresponsabilidad en materia de prevención en salud.

Al respecto, en Perú, frente al sistema de prestación de servicios de salud, se considera que "Es indispensable también sentar las bases de un nuevo contrato

${ }^{865}$ AGUIRRE HUACAJA, Enrique. La corresponsabilidad operativa en la atención primaria a la salud. En: Salud Pública de México. Vol. 36 N 32 (marzo-abril, 1994). p. 211.

${ }^{866}$ AGUIRRE HUACAJA, Enrique. Op. Cit. p. 211.

867 Ibíd. p. 212.

868 Ibíd. p. 212.

869 BECERRIL MONTEIKO, Víctor; Medina, Guadalupe \& Aquino Rosana. Sistema de salud en Brasil. En: Salud pública de México. Vol.53. supl. 2 (ene. 2011). p. 124. 
social entre los servicios de atención y la población, basado en la corresponsabilidad individual y colectiva sobre la salud. Esto requiere, entre otras cosas, del fortalecimiento de la descentralización y los CLAS ${ }^{870 "}$. Puede colegirse el aspecto intersectorial que se predica del derecho a la salud frene al principio de la responsabilidad conjunta.

En Venezuela, por su parte, el principio de corresponsabilidad está elevado a rango constitucional, Anzola Nieves manifiesta que: "La corresponsabilidad, en la actualidad, se concibe como un principio constitucional del novísimo constitucionalismo social y de la democracia que se puede ejercer, en Venezuela, en los ámbitos económico, social, político, cultural, geográfico y militar; de acuerdo a la Constitución venezolana de 1999"871.

Así, la consagración en el texto político responde también al embrionario modelo de Estado que se gestaba para la época de expedición de la constitución en el país fronterizo.

En el texto constitucional venezolano, la corresponsabilidad no tiene como estandarte exclusivo al derecho a la salud, también es concebido en terrenos del derecho a la educación, al trabajo, en materia económica y militar. Para el asunto puntual que nos ocupa, "[...] los Arts. 83 y 84 proclaman también de manera novedosa, deberes formales tanto para el Estado venezolano como para la sociedad, en donde éstos deben actuar conjuntamente para la concreción de los derechos y satisfacción de las necesidades de la sociedad en materia de salud"872. De tal, que se presume el trabajo mancomunado del Estado y la sociedad en procura de la satisfacción del derecho.

La corresponsabilidad entonces, puede interpretarse con tintes polisémicos, que exigen la inmersión de varios actores en la implementación y ejecución de políticas públicas, máxime cuando éstas tratan sobre derechos sociales como lo es el derecho a la salud, por tanto, la noción de corresponsabilidad "[...] se fundamenta en una concepción de democracia participativa, en la que la gestión pública no se limita a la gestión de las instituciones del Estado sino que involucra a la sociedad civil en la gestión de lo público"873.

870 ALCALDE RABANAL, Jacqueline; LAZO GONZÁLEZ, Oswaldo \& NIGENDA, Gustavo. Sistema de salud en Perú. En: Salud pública México. vol.53. supl.2 (ene. 2011). p. 252.

871 ANZOLA NIEVES, Aurora. La corresponsabilidad como principio constitucional en Venezuela. En: Compendium. vol. 14, núm. 27. (julio-diciembre, 2011). p. 61.

872 lbíd. p. 72.

${ }^{873}$ ANZOLA NIEVES, Aurora. Op. Cit. p. 61. 
Con mérito de lo anterior, permite aseverar que la intervención en asuntos relacionados al Sistema General de Seguridad Social en Salud, no tiene como único actor al Estado, se requiere de una articulación intersectorial que conforman la comunidad, la familia, el profesional en medicina pero, sobre todo, el individuo, consciente de sus deberes, que le permita al afiliado dimensionar las amenazas que le atañen si no asume un compromiso serio y responsable, con él mismo, con su salud y con la sociedad, de manera que, se logre la consolidación de un objetivo que, en teoría está encaminado a buscar el mejoramiento de la calidad de vida de los ciudadanos pero que, ante la inmutabilidad de los mismos, relegan como simple retorica la aplicación de principios que puedan llegar a ser el antídoto que necesitan las afecciones que ostenta el sistema de salud en nuestro país.

A modo de colofón, el principio de corresponsabilidad que requiere Colombia es ese aditamento que resulta de la compilación de esfuerzos de los actores participes en el sistema de salud en nuestro país, la ausencia de esa cooperación precariza la prestación de los servicios y, dada la transversalidad acorde a su naturaleza, afecta el principio de la dignidad humana de los usuarios. Aunado a lo anterior, la inexistencia de un compromiso univoco en favor del sistema de salud, fomenta el desequilibrio del carácter económico que no se desprende del derecho a la salud, premisa que tiene respaldo en el célebre adagio popular, que adaptado en términos monetarios, es más económico prevenir que curar, de ahí la importancia de la educación e ilustración a la sociedad, a las entidades prestadoras de servicios de salud, a los galenos y al afiliado del novísimo principio de corresponsabilidad del que aún no se seca la tinta en las disposiciones normativas que lo consagran.

La corresponsabilidad requiere entonces de la deconstrucción de la relación vertical sociedad civil-Estado y del surgimiento de una transformación que avive una concientización social en donde no se asuman roles pétreos como receptores de esfuerzos, por el contrario, se requiere de una posición activa que coadyuve al afianzamiento del interés general mediante la aprehensión consciente del papel que cada uno desempeña en la optimización del derecho a la salud en Colombia.

Con mérito de lo anterior, se concluye que la intervención en asuntos relacionados al Sistema General de Seguridad Social en Salud, no tiene como único actor al Estado, pues se requiere de una articulación intersectorial que conforman la comunidad, la familia, el profesional en medicina, y sobre todo, el individuo, mediante el fomento de la educación social, que le permita al afiliado dimensionar las amenazas que le atañen si no asume un compromiso serio y responsable con él mismo, con su salud y con la sociedad, de manera que se logre la consolidación de un objetivo que en teoría está encaminado a buscar el mejoramiento de la calidad de vida de los ciudadanos, pero que ante la inmutabilidad de los mismos, 
relegan como simple retorica la aplicación de principios que puedan llegar a ser el antídoto que necesita el sistema de salud en nuestro país. 


\section{CONCLUSIONES}

Este trabajo de investigación estuvo direccionado a documentar un derecho fundamental vacuamente consagrado en la legislación hasta la fecha e interpretado de manera prolifera por la jurisprudencia constitucional de forma poco unificada. Este es el derecho fundamental a la salud, el cual se ha basado en diversas teorías, pero que hoy es reconocido por la máxima Corporación de lo constitucional como un derecho fundamental de carácter autónomo, y así como por la Ley 1751 de 2015, que reconoció y reguló dicha naturaleza.

Sin duda alguna, la salud es una condición compleja y fundamental para todo individuo en aras de materializar una vida en condiciones de dignidad. No obstante, la garantía de la misma siempre ha sido difusa, al definirse como un servicio o un derecho de carácter prestacional, de contenido programático y no práctico, que requiere como presupuesto para su materialización de la existencia de recursos y de acciones afirmativas por parte del Estado. La salud es un derecho cuya garantía representa una de las mayores erogaciones de recursos por parte del Estado, puesto que su garantía completa exige un diagnóstico y tratamiento de calidad, que asegure la calidad de vida de los pacientes, máxime frente a enfermedades catastróficas y de alto costo. Empero la magnificencia del alcance y contenido del derecho a la salud y los pronunciamientos de la alta Corte sobre la materia, en Colombia se continúa atendiendo a este derecho con base en las teoría del servicio público, que apuntan a dar prevalencia al componente privado, a la sostenibilidad del Sistema y al lucro, desconociendo el sinnúmero de pronunciamientos sobre las regulaciones restrictivas de dicho Sistema, que dan significado a las anomias contenidas dentro de la ley, reconociéndolo como un derecho fundamental y autónomo en procura de garantizar a cada paciente el máximo posible en materia de salud cuando su condición lo amerita y por encima de las barreras presupuestales.

Dicha noción constitucional resaltada a lo largo del texto es de crucial importancia, ello porque sin duda implementa medidas del todo radicales en procura de lograr la materialización de un derecho susceptible de ser desconocido a partir de la estructura mercantilista a la que la ley ha permitido otorgarle un poder administrativo determinante. Los cambios en la concepción sobre la salud, sin duda, fueron producto de una evolución y apalancados por instrumentos internacionales, cuya incorporación, de ninguna manera, fue inmediata ni universal. Para lograr el entendimiento de la salud como derecho fundamental autónomo, la Corte transitó por las teorías del servicio público esencial y de la conexidad para, posteriormente, a través de un gran número de pronunciamientos, fijar en cada caso en concreto 
qué era y qué no cubierto por esta última noción para así dar significado y trazar lineamientos o reglas objetivas para lograr su materialidad.

De estos lineamientos, se desprende que la salud es un derecho fundamental autónomo, lo cual significa que se trata de un derecho inherente a la naturaleza del ser humano, que es legítimo, que deviene de la consideración exclusiva del hombre como sujeto de derechos y destinatario de la justicia y que es deseable para todos en igualdad de condiciones. A su vez, el término de autonomía lo exonera del condicionamiento otrora existente para su reconocimiento, este era, tener conexidad con otro derecho fundamental a efectos de ser exigible, verbigracia, que la vida del paciente estuviera en peligro para proceder a su protección. Hoy, por el contrario, lejos de requerir la salud conexión grave con otros derechos para ser exhortados, existe y tiene exigibilidad por sí mismo, lejos de otra consideración.

Sin embargo, no por ellos se puede caer en la interpretación equivoca que se arraiga socialmente cuando se esboza que el derecho a la salud es un derecho fundamental autónomo, esto es, la creencia de que dicho termino contiene una protección automática frente a todo requerimiento de manera universal. Dar tal significancia a dicho contenido sería sin duda un error, pues aunque efectivamente la salud es un derecho fundamental y goza de autonomía, se hace exigible solo frente a unos mínimos de prestaciones ínsitamente relacionados con condiciones de vulnerabilidad, necesidad, incapacidad de pago, etc., mínimos que a pesar de que no se restringen al Plan de beneficios, sí imponen límites a la universalidad y cobertura total del derecho, que desde la noción Constitucional también se trata de un ideal.

Corolario, considero que la fundamentalidad del derecho a la salud se muestra esencial y se cataloga como tal en la teoría, pero su materialiazacion es independiente a la posibilidad de su realización en la práctica. Sin duda, bajo esta nueva teoría de la Corte, en todos los casos la salud representa un derecho fundamental, pero su exigibilidad está condicionada a reglas claramente establecidas y restringida por el principio de progresividad, que limita el inmediato cumplimiento de todas las obligaciones que se derivarían del ámbito de protección de un derecho constitucional. Tales límites, no deben ser entendidos como barreras, puesto que son necesarios lineamientos para el uso racional de los recursos, con miras a dar garantía a los derechos de los pacientes más necesitados o en mayor situación de vulnerabilidad. No obstante, la concepción de la salud en este último entendido significa un avance absolutamente significativo en la materia, en tanto en ningún caso desampara a quienes están en condición de vulnerabilidad a su suerte, sino que por el contrario lo adopta como un sujeto de prestaciones sin límite, siempre que sea incapaz de sufragarlas por sí mismo. 
Como se ve, son fijas las normas para, por un lado, dar garantía del derecho a la salud y, por otro, mantener la sostenibilidad del Sistema en el tránsito hacia la universalidad, la Corte Constitucional en variadas oportunidades a desconocido o modificado la estructura del último señalado y su regulación encaminada a poner barreras a dicho derecho o a dar una interpretación restrictiva frente a las anomias. Todo ese camino en busca del reconocimiento de unos mínimos qu e se compadezcan con el principio pro homine. Compilar y conocer a partir de tal trayectoria, cuál es finalmente el resultado del trabajo de la Corte, en punto de cómo se debe entender hoy el derecho a la salud, su contenido, su alcance, sus límites, sus barreras, sus características y sus presupuestos, sin duda redunda en una conveniente retroalimentación académica, ello frente a la falta de una descripción concreta y unificada de dichos contenidos.

La Corte en el emanar de sus decisiones ha intentado acompasar la naturaleza de la salud como derecho fundamental, con la estructura legal que sirve de fundamento a la prestación de dicho servicio que se debe prestar en su garantía, empero, el referido trabajo es arduo frente a la incompetencia de la Corporación en materia legislativa, por más intensiones activistas de la misma, máxime frente a la presencia de actores que a toda costa intentan desnaturalizar los fines del Sistema, y los principios en que se funda. Lo anterior, se hace claro de cara a la diaria peregrinación de los pacientes frente a las Empresas Promotoras de Salud, encaminadas a ofrecer a priori negativas a sus pacientes respecto a cualquier tipo de prestaciones, en aras de proteger sus intereses económicos. Los fines mercantiles de las EPS en Colombia sin duda son el problema del Sistema, tal y como se evidencia, verbigracia, en el hecho de que el $70 \%$ de los pacientes deba acudir al mecanismo de la tutela $p$ ara exigir los medicamentos y servicios incluidos dentro del POS ${ }^{874}$, cuyo financiamiento está asegurado por el Estado y dirigido de manera previa a dichas empresas.

Las situaciones en comento carentes de justificación son posibles gracias al enorme poder político y económico que han adquirido estas empresas en nuestro país, que las exime de controles gubernamentales y que las apoya desde el ámbito legislativo. La narrada situación impensada dentro del Estado Social de Derecho en el cual el componente social exige el esfuerzo de todo el aparato orgánico de la Constitución en garantía de los derechos fundamentales, lastimosamente es el origen de la inclemente situación que viven los pacientes en el devenir de su atención médica. Frente a dicho supuesto, la crítica orientada desde el ámbito académico resulta una herramienta de gran utilidad para el conocimiento y empoderamiento social, pero más allá de ello es exigible y es pretendido desde este ámbito enfatizar en propuestas con miras a plantear soluciones de fondo.

874 AGUDEL CALDERÓN, Carlos Alberto y otros. Sistema de salud en Colombia: 20 años de logros y problemas. Op. Cit. p. 2818. 
De allí, que resulte imperativo, en primera medida, señalar la necesidad de replanteamiento del Sistema de salud de una manera compasiva con los fines requeridos, en el cual se elimine dentro de sus actores a las Empresas Promotoras de Salud o de no ser posible se limite su monopolio a través de la incorporación en el mercado de competencias fijas, verbigracia, Empresas Promotoras de Salud sin ánimo de lucro, frente a lo cual necesariamente las EPS se vean abocadas a reducir sus costos de operación. Seguramente, la incorporación de medidas de tal naturaleza haría transparente el accionar de tales instituciones.

Los visos claves del nuevo diseño de la estructura encaminada a prestar tal servicio público esencial, debe abarcar los elementos esenciales para dar garantía al derecho materia de esbozo, estos son según el Comité de Derechos Económicos, Sociales y Culturales:

\begin{abstract}
[...] disponibilidad, accesibilidad, aceptabilidad y calidad. (I) Cada estado debe tener disponibles un número suficiente de establecimientos, bienes y servicios públicos de salud y centros de atención de la salud, así como de programas. (ii) Los establecimientos, bienes y servicios de salud deben ser accesibles a todos, sin discriminación alguna. (iii) Los establecimientos, bienes y servicios de salud deberán ser (aceptables) respetuosos de la ética médica y culturalmente apropiados, es decir respetuosos de la cultura de las personas, las minorías, los pueblos y las comunidades, a la par que sensibles a los requisitos del género y el ciclo de vida, y deberán estar concebidos para respetar la confidencialidad y mejorar el estado de salud de las personas de que se trate. (iv) Además de aceptables desde el punto de vista cultural, los establecimientos, bienes y servicios de salud deberán ser también de buena calidad, apropiados desde el punto de vista científico y médico ${ }^{875}$.
\end{abstract}

Con miras a que tal contenido no sea solo un catálogo retorico, se hace necesaria la incorporación de acciones y procedimientos que deben variar según si se trata de un bienes y servicios incluidos en el plan o, por el contrario, no contemplados 0 excluidos de este, entendiendo que el primero es un derecho fundamental exigible consecuencialmente en todos los casos y, por el contrario, los segundos lo son solo dependiendo de las características del caso en concreto. Los diferentes mecanismos deben garantizar, en cualquiera de los dos eventos, que la tutela sea el último mecanismo o última ratio para dar protección a dicho derecho, ante la eficacia de los trámites administrativos sumarios; así mismo, debe garantizar el

875 Aplicación del Pacto Internacional de los Derechos Económicos, Sociales y Culturales. Observación general 14. Op. Cit. p. 4. 
estudio de las contingencias de los pacientes ante la no inclusión expresa dentro del POS de lo requerido, estudio frente al cual se debe determinar de manera motivada de cara a los supuestos si procede o no brindar a la prestación. Para colaborar con este último fin, deben compilarse a efecto de su uso las diferentes reglas jurisprudenciales establecidas por la Corte Constitucional, con el objeto de concretizarlas de manera analógica en cada caso en concreto.

Con dicho propósito, también ha de promoverse el apoderamiento social, la creación de asociaciones de pacientes, de fundaciones según el tratamiento de patologías, entre otras, y su participación activa y representatividad en cada uno de las Empresas e Instituciones que prestan los servicios con miras a aguardar la vocería de quienes directamente se ven afectados o beneficiados por el contenido del Sistema. En la misma carrera, debe fortalecerse la función de regulación que se compadezca con las particularidades de cada paciente. La Comisión reguladora del Salud, CRES, creada mediante la Ley 1122 de 2007, ahora funciones asumidas por el Ministerio de Salud y Proteccion Social, debe desplegar las facultades otorgadas por la norma, sobre todo, las enfocadas a crear un Plan de beneficios traducido en un Plan Obligatorio de Salud que sea legítimo y producido por los pacientes en consideración a sus necesidades. No se pretende pues, que manifiestamente sería un exabrupto, exigir que todos los medicamentos y servicios en salud posibles estén incluidos dentro del Plan, sin embargo, este debe ser fruto de una concertación, en la cual el criterio de limitación frente al conjunto bienes y servicios sea el criterio necesidad, y no el presupuestal.

A efectos del logro del buen funcionamiento del Sistema, a su vez, deben crearse y fortalecerse los controles a todos los actores del mismo, tanto EPS, IPS, ESE, etc.; dichos controles deben ser permanentes y desenvolver el conjunto de medios coercitivos como multas y otras sanciones, a efectos de impeler a una buena prestación de los servicios. No obstante, para el logro de este particular ha de entenderse que no solo son la Superintendencia de Salud y el Ministerio de Salud son los encargados de direccionar, controlar y vigilar los servicios ofrecidos, sino que, por el contrario, debe incluirse la participación activa de instituciones como la Procuraduría, la Defensoría del Pueblo y las Personerías, entes que dentro de su catálogo funcional contiene asegurar el respeto por los derechos fundamentales. Dichos controles deben ser periódicos y serios, y deben partir mínimamente de un plan concatenado en materia programática y de recursos, en el cuales se establezcan metas e indicadores de gestión. "No poder garantizar de manera instantánea el contenido prestacional del derecho es entendible por las razones expuestas; pero carecer de un programa que de forma razonable y adecuada conduzca a garantizar los derechos en cuestión es inadmisible 
constitucionalmente"876. Los administradores del Sistema no pueden justificar de manera eterna su inacción continuada en la falta de recursos ni en la progresividad para restringir su actividad, ello porque la protección del mismo se cobija en el progresivo aumento de las garantías y prestaciones que de él se derivan, que suponen el diseño e implementación de políticas públicas y planes de acción con dichos fines.

Los referidos mecanismos de control necesariamente deben basarse en un sistema, como se dijo, en estadísticas, en trabajos de campo, en el contacto directo con los pacientes, a efectos de medir la gestión y evaluar si la estructura, organización y gestión del Sistema, evoluciona hacia el reconocimiento y efectividad del derecho a la salud, o continua de suyo significando una barrera para su goce.

De todo lo resaltado, es dable concluir de manera ostensible que empero estamos frente a un camino abonado hacia el reconocimiento, exigibilidad y efectividad del derecho a la salud en las condiciones tan garantistas, pero no absolutas fijadas por la Corte Constitucional y por la Ley, se mantiene la necesidad de adecuar la estructura del sistema de salud y de imponer medidas de control, regulación, vigilancia y empoderamiento social, en aras de avanzar en una misma línea hacia la universalidad, accesibilidad, integralidad y fundamentalmente la corresponsabilidad del mismo.

A partir de este somero análisis, se pretendió abordar, por primera vez, un tema amplio pero soslayado y, de tal forma, abrir una línea de investigación dentro de la cual se circunscriban propuestas que inmiscuyan herramientas útiles para el logro del fin propuesto: la garantía del derecho a la salud, que como se vio no es lograble a la luz de la organización del actual Sistema. Se espera que para tal fin la descripción del derecho en particular, la fijación de su evolución jurisprudencial, su noción y su alcance en el marco de las garantías del Estado Social de Derecho y la filosofía de los derechos sociales y prestacionales haya sido de utilidad.

Resulta entonces importante señalar, que si la ineficacia del sistema de salud, no resuelve el problema al interior del mismo, el aporte que este trabajo entrega a la solución del problema planteado que corresponde a la propuesta, según la cual, el Estado Social de Derecho, fundamento del marco constitucional colombiano, puede asumir el derecho fundamental a la salud desde la corresponsabilidad

${ }^{876}$ COLOMBIA. CORTE CONSTITUCIONAL DE COLOMBIA. Sentencia T- 760 de 2008. Op. Cit. p. 42. 
Estado - Sociedad, en donde el afiliado correlativamente hace un uso racional del sistema desde la percepción de la prevención y el autocuidado.

Es evidente que la propuesta varía el paradigma social de los derechos como una concepción unidireccional de exigencia y cargo del Estado o del sistema de seguridad social en salud, y construye una bidireccionalidad de correspondencia que mantiene el equilibrio en el sistema, toda vez que la persona entiende la salud como una obligación propia exigible de manera individual. Asumimos entonces, por vía de ejemplo, que la atención preventiva en la primera infancia conserva un marco normativo, que vincula la obligación del Estado, pero igualmente vincula deberes del coasociado.

Si los padres de un niño o niña cumplen cabal y oportunamente con el esquema de vacunación básico y suplementario, pero además acuden al sistema de prevención temprana de la nutrición infantil y el control pediátrico preventivo, necesariamente el sistema debe premiar ese compromiso en el cumplimiento de los deberes con beneficios en el orden educativo de esos mismos infantes con la entrega de becas o subsidios para esos fines o similares.

Cuando la persona no cumple sus deberes de control, prevención y cuidado preventivo temprano tendrá como consecuencias el deber de generar aportes en copagos al sistema, mayor número de semanas de cotización para obtener la pensión o consecuencias similares.

Inicialmente la propuesta de la corresponsabilidad debe propender por la educación social a la cultura de la prevención y no de la curación, con lo cual, se racionaliza el sistema en cuanto al uso del mismo, ya que entre mayor prevención en salud menor tratamiento en curación, y esta correspondencia, como su nombre lo indica, en la corresponsabilidad estructura las bases del equilibrio financiero y la sostenibilidad del sistema en los términos de la integralidad y cobertura total en salud.

Ahora esta propuesta surge del análisis de la problemática en el sistema de salud que ha avanzado en su reconocimiento desde la consideración de ser un servicio hasta el reconocimiento actual como derecho fundamental, y la permanencia de la imposibilidad de cubrimiento integral y pleno a las necesidades de la población colombiana, e igualmente se soporta en los resultados obtenidos en el estudio de la Evaluación Integral del Equilibrio Financiero del Sistema General de Seguridad 
Social en Salud, elaborado dentro del marco de cooperación solicitada por el Ministerio de Salud a la OPS/OMS. ${ }^{877}$

Las variables que afectan el equilibrio financiero de manera significativa están relacionadas a los costos de medicamentos, procedimientos y atención en salud, pero igualmente a los costos que se producen, y se habían podido advertir bajo un sistema de acción preventiva temprana ejercida por el Estado, pero asumida como un deber social por el ciudadano.

Los estímulos que se entregan por el Estado al ciudadano que asume un deber de prevención temprana a nivel individual y de su núcleo familiar, generan a mediano plazo la variación del comportamiento asistencialista por una cultura de la prevención en salud.

La propuesta se encamina a que el Estado asuma como una política publica el sistema de corresponsabilidad social en el reconocimiento de la fundamentalidad del derecho a la salud en Colombia.

Se puede inferir de esta manera y atendiendo la recomendación dada, y en donde se varió de la condición negativa, inicialmente argumentada, de la ineficacia del sistema de salud en Colombia a la construcción del trabajo bajo un marco referencial que asume el desarrollo histórico de la evolución del derecho a la salud, incorporando al análisis el concepto y alcance del Estado social de derecho, del concepto de derechos sociales, la evolución hacia el concepto de uis fundamentalidad de la salud, desde el constructo doctrinal y jurisprudencial.

La variación en el análisis permite ahora determinar el alcance, las obligaciones, limites, cobertura y caracterización del sistema de salud y su posibilidad real de materialización a la población.

Esta proyección temática, ubica el desarrollo del trabajo en el contexto colombiano, para lo cual se realiza un recorrido histórico, teórico y jurisprudencial, desde el análisis crítico de la Ley 1751 de 2015, que reconoció el derecho a la salud como fundamental, siguiendo la interpretación realizada por la Sentencia C-313 de 2014, la cual, en análisis previo a la norma estatutaria, que estableció la prohibición de regresividad frente a las reglas jurisprudenciales sentadas, igualmente se estudió

877 MINISTERIO DE SALUD. Dirección General de Aseguramiento. Evaluación integral del equilibrio financiero del sistema general de seguridad social en salud. Bogotá - Colombia. 
la ley 1438 de 2011, en donde se incorpora la corresponsabilidad como regla rectora del Sistema de Salud.

En este punto, el trabajo establece el principal aporte a la teoría jurídica para la solución del problema propuesto, como es el desarrollo temático del principio de corresponsabilidad como elemento esencial a la fundamentalidad del derecho a la salud en Colombia.

De lo estructurado en el marco del Estado Social de Derecho, sobre el que soporta la Carta Política de 1991, el trabajo devela una condición esencial en la fundamentalidad del derecho a la salud como es, que si bien existe una consagración de la salud como derecho y que el mismo se planeta a cargo del Estado de manera universal e impersonal, esta condición de derecho fundamental solo es posible, si es correlativa a la obligación del Estado en cuanto a garantizarlo a todas las personas en el territorio nacional se establece la obligación o el deber constitucional social, bajo el principio de solidaridad previsto en la misma Constitución, que cada persona asuma la responsabilidad del derecho como parte integral y esencial de su propia vida.

En la corresponsabilidad la fundamentalidad del derecho a la salud surge como un deber del Estado desde el mismo momento en que el ser existe en el ámbito social, con lo cual se debe garantizar desde lo presupuestal y las políticas públicas su implementación y funcionalidad, pero además aparece un elemento bidireccional, igualmente superior, que encarna el deber constitucional de la persona a asumir una actitud activa frente al derecho, bajo el entendido que el derecho hace parte de su propia existencia, con lo cual debe establecer y acatar las policías y acciones de prevención, educación y mejoramiento social en cuanto a salud, y no solamente esperar a convertirse en usuario pasivo del Sistema de Salud.

Evidentemente la investigación transforma el patron social de los derechos fundamentales, donde la sociedad solo percibe la obligación del Estado en cuanto a su garantía y cumplimiento, para incorporar igualmente un elemento de deber social correspondiente que obliga a la persona a asumir una carga activa sobre su propio derecho.

La propuesta implica la corresponsabilidad Estado - Persona en el derecho a la salud, lo cual envuelve una composición bipartita en el equilibrio del sistema y un derecho- deber para toda persona. 
Tenemos entonces, a manera de ejemplo, que la atención preventiva en la primera infancia, que ya posee un marco normativo, corresponde a una obligación del Estado, vinculando igualmente deberes del aficilado, inicialmente en un régimen premial que otorga beneficios a la persona que cumple con los planes y políticas de prevención y atención primaria, a partir de ahí se propone la construcción de una política pública, que reduzca la problemática del sistema de salud en Colombia.

El trabajo establece este elemento como una condición jurídica que pondera la obligación del Estado Social de Derecho frente a la obligación de toda persona de asumir un deber social de responsabilidad frente a su propio derecho a la salud, el derecho a la salud de su familia y el derecho a la salud de los demás coasociados.

La conclusión en el aporte establece que, el derecho a la salud del colombiano, como derecho fundamental constitucional, se corresponde correlativamente, y en el mismo rango constitucional el deber social de cada persona y su núcleo familiar, de procurar su autocuidado, como actores significativos del Sistema de Salud. El Estado tiene la carga de garantizar de forma plena mi derecho a la salud, si como ciudadano he asumido un comportamiento responsable en cuento al mismo derecho. Un ejemplo que nos permite visualizar esta condición es que no resultaría bajo el mismo rango de análisis quien ha afectado voluntariamente $y$ conscientemente su derecho, como el caso del fumador, frente a la persona que responsablemente ha asumido el deber social de prevención y educación en cuanto a este mismo derecho a la salud.

Se trata de una desigualdad positiva de orden constitucional que refuerza la protección en la corresponsabilidad y que garantiza el derecho cuando no se cumple con el deber social. En ningún caso cesa la carga del Estado frente a la garantía del derecho, pero se crea un ámbito privilegiado para quien asume el deber social de corresponsabilidad, lo que debe evolucionar, al sistema social corresponsable, estos lineamientos permitirán la construcción de una política pública, que mitigue la problemática la interior del Sistema de Salud Colombiano. 


\section{BIBLIOGRAFÍA}

AGUDELO CALDERÓN, Carlos Alberto y et al. Sistema de salud en Colombia: 20 años de logros y problemas. En: Ciencia y Salud colectiva, Instituto de Salud Pública. Universidad Nacional de Colombia. 16(6) 2011. p. 2817-2828.

AGUILERA PORTALES, Rafael y ESPINO TAPIA, Diana. Fundamento, garantías y naturaleza jurídica de los derechos sociales ante la crisis del Estado Social de Derecho. En: Revista Telemática de Filosofía del Derecho. № 10 (2006/2007). p. 111-139.

AGUILÓ BONET, Antoni Jesús. Los Derechos Humanos como campo de luchas por la diversidad humana: Un análisis desde la sociología crítica de Boaventura de Sousa Santos. En: Universitas Humanística. N 68 (jul-dic, 2009). p. 180-205.

AGUIRRE HUACAJA, Enrique. La corresponsabilidad operativa en la atención primaria a la salud. En: Salud Pública de México. Vol. 36 № 32 (marzo-abril, 1994). p. 210-213.

ALCALDE RABANAL, Jacqueline; LAZO GONZÁLEZ, Oswaldo \& NIGENDA, Gustavo. Sistema de salud en Perú. En: Salud pública México. vol.53. supl.2 (ene. 2011). p. 243-254.

ALEXEI ESTRADA, Julio. Economía y Ordenamiento Constitucional. En: Homero Cuevas et al. Teorías Jurídicas y Económicas del Estado. 1a ed. Bogotá.: Universidad Externado de Colombia, 2002. p. 171-198.

ALEXY, Robert. Teoría de los derechos fundamentales. Madrid.: Centro de Estudios Políticos y Constitucionales, 2003.

ÁLVAREZ CASTAÑO, Luz Stella. El derecho a la salud en Colombia: una propuesta para su fundamentación moral. En: Revista Panamericana de Salud Pública.18 (2) (2005). p. 129-135. 
ÁLVAREZ DÍAZ, Oscar Luis. Estado Social de Derecho, Corte Constitucional y desplazamiento forzado en Colombia. Bogotá.: Siglo del Hombre Editores, 2008. p. 26.

ANZOLA NIEVES, Aurora. La corresponsabilidad como principio constitucional en Venezuela. En: Compendium. Vol. 14, núm. 27. (Julio-diciembre, 2011). p. 61-80.

ARAGÓN REYES, Manuel. Los problemas del Estado social. En: Sistema. N $118-$ 119. (1994). p. 23 y ss.

ARANGO, Rodolfo. El Concepto de los derechos sociales fundamentales. Bogotá.: Legis, 2005.

ARTIGRAS, Carmen; FRANCO, Rolando y FRANCO GUZMAN, Carmen. Derechos económicos, sociales y culturales en América Latina: su situación actual. En: Anales de la Cátedra Francisco Suárez. 35 (2001) p. 24-49.

BALLEN, Rafael. El negocio de la Salud. En: Revista Semana. Edición 20 de febrero de 2012. Sección de Opinión.

BASTIDA FREIJEDO, Francisco José. El fundamento de los derechos fundamentales. En: Revista electrónica del Departamento de Derecho de la Universidad de La Rioja. № 3 (2005). p. 41-56.

Teoría General de los Derechos Fundamentales en la Constitución Española de 1978: Los Sujetos de los Derechos Fundamentales. Madrid: Tecnos, 2004.

BASTIDAS MORA, Patricia. El modelo constitucional del Estado Social y democrático de derecho, sus desafíos y la constitucionalizarían del proceso. En: Revista Via luris. $N^{\circ} 7,2009$. p. 45-59.

BECERRIL MONTEIKO, Victor; Medina, Guadalupe \& Aquino Rosana. Sistema de salud en Brasil. En: Salud pública de México. Vol.53. supl. 2 (ene. 2011). (citado el 19 de marzo de 2017). p. 120-131. 
BENDA, Ernesto. El Estado Social de Derecho: Manual de Derecho Constitucional. 2a ed. Madrid.: Marcial Pons, 2001.

BOBBIO, Norberto. Presente y porvenir de los derechos humanos: El tiempo de los derechos. Madrid.: Ed. Sistema, 1991.

CAMACHO LARAÑA, Ildefonso. Doctrina social de la Iglesia: quince claves para su comprensión. Bilbao.: Editorial Desclée de Brouwer, 2009.

CASCAJO CASTRO, Jose Luis. DirittiSociali. Enciclopedia del Diritto, Vol. XII. Milán.: Giuffré.

CASTRO BUITRAGO, Erika; RESTREPO YEPES, Olga y GARCÍA MATAMOROS, Laura. Historia, concepto y estructura de los derechos económicos, sociales y culturales. En: Revista Estudios Socio-Jurídicos. Vol. 9, núm. (Abril, 2007). p. 77108.

COLOMBIA. MINISTERIO DE SALUD Y PROTECCIÓN SOCIAL. Objetivos y Funciones. [Sitio Web]. [Consulta: 30 de diciembre de 2016]. Disponible en: https://www.minsalud.gov.co/Ministerio/Institucional/Paginas/institucionalobjetivos-funciones.aspx.

COLOMBIA. MINISTERIO DE SALUD Y PROTECCIÓN SOCIAL. Plan Decenal de Salud Pública 2012-2021: La salud en Colombia la construyes tú. Bogotá, D.C.: Imprenta Nacional de Colombia, 2013.

COLOMBIA. SUPERINTENDENCIA NACIONAL DE SALUD. Objetivos y Funciones. [Sitio Web]. [Consulta: 30 de diciembre de 2016]. Disponible en: https://www.supersalud.gov.co/es-co/superintendencia/nuestra-entidad/objetivos$y$-funciones.

COLOMBIA. SISBÉN. ¿Qué es el SISBÉN? [Sitio Web]. [Consulta: 30 de diciembre de 2016]. Disponible en: https://www.sisben.gov.co/Informaci\%C3\%B3n/EISisb\%C3\%A9n.aspx\#.WGYUjPI 97IU. 
COMBELLAS, Ricardo. Una Constitución para el Futuro: El debate Constitucional en Venezuela. Caracas.: Fundación Konrad Adenauer, 1982.

CONTRERAS BAUTISTA, Juan Darío. Derecho y Economía de la Salud en Colombia. Bogotá.: Librería Ediciones del Profesional, 2009.

DE ROUX, Carlos Vicente y RAMíREZ, Juan Carlos. Derechos económicos, sociales y culturales, economía y democracia. Bogotá.: Serie estudios y perspectiva, 2004.

DE SOUSA SANTOS, Boaventura y LEITAO MARQUES, Manuel. Los Tribunales en las Sociedades Contemporáneas. En: Revista Pensamiento jurídico. No.4. Universidad Nacional de Colombia (2007: Bogotá).

DEFENSORIA DEL PUEBLO COLOMBIA. Informe: La tutela y el derecho a la Salud. 2012.

DÍAZ, Elías. Estado de Derecho y sociedad democrática. 9a ed. Madrid.: Taurus, 1998.

DUQUE QUINTERO, Sandra; GÓMEZ RÚA, Natalia \& RIVERA AGUIRRE, Christian. Sobre la materialización del principio de solidaridad en el sistema general de salud colombiano. En: Revista CES DERECHO. Vol. 4, No.2 (Julio-diciembre, 2013). p. 57-70.

DURÁN, Víctor Manuel. Estado Social de Derecho y Participación: Ponencia VII. En: Conferencia latinoamericana de trabajadores de los servicios públicos. México, 2001. p. $18-19$.

DUVERGER, Maurice, Institutions politiques et droit constitutionnel. Paris.: Presses Universitaires de France, 1963.

ESTILO DE VIDA. Bajo lupa, 16 EPS del régimen subsidiado que les deben a hospitales. En: El Tiempo. (24 de junio de 2014). (En línea). http://www.eltiempo.com/estilo-de-vida/salud/supersalud-investiga-a-16-eps-delregimen subsidiado-por-deudas-/14162615. (Citado el 07 de junio de 2015). 
ESTRADA, Alexei Julio. La eficacia de los derechos fundamentales entre particulares. Bogotá, Universidad Externado de Colombia, 2000.

FARIÑAS DULCE, María José. Los derechos humanos: desde la perspectiva sociológico-jurídica a la actitud posmoderna. 2a. ed. Madrid.: Dykinson, 2006.

FARRERA BRAVO, Gonzalo. Socialdemocracia (del Marxismo a la Tercera vía) En: Revista Matices. N6 (2008). p. 66-83.

FORTSTHOF, Ernst. Citado por PÉREZ LUÑO, Antonio Enrique. Derechos Humanos, Estado de Derecho y Constitución. 10ª Edición.: TECNOS, 2010.

FUNDACIÓN MENONITA COLOMBIANA PARA EL DESARROLLO MENCOLDES. Mesa de trabajo de Bogotá sobre desplazamiento interno. En: Boletín No. 13. (Sept, 2005).

GARCÍA HERRERA. Miguel Ángel. Poder Judicial y Estado social: Corrupción y Estado de derecho. Madrid.: Trotta, 1996.

GARCIA PELAYO, Manuel. Las transformaciones del Estado contemporáneo. $2^{\underline{a}}$ edición. Madrid.: Alianza Universidad, 1995.

Manual de Derecho Constitucional Comparado. Madrid.: Alianza Editorial, 1984.

GIL RENDÓN, Raymundo. Los Derechos Fundamentales y la Impartición de Justicia (en línea). http://www.tfjfa.gob.mx/investigaciones/pdf/losderechosfundamentalesylaimpartici ondejusticia.pdf.

GOMEZ IZASA, Maria Cristina. La historia del Estado Social de Derecho. Universidad de Antioquia, 2006. (En línea) http://bibliotecadigital.udea.edu.co/bitstream/10495/2272/1/La\%20historia\%20del \%20estado\%20social\%20de\%20derecho.pdf. 
GRANDA MARÍN, Alberto. Asamblea Nacional Constituyente y Constitución Política de 1991 En: Revista Pensamiento Humanista. No. 2. (1994).

HELLER, Herman. ¿Estado de derecho o dictadura? En: Escritos Políticos. Trad. GÓMEZ, S. Madrid.: Alianza, 1985.Socialismo y Nación. En: Escritos Políticos. Trad. GÓMEZ, S. Madrid.: Alianza, 1985. p. 135-234.

HIGUERA JIMÉNEZ, Diego Mauricio; Alonso Niño, Edwin Hernando Derechos Sociales Fundamentales, problemática hermenéutica en el derecho a la salud en Colombia Revista VIA IURIS, núm. 12, enero-junio, 2012, pp. Fundación Universitaria Los Libertadores Bogotá, Colombia

JARAMILLO PÉREZ, Iván. El futuro de la salud en Colombia: la puesta en marcha de la ley 100. Bogotá, D.C.: Fescol, 1999.

JIMÉNEZ, Natalia Cecilia. Análisis del Sistema de Salud colombiano desde la perspectiva de la nueva gerencia pública. Monografía de Grado Politóloga. Bogotá. Universidad Colegio Mayor Nuestra Señora del Rosario. Facultad de Ciencia Política y Gobierno. 2013.

JUAN PABLO II. Encíclica Centesimus Annus (1 de mayo de 1991).

JUAN XXII. Encíclica Mater et Magistra (15 de mayo de 1961).

LASPRILLA VILLALOBO, Carlos José y SANCLEMENTE MACHADO, Daniela. El Juez de Tutela como arquitecto del estado social de derecho. En: Tesis y Trabajos de Grado Ciencias Jurídicas. Pontificia Universidad Javeriana, Bogotá D.C., 2013. p. 18-19.

LEMA AÑÓN, Carlos. Apogeo y crisis de la salud: Historia del derecho a la salud en el siglo XX. Madrid.: Dykinson, Instituto de Derechos Humanos Bartolomé de las Casas, 2010.

LEÓN XIII. Encíclica Rerum Novarum (05 de mayo de 1891). 
LEÓN XIII. Encíclica Rerum Novarum (05 de mayo de 1891).

LÓPEZ OLIVA, José. La Constitución de Weimar y los Derechos Sociales. La influencia en el contexto constitucional y legal colombiano a la luz de los derechos sociales asistenciales a la seguridad social en salud. En: Prolegómenos - Derechos y Valores. Volumen XIII, No. 26 (Jul - Dic, 2010). p. 233-243.

LUCAS VERDU, Pablo. La Lucha por el Estado de Derecho. Bolonia.: Publicaciones del Real Colegio de España, 1975.

La Lucha por el Estado de Derecho. Bolonia.: Publicaciones del Real Colegio de España, 1975.

MANRIQUE REYES, Alfredo. La Constitución de la Nueva Colombia. Bogotá.: Editorial Presencia, 1991.

MARTíNEZ CABALLERO, Alejandro. Apuntes sobre el concepto de Estado Social en la Constitución Colombiana. En: Revista del Colegio Mayor de Nuestra Señora del Rosario. No. 557. (Jun-Jul, 1992).

MATIAS CAMARGO, Sergio Roberto. La Asamblea Nacional Constituyente de 1991 y el Nuevo Constitucionalismo Latinoamericana. En: Diálogos de Saberes. No. 44 (Ene - Jun, 2016). p. 29-44.

MEIL LANDWERLIN, G. El Estado Social de Derecho: Forsthoff y Abendroth, dos interpretaciones teóricas para dos posiciones políticas. En: Revista de Estudios Políticos. № 42 (Nov-Dic, 1984). p. 211-225.

MESA DE TRABAJO DE BOGOTÁ SOBRE DESPLAZAMIENTO INTERNO. Boletín No. 13. Septiembre de 2005.

MIJANGOS GONZÁLEZ, Javier. Los derechos fundamentales en las relaciones entre particulares. 1를 Edición. México.: Porrúa, 2004. 
ORTIZ GUTIERREZ, Julio. Los derechos fundamentales en el ordenamiento constitucional de Colombia: Una aproximación a la jurisprudencia de la Corte Constitucional. Citado por: TEROL BECERRA, Javier. Derecho Constitucional para el siglo XX. Madrid.: Aranzadi, 2006.

Los derechos fundamentales en el ordenamiento constitucional de Colombia: Una aproximación a la jurisprudencia de la Corte Constitucional. En: Derecho Constitucional para el siglo XXI: actas VIII Congreso Iberoamericano de Derecho Constitucional. Vol. 1, 2006. p. 985-1030.

PECES-BARBA, Gregorio. Reflexiones sobre los derechos sociales. En: coord. GARCIA MANRIQUE Ricardo. Derechos sociales y ponderación. 6 Ed. Madrid.: Fundación Coloquio Jurídico Europeo, 2009. pp. 85-102.

PERDOMO CASTAÑO, Carlos Alberto. Derechos fundamentales a medias e integralidad de derechos. Bogotá.: Defensoría del Pueblo, 2011.

PICARD DE ORSINI, Marie y USECHE, Judith. Una Nueva Dimensión del Estado de Derecho: El Estado Social de Derecho. Caracas.: Provincia, 2006.

PINILLA CAMPOS, Ernesto. ¿Es viable el Estado Social de Derecho en la sociedad colombiana? En: Revista Pensamiento Jurídico. No. 15. Universidad Nacional de Colombia. 1992. p. 237-260.

PIO XI. Encíclica Quadragesimo Anno (15 de mayo de 1931).

PISARELLO, Gerardo. Los derechos sociales en el constitucionalismo democrático. En: Boletín Mexicano de Derecho Comparado. № 92 (2006, México).

PRADO HERRERA, Gerardo Gianni. Los derechos fundamentales y la aplicación en la justicia constitucional. Buenos Aires.: El Cid Editor, 2009.

PRIETO SANCHÍS, Luis. Estudios sobre derechos fundamentales. Madrid.: Editorial Debate, 1990. 
REDACCIÓN SALUD. Cada cinco minutos hay una nueva tutela en el País. (4 de septiembre de 2013). (En línea). http://www.eltiempo.com/archivo/documento/CMS-13045163. (Citado el 04 de septiembre de 2013).

REDACCIÓN VIVIR. El caso Saludcoop según la Contraloría (en línea) En: EL ESPECTADOR. Sección salud. (7 Nov 2013). (En línea). http://www.elespectador.com/noticias/salud/el-caso-saludcoop-segun-contraloriaarticulo-457191 (citado 05 de julio de 2015).

RIVEROS PARDO, Daniel Felipe. Los derechos económicos, sociales y culturales como derechos subjetivos: una visión estructural. En: Revista Derecho del Estado. $\mathrm{N}^{\circ} 24$ (Jul, 2010) p. 29-43.

RODRÍGUEZ GARAVITO, Cesar. El derecho en América Latina. Un mapa para el pensamiento jurídico del siglo XXI. Bueno Aires.: Siglo Veintiuno Editores, 2011.

RODRÍGUEZ MUÑOZ, Iveth e IBARRA LOZANO, Jairo. Del Estado de Derecho al Estado Social de Derecho. En: Revista Justicia Juris. Vol. 10. (Oct., 2008). p. 9-13.

ROJO PÉREZ, Nereida, GARCÍA GONZÁLEZ, Rosario. Sociología y salud. Reflexiones para la acción. En: Red Revista Cubana de Salud Pública. vol.26, n.2. (2006). p. 91-100.

SÁNCHEZ CANO, Hernán; QUINTERO GARCÍA, Harvey y ARDILA QUIRÓS, Juan. Modelo Económico para un Estado Social de Derecho: Caso Colombiano. Trabajo de grado Abogado. Medellín: Universidad de Antioquia. Facultad de Derecho. 2007.

SÁNCHEZ VÁSQUEZ, Rafael. La trascendencia del constitucionalismo social en América Latina (Caso México) En: Cuestiones Constitucionales. №.27 (Julio Diciembre, 2012). p. 251-309.

SILVA HENAO, Juan Fernando. Evolución y origen del concepto de "Estado Social" incorporado en la Constitución Política Colombiana de 1991. En: Revista Ratio Juris, Vol. 7, № 14 (Ene.-Jun. 2012). 
SOLS LUCÍA, José. Cinco lecciones de pensamiento social cristiano. Madrid.: Editorial Trotta, S.A., 2013.

TASCÓN, Enrique. Derecho Constitucional Colombiano. Citado por COPETE LIZARRALDE, Álvaro. Lecciones de Derecho Constitucional Colombiano. Bogotá.: Ediciones Lerner, 1960.

TORRES ÁVILA, Jheison. El mandato del Estado Social de Derecho en la Constitución colombiana: los derechos sociales y el mínimo vital. Bogotá.: Ediciones USTA, 2012.

TORRES MOLINA, Ramón. Cátedra II Historia Constitucional. Facultad de Ciencias Jurídicas y Sociales. Universidad Nacional de La Plata (en línea). En: https://historiaconstitucional.wordpress.com/2013/04/19/la-reforma-de-laconstitucion-y-el-constitucionalismo-social/ (Citado 15 de diciembre de 2016).

UNIVERSIDAD DEL VALLE. Tutelas en salud siguen aumentando: Defensoría del Pueblo. En: http://salud.univalle.edu.co/comunicandosalud/wpcontent/uploads/2015/04/08.04.2015-Tutelas-en-salud-siguen-aumentandoDefensor\%C3\%ADa-del-Pueblo.-p\%C3\%A1g-8.pdf

URZOLA GUTIÉRREZ, Daniela. Boaventura de Sousa Santos y la reconstrucción intercultural de los derechos humanos. En: Revista Jurídicas. 9(2). (jul-dic, 2012). p. $175-188-$

VALADÉS Diego. Problemas constitucionales del Estado Social de Derecho. 2a Ed. Buenos Aires.: Astrea, 2004.

VELASCO CRIADO, Demetrio. Derechos humanos y doctrina social de la Iglesia: del anatema al diálogo. Bilbao.: Publicaciones de la Universidad De Deusto, 2000.

VERNENGO, Roberto. Legalidad y legitimidad: fundamentos morales del derecho. En: Revista de Estudios Políticos. Centro de Estudios Constitucionales. No. 77 (1992). p. 259-266. 
VILA CASADO, Iván. El estado. En: Fundamentos del Estado Derecho. $2^{\underline{a}}$ edición. Bogotá.: Editorial Legis, 2007.

VILLAR BORDA, Luis. Estado de Derecho y Estado Social de Derecho. En: Revista Derecho del Estado. № 20 (Feb. 2007). P. 73-96.

\section{Jurisprudencia}

COLOMBIA. CORTE CONSTITUCIONAL DE COLOMBIA, Sentencia T-083 de 2008. M.P.: Mauricio González Cuervo. Bogotá, D.C.

COLOMBIA. CORTE CONSTITUCIONAL DE COLOMBIA, Sentencia T-1041 de 2005. M.P.: Humberto Antonio Sierra Porto. Bogotá, D.C.

COLOMBIA. CORTE CONSTITUCIONAL DE COLOMBIA, Sentencia T-1138 de 2005. M.P.: Rodrigo Escobar Gil. Bogotá, D.C.

COLOMBIA. CORTE CONSTITUCIONAL DE COLOMBIA. Sentencia T-016-07. M.P.: Humberto Sierra Porto.

COLOMBIA. CORTE CONSTITUCIONAL DE COLOMBIA. Sentencia T-229/12. M.P.: Gabriel Eduardo Mendoza Martelo. Bogotá, D.C.

COLOMBIA. CORTE CONSTITUCIONAL DE COLOMBIA. Sentencia T-683 de 2003. M.P.: Eduardo Montealegre Lynett. Bogotá, D.C.

COLOMBIA. CORTE CONSTITUCIONAL DE COLOMBIA. Sentencia C- 126/00. M.P.: Carlos Arturo Martínez Caballero. Bogotá, D.C.

COLOMBIA. CORTE CONSTITUCIONAL DE COLOMBIA. Sentencia C- 408 de 1994. M.P.: EDUARDO CIFUENTES MUÑOZ.

COLOMBIA. CORTE CONSTITUCIONAL DE COLOMBIA. Sentencia C-075-1997. M.P.: Hernando Herrera Vergara. Bogotá. 
COLOMBIA. CORTE CONSTITUCIONAL DE COLOMBIA. Sentencia C-111/06. M.P.: Rodrigo Escobar Gil. Bogotá.

COLOMBIA. CORTE CONSTITUCIONAL DE COLOMBIA. Sentencia C-131 de 1993. M.P. Alejandro Martínez Caballero. Bogotá.

COLOMBIA. CORTE CONSTITUCIONAL DE COLOMBIA. Sentencia C-132 de 2012. M.P.: Humberto Antonio Sierra Porto. Bogotá, D.C.

COLOMBIA. CORTE CONSTITUCIONAL DE COLOMBIA. Sentencia C-197/12. M.P.: Jorge Ignacio Pretelt Chaljub. Bogotá, D.C.

COLOMBIA. CORTE CONSTITUCIONAL DE COLOMBIA. Sentencia C-228/10. M.P.: Luis Ernesto Vargas Silva. Bogotá, D.C.

COLOMBIA. CORTE CONSTITUCIONAL DE COLOMBIA. Sentencia C-252/10. M.P.: Jorge Iván Palacio Palacio. Bogotá, D.C.

COLOMBIA. CORTE CONSTITUCIONAL DE COLOMBIA. Sentencia C-313/14. M. P. Gabriel Eduardo Mendoza Martelo. Bogotá.

COLOMBIA. CORTE CONSTITUCIONAL DE COLOMBIA. Sentencia C-449 de 1992. M.P. Alejandro Martínez Caballero. Bogotá.

COLOMBIA. CORTE CONSTITUCIONAL DE COLOMBIA. Sentencia C-463/08. M.P.: Jaime Araújo Rentería.

COLOMBIA. CORTE CONSTITUCIONAL DE COLOMBIA. Sentencia C-529 de 2010 M.P.: Mauricio González Cuervo. Bogotá.

COLOMBIA. CORTE CONSTITUCIONAL DE COLOMBIA. Sentencia C-566 de 1995. M.P. EDUARDO CIFUENTES MUÑOZ. Bogotá. 
COLOMBIA. CORTE CONSTITUCIONAL DE COLOMBIA. Sentencia C-587/92. M.P. Ciro Angarita Barón. Bogotá.

COLOMBIA. CORTE CONSTITUCIONAL DE COLOMBIA. Sentencia C-603-98 M.P.: Jaime Araújo Rentería. Bogotá.

COLOMBIA. CORTE CONSTITUCIONAL DE COLOMBIA. Sentencia C-615 de 2002. M.P.: Marco Gerardo Monroy Cabra. Bogotá, D.C.

COLOMBIA. CORTE CONSTITUCIONAL DE COLOMBIA. Sentencia C-623-04. M.P.: Rodrigo Escobar Gil. Bogotá.

COLOMBIA. CORTE CONSTITUCIONAL DE COLOMBIA. Sentencia C-760/04. M.P.: Rodrigo Uprimny Yepes. Bogotá, D.C.

COLOMBIA. CORTE CONSTITUCIONAL DE COLOMBIA. Sentencia C-974 de 2002. M.P.: Rodrigo Escobar Gil. Bogotá, D.C.

COLOMBIA. CORTE CONSTITUCIONAL DE COLOMBIA. Sentencia No. T-409/95. M.P.: Antonio Barrera Carbonell. Bogotá, D.C.

COLOMBIA. CORTE CONSTITUCIONAL DE COLOMBIA. Sentencia SU-157 de 1999. M.P.: Alejandro Martínez Caballero. Bogotá, D.C.

COLOMBIA. CORTE CONSTITUCIONAL DE COLOMBIA. Sentencia SU-6241999. M.P Alejandro Martínez Caballero. Bogotá.

COLOMBIA. CORTE CONSTITUCIONAL DE COLOMBIA. Sentencia SU-819 de 1999. M.P.: Álvaro Tafur Galvis. Bogotá.

COLOMBIA. CORTE CONSTITUCIONAL DE COLOMBIA. Sentencia T-016/07. M.P.: Humberto Antonio Sierra Porto. Bogotá.

COLOMBIA. CORTE CONSTITUCIONAL DE COLOMBIA. Sentencia T-032-2012. M.P.: Jorge Ignacio Pretelt Chaljub. Bogotá. 
COLOMBIA. CORTE CONSTITUCIONAL DE COLOMBIA. Sentencia T-060-2007. M.P.: Humberto Antonio Sierra Porto. Bogotá.

COLOMBIA. CORTE CONSTITUCIONAL DE COLOMBIA. Sentencia T-073/13. M.P.: Jorge Ignacio Pretelt Chaljub. Bogotá, D.C.

COLOMBIA. CORTE CONSTITUCIONAL DE COLOMBIA. Sentencia T-099/99. M.P.: Alfredo Beltrán Sierra. Bogotá, D.C.

COLOMBIA. CORTE CONSTITUCIONAL DE COLOMBIA. Sentencia T-1024 de 2010. M.P.: Humberto Antonio Sierra Porto. Bogotá, D.C.

COLOMBIA. CORTE CONSTITUCIONAL DE COLOMBIA. Sentencia T-1078/07. M.P.: Humberto Antonio Sierra Porto. Bogotá, D.C.

COLOMBIA. CORTE CONSTITUCIONAL DE COLOMBIA. Sentencia T-1081/01. M.P.: Marco Gerardo Monroy Cabra. Bogotá, D.C.

COLOMBIA. CORTE CONSTITUCIONAL DE COLOMBIA. Sentencia T-111/03. M.P.: Marco Gerardo Monroy Cabra. Bogotá, D.C.

COLOMBIA. CORTE CONSTITUCIONAL DE COLOMBIA. Sentencia T-116 de 1993. M.P.: Hernando herrera Vergara. Bogotá, D.C.

COLOMBIA. CORTE CONSTITUCIONAL DE COLOMBIA. Sentencia T-1214/08. M.P.: Humberto Antonio Sierra Porto. Bogotá, D.C.

COLOMBIA. CORTE CONSTITUCIONAL DE COLOMBIA. Sentencia T-154/14. M.P.: Luis Guillermo Guerrero Pérez. Bogotá, D.C.

COLOMBIA. CORTE CONSTITUCIONAL DE COLOMBIA. Sentencia T-174-2013. M.P.: Jorge Iván Palacio. Bogotá, D.C. 
COLOMBIA. CORTE CONSTITUCIONAL DE COLOMBIA. Sentencia T-180/13. M.P.: Jorge Ignacio Pretelt Chaljub. Bogotá, D.C.

COLOMBIA. CORTE CONSTITUCIONAL DE COLOMBIA. Sentencia T-204 de 2000. M.P.: Fabio Morón Díaz. Bogotá, D.C.

COLOMBIA. CORTE CONSTITUCIONAL DE COLOMBIA. Sentencia T-204-2000. M.P.: Fabio Morón Díaz. Bogotá, D.C.

COLOMBIA. CORTE CONSTITUCIONAL DE COLOMBIA. Sentencia T-207-1995. M.P.: José Gregório Hernández Galindo. Bogotá, D.C.

COLOMBIA. CORTE CONSTITUCIONAL DE COLOMBIA. Sentencia T-214-2013, M.P.: Luis Ernesto Vargas Silva. Bogotá, D.C.

COLOMBIA. CORTE CONSTITUCIONAL DE COLOMBIA. Sentencia T-227 de 2003. M.P: José Gregorio Hernández. Bogotá.

COLOMBIA. CORTE CONSTITUCIONAL DE COLOMBIA. Sentencia T-234 de 2013. M.P.: Luis Guillermo Guerrero Pérez. Bogotá.

COLOMBIA. CORTE CONSTITUCIONAL DE COLOMBIA. Sentencia T-237/03. M.P.: Jaime Córdoba Triviño. Bogotá, D. C.

COLOMBIA. CORTE CONSTITUCIONAL DE COLOMBIA. Sentencia T-271-1995. M.P.: Alejandro Martínez Caballero.

COLOMBIA. CORTE CONSTITUCIONAL DE COLOMBIA. Sentencia T-298 de 2008. M.P.: Jaime Córdoba Triviño. Bogotá, D.C.

COLOMBIA. CORTE CONSTITUCIONAL DE COLOMBIA. Sentencia T-323-13. M.P.: Jorge Ignacio Pretelt Chaljub. Bogotá, D.C. 
COLOMBIA. CORTE CONSTITUCIONAL DE COLOMBIA. Sentencia T-346 de 2009. M.P.: María Victoria Calle Correa. Bogotá, D.C.

COLOMBIA. CORTE CONSTITUCIONAL DE COLOMBIA. Sentencia T-361/14. M.P.: Jorge Ignacio Pretelt Chaljub. Bogotá, D.C.

COLOMBIA. CORTE CONSTITUCIONAL DE COLOMBIA. Sentencia T-402 de1992. MP: Ciro Angarita Barón. Bogotá.

COLOMBIA. CORTE CONSTITUCIONAL DE COLOMBIA. Sentencia T-406 de 1992. M.P. Ciro Angarita Barón. Bogotá.

COLOMBIA. CORTE CONSTITUCIONAL DE COLOMBIA. Sentencia T-438/09. M.P.: Gabriel Eduardo Mendoza Martelo. Bogotá, D.C.

COLOMBIA. CORTE CONSTITUCIONAL DE COLOMBIA. Sentencia T-447 de 1994. M.P.: Vladimiro Naranjo Meza. Bogotá, D.C.

COLOMBIA. CORTE CONSTITUCIONAL DE COLOMBIA. Sentencia T-490 de 2006. M.P.: Marco Gerardo Monroy Cabra. Bogotá, D.C.

COLOMBIA. CORTE CONSTITUCIONAL DE COLOMBIA. Sentencia T-494 de 1993. M.P.: Vladimiro Naranjo Mesa. Bogotá, D.C.

COLOMBIA. CORTE CONSTITUCIONAL DE COLOMBIA. Sentencia T-505 de 1992. M.P Eduardo Cifuentes Muñoz. Bogotá.

COLOMBIA. CORTE CONSTITUCIONAL DE COLOMBIA. Sentencia T-539/13. M.P.: Jorge Ignacio Pretelt Chaljub. Bogotá, D.C.

COLOMBIA. CORTE CONSTITUCIONAL DE COLOMBIA. Sentencia T-556/98. M.P.: Jose Gregorio Hernández Galindo. Bogotá. 
COLOMBIA. CORTE CONSTITUCIONAL DE COLOMBIA. Sentencia T-573/05. M.P.: Humberto Sierra Porto. Bogotá, D.C.

COLOMBIA. CORTE CONSTITUCIONAL DE COLOMBIA. Sentencia T-597/93. M.P.: Eduardo Cifuentes Muñoz.

COLOMBIA. CORTE CONSTITUCIONAL DE COLOMBIA. Sentencia T-618 DE 2000. M.P.: Alejandro Martínez Caballero. Bogotá.

COLOMBIA. CORTE CONSTITUCIONAL DE COLOMBIA. Sentencia T-650/13. M.P.: Alberto Rojas Ríos. Bogotá, D.C.

COLOMBIA. CORTE CONSTITUCIONAL DE COLOMBIA. Sentencia T-712/07. M.P.: Rodrigo Escobar Gil. Bogotá, D.C.

COLOMBIA. CORTE CONSTITUCIONAL DE COLOMBIA. Sentencia T-736 de 2004. M.P.: Clara Inés Vargas Hernández. Bogotá, D.C.

COLOMBIA. CORTE CONSTITUCIONAL DE COLOMBIA. Sentencia T-745 de 2013. M.P.: Jorge Iván Palacio Palacio. Bogotá.

COLOMBIA. CORTE CONSTITUCIONAL DE COLOMBIA. Sentencia T-752/07. M.P.: Clara Inés Vargas Hernández. Bogotá, D.C.

COLOMBIA. CORTE CONSTITUCIONAL DE COLOMBIA. Sentencia T-754/05. M.P.: Jaime Araújo Rentería.

COLOMBIA. CORTE CONSTITUCIONAL DE COLOMBIA. Sentencia T-859 de 2003. M.P.: Eduardo Montealegre Lyneth.

COLOMBIA. CORTE CONSTITUCIONAL DE COLOMBIA. Sentencia T-933/13. M.P.: Jorge Ignacio Pretelt Chaljub. Bogotá, D.C. 
COLOMBIA. CORTE CONSTITUCIONAL DE COLOMBIA. Sentencia T-970/08. M.P.: Marco Gerardo Monroy Cabra. Bogotá, D.C.

COLOMBIA. CORTE CONSTITUCIONAL DE COLOMBIA. SentenciaT-042 de 1996. M.P.: Carlos Gaviria Díaz. Bogotá, D.C.

COLOMBIA. CORTE CONSTITUCIONAL DE COLOMBIA. Sentencia T-760 de 2008. M.P.: Manuel José Cepeda Espinosa. Bogotá, D.C.

COLOMBIA. CORTE CONSTITUCIONAL DE COLOMBIA. T-406 de 1992. M.P.: Vladimiro Naranjo Mesa. Bogotá, D.C.

COLOMBIA. CORTE CONSTITUCIONAL DE COLOMBIA. T-484 de 1992. M.P.: Fabio Morón Díaz. Bogotá, D.C.

COLOMBIA. CORTE CONSTITUCIONAL DE COLOMBIA. Sentencia C-566-1995. M.P.: Eduardo Cifuentes Muñoz. Bogotá.

COLOMBIA. CORTE CONSTITUCIONAL DE COLOMBIA. Sentencia T-336 de 1995. M.P: Vladimiro Naranjo Meza.

COLOMBIA. CORTE CONSTITUCIONAL DE COLOMBIA. Sentencia T-859 de 2003. M.P.: Eduardo Montealegre Lyneth.

COLOMBIA. CORTE CONSTITUCIONAL DE COLOMBIA. Sentencia T-941 del 24 de julio de 2000. M.P Alejandro Martínez Caballero.

\section{Normas}

ALEMANIA. CONSTITUCIÓN DEL IMPERIO (REICH) ALEMÁN. En: Textos Constitucionales españoles y extranjeros. Zaragoza.: Editorial Athenaeum, 1930. 
Aplicación del Pacto Internacional de los Derechos Económicos, Sociales y Culturales. Observación general 14. El derecho al disfrute del más alto nivel posible de salud. 2000. (en línea). http://hrlibrary.umn.edu/gencomm/epcomm14s.htm.

ASAMBLEA GENERAL DE LAS NACIONES UNIDAS. Conjunto de Principios para la protección de todas las personas sometidas a cualquier forma de detención o prisión. 1988. (en línea). http://www.ohchr.org/SP/Professionallnterest/Pages/DetentionOrImprisonment.as px.

ASAMBLEA GENERAL DE LAS NACIONES UNIDAS. Convención Internacional sobre la Eliminación de todas las Formas de Discriminación Racial. 1965. (en línea). http://www.ohchr.org/SP/Professionallnterest/Pages/CERD.aspx.

ASAMBLEA GENERAL DE LAS NACIONES UNIDAS. Convención internacional sobre la protección de los derechos de todos los trabajadores migratorios y de sus familiares. 1990. (en línea). http://www.ohchr.org/SP/Professionallnterest/Pages/CMW.aspx.

ASAMBLEA GENERAL DE LAS NACIONES UNIDAS. Convención sobre la eliminación de todas las formas de discriminación contra la mujer (CEDAW). 1997. (en línea) http:/www.humanium.org/es/wpcontent/uploads/2013/10/Convenci\%C3\%B3n-Discriminaci\%C3\%B3n-Racial.pdf.

ASAMBLEA GENERAL DE LAS NACIONES UNIDAS. Convención sobre los Derechos del Niño. $1989 . \quad$ (en línea). http://www.ohchr.org/SP/Professionallnterest/Pages/CRC.aspx.

ASAMBLEA GENERAL DE LAS NACIONES UNIDAS. Convención sobre los derechos de las personas con discapacidad. 2006. (en línea). http://www.un.org/esa/socdev/enable/documents/tccconvs.pdf.

ASAMBLEA GENERAL DE LAS NACIONES UNIDAS. Declaración de los Derechos del Niño, 1959. (En línea). http://www.humanium.org/es/wpcontent/uploads/2013/09/Declaraci\%C3\%B3n-de-los-Derechos-delNi\%C3\%B101.pdf. 
ASAMBLEA GENERAL DE LAS NACIONES UNIDAS. Declaración Política y Plan de Acción Internacional de Madrid sobre el Envejecimiento. 2002. (en línea). https://social.un.org/ageing-working-group/documents/mipaa-sp.pdf.

ASAMBLEA GENERAL DE LAS NACIONES UNIDAS. Declaración sobre el progreso y el desarrollo en lo social. Washington, 1969. (en línea). http://www.ohchr.org/SP/Professionallnterest/Pages/ProgressAndDevelopment.as px.

ASAMBLEA GENERAL DE LAS NACIONES UNIDAS. Observaciones generales aprobadas por el Comité de Derechos Humanos. (en línea). http://www.derechos.org/nizkor/ley/doc/obgen2.html\#Prohibicion.

ASAMBLEA GENERAL DE LAS NACIONES UNIDAS. Pacto Internacional de Derechos Económicos, Sociales y Culturales. 1966. (en línea). http://www.ohchr.org/SP/Professionallnterest/Pages/CESCR.aspx.

ASAMBLEA GENERAL DE LAS NACIONES UNIDAS. Principios de ética médica aplicables a la función del personal de salud, especialmente los médicos, en la protección de personas presas y detenidas contra la tortura y otros tratos o penas crueles, inhumanas o degradantes. 1982. (en línea). http://www.cidh.org/privadas/principiosdeetica.htm.

ASAMBLEA MUNDIAL DE LA SALUD. Constitución de la Organización Mundial de la salud. Nueva York (1946). Documentos básicos, suplemento de la 45a edición (2006). (En línea) http://www.who.int/governance/eb/who_constitution_sp.pdf.

COLOMBIA. CONCEJO MUNICIPAL DE BOGOTÁ D.C. Acuerdo 485 de 2011 (27, diciembre 2011). Por el cual se establecen medidas educativas encaminadas a la erradicación del castigo físico, humillante y denigrante en contra de los niños, niñas y adolescentes de Bogotá, D.C. Registro Distrital, Bogotá, D.C. 2011. № 4804.

COLOMBIA. CONGRESO DE LA REPÚBLICA DE COLOMBIA. Decreto 128 DE 2010 (21, enero, 2010). Declarado INEXEQUIBLE por la Corte Constitucional mediante Sentencia C-258 de 2010. Por medio del cual se regulan las prestaciones excepcionales en salud y se dictan otras disposiciones. Diario Oficial, Bogotá D.C. 2010. $N^{\circ} 47.599$. 
COLOMBIA. CONGRESO DE LA REPÚBLICA DE COLOMBIA. Ley 1122 de 2007 (9, enero, 2007). Diario Oficial. Bogotá, D.C. 2007. No. 46.506.

COLOMBIA. CONGRESO DE LA REPÚBLICA DE COLOMBIA. Ley 1346. (31, julio, 2009) Por medio de la cual se aprueba la "CONVENCIÓN SOBRE LOS DERECHOS DE LASPERSONASCON DISCAPACIDAD", adoptada por la Asamblea General de la Naciones Unidas el 13 de diciembre de 2006. Diario Oficial. Bogotá, D.C. 2009. № No. 47.427.

COLOMBIA. CONGRESO DE LA REPÚBLICA DE COLOMBIA. Ley 1392 de 2010 (2, julio, 2010). Por medio de la cual se reconocen las enfermedades huérfanas como de especial interés y se adoptan normas tendientes a garantizar la protección social por parte del Estado colombiano a la población que padece de enfermedades huérfanas y sus ciudadores. Diario Oficial, Bogotá D.C. 2010. № 47.758.

COLOMBIA. CONGRESO DE LA REPÚBLICA DE COLOMBIA. Ley 1438 de 2011 (19, enero, 2011). Por medio de la cual se reforma el Sistema General de Seguridad Social en Salud y se dictan otras disposiciones. Diario Oficial, Bogotá D.C. 2011. $N^{\circ} 47.957$.

COLOMBIA. CONGRESO DE LA REPÚBLICA DE COLOMBIA. Ley 1751 (16, febrero, 2015). Por medio de la cual se regula el derecho fundamental a la salud y se dictan otras disposiciones. Diario Oficial, Bogotá D.C. 2015. № 49427.

COLOMBIA. CONGRESO DE LA REPÚBLICA DE COLOMBIA. Ley 508 de 1999 (29, julio, 1999). Por la cual se expide el Plan Nacional de Desarrollo para los años de 1999-2002. Diario Oficial, Bogotá D.C. 1999. № 43.651.

COLOMBIA. CONGRESO DE LA REPÚBLICA DE COLOMBIA. Proyecto de Ley Estatutaria 209 de 2013 Senado. Por medio de la cual se regula el derecho fundamental a la salud y se dictan otras disposiciones. Gaceta del congreso. Bogotá, D.C. N 116. 2013.

COLOMBIA. CONGRESO DE LA REPÚBLICA DE COLOMBIA. Proyecto De Ley No.210 De 2013. Por medio de la cual se redefine el sistema general de seguridad Social en salud y se dictan otras disposiciones. Bogotá, D.C. 
COLOMBIA. CONGRESO DE LA REPÚBLICA. Ley 100. (23, diciembre, 1993). Por la cual se crea el sistema de seguridad social integral y se dictan otras disposiciones. Diario Oficial. Bogotá, D.C., 1993. No. 41148.

COLOMBIA. Constitución Política de Colombia. 35a Ed. Bogotá.: Legis, 2016.

COMITÉ DE DERECHOS ECONÓMICOS, SOCIALES Y CULTURALES DE NACIONES UNIDAS. Observación general 14. p. 1.

COMITÉ PARA LA ELIMINACIÓN DE LA DISCRIMINACIÓN CONTRA LA MUJER. Recomendaciones Generales. Recomendación General № 15. 1990. (en línea). http://www.un.org/womenwatch/daw/cedaw/recommendations/recomm-sp.htm.

COMITÉ PARA LA ELIMINACIÓN DE LA DISCRIMINACIÓN CONTRA LA MUJER. Recomendaciones Generales. Recomendación General № 19. 1991. (en línea). http://www.un.org/womenwatch/daw/cedaw/recommendations/recomm-sp.htm.

COMITÉ PARA LA ELIMINACIÓN DE LA DISCRIMINACIÓN CONTRA LA MUJER. Recomendaciones Generales. Recomendación General № 18. 1990. (en línea). http://www.un.org/womenwatch/daw/cedaw/recommendations/recomm-sp.htm.

CONFERENCIA DIPLOMÁTICA PARA ELABORAR CONVENIOS INTERNACIONALES. Convenio de Ginebra para aliviar la suerte que corren los heridos y los enfermos de las fuerzas armadas en campaña. Ginebra, 1949. (en línea). https://www.icrc.org/spa/resources/documents/treaty/treaty-gc-25tdkwc.htm.

CONFERENCIA DIPLOMÁTICA PARA ELABORAR CONVENIOS INTERNACIONALES. Convenio de Ginebra relativo al trato debido a los prisioneros de guerra. Ginebra, $1949 . \quad$ (En línea). https://www.icrc.org/spa/resources/documents/treaty/treaty-gc-3-5tdkwx.htm

CONFERENCIA DIPLOMÁTICA PARA ELABORAR CONVENIOS INTERNACIONALES. Convenio de Ginebra relativo a la protección debida a las personas civiles en tiempo de guerra. Ginebra, 1949. (En línea). https://www.icrc.org/spa/resources/documents/treaty/treaty-gc-4-5tdkyk.htm. 
CONFERENCIA GENERAL DE LA ORGANIZACIÓN INTERNACIONAL DEL TRABAJO. Convenio sobre pueblos indígenas y tribales. 1989. (en línea). http://www.ilo.org/wcmsp5/groups/public/@ed_norm/@normes/documents/publicat ion/wcms_100910.pdf.

CONFERENCIA INTERNACIONAL DE DERECHOS HUMANOS. Proclamación de Teherán. 1968, (en línea). http://hrlibrary.umn.edu/instree/spanish/sl2ptichr.html.

CONFERENCIA INTERNACIONAL SOBRE ATENCIÓN PRIMARIA DE SALUD. Declaración de Alma-Ata. URSS, 1978. (en línea). ttp://www.paho.org/hq/index.php?option=com_docman\&task=doc_view\&gid=1900 4\&ltemid=2518.

CONFERENCIA MUNDIAL DE DERECHOS HUMANOS. Declaración y Programa de acción de Viena. 1993. (en línea). http://www.ohchr.org/Documents/Events/OHCHR20/VDPA_booklet_Spanish.pdf.

CONSEJO DE EUROPA. Carta Social Europea. Turín, 1961. (en línea). http://hrlibrary.umn.edu/euro/spanish/Sz31escch.html.

CONVENCIÓN AMERICANA SOBRE DERECHOS HUMANOS. Protocolo de San Salvador. 1988 (en línea). http://www.hchr.org.co/documentoseinformes/documentos/html/pactos/protocolo_ san_salvador.html.

NACIONES UNIDAS Y ORGANIZACIÓN MUNDIAL DE LA SALUD. EI derecho a la salud. Folleto informativo № 31. (En línea). http://www.ohchr.org/Documents/Publications/Factsheet31sp.pdf.

NOVENA CONFERENCIA INTERNACIONAL AMERICANA. Declaración Americana de los Derechos y Deberes del Hombre. Bogotá, 1948. p. 3. (en línea). http://www.hchr.org.co/documentoseinformes/documentos/carceles/2_Interameric anos/1_Instrumentos/1_Generales_DH/2111_Decla_Americana_DS_Deb_H.pdf.

ORGANIZACIÓN DE LAS NACIONES UNIDAS. Declaración Universal de los Derechos Humanos, United Nations. 2008. (en línea) http://www.un.org/es/documents/udhr/index_print.shtml. 
ORGANIZACIÓN IBEROAMERICANA DE SEGURIDAD SOCIAL. Código Iberoamericano de Seguridad Social. (En línea). http://www.oiss.org/IMG/pdf/CODIGO_IBEROAMERICANO2.pdf.

ORGANIZACIÓN MUNDIAL DE LA SALUD. El derecho a la salud. Nota Descriptiva № 323 noviembre de $2013 . \quad$ (En línea) http://www.maternoinfantil.org/archivos/smi_D494.pdf.

Tratado de Versalles (1919) (en línea) http://www.dipublico.org/1729/tratado-depaz-de-versalles-1919-en-espanol/ (citado 16 de diciembre de 2016). 